\title{
Inas
}

97, (1) 4

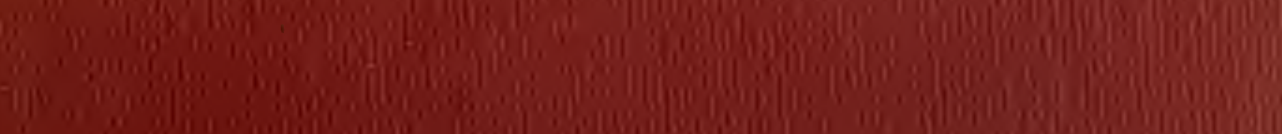

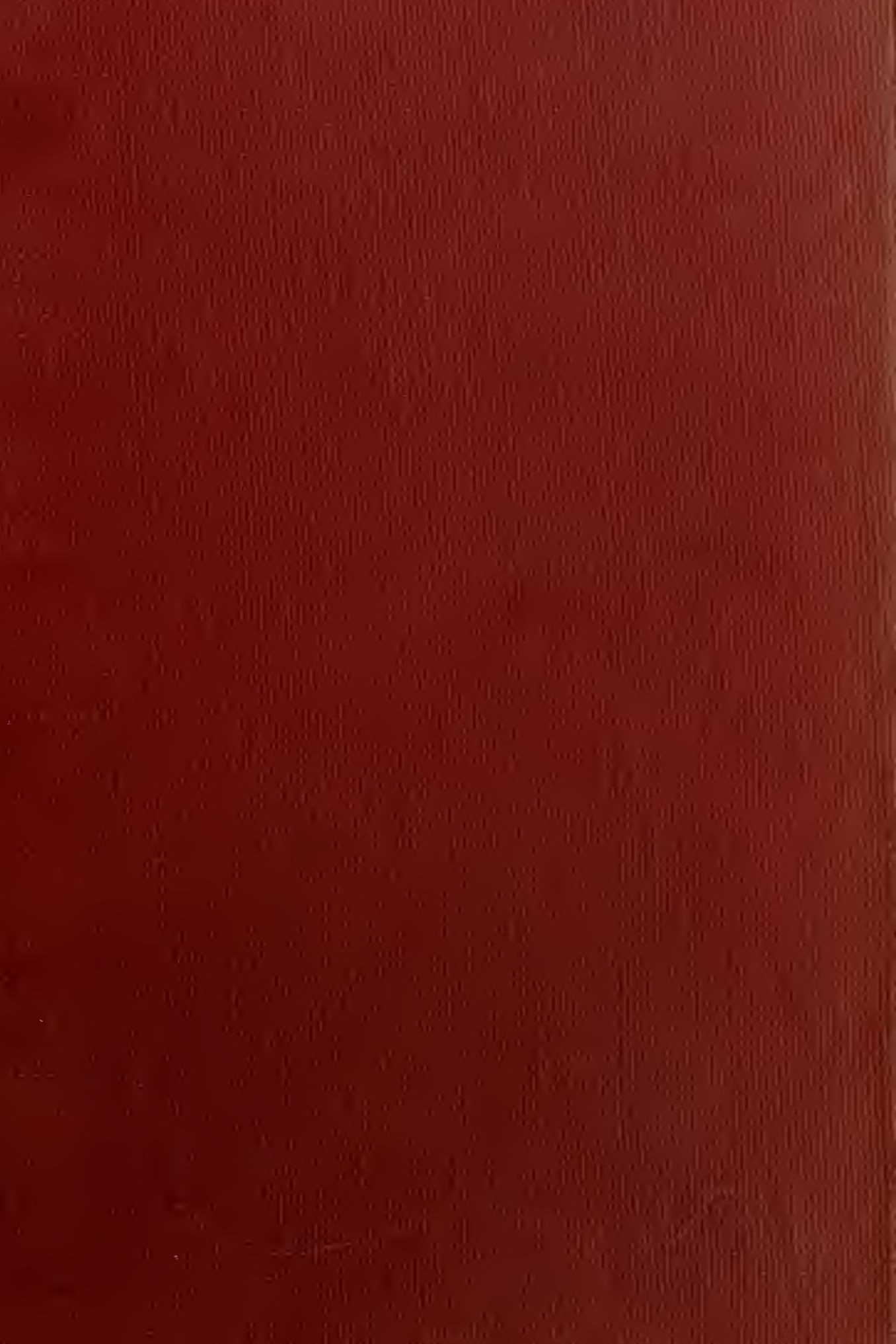





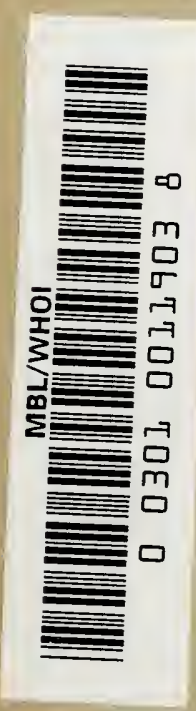




\section{Gestaltung und Vererbung.}

Eine Entwickelungsmechanik der Organismen.

Ton

Dr. Wilhelm Haacke.

Mit 26 Abbildungen im Text.
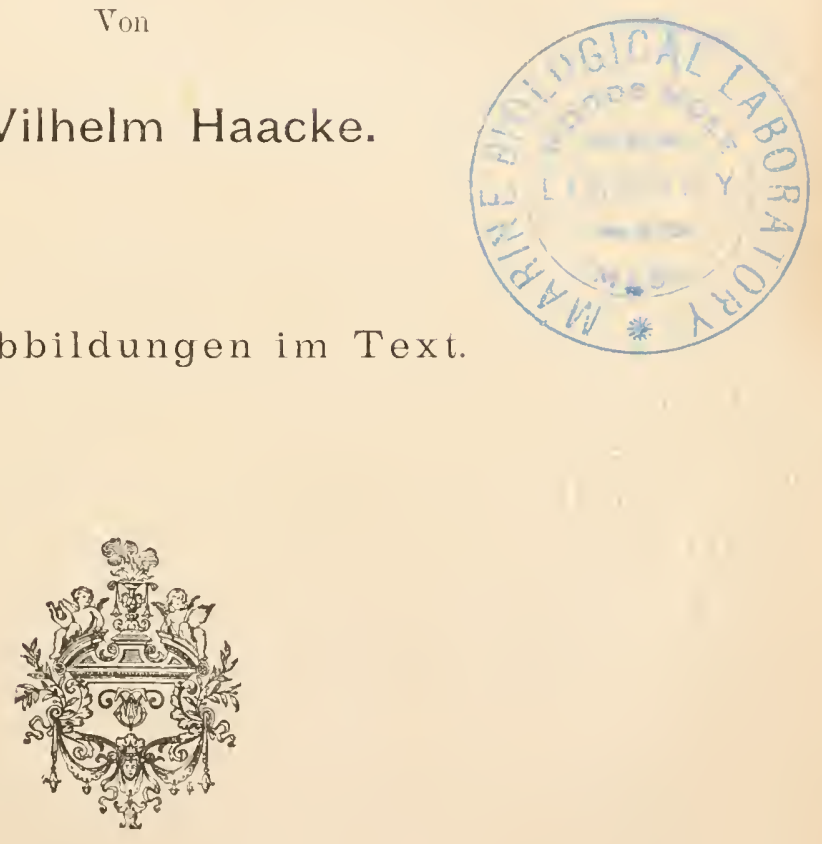

\section{Leipzig}

T. O. Weigel Nachfolger (Chr. Herm. Tauchnitz)

1893. 
Das Recht der Übersetzung in fremde Sprachen ist rorbehalten.

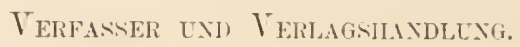




\section{Vorwort.}

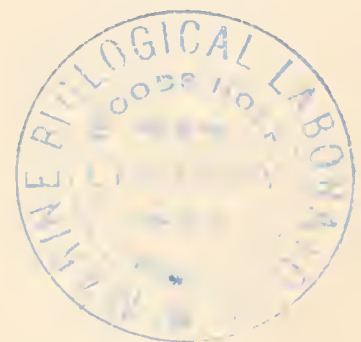

In seinem Werke „Das Keimplasma“ (Jena 1892) srlaubt Herr A ugust We ismanu „fürmlich" bewiesen zu haben, dass nur eine ..evolutionistische", besser präformistische, Theorie, eine Lehre, die den Organismus im Keime auf die eine oder andere Art in allen seinen Teilen vorgebildet sein lässt, die Vererbung erklären könne, dass dagegen eine epigenetische Theorie, also eine solche, die den Organismus auf einen in allen seinen Teilen gleichen Bildungsstoff zurückfülırt, unmüglich sei. In vorliegenden Werke finden meine Leser den thatsächlichen Beweis rom Gegenteil. We ismann hält die Vererbung ,crworbener" Eigenschaften für unmöglich; ich weise sie hier als mechanische Notwendigkeit nach.

Gelegentlich dieser Beweise lege ich den berufsmässigen Forschern aller Fächer, den denkenden Naturfreunden, den Ärzten, Züchtern, Mathematikern und Philosophen, sowie endlich allen Gebildeten, die sich für die ron mir behandelten Gegenstände interessieren, eine Gestaltungs- und Vererbungslehre ror, die im Laufe ron zwölf langen Jahren, während vielfach wechselnder Lebensschicksale, auf den blauen Wogen des Weltmeeres und den grïnen Gefilden Neuseelands, in den düsteren Urwäldern Neuguineas und auf den bunten Korallenriffen der Torresstrasse, in den schattenlosen Parklandschaften Australiens und den saftigen Buchenwäldern der deutschen Heimat, auf der Jagd und beim Fischfang, inl Museum und Tiergarten, hinter dem Mikroskop und ror dem Zuchtbehälter, auf 'Tierausstellungen und im akademischen Hörsaal allmählich herangereift ist.

Über die vielfachen Wandlungen, die meine Anschauungen erleiden mussten, ehe ich meinen Lesern etwas Fertiges bieten kounte, darf ich glücklicherweise schweigen. Es ist Selbstüberschätzung, "Torarbeit für eine Theorie“ durch den Druck zu verbreiten. Dagegen glaubte ich meinen Lesern eine leicht verständliche und abgerundete Darstellung schuldig zu sein. Aus diesem Grunde habe ich das vorliegende Buch im Juni und Juli dieses Jahres zwei mich abwechselnd besuchenden Stenographen im Terlaufe ron wenigen Wochen in die Feder diktiert. Was die Darstellung dadurch an Frische gewonnen hat, wird, so hoffe 
ich, manche durch diese Art der Niedersehrift bedingte Mïngel aufwiegen. Mit dem ermïdenden und ron der sache ablenkenden schriftstellerischen Handwerkszeug, mit Anmerkungen, Litteraturbelegen und allen den störenden Tebendingen, die ron manchen Schriftstellem sonderbarerweise fiir das Merlimal echter Wissenschaftlichkeit gehalten werden, habe ich meine Leser so vicl wie möglich rerschont. Den ron mil angewandten deutschen 'Tier- und I'tlanzennamen sind im Register die wissenschaftlichen Tamen hinzugefügt.

Ich glanbe nicht, dass meine Lehre an unlösbaren inneren Widersprüchen leidet. Scheinbare Widersprïche und sich widersprechende lïnzetheiten fler J)arstellung, die sich beseitigen lassen, aber ron mir übersehen sind, werden in meinem Buche nicht fehlen. Für sie bitte irh den Leser um Tachsicht. Sollte es sich aber herausstellen, dass meine 'Theorie unhaltbar ist, so werde ich mich keinen Augenblick bedenken, sie in aller Form $z u$ widerufen.

Ein grosser 'Teil meiner Ausfïlnungen musste sich gegen die Lehren eines Schriftstellers richten, der, wie ein englischer Forscher, M areus Hartog, sagt, während eines zchnjälnigen Feldzuges glänzende krfolge, die ihn mit seltenem Ansehen umwoben haben, errungen hat. I. h habe den Mut gefunden, die abentenerlichen Theorien und heillosen Widersprïiche dieses erfolgreichen Schriftstellers rïicksichtstos blosszustellen, und bin überzengt, dass die Wissensehaft es nir danken wirt. Dass ich dabei zu unbarmherzig verfahren wäre, wird niemand zu behaupten wagen, welcher die den ehrlichen Gegner kränkende Geringsehätzung, mit der sich Herr W o ismann äber die sehwerwiegendsten Einwände hinwegsetz. an sich selbst oder an anderen erfilhen hat.

Weisman nennt scine Lrhe eine "Wrolutionstheorie". Dil diese Bereichnung, weil man in der englischen Litteratur durunter die moderne Entwickelungstehre versteht, notwendigerweise \%u Missverstindnissen fühnen muss, habe ich sie grundsitzlich rermieden.

Es rerbleibt mir noch die angenchme Aufgabe, denjenigen, welche beim Zustandekommen dieses Buches behilflich waren. zu danken. l'ür die Umzeichnung meiner rohen skizzen grebührt mein Dank zweien meiner

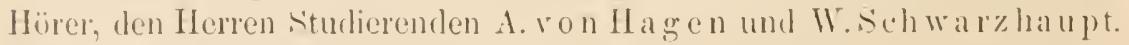
Ifrinen beiten stenugraphen, den Herren Bernheim und Wilhelm, habe ich für ihre gewissenhafte Arbeit und grosse /aurerlissigkeit zu dankien.

Dillmstadt, im olitober lis!: 


\section{Inlaaltsübersicht.}

\section{Einleitung}

II. Das Wesen der Entwickelung . . . . . . . . . . . 9

a. Beseitigung des Präformismus . . . . . . . . . . . . . . 9

b. Das Wesen der organischen Formbildung. . . . . . . . . . 18

1. Epimorphismus und Paramorphismus . . . . . . . . . 19

2. Orthogenesis und Amphigenesis . . . . . . . . . . . 31

e. Korrelation und Autonomie . . . . . . . . . . . . . . . 35

d. Nie Ersachen der Umbildung. . . . . . . . . . . . . 43

e. Die Trüger der Vererbung . . . . . . . . . . . . . . . 49

f. Die Bedentung der Eigenschaften . . . . . . . . . . . . 54

1. Redeutungsrolle und indifferente Eigenschaften . . . . 54

2. Direkt und indirekt benutzte Einrichtungen . . . . . . . 60

3. Erhaltungsmässige und nichterhaltungsmässige Eigenschaften 63

g. Die Arten der Auslese . . . . . . . . . . . . . . . . 65

1. Ökonomische Auslese und Rückbildung . . . . . . . 65

2. Organauslese und Personenauslese . . . . . . . . . . 70

3. Konstitutionelle und dotationelle Auslese. Individual - und Rassenseleltion . . . . . . . . . . . . . 73

h. Nischung und Entmischung. . . . . . . . . . . . 77

1. Separation und Kongregation . . . . . . . . . .

2. Amphimixis und Apomixis. . . . . . . . . . . . . 80)

i. Zusammenfassung. Beweise für die Tererbungerworbener Eigenschafteu 10.4

III. Gestaltung und Vererbung . . . . . . . . . . . . 112

a. Die Aufgaben der Theorie . . . . . . . . . . . . 112

b. Die Gemmarienlehre . . . . . . . . . . . . . . 117

c. Das Wesen der Assimilation . . . . . . . . . . . . . . 130

d. Die Entstehung der Grundformen. . . . . . . . . . . . 139

e. Die Entstehung der Organe . . . . . . . . . . . 166

f. Die Entstehung der Ausrüstung . . . . . . . . . . . . . 185

g. Die Entstehung der Faunen . . . . . . . . . . . 193 
h. Die Erthlirung des Epinorphismus . . . . . . . . . . 204

i. Geschlechtliche Fortpflanzung . . . . . . . . . . . . . . 207

k. Ungeschlerhtliche Fortptlanzung und Regeneration . . . . . . 217

1. Jischung und Rückschlag . . . . . . . . . . . . . . . 231

m. Generationswerhel und Polymorphismus . . . . . . . . . . 275

n. Die Vererbung von V'erstïmmelungen . . . . . . . . . . . 295

o. Zweifelhafte Vererbungserscheinungen . . . . . . . . . 301

1. Periodicch erworbene Eigenschaften . . . . . . . . . . . . 30.

IV. Die Gemmarientheorie und ältere Ansichten . . . . $30 s$

V. Die Konsequenzen von Irrlehren . . . . . . . . . . 322

VI. Die Aufgaben der Biologie . . . . . . . . . . 324

Litteraturverzeichnis . . . . . . . . . . . . 330

Altorentegister . . . . . . . . . . . . . . . 331

sallegister . . . . . . . . . . . . . . . 332

Errata. . . . . . . . . . . . . . . 337 


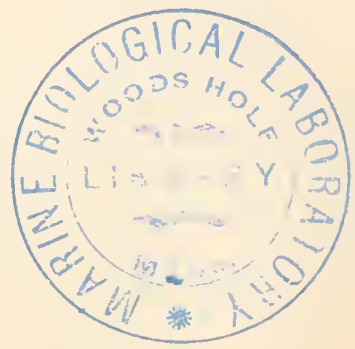

\section{Gestaltung und Vererbung.}

Nulla est praeformatio! 
.1)a nun das Keimplasma oder die Vererbungssubstanz nach allgemeiner heutiger Vorstellung nieht ein Organismus ist im Simne eines mikroskopischen I'rbildes, das sıch nachlıer nur zu vergrössem lättc, um als fertiger Grganismus dazustelen, da wir sogar bestimmt wissen, dass dem nicht so ist, so müssen also die gesammten Entwicliclungstendenzen des ḱcimes in der eigenthümlichen Zusammensetzung, gewissermaassen den A ufbau ans kleinsten Theilchen, vielleicht anch in chemischen liggenthümlichlieiten jenes keimplasma gegeben seiu."

Algest Whismin. 1508. 


\section{Einleitung.}

Der Versuch einer Lösung des Vererbungsproblems und aller anderen von ihm berührten Fragen, den ich in dem vorliegenden Werke den Biologen aller Richtungen biete, fällt in eine ungünstige Zeit. Das Ende des neunzehnten Jahrlumderts sielt die Wissenschaft ron den Leberresen in einer Zerfahrenheit, wie sie noch nie zuror bestand, und, das müssen wir leider hinzufügen, wie sie keiner anderen Wissenschaft eigen ist. Bezeichnend dafür ist, dass nicht einmal über den Namen. den man der Wissenschaft ron den Organismen zu geben hat, Einigkeit herrscht. Während eine Anzahl ihrer Vertreter sie mit dem Namen der Biologie belegt. wird von einer vielleicht ebenso grossen Anzahl von Biologen mit diesem Tamen nur ein kleiner Zweig der Wissenschaft bezeichnet. Und diese Unsicherheit über das, was man alles unter dem Begriffe der Biologie zusammenzufassen hat, ist typisch für alle Zweige unserer Wissenschaft.

Auch darüber herrscht keine Einigkeit, welche Wertschätzung man den einzelnen Zweigen der Biologie angedeihen lassen soll. Man kann diese Zweige im allgemeinen in morphologische und phrsiologische sondern, in solche, welche die Formen der Organismen, und in die, welche ihre Lebensäusserungen zum Gegenstande haben. Allein sowohl die Morphologie, wie sie hente entwickelt ist, als auch die Physiologie lassen grosse biologische Thatsachengebiete abseits liegen, und rechnen diejenigen Forscher, welche sich dieser Gebiete angenommen haben, kaum noch zu den ihrigen. Noch immer giebt es eine grosse Anzahl ron Morphologen, die keine Verständigung mit den sogenannten Systematikern suchen, derjenigen gar nicht zu gedenken, die sich mit der Beobachtung des Tieres in der freien Natur beschäftigen. 
Aber auch manche Systematiker sind sich keineswegs klar darüber, welche $/$ wecke ihre Wissenschaft eigentlich rerfolgt, denn viele Vertreter der Systematik suchen weder unter sich, noch mit der Morphologie und Phỵsiologie Füllung zu gewinnen. Wer sich mit der Sýstematik der Vögel beschäftigt, braucht sich leider nicht um die allgemeinen Ergebnisse, welche die Systematik etwa der Insekten oder der Fische geliefert hat, zu bekümmern. Es ist vielen Systematikern auch ziemlich gleichgültig, was die Morphologen in Bezug auf die ron ihnen behandelten Tiergruppen erforscht haben. Die Biologie der Zukunft nuss aber eine Wissenschaft werden, die sich mit gleicher Liebe um die Formen, wie um die Lebensverrichtungen der Organismen kümmert, welche die Systematik, die Wissenschaft ron dem Verhältnisse der Tiere zu ihrer Umgebung, die geographische Verbreitung und die Paläontologie gleich hoch stellt und ihnen dieselbe Wertschätzung angedeihen lässt, wie der Morphologie und der Physiologie.

Wir sind heute noch weit davon entfernt, dieses Ziel erreicht zu haben, und wenn wir es jemals thun sollen, so ist zunäclist die Einsicht nötig, dass die Zustände der Biologie ron heute zerfahrene und unhaltbare sind. Wir müssen uns klar darüber werden, dass wir die Lösung aller Fragen, welche die organische Natur uns vorlegt, gleichzeitig in Angriff nehmen müssen, und dass ein lebendiger Verkehr zwischen allen Zweigen der Wissenschaft zu jeder Zeit unerlässlich ist.

Wir dürfen nicht das Recht beanspruchen, den Versuch der Lösung irgend einer biologischen Frage auf spätere Keiten zu verschieben. Wenn wir das thun, so werden die Zeiten nie kommen, ron welchen eine Klärung der heutigen verworrenen Verhältnisse der Biologie erhoflt wird. Jede Zeit und jeder Forscher haben die Pflicht, sich ein Gresamtbild von der der Forschung zugänglichen Natur zu machen. Nur ladurch verdient sich die Wissenschaft ihre Existenzberechtigung; denn mit denı Forschen allein ist es nicht gethan.

Der Forscher ist, sofern er nicht auf jede mündliche oder schriftliche Äusserung verzichtet, immer auch Lehrer, ob er nun etwa an einer Hochschule wirkt, oder dem öffentlichen Leben durchaus fern stcht, ob er die Früchte seiner Forschungsthätigkeit weiteren Kreisen oder nur deqn engen Kreise seiner speziellen Fachgenossen zugänglich macht. Wer irgend eine Thatsache entdeckt hat, der hat auch die Pflicht, diese Thatsache der Allgemeinheit in einer solchen Form zu bieten, dass sie ron der Wissenschaft ohne weiteres verwertet und 
dem Lelırgebäude ohne Schwierigkeit eingefügt werden kann. Denn eine Thatsache, welche in unbrauchbarer Form geboten wird, ist nicht nur nutzloser, sondern erschwerender und deshakb schädlicher Ballast.

Die Biologie besitzt aber noch nicht in allen ihren Vertretern Forscher, welche die Notwendigkeit begreifen, dass das, was sie erforscht haben, sich auch olme Umstände in den Gesamtbau der Wissenschaft einschieben lassen muss. Mancher Biologe häuft Baumaterial an, unbekünmert darum, ob er damit Bausteine liefert, die für das von der Wissenschaft aufzuführende Gebäucle in die passende Form gebracht sind oder nicht. Auf diese Weise sammelt sich nicht nur eine grosse Ienge von Haufen nicht zu einander passender Bausteine an, sondern um diese immerhin nicht allzu grosse Fülle brauchbaren wissenschaftlichen Materials sind noch Berge von Schutt, bestehend aus dem Abfalle, der sich bei der Bearbeitung der Bausteine ergeben hat, aufgetiirmt.

Durch diesen völtig unbrauchbaren und hinderlichen Schutt hat sich derjenige hindurchzuarbeiten, der nach Material für ein wissenschaftliches Lehrgebäude sucht; denı die Art und Weise, wie manche auf dem Felde der Biologie arbeitenden Forscher ihre Forschungsergebnisse der Allgemeinheit darbietelı, ist nicht dazu angethan, das Suchen nach geeignetem Material zur Lösung einer allgemeinen Frage zu erleichtern.

Unsere wissenschaftlichen Publikationen wimmeln von Nebensächlichkeiten, von Prioritätsstreitigkeiten, von überflüssigen Citaten und voluminösen Literaturbelegen, nicht minder auch von weitläufigen Auseinandersetzungen über die Technik des Untersuchungsverfahrens, so dass man von vornherein darauf verzichten muss, all dieses zum Teil völlig wertlose Material nach brauchbaren Thatsachen zu durchwühlen, wenn man an der Lösung irgend einer allgemeinen Frage, sei sie auch noch so beschränkten Umfanges, arbeitet. Man muss sich gewöhnlich mit dem begnügen, was einem selbst von allen einschlägigen Thatsachen gegenwärtig ist, und dass das nicht allzu viel sein wird, ist von vornherein klar bei der ungehenern Ausdehnung des Gebietes biologischer Forschung.

Besser würde es um unsere Wissenschaft stehen, wenn jeder Forscher sich benühen wollte, mit wenig Worten alles das hervorzuheben, was 
rine ron ihm veröffentlichte Arbeit an neuen Thatsachen bringt. und in welcher Weise die cinzelnen Thatsachen für die cinzelnen Zweige der allgemeinen Biologie zu verwerthen sind, in welche Fächer des grossen biologischen Magazins sie hineinpassen, welche Thatsachen nur in ein cinziges Fach, und welche von ihnen in mehreren zugleich ihren Platz finden müssen; denn es wird selten eine neue biologische Thatsache geben, die nicht für eine grosse Reile allgemeiner biologischer Forschungszweige von Bedeutung wäre. Allein, wenn dies geschehen sollte, so müsste wenigstens über die allgemeinsten Gesichtspunkte der biologischen Wissenschaft Finigkeit herrschen; aber das ist keineswegs der Fall. Es giebt keine Wissenschaft, in welcher die Stellungnahme zu den Grundprinzipien so gleichgültig wäre, wie in der Biologie. Ob sich etwa erworbene Eigenschaften rererben oder nicht, ist cine Frage, um welche sich der Forscher nicht zu kümmern braucht, falls er nur fleissig an der Aufläufung der von ihm gefundenen unbehauenen Bausteine arbeitet.

Keine Wissenschaft bedarf so sehr der Unirersalitiit wie dic Biologie: gleichwohl giebt es keine andere Wissenschaft. in weleher Einseitigleit sich sn breit machte, wie in der unserigen. Und das ist nicht zu verwundem, demn bei der herrschenden Gleichgültigkeit gegen allgemeine Fragen findet oft nur derjenige noch Anerkennung, der dickleibige Folianten, die man nicht zu lesen braucht, mit zahlreichen schönen Tafeln, die man gelegentlich eimmal durchblättert, verfasst. Die Scheu ror der Beschäftigung mit allgemeinen fragen ist deshalb wohl zu begreifen.

Ebenso charakteristisch für unsere heutigen Zustände wie diese Angst vor Verallgemeinerungen ist das Verhältnis der Theoretiker zu den Praktikern. Wer etwa als Züchter thätig ist. hat meistens von der Theorie ler Züchtung keine Ahnung, und er braucht sie auch nicht zu haben, weil er mit seinen pralitisehen Erfahrungen riel weiter kommt als mit der 'Theorie; denn so wenig wie die Praktiker auf die Theorie Rücksicht nehmen, haben sich die 'Theoretiker um das, was den Praktikern längst in Fleisch und Blut ïbergegangen ist, beliümmert.

Man sollte meinen, dass derjenige, weleher ïber Vererbung schreibt, sich grüntlich mit der praktischen 'l'ierzucht befasst haben müsste; allem es genügt heute leider, dass man Darwin's Werke fort und fort citiert. Die V'ererbungstheoretiker bedenken dabei nicht, dass nur solche Vererbnngsiersuche Wert haben, die anf Grund einer bis in 
alle Einzelheiten ausgebauten Theorie angestellt worden sind, die gemacht wurden, um allgemeine Prinzipienfragen zu lösen. Das aber ist bei den meisten Vererbungsversuchen, die bis auf Darwin's Zeiten und seit seinem Auftreten bis zur Gegenwart angestellt worden sind, nicht der Fall gewesen. So stehen wir denn vor der unabweisbaren Notwendigkeit, aufs neue systematische Zü̈chtungsversuche, die von ganz bestimmten Prinzipien ausgehen und nach völlig feststehenden Gesichtspunkten hin unternommen werden, anzustellen.

Mit einer Behandlung der Frage nach dem Wesen der Vererbung lediglich auf Grund solcher Züchtungsversuche ist es aber keineswegs gethan. Wer heute ein Buch über Vererbung schreiben will, muss zu gleicher Zeit alle Fragen der Abstammungslehre überhaupt in eingehender Weise behandeln. Meine Beschäftigung mit diesen Fragen reicht zurück bis in meine Schuljahre; die Vererbungslehre speziell hat mich aber erst seit etwa zwölf Jahren in Anspruch genommen. Auf meiner Segelschiffreise vou London nach Neuseeland gelangte ich zu einer ähnlichen Vererbungstheorie, wie sie später von $W$ eismann aufgestellt wurde: sie gipfelte darin, dass das Keimplasma auf besonderen Bahnen von den elterlichen Keimdrüsen auf die der Nachkommen übertragen wird. Ich unterliess es, hiese Theorie zu veröffentlichen, weil mich eine, wie es scheint völlig unbekannt gebliebene, Dissertation meines Freundes Ot to Plarre darüber belehrte, dass Anschauungen, wie sie später Weismann entwickelte und wie sie von mir auf meiner Fahrt nach Neuseeland gewonnen waren, durchaus nichts Neues seien.

Ich kann es nur als ein Glück betrachten, dass ich es damals unterlassen habe, meine Vererbungstheorie vorzeitig zu veröffentlichen; denn fortgesetzte Beschüftigung mit dem Gegenstande und mit den übrigen Fragen der Abstammungstehre zeigte, dass die inzwischen von Weismann veröffentlichte Lehre von der "Kontinuität ches Keimplasmas" in ter Form, die Weismann ihr gegeben hat, und die sie auch ron mir, wenu auch in viel geringerer Vollendung, erhalten haben wïrde, unhaltbar sei. Die Beobachtung lebendiger höherer Tiere lehrte mich später, dass das Leugnen der Vererbung erworbener Eigenschaften, zu welchem auch ich auf Grund meiner unzulänglichen Erstlingstehre geneigt war, gleichbedeutend sei mit einem Verzicht auf jegliches kausale Verständnis der Welt der Lebewesen.

Ich gewann dadurch die unerschütterliche Überzeugung, dass das Suchen nach einer Theorie, welche die Vererbung erworbener Eigenschaften 
erklärt, von Erfolg gekrönt sein müsse. Unerwarteterweise bot sich aber die rïsung der dadurch gestellten Aufgabe früher, als ich es erhofft hatte, früher noch, als ich eingehend an den Versuch dieser Lösung herantreten konnte. Ich war nämlich vorerst darauf bedacht, eine Vererbungstheoric ohne Rücksicht auf die Vererbbarkeit erworbener Eigenschaften, an welche ich noch im Jahre 1888 zweifelte, zu finden. Aber als ich nach erheblichen Mühen endlich zu der in diesem Buche vorzutragenden Theorie der Epigenesis gelangt war, zeigte sich, dass ich damit auch die Erklärung der Vererbung erworbener Eigenschaften gefunden hatte. Ja, ich erkannte, dass erworbene Eigenschaften sich mit Naturnotwendigkeit vererben müssen.

Meine in grossen Massstabe an einem aus vielen erblichen Rassen bestehenden Material von über 3000 Mäusen angestellten Züchtungsversuche belehrten mich ferner über die Bedeutung eingehender Untersuchungen derjenigen Vererbungserscheinungen, die Weismann für seine 'Theorie der Amphimixis verwertet hat, und zeigten mir, dass die "Vermischung der Individuen" ganz andere Folgen hat, als die, welche W eismann ihr zuschreibt. Während der Beschäftigung mit diesen vererbungstheoretischen Fragen war ich aber auch fortgesetzt genötigt, mich um die Systematik, Ökologie und Geographie der Tiere zu kümmern, und; die dabei gewonnenen Ergebnisse blieben nicht ohne Bedeutung für meine Vererbungstheorie, so dass ich die letztere nummeìr als Skizze einer umfassenden Entwickehungslehre, einer allgemeinen Keimes- und Stammesgeschichte der liere und Pflanzen mitzuteilen in der Lage bin.

Die hier entwickelte 'Theorie steht in ihren Grundzügen schon seit Jahren fest. Obwohl sie nicht das Ergebnis flüchtiger Laune, sondern die Frucht langjähriger Beobachtungen und fast ununterbrochenen eingehenden Nachdenkens ist, so hätte ich doch gerne noch einige Jahre an ihrer Vervollkommnung gearbeitet, wenn nicht die Rücksichtnahme auf spezielle Arbeiten, die ich vorhabe, mich schon jetzt zu einer Verïffentlichung dieser Theorie zwängen.

Alle Einzelfragen der Tierkunde, dio mich in den letzten Jahren beschäftigt laben und nummehr ihrer Bearbeitung harren, erwiesen sich als der Behandlung unzugänglich, wenn ich nicht vorher meine Entwickelungslehre der Öffentlichkeit übergeben wollte, denn meine speziellen Untersuchungsgebiete und die Gegenstände, mit denen sie sich beschïftigen, gliederten sich ohne mein Zuthun so innig an die allgemeine Theorie 
an, dass ich ihre Behandlung nicht ohne Rücksichtnahne auf letztere unternehmen kann. Es ist somit ein äusserer Grund, der mich schon jetzt zur Veröffentlichung meiner Lehre veranlasst.

Ich habe mich bemüht, meine Lehre in möglichster Klarheit rorzutragen. Um dieses zu erreichen, habe ich sie schon seit Jahren in meinen akademischen Vorlesungen an der technischen Hochschule zu Darmstadt vor einem grösseren Kreise allgemein naturwissenschaftlich gebildeter Hörer behandelt und ausserdem in meiner "Schöpfung der Tierwelt", die etwa gleichzeitig mit diesem Buche vollendet vorliegen wird, als das Gerippe benutzt, um welches herum sich in diesem für einen grösseren Leserkreis bestimmten Werke die speziellen Thatsachen der Tierkunde gruppieren. Ich wollte gleichzeitig mit der kritischen Darlegung meiner Lehre ihre Anwendbarkeit auf alle Zweige der Tierkunde darthun, und bitte diejenigen meiner Leser, welche die praktische Anwendung meiner Lehre kennen zu lernen wünschen, zu meiner „Schöpfung der Tierwelt" zu greifen.

In diesem Werke konnte ich allerdings die in vielen Punkten neue Lehre nur in ihren allgemeinsten Grundzïgen geben, und ich musste auch dabei auf eine Kritik anderer Theorien verzichten. Eine solche Kritik, so wenig dankbar sie sein mag, ist aber unerlässlich. Wer ein neues Gebäude aufführen will, muss den Platz, auf welchem es sich erheben soll, zunächst von Schutt und Gestrüpp säubern. Das vorliegende Werk hat es also nicht allein mit der Darlegung meiner Lehre zu thun, sondern ebenso sehr mit einer eingehenden Kritik derjenigen Anschauungen und Lehren, die sich mit meinen Ansichten nicht vertragen.

Diese Kritik sowohl, als auch meine eigene Theorie machen ein Eingehen auf alle allgemeinen Fragen der morphologischen Biologie nötig und erheischen Rücksichtnahme auf alle einzelnen Zweige des ganzen grossen Baumes der Wissenschaft von den Lebewesen. Nicht minder unerlässlich erscheint mir dabei eine scharfe Gegenüberstellung der zur Zeit bestehenden und aller überhaupt möglichen Alternativen über entwickelungsgeschichtliche Fragen.

Weder die Forderung zulänglicher Fragestellung, noch die ausreichende Rücksichtnahme auf alle biologischen Thatsachen, noch auch die nach scharfer Beleuchtung der strittigen Fragen ist in allen Fällen erfüllt worden, wo es sich um die Lösung biologischer Probleme gehandelt hat. Wenn ich nun auch glaube, dass ich diesen Forderungen gerecht ge- 
worden bin, so muss ich doch anderseits mich zu einer verbältnismässig grossen Unwissenheit auf den Gebieten der Botanik und Pathologie bekennen. - Wo es sich um das Anführen ron Beispielen handelt, muss ich mich im grossen und ganzen auf meine Spezialwissenschaft beschränken. Ich glaube aber denuoch, dass mein Buch auch für den Botaniker und den Pathologen, nicht minder auch für den Philosophen und den praktischen Züchter, kurzum für alle, die sich mit biologischen Fragen beschäftigen, von einiger Bedeutung sein wird. 


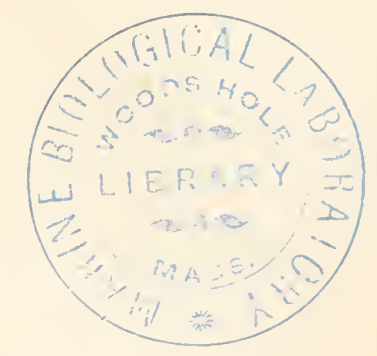

\section{Das Wesen der Entwickelung.}

\section{a. Beseitigung des Präformismus.}

Wer die neuesten Untersuchungen über das Vererbungsproblem kennt, weiss, dass die Entscheidung der allgemeinsten biogenetischen Frage, die schon die Naturforscher früherer Jahrhunderte beschäftigte. auch heute noch nicht endgültig getroffen ist. Diese Entscheidung hat festzustellen, ob die Vererbung auf Präformation oder auf Épigenesis beruht, ob also von den Erzeugern auf die Nachkommen Zeugungsstoffe übertragen werden, die schon alle Teile des künftigen Lebewesens vorgebildet enthalten, oder ob sich die Organismen aus Keimen entwickeln, die durchweg aus homogenem, einheitlichem Baustoff bestehen und erst nach und nach auf dem Wege der Neubildung alle die verschiedenen Eigenschaften annehmen, durch welche sich ihre Eltern auszeichneten.

Wir können, um eine präzise Fragestellung zu ermöglichen, sagen, dass die Präformationstheorie ein polymiktes Plasma, also einen Bildungsstoff annimmt, der sich aus vielen verschiedenen Substanzen aufbaut und diese in bestimmter Weise angeordnet enthält, während die Theorie der Epigenesis ein monotones Plasma als Bildungsstoff roraussetzt, also eine Keimsubstanz, die aus lauter gleichen Elementen zusammengesetzt ist. Die erste Frage, mit der sich jede Vererbungstheorie abzufinden hat, ist also die, ob das Keimplasma ein monotones oder ein polymiktes ist.*)

Weismann, Roux, de Vries und andere gehen von einem polymikten Keimplasma aus. Dreyer dagegen, der neuerdings ausge-

*) Die Ausdrücke ,poiymikt" und ,monoton" verdanke ich Haeckel's ,PlanktonStudien". 
dehnte Untersuchungen über die Gerüstbildungsmechanik, insbesondere der niederer Organismen angestellt hat, kommt beispielsweise bei den Radiolarien zu dem Ergebnis, dass ihre Skelette sich in einem Wabenwerk von Plasma und Vakuolenflüssigkeit, dessen Konfiguration lediglich durch die Gesézze der Flüssigkeitsmechanik beherrscht und durch \%ufälligkeiten bedingt wird, ablagern. Er stellt sich vor, dass das Plasma der Radiolarien von einer grossen Anzahl grösserer oder kleinerer Vakuolen durchsetzt ist und dass diese bald so, bald anders angeordnet sein können, je nachdem äussere Verlıältnisse hier in dieser, dort in jener Weise auf ihre Bildung eingewirkt haben. Er vergleicht das Wabenwerk des Radiolarienkörpers mit dem Blasenșrstem, das beim Ausschenken einer Flasche Bier in den entleerten Teile der Flasche zurückbleibt. An einem solchen kann man beobachten, dass hier und da cine Blase platzt. und dass sich darauf das Ganze, den Gesetzen der Flüssigkeitsmechanik gehorchend, neu anordnet.

Demnach wäre also der unendlich mannigfaltige Bau, welchen die Radiolarienskelette zeigen können, lediglich aus den Gesetzen der Flüssigkeitsmeclıanik zu erklären, ohne dass das Plasma der Radiolarienarten überhaupt artlich unterschieden zu sein brauchte, und das Vererbungsproblem käme auf die Frage hinaus, ob das Kind seinen Eltern nicht etwa blos deshalb gleicht, weil sein formloses Plasma ähnlichen äusseren Lebensbedingungen unterworfen ist, wie sie für die Formbildung des elterlichen Plasmas bestanden haben. Wir hätten also zwischen Dreye 1 einerseits und den genannten Forschern anderseits den denkbar grössten Gegensatz.

Ich glaube nicht, dass Dreyer vollkommen das Richtige getroffen hat, dass sich aber die übrigen genannten Forscher im Irrtum befinden, werde ich nachweisen. Dass sich die Vererbung mehr oder minder auf die Scite schicben lässt, wie Dreyer es für möglich hält, erscheint mir ausgeschlossen. Ich stimme vielnehr darin den Präformisten bei, dass die Annahme eines aus geformten Elementen bestehenden Plasmas unerlässlich, dass die Vererbung an bestimmte 'Träger gebunden ist. Dass diese aber unter sich ungleich seien, wie es auch O. Hertwig, der sich zur Theorie der Epigenesis bekennt, annimmt, hoffe ich als den Grundirrtum der neuesten Vererbungstheorien darthun zu können. Die bis in die minutiösesten Finzelheiten ausgebaute Präformationstheorie We is ma nn's soll uns zeigen, dass die Annahme einer erblichen Prïformation verschiedener Vererbungsträger hinauslaufen muss auf die gleichzeitige Èr- 
schaffung aller Individuen einer Organismenart, die bestimmt sind, die Erde zu berölkern.

Weismann denkt sich das Keimplasma aufgebaut aus "Iden" und jedes Id zusammengesetzt aus „Determinan te n“, die sich ihrerseits wieder aus „Biophoren "konstituieren. Jede Determinante soll sich in bestimmter" Weise aus Biophoren zusammensetzen und ebenso jedes Id aus den Determinanten. Die Determinanten entsprechen den einzelnen Zellen oder kleinen Zellgruppen des Körpers, und das Id hat deshalb einen nahezu ebenso komplizierten Bau, wie der entwickelte Tier- oder Pflanzenorganismus. Bei der Keimesgeschichte soll sich nun das Id in seine Determinanten zerlegen, während sich die letzteren in ihre Biophoren auflösen. Damit dieser Zerlegungsprozess in der richtigen Reihenfolge vor sich geht, ist Weismann zu der Annahme gezwungen, dass das Id einen festgeregelten architektonischen Aufbau hat, etwa so, dass heispielsweise die Ide bilateral-symmetrischer Tiere gleichfalls bilateralsymmetrisch sind. Weism an $n$ hat diese Annahme mit Recht als unerlässlich erkannt, denn das Id wird während der Keimesentwickelung in seine Determinanten und Biophoren zerlegt. Die eine feste Architektonik des polymikten Keimplasmas verwerfende Ansicht aber, wonach sich die bunte Schar der Biophoren, aus welchen die nächste Generation entstehen soll, erst wieder in den Keimzellen zusammenzufinden hätte, um durch regelrechte architektonische Aneinanderlagerung den Organismus zu bilden, stösst auf die grössten Schwierigkeiten. Eine solche Hypothese hat die Darwin'sche Pangenesislehre so unannehmbar gemacht; aber auch wenn man mit de Vries annimmt, dass "Pangene" aller Art in sämtlichen Zellkeimen vorhanden sind, bleibt deren regelrechte Verteilung unbegreiflich, und Weisman n bekämpft deshalb mit vollem Recht die bezüglichen Anschauungen von de Vries. Da Weismann dieses mit grossem Glïck thut, so weiss ich nichts Besseres, als seine klaren und sachgemässen Ausführungen gegen de Vries hier folgen zu lassen. Weismann sagt von den Schlussfolgerungen des holländischen Botanikers:

„Der Grundgedanke der ganzen Deduktion ist gewiss vollkommen richtig; als ich vor einem Jahrzehnt zuerst anfing, mich in das Problem der Vererbung zu vertiefen, glaubte ich noch an die Möglichkeit einer epigenetischen Theorie, habe sie aber auch längst als ummöglich erkannt, wie man im Verlauf dieses Buches sehen wird. Auch ich denke mir die Vererbungssubstanz aus ,Anlagen` zusammengesetzt und glaube sogar, diese Annahme als unvermeidlich und als eine völlig gesicherte 
nachweisen zu können. Aber ich meine nicht, dass wir mit, Pangenen ausreichen zur Erklärung der V'ererbungserscheinungen. de Vries lässt die Keimsubstanz aus einer Menge rerschiedener Arten von Pangenen bestehen, von denen so viele vorhanden sein müssen, als, Eigenschaften bei der Art vorkommen. Diese Pangene denkt sich nun de V ries nicht in festem geordneten Verband, sondern frei mischbar, wie es der angenommenen freien Mischbarkeit der Eigenschaften` entspricht. Höhere Einbeiten, die etwa eine bestimmte Zahl Pangene geordnet zusammenhielten, bekümpft er als eine überflüssige Annahme, und darin scheint mir der schwache Punkt seiner Aufstellungen zu liegen.

..In dem Abschnitt über die Beherrschung der Zelle durch die Kernsubstanz werde ich mich dem - wie ich glaube - sehr glücklichen Gedanken von de Vries anschliessen, nach welchem materielle Teilchen aus den Kern austreten und in den Bau des Zellkörpers eingreifen. Diese Teilchen entsprechen den ,Pangenen', sie sind die ,Eigenschaftstrüger' der Zelle; durch ihre Natur, durch ihre verschiedenen Arten und durch die Verhältniszahl derselben wird auch nach meiner Ansicht der Zelle inr spezifischer Stempel aufgedrücht.

„A Aber berulit denn der Charakter einer Art blos auf diesen primären ,Eigenschaften' der Zellen? Giebt es nicht, Eigenschaften'sehr verschiedener Ordnung? primäre, sekundäre u. s. w.? Die ,Pangene' sind primäre Eigenschaftsträger, ihre blosse Anwesenheit in der Vererbungssubstanz sargt noch gar nichts oder doch sehr wenig über den Charakter einer Art ans. Wenn z. B. in der Eizelle einer Pflanze, Chlorophyll-Pangene enthalten sind, so können wir daraus keinen weiteren Schluss auf ihre Artcharaktere machen, als dass sie irgend welche grüne Zellen besitzen wird; wo dieselben liegen, welche Teile der Pflanze griin, welche etwa ,panaschiert' sein werden, ob grüne, ob weisse oder anderswie gefürbte Blüten an ihr entstehen werden, lässt sich daraus nicht entnehmen. Erst wenn wir in der lieinsubstanz Gruppen von Pangenen entdeckten, von welchen die einen für Blätter, die anderen für Blüten bestimmt wären, künnten wir sagen, ob die letzteren grün oder anderswie ausfallen werden.

"De Vries erwähnt einmal die Zebrastreifung. Wie soll ein Charaliter wie dieser vererbbar sein, wenn im Keim blos verschiedene Arten ron Pangenen lose nebeneinander liegen, ohne zu festen und als solche vererbbaren Gruppen verbunden zu sein? Zebrapangene kamn es nicht greben, weil die Zebrastreifung keine Zellen-Eigenschaft 
ist; es kann vielleicht kurz gesagt , schwarze' oder , weisse' Pangene geben, deren Anwesenheit die schwarze oder weisse Färbung einer Zelle bedingen. Aber die Zebrastreifung beruht nicht auf Entwickelung ron Schwarz und Weiss innerhalb einer Zelle, sondern auf der regelmässigen Abwechselung ron Tausenden streifenweise angeordneten schwarzen oder weissen Zellen.

„De Vries bezieht sich auch einmal anf die zuweilen durch Rückschlag auf eine weit zurückliegende Stammform entstehende langstengelige Abart der alpinen Primula acaulis. Auch hier kann der Charakter der Langstengeligkeit nicht auf ,Langstengel-Pangenen' bernhen, denn die Langstengeligkeit ist keine intracelluläre Eigenschaft. Ebensowenig die spezifische Form der Blätter u. s. w. Der gesägte Rand eines Blattes kann nicht auf der Anwesenheit von ,Säge-Pangenen beruhen, sondern er berulit auf eigentiimlicher Anordnung der Zelien des Blattrandes. Ebenso verhält es sich fast bei allen Charakteren, die wir als sichtbare, Ligenschaften' der Art, Gattung, Familie u. s. w. bezeichnen, so bei der Grösse, Strulitur, Befilzung, Gestalt eines Blattes, den charakteristischen und oft so durchans konstanten Farbenflecken auf Blumenblättern (Orchideen) u. s. w. Alle diese ,Eigenschaften' kommen nur durch das ordnungsmässige Zusammenwirken vieler Zellen zu stande. Oder denke man an ,Eigenschaften" des Menschen, an seine Schädel-, seine Nasenform u. s. w. Alle diese so charakteristischen ,Eigenschaften* können nicht einfach nur auf der blossen Anwesenheit der Pangene im Keim beruhen, welche die Hunderte und Tausende verschiedener Zellen bilden sollen, die die betreffende ,Eigenschaft zusammensetzen, sondern sie müssen auf einer festen und von Generation auf Generation übertragbaren Gruppenbildung der, Pangené oder irgend welcher andern primärer Elemente des Keimes beruhen.

„Das Charakteristische der Art kann nicht blos auf Anzahl und Verhältnis der Pangene im Keim beruhen. Es liessen sich ganz wohl zwei recht verschieden gebaute Arten denken, deren Pangen-Material des Keimes nach Art und Zahl gleich wäre; der Unterschied würde dann lediglich in einer Gruppenbildung von Pangenen im Keim liegen. Allerdings führt de Tries, die systematische Differenz auf den Besitz verschiedener Arten von Pangenen'zurück und meint, die Anzahl der gleichartigen Pangene in zwei Species sei das wirkliche Maass ihrer Verwandtschaft, allein dieser Ausspruch scheint mir nicht ganz zu stimmen mit der Grundansehauung, von welcher ausgegangen wird, und nach 
welcher, der Charakter jeder einzehnen Art aus zahlreichen erblichen Eigenschaften zusammengesetzt ist, von denen weit ans die meisten bei fast nn\%ibligen anderen Arten wiederkehren'. Wird doch ausdriicklich herrorgehoben, dass die grosse Anzahl verschiedener l'angene, welche ,zum Autbau einer einzelnen Art schon gehört, doch nicht zu einer ganz unfassbaren Menge verschiedener Pangene in der gesamten Organismenwelt führt, weil zum Aufbau dieser, eine im Verhältnis zur Artenzahl geringe Anzahl von einheitlichen erblichen Eigenschaften ausreicht. Jede Art erscheint uns als ein äusserst kompliziertes Bild, die ganze Organismenwelt aber als das Ergebnis unzälliger verschiedener Kombinationen und Permutationen von relatir wenigen Faktoren.

"Der hier so klar und bestimmt ausgesprochene Gedanke des Aufbaues zahlloser Arten aus rerschiedenen Zusammenstellungen relativ weniger Pangene zeigt, dass auch rom de Vries'schen Standpunkt aus nicht das den Keim zusammensetzende Material an Pangenen in erster Linie das Bestimmende für den Charakter der Art sein kann, sondern in viel höherem Grade die Anordnnng desselben, oder wie ich es später bezeichnen werde: die Architektur les Keimplasma's.

"Wohl spricht auch de Vries an verschiedenen Stellen von,Gruppen" ron Pangenen, aber er streift den Gedanken nur und verweist seine Anstührung auf die noch zu erwartenden weiteren Aufschlüsse über den Mechanismus der Kernteilung. So wichtig aber ohne allen Zweifel die von le V ries vertretene Grundanschaumg einer Zusammensetzung der Ḱeimsubstanz aus primären Anlagen ist, so täuscht sie doch leicht über lie 'Tragweite ihres Frklärungsvermögens; ohne die Annahme einer Bildung vieler, einander umfassenden Ordnungen von Gruppen solcher primärer Anlagen kommt man nicht zur Erklärung auch nur der einfachsten Ontogenese, geschweige denn der verwickelten Erscheinungen les Rückschlags und der amphigonen Vererbung überhaupt. Die Darwin'sche P'angenesis leistet hier noch mehr als die de Vries'sche Abänderung dersclben, insufer'n sie cloch wenigstens mit Zellen-Anlagen operiert, withrend die blosse Anwesenheit einer bestimmten Pangen-Gesellschaft in krim nicht einmal sicherheit dafür gew ihht, lass die gleichen tellen beim hinde \%u stande kommen, wie sie beim Elter rorhanden war'n; denn der Clarakter der einzelnen \%elle wird durch eine bestimmte Auswahl ron Pangenen bestimmt. Wenn freilich angenommen wird, dass die erfurderliclien Pangene überall da beisammen liegen und zur Verfïgung stehen, wo man sie \%ur Erklärung einer Vererbungserscheinung 
braucht, dann ist die Erklärung nicht mehr schwer, aber mir scheint, dass es eben gerade darauf ankäme, zu zeigen, wieso die Beschaffenheit des Keimes es bedingen kann, dass die rechten Anlagen immer am rechten Ort sein müssen.

„De Vries spricht, wie gesagt, gelegentlich von Pangen-Gruppen, auf der andern Seite aber verwahrt er sich gegen jede ,höhere Einheiten im Keim als überflüssig. Ich kann diesen Widerspruch nur daraus verstehen, dass er die ,Eigenschaften für selbständig und völlig frei mischbar hält, somit eines Keim-Mechanismus bedarf, der ihre Trennung in beliebiger Weise gestattet. Verhielte sich dies wirklich so, wären die Anlagen nicht im Keim schon zu festen Gruppen verbunden, wie könnten jemals komplizierte, aus vielen rerschiedenartigen Zellen in bestimmter Anordnung zusammengesetzte Charaktere, z. B. ein Augenfleck auf einer bestimmten Feder eines Vogels, zum festen Artcharakter geworden sein? Ich bin der Ansicht, dass die Selbständigkeit und freie Mischbarkeit der Eigenschaften eine Täuschung ist, hervorgerufen durch die amphigone Fortpflanzung. Der Abschnitt über amphigone Vererbung, Rückschlag u. s. w. wird zeigen, wie ich mir das Zustandekommen dieses Scheins einer freien Mischbarkeit der vereinzelten Eigenschaften rorstelle.

„Es wird im Verlauf dieses Buches noch vielfach herrortreten, in wie vielen und gerade den wichtigsten Punkten ich nit dem holländischen Botaniker auf dem gleichen Boden stehe, ich glaube aber allerdings, dass seine ,Pangene oder ähnliche kleinste Lebensteilchen allein zum Aufbau einer Vererbungstheorie noch nicht genügen, dass noch einiges hinzugefügt werden muss, um die Erscheinungen im Prinzip wenigstens begreif bar zu machen."

So weit Weismann. Ich habe diese Ausführungen gegen de Vries, denen ich natürlich nur insofern beistimme, als ich für den Bestand einer präformistischen Vererbungstheorie die Annahme eines bunt zusammengesetzten, aber einer bestimmten Architektur folgenden Keimplasma's für unerlässlich halte, hier unverkürzt hergesetzt, um nunmehr auf Grund dieser unwiderlegbaren Einwände zu zeigen, dass Weismann 's Determinantenlehre ebenfalls unmöglich ist, wenn man nicht ihre Konsequenzen ziehen und aus dem Lager der Wissenschaft in das des theologischen Dogmatismus übergehen will.

Weismann gelangt zu der Folgerung, dass in jeder Keimzelle nicht blos ein Id vorhanden ist, sondern deren viele. Ein Teil von diesen wird während der Keimesgeschichte in Determinanten zerlegt und 
in Biophoren aufgelöst, ein anderer Teil dagegen bleibt ruhig liegen nnd aus ihm entstehen die Individuen der folgenden Generationen. Da aber die Ide allmählich aufgebraucht werden müssten, folgert W e isman n weiter, dass sich die nicht zur Auflösung in Determinanten und Biophoren gelangenden Ide durch Teilung fortptlanzen und sich dadurch fort und fort vermehren, so dass immer Reserve-Ile für künftige Generationen rorhanden sind. Leider aber kommt die Vermehrung der Ide durch Teilung: auf dasselbe hinaus, wie fortgesetzte Neuschöpfung, denn bei der Teilung muss das Id notwendigerweise zu Grunde gehen.

Wir könnten, um die Teilung zu verstehen, zunächst annehmen, dass die einzelnen Determinanten des Ides durch Vermehrung ihrer Biophoren wachsen. Wenn das der Fall wäre, so müssten die lde sich auch bei ihrer Vermehrung in ihre einzelnen Biophoren auflösen; wie diese sich aber wieder in der durch die Körperarchitektonik der betreffenden Organismenart geforderten Weise zusammenfinden sollten, ist, wie Weismann durch seine Ausführungen gegen de Vries selbst gezeigt hat, nicht einzusehen; aus Unordnming kann keine Ordnung entstehen. Weismann ist denn auch überhaupt nicht auf die Frage, auf welche Art und Weise the lde es fertig bringen, sich dureh Teilung zn vermehren, eingegangen.

Die soeben angestellten Betrachtungen zwingen uns also dazu, die Annahme, dass die Ide sich durch das Wachstum ihrer einzehnen Determinanten vermelnen, zu verwerfen. Da bleibt denn weiter nichts als die andere übrig, dass sich ein Teil des Ides ohne vorherige Vergrösserung seiner Determinanten abspaltet und dass sich beide Teilstïcke wieder zu einem Ganzen vervollständigen. Macht man aber diese Annahme, so versteht man nicht, wie das Id, das ja dann durch Wachstum nicht veründert ist, dazı kommen soll, sich röllig willkürtich in zwei oder mehrere Stücke zu spalten. Eine solche Spaltung kommt einem Deus ex machina gleich. Wir können deshalb anstatt ihrer ebenso gut eine Neuschöpfung des Ids durch Gott amnehmen. Gesetzt aber auch, die Zerklüftung des Ids wäre irgendwie auf mechanische Weise verständlich zu machen, so müssten wir doch daran verzweifeln, die Vervollständigrung des zerbröckelten Ids zu einem Ganzen zu begreifen, denn ein Id ist kein Kristall, sondern besteht aus einer grossen Anzahl ron Teilen, die in hohen Grade roneinander abweichen mol sich nach Weismann is Annahme unabhängig roneinander veründern können.

Wie sollte num der Bruchteil eines Ils dazu kommen, sich wieder in regelrechter Weise zu ergänzen? Man müsste doch annehmen, dass 
die an der Bruchfläche liegenden Determinanten, beziehungsweise die sie zusammensetzenden Biophoren aus der umgebenden Nährsubstanz durch Assimilation neue Biophoren und Determinanten bilden. Allein dadurch würden nur solche Lebensträger und Bestimmungsstücke entstehen können, wie sie zufälligerweise an der Bruchfläche liegen, und das Id müsste sich deshalb in einer Weise ergänzen, die nun und nimmermehr zu derjenigen Vervollständigung führen könnte, welche von dem architektonischen Aufbau des Körpers verlangt wird. Das könnte nur dann der Fall sein, wenn die neu assimilierten Biophoren sich je nach ihrer Lage ungleich ausbildeten. Damit aber wäre die Präformation in ihr Gegenteil, nämlich in Epigenesis verwandelt, und wenn wir für die Vermehrung der Ide durch Teilung eine epigenetische Theorie annehmen müssen, so wird sich uns auch für die Erklärung der Vererbung überhaupt eine solche als die einzig zulässige aufdrängen. Terwerfen wir aber eine epigenetische Erklärung, so bleibt die Vermehrung der Ide durch Teilung ein unlösbares Rätsel, und es bleibt dann weiter nichts übrig, als dafür entweder-immer neue Schöpfungsakte Gottes anzunehmen, oder die Keime sämtlicher zukünftiger Vertreter einer Organismenart in den ersten von Gott erschaffenen Individuen dieser Art eingeschachtelt sein zu lassen.

Dass aber die Annahme sich fortwährend wiederholender Neuschöpfungsakte wenig Befriedigendes für sich hat, haben schon die alten Präformationstheoretiker gewusst. Sie liessen deshalb die Keime der späteren Generationen in die jeweilig lebenden Vertreter der Tier- und Pflanzenarten eingeschachtelt sein und sagten, dass bei der Erschaffung der Stammeltern der Tier- und Pflanzenarten auch gleichzeitig Keime für alle folgenden Generationen erschaffen worden wären. Wenn unsere neuen Präformationstheoretiker sich nicht zu der Annahme, dass bei jedem Zeugungsakte eine Neuschöpfung durch Gott stattfindet, bequemen wollen, was natürlich nur mit einem Verzicht auf die wissenschaftliche Erklärung der Vererbung geschehen könnte, so bleibt ihnen nichts weiter übrig, als zu der alten Einschachtelungstheorie zurückzukehren.

Jede Annahme persönlicher Schöpfungsakte ist aber unwissenschaftlich, weil sie sich vermisst, die Grenzen des Naturerkennens zu überschreiten.

Wir sind also zu dem Ergebnis gelangt, dass die Vererbung nicht an ein polymiktes Plasma gebunden sein kann. Weismann hat uns gezeigt, dass die vielfach verschiedenen Vererbungsträger, die der Prä- 
formisnus annehmen muss, nicht ungeordnet durcheinander gemischt sein können. Sind sie aber, wie Weismann annimmt und annehmen muss, architektonisch geordnet, so können die "Ide", welche sie bilden, sich nur auf dem Wege der Epigenesis vermehren. Die Epigenesis, deren Unmöglichkeit W e isman n „förmlich“ nachgewiesen zu haben wähnt, erscheint, von We ism an n allerdings unbemerkt, wieder wohlgemut auf der „Keimbahı", um dafür zu sorgen, dass es Weismann's Iden nicht an Nachkommen fehlt. Weismann's Determinantenlehre ist ein schönes Spielzeng, dessen Uhrwerk mit grosser Umsicht und Exaktheit ausgefeilt worden ist; aber ein Perpetuum mobile hat auch Weismann nicht fertig gebracht. Das Schicksal aller eingebildeten Erfinder des Perpetuum mobile hat auch ihn ereilt; sein Perpetuum continuum zerreisst, sobald sich die einen Irle in Determinanten und Biophoren aufgelöst und die anderen durch den umbesonnenen Versuch, sich zu vermehren, unfreiwilligen Selbstmord begangen haben. "Sterblicher" und weniger "kontinuierlich" als W'eismann's "Keimplasma" dürfte nicht leicht irgend ein anderes Ding im Himmel oder auf Erden sein.

Der Präformismus ist damit endgültig beseitigt. Wir könnten ihn also ruhig seinem Verfall überlassen, zumal man nach Goethe's Rat nicht mit dem Irrtum streiten, sondern ihn nur andeuten soll. Aber der Weismannismus hat schon zu viel Verwüstungen auf den Gefilden der Biologie angerichtet, als dass wir ihn unseziert begraben dürften. Wir haben uns also wenigstens mit dieser grössten Leistung präformistischer Treibhauskultur noch weiter zu befassen.

\section{b. Das Wesen der organischen Formbildung.}

Wer zur Entscheidung der Frage gelangen will, ob eine Vererbungslehre auf Präformismus oder Epigenesis zu begründen ist, der muss eine richtige Anschaunng iber das Wesen der organischen Form zu gewinnen suchen. Das Wesen der Form lässt sich aber nur dadurch richtig beurteilen, dass man Formen reihen aufzustellen sucht. ihre Glieder untereinander vergleicht und die Unterschiede herrorhebt, die gleichwertige Formen von ungleichwertigen trennen. Da die Präformationstheorie darauf hinausläuft, alles, was wir am Organismus beobachten, als gleich gut angepasst darzuthun, so können wir erstens fragen, was denn den Unterschied zwischen höheren und niederen 
Tieren, der uns so unverkenubar entgegentritt, bedinge, ob höhere Tiere besser angepasst sind als niedere oder ob die Entwickelungshöhe nicht durch die Vollkommenheit der Anpassung bedingt wird. Wir müssen ferner fragen, ob die Anpassung entarteter Tiere, also etwa der Parasiten, eine Vervollkommnung bedeute, oder ob wir auch bei jenen zwischen Entwickelungshöhe einerseits und Anpassungsvollkommenheit anderseits zu unterscheiden haben. Daran wirl sich die weitere Frage schliessen, ob die Variabilität nur nach einer Richtung oder nach allen Richtungen hin arbeitet, und ob die einzelnen Teile eines Individuums in Abhängigkeit roneinander variieren oder nicht, ob sie also durch Korrelation beherrscht werden, oder ob ihnen Autonomie zukommt. Bei dieser Frage werden wir zwischen wahrer und falscher Korrelation zu unterscheiden haben, lenn von Korrelation sprechen auch die Präformationstheoretiker. Es fragt sich aber, ob das, was sie unter Korrelation verstehen, wirklich solche ist; denn die Annahme echter Korrelation bedingt eine Verwerfung jeglicher präformistischer Anschauungen.

\section{Epimorphismus und Paramorphismus.}

Der orthodoxe Darwinismus, welcher zur Zeit immer noch Zoologie und Botanik beherrscht und namentlich von Weismann auf die Spitze getrieben worden ist, hat die Sucht gezeitigt, in jeder einzelnen Einrichtung der Tiere und Pflanzen eine zweckmässige Anpassung zu erblicken. Eine solche Anschauung verträgt sich freilich gut mit der Präformationstheorie, die eine Autonomie der im Keimplasma durch distinkte Keimpartien vorgebildeten Organe annimmt. Weismann lässt, wie wir gesehen haben, das Id, das einem tierischen oder pflanzlichen Artvertreter entsprechen würde, zusammengesetzt sein aus Determinanten, und er lässt diese letzteren aus selbständig variierenden Biophoren bestehen. Es herrscht also nach Weismann's Anschauung volle Autonomie der einzelnen Organe im Körper, denn diese können natürlich nur dann selbständig variieren, wenn jedes für sich im Keime vorgebildet ist. Es fragt sich nur, ob die einzelnen Organe eines tierischen oder pflanzlichen Individuums auch wirklich selbständig variieren, wie Weismann stillschweigend voraussetzt. Wenn alle Einrichtungen eines Organismus sich unabhängig voneinander verändern können, wenn sie demnach alle in zweckmässiger Weise aneinander und an die Aussenwelt angepasst sind, dann kann von einer Unterscheidung verschiedener Entwickelungshölıen nicht die Rede sein, denn die Naturzüchtung würde 
dann dafür sorgen, dass alle Tier- und Pflanzen-Arten in allen ihren Eigenschaften so vollständig ihren Lebensbedingungen angepasst sind, dan- sie atle auf gleicher Entwickelungshöhe stehen; es fragt sich aber. ob das thatsächlich der Fall ist. Wir haben also darüber zu entschei(ten. ob sich unabhängig ron zweckmässigen Einrichtnngen höhere und niedere Entwickelungsstufen unterscheiden lassen, oder ob das nicht angeht, und ob alle Einrichtungen der Organismen gleich vollkommen den Lebensbedingungen angepasst sind oder nicht.

Die Thatsache, dass hier wie dort eine Abstufung stattfindet, die höhere und niedere Entwickelungsstufen, vollkommenere und unvollkommenere oder gar fehlende Anpassung unterscheiden lässt, könuten wir als Epimorphismus bezeichnen. Jit dem Namen Paramorphismus würde dagegen ein Verhalten der organischen Natur zu benennen sein, wonach Entwickeluugshöhe und Anpassuugsvolkommenheit als gleichbedeutend zu betrachten sind und ein Unterschied zwischen vollkommenen und unvollkommenen Einrichtungen nicht besteht.

Wir bekennen uns zur Epigenesis und haben demgemäss zunächst den Nachweis zu führen, dass es unablüngig von jeglicher Aupassung an bestimmte äussere Verhältnisse eine Abstufung der organischen Formen nach ihrer Entwickelungshöhe giebt.

Dabei werden wir zweckmässigerweise zunächst diejenigen tierischen Individualitäten untereinander vergleichen, die bei den meisten vielzelligen Tieren die Art repräsentieren; das sind die tierischen Personen. An die Vergleichung der Personen hat sich dann eine solche der Organe, aus welchen die Personen zusammengesetzt sind, und die der Stöcke, die aus mehreren Personen bestehen, anzuschliessen.

Der Epimorphismus der Tierpersonen in Bezug auf ihre Entwickelungshöhe, die nichts mit der Anpassungsvollkommenheit 'zu' thun hat, ist unverkenubar für alle diejenigen, die nicht durch einreitige Vererbungs- und Umbildungstheorieen an einer unbefangenen Würdigung der Naturerscheinungen gehindert werden. Vergleichen wir zunächst die erwachsenen Personen der gegenwärtig lebenden Tiere niteinander, stellen wir also ein System der Entwickelungsabstufungen innerhalb zusammengehöriger Gruppen auf, so zeigt es sich schon bei Vergleichung der Grösse. dass diese unabhäugig ist von besonderen Anpassungen. In allen Tiergruppen ohne Ausnahme läuft neben der Abstufung der Entwickelungshöhe auch eine solche der Grösse einher; das ist unzweifelhaft für denjenigen, der die Vergleiche in richtiger Weise 
vornimmt, d. h. solche Entwickelungsreihen aufstellt, die einigermaassen wenigstens der Vorfahrenreihe der betreffenden Tiere entsprechen. Man darf nicht etwa einen Kolkraben und einen Strauss miteinander vergleichen und dann sagen: der Strauss, der ja doch auf viel tieferer Entwickelungsstufe steht als der Kolkrabe, widerlege durch seine Körpergrösse den Satz, dass Körpergrösse und Entwickelungshöhe gleichbedeutend sind. Man muss vielmehr einen Kolkraben mit den übrigen Arten der Gattung Corvus und diese mit den übrigen Gattungen der Corviden vergleichen und von hier aus den Vergleich über andere Singvogelgruppen ausdehnen. Es ergiebt sich dann, dass mit zunehmender Körpergrösse bei den Vorfahren der Raben auch eine Erhöhung der Entwickelungsstufe einherging, und dasselbe sehen wir überall in der Tierwelt, wo wir die Vergleiche in richtiger Weise anstellen. Vergleichen wir etwa die Menschenaffen mit den Hundsaffen, so finden wir, dass sie im Durchschnitt weit grösser sind als diese; wir sehen ferner, dass die letzteren in ihrer durchschnittlichen Körpergrösse hoch über den auf tieferer Entwickelungsstufe stehenden Breitnasen stehen, dass diese ihrerseits wieder viel grösser sind als die kleinen Krallenaffen, und dass wir unter den Halbaffen die kleinsten Vertreter der Vierhänder antreffen. In ähnlicher Weise nimmt die durchschnittliche Körpergrösse in allen übrigen Tierabteilungen mit zunehmender Entwickelungshöhe gleichfalls zu. Es ist überflüssig, dafür noch weitere Beispiele anzuführen, denn jeder, der seine Augen nicht verschliessen muss, um dem Anblick ihm unangenehner Dinge zu entgehen, wird leicht die Thatsache feststellen können, dass das Gesetz zunehmender Körpergrösse das gesante Tierreich beherrscht, und ich glaube, dass auch die Botaniker zu ähnlichen Schlüssen in Bezug auf die Pflanzen gelangen werden.

Dass aber die Körpergrösse gleichbedeutend ist mit Anpassungsvollkommenheit, lässt sich nicht behaupten. Viele Riesentiere der Vorwelt mussten deshalb zu Grunde gehen, weil ihre Körperdimensionen zu gewaltige waren. Wenn allein Anpassungszweckmässigkeit die Entwickelung der organischen Welt beherrschte, so wäre nicht einzusehen, weshalb es überhaupt Organismen von so ungleicher Körpergrösse giebt, wie wir sie thatsächlich antreffen. Wenn, wie Weismann will, Körperplasma und Keimplasma nichts miteinander zu thun haben, wenn das Körperplasma nur da ist, um die Ernährung des Keimplasma's zu besorgen, wenn also etwa der gewaltige Walfisch nur die Bedeutung hat, seine Keimzellen in der Welt herumzutragen, wie es doch nach Weismann'schen An- 
schauungen nicht anders sein kann, so sieht man nicht wohl ein, weshalb die Natur solcher Riesentiere bedurft hat, um eine geringe Anzahl winziger mikroskopischer Objekte im Meere spazieren zu fülıren. Die vielgerülımte Sparsamkeit der Natur erscheint hierbei in sonderbarem Lichte, und das vergötterte Selektionsprinzip scheint doch manchmal recht unbrauchbare Dinge gezeitigt zu haben. Wenn thatsächlich alle einzelnen Einrichtungen der Tiere und Pflanzen zweckmässige Anpassungen bedeuten, wenn, wie We is mann will, an den Walfischen geradezu alles angepasst ist, so kann man nur staunen über die Iühe, welche es machen muss, etliche winzige Keimzellen des Walfisches im Meere fortzubewegen.

Wenn zweckmässige Anpassung allein die Welt beherrschte und alle einzelnen Teile des Organismus aufs genaueste ihren Aufgaben entsprächen, wenn die Natur unbarmherzig jede unzweckmässige Einrichtung zerstörte, so dürfte die Körpergrösse der Organismen niemals die Grenze überschritten haben, die durch die Grösse der Keimzellen bedingt wird. Eine Schöpfung melırzelliger Organismen und eine T'rennung von Keimzellen und Körperzellen könnte niemals stattgefunden haben; denn da es sich nach den Anschanungen Weismann's und seiner Anhänger, welche die Natur lediglich durch ein auf die Spitze getriebenes Selektionsprinzip beherrscht sein lassen, um nichts weiter handeln kann, als dass die Tier- und Pflanzenarten thunlichst vor dem Aussterben beschützt werden, da es ferner lediglich Zellen mit Keimplasma sind, welche die Fortpflanzung besorgen, so sind alle anderen \%ellen überflüssig und müssten deshalb nach orthodoxer darwinistischer Anschauung vom Übel sein. Die Organismenschöpfung hätte nie über die Bildung etwa von Bakterien linauskommen dürfen, und diese zeigen ja auch, dass sie vollkommen befähigt sind, ilıre Art zu erhalten, während grosse Tiere, wie Walfisch und Elefant, sich nur äusserst langsam fortpflanzen. Die Abstufung der Grössenverhältnisse in Tier- und Pflanzenreich spricht also durchaus dagegen, dass alle einzelnen Einrichtungen des Tier- und Pflanzenkörpers besonderen Anpassungen ihre Entstehung rerdanken. Die Grössenverhältnisse der Organismen zwingen uns zu der Annahme eines Epimorphismus, einer Abstufung in Bezug auf die Entwickelungshöhe, welch' letztere nichts mit Anpassungsvollkommenheit zu thun hat.

Das Gleiche lehren uns die geometrischen Grundformen der Tiere und Pflanzen. Man kann olne alle Bedenken behaupten, dass aus Tieren, deren Grundformen durch gleiche Achsen bedingt werden, sich solche zu entwickeln trachten, bei welchen die Achsen ungleich sind, 
bei welchen die allseitige Symmetrie melır und mehr abzunelımen bestrebt ist. Das lehren eine grosse Reihe von Tiergruppen. Die Grundformen der Medusen nehmen ihren Ausgang von einer regelmässigen Pyramide, einer geraden Pyramide, die durch gleiche Kreuzachsen bedingt wird. Solche Formen gehen in die mit zwei ungleichen Kreuzachsen, deren Grundfläche ein zweischneidiges oder amphithektes Vieleck, in den meisten Fällen ein Rhombus ist, über. Bei diesen Formen sind die gleichwertigen Körperstücke einander paarweise symmetrisch-gleich und kongruent. Durch weitere Abnahme der ursprünglich allseitigen Symmetrie entstehen zweiseitig-symmetrische Formen, die nur noch aus spiegelbildlich gleichen, aber nicht melır aus kongruenten Hälften zusammengesetzt sind. Endlich giebt es bei den Medusen auch unsymmetrische Formen, die zwar aus zwei kongruenten, aber aus unsymmetrischen Hälften zusammengesetzten gleichwertigen Körperstücken bestehen; solche Formen sind die Velellen. Wir sehen nun, dass die Abnalıme der Symmetrie eine Zunahme der Organisationshöhe bedeutet, denn das zeigt sich unverkennbar bei Vergleichung der sonstigen Organisationsverhältnisse der Medusen, die sich durch ungleiche Grundformen unterscheiden. Es geht aber aus einer solchen Vergleichung aufs deutlichste hervor, dass die Grundform bei den Medusen nichts zu thun hat mit der Anpassungsvollkommenheit. Eine quadratpyramidenförmige Meduse ist ebenso gut zu leben befähigt wie eine, deren Grundform einer rhombischen Pyramide entspricht.

Eine älnnliche Grundformenreihe wie bei den Medusen können wir bei den Korallen aufstellen. Die Aktinien und ihre Verwandten haben zwei Symmetrieebenen; die Edwardsien stehen in der Mitte zwischen den Aktinien und den Oktokorallen, welch' letztere nur noch eine einzige Symmetrieebene besitzen. Ähnliches finden wir bei den Seeigeln. Die Entwickelung der Grundform hat ihren Ausgang genommen von Arten mit regelmässig fünfseitiger Pyramidenform, wie wir sie bei den ältesten Seeigeln finclen. Es bildet sich aber nach und nach anstatt der fünf Symmetrieebenen eine einzige heraus, so dass wir schliesslich bei ausgesprochen bilateral-symmetrischen Formen anlangen. In allen Gruppen der echten Mollusken herrscht das Streben, aus symmetrischen Tieren unsymmetrische zu machen, und ähnliches lässt sich für andere Tiergruppen behaupten. Asymmetrie ist das Ziel der Grundformenentwickelung, allseitige Symmetrie bildet ihren Ausgangspunkt. Dass die Grundformenverhältnisse in allen Tiergruppen zweckmässige Anpassungen an eigenartige Existenzbedingungen bedeuten, wird nur derjenige zu be- 
haupten wagen, der durch unzulängliche Vererbungslehren zu einer solchen Behauptung gezwungen ist. Es ist zwar sicher, dass die symmetrische Körperform bein Vogel und beim Fisch eine recht zweckmässige ist, allein was hat die leichte Andeutung einer Asymmetrie bei den Ktenophoren oder Kammquallen mit dem Wohl und Wehe dieser Tiere zu thun? Weshalb sollten sich Medusen mit einem Tentakel wohler befinden, als solche mit vieren? Weshalb sollten sie weniger leicht dem Untergange preisgegeben sein? Man kann sogar behaupten, dass solche Medusen recht unzweckmässig gebaut sind. Es lässt sich also die Abstufung der Girundformen, die uns in vielen Tiergruppen so unverkennbar entgegentritt, in keiner Weise mit demjenigen Nützlichkeitsprinzip in Einklang bringen, das in jeder Einrichtung eine besondere Leistung der Naturzüchtung erblickt, und was in dieser Beziehung von den Tieren gilt, gilt auch von den Pflanzen, denn regelmässige Blüten werden so gut befruchtet wie unregelmässige. Die Grundformenverhältnisse der Organismen lassen einen Epimorphismus erkeunen, der nichts mit Anpassungsvollkommenheit zu thun hat, sondern sich lediglich auf die Entwickelungshöhe bezicht.

Nichts mit dem Niitzlichkeitsprinzip zu thun hat auch die allmähliche Verminderung lomologer Organe, die bei den Tieren im Laufe der Stammesgeschichte stattgefunden hat. Auch durch Vergleichung der Anzahl homologer Organe in einer Organismenreihe erkennen wir aufs unzweideutigste einen Epimorphismus. So vermindert sich die Anzahl der Zehen bei den Säugetieren stetig innerhalb fast aller $A b$ stammungsreihen. Die Anzahl der Wirbel wird in fast allen Reihen der Wirbeltiere fortwährend vermindert, so dass beispielsweise der Schwanz der Säugetiere immer kürzer wird und endlich schwindet. Ähnliches lehren die Gliedertiere, z. B. die Krebse. Die Zahl ihrer Folgestï̈cke oder Metameren nimmt ab und die ihrer Gliedmaassen wird reduziert. Jan wird vielleicht versucht sein, hierin eine zweckmässige Einrichtung zu erblicken, weil eine geringere Anzahl ron Organen eine bessere Anpassung im einzelnen zulasse. Allein die Asseln und andere niedere Krebse erfreuen sich ebenso gut ihres Daseins wie die Krabben, und die Tausendfüsse existieren ebenso gut wie die Insekten. Unter den letzteren befinden sich die mit vier Flügeln ebenso wohl wie die zweiflügeligen. Der Mensch, der doch allgemein als das höchstentwickelte Säugetier betrachtet wird, hat noch an Hand und Füssen die fünf Zehen seiner ältesten Vorfahren im Stamme der Säugetiere, und eben deswegen 
ist er befähigt, Kunstwerke auszuführen, wie sie kein anderes Tier anzufertigen vermag. Vervollkommnung der Anpassung geht also keineswegs Hand in Hand mit der Reduktion gleichwertiger Organe. Was hat mit der Anpassungsvollkommenheit etwa die Terkürzung des Schwanzes bei den Säugetieren zu thun? Wir gelangen durch diese Betrachtungen zu dem Satze, dass die Reduktion homologer Organe im Laufe der stammesgeschichtlichen Entwickelung einen Epimorphismus bedeutet, der unabhängig ist von zweckmässiger Anpassung im einzelnen.

Ein ähnlicher Epimorphismus ergiebt sich in Bezug auf die relativen Grössenverhältnisse der einzelnen Gliedmaassen innerbalb einer Tiergruppe. Bei den Säugetieren nimmt im grossen und ganzen die Anzahl der Beine stetig ab, die der Arme ebenso stetig zu, und ich werde demnächst zeigen, dass dieser Epimorphismus nichts zu thun hat mit der Anpassung, dass sich die Anpassung der Organe im einzelnen viel mehr nach dieser Abstufung der Entwickelungshöhe zu richten hat. Für die Zeichnung der Tiere ist der Epimorphismus der Entwickelungshöhe durch Eim er festgestellt worden. Dieser verdienstvolle, aber leider vielfach rerkannte Naturforscher hat gezeigt, dass die Verteilung der Farben bei den Tieren nach festen Gesetzen erfolgt. Bei den Säugetieren geht Fleckenzeichnung aus Längsstreifung und die Querstreifung aus Fleckenzeichnung hervor, und wenn sich damit auch die Zeichnung der Schmetterlinge und Vögel vielleicht nicht vergleichen lässt, so zeigt sich doch überall ein unverkennbarer Epimorphismus. Bei den Vögeln besteht dieser darin, dass buntgezeichnete Tiere Einfarbigkeit anstreben. Man braucht, um dieses sofort zu sehen, nur die Raben mit ihren tiefer stehenden Verwandten, den Paradiesvögeln, zu vergleichen, oder die kleinen überaus bunten Papageien Australiens neben die Kakadus und Aras zu stellen. Sowohl unter den Kakadus als auch unter den Aras sind die höchstentwickelten Formen, also einerseits der Arara-Kakadu, anderseits der Hyacinth-Ara, durch Einfarbigkeit ausgezeichnet. Der Epimorphismus der Entwickelungshöhe zeigt sich in der That nirgends so gut, wie an der Zeichnung der Tiere, mögen nun die Gesetze, welche Eimer aufgestellt hat, das Richtige getroffen haben oder anderen Platz machen müssen. Dass die Entwickelung der Zeichnung durch strenge Gesetzmässigkeit beherrscht wird, lässt sich nicht in Abrede stellen, und diese Gesetzmässigkeit bedeutet keineswegs eine Anpassung an äussere Verhältnisse, sondern bringt lediglich einen Epimorphismus der Entwickelungshöhe zum Ausdruck. 
Der Lpimorphismus der Osgane lässt sich schwieriger feststellen, als derjenige ganzer Personen, soweit wenigstens die Entwickelungshöhe der Organe betroffen wird; indessen zeigt sich doch auch bei ihnen vielfach eine unverkennbare Abstufung der letzteren. Als Beispiel führe ich das Hirschgeweih an, dessen Entwickelung mit kleinen, kurzen, bleistiftdicken Stangen begonnen und zu dem stattlichen Kopfschmuck des Wapiti und dem gewaltigen Geweih des Riesenhirsehes geführt hat. Die Anzahl der Sprosse nimmt stetig in gesetzmässiger Weise zu, und die Sprosse zeigen das Bestreben, miteinander zu verschmelzen und Schaufeln zu bilden. Man braucht nur Abbildungen von Hirschen miteinander zu rergleichen, um sich ron diesem Epimorphismus der Entwickelungshöhe eines Organes zu iiberzeugen, und wer lebende Hirsche beobachtet hat, der kann sich der Einsicht nicht verschliessen, dass grosse Hirscligeweihe doch recht unzweckmässig sind; verdankt doch vielleicht der Riesenhirsch dem gewaltigen Geweih seinen Untergang. Ähnliches wie für das Geweih der Hirsche gilt für die Hörnerformen der Antilopen und anderer Wiederkäuer. Bei den Büffelı hat die Entwickelung der Hörnerform ihren Ausgang genommen von graden, spitzen Hörnern, wie wir sie noch bei der Anoa ron Celebes finden. Den Hörnern der Anoa gleichen die der jüngeren Büffelkälber; sie biegen sich dann später auf die Seite und bilden endlich die gewaltigen Hornplatten auf dem Schädel des Kafferbüffels. Dass dessen Gehörn aber zweckmässiger wäre, als das der Anoa, lässt sich nicht behaupten; im Gegenteil erscheint das letztere viel mehr geeignet zu erfolgreicher Bekümpfung von Gegnern, als das des Büffels. Ein ähnlicher Epimorphismus lässt sich für die Hörnerform der Gnus und aller anderen Antilopen feststellen; sie hat nichts zu thun mit zweckmässiger Anpassung. So ergiebt sich auch bei Organen ein Epimorphismus der Entwickelungshöhe, für welche jeder Belege zu finden wissen wird.

Dasselbe gilt für den Epimorphismus der Stöcke; auch dieser ist unverkennbar, zumal bei den PHanzen; aber auch für die Tiere hat er Gültigkeit. Solches lehren beispielsweise die Grundformen der Stöcke bei den Korallen. Wir finden hier eine ähnliche Übergangsreihe ron vielseitig- zu zweiseitig-symmetrischen Stöcken, wie bei den Personen der Korallen; wir brauchen nur die Grundformen der Pennatuliden untereinander zu vergleichen. Ilit zweckmässiger Anpassung haben diese nichts zu thun; ebensowenig lässt sich das letztere von der zunehmenden Einheithichkeit der Stöcke bei den Siphonophoren behaupten; diese zeigen 
das unverkennbare Bestreben, ihren schwimmenden Polypenstock einheitlicher zu gestalten, so dass er mehr und melır einer einzelnen Person ähnlich wird.

Nach alledem kommen wir zu dem Ergebnis, dass die Entwickelungshöhe der Tiere eine ganz unzweidentige Abstufung zeigt, dass ein unverkennbarer Epimorphismus sie beherrscht. In Bezug auf diese Entwickelungshöhe, die nichts mit zweckmässigen Einrichtungen im einzelnen zu thun hat, sind die Tiere durchaus ungleichwertig. Sehen wir nummehr zu, ob sich auch für die mehr oder minder weitgehende Anpassung ähnliches ergiebt oder nicht!

Die Höhe der Anpassung ist nicht an die der Entwickelung gebunden, und vielleicht könnten deshalb alle Tiere gleich gut angepasst sein, obwohl sie nicht auf gleicher Entwickelunghöhe stehen. Das ist aber nicht der Fall; es giebt sicher Tiere, die besser angepasst sind als andere. Die Wanderratte hätte niemals die Hausratte verdrängen können, wenn diese ihrem Wohngebiete gut angepasst gewesen wäre. Obwohl die Wanderratte aus einem anderen Gebiete zu uns nach Europa kam, hat sie dennoch die Hausratte in verhältnismässig kurzer Zeit bis auf wenige Reste verdrängt. Das hätte nicht möglich sein können, wenn die Organe der Tiere unabhängig voneinander variieren, wenn also für jedes Organ zu jeder Zeit die Möglichkeit gegeben ist, sich neven Anforderungen entsprechend umzüchten zu lassen. Wir finden aber, dass die Organe ungleich gut angepasst sind, dass ein und dasselbe Tier gut und schlecht angepasste Organe besitzt. Das könnte nicht der Fall sein, wenn jedes für sich variierte, wenn also präformistische Vererbungstheorien das Rechte getroffen hätten. Epigenetische setzen Wechselwirkung, Korrelation voraus, und wo Korrelation herrscht, sind die Organe voneinander abhängig und können sich deshalb nicht in beliebiger Weise an die Aussenwelt anpassen. Neben dem Epimorphismus der Entwickelungshöhe finden wir also auch einen Epimorphismus der Anpassungsvollkommenheit.

Dieses Gesetz bleibt auch in Geltung, wenn wir nicht nur die heutige Tierwelt ins Auge fassen, sondern die Faunen der verschiedenen Erdperioden miteinander vergleichen. Neben einem unzweideutigen geologischen Epimorphismus, der sich in der Entwickelung aller Tiergruppen dadurch ausspricht, dass höhere Formen auf niedere folgen, finden wir ebenso unzweideutig, dass die Anpassungsvollkommenheit unabhängig von geologischer Stufenfolge ist. Wir finden schon in den ältesten Erd- 
schichten 'liere, die in hochgradiger Weise ihren Lebensbedingungen angrepasst gewesẹn sein müssen. Eine Präformationstheorie vermag den geologischen Epimorphismus der Entwickelungshölie nicht zu erklären. denn da sie alle Tiere als gleich gut angepasst betrachten muss. so müsste es möglich gewesen sein, dass die Entwickelung einer Tiergruppe bald nach vorwärts und bald nach rückwärts erfolgte. Warum sich die Tiere unaufhörlich in einer Richtung weiter gebildet haben, ist nach prïformistischer Ansicht nicht einzusehen. Es hätte, wie bereits $\mathrm{N}$ ä geli ausgefülnt hat, ein unsicheres Hin- und Herschwanken geben müssen, denn die Lebensbedingungen haben vielfach gewechselt und sind keineswegs nach einer Richtung hin verändert worden. Vögel hätten sich wieder zu Reptilien umbilden müssen, wenn die Entwickelung allein von Zweckmässigkeitsrücksichten in Bezug auf Einzelheiten beherrscht wird. Aus höheren Säugetieren hätten wieder niedere werden müssen, kurz ein Epimorphismus hätte nicht eintreten können. Bei Präformation, bei Autonomie der einzelnen Vererbungstrüger des Keimplasma`s, ist Volwärts- und Rückwärtsentwickelung möglich. Der Epimorphismus lässt sich mit ihr niclit vereinigen.

Dasselbe gilt ron dem geographischen Epimorphismus, der noch wenig Beachtung gefunden hat, aber berufen ist, ein entscheidendes Wort in entwickehungsgeschichtlichen Fragen zu sprechen. Die Verbreitungsgebiete der Säugetiere sind in unverkennbarer Weise abgestuft. Australien, Madagaskar, Afrika und der Norden der alten Welt zeigen einen geographischen Epimorphismus, wie er schöner nicht gedacht werden kann. Australien belıerbergt Beuteltiere und Ursäuger, Madagraskar niedere Vierhänder, die Halbaffen, und tiefstehende Raubtiere und Insektenfresser, Afrika eine Reihe höherer Tierformen, wie sie in Madagaskar noch fehlen, und aus der Säugetiergeschichte des Nordens der östlichen Errdhalbkugel geht hervor, dass hier die höchsten Formen gelebt haben müssen, zu welchen es die Süugetiere überhaupt gebracht haben. Ist doch auch dieses Gebiet die Heimat der höchstentwickelten Menschenrassen. Ich kann bei diesem geographischen Epimorphismus ler Säugetiere hier nicht länger verweilen und verweise denjenigen, der Weiteres darüber nachzulesen wünscht, auf meine "Sehöpfung der lierwelt". Ich will nur noch darauf hinweisen, dass auch für die Vögel ein ähnlicher funnistischer Epimorphismus gilt. In äusserst auffïlliger Weise zeigen das die Hühnervögel. Ihre tiefststehenden Formen, die Kiwis und Moas, finden wir in Neuseeland; etwas höher stehen die 
Walnister, australische Hühnervögel, und die merkwürdigen Hühner Südamerikas, und je mehr wir uns nach dem Norden hin bewegen, desto höhere Formen erhalten wir; die höchststehenden sind die Waldhühnel des Nordens. Von den Spechten muss dasselbe gesagt werden; hoch entwickelte Spechte finden wir im Norden, tiefstehende im Süden, und ich glaube in meiner „Schöpfung der Tierwelt"6 den Nachweis geführt zu haben, dass die Entwickelungshöhe abhängig ist von der Ausdehnung des Wohngebietes, vorausgesetzt dass sich sonst alles andere gleichbleibt. In Bezug auf die verschiedenen Faunengebiete der Erde haben wir also von einem Epimorphismus der Entwickelung zu sprechen.

Dagegen ist ein Paramorphismus der Entwickelungshöhe ebenso unverkennbar, wenn wir die Tiere eines einzelnen Wohngebietes untereinander vergleichen, soweit solches durch die Verbreitungsmöglichkeiten der verschiedenen Tiergruppen, die ja sehr verschieden sind, ellaubt wird. Ein Land, das von tiefstehenden Säugetieren bewohnt wird, beherbergt auch tiefstehende Vögel; wir brauchen nur an das australische Faunenreich $z u$ erinnern, wo wir neben Beuteltieren und Ursäugern Emus und Kasuare, Grossfusshühner, Kiwis und andere tiefstehende Togelformen finden. Ähnliches gilt für Sïdamerika. Geographischer Epimorphismus der gesamten Tiergebiete muss ja durch geographischen Paramorphismus in Bezug auf die Bewohner eines einzelnen Gebietes bedingt sein. Wenn man sich näher mit tiergeographischen Fragen beschäftigen wollte, wozu leider nur geringe Aussicht vorhanden ist, würde man diesen Satz überall bestätigt finden, sobald bei den Vergleichungen die nötige Umsicht beobachtet wird.

Wie der geographische Epimorphismus bei Annahme von Präformismus zu erklären ist, vermag ich nicht einzusehen, denn Präformismus setzt gleiche Anpassungsvollkommenheit voraus; für ihn ist Anpassungsvollkommenheit gleichbedeutend mit Entwickelungshöhe; dann aber könnte es keine faunistischen Abstufungen geben.

Vergleichen wir die einzelnen Länder der Erde miteinander in Bezug auf die Anpassungsvollkommenheit der von ihnen bewohnten Tiere, so finden wir überall gute und schlechte Anpassungen. Während die Tiere südlicher Länder allerdings häufig in hohem Grade einseitig angepasst sind, sind die des Nordens durchweg vielseitiger, aber in jedem Falle ebenso gut angepasst wie jene. Die Faunen der Erde zeigen, dass in Bezug auf Anpassungsvollkommenheit sich ein Paramolphismus für die Gesamtheit der Faunengebiete feststellen lässt. Der 
Präfornismus wird das Nebeneinanderbestehen dieses Paramorphismus und jenes Epimorphismus schwerlich erklären können, denn nach ihm ist Entwickelungshöhe und Anpassungsrollkommenheit gleichbedeutend. Dem geographischen Epimorphismus und Paramorphismus der Entwickelungshöhe und Anpassungsvollkommenheit wird also nur eine epigenctische Theorie gerecht, weil diese Korrelation zur Voraussetzung hat, Korrelation der einzelnen Zellen des Körpers und nicht minder auch Ablı̈ngigkeit der Bewohmer eines Landes von dessen Eigentümlichkeiten. Jene Korrelation muss bedingen, dass unter übrigens gleichen Umständen die Entwickelungshöhe ron der Geschichte, die Anpassung im einzelnen von der Beschaffenheit eines Landes abhängt, wie wir später klar sehen werden.

Zu einem ähnlichen Ergebnis gelangen wir, wenn wir die Entwickelungsgeschichte des Individuums in Bezug auf die hier vorliegenden Fragen zu Rate ziehen. Sie lehrt uns, dass die Aupassung der einzelnen Organe auf gleicher ontogenetischer Stufe ungleich weit gediehen ist, dass also hier Epimorphismus herrscht, und ferner, dass die Anpassung des einzelnen Organes auf seinen verschiedenen ontogenetischen Stufen ungleich vollkommen ist, was wiederum Epimorphismus bedingt. Die Entwickelungshöhe ist auf verschiedenen ontogenetischen Stufen ungleich für die einzelnen Organe, und die Entwickelungshölıe der einzelnen Organe rerglichen untereinander ist ungleich auf einer und derselben Stufe; aber die ontogenetische Entwickelungshöhe des gesamten Körpers nimmt bei Tieren, die nicht infolge von Parasitismus oder ähnlicher einseitiger Lebensweise verkümmert sind, in grossen und ganzen zu.

Wie erklärt die Präformationstheorie diese Thatsachen? Nach ilır sind die kleinsten Teile des Körpers autonom; es dürfte deshalb einen Epimorphismus, wie ihn die Ontogenie aufweist, nicht geben. Alle Teile des Körpers müssten auf jeder ontogenetischen Stufe gleich gut angepasst sein, denn sonst hätte das Zweckmässigkeitsprinzip eingreifen und die weniger oder zu gut angepassten Teile beseitigen müssen. Augen und Ohren des Menschen dürften sich erst kurz vor dem Gebrauch aus bis dahin schlummernden Biophoren entwickeln. Aber die einzelnen Teile des Organismus entwickeln sich, weil Epigenesis die organische Welt beherrscht, in Abhängigkeit voneinander. Epigenesis bedeutet Korrelation und diese lïsst keinen ontogenetischen Paramorphismus der Aupassungsvoltkommenheit auf gleicher Entwickelungsstufe zu, denı 
in einem Gesamtsystem haben sich die einzelnen Teile nacheinander zu richten, und jedes kann sich nicht auf beliebige Weise seiner Umgebung anpassen. Wenn die Präformationstheorie die ungleiche Anpassung der Organe während der Keimesentwickelung erklären will, so muss sie notwendigerweise eine Einschachtelung der Organkeime, also der Determinanten ineinander vornehmen. We ismann nimmt ja auch an, dass Biophoren, Determinanten und Ide so lange latent bleiben, bis ihre Zeit gekommen ist. Dieses Latentbleiben lässt sich aber auf keine andere Weise erklären, als dass man die betreffenden Gebilde eingeschachtelt sein lässt in diejenigen, die ihnen in der Entwickelung vorausgehen, denn andernfalls könnten sie nicht in unthätiger Ruhe verharren, da die Entwickelung doch auch nach Weismann's allerdings inkonsequenter Ansicht von Mechanismus und Chemismus beherrscht wird, da also jederzeit eine Wechselwirkung der nebeneinander liegenden Stoffe nicht nur möglich ist, sondern überhaupt nicht ausbleiben kann. Der Präformismus muss notwendigerweise die Einschachtelungstheorie auch nach dieser Seite hin ausdehnen.

\section{Orthogenesis und Amphigenesis.}

In allgemeinen hat die Entwickelung der Organismen nach oben hin stattgefunden, d. h. es haben sich die höheren Entwickelungsstufen aus den niedrigeren hervorgebildet. In vielen Fällen ist jedoch das Umgekehrte geschehen; manche Tiere, beispielsweise die Parasiten und viele Haustiere, sind degenerirt, und dasselbe gilt von vielen Organen auch bei hochentwickelten Tieren.

Vor allem sind die Parasiten geeignet, das Wesen der Weismann'schen Präformationslehre zu beleuchten; sie muss diese Tiere als ebenso hoch entwickelt ansehen, wie etwa einen Elefanten oder den Menschen, denn nach Weismann ist alles nur angepasst, nach ihm existiert nichts, das nicht zweckmässig wäre. Für We ismann's Präformismus giebt es nur Anpassungsvollkommenheit.

Wir werden später Gelegenheit haben zu sehen, auf welche Weise sich die Theorie der Epigenesis mit der Abstufung der Tierwelt ihrer Entwickelungshöhe nach und mit der Degeneration der Organe und ganzer Tiere abfindet, und wie die Präformationstheorie die Entartung zu erklären sucht. Im Anschluss an unsere bisherigen Betrachtungen haben wir aber zunächst zu fragen, ob die Variabilität eine allseitige ist, vder 
ob sie nur nach vorgeschriebener Richtung hin erfolgt. ob wir Amphigenesis oder Orthogenesis feststellen können.

Betrachten wir zunächst ein einzelnes Organ, etwa das Auge, so sehen wir, dass dieses sich aus einem einfachen Pigmentbecher, der eine Linse erhält, nach und nach zı jenem hochentwickelten Sinneswerkzeug entwickelt, wie wir es etwa bei den Raubrögeln antreffen. Ein Hin und Her in seiner Entwickelung hat es innerhalb einer zusammenhängenden Abstammungslinie nicht gegeben, und wenn es verkümmert, bildet sich ein Teil mit oder nach dem anderen zurïck; ist es geschwunden, so kann es nie wiederkehren. Es kann vielleicht an seine Stelle ein nenes Organ, etwa ein Taster treten, wic er sich bei den Caccilien findet, aber ein einmal verschwundenes Organ kommt in der früheren Form nie wieder zum Torschein. Das gilt für sämtliche Organe der Tiere und Pflanzen; ihre Entwickelung ist, abgesehen von einigen Fällen plötzlichen Rückschlags, die wir später erörtern werden, eine orthogenetische. Genau dasselbe muss über den Gesamtkörper der Tiere und Pflanzen ausgesagt werden. Innerhalb jeder Abstammungslinie ist die Entwickelung immer nur nach einer Richtung hin ror sich gegangen, überall hat $\mathrm{O} r$ th ogenesis stattgefunden. Die Säugetiere sind vielleicht von Amphibien abzuleiten, diese von tiefstehenden Fischen, wie die letzteren von schädellosen Wirbeltieren; aber nie und nirgends ist ein Säugetier wieder zum Amphibium, ein Amphibium wieder zum Fisch geworden. Das Pferd können wir in ununterbrochener Stufenfolge ron fünfzehigen Vorfahren ableiten. Aber wenn auch gelegentlich durch Rückschlag die Anzahl seiner Zehen wieder verdoppelt wird, so ist es doch völlig ausgeschlossen, dass aus den heutigen wild lebenden Pferden dermaleinst wieder fünfzehige Tiere werden.

Wie will die Präformationslehre diese Thatsachen erklären, die Thatsache, dass die Entwickelung unter allen Umständen stets nach einer Richtung hin erfolgt, und dass ein einmal geschehener Schritt nientals wieder rückgängig gemacht worden ist, dass es also keine Amphigenesis giebt. Im Laufe der wechselvollen Geschichte unseres Planeten müsste eine derartige Rückentwickelung doch oft genug vorteilhaft geresen sein, namentlich dann, wenn dic Verhältnisse wieder denen ähnlich wurden, die ehedem geherrscht hatten. Man kann sich sehr wohl rorstellen, dass es für flugunfähige Laufvögel unter Umständen von grossem Vorteil gewesen sein müsste, wieder zu fliegenden Vögeln zu werden. Solches oder ähnliches ist niemals geschehen. Und doch hätte es leicht eintreten 
müssen, wenn die Präformationstheorie mit ihrer Annahme autonomer Vererbungsträger Recht liat.

Diese ron Weismann sogenannten Biopheren haben ja doch die Fähigkeit, sich nach allen Richtungen hin umzubilden; sie müssen für jeden Schritt vorwärts auch einen entsprechenden Schritt rückwärts thun können. Wenn sie das nicht fertig bringen, dann sind sie eben nicht autonom. Wenn sie aber geschehene Schritte ungeschehen zu machen rermögen, so hätte oft genug eine Rückzüchtung stattfinden müssen. Die Paläontologie zeigt aber, dass solches auch nicht in einem einzigen Falle geschehen ist. Gewiss, die Parasiten sind degeneriert, aber auch sie haben sich stets in gerader Richtung ungebildet. Die Vorfahren der unförmigen Sackkrebse waren keine Tiere, die den letzteren irgendwie ähnelten.

Folgen wir aber der Epigenesislehre, so begreifen wir, dass sich die Tiere wohl oder übel in einer Richtung weiterentwickeln müssen, denn die Theorie der Epigenesis nimmt ein monotones Keimplasma, also Abhängigkeit jeder Zelle des Körpers von dem gesamten Keimplasma an, und dieses lässt nur Entwickelung nach einer Richtung hin zu. Verändert sich das Keimplasma durch irgend welche Einflüsse, so verändern sich sämtliche Organe des Körpers. Wirken weiterhin dieselben oder andere Umbildungsursachen auf das reränderte Keimplasma ein, so treffen sie ein anderes Plasma als zuvor, und dasselbe geschieht, wenn neue Einflüsse von aussen wieder und wieder V'eränderungen im Plasma hervorbringen. Alle Umbildungsursachen arbeiten jedesmal mit einem anderen Plasma und eine Rückentwickelung kann deshalb nicht stattfinden.

Freilich bleibt dabei noch unerklärt, warum die Höhe der Organisation allmählich zunimmt. Diese Zunahme der Organisationshöhe werden wir später ursächlich zu begründen haben. Jedenfalls ist die Präformationstheorie mit der unumstösslichen Thatsache der Entwickelung nach einer Richtung hin völlig unvereinbar, weil sie nur durch die Annahme autonomer Biophoren bestehen kann.

Der Satz, dass die Entwickelung nach einer Richtung hin stattfindet, gilt aber nur für die durch Abstammung in auf- und absteigender Linie verbundenen Glieder einer Entwickelungsreihe, nur für die gerade Vorfahren- und Nachkommenlinie jedes tierischen Individuums. Von einem Punkte aus, wo sich eine Abstammungslinie in zwei oder mehrere Äste spaltet, kann die Entwickelung nach mehreren Seiten hin stattfinden: 
aber auch dann, wemn sich eine Abstanmungslinie gegabelt hat, laufen ihre Zweige oft annähernd parallel. So sehen wir beispielsweise; dass der Daumen sich sowohl bei den Affen der Alten, als auch hei denen der Neuen Welt rückzubilden bestrebt ist, und die Nager und Insektenfresser bilden zwei Gruppen niederer Säugetiere, deren Entwickelung in hohem Grade parallel gelaufen ist. Den Eichhörnchen unter den Nagern entsprechen die Spitzhörnchen unter den Insektenfressern, die Igel unter den letzteren finden ihr Gegenstück in den Stachelschweinen und deren Terwandten unter den Nagern, die Entwickelung der Spitzmäuse licf der der Yäuse parallel, und ein solcher Parallelismus lässt sich für fast alle anderen verwandten Tiergruppen und nicht minder auch bei den Pflanzen feststellen.

Wie findet sich die Prïformationstheorie mit diesen Thatsachen ab? Sie kann sie nicht erklären, weil sie autonome Vererbungstrïger, die in grosser Anzahl das Keimplasma zusammensetzen, annehmen muss. Das monotone Ḱeimplasma der Epigenesislehre ermöglicht dagegen Entwickelungsreihen, die zwar von einem Punkte aus divergieren, aber dennoch in mancher Beziehung parallel laufen.

Dieser Parallelismus ist oft genug ein solcher, mit welchem Anpassungsähnlichkeiten nichts zu thun haben können. In allen Weichtiergruppen tritt, wie wir gesehen haben, das Bestreben hervor, unsymmetrische Tiere zu bilden. Dieses lässt sich nur auf die Eigentümlichkeiten des monotonen Plasma's der Urweichtiere zurüchführen, weil das letztere entweder schon hier die ersten Spuren der Asymmetrie bewirkte, oder weil es die Fähigkeit hatte, sie in den einzelnen Abstammungsreihen der Weichtiere hervorzubringen. Dadurch, dass es nicht aus antonomen Biophoren zusammengesetzt war, sondern einen monotonen Bau hatte, in welchem Veränderungen, welche die betreffenden 'Tiere unsymmetrisch werden liessen, eintreten konnten, musste es überall eine Umbildung nach einer Richtung hin bewirken. Wenn man autonome Biophoren annimnt, so vermag man nicht einzusehen, weshalb Asymmetrie in allen Gruppen cchter Weichtiere einzutreten bestrebt gewesen ist, denn als eine Anpassung an ähmliche Lebensbedingungen kann sie unmöglich aufgefasst werden. 


\section{c. Korrelation und Autonomie.}

An der Thatsache der K or relation muss jede Präformationstheorie scheitern. Wer sich freilich zur Rettung unhaltbarer Vererbungslehren einzureden sucht, dass die einzelnen Organe des Tier- und Pflanzenkörpers unabhängig voneinander variieren, der kann nicht die Überzeugung gewinnen, dass alle Zellen des Körpers sich verändern, wenn eine einzige von ihnen umgebildet wird. Und doch ist dieser Satz, auf welchen sich die Epigenesistheorie gründet, absolut unanfechtbar, denn auch die allernächstrerwandten Tier- und Pflanzenarten und schwer voneinander zu trennende Rassen einer Art unterscheiden sich bei genauem Zusehen in aller und jeder Beziehung voneinander. Dasselbe gilt von den Individuen einer Art. Wir dürfen mit vollkommener Sicherheit behaupten, dass zwei Tiere, die in Bezug auf eine einzige Zelle voneinander abweichen, es auch in allen anderen thun. Derjenige Systematiker, welcher diesen Satz umstösst, wird nicht gefunden werden. Denn, wer nur seine Augen offen hat, kann ibn auf Schritt und Tritt bestätigt finden. Was aber sagen die Präformationstheoretiker dazu?

Weismann lält sich überhaupt nicht bei dieser Frage auf. Er betrachtet es von vornherein als ganz selbstverständlich, dass alle Organe des Körpers unabhängig voneinander variieren, und begründet durch diese röllig unbegreifliche Annahme seinen sogenannten „förmlichen Beweis" dafür, dass nur eine Präformationstheorie die Vererbung zu erklären vermag. Dagegen giebt de Tries sich Mühe, die Behauptung, dass die einzelnen Teile der Organismen unabhängig voneinander variieren, einigermaassen zu beweisen. Da Weismann den Satz von der autonomen Variabilität der Organe fast stillschweigend als selbstverständlich hinstellt und gar nicht daran denkt, ihn irgendwie zu begründen, so müssen wir uns an de Vries halten, um diese uns unbegreifliche Behauptung in ihr rechtes Licht zu setzen.

De Vries sagt, dass man früher jede Art als eine Einheit betrachtet labe und die Gesamtheit ihrer Artmerkmale als ein einheitliches Bild, und wundert sich darüber, dass die neuesten Theorien der Vererbung dieses Bild als ein der weiteren Zerlegung nicht bedürftiges hinnehmen. Das Licht der Abstammungslehre zeigte nach de V ries, dass die Artcharaktere aus einzelnen voneinander mehr oder weniger unabhängigen Faktoren zusammengesetzt sind. Fast jeden dieser letzteren soll man bei zahlreichen Arten finden, und ihre wechselnde Grup- 
piernng und Verbindung soll die ausserordentliche Mannigfaltigkeit der Organismenwelt bedingen. Sogar die einfachste Vergleichung der verschiedenen Oryanismen führt nach de V ries zu der Überzeugung von der zusammengesetzten Natur der Artmerkmale. Dieselben Blattformen, dieselben gröberen und feineren Einkerbungen des Blattrandes sollen nach der Ansicht des holländischen Botanikers bei zahlreichen Arten wiederkehren, und schon dic gewöhnliche Terminologie soll lehren, dass die Bilder säntlicher Blattformen aus einer verhältnismässig geringen Zahl von einfacheren Eigenschaften zusammengesetzt sind. - Es wäre überflüssig, meint de Vries, die Beispiele zu häufen, denn sie seien einem jeden leicht zugänglich, und es komme nur darauf an, sich in den Gedanken, dass die Natur der Artmerkmale eine zusammengesetzte ist, so vollständig einzuleben, dass man überall die Zusammensetzung des Bildes aus seinen Einzelheiten klar durchschaut.

Freilich, darauf kommt es allerdings an! Wer sich nicht in den Gedanken einer unmöglichen Vererbungstheorie eingelebt hat, der wird völlig anderer Ansicht sein, dem wirl sich niemals zeigen, dass der Charakter jeder einzelnen Art aus zahlreichen erblichen Eigenschaften zusammengesetzt ist, von denen weitaus die meisten bei fast unzähligen anderen Arten wiederkehren, der kann unmöglich glauben, dass die Faktoren, welche den Charakter der einzelnen Arten zusammensetzen, ron ungleichem Alter sind, wie de Vries behauptet. Keine Überlegung vermag dem, der sich nicht dem Präformismus in die Arme geworfen hat, zu zeigen, dass die Merkmale einzeln oder in kleinen Gruppen erlangt worden sind. Ein solcher wird auch parallele Anpassungen in entfernten T'eilen des Stammbaumes nicht zır Begründung einer Autonomie der Vererbungsträger heranziehen und die insektenfressenden Pflanzen nicht zur Aufstellung der Behauptung benutzen, dass das Leimplasma ein Mosaik ist, weil Pflanzen der verschiedensten natürlichen Familien sich zu Insektenfressern umgebildet baben und deshalb „Pangene" in ihrem Keimplasma führen müssen, welche diese Eigenschaft bedingen, sie deshalb lervorbringen können, weil sie unabhängig von den übrigen Pangenen des liörpers sind. Auch die Wüsten- und Ameisenpflanzen wird nur der Präformationstheoretiker zur Begründung der Autonomie der Pangene oder Biophoren levanziehen.

Man wird wohl zugeben, meint de Vries, dass eine sehr grosse Übereinstimmmug obwaltet zwischen der Weise, in der sich Organe einer einzelnen Pflanze roneinander unterscheiclen, und den Unterschieden 
zwischen zwei differenten Arten. Er meint, dass beide offenbar auf wechselnden Verbindungen und wechselnder Auswaht aus einer grossen Reihe gegebener Faktoren beruhen, und glaubt, er brauclıe dafür kein Beispiel anzufülıren. Fälle, wo die Natur eines Organes noch nicht entschieden ist, sondern noch durch die äusseren Einflüsse bestimmt werden kann, führen nach de Vries gleichfalls zu der Schlussfolgerung, dass sich die Artcharaktere bunt zusammensetzen.

Trotz alledem müssen wir bestreiten, dass jede eingehende Betrachtung des Artcharakters und jede Vergleichung mit anderen Merkmalen dazu führt, ersteren als ein zusammengesetztes Bild aufzufassen, dessen Komponenten in verschiedenster Weise nischbar sind. Wer wirklich ohne Voreingenommenlreit eine Tier- oder Pflanzenart eingehend betrachtet und ihre Merkmale mit denen anderer vergleicht, wird vielmehr zu der unumstösslichen Überzeugung gelangen, dass jede Organismenart ein durchans einheitliches Bild bietet, und dass deshalb das Variieren der einzelnen erblichen Eigenschaften nicht unabhängig voneinander erfolgen kann.

Alle einzelnen Behauptungen und Beispiele von de Vries, die das autonome Variieren der Organe beweisen sollen, sind ohne Ausnahme unhaltbar. Die langgriffelige und kurzgriffelige Form der Primehn und die drei verschiedenen Blütenformen bei Flachsarten zeigen, dass hier Korrelation und keine Autonomie der einzelnen Organe besteht; denn es lrandelt sich hier nicht um alle möglichen Übergänge, sondern um im grossen und ganzen feststehende Formen. Diese lassen sich nur auf ein einheitliches Keimplasma zurückführen, durch welches, etwa bei den kurzgriffeligen Primeln, alle anderen Eigenschaften der letzteren mitbedingt werden. Versuche über Varietätenbildung, die von Pflanzenzüchtern im grossen angestellt worden seien, sollen nach de Vries lehren, dass fast jede Eigenschaft unabhängig von der anderen variieren kann. Zahlreiche Varietäten sollen sich nur in einem Merkmale ron ihren Stammformen unterscheiden.

Obwohl ich kein Botaniker bin, so muss ich mir doch erlauben, die Begründbarkeit dieser Behauptung auf das allerentschiedenste in Abrede zu stellen. Man vergleiche doch nur einmal die Varietäten der Stachelbeere, die lediglich nach der Beschaffenheit der Früchte bewertet werden, miteinander. Wo man die reifen Beeren unterscheiden kann, wird man in allen Fällen auch wohl unterschiedene Blätter finden. Ich habe in diesem Sommer zahlreiche Varietäten von Kirschen miteinander verglichen 
und gefunden, dass verschiedene Früchte auch ebenso ungleiche Stengel haben. Züchtet man Kirschen der Stengel wegen?

Noch bedenklicher als das Angeführte ist manches andere, was de Vries über das unahhängige Variieren der einzelnen erblichen Eigenschaften sagt. Er führt an, lass zusammengehörige Merkmale oft grup pen weise variecen, giebt also zu, dass the Pangene doch nicht so ganz autonom sind, aber dennoch glaubt er, dass solche Gruppen sich gleichzeitign umbildender Pangene keinen Einfluss auf die ïbrigen Gruppen ausüben: ich meine, dass es besser gewesen wäre, auch das gruppenweise Varieren in Abrede zu stellen. Es fördert auch de Vries' Sache nicht, wenn er behauptet, dass eine Pflanze, bei welcher eine Vermehrung der Zahl der Blumenblätter mit blumenblattähnlicher Entwickelung des Felches oder der Hochblätter zusammengeht, im übrigen normal bliebe, und dass sich bei Papaver somniferum polycephalum zahlreiche Staubgefässe zu Fruchtblättern umbilden, während alles andere an der Varietät dagegen unverändert bliebe.

Solche Beispiele giebt es, sagt de Tries, sowohl im Pflanzenreiche als auch bei Ticren zahlreiche. Allerdings! Aber die, welche de Tries anfühnt, beweisen eben, dass es ein unabhängiges Variieren nicht giebt. Auf die Behauptung, dass das Zusammenvarieren mehrerer Merkmale Ausnahme, unabhängiges Variieren Regel sei, lässt de Vries gleich das Zugeständnis folgen, dass es sich in den meisten Fällen nicht entscheiden lasse, ob das betreffende Merkmal durch eine einzelne oder lurch eine kleine Gruppe von erblichen Eigenschaften bestimmt wird. Ein schönes Beispiel für die Abhängigkeit der Merkmale voneinander führt de V ries in der Primula acaulis var. caulescens an, allerdings ohne dabei zu merken, wie wenig es einem unabhängigen Tariieren der die Merkmale zusammensetzenden Pangene entspricht, Diese Varietät entsteht von Zeit zu Zeit unter zahhreichen ungestielten Primeh, hat damn aber eine ähnliche Infloreszenz, wie die nächstrerwandten schirmtragenden Arten. Das zeigt doch wohl zur Genüge, dass Variation der Merkmale nicht an autonome Pangene gebunden ist, einerlei ob es sich um Fortentwickelung oder Küickschlag handelt.

De Tries stellt unter anderem fest, dass die erblichen Eigenschaften ganz gewöhnlich zu kleineren und grösseren Gruppen vereinigt sind, welche sich wie Einheiten benehmen, indem die einzehnen Glieder der Gruppe gewölnnlich zusammen in die Erscheinung treten. Von hier aus ist kein weiter Schritt mehr bis zur Anerkennung der Thatsache, dass für das 
Tariieren der einzelnen Eigenschaften des Kööpers, für die Abänderung seiner Zellen, der Satz gilt: „Line mit allen und alle mit einer", und ich glaube, auch de Vries wird sich zu diesem Satze bekehren lassen, wenn ihm der Nachweis gebracht wird, dass eine präformistische Vererbungstheorie, und sei sie auch noch so ins einzelne ausgearbeitet, zu den auf die Dauer unhaltbaren Dingen gehört.

Wir liaben es Weismann, der eine sauber ausgearbeitete, wenn auch nicht die letzten Konsequenzen ziebende Theorie der Präformation geliefert hat, zu danken, dass wir mit der Zurückweisung des Präformationsgedankens so leichtes Spiel haben werden. Vorerst aber müssen wir die Frage, ob Korrelation oder Autonomic die organische Entwickelung beherrscht, noch etwas näher ins Auge fassen.

Unter Korrelation hat man die verschiedensten Dinge zusammengeworfen, so dass es unerlässlich ist, klar zu bezeichnen, was darunter verstanden werden muss.

Sehr vieles, was man als Korrelation auffasst, hat mit ihr nichts zu thun. Vor allen gilt dieses von der Anpassung eines Organs an andere. Wenn sich bei den Säugetieren die Milchdrüsen dann zur Thätigkeit anschicken, wenn das Junge geboren werden soll, wenn sich beim Weibchen des Ameisenigels zur Zeit, wo das Ei gelegt werden soll, ein Brutbeutel bildet, so hat dies nichts mit echter Korrelation zu thun. Das sind Anpassungen, die zwar in indirekter Abhängigkeit voneinander entstanden sind, Einrichtungen, von welchen die eine die andere indirekt bedingt hat, aber für die Geschlechtsorgane sind Milchdrüsen und Brutbeutel ursprünglich Aussenwelt, und ilıre jetzt bestehende Abhängigkeit roneinander hat sich erst almählich herausgebildet und ist dadurch zu einer erworbenen Korrelation geworden. Dassclbe gilt von den Einrichtungen, die den Hirsch befähigen, ein sclıweres Geweih zu tragen, und von vielen anderen Dingen. In Bezug auf solche Abhängigkeitsverhältnisse ist jedes Organ für das andere Aussenwelt.

Wahre Korrelation zeigt sich dagegen oft an Teilen, die überhaupt nichts weiter miteinander zu thun haben, als dass sie demselben Keimplasma ihre Entstehung verdanken. Wenn das Keimplasma ein monotones ist, so müssen eben sämtliche Organe des Körpers in Abhängigkeit voneinander oder vielmehr von diesem monotonen Keimplasma variieren. Auch Weismann führt Fälle von wahrer Korrelation an, beispielsweise die bekannte Thatsache, dass weisse Katzen mit blauen Augen taub sind, und erklärt das einfaclı durch die völlig willkürliche Annahme, dass die 
betreffenden Biophoren im Keimplasma wohl nebeneinander liegen und deshalb durch äussere Einfliisse gleichzeitig verändert werden müssen. Bleiben wir einmal bei diesen Gedanken einen Augenblick stehen!

Sach Weismann variieren die beiden Körperlülften bilateral-symmetrischer Tiere unabhängig roneinander, was z. B. durch die unregetmässige Scheckung der Haustiere bewiesen werden soll. Wenn Weismann hierin Recht hat, dann liegen also wohl die den symmetrischen Körperstellen entsprechenden Biophoren im Id nicht nebeneinander? Es giebt aber zahlreiche Fälle, wo, wie wir gleich sehen werden, Nebenoder Gegenstücke des Körpers gleichzeitig in dieser oder jener Beziehung variieren, gleichzeitig völlig abnorme Bildungen zeigen; demnach liegen sie also im Keimplasma doch woll nebeneinander? Ich muss es Weismann überlassen, aus diesem Dilemma einen Ausweg zu finden.

Beispiele für Korrelation anzuführen, ist eigentlich nicht nötig, denn alle Tier- und Pflanzenarten, die uns die systematische Biologie kennen gelehrt hat und kennen lehren wird, liefern durch jedes beliebige Paar einzelner Merkmale einen Beweis dafür, dass Korrelation alles und jedes Geschehen in der Organismenwelt beherrscht. Trotzdem will ich einige gelegentlich von mir beobachtete Fälle abnormer Korrelation hier mitteilen.

Ich kenne einen Herrn, bei welchem Mittel- und Goldfinger an beiden Händen miteinander verwachsen sind, und führe diese Beobachtung hier an, um es Weismann und anderen Präformationstleoretikern zu überlassen, daraus zu schliessen, dass die Determinanten der beiden Körperhälften des Xenschen in unmittelbarer Nachbarschaft im Id liegen, auch wenn sie soweit voneinander getrennten Teilen entsprechen, wie es rechte und linke Hand sind. Wenn sie aber nebeneinander liegen, wie kommt es dann, dass der rechte Arm und die rechte Hand mehr gebraucht werden als die linke? Diesem Beispiele reiht sich der ron mir beobachtete Fall eines kleinen, inzwischen leider verstorbenen Mädchens an, das an beiden Zeigefingern nur ein einziges Gelenk besass, und auch der eines Albinos rom Riesensturmvogel, den ich in Australien erhielt, gehört hierher. Das Tier ist weiss, aber im Sclıwanz hat jederseits dio zweite Feder von aussen ilıre ursprïngliche chokoladenbraune Fürbung bewahrt.

Ähnlich sind die übrigen Fälle, die mir jetzt gerade ins Gedächtnis kommen. Meerschweinchen erhalten mitunter an den Hinterbeinen eine vierte Zelıe, eine kleine rudimentäre Afterzehe. Gewöhnlich tritt diese an beiden Beinen auf, manchmal aber anch nur an einem. Wie findet 
sich Weismann mit diesem wechselnden Verhalten ab? Sähe nian die Afterzehe immer an beiden Hinterbeinen auftreten, so würde man sagen, die Determinanten der Beine liegen nebeneinander in den Iden des Keimplasma's. Würde man immer nur eine Afterzehe bei Meerschweinchen beobachten, so würde man das gerade Gegenteil belıaupten. Ich muss es wieder Weismann überlassen, aus diesem Dilemma einen Ausweg zu finden, und werde später zeigen, dass es für die Epigenesislehre, die ein monotones Keimplasma und universelle Korrelation annimmt, nicht existiert. Ein weiterer Fall ist der einer Ziege, die meines Wissens noch heute im zoologischen Garten in Frankfurt lebt, bei welcher eine beiderseitige Verdoppelung einer Zitze eingetreten ist.

Aus diesen und vielen anderen ähnlichen Fällen geht unzweifelhaft hervor, dass die beiden Körperhälften zweiseitig-symmetrischer Tiere nicht unabhängig voneinander variieren, und ganz dasselbe gilt von den gleiclwertigen Stücken strahlenförmiger Tiere.

Bei Larven einer australischen Meduse, Monorhiza haeckeli, bleiben gelegentlich vier Sinneskolben hinter den mit ihnen abwechselnden übrigen vier zurück. Die einen liegen in den Körperradien erster Ordnung, perradial, die anderen in denen zweiter, interradial; die rier perradialen variieren also gleichzeitig miteinander, und ebenso die vier interradialen. Was sagt Weismann dazu: Liegen die Determinanten gleichnamiger Radien in Id etwa nebeneinander, obwohl die Perradien und Interradien in erwachsenen Tiere miteinander abwechseln? Wenn das der Fall ist, dann werden perradiale und interradiale Organe bei den Medusen jedenfalls durch verschiedene Determinanten des Ids bestimmt, und die Determinanten der perradialen Organe liegen dann nicht neben denen der interradialen. Indem ich diesen Hinweis den Präformationstheoretikern überlasse, will ich nur anführen, dass ich eine Cyanea muellerianthe gefunden habe, bei welcher sowohl die perradialen Okularläppchen als auch die interradialen abnormerweise durch tiefe Einkerbungen von den benachbarten Randlappen getrennt waren. Bei Cyanea liegen also wohl die Determinanten perradialer und interradialer Organe im Id nebeneinander, weil sie gleichzeitig variieren?

An dieser Deutung müssen wir abel wieder irre werden, wenn wir noch einmal die Monorhiza liaeckeli betrachten, die nur an dem einen Stück ihrer vier Mundarmpare, und zwar immer an dem linken, ein langes und dickes dreikantiges Anhängsel, einen sogenannten Terminalknopf trägt. Bei dieser Meduse sind also die beiden Hälften des einen 
ler vier Nebenstïcke oder Parameren des Körpers unșmmetrisch entwickelt, im Gegensatz zu denen der drei übrigen, und die Determinanten der Parameren müssten demnach als autonom betrachtet werden, obwohl. wic ich oben gezeigt habe, die perradialen und ebenso die interradialen Organe zusammen rarieren. Die Prïformationstheorie weiss ans diesen sich anscheinend so sehr widersprechenden Thatsachen keinen Ausweg zu finden. Wir werden aber zeigen, dass sich auch die eigentümliche, ohnegreichen dastehende Grundform der Monorhiza sehr wohl durch die Annalnme eines monotonen Keimplasma's und einer unirersellen Korrelation begreifen lässt.

Diesen Beispielen aus dem Tierreiche lasse ich einige aus dem Pflanzenreiche folgen.

Ich labe früher einmal eine Linaria vulgaris beobachtet, die an sämtlichen Blüten anstatt eines Sporns deren drei hatte. Hier stehen also sämtliche Blüten miteinander in Korrelation oder sind riehmehr in gleicher Weise rom Keimplasma abhängig. Ähnliches gilt von den Blättern aller Pflanzen. Einen besonders lehreichen Fall rerdanke ich dem ausgezeichneten Beobachtungstalent meines leider zu früh verstorbenen Freundes und Kollegen Wilhelm Jännicke. Er hat an Brombeeren die Thatsache festgestellt, dass die fünfteiligen Blätter aus dreiteiligen entstehen, entweder dadurch, dass sich ron dem mittleren Blättchen jederseitig zwei neue abspalten, oder dadurch, dass sich jederseits ron den beiden Seitenblïttchen nach dem Stiele zn ein neues Blättchen abtrennt. In allen Füllen aber zeigt der Umstand, dass an einer und derselben Pflanze sümtliche Blätter den gleichen Teilungsmodus folgen, dass sich die Bildungsweise der fünfgeteilten Blätter durch Spaltung des mittleren Blättchens nicht mit derjenigen durch Abtrennung neuer Blättchen ron den beiden Seitenblättchen verträgt. Die T'endenz der Teilung ist an allen Blättern einer und derselben Pflanze dieselbe; alle Blätter stehen in Kiorrelation. Selten scheinen diejenigen Fälle zu sein, wo sowohl an dem mittleren Blättchen als auch an den Seitenblättchen der Anfang zur Bildung neuer Blättchen gemacht worden ist. Jännicke hat diesen Fall nicht beobachtet, ich nur einigemale. Die beginnende T'eilung war nur an gedeutet und zeigte dadurch, dass Korrelation die Bildung der Organismen beherrscht, denn wenn sie das nicht thäte, damn hätte dio T'eilung weiter fortschreiten müssen, und Pflanzen, an denen sich sowohl das mittlere wie die Seitenblättehen völlig geteilt 
haben, dürften keine Seltenheit sein, wenn die Elementarteile der Pflanzen sich autonom rerhalten.

Diesen botanischen Beispielen möge noch eines aus dem Tierreiche folgen, bei welchem die Korrelation in anderer Weise zum Ausdruck liommt, als in den rorher genannten Fällen. Es betrifft den Satansaffen (Pithecia satanas), dessen Haut sich durch eine ausserordentlich weitgelende Neigung zur Faltenbildung auszeichnet, was nur durch Korrelation erklärt werden kann. Zwischen den Fingern des Affen finden sich Ansätze von Schwimmhäuten, ringsum vom Halse laufen starke Falten herunter zum Rumpf. Eine lange Falte zieht sich an der Beugeseite des Armes entlang, und Ellenbogen und Knie sind durch eine rom ersteren sich an dem Körper herunterziehende und bis zum Knie verlaufende Falte miteinander rerbunden. Eine ähnliche Falte findet sich zwischen Ober- und Unterschenkel.

Beispiele wie diese liessen sich tausendweise beibringen. Weismann vermag sie nicht zu erklären, führt er doch sogar die symmetrische Zeichnung bunter Tiere auf das Nützlichkeitsprinzip zurück, da nach seiner Ansicht die beiden Körperhälften unabhängig voneinander variieren. Allein wie remag das Nïtzlichkeitsprinzip es zu erklären, dass sich auf der einen Seite eines symmetrischen Tieres genau dieselben Flecke und Streifen finden, wie auf der anderen? Absolute, aber nur wenig variierende Unregelmässigkeit wäre doch hier ron viel grösserem Vorteile als symmetrische Zeichnung, denn diese verrät das Tier viel cher als röllige Regellosigkeit der Pigmentverteilung. Es ist eben unausbleiblich, dass die I'räformationstheorie überall mit sich selbst in Widerspruch gerät.

Ich verzichte auf weitere Begründung des Satzes ron der unirersellen Korrelation, die sämtliche Teile eines Organismus beherrscht, denn das Angeführte genügt, um eine klare Antwort auf die Frage nach dem Wesen der Formbildung zu geben. Diese Antwort lautet: Das Wesen der Formbildung besteht in Korrelation oder, was dasselbe ist, in Gleichgewicht. Dass der Begriff dieses Gleichgewichts ein rein mechanischer ist, werden die späteren Teile dieses Buches zeigen.

\section{d. Die Ursachen der Umbildung.}

Nach den Erkenntnissen, zu welchen wir im vorigen Abschnitte gelangt sind, können die Ursachen, durch relche die Organismen 
umgebildet werden, nur in physischen bestehen, denn metaphysische sind völlig ausgeschlossen, insofern sie nicht die allgemeinen Eigenschaften der gesamten Weltmaterie betreffen. Wer auf dem Boden der Epigenesis steht, muss dies unbedingt zugeben. Dagegen könute leicht gezeigt werden, dass eine konsequente Präformationstheorie Unterschiede machen müsste, nicht nur zwischen den Organismen und anorganischen Naturkörpern, sondern sogar zwischen den rerschiedenen Zuständen der einzelnen Elemente der Chemie. Allein in diesem Abschnitte wollen wir von der Annahme ausgehen, dass auch die Präformationstheoretiker nach bewirkenden Ursachen suchen dürfen, wie sie es auch in der That zu thun vorgeben, und da handelt es sich zunächst um die Frage, ob die Umbildungsursachen innere, d. h. lediglich innerhalb des Organismus gelegene sind, oder ob äussere Ursachen die Umformung des Organismus bewirken.

Diese Frage hängt eng mit der anderen zusammen, ob sich somatogene, d. h. vom Körper, nicht aber von den Keimzellen erworbene Umbildungen vererben können, oder ob nur blastogene Unbildungen, also solche, welche lediglich die Keimzellen betreffen, dazu befähigt sind. W eismann und andere Präformisten leugnen das erstere und schreiben allein den blastogenen Unbildungen Erblichkeit zu. Sie geraten dadurch iı ein merkwürdiges Dilemma, denn da die Keimzellen in den allermeisten Fällen wohlgeborgen im Körper liegen, so sollte man meinen, dass gerade der Körper einen Einfluss auf sie gewimnen wïrde und dass äussere Ursachen eine geringe oder gar keine Rolle bei ihrer Umbildung spielen würden. Das geben aber die Präformisten nur insoweit zu, als die allgemeinen physikalischen und chemischen Lebensbedingungen, welche die Keimzellen im Körper rorfinden, allerdings Einfluss auf sie haben, während dagegen morphologische Veränderungen des Körpers keinen Einfluss auf die Keimzellen gewinnen sollen. Es sind also, da ja der Körper ron den chemischen und physikalischen Eintlüssen der Aussenwelt abhängt, lediglich direkte äussere Einwirkungen auf das Keimplasma, durch welches nach Weismann und seinen Anhängern Umbildung in letzterem bewirkt wird.

Auch nach unserer Anschauung sind alle Umbildungsursachen, von welchen das líeimplasma betroffen werden kann, in letzter Linie äussere. Es liesse sich somit eine erfreuliche Uhereinstimmung zwischen der neuen Präformationstheorie und der Epigenesislehre konstatieren, allein es fragt sich, ub die Annahme Weismann's, dass die Umbildungen der Keim- 
zellen lediglich durch allgemeine physikalische und chemische Ursachen bedingt werden, sich mit seinen sonstigen Anschauungen verträgt.

Die vielzelligen Organismen müssen von einzelligen abgeleitet werden und diese von solchen, deren Plasma aus lauter gleichen Biophoren zusammengesetzt war. Wie ist es dann gekommen, dass diese im Laufe der Stammesgeschichte einander immer unähnlicher geworden sind? Weismann führt dieses auf die verschiedenen Ernährungseinflüsse, welche die einzelnen Biophoren trafen, zurïck, aber es fragt sich denn doch, ob ein winziges Klümpchen Keimplasma wirklich gross genug ist, um in seinen einzelnen Teilen ganz verschiedenartige Umbildungen erleiden zu können. Nach allem, was wir über die direkte Umbildung der Organismen durch äussere Einflüsse wissen, können wir nicht wohl annehmen, dass die Einflïsse, welche die unter sich gleichen Biophoren eines winzigen Klümpchens Keimplasma treffen, so verschiedenartige sind, dass daraus ein hochorganisiertes Id hätte entstehen können. Wenn wir etwa Kälteformen von. Schmetterlingen züchten, so werden alle die Färbung der Flügel hervorbringenden Plasmateile in hohem Grade gleichmässig verändert. In diesem Falle hätten wir es mit einer rein physikalischen Umbildungsursache zu thun, die allerdings eine Abänderung der bei der Entwickelung vor sich gehenden chemischen Prozesse zur Folge hat. Züchten wir Artemia salina, einen kleinen Salzwasserkrebs, in versüsstem Wasser und fahren wir damit und mit der Versüssung einige Generationen hindurch fort, so erhalten wir Krebse, die der Gattung Branchipus zugerechnet werden müssen, und diese lehren uns, dass das gesamte Plasma eine Umbildung durch die Entziehung des Salzes erfahren hat. Dasselbe geschieht, wenn wir den Salzgehalt des Wassers, in welchem die Artemien leben, erhöhen und dadurch aus der Artemia salina die Artemia milhauseni züchten. Die Süsswasserform des Stichlings unterscheidet sich nicht nur in einer, sondern in fast allen Beziehungen von der Seeform. Albinismus und Melanismus betrifft gewöhnlich das ganze Tier, und wenn wir Kanarienvögel durch Fütterung mit Cayennepfeffer färben, so werden nicht bloss einige Federn in ihrer Färbung verändert. Wenn Schafe, Kälber oder Hähne kastriert werden, so nimmt der gesamte Körper andere Eigenschaften an, trotzdem die einen Organe nahe beim Hoden gelegen sind, die anderen aber sich selır weit entfernt davon befinden.

Aus diesen Beispielen geht zur Genüge hervor, dass gleiche Plasmapartien des Körpers durch gleiche äussere Ursachen in gleicher Weise 
becinflusst werlen, und die Beispiele lassen sich noch stark rermehren. In hohen Torden der Kolonie Sü̈daustralien bekommen die dort lebenden Europäer sehr gewöhnlich Kinder mit roten Haaren, was jedenfalls durch das Klima bewirkt wird: und es ergiebt sich daraus zur Evidenz, dass alle Plasmateile der Keime, aus welchen sich rotharige Ablömmlinge eingewanderter Europäer entwickelt haben, gleichmässig beeinflusst worden sind. Dieses Beispiel zeigt, dass blastogene Veränderungen, die durch irgend welche chemische oder physikalische Finflüsse der Aussenwelt hervorgerufen worden sind, sich in allen Teilen des Keimplasma's vollziehen. Wollen wir annehmen, dass die menschlichen Haare durch einzelne Determinanten im I'lasnı rorgebildet sind, was wir ja bei der Annahme der Weismann'schen Präformationstheorie doch thun miissten, da die Haare auf einem und demselben Kopfe thatsächlich sehr oft roneinander abweichen, z. B. zu sehr verschiedenen Zeiten grau werden, so müssen wir zu dem Schlusse gelangen, dass das heisse Kilima Inneraustraliens alle Determinanten der Haare gleichmässig umbildet.

Der Albinismus beruht sicher auf blastogenen Veränderungen, und dennoch betrifft er gewöhnlich nicht nur das gesamte Pigment der Haut, sondern auch das der Augen, ja, wir wissen, dass weisse Katzen mit blauen Augen gewöhnlich taub sind.

Diese und andere Beispiele, welche wir anführen könnten, beweisen, dass gleiche äussere Einflüsse, die den Keim, sei es direkt, sei es durch den Körper seines Erzeugers hindurch, treffen, auf gleiche Plasmapartien gleichmässig einwirken. Es ist also ummöglich, dass die aus gleichen Bioplıren zusammengesetzten Wesen, von welchen nach Weismann's Ammahme die Tiere und Pflanzen abstammen müssen, ungleiche Ausbildung der einzelnen Teile ihrer Ide erfahren haben können. Wenn dem aber so ist, dam ist eine P'räformationstheorie, eine Theorie, welche tas Keimplasma aus Iden, die sich aus schr verschiedenen Determinanten und Biophoren aufbanen, zusammengesetzt sein lässt, nicht möglich. Es bleibt deshalb für den Präformismus kein anderer Ausweg übrig, als das Plasma ter ältesten Organismen, welche auf der Erde gelebt haben, schon aus ungleichen Biophoren zusammengesetzt sein zu lassen, kurz, in dem Plasma dieser Organismen schon die Sonderexistenz aller Determinanten der Teile, die bei den höheren Tieren und Pflanzen verschielen sind, anzunchmen; denn wenn der Präformismus die ältesten Lebewesen aus einer oder aus einer geringeren Anzahl ungleicher Biophorenarten zusammengesetzt sein lïsst, so luätte sich die Anzahl ungleicher 
Biophorenarten unmöglich vermehren können. Wenigstens konnten die Biophoren dann nicht die grossen Verschiedenheiten erwerben, die sie nach Weismann doch thatsächlich haben sollen. Übrigens steht die W eismann'sche Annahme, dass gleichzeitige Abänderung rerschiedener' Organe auf gleichzeitige Beeinflussung ihrer nebeneinander liegenden Determinate zurückzuführen ist, in rollkommenem Widerspruch mit der von Weismann behaupteten Autonomie der Determinanten.

Es führen uns somit auch diese Betrachtungen mit Notwendigkeit wieder dahin, dass der Präformismus nicht um die Annahme herumkommt, dass die ältesten Lebewesen von Gott geschaffen sind und in aller und jeder Beziehung so rorgebildet wurden, dass sich aus ihnen mit Notwendigkeit die Organismenreihen entwickeln mussten, deren IIitglieder später die Erde bewohnen sollten.

Wir aber gelangen wiederum zu der unerschütterlichen Überzeugung, dass es lerliglich Korrelation sein kann, die das Werden des Organismus stammesgeschichtlich und keimesgeschichtlich beherrscht, und dass ron einer Independenz seiner einzelnen Teile, ron einer Autonomie der Determinanten und Biophoren keine Rede sein kann, dass es somit überhaupt keine besonderen Determinanten im Keimplasma giebt.

Es fragt sich jetzt aber auch für uns, ob wir bei Annahme der Epigenesis gleichfalls die Möglichkeit der Keimesbeeinflussung durch somatogene Umänderungen leugnen müssen, oder ob wir ihre Annahme nicht umgehen können. Un diese Frage zu beantworten, müssen wir scharf zwischen solchen somatogenen Einflüssen, die allgemeiner physikalischer oder chemischer Natur sind, und lokalen somatogenen Umbildungsursachen unterscheiden. Die ersteren würden überhaupt zu allen denjenigen physikalischen und chemischen Einwirkungen auf das Keimplasma gehören, die entweder direkt durch die Aussenwelt oder durch die Vermittelung des die Keimzellen umschliessenden Körpers bewirkt werden; sie gehören also nicht zu den eigentlichen somatogenen Umbildungsursachen des Keimplasma's. Es fragt sich also, ob sich Veränderungen, wie sie etwa durch den Gebrauch und Nichtgebrauch der Organe, durch spezielle Anpassung an die Aussenwelt, denen beispielsweise die Gesässschwielen ihr Dasein verdanken, durch psychische Einflüsse im Gehirn und andere Ursachen hervorgebracht worden sind, sich thatsächlich vererben oder nicht. 
Lamarck liat auf solche Veränderungen seine Abstammungslehre aufgebaut, und anch Darw in hat ilıre Erblichkeit nicht geleugnet. Viele sciner heutigen Jünger dagegen, mit Weismann an der Spitze, stellen die Möglichkeit einer solchen Vererbung entschieden in Abrede, wenigstens geben sie nicht zu, dass irgend etwas für die Vererbbarkeit derartiger Abänderungen spräche.

Wir werden später sehen, dass sich somatogene Abänderungen mit absoluter Notwendigkeit vererben müssen: hier haben wir aber zunächst nur die Frage zu entscheiden, wie sich damit die Epigenesistheorie verträgt und ob nicht zu der Annahme der Erblichkeit somatogener Abänderungen besser die Präformationstheorie passt.

Wenn z. B. das Haar an der Innenseite der Schwanzspitze eines mit einem Greifschwanz rersehenen Affen durch den Gebrauch geschwunden ist und sich eine förmliche Greiflläche, wie wir sie etwa bei den Ǩlammeraffen finden, gebildet hat, so können wir fragen, ob diese Veränderungen nur einen Teil des Keimplasma's betreffen oder das gesante Keimplasma. Hier scheint zunächst die Präformationstheorie den Vorzug zu verdienen; denn wir sehen vor der Hand nicht ein, wieso ein Einfluss auf das gesamte Keimplasma durch lokale V'eränderungen an der Schwanzspitze eines Säugetieres zur Geltung kommen sollte. Wir werden aber später sehen, dass sich diese Schwierigkeit leicht ïberwinden lässt, dass sie überhaupt keine ist.

Dagegen können wir hier schon zeigen, dass die Annahme einer Präformation der Teile des Körpers im Keimplasma auf noch riel grössere Schwierigkeiten stösst, sobald wir die Vererbung somatogener Eigenschaften amnehmen. Wie sollen wir uns vorstellen, dass ein durch Nichtgebrauch verkümmertes Auge seinen mangelhaften Zustand auf die Augendeterminanten in den Keimiden des betreffenden Tieres überträgt? Solche Übertragung könnte doch entweder nur durch Keimchentransport, wie ihn Darwin annahm, erfolgen, oder man müsste annchmen, dass das Auge in geheimnisvoller Weise mit den Augendeterminanten in den Iden der Keimzellen des betreffenden Tieres zusammenlüngt. Im letzteren Falle wäre also die Annalıme einer dynamischen Úbertragung notwendig; es wäre aber dabei nicht einzusehen, weshalb diese nur die Determinanten des Auges beträfe. Weismann liat ganz recht, wenn er sagt, er kömne sich eine solche Übertragung nicht rorstellen. Allein das gilt, wie wir sehen werden, nur bei der Annahme einer Präformationstheorie. 
Monotones Keinplasma wird gleichmässig in allen seinen Teilen umgebildet, sei es, dass es von somatogenen oder von allgemeinen physikalischen und chemischen Einflüssen betroffen wird, und wir werden später zu zeigen haben, dass sich daraus sehr wohl die Vererbnng jeglicher Art von erworbenen Eigenschaften erklärt.

\section{e. Die Träger der Vererbung.}

Mit den im vorhergehenden Abschnitte angestellten Betrachtungen sind wir bei der Frage angelangt, was wir als den oder die Träger ler Vererbung zu betrachten haben. Da wir eine Vererbung somatogener Eigenschaften aunelmen, so können wir auch nicht umhin, die Vererbung von lokalen Abänderungen an irgend welchen Körperstellen zuzngeben. Wir miissen somit die Annahme einer Pangenesis, einer Vererbung von allen Teilen des Körpers ans machen, müssen uns vorstellen, dass das Keimplasma von jeder einzelnen Zelle des Körpers aus beeinflusst werden kann, und demnach haben wir zunächst die Frage zu beantworten, ob diese Übertragung auf dynamischem Wege geschieht, oder ob dazu eine Annahme von Keimchen, die nach den Keimzellen transportiert und in ihnen abgelagert werden, nötig ist. Die Annahme bunt durcheinander gewürfelter Keimchen haben wir schon früher durch Citation der lichtvollen Ausführungen Weismann's gegen de Vries als ummöglich dargethan. Wenn wir also eine Vererbung somatogener Abänderungen amehmen, so gelangen wir zu der Anschauung, dass diese anf dynamischem Wege auf die Keimzellen übertragen werden.

Es ist nicht schwierig, die Notwendigkeit dieser Übertragung einzusehen, wenn wir bedenken, dass alle Teile des Körpers, alle einzelnen Zellen miteinander in Korrelation stehen, dass der Körper einen Gleichgewichtszustand darstellt, der durch alle äusseren Einflüsse geändert werden und demnach eine Umstimmung der Zelken und damit der Elemente ihres Plasina's gestatten muss.

Die gewomnene Erkenntnis führt uns zu der weiteren Frage, ob es der Kern oder der Leib der Zelle ist, den wir als Träger der Vererbung anzusehen haben. Ist es der $\mathrm{Kern}$, so ist die dynamische Übertragung somatogener Fornueränderungen auf die Keimzellen nicht einzusehen, deun der Kern liegt im Innern der Zelle und die Zellen berüluren sich gegenseitig nur durch ihre Leiber, durch das ausserhalb des Kernes gelegene Plasma. Wir gelangen deshalb notwendigerweise zn 
der Anschauung, dass es in erster Linie das Plasma des Zell leibes is t, das wir als Träger der Vererbung anzusehen haben, und damit setzen wir uns in bewussten und scharf ausgesprochenen Gegensatz zu der heute fast universellen Anschauung, dass lediglich der Kern der Träger der Vererbung ist.

Ich muss gestehen, dass mir die Herrschaft, welche diese Anschauung gewonnen hat, völlig unbegreiflich ist, denn thatsächlich wird sowohl der Kern als auch der Körper des Eies und des Samenfadens auf das zu zeugende Individuum übertragen, und man hätte doch glauben sollen, dass die Entdeckung eines organischen Mittelpunktes des Zellleibes, die Auffindung des Centrosonı, die Alleinherrschaft des Kernes beseitigt hätte. Solange man freilich, wie Oscar Hertwig es thut, das Centrosoma zum Kern rechnet, lässt sich schwer über die Frage streiten, ob der Kern oder der Zellleib der hauptsächliche Träger der Vererbung sei. Es kann aber nicht lange mehr zweifelhaft bleiben, dass nicht der Kern, sondern das Centrosoma der organische Mittelpunkt der Zelle ist, denn wer unbefangen alles das überblickt, was wir neuerdings über die Vorgänge der Zellteilung und den Bau des Zellkörpers erfahren haben, mnss zu der Ansicht gelangen, dass das Centrosoma und nicht der Kern die erste Rolle im Aufbau der Zelle spielt.

Weismann, in dessen Vererbungstheorie nur die Annahme, dass der Kern der Träger der Vererbung sei, hineinpasst, geht über die Frage nach der Rolle des Centrosoma ziemlich kurz hinweg; er hält sie mit einem Vergleich für erledigt. Den Kern vergleicht er einem Haufen Getreide und das Centrosoma nit einem Pferd, das diesen fortzuschaffen bestimmt ist. Er sagt dann, da das P'ferd nicht zugleich Getreide sei, könne das Centrosoma, das den Kern bewegt, nicht auch Vererbungsträger sein. Tergleiche hinken bekanntlich, und dieser We ismann'sche thut es recht sehr. Wir wollen einmal einen Augenblick bei ilm verweilen. Wenn ein Droschkenkutscher auf seinen Sohn ein Pferd nebst ciner Quantität Hafer für letzteres vererbt, so darf man fragen, was das Wesentliche für den Soln ist. Wer behaupten wollte, dass es der Hafer sei, dem würde man einwenden müssen, dass der Sohn den Hafer doch nicht ror den Wagen spannt, sondern dass für sein Geschäft das Pferd das Wichtigste ist, und hinzufügen, dass das Pferd sich auch mit anderem Hafer als den geerbten begnügen würde. In unserem Vergleich ist das Centrosoma das Pferd und der Zellkern der Hafer. Allein man wird mir mit Recht einwenden, dass auch durch diesen Vergleich nichts bewiesen 
sei; iclı wollte auch nur das Unzulängliche des Weismann'schen Tergleichs, der weiter nichts ist, als eine petitio principii, darthun.

Man wird aber Thatsachen gegen mich vorzubringen suchen und rol allem auf die Experimente B overi's hinweisen, der Seeigeleier ihres Kernes beraubte und nach deren Befruchtung mit Spermatozoen einer anderen Art Larven dieser letzteren entstehen sah. In Boveri's Experimenten ist aber jedenfalls mit dem Kern auch das Centrosoma aus dem Ei entfernt worden, und es braucht deshalb niemanden zu wundern, dass das Centrosoma des Samenfadens dann allein die Zelle beherrscht. Es ist also durch den Hinweis auf die Boveri'schen Experimente keineswegs meine Anschauung, dass der formgebende Stoff des Tierlörper's im Plasma des Zellleibes, vor allem in dessen organischem Mittelpunkt, dem Centrosoma, zu suchen ist, widerlegt, und mir sind keine anderen Tersuche bekannt, auf welche sich die Anschauung, dass der Kern allein die Vererbung bewirkt, stïtzen könnte. Es sind übrigens auch schon etliche Angriffe auf diese zur Zeit herrschende Ansicht erfolgt, vor allem von Seiten Bergh's und Verworn's. Ersterer sagt mit Recht, dass, wo eine Übertragung von Kern und Centrosoma stattfindet, unmöglich der Kern allein der Träger der Vererbung sein kann, und Verworn weist darauf hin, dass dasjenige, was wirklich vererbt wird, der Stoffwechsel zwischen Kern und Zelle ist. Verworn und andere haben ja den Kern als ein Stoffwechselorgan der Zelle erkannt, und es braucht uns deshalb nicht zu wundern, dass Zellen, die des Kernes beraubt sind, zu Grunde gehen und dass das pathologisch gewordene Plasma solcher Zellen bei der Vererbung keine Wirksamkeit mehr entfalten kann.

Kommen wir noch eimmal auf jenen Weismann'schen Vergleich mit Getreide und Pferd zuriick, so können wir mit Recht sagen, dass ein Pferd, das der Vater auf seinen Sohn vererbt, dem letzteren nichts nützen kann, falls der Vater nicht auch dafür sorgt, dass sein Sohn das Pferd in genügender Weise mit Futter versehen kann. Ein Pferd, das nicht gefüttert wird, muss Hnngers sterben, und ein Centrosoma, das seines Stoffwechselorgans beraubt wird, muss notwendigerweise zu Grunde gehen. Wir kommen demnach zu der Entscheidung, dass der Zellleib mit dem Centrosoma als organischen Mittelpunkt mindestens eine ebenso grosse Rolle bei der Tererbung spielt wie der Zellkern. Nur diese Annahme verträgt sich mit der Vererbung somatogener Eigenschaften, während deren Verwerfung nur zu der Anschauung stimmt, dass allein 
der Kern der Träger der Vererbung ist. Wir brauchen uns deshalb auch nicht darüber zu wundern, lass Weismann, der die Vererbung erworbener Eigenschaften nicht zu erklären rermag, das Centrosoma mit einem hinkenden Tergleich abthut und denjenigen das Recht. in Tererbungsfragen mitzureden, abspricht, die zweicrlei Vererbungsträger annelmmen.

W e ismann, der eine solche Annahme rerwirft, lässt die Vererbung aber an eine ganze Compagnie individuell verschiedener Träger, die zahlreich in jedem Keimplasma vorhanden sind, gebunden sein. Wir wollen uns nicht weiter bei der Inkonsequenz dieser Annahme aufhalten, sondern nur den Beweis führen, dass diese Ide, welche die „Kiontinuität des Keimplasma's" sichern sollen, vermöge der Eigenschaften, die We ismann ihnen andichtet, die Tererbung individueller Eigenschaften, auf welchen allein nach Weismann die zweckmässige Fortbildung der Organismenwelt beruht, erfolgreich rereiteln.

Bekanntlich zerfïllt der Kern der Zelle bei der Teilung der letzteren in eine Anzahl ron Gebilden, die man als Kernstäbe, Kernschleifen und dergleichen mehr bezeichnet hat und am besten Chromosomen nennt. We ismann hat für diese Gebilde den Namen Idanten eingeführt, weil in ilmen die Ide stecken gleich Pillen in einer Schachtel. Die Ide sind aus den Determinanten der Zellen zusammengesetzt, diese aus den selbständig variierenden Biophoren oder Lebensträgern. Bei der Zellteilung teilen sich die Chromosomen. Nach Weismann werden dabei die "Ide" in Gruppen von Determinanten zerlegt, so dass endlich jede Körperzelle nur durch eine Determinante bestimmt wird. Die zerlegten Ide können natürich ihre Eigenschaft nicht mehr auf die Individuen der nächsten Generation übertragen, weil ihre Determinanten sich nicht wieder sammen lassen. We ismann sorgt deshalb dafür, dass die noch unzerlegten Ide sich rechtzeitig rerdoppeln, damit ein Teil der aus dieser Verdoppelung hervorgegangenen Ide unzerstückelt in die nächste Generation hinüberschlummern kann, um erst dort zum eigentlichen Leben oder vielmehr zum Sterben zu erwachen, d. h. sich auch zu zerstückelı, um die Individuen der nächsten Generation durch ihre Bestimmungsstücke zu determinieren und damn im zerlegten Zustande mit den determinierten Individuen $z u$ sterben. Wir sehen jetzt ab davon, dass die Verdoppelung der Ide, welch letztere nach Weismann ,im Kern der befruchteten Keimzelle oder auch schon vorher doppelt vorhanden" sein müssen, ein Ding der Unmöglichkeit ist, wenn man nicht entweder 
zur Epigenesis oder zur alten Einschachtelungstheorie zurückkehren will, sondern nelmmen einmal an, die Ide könnten sich wirklich verdoppeln, un ,einmal in aktirem und zerlegbarem und einmal in inaktivem und gebundenem Zustande" vorhanden zu sein. Die ersteren haben nach Weismann die Ontogenese zu leiten, die letzteren sollen passiv den Urgeschlechtszellen zugeführt werden. Im Leben des betreffenden individuellen Organismus spielen also nur die ersteren eine Rolle. Sind die Determinanten, aus welchen sie zusammengesetzt sind, gut, haben deren Biophoren in der erforderlichen Richtung variiert, oder sind sie, falls Variation schädlich war, in dem von den Lebensbedingungen erheischten Zustande geblieben, so besteht das betreffende Individuum den Kampf ums Dasein, andernfalls nicht. Wir nehmen an, die ,aktiven und zerlegbaren" Ide entsprechen den an sie gestellten Anforderungen; werden es dann auch die ,inaktiven und gebundenen", die auf die nächste Generation übergehen und erst hier ,aktiv und zerlegbar" werden, thun? Werden sie die Eigenschaften des Eilters auf die Nachkommen übertragen? Das hängt von der Wohlgewogenheit ihrer autokratischen Biophoren ab, denn obwohl die inaktiven Ide Zwillingsgeschwister der aktiven sind, so wachsen sie und teilen sich dabei doch fortwährend, wodurch sie sich verändern. Hören wir Weismann über diesen Gegenstand!

„Da das Keimplasma,“ sagt er', „einem sehr starken Wachstum unterworfen ist von der befruchteten Eizelle bis zu den Keimzellen des Nachkommen, so werden seine Lebenseinheiten, die Biophoren und Determinanten, fortwährenden kleinsten Schwankungen in ihrer Zusammensetzung unterworfen sein."

Da diese kleinsten Schwankungen aber das einzige sind, worauf nach We ismann die Anpassung der Organismen beruhen kann, so ist die Vererbung individueller Eigenschaften, durch welche nach Weismann doch in letzter Linie alle nützlichen Eigenschaften der Organismen zu stande gekommen sind, ein Ding des absoluten Zufalls, dem die „fortwährenden kleinsten Schwankungen“" in der Zusammensetzung der Biophoren und Determinanten können in der einen Generation in dieser, in der nächsten in gerade entgegengesetzter Richtung erfolgen. Eine Vererbung individueller Eigenschaften giebt es also nicht! Das Kind kann wohl zufällig die individuellen Eigenschaften des Elters haben, aber eine Notw en digk eit für dieV er er bung dieser Eigenschaften besteht nicht. Weshalb sie trotzdem vererbt werden, weiss Weismann also nicht zu erklären. Er ist gezwungen, sich dem Zufall in die 
Arme zu werfen. Will er das nicht, will er etwa ,dauernde, sich gleichbleibende Einflüsse, z. B. klimatische", wiihrend mehrerer Generationen auf seine Biophoren einwirken lassen, um sie dem Zufall zu entreissen, so muss er die alles beherrschende Bedeutung, die indiriduelle Variationen in seiner Theorie haben, preisgeben, denn ,dauernde, sich gleichbleibende Einflüsse, z. B. klimatische", welche die „kleinsten Schwankungen im Laufe der Zeit und der Generationen summieren", führen $n i c h t z u$ individuellen, sondern zu Rasseneigentümlichkeiten, weil die unter einem und demselben Klima lebenden Organismen alle miteinander von ihnen betroffen werden. Billigerweise lassen wir W eismann die Wahl zwischen dem wunderbaren Zufall, der so überaus oft die Vererbung individueller Eigenschaften bewirkt, und der Preisgabe des Fundamentes seiner Theorie. Uns geht diese, dem Autor des ,Keimplasma's" und seiner "Kontinuität" unerlïssliche Wahl, die freilich keineswegs angenehm ist, da sie für ihn eine Entscheidung für eines von zwei Übeln bedeutet, nichts an, denn wir wollen mit den $W$ eismann schen direktionslosen Tererbungsträgern, den „Biophoren“, von vornherein nichits zu thun haben. Unser. Vererbungsträger ist in erster Linie das mo no to ne Plasma des Zellleibes, insbesondere des Centrosoma, in zweiter die gleichfalls monotone Substanz der Chromosomen des Kernes. Die Verschiedenheit der Rollen, die diese beiden Vererbungsträger spielen, werden wir später kennen lernen.

\section{f. Die Bedeutung der Eigenschaften.}

\section{Bedentungsvolle und indifferente Eigenschaften.}

Wer die Weismann'sche Präformationstheoric annimmt, kann alle Eigenschaften der Organismen nur als nützliche oder wenigstens nur als bedeutungsvolle, die dem Individuum nützen oder schaden können, betrachten. Sind sie nützlich, so werden sie durch Naturzüchtung erhalten; besitzt ein Individuum aber schädliche Eigenschaften, so wird es, und damit seine Eigenschaften, durch natürliche Zuchtwahl beseitigt. Alle Eigenscliaften der Organismen müssen dem Darwinisten Weismann'scher Richtung von Bedeutung sein, entweder als zu erhaltende und zu verbessernde, oder als schädliche, mindestens als übertlüssige, umnötigerweise zu crnährende und deshalb zu beseitigende. Bedeutungslose, indifferente Eigenschaften kimn es für den, der sich zur Weis- 
mann'schen Präformationstheorie bekennt, nicht geben, lagegen muss der, welcher auf dem Boden der Epigenesislehre steht, erwarten, dass viele Eigenschaften bedeutungshos sind, denn nach der Epigenesislehre stehen alle T'eile des Körpers miteinander in Korrelation, keiner kann unabhängig von den übrigen variieren, und deshalb können nicht wohl alle Teile eine gleich grosse Bedeutung für den Organismus haben, sofern diese Bedeutung an ihre besonderen Eigenschaften geknüpft ist. Die Epigenesisłehre muss also notwendigerweise zu dem Schlusse gelangen, dass eine grosse Anzahl mehır oder minder beständiger Merkmale des Tier- und Pflanzenkörpers bezüglich ihrer besonderen Eigenschaften völlig bedeutungslos und nur deshalb vorhanden sind, weil der Organismus ein Gleichgewichtssystem darstellt, weil jeder seiner Teile in Abhängigkeit von allen übrigen Teilen variiert. Es fragt sich nun, was uns die Thatsachen in Bezug auf diese Frage lehren.

Weismann kann indifferente Eigenschaften nicht gebrauchen, deshatb leugnet er einfach, dass sie in einem anderen Zustande als dem hochgradiger Verkümmerung oder des ersten Anfanges existieren, aber eine unbefangene Betrachtung der Organismen lehrt, lass stark ausgebildete indifferente Eigenschaften in grosser Anzahl vorhanden sind.

Zu ilmen gehören zunächst noch viele rudimentäre Organe; lie grosse Zähigkeit, mit welcher diese sich vererben, zeigt, dass sie tief im Bauplan des Organismus begründet sind, dass sie mit Notwendigkeit immer wieder hervorgebracht werden müssen, trotzdem sie keine Bedeutung für den Körper und sein Leben mehr haben. Die rudimentären Organe, die oft noch von ansehnlicher Grösse sind, sprechen ebenso sehr gegen Weismann, wie die indifferenten Eigenschaften, die nicht auf Verkümmerung von Organen beruhen. Rudimentäre Organe giebt es aber in grosser Menge.

Was kann es für einen Nutzen haben, dass in der Blüte des Salbei neben den zwei thätigen Staubgefässen noch zwei völlig unbrauchbare vorhanden sind? Wie kommt es, dass viele Tiere noch woht entwickelte Afterzehen besitzen, Zehen, die völlig ausser Gebrauch gesetzt sind und ebenso gut fehlen könnten? Allerdings werden solche Organe vielfach nicht als indifferent, sondern als schädlich hingestellt: die natürliche Zuchtwahl soll auch danach trachten, sie zu beseitigen, eine Ansicht, die jedenfalls besser zur orthodoxen Zuchtwahltheorie passt, als die von der Indifferenz der rudimentüren Organe. Diese kömnten aber nur deshalb schädlich sein, weil sie anderen Organen Nahrung entziehen und 
zu ihrem cigrencen Aufbau benutzen, der von keiner Bedeutung mohr für den Körper ist. Wenn wir aber diese Frage näher ins Auge fassen, so crgiebt sich, dass geringe Unterschiede in der Grösse der meisten rudimentïren Organe von keinerlei Bedeutung für ilıre 'Träger sind, und dass Naturzïchtung auch deshalb nicht bestrebt sein kann, sie zu beseitigen. 'Thatsächlich variiert ja oft die Grösse der rudimentären Organe ausserordentlich, und diejenigen Organismen, die sie stärker entwickelt haben als ihre Artgenossen, gedeihen ebenso gut wie diese und widerlegen dadurch den Satz, dass Naturzüchtung bestrebt ist, Organe zu beseitigen, die keinen Nutzen mehr haben, sondern schädlich sind, weil sie den übrigen Organen Nahrung entziehen.

An der Hand des Plumplori sitzt ein rudimentärer Zeigefinger; er ist völlig nutzlos, wird aber doch mit '/ähigkeit vererbt, und wenn er auch im Schwinden begriffen ist, so kann es sich dabei in jeder Generation bloss um eine durchschnittliche Gewichtsverminderung ron vielleicht weniger als $1 / 1000$ Milligramm handeln. Wird jemand emstlich behaupten wollen, dass das Wohl und Wehe der Art daron abhängt, dass ein Milligramm Körpersubstanz dem \%eigefinger entzogen wird und sich gleichmässig auf die übrigen Organe des im Verhältnis zur Grösse des Zeigefingers sehr bedentenden Körpers verteilt? Der Zeigefinger des Plumplori ist also thatsaichlich weder ein schädliches, noch ein nützliches Organ, sondern ein röllig gleichgïltiges, und dasselbe gilt ron sehr vielen anderen Organen.

Viele Säugetiere haben am Unterkiefer ein Haarbüschel stehen, das aus einer bestimmten Anzahl von Haaren, in für jede Art charaliteristischer Weise zusammengesetzt ist. Bei den grösseren Süugetieren nun, beispielsweise bei Hirschen, bei der Anoa, bei Hunden und vielen anderen, ist dieses Haarbüschel ohne Bedentung. Wenn man aber den einzelnen Haaren auch noch einen geringen Grad ron Tastsinn zugestehen will, so ist es doch völlig gleichgültig, ob diese Haare mehr oder weniger regelmässig gestellt sind. Trotzden ist die Figur, die sie durch ihre Ansatzstellen bilden, eine ausserordentlich regelmässige und konstante. Es ist völligr unmöglich, der geometrischen Form dieser gewöhnlich selır kleinen Figur, die gewöhnlich nur einen Raum von wenigen Quadratmillimetern einnimmt, irgend welchen \%weck zuzuschreiben. Dasselbe gilt für die Stellnng der meisten Haare au Rumpfe der Säugetiere. Ich habe den Nachweis fülnen können und werde ihn in spaiteren Publikationen noch näher zu begriunden haben, dass bei manchen Säugetieren, 
wenn nicht bei vielen oder den meisten, die Haare in Querbänder gestellt sind, welche den einzelnen Abschnitten der Wirbelsäule entsprechen, einerlei ob die Haare an Grunde anders gefärbt sind, als an der Spitze, ob also auf diese Weise die Bänderung sichtbar zum Ausdruck kommt, oder ob die Haare in ihrer ganzen Länge gleichgefärbt sind. Jedenfalls giebt es zahlreiche Tiere mit dieser Haarstellung, die sich allerdiugs meistens nur bei genauerer Untersuchung und oft nur gelegentlich, insbesondere bei günstiger Beleuchtung, zeigen wird. Es geht aus dieser Bänderung mit Sicherheit herror, dass es sich dabei um eine Korrelationserscheinung handelt, die im übrigen von keinerlei Bedeutung ist, die nicht über das Wohl und Wehe der betreffenden Tierarten entscheiden kann.

Ganz dasselbe gilt in sehr vielen Fällen von den Flecken und Streifen, die wir bei zahlreichen Tieren finden. Man kann so weit gehen, zu behaupten, dass die Zeichnung, die, wie Eimer gezeigt hat und wie ich überall bestätigt finde, von einer ausserordentlich lıohen Gesetzmässigkeit beherrscht wird, in den meisten Fällen völlig ohue Bedeutung ist, und dass es vom Standpunkte des Nützlichkeitsprinzips aus viel mehr auf die Färbung selbst ankommt, als auf die Terteilung der Farben über den Körper. Wer nicht so weit gehen will, diese Behauptung zu unterschreiben, der wird doch jedenfalls zugestehen müssen, dass es viele sehr konstante Eigentümlichkeiten der Zeichnung giebt, die nicht wohl von irgend einer Bedeutung sein können, die völlig indifferent sind. Auf dem Schwanze vieler Hundearten finden wir beispielsweise einen schwarzen Fleck, der äusserlich das Vorhandensein einer Drüse anzeigt. Welchen Unterschied kann es aber machen, ob die Haare, welche diese Drüse ungeben, dunkel oder hell gefärbt sind, ob sie sich von der Umgebung unterscheiden oder nicht. Dass sie es dennoch thun, ist für die Fortexistenz der betreffenden Hundearten völlig gleichgültig. Keinerlei Nutzen gewährt auch ein sehr beständiges schwarzes oder dunkles Querband an der Innenseite des Vorderbeines bei Katzen. Es dürfte bei den allermeisten Katzenarten gefunden werden und zeigt schon durch seine verborgene Lage, dass es von gar keiner Bedeutung ist. Man sieht es meist nur dann, wenn man sich Mühe giebt, es wahrzunehmen; trotzdem hat es sich mit ungewöhnlicher Zähigkeit bei den allermeisten Katzenarten gehalten. Es muss tief in der Organisation des Katzenkörpers begründet sein, eine Korrelationserscheinung darstellen, die mit Notwendigkeit fast bei allen Katzen 
zum Ausdruck kommen muss; aber irgend welche Bedeutung für das Fortbestehen des Katzengeschlechts hat es nicht, es kann deslialb auch unmöglich durch die Natur herangezüchtet worden sein.

Die Zeiclınung der Tigerpferde ist ungewöhnlich mannigfaltig, und ihre Unterschiede können nicht durch die Nützlichkeitstheorie erklärt werden. Trotzdem ist es möglich, eine Anzahl ron Tigerpferdarten zu unterscheiden. Das echte Zebra ist ganz anders gezeichnet als das Quagga und der Dauw. Auch der eingefleischteste Darwinist wird nicht behaupten mögen, dass er eine Erklärung für die Verschiedenartigkeit der Zeichnung bei diesen und anderen Tieren geben könnte, er wird sich damit begnügen zu sagen, dass, weil Darwin mit seiner Theorie im Rechte sei, alles eine Bedeutung haben müsse, und dass also auch die konstante Zeichnung der Tiere eine nützliche Einrichtung sein müsse: Wer aber eine derartige Erklärung abgiebt, der verlässt damit den Boden der Wissenschaft. Die Behauptung, dass alles nützlich sein müsse, weil es nur durch Züchtung herrorgebracht sein köme, involviert einen Zirkelschluss.

Die Zuchtwahllehre geht bekanntlich von der Thatsache aus, dass die Organismen durch eine grosse Anzahl auffïlliger nützlicher Einrichtungen vor den Anorganismen ausgezeichnet sind. Sie sucht nachzıweisen, dass Naturzüchtung diese nützlichen Einrichtungen gesteigert und zu der hohen Vollendung gebracht habe, die wir thatsächlich an (len Organismen rorfinden. Wer aber sagt, dass das, was thatsäclılich besteht, auch ron Bedeutung sein müsse, der macht eben die Folgerung z111 Voraussetzung. Was nützlich ist, muss nach der ZuchtwahHlehre gezüchtet sein, was aber noch nicht als bedeutungsvoll erkannt ist, das darf man niclıt als gezüchtet hinstellen, sonst würde man ja von der Grundvorstellung ausgehen, dass alles gezüchtet wäre und deshalb von Bedeutung sein müsse. Zuerst müsste doch durch die Thatsachen der Nachweis gebracht worden sein, dass alles, was besteht, von Bedeutung ist. Dieser Nachweis ist aber nicht zu führen.

Zu den angefülıten Beispielen kommen die anderer Eimrichtungen, die ebensowenig gezüchtet sein können wie die genannten. Viele Katzen haben auf dem Ohre einen weissen oder wenigstens hellen Fleck; einen Nutzen kann dieser nicht wohl haben, denn er verrät den schleiclienden Tiger, Jaguar oder Leopard höchstens seiner Beute. Etliche Antilopen und ebenso der Urbüffel von Celebes lıben je zwei weisse Flecke auf den Wangen, wie wir sie ausser bei der Anoa beispielsweise 
bei der Nilgauantilope und bei der Schimantilope finden. Diese Flecke können nicht wohl von irgend welcher Bedeutung sein. Man könnte vielleicht daran denken, sie etwa bei der Nilgauantilope als ein Erkennungszeichen zu betrachten, aber man wird diese Idee aufgeben müssen, sobald man einsieht, dass die Flecke auf weite Entfernungen nicht sichtbar sind, sondern nur auf kurze Strecken hin wirken. In der Nähe erkennen sich die Tiere aber ohnehin schon und brauchen deshalb nicht noch zwei kleine weisse Flecke auf den Wangen als Erkennungsmittel. Wenn wir die Flecke aber dennoch als Erkenmungszeichen gelten lassen wollen, weil die Antilopen Steppentiere sind, so stehen wir den hellen Flecken auf der Wange der Anoa ratlos gegenüber, denn dieses Tier lebt in den dichten Urwäldern von Celebes und kann sich seinen Artgenossen nur durch die Stimme oder den Duft verraten.

Bei den Haustauben sind die Nackenfedern, wie schon Darwin bemerkt hat, oft etwas nach oben gerichtet, und da solches bei rerschiedenen Haustaubenrassen, aber nicht bei deren Stammform, der wilden Felsentaube, vorkommt, so können wir diese Federstellung nur als eine Korrelationserscheinung betrachten, die tief im Organismus des Taubenkörpers begründet ist. Zu diesem Schlusse werden wir um so eher gelangen, wenn wir nach oben gerichtete Nackenfedern auch bei wilden Taubenarten, beispielsweise bei der Zahntaube von Samoa, finden. Was von diesen Nackenfedern der Tauben gilt, findet auch auf die Troddeln, die am Halse domestizierter Ziegen aufzutreten pflegen, Anwendung. Diese können keinerlei Bedeutung haben, müssen aber tief im Bau des Ziegenkörpers wurzeln, denn sie vererben sich mit grosser Zähigkeit und kommen bei verschiedenen Rassen vor. Dass die Blattformen der Pflanzen in manchen Fällen von Bedeutung sind, soll nicht geleugnet werden, daraus aber den Schluss zu ziehen, dass sie es überall sein müssen, ist durchaus unwissenschaftlich. Den Brombeersträuchern kann es völlig gleichgültig sein, ob ihre Blätter dadurch aus dreiteiligen zu fünfteiligen werden, dass sich von den beiden unteren Blättchen zwei neue abzweigen, oder dass dieses an dem mittleren Blättchen geschieht.

Die Beispiele, die wir für die ausserordentlich grosse Anzahl indifferenter Einrichtungen im Tier- und Pflanzenreich anführen könnten, werden von verschiedenen Ultradarwinisten verschieden beurteilt. W eis mann erblickt in allen Einrichtungen entweder nur nützliche, oder solche. die sich auf dem Wege zunehmender Vollendung oder zunehmender Verkümmerung befinden. Wallace dagegen sagt, dass die Organismen nur 
solche Einrichtungen hätten, welehe entweder nützlich sind oder mit nützlichen in Korrelation stelıen. Dadurch giebt ler Mitbegründer des Darwinismus das Bestehen einer wirklichen und echten Korrelation zu. Wie diese abel zu erklären sei, sagt er nicht. Womn eine solche horrelation besteht, so können die Eigenschaften nicht wohl unablıängig voneinander variieren, und es dïrfte dann der natïrlichen Zuchtwahl schwer sein, jede einzeln zu züchten. Wer annimmt, dass die einzelnen Eigenschaften gezïchtet werden, der muss notwendigerweise auch unabhängiges Variieren jeder Eigenschaft annehmen. Wenn man die Vererbung erworbener Eigenschaften leugnet, so kann man die Entstehung \%weckmässiger Einrichtungen eben nur durch die natürliche Zuchtwahl erklären, und diese kann nur dann wirksam werden, wenn die Eigenschaften sich nicht gegenseitig in ihrer Entwickelung stören, wenn das Keimplasma ein polymiktes und kein monotones ist. Der auf die Spitze getriebene Darwinismus steht und fällt mit der Annahme der Präformationstheorie. Ist diese zu rerwerfen, so mïssen die Ultradarwinisten ihre Ansichten stark modifizieren.

\section{Direkt und indirekt benutate Einrichtungen.}

Un die Bedeutung der Eigenschaften richtig zu beurteilen und danach die Entscheidung zu treffen, ob Präformation oder Epigenesis die Entwickelnng beherrscht, müssen wir weiter fragen, ob alle Einrichtungen direkt benutzt werden, oder ob manche nur indirekt ihren Trägern zu gute kommen. Eigenschaften, die in direkter Beziehung zu dem Gebrauch oder Nichtgebrauch der Organe stehen, werden sich als durch diese Faktoren hervorgebrachte auffassen lassen, falls man die Vererbung somatogener Eigenschaften anerkennt. Dagegen wird man für zweckmässige Einrichtungen, die nicht direkt gebrancht werden, andere Erklärungsmittel suchen müssen, und es fragt sich deslıalb, ob die grössere Anzahl der Eigensehaften direkt, oder ob die meisten indirekt benutzt werden, und ob nicht etwa alle Einrichtungen entweder mittelbar oder unmittelbar gebraucht werden.

Dass es nur mittelbar benutzte Einrichtungen giebt, muss unbedingt verneint werden, denn Organe wie die Muskeln, die Sinnesorgane und viele andere sind Einrichtungen, die ummittelbar gebraucht werden. Bei den Knochen, Schalen und bei vielen Schutzorganen, Stacheln und dergleichen sind wir oft im '/weifel, ob sie direkt gebraucht oder nur indirekt 
benutzt werden. Allerdings werden auch viele dieser Organe direkt gebraucht; aber es fragt sich, ob sie alle als durch den frebrauch erworben erklärt werden können. Wir hätten also solchen Eigenschaften, die wir uns als durch den Gebrauch erworben oder durch den Gebrauch rerloren gegangen denken können, andere gegenüber zu stellen, bei denen dieses zweifelhaft ist, obwohl auch sie direkt benutzt werden. Endlich aber giebt es noch eine grosse Menge von Eigenschaften. die nur indirekt zur Geltung kommen, und von diesen muss in erster Linie die Färbung genannt werden. Wenn ein Tier durch seine weisse Farbe den Schneegefilden des Nordens angepasst ist, so kommt ihm diese Eigenschaft nur indirekt zu gute, entweder dadurch, dass es von seinen Beutetieren nicht bemerkt wird, oder dadurch, dass es sich vor seinen Feinden verbergen kann. Ähnliches gilt für die Form mancher Eier von Vögeln, die auf Felsklippen brüten und deren eigentïmliche Eiform ein Herunterrollen der Eier von den Felsen einigermaassen verhütet. Solche Einricbtungen sind nur von indirektem Nutzen und können deshalb nicht auf den Gebrauch oder Nichtgebrauch der Organe zurückgeführt werden.

Zu derartigen Eigenschaften kommen aber noch andere, die zwar auch direkt gebraucht werden, die aber nicht durch entsprechenden Gebrauch hervorgerufen sind. Bei dem Fingertier ist der Mittelfinger stark verkümmert; er ist, rerglichen mit den übrigen, sehr dünn, was ich mir dadurch erkläre, dass das Tier beim Greifen Daumen und Zeigefinger gegen den vierten und fünften Finger wirken lässt, wodurch der Mittelfinger ausser Gebrauch gesetzt wurde und infolgedessen rerkümmerte. Aber das Tier hat es gelernt, ihn in neuer Weise zu gebrauchen; es benutzt ihn nämlich, um mit seiner Hilfe Insekten und deren Larven aus engen Baumritzen hervorzuholen. Einen ähnlichen Fall laben wir bei den Spechten, deren Männchen bekanntlich zur Paarungszeit durch ein eigentümliches Schnarren ihre Gefühle dem Weibchen kundgeben. Sie erzeugen dieses Schmarren mit dem Schnabel, den sie gegen einen dürren Ast oder dergleichen vibrieren lassen. Der Spechtschnabel ist nun in seiner eigentümlichen Form eine Einrichtung, die man, wenn man die Vererbung somatogener Eigenschaften annimmt, wolsl durch die Wirkungen des Gebrauchs erklären kann. Aber die Benutzung des Schnabels als Organ der Hitteilung kann erst eingetreten sein, nachdem der Specht schon in hohem Grade an seine eigentiimliche Lebensweise angepasst war. Diese Beispiele liessen sich noch leicht durch andere vermehren. 
Wir kommen also zu dem Ergebnis, dass es sowohl direkt als aucl indirekt benutzte Einrichtungen giebt, und dass die Bedeutung der Einrichtungen ursprüinglich eine andere gewesen sein kann, als sie es später ist, und es fragt sich, wie sich mit diesen. Ergebnis einerseits die Präformationstheorie, andererseits die Epigenesislehre in Einklang bringen lässt.

Die Präformationstheorie lässt sich schwer mit dem Bestehen direkt benutzter Einrichtungen vereinigen, denn nach ihr variieren ja die einzelnen Teile des Keimplasma's in beliebiger Weise, und jede Eimichtung ist demnach in letzter Linie eine indirekt benutzte. Da aber der Körper in den allermeisten Fällen durch eine grosse Anzahl einzelner Einrichtungen ausgezeichnet ist, so wäre es schwer zu verstehen, wie die Organismen dazu gekommen sind, von den zufaillig entstandenen brauchbaren Einrichtungen auch den rechten Gebrauch zu machen. Wenn beispielsweise der Spechtschnabel durch zufälliges Tarieren seiner Determinanten die bekannte Meisselform erhielt, so mussten gleichzeitig auch die Determinanten des Gehirns in günstiger Richtung variieren, um dem Spechte zu sagen, in welcher Weise er seinen Schnabel zu benutzen hatte. Die Spechte sind aber nicht bloss durch ihren Schnabel und durch die ron ihm gemachte zweckmässige Verwendung in hohem Grade als Charaktervögel gekennzeichnet, sondern noch durch eine ganze Reihe anderer Einrichtungen: die lange hervorstreckbare Zunge, die eigentümlichen Beine, die steifen Schwanzfedern und alles, was damit zusammenhängt. Wie soll man es sich vorstellen, dass die Vorfahren der Spechte es verstanden haben, alle diese unabhängig voneinander entstehenden Einrichtungen in der richtigen Weise zu verwerten? Die Präformationstheorie kämpft also mit grossen Schwierigkeiten, welche der Epigenesislehre nicht anhaften, denn nach der Epigenesislehre stehen alle Teile des Körpers miteinander in Korrelation, und die direkt benutzten Einrichtungen sind durch entsprechenden Gebrauch entstanden, und zwar in vielen Fällen gleichzeitig. Das letztere ist sicher bei den Spechten der Fall gewesen, die ihre sämtlichen eigentümlichen Einrichtungen gleichzeitig durch den Gebrauch erworben und alle durch fortgesetzten Gebrauch gleichmässig und stetig gesteigert haben, so dass sich jede einzelne Einrichtung im Gleichgewicht mit den anderen befand.

Wie die Vererbung dieser Einrichtungen zu erklären ist, ist eine Frage, mit welcher wir es in diesem Kapitel noch nicht zu thun haben, aber sovicl ist schon hier sicher, dass die Theorie der Epigenesis eine viel annehmbarere Erklärung für direkt benutzte Einrichtungen giebt, als 
die Präformationslehre, und wir werden auch zeigen, dass sie auch indirekt benutzte Eigenschaften zu erklären weiss, denn es müssen der Epigenesistheorie gemäss, da alle Eigenschaften miteinander in Korrelation stehen, eine grosse Menge ron zunächst bedeutungslosen Einrichtungen getroffen werden, die später indirekt dem betreffenden Organismus nützlich oder schädlich werden können. Eine Auslese lässt also auch die Epigenesislehre zu, nur dass sie ihr keine so ausschliessliche Bedeutung zugesteht, wie es die Präformationstheorie thun muss, die in letzter Linie nur indirekt benutzte Einrichtungen kennt.

\section{Erhaltungsmässige und nichterhaltungsmässige Eigenschaften.}

Um über die Auslese, die jedenfalls in der Natur stattgefunden hat, zu einem sicheren Urteil zu gelangen, müssen wir mit Möbius erhaltungsmässige und nichterhaltungsmässige Eigenschaften unterscheiden. Wenn die Präformationstheorie im Recht ist, so hätten Einrichtungen, die den betreffenden Tieren eine Zeit lang gute Dienste erwiesen haben, damn aber zu ihrem Untergange führten, gar nicht entstehen können, sondern die natürliche Zuchtwahl hätte rechtzeitig dafür sorgen müssen, dass dergleichen Einrichtungen wieder in zweckmässiger Weise abgeändert wurden, weil ja nach den Anschauungen der Ultradarwinisten jedes Tier und jede Pflanze jeder Zeit so weit, wie erforderlich, ihren Lebensbedürfnissen angepasst ist. Es hätten, wenn diese Theoretiker recht haben, nicht ganze Tiergruppen aussterben dürfen, wie es die Trilobiten, die grossen Saurier, die Ammoniten und viele andere gethan haben. Ist dagegen die Epigenesislehre im Recht, so mussten einerseits durch fortgesetzten Gebrauch, andererseits durch Korrelationsverhältnisse Einrichtungen geschaffen werden, die endlich, weil sie eben durch fortgesetzte Übung gesteigert wurden und weil eine beständige Korrelation stattfindet, nicht mehr rückgängig gemacht werden konnten und deshalb oft das Aussterben ihrer Träger bedingen mussten.

Zu diesen Eigenschaften gehört vor allen Dingen die zu beträchtliche Grösse. Wir haben gesehen, dass die Grösse im Entwickelungsrerlaufe eines und desselben Tierstammes stetig zuzunehmen bestrebt ist, und können deshalb verstehen, warum sie in manchen Fällen so enorm wurde, dass die betreffenden Tiere aussterben mussten. Sie fanden entweder nicht mehr die nötige Nahrung oder wurden zu unbeholfen oder sonst irgendwie durch die Grösse zu sehr benachteiligt. Ihrer Körpergrösse 
Laben die Riesentiere der Torwelt es zu verdanken gehabt, dass sie ausirestorben sind, und andere sind der zu starken Ausbildung einzelner Orgatne zum Opfer gefallen. So sind die Säbeltiger infolge tler enormen Grösse ihres oberen Eckzahnes, der wohl noch als Waffe gute Dienste leistete, aber eine entsprechende Entwickelung der Backenzähne verhinderte, zu Cirunde gegangen, und der Riesenhirsch verdankt seinen Untergang wahrscheinlich seinem übermächtig gewordenen Geweih. Der Hirscheber soll oft dadurch sterben, dass sich seine oberen Eckzälne ins Fleisch hineinbohren, und bei Muftlons habe ich oft die Beobachtung gemacht, dass ihre Hörner in den Nacken himeinwachsen, hïssliche Wunden und Eiterungen erzeugen und, wenn sie nicht den Tod des Tieres herbeiführen sollen, abgesïgt werden müssen. Die Mufflons sind aber noch nicht zu Haustieren geworden, und es ist deshalb sicher, dass auch im freilebenden \%ustande manche dnrch ihre zu stark ausgebildeten Hörner getötet werden.

Mit diesen Thatsachen rerträgt sich die Präformationsthcorie, die unabhängiges Varieren der einzehnen Biophoren des Keimplasma's mit nachfolgender Auslese amimmt, nicht, sondern nur die Epigenesistheorie lässt sich mit ihnen in Einklang bringen. Wemn die Präformationstheorie bestehen will, so muss sic es cinfach leugnen, dass dergleichen nicht erhaltumgsmässige Eigenschaften überhaupt ausgebildet worden sind. Freilich wird sie damn den Untergang der betreffenden Tiere nicht wohl erklären kömen. Wenn wir nach alledem zur Entscheidung der Frage kommen, ob die Einrichtungen der Organismen direkter Anpassung oder der Auslese ihren Ursprumg rerdanken, so werden wir einen grossen Teil, vielleicht den allergrössten ihrer Eigenschaften, auf direkte Anpassung zurückführen, dagegen eine Anzahl auch durch Auslese erklären, insofern manche Eigenschaften nicht direkt benutzt werden können. Die Epigenesistehre weiss sich also sowohl mit der direkten Anpassung als auch mit der Auslese indirekt benntzter Einrichtungen abzufinden, während die Präformationstheorie nur Auslese kennen darf.

Um zu sehen, welcher Art die Auslese sein darf, falls die Präformationstheorie oder die Epigenesislehre unsere biogenetischen Anschanungen beherrschen soll, müssen wir uns nummehr über die Arten der Auslese eingehender orientieren. 


\section{g. Die Arten der Auslese.}

\section{1. Ökonomische Auslese und Riickhidlung.}

Wenn alle Teile des Organismus in der Keimzelle vorgebildet sind, so wird die Auslese eine ganz andere Bedeutung haben, als wenn sich der Organismus aus einem monotonen Keimplasma entwickelt, wie es die hier vorzutragende Epigenesislehre annimmt. Der Präformismus schliesst die Vererbung erworbener Eigenschaften aus, weil es auf Grund dieser Lehre nicht einzusehen ist, wie durch äussere Einflüsse oder den Gebrauch erworbene Veränderungen eines Organes auf die Determinanten des betreffenden Organes in den Keimzellen übertragen werden könnten, denn eine direkte Verbindung des durch äussere Einflüsse oder den Gebrauch oder Nichtgebrauch veränderten Organes mit den Determinanten der Keimzellen, aus welchen die nächste Generation hervorgehen soll, ist ausgeschlossen, weil diese Determinanten im festen Verbande des "Ids" liegen und von anderen Determinanten umgeben sind. Ausserdem liegen ja nach Weismann's präformistischer Ansicht die Ide im Zellkern, und man müsste schon annehmen, dass durch den Zellkörper hindurch Verbindungsfäden gehen, welche die Determinanten mit den Organen, welche sie zu determinieren haben, in Konmunikation setzen. Eine solche Annahme ist, wie nicht näher ausgeführt zu werden braucht, völlig ausgeschlossen, und aus diesem Grunde muss der Präformismus die Vererbung erworbener Eigenschaften leugnen. Dagegen kann die Theorie der Epigenesis nicht ohne sie auskommen.

Man könnte zwar zunächst annehmen wollen, dass auch eine epigenetische Vererbungstheorie lediglich durch das Überleben des Passendsten die Organe allmählich heranzüchten und weniger gut angepasste Organe durch Naturzüchtung vollkommener werden lassen könne. Allein wenn das Keimplasma ein monotones ist, wenn also sämtliche Zellen des Körpers von diesem monotonen Keimplasma aus bestimmt werden und deshalb notwendigerweise in Korrelation stehen müssen, so ist nicht einzusehen, wie die Anfänge eines Organes, die der Selektion das Material liefern müssen, überhaupt ohne Hilfe direkter Anpassung entstanden sein sollen. Sie können vielmehr nur dadurch hervorgebracht worden sein, dass der Körper sich selbst seine Organe bildet und dass diese auf die Nachkommen vererbt werden. Weil die einzelnen Teile des Körpers sich direkt an die Aussenwelt anpassen, aber zu jeder Zeit miteinander in Korrelation stehen, können zwar gleichzeitig an verschie- 
denen Stellen des Körpers die verschiedensten Anpassungen stattfinden; aber alle müssen sich miteinander ins Gleichgewicht setzen, so dass die durch verschiedenartige Umbildungen veränderte Konstitution des Keimplasma's gleichzeitig mit allen Anpassungen des Körpers in Korrelation steht. Das Kémplasma muss deshalb, wie wir später noch besser begreifen werden, notwendigerweise die neu erworbenen Anpassungen in der nächsten Generation reproduzieren.

Es fragt sich nun, ob der Präformismus oder die letztere Annahme besser mit den Thatsachen in Einklang zu bringen ist, ob die Auslese wirklich das leisten konnte, was thatsächlich entstanden ist, oder ob wir wenigstens die Mchrzahl der zweckmässigen Einrichtungen nicht besser durch die Vererbung erworbener Eigenschaften erklären können.

Um über diese Frage zu entscheiden, ist eine Betrachtung der Umstände, welche zu der Ausbildung von rudimentären Organen geführt haben, erforderlich.

Wenn man eine Vererbung erworbener Eigenschaften annimmt, so sind die rudimentären Organe ohne weiteres erklärt; es sind Organe, die durch Nichtgebrauch verkümmert und in der verkümmerten Gestalt auf die Nachkommen übertragen worden sind. Bei den letzteren verkümmern sie durch fortgesetzten Nichtgebrauch noch mehr und müssen deshalb endlich verschwinden. Ein Organ, das nicht gebraucht wird, wird auch nicht genügend ernährt, wenigstens in all den Fällen nicht, wo dieses Organ aktiv gebraucht wird. Dafür Beweise anzuführen, ist überflüssig, denn die bezüglichen Thatsachen sind allbekannte. Der Präformismus aber muss selır weit ansholen, um das Verkümmern nicht gebrauchter Organe zu erklären, und er hat es auf zweierlei Weise versucht.

Vor dem Auftreten Weismann's, der eine energische Bekämpfung der Lehre von der Vererbung erworbener Eigenschaften inaugurierte, erliärte man das Verkümmern nicht gebrauchter Organe vielfach durch eine Art der Auslese, die wir, wenn sie existierte, als ökonomische Auslese bezeichnen könnten. Man sagte, dass Organe, die nutzlos sind, auch nicht mehr ernährt zu werden brauchen, und dass es nicht gut ist, wenn sie noch ferner ernährt werden, weil dadurch wichtigen Organen Nahrung entzogen wird. Es hätte also eine Zuchtwahl stattgefunden, welche bewirkte, dass diejenigen Tiere, bei welchen nicht gebrauchte Organe zufälligerweise spärlicher, dafür aber die wichtigen Organe besser ernährt wurden als bei anderen Tieren, grössere Erfolge im Kampf ums Dasein gehabt hätten als diese, dass jene überlebt und ihre etwas zurück- 
gebildeten unnützen Organe auf ihre Nachkommen vererbt hätten. Bei den Nachkommen hätte derselbe Selektionsprozess stattgefunden, und auf diese Weise wären endlich die nicht mehr gebrauchten Organe mehr oder minder vollständig zurückgebildet worden. . Wir haben aber schon früher gesehen, dass eine solche Annahme nicht haltbar ist, denn bei Organen, die im Verhältnis zum Gesamtkörper sehr klein sind, kann die winzige Menge von Nahrung, welche ihnen entzogen wird, keine irgendwie geartete Rolle in dem Haushalt des betreffenden Organismus spielen.

Bei vielen Tieren finden wir Afterzehen, die klein und völlig ausser Gebrauch gesetzt sind. Die betreffenden Zehen sind bei anderen Tieren noch gross und in Thätigkeit, bei noch anderen aber völlig geschwunden. Man kann sich nun leicht vorstellen, dass solche Zehen durch die schädlichen Folgen des Nichtgebrauchs nach und nach verkümmern, weil sie nicht melır in genügender Weise ernährt werden. Wenn aber die Ernährung nicht vom Gebrauch oder Nichtgebrauch abhängt, sondern wenn es rein zufällig ist, ob ein Organ besser oder weniger gut ernährt wird, so ist es schwer zu verstehen, wie dergleichen Zehen völlig geschwunden sein können. Sie mïssen doch durch das Stadium, das heute von den winzigen Afterzehen repräsentiert wird, hindurchgegangen sein, und man müsste dann annehmen, dass die mehr oder minder gute Ernährung etwa der Afterzehe eines Hundes, wie wir sie bei vielen Haushunden finden, und wie sie die wildlebenden fünfzehigen Vorfahren des Hundes besessen haben mïssen, über das Wohl und Wehe der Art entscheidet. Ein grosser Teil unserer Haushunde stammt rom Wolf ab; die Vorfahren des Wolfes hätten also eine kleine Afterzehe gehabt, und ihre mehr oder weniger gute Ernährung hätte über das Schicksal der betreffenden Individuen entschieden. Da es sich bei einem so kleinen Gebilde in jeder Generation nur um geringe Bruchteile eines Milligramms ron Nährsubstanz gehandelt haben kann, so müsste man annehmen, dass diese minimalen Gèwichtsmengen, die sich auf den Gesamtkörper verteilten, genügt hätten, um die einen Wölfe überleben, die anderen aber Hungers sterben zu lassen. Ich glaube kaum, dass die Präformisten zu dieser Annahme ihre Zuflucht nehmen werden. Das hat auch Weismann gefühlt, und deshalb hat er seine Theorie der Panmixie erfunden, um die Verkümmerung. nicht gebrauchter Organe zu erklären.

Unter Panmixie versteht $W$ eis mann das Folgende: Er lässt, wie es ja der Präformismus notwendigerweise thun muss, sämtliche Organe im Keime vorgebildet sein, nur vom Keim aus variieren und sagt dann, dass 
die natürliche Zuchtwahl darüber entscheidet, ob die Variationen, welche die Determinanten und ihre Biophoren erlitten haben, von Bestand sein sollen oder nicht. Haben sie so variiert, dass sie eine Verkümmerung eines wichtigen Organes herbeifülıren, so muss das betreffende Tier im Kampf ums Dasein zı Grunde gehen, haben sie dagegen in der erforderlichen Weise variiert, oder sind sie, falls keine Teränderung nötig, noch ebenso gut wie in der vorhergehenden Generation, so überlebt das betreffende Individuum. Bei Organen aber, welche nicht mehr gebraucht werden, kommt es nicht darauf an, ob ihre Biophoren nach der einen oder nach der anderen Richtung hin variieren; sie können sich nach allen möglichen Richtungen hin verändern, ohne dass dadurch etwas äber den Fortbestand des betreffenden Individuums entschieden wird. Da nun die Biophoren nach Weismann immer bald nach dieser, bald nach jener Richtung hin abändern, und zwar in dem einen Individuum hierhin, in dem anderen dorthin, so kommen infolge der geschlechtlichen Vermischung verschiedener Individuen in den ron den Determinanten bestimmten Organen schlechtere und bessere Biophoren nebeneinander zu liegen. Das Organ verändert sich, aber die durch allseitige Mischung, durch Panmixie erzeugte Veränderung ist für die betreffende Art nicht nachteilig, weil die Organe nicht mehr gebraucht werden. Auf diese Weise soll ein überflüssiges Organ allmählich völlig rudimentär und zum Schwinden gebracht werden. Indessen kann man sich auf Grund der Weismann'schen Pammixielehre zwar vorstellen, dass es verschlechtert wird; dass es aber infolge "Aufhörens der Zuchtwahl" zugleich verschwinden kann, ist völlig unbegreiflich, ist eine absolut unbegründete Annahme Weismann's und seiner Anhänger.

Stellen wir uns einmal vor, , ein Auge wäre überflüssig geworden, wie es bei 'Tieren, die in Höhlen eingewandert sind, oft der Fall gewesen ist. Die einzelnen Teile des Auges werden durch verschiedene Determinanten bestimmt, und die Biophoren, welche diese Determinanten zusammensetzen, variieren nun nach allen Richtungen hin. Durch die geschlechtliche Mischung kommen etwa in der Linse des Auges gute und schlechte Biophoren nebeneinander zu liegen und verïndern nun die Linse in entsprechender Weise. Das können wir uns, wenn wir auf dem Standpunkte des Präformismus stehen, recht gut vorstellen. Wie aber kommt es, dass die Linse und die übrigen Organe kleiner werden, dass sie endlich völlig schwinden? Das ist auch durch Weismann's Panmixie nicht begreiflich zu machen, denn wenn Variation 
nach allen möglichen Richtungen hin stattfinden kann, wenn Panmixie alle möglichen Biophoren in eine und dieselbe Zelle zusammenbringt, Biophoren, die ein geringes, und andere, die ein starkes Wachstum verursachen, so kann das Organ nie und nimmer kleiner werden und verschwinden, denn neben Biophoren, die sich in Bezug auf ihre Wachstumsenergie gleich bleiben, werden wir immer solche finden, welche eine starke, und andere, die eine geringe Wachstumsenergie haben. Diese beiden letzten Gruppen von Biophoren werden sich in ihrer Wirkung gegenseitig aufheben, und es kann deshalb wohl eine Verschlechterung des Organes eintreten, aber das Organ kann nie zum Schwinden gebracht werden, es sei denn, dass ökonomische Auslese es hinwegzüchtet, was, wie wir gesehen haben, $z u$ den gewagtesten Annahmen führen muss.

Es fragt sich allerdings, ob Organe, die verschlechtert worden sind, dem betreffenden Organismus nicht direkt schädlich und deshalb durch Naturzüchtung beseitigt werden. Da, wenn wirklich Panmixie besteht, das überflüssig gewordene Organ, wie wir gesehen haben, nicht kleiner, sondern nur unbrauchbar werden kann, so könnte man annehmen, dass dergleichen Organe hinderlich sind und deshalb durch Selektion ausgemerzt werden. Man hat nun angenommen, dass solche Organe Krankheiten unterworfen sein und deshalb unter Umständen recht nachteilig werden können. Allein krank kann jedes Organ, kann der gesamte Tierkörper werden, und wenn die Möglichkeit, dass ein Organ krank wird und dadurch ïber den Bestand der betreffenden Art entscheidet, verhindert werden soll, so müssen eben Tiere gezüchtet werden, die überhaupt keinen Körper haben und deshalb auch nicht krank werden können. Schadet also das Vorhandensein eines rudimentären Organes nicht, obwohl es Krankheiten unterworfen sein kann, so bleibt es in den allermeisten Fällen nicht einzusehen, weshalb ein indifferentes Organ durch Naturzüchtung beseitigt werden kann. Was schaden einem Säugetiere die kleinen Afterzehen? Davon, ob sie rorhanden sind oder nicht, hängt doch sicher das Wohl und Wehe des betreffenden Tieres nicht ab. Es lässt sich also auf keine Weise einsehen, wie Organe rudimentär werden und verschwinden können, wenn man die Vererbung erworbener Eigenschaften nicht annehmen will.

Wenn wirklich Panmixie besteht, so müssten die Organe wenigstens ihre ursprüngliche Grösse behalten. Das thun sie aber, wie die Thatsachen lehren, keineswegs. Es kann also keine Panmixie und folglich 
auch kein polymiktes Keimplasma geben. Damit ist die Unzulässigkeit des Präformismus dargethan und einzig und allein der Epigenesislehre die Existenzberechtigung zugewiesen.

Auf das röllig Unzulängliche der Weismann'schen Panmixietheorie hat man schon oft hingewiesen, aber Weismann hat darauf so wenig geantwortet, wie auf manche andere Widerlegungen seiner Ansichten, ein Verfahren, das sich empfiehlt, wenn man unhaltbare Lehren $z u$ verteidigen hat. Hiervon abgesehen, ist es völlig unbegreiflich, dass die Theorie der Panmixie Anhänger und gar Verteidiger gefunden hat. Diese Theorie ist so wunderbar, dass sie dem in entwickelungstheoretischen Sachen eine Autorität ersten Ranges beanspruchenden englischen Philosophen Herbert Spencer durchaus unbegreiflich ist, trotzdem er ausdrücklich darauf aufmerksam gemacht wurde, dass er We ismann nicht verstanden habe. Und doch hat Romanes, der ihn sagte, dass er die Theorie der Panmixie missverstehe, recht, denn aus Spencer's nevester Publikation geht hervor, dass er Weismann's Panmixie immer noch nicht begriffen hat. Das ist nicht gerade ein gutes Zeichen für diese Lehre; denn um sie einzusehen, muss allerdings der an naturwissenschaftliches und philosophisches Denken Gewöhnte ein gewagtes geistiges Salto mortale vornehmen, wie es für ein Gehirn, das noch nicht allzusehr von falschen Theorien beeinflusst worden ist, nicht leicht ausführbar sein mag.

\section{Organauslese und Personenauslese.}

Die rudimentären Organe können uns dazu dienen, weitere Fragen in Bezug auf die Auslese zu stellen. Wenn überflüssig gewordene Einrichtungen durch ökonomische Auslese nach und nach beseitigt werden. so kommen minimale Unterschiede der einzelnen Organe für die Selektion in Betracht, wie es ja der Darwinismus auch thatsïchlich annimmt. Es fragt sich aber, ob dergleichen geringfügige Unterschiede einzelıel. Organe wirklich ausschlaggebend für das Überleben eines Individuums sind, ob also eine Organauslese, eine Auslese nach der etwas mehr oder weniger guten Beschaffenheit der einzelnen Organe thatsächlich existieren kann. Der orthodoxe Darwinismus muss sie annehmen, denn ohne eine solche Organauslese könnte er nicht bestehen. Diese Organauslese ist aber eine völlig in der Luft schwebende Annahme, weil der Darwinismus auch nicht ein einziges Beispiel dafür vorbringen kann, dass geringe Unterschiede in einem einzelnen Organ wirklich ïber das 
Bestehen eines Individuums entscheiden. Vielmehr ist nur die Annahme gestattet, dass es auf die Gesamttüchtigkeit des ganzen Körpers ankommt, dass die Organe in der richtigen Weise zusammenwirken müssen, dass der Mangel eines Organes durch die bessere Beschaffenheit eines anderen kompensiert werden kann.

Dass eine Kompensation wirklich stattfindet, dafür lassen sich viele Beispiele anführen. In den zoologischen Gärten herrscht oft ein erbitterter Kampf ums Dasein unter zahlreichen seiner verschiedenen Insassen. Es ist nicht möglich, alle Tiere getrennt zu halten, und man setzt manche Säugetiere, beispielsweise Affen, und die meisten Vögel in Gesellschaftskäfige. Dass in diesen ein rücksichtsloser Kampf ums Dasein herrscht, wird jeder Tiergärtner, der einige Erfahrung hat, zugeben. Jeder Vogelwirt, der längere Zeit Vögel in Gesellschaftskäfigen gehalten hat, wird es bestätigen. Bei in Gesellschaft gehaltenen Tieren beobachtet man nun leicht, dass es keineswegs darauf ankommt, ob das eine oder' das andere Organ besonders gut entwickelt ist, denn manche Organe fehlen oft völlig. Häufig tritt der Fall ein, dass ein Vogel ein Auge verliert, dass er auf einem oder beiden Flügeln lahm wird, dass ihm ein Bein oder mehrere Zehen fehlen, und dennoch gedeiht er ebenso gut wie die am besten gedeihenden unter den anderen, obwohl manche Vögel durch den Kampf ums Dasein, der im Gesellschaftskäfig herrscht, zu Grunde gerichtet werden. Die Auswahl der Vögel, die man in einem gemeinsamen Käfig zusammenbringen will, muss immer eine sorgfältige sein, weil man leicht wertvolle Stiicke verliert, was weder dem Liebhaber noch dem Tiergärtner angenehm ist. Deshalb wird auf die zweckmässigste Zusammenstellung der Bevölkerung eines Gesellschaftskäfigs grösstmögliche Umsicht verwandt. Trotz alledem gehen manche Vögel zu Grunde, weil sie dem im Käfige entbrennenden Kampf ums Dasein nicht gewachsen sind.

Untersucht man nun die gestorbenen Vögel, so zeigt sich nicht etwa regelmässig, dass diese deshalb zu Grunde gehen, weil das eine oder das andere ihrer Organe nicht in der richtigen Weise beschaffen war, sondern man sieht vielmehr, dass es ledighich auf die mehr oder minder kräftige Konstitution der Tiere ankommt, dass die kleinen Abweichungen in der Beschaffenheit der einzelnen Organe nichts mit Leben oder Sterben der Tiere zu thun haben. Ich habe eine grosse Anzahl verstünmelter Tiere beobachtet und die Bemerkung gemacht, dass gerade diese nicht leicht zu Grunde gehen, denn wenn sie die Verstüm- 
melung ïberleben, so haben sie eben eine kräftige Konstitution, die sie anch ferner am Leben erbält, und für den Verlust eines Organes wissen sie sich leicht dadurch schadlos zu halten, dass sie andere Organe ausgiebiger als rorher gebrauchen. Man kann es in einem Tiergarten oft genug sehen und selbst erleben, lass gerade verstümmelte Tiere, die keine Zierde ihrer Behausung bilden, deren Tod man förmlich erhofft, obwohl man sie nicht gern umbringen oder fortschaffen will, am längsten leben, während unverstïmmelte Exemplare zu Grunde gehen, und man gewinnt so die Überzeugung, dass kleine Abweichungen in der Beschaffenheit des einen oder anderen Organes nicht über die Existenz eines Tieres und somit auch nicht über die einer Organismenart entscheiden.

Was uns gefangene Tiere lehren, sehen wir auch an wild lebenden. Frösche, die ein Hinterbein verloren haben, leben gleichwohl weiter und springen dann eben mit dem anderen Hinterbein, und angesichts solcher Thatsachen will man behaupten, dass die natïrliche Zuchtwahl Tiere ausmerzen könne, bei denen ein Hinterbein vielleicht 1 oder 2 Millimeter kürzer ist als dlas andere? Die meisten Echinodermen besitzen fünf melır oder minder gleichwertige Körperstiicke, und bekanntlich ist die Fünfzahl für die Echinodermen ausserordentlich charakteristisch, so dass die Nützlichlieitstheoretiker annehmen müssen, dass sie von höchster Bedeutung für das Bestehen dieser Tierklasse ist. Namentlich müsste das von solchen Echinodermen gelten, bei welchen, wie bei den Seeigeln, keine Arten mit vier oder sechs Körperstücken vorkommen. Trotzdem gedeihen vier- und sechszählige Seeigel, wie sie manchmal rorkommen, ebenso gut wie die normalen fünfzähligen. Man kann also nicht annehmen, dass Organauslese Abweichungen von der Fünfzahl hätte ausmerzen können. Ähnliches gilt bei den Medusen. Die Melırahl der Quallen ist vierzählig, d. h. der Körper wird aus vier gleichwertigen Stücken gebildet. Es kommen aber bei der Ohrenqualle unserer Ostsee häufig drei-, fünf- und sechszählige vor, und solche Individuen sind oft auffallend gross und sehr fruchtbar, wie ich vielfach feststellen konnte. Es hat also die grössere oder geringere Anzahl gleichwertiger Körperstücke nichts mit dem Bestehen der betreffenden Arten zu schaffen.

Ein Gleiches lehrt das Hirschgeweih. Die Anzahl seiner Siprosse hat im Laufe der Stammesgeschichte erheblich zugenommen, und die Präformisten müssen annehmen, dass Naturzüchtung diese Zunahme bedingt hat. Wie aber kommt es dann, dass die Anzahl der Sprosse sich ontogenetisch so langsam vermehrt? Bei dem Edelhirsch und seinen 
Verwandten nimmt sie an einer einzelnen Geweihstange jührlich nur um ein oder wenige Stücke zu, und trotzdem pflanzen sich auch diese Hirsche fort, trotzdem überleben auch sie im Kampf ums Dasein!

Kleine Schwankungen eines einzelnen Organes kömmen also unmöglich über den Bestand einer Organismenart entscheiden; es kann nur Personenauslese, d. h. Auslese solcher Personen, die im Durchschnitt ilırer Organe tüchtig sind, stattfinden. Dagegen entscheiden Schwankungen eines einzelnen Organes nicht ïber den Fortbestand eines Individuums.

Die Organe leben ja nicht für sich allein, sondern sie bilden Bestandteile eines vielfach zusammengesetzten Körpers, und dennoch können die Präformisten nicht um die Annahme herumkommen, dass ungenügende Beschaffenheit eines einzelnen Organes schon das Aussterben des betreffenden Organismus zur Folge haben muss, denn sonst könnte keine Steigerung eintreten in Bezug auf die weitere Ausbildnng der einzelnen Organe. Wenn das eine Tier überlebt, weil es vielleicht sehr gute Augen hat und dadurch seine minder gut entwickelten Gehörorgane kompensiert, so überlebt das andere vielleicht, weil es bei ihm gerade umgekehrt ist. Es kann nun gar nicht fehlen, dass sich häufig Individuen, von denen das eine nur dieses, das andere nur jenes Organ gut ausgebildet hat, geschlechtlich miteinander verbinden; bei ihren Nachkommen müssen also die Abweichungen von der Norm wieder ausgeglichen werden; und das geschieht auch thatsächlich, wie jeder Tierzüchter weiss. Es kann also durch Organauslese ummöglich eine Steigerung der Aupassungshöhe hervorgebracht werden, oder höchstens nur dann, wenn nur solche Tiere ïberleben, die in Bezug auf alle Organe das erforderliche Verhalten zeigen. Dass das für den Fortbestand des Individuums aber keineswegs nötig ist, haben unsere obigen Beispiele gezeigt, und damit ist die Möglichkeit, dass Variationen eines Organes über das Wohl und Wehe der Art bestimmen können, ausgeschlossen. Da aber die Präformationstheorie nicht ohne die Annahme einer Auslese nach einzelnen Organen auskommen kann, so ist sie wiederum als unhaltbar nachgewiesen und die Epigenesislehre allein als berechtigt dargethan.

\section{Konstitutionelle und dotationelle Auslese. Individual- und Rassenselektion.}

Wenn es nur Personenauslese giebt, so ist die weitere Frage zu beantworten, ob diese nach der Konstitution oder nach der Ausstattung ihre Wahl trifft. 
Unter Konstitution verstehen wir das Verhalten des Körpers zu den allgemeinen chemischen und physikatischen Einflüssen der Aussenwelt. Ein Tier, das Hunger ertragen, das grosse Hitze und grosse Kialte aushalten, das ebenso gut in stark salzigem wie in schwach salzigem Wasser leben kann, besitzt eine gute Konstitution. Gute Konstitution beruht auf Unempfindlichkeit gegen schädigende Einflüsse, wie sie durch Mangel an Nahrung, durch das Klima und durch viele andere Einflüsse allgemeiner Natur bedingt werden, mangelhafte Konstitution auf dem Gegenteil. Unter A usstattung ist dagegegen die melir oder minder gute Gliederung, das leichtere oder schwierigere Zusammenwirken der einzelnen Organe, also der glatte Gang der Körpermaschine, ausserdem aber auch die Anpassung, die sich in Einrichtungen wie die Schutzfärbung und dergleichen ausspricht, zu verstehen. Wir können also von einem Überleben desGutkonstituierten oder, wie ich mich anderswo ausgedrückt habe, des Bestgefügten, und ron einem Überleben des Gutausgestatteten, also entweder des Gutgegliederten oder des Gutgeriusteten sprechen.

Dass es eine Auslese, welche die A usstattung betriff, giebt, ist nicht zu bezweifeln. Wüstentiere sind mit einen sandfarbigen, Schneetiere mit einem weissen Kleide ausgestattet, und solche Kzleider können in den meisten Füllen nicht durch direkte Anpassung der Organe hervorgebracht worden, sie müssen gezüchtet sein. Die Wanderratte, die unsere Hausratte verdrängt hat, hat vielleicht durch ihre Konstitution, wahrscheinlich aber auch durch ihre bessere Ausstattung, durch ihre beträchtlichere Körpergrösse und ilır starkes Gebiss gesiegt. Flugunfihihge Inselvögel sind nicht gut ausgestattet, sie sind deshalb auch viel schneller ausgerottet worden als die flugbegabten Vögel derselben Insehn.

Aber neben der Ausstattung entscheidet immer noch die lionstitution und in manchen Fällen entscheidet diese ausschliesslich; das können wir in zoologischen und botanischen Gürten leicht feststellen. Es handelt sich dort nicht darum, ob das eine oder das andere Organ der betreffenden Tiere und Pflanzen mehr oder minder gut entwickelt ist, sondern darum, ob die in Betracht kommenden Individuen eine gute oder schlechte Konstitution haben, und in den allermeisten Fällen wird die Konstitution in erster Linie darüber entscheiden, ob ein Organismus ïberleben soll oder nicht. Viele Organismen gehen schon als Keimzellen vder als junge Tiere infolge ihrer schlechten Konstitution zu Grunde. Wir haben also zu unterscheiden zwischen konstitutioneller und 
dotationeller Auslese, und zu untersuchen, welche Ergebnisse die eine und welche die andere Art der Auslese zeitigt.

Für die Auslese innerhalb einer Art, für den Kampf ums Dasein unter den Individuen einer und derselben Tier- oder Pflanzenspecies, kann die Dotation nur in seltenen Fällen ausschlaggebend sein, und zwar deshalb nicht, weil die Unterschiede zwischen den einzelnen Individuen meist so gering sind, dass sie beim Kampf ums Dasein nicht in Betracht kommen. Der Weismann'sche Präformismus leugnet aber einfach die Bedeutungslosigkeit der geringen Unterschiede, die man thatsächlich feststellen kann, und behauptet, dass sie ron ausschlaggebender Bedeutung sind. Leider steht diese Behauptung auf schwachen Füssen; sie wird auch nicht durch eine einzige thatsächliche Beobachtung begründet.

Ich habe bei Tieren, die zu Grunde gegangen waren, Untersuchungen darüber angestellt, ob sie sich wohl in dem einen oder anderen Punkte von ihren Artgenossen, die leben geblieben waren, unterschieden, und zwar niclit etwa bei gefangenen Tieren, sondern bei freilebenden. An den Strand geworfene Seeigel habe ich mit ihren ron mir selbst gefangenen überlebenden Artgenossen reglichen, und ich habe auch nicht in einem einzigen Fall einen Unterschied gefunden. An der Südküste Australiens habe ich beobachtet, dass die dort unter den zur Ebbezeit blossgelegten Steinen lebenden Asseln häufig von einem Stein zum anderen laufen und dabei den zwischen den Steinen liegenden Sandboden überschreiten müssen. Diese Asseln haben ein sandfarbenes Kleid, sind also durch ihre sympathische Färbung geschiitzt. Ich habe nun einmal mit den Feldstecher einen Fischreiher beobachtet, der ruhig zwischen den Steinen stehend nach den von einen Stein zum andern laufenden Asseln stiess und viele von ihnen erbeutete. Diesen Reiher habe ich geschossen und die in seinem Magen befindlichen Asseln in Bezug auf ihre Färbung mit von nir gefangenen verglichen; ich habe auch nicht den leisesten Unterschied dabei feststellen können.

Wir können also nicht annehmen, dass es dotationelle Auslese von Individuen giebt, und wenn sie wirklich bestände, so würde sie nicht zur Fortbildung der Organismenarten beitragen können. Die geschlechtliche Mischung würde dann jede Art nur auf derselben Ausstattungsstufe halten.

In sehr vielen Fällen entscheidet der Zufall über den Fortbestand eines Individuums. Die südaustralischen rom Reiher erbeuteten Asseln 
sind sicher nur deshalb gefangen worden, weil sie znfällig nicht ruhig unter den Steinen verharrten.

Es fragt sich aber, wie sich die Konstitution zu dem zufälligen Überleben der Individnen einer Organismenart verhält, und da müssen wir sagen, dass die Konstitution unter allen Umständen eine grosse Rolle spielt, insofern als Individuen mit einer guten Konstitution in allen Lebenslagen grössere Aussicht auf Fortbestand haben, als solche mit schlechter. Es herrscht also sicher eine konstitutionelle Indiridualselektion innerhalb einer Organismenart, dagegen herrscht innerhalb einer und derselben Tier- und Pflanzenrasse keine dotationelle Individualselektion. Wir haben aber gesehen, dass sympathische Färbung und andere zweckmässige Einrichtungen nur durch dotationelle Zuchtwahl erklärt werden können, und müssen deshalb fragen, ob es neben der individuellen Auslese noch eine andere Art der Auslese giebt, und diese Frage ist ohne weiteres zu bejahen.

Es giebt Auslese zwischen verschiedenen Rassen und auch zwischen verschiedenen Arten. Bei der Vertreibung der Haus- durch die Wanderratte handelte es sich um Auslese der Angehörigen zweier verschiedener Arten. Es wurden nur die Individuen der Wanderratte erhalten, und die meisten Hausratten gingen zu Grunde. Es ist nun klar, dass bei dieser Rassenselektion, welche wir der Individualselektion gegenüberstellen müssen, sowohl die konstitutionelle als auch die dotationelle Auslese in Betracht kommen kann. Wir können uns also sympathische Färbung und dergleichen durch eine dotationelle Rassenauslese erklären.

Dieses Ergebnis, dass ausser Indivirlualselektion auch eine Rassenauslese stattfindet, verträgt sich nicht mit der Präformationstheorie, wohl aber mit der der Epigenesis, denn die erstere muss ausser Rassenselektion dotationelle Individualselektion annehmen, weil sie sonst die Entstehung der Arten und ihre Erhaltung nicht erklïren kann, und weil viele Organismenarten, insbesondere unter den Tieren, nur ein sehr enges Verbreitungsgebiet besitzen, in welchem von Rassenauslese überhaupt nicht die Rede sein kann. Es giebt Kolibriarten, die anf einen einzigen Bergkegel der Anden beschränlit sind, und Forellenarten, die nur einen einzigen kleinen See bewohnen. In so eng begrenzten Gebieten ist oft wenigstens keine Rassenanslese möglich, und die Erhaltung der Art könnte hier nur llurch dotationelle Individualselektion erfolgen, wenn anders die Charaktere, durch welche sich die betreffende Art von ihren Verwandten unterscheidet, nützlich für die Art sind, was ja die Präforma- 
tionstheorie annehmen muss. Nun haben wir aber gesehen, dass die Individualselektion nur die Konstitution, nicht aber die Ausstattung betreffen kann, dass sie deshalb auch nicht geeignet ist, Ausstattungscharaktere zu züchten. Individualselektion züchtet nur gute Konstitutionen, und deshalb ist auf Grund der Epigenesistheorie nur die Annahme einer dotationellen Rassen zuchtwahl möglich. Wenn nun aber Rassenselektion stattfinden soll, so setzt sie die Entstehung der Rassen auf anderem Wege als durch dotationelle Individualselektion voraus. Wir werden später diesen Weg der Entstehung von neuen Rassen aus vorhandenen Arten kennen lernen. Es handelt sich aber zunächst um die Frage, ob auf einem und demselben Gebiete zwei oder mehrere neue Rassen aus einer aus mehr oder minder gleichen Individuen bestehenden Art entstehen können, ob die Rassenselektion also von vornherein einsetzen kann, oder ob sich unterschiedene Rassen nur auf getrennten Gebieten entwickeln können.

Diese Frage hängt nahe zusammen mit der anderen, ob die Mischung der Individuen, die notwendigerweise in einen und demselben Gebiete stattfinden muss, und welche nach Weismann eine so grosse Rolle spielt, wirklich das zu leisten vermag, was das derzeitige Haupt der Präformationstheorie ihr zuschreibt. Im folgenden Abschnitte werden wir uns demgemäss mit den Fragen der Individuen- und Rassenmischung zu beschäftigen haben.

\section{h. Mischung und Entmischung.}

\section{Separation und Kongregation.}

Eine grosse Rolle bei Entscheidung entwickelungstheoretischer Fragen spielt die Frage, ob sich eine Tierart auf einem und demselben Gebiete in mehrere neue Arten spalten kann oder nicht. Bekanntlich ist das erstere ron Moritz Wagner entschieden bestritten worden, und wenn seine Ausführungen mehr Beachtung gefunden hätten, wenn die modernen Entwickelungstheoretiker sich ïberhaupt mehr um die einzelnen Tier- und Pflanzenarten kümmern wollten, so hätte Wagner längst die Zustimmung finden müssen, die er in der That verdient. Wenn auch nicht alles, was er gesagt hat, haltbar ist, so hat er doch darin recht, dass auf einem beschränkten Verbreitungsgebiet sich kaum jemals zwei oder mehr Arten aus einer Stammart entwickeln können, 
vorausgesetzt, dass allseitige Mischung der Individuen der betreffenden Art möglich ist.

Zu dieser Entscheidung gelangen wir, wenn wir die Folgen einer solchen Mischung ins Auge fassen. Dass die Individuen der Organismenarten, d. h. die einzelnen Vertreter der Art, unablängig roneinander variieren, lässt sich nicht leugnen. Aber die Variationen sind, wie wir gesehen haben, niemals so ausgiebig, dass dotationelle Individualselektion daraufhin ihre Wirksamkeit entfalten könnte. Gesetzt aber, sie thäte es dennoch, was wäre alsdann die Folge? Ohne Zweifel keine andere als die, dass in dem einen Individum dieses, in dem anderen jenes Organ das Überleben bedingen würde, und das müsste des weiteren zur Folge haben, dass sich Individuen, die nach ungleichen Richtungen hin abgeändert sind, miteinander fortpflanzen und somit ihre Ungleichheiten in ihren Nachkommen wieder ausgleichen. Die Art könnte also nicht rom Flecke kommen, wenn sie nicht durch andere Mittel mmgebildet wird, und sie könnte sich auch nicht in mehrere Arten spalten, denn wenn auch dotationelle Individualselektion das Überleben nach bestimmter Richtung abgeänderter Individuen bewirken wïrde, so wïrden doch sicher die einen nach dieser, die anderen nach jener Richtung abgeändert sein, und wer wollte dafür garantieren, dass sich in gleicher Richtung abgeänderte Individuen miteinander paaren und deshalb ihre Abänderungen auf die Nachkommen vererben? Ist das letztere aber nicht möglich, so können aus einer Art auf besclränktem Verbreitungsgebiete, wo eine Mischung nach allen Seiten hin möglich ist, nicht zwei oder mehrere Arten werden.

Anders ist es dagegen, wenn eine Art über ein weites Gebiet verbreitet und allseitige Mischung deshalb ausgeschlossen ist. Wenn sich immer oder vorwiegend nur diejenigen Individuen miteinander paaren, die innerhalb eines der untergeordneten Bezirke des Gesamtgebietes der Art wohnen, dann muss sich in jedem Teilgebiet eine neue Rasse und oft auch eine neue Art heranbilden, weil die Konstitution der betreffenden Individuen nicht in allen Gebieten in gleicher Weise abgeändert ist, und weil deshalb in dem einen eine andere Mischung zu stande kommt, als in dem anderen. Auf diese Weise können aus einer weit verbreiteten Art leicht eine grosse Anzahl neuer Rassen entstehen. Mit diesen kann aber die Präformationstheorie nichts anfangen, denn sie kann ohne dotationelle Individualselektion nicht auskommen; dass aber diese zu nichts führt, haben wir bereits gesehen. Dagegen stimmt die 
Epigenesislehre gut zu diesen Schlussfolgerungen, weil sie ausser der konstitutionellen Auslese, die zum Überleben der bestgefügten Individuen führt, noch eine direkte Anpassung durch den Gebrauch und Nichtgebrauch der Organe in jedem einzelnen Gebiete annimmt. Diese bedingt, dass eine Umbildung der Arten zu stande kommen muss, weil alle Individuen sich in gleicher Weise den Lebensverhältnissen ihres Wohngebietes und denjenigen Veränderungen, die durch konstitutionelle Zuchtwahl mit nachheriger Mischung zu stande gekommen sind, anpassen müssen.

Vergleichen wir mit dicsen Schlussfolgerungen dic Thatsachen, so finden wir sie wenigstens auf dem Gebiete der Zoologie vollkommen bestätigt. Nächstrerwandte Arten bewohnen nicht dieselben Gebiete, und wenn sich ihre Verbreitungsgebiete auch oft miteinander decken, so geschieht das letztere doch nur teilweise. Es giebt keine nächstverwandten Tierarten oder Tierrassen, von denen mit Sicherheit nachgewiesen ist, dass ihre Verbreitungsgebiete sich vollständig decken, vielmehr finden wir, und es ist ein grosses Verdienst Moritz Wagner's, uns darauf aufmerksam gemacht zu haben, dass sich die Verbreitungsgebiete der nächstverwandten Tierarten im grossen und ganzen wie die Maschen eines Netzes aneinanderreihen. Wenn auch an den Ränderı der Verbreitungsbezirke teilweise Deckung eintreten kann, so ist doch diese keine ursprüngliche.

Es sollte eigentlich überflüssig sein, Belege für diese Thatsachen anzuführen, denn wer systematische Monographien durchsehen will, wird finden, dass Wagner im Recht ist. An unsern deutschen Dompfaffen schliesst sich im Osten der grosse russische, dem Gebicte unserer Nachtigall reiht sich dort das des Sprossers an. Die Elbe bildet die Grenze der Verbreitungsgebiete zwischen Raben- und Nebelkrähe. Es giebt eine sïdwest- und eine nordostdeutsche Unkenart. Unsere deutsche Sumpfmeise wird auf den Alpen durch die Alpensumpfmeise, in Skandinavien durch die nordische, vertreten, und mit dieser Aufzählung könnten wir so lange fortfahren, bis wir jede einzelne Tierart namhaft gemacht haben. Zwar hat Nägeli vom botanischen Standpunkte aus die Lehre Wagner's heftig bekämpft, allein für die Pflanzen gelten andere Verbreitungsbedingungen als für die Tiere; aber ich bin überzeugt, dass dennoch schliesslich der Satz, dass sich eine Art in einer und derselben Gegend nur zu einer einzigen neuen Art umbilden kann, auch für die Pflanzen Gültigkeit hat, denn eine Trennung einer Art in mehrere neue Arten ist bei der Möglichkeit allseitiger Mischung der Individuen auf keine 
andere Weise denkbar. Übrigens giebt auch Nägeli schliesslich zu, dass der letzte Grund, weshalb sich auf einem und demselben Gebiete, wie es bei Pflanzen vorkommen soll, also ,gesellschaftlich", wie Nïgeli sagt, neue Arten bilden, dadurch gegeben ist, lass die Vorfahren der betreffenden gesellschaftlich entstandenen Arten verschiedene Verbreitungsgebiete innegehabt haben. Dann aber waren die, wenn vielleicht auch äusserlich kaum zu unterscheidenden Vorfahren der "gesellschaftlich" entstandenen Arten schon innerlich ungleich, und die Anschauungen Wagner's finden somit auch auf botanischem Gebiete ihre Bestätigung. Die Spaltung der Arten findet auf dem Wege der Separation, nicht aber bei Kongregation statt.

\section{Amphimixis und Apomixis.}

Bewohnt eine Organismenart ein begrenztes Gebiet, so muss durch die geschlechtliche Mischung jede grössere Ungleichheit unter den einzelnen Individuen wieder beseitigt werden. Die Mischung hätte also zur Folge, dass die Individuen sich im grossen und ganzen inmer gleich bleiben. We ismann lïsst aber grerade diese Mischung, für die er den Namen Amphimixis erfunden hat, eine grosse Rolle bei der Umbildung der Arten spielen. Er meint, dass durch sie der Naturzüchtung genügendes Material zur Auswahl geboten würde.

Wenn sich die Plasmen zweier verschiedener Individuen miteinander mischen, so gleichen sie nach Weismann nicht etwa ihre Verschiedenheiten aus, sondern sie behalten ihre Eigenschaften bei. Es sind also durch die Mischung polyplasmatische lieimzellen gebildet worden.

Die ältesten, sich noch ungeschlechtlich vermehrenden Vorfahren der Organismen wurden nach Weismann direkt durch die Lebensbedingungen umgebildet, und dadurch, dass geschlechtliche Fortpflanzung bei ihren Nachkommen eingeführt wurde, entstand durch die Vermischung zweier Individuen, deren Vorfahren sich bis dahin lediglich durch Teilung fortgepflanzt hatten, ein neues Individuum mit zwei Plasnıarten. Dieses konnte sich mit einem ebenfalls aus zwei Plasmen zusammengesetzten Individuum wieler geschlechtlich mischen, und so entstanden nach und nach Organismen, die aus 4, 8, 16, 3.2 und endlich aus einer grossen Anzahl verschiedener "A h neuplasmen" zusinmmengesetzt waren. Die Anzahl der Ahmenplasmen wurle nach IV eism ann endlich so gross, dass sie nicht mehr wachsen konnte, weil in den Keinzellen kein genügender Raum mehr war. Fs hätte darauf also entweder 
die geschlechtliche Mischung aufhören müssen, oder es musste eine Einrichtung geschaffen werden, durch welche die Zahl der Ahnenplasmen auf die Hälfte reduziert wurde, ehe sich die Keimzellen miteinander verbanden; das soll durch die Reduktionsteilung, welcher das Ei und ebenso auch die Samenzelle bei der Keimzellenreifung unterworfen ist, geschehen. Indem nun bei dieser Reduktionsteilung bald die eine, bald die andere Kombination von Ahnenplasmen ausgestossen wird, sollen die in den Zellen zurückbleibenden, die sich wieder mit denen der Keimzelle des entgegengesetzten Geschlechtes mischen, in immer neuer Weise kombiniert werden, so dass die natïrliche Zuchtwahl stets ein ausgiebiges Material vorfindet.

Es stammen also nach dieser Anschauung die Unterschiede der verschiedenen Ahnenplasmen, die Weismann jetzt "Ide" nennt, von den noch nichtsich geschlechtlich fortpflanzenden Vorfahren der heutigen Organismen her, und Weismann sagt ausdrücklich auf Seite 85 seines Keimplasmabuches: „Gäbe es Tiere, in deren Vorfahrenreihe geschlechtliche Fortpflanzung niemals hineingespielt hätte, so müssten diese Ide untereinander völlig gleich sein." Die Ide sind nach ihm in den Kernstäbchen oder Chromosomen, die Weismann „Idanten" nennt, aufgestapelt und pflanzen sich durch Teilung fort. Dem Einwande, der Weismann gemacht wurde, dass aus dem Plasma einfachster Urwesen doch nicht das eines Menschen oder eines anderen hochentwickelten Organismus durch blosse Mischung entstehen könne, begegnet We is man n neuerdings dadurch, dass er sagt, dass diese Ide durch äussere Einflüsse verändert wurden und dass sich ihr Plasma deshalb im Laufe der Generationen geändert hätte. Theoretisch würde also eines dieser Ide für die Keimesentwickelung genügen. Ich habe aber schon im Jahre 1888 gezeigt, dass die Anzahl der Ahnenplasmen, die von den einzelligen Vorfahren der vielzelligen Tiere und Pflanzen, bei welchen noch in divi duelle Unterschiede direkt durch äussere Einflüsse hervorgebracht werden konnten, herrühren sollen, immer geringer werden musste, dass die Verschiedenheit der Ide und damit die Verschiedenartigkeit der Individuen im Laufe der Generationen notwendigerweise abnehmen muss. Weismann hat diesen Einwand, der seiner ursprünglichen Ahnenplasmentheorie verderblich ist, unbeachtet gelassen, ich aber muss ihn wiederholen, weil We ismann auf Seite 85 des „Keimplasma" noch derselben Ahnenplasmentheorie wie früher folgt und deshalb vielleicht zu ihr zurückkehren möchte, falls seine neue Theorie als unhaltbar nachgewiesen wird. 
Wir wollen von den Sat\%e W eismann's, dass die Ide eines Tieres, in dessen Vorfahrenreihe niemals geschlechtliche Fortpflanzung hineingespielt hat, untereinander gleich sein müssen, ausgehen. Diese Behauptung Weismann's seheint sich zwar auf die einzelnen Individuen solcher Tierarten zu bezichen. Wenn Weisman $\mathrm{n}$ aber annimmt, dass auch in den Individuen dieser Arten eine Verrielfachung der Ide, etwa auf dem Wege der 'leilung, stattgefunden hat, so müssten die Ide auch in jedem Individuum verschieden untereinander werden können, sind doch nach Weismann sogar die Determinanten innerhalb eines und desselben Ides verschierlen geworden! Weismann's Determinantenlehre hat nur dann einen Sinn, wenn aus den gleichen Biophoren eines Urides ungleiche Lebensträger und somit Determinanten für besondere Organe werden konnten. War aber dieses möglich, so mussten auch die verschiedenen Ide eines Keimplasma's ungleich werden können, und zwar noch viel leichter als die Biophoren eines und desselben Ides, denn die Ide sind relativ weit voneinander getrennt, während die Biophoren eines Ides viel dichter beisammen liegen. Konnten die Ide eines Individuums aber trotzdem nicht ungleich werden, so mussten sie auch bei allen Nachkommen eines und desselben Individ u u ms einander gleich bleiben, denn dann musste das Ungleichwerden der Ide durch irgend eine geheimnisvolle Figenschaft verhindert werden, die aber dem Ungleichwerden der Biophoren innerhalb eines und desselben Ides nichts in den Weg legte. Besteht Weismann's Behauptung auf Seite 85 zu Recht, dann muss Weismann auch zugeben, dass sich bei Tieren, deren Vorfahren sich niemals geschlechtlich fortpflanzten, die Ide in allen Nachkommen eines Individuums gleich bleiben mussten, denn anzunehmen, dass die Ide bei verschiedenen Nachkommen eines Individuums ungleich werden, bei einem und demselben Individuum aber gleich bleiben müssen, würde allzu willkürlich sein. Auf alle Fälle müsste Weismann, falls er die Ide in verschierlenen Individuen verschieden werden lässt, einräumen, dass eine geringe Verschiedenheit in der Ausbildung der Ide eines und desselben Keimplasma's auch bei Tieren, in deren Fortpflanzung geschlechtliche Mischung niemals hineingespielt hat, möglich ist. Das aber leugnet Weismann auf Seite 85 ausdrücklich und damit leugnet er die Möglichkeit einer ungleichen Ausbildung der Ide bei Tieren, die von einem Individuum herstammen. Alle Ide, die von einem sich noch nicht geschlechtlich fortpflanzenden Urwesen herstammen, müssen also einander vö̈lig gleich sein, und 
das entspricht auch Weismann's früheren Ansichten über die Bedeutung der Reduktionsteilungen, Ansichten, die auf Seite 85 vom „Keimplasma“ wieder zum Durchbruch gelangen. Wir nehmen also an, der citierte Satz auf Seite 85 bringe die W eism an n'sche Ansicht, deren Konsequenz wir oben gezogen haben, zum Ausdruck. Dann aber könnte auch bei solchen Arten, die mehrere Ide in ihren Zellen besitzen, individuelle Variabilität nur durch geschlechtliche Fortpflanzung, nur durch verschiedenartige Mischung der von verschiedenen Urindividuen herstammenden Ide eintreten, und die natürliche Zuchtwahl würde immer diejenigen Mischungen auslesen, die jeweilig am besten sind.

Wir wollen jetzt einmal, wie ich es schon im Jahre 1888 gethan habe, untersuchen, in wie hohem Grade es wahrscheinlich ist, dass die in einer Generation einer Tier-oder Pflanzenart enthaltenen Ide auch noch in der nächsten vorhanden sind, nachdem natürliche Zuchtwahl ihre Wirksamkeit entfaltet hat, und ich lasse meine früheren Ausführungen hier ziemlich unverändert folgen.

Weismann hat bei seiner Theorie nicht in Betracht gezogen, dass die Anzahl der Individuen jeder Tier- und Pflanzenart im Durchschnitt jahraus jahrein dieselbe bleibt. Jedes Tierpärchen hat durchschnittlich nur zwei Kinder, die wieder zur Fortpflanzung gelangen; hätte es etwa deren drei, so müsste die Anzahl der Individuen einer Art schon nach wenigen Generationen ins Ungeheuerliche gestiegen sein. Auf jedes Tiermännchen und jedes Tierweibchen kommen indessen durchschnittlich z w ei wieder zur Fortpflanzung gelangende Kinder, weil bei geschlechtlich differenzierten Tieren jedes Individuum zwei Eltern hat. Dasselbe gilt für diöcische Pflanzen. Hermaphroditische Tier- und Pflanzenindividuen haben durchschnittlich nur einen überlebenden Nachkommen.

Wenden wir nun, nachdem wir uns diese von Weismann unberiicksichtigt gelassene, aber nichtsdestoweniger unumstössliche Thatsache ins Gedächtnis zurückgerufen haben, die Weismann'sche Reduktionsund Mischungstheorie der Ahnenplasmen auf die beiden überlebenden Kinder einer II utter aus irgend einer Tierart an!

Wir wollen annehmen, dass die Anzahl der Ahnenplasmen, aus welchen das mütterliche Keimplasma zusammengesetzt ist, 4 beträgt. Diese 4 Ahnenplasmen wollen wir mit $v, x, y$ und $z$ bezeichnen. Die Anzahl der möglichen Kombinationen von Ahnenplasmen in den durch Ausstossung der Richtungskörper befruchtungsfähig gewordenen Eizellen unseres Individuums muss, da nur zwei Ahnenplasmen in der Keimzelle 
zurückbleiben, $=\frac{4.3}{1.2}=6$ sein, und diese 6 Keimplasmahälften sind die folgenden: $v x, v y, v z, x y, x z, y z$. Da unser Mutterindividuum zwei wieder zu Eltern werdende Kinder hat, so sind in diesen beiden zusammengenommen $6^{2}=36$ Kombinationen von mütterlichen Keimplasmahälften möglich, und zwar:
1) $v x, v x$.
7) $v y, v x$.
13) $v z, v x$.
19) $x y, v x$.
25) $x z, v x$.
31) $y z, v x$.
2) $v x, v y$.
8) $v y, v y$.
14) $v z, v y$.
20) $x y, v y$.
26) $x z, v y$.
32) $y z, v y$.
3) $v x, v z$.
9) $v y, v z$.
15) $v z, v z$.
21) $x y, v z$.
27) $x z, v z$.
33) $y z, v z$.
4) $v x, x y$.
10) $v y, x y$.
16) $v z, x y$.
22) $x y, x y$.
28) $x z, x y$.
34) $y z, x y$.
5) $v x, x z$.
11) $v y, x z$.
17) $v z, x z$.
23) $x y, x z$.
29) $x z, x z$.
35) $y z, x z$.
6) $v x, y z$.
12) $v y, y z$.
18) $v z, y z$.
24) $x y, y z$.
30) $x z, y z$.
36) $y z, y z$.

Durch Worte erläutert, bedeutet beispielsweise die erste Kombination, dass sowohl in dem ersten als auch in dem zweiten der beiden Kinder die von der Mutter stammende Ahnenplasmenkombination $v x$ enthalten sein kann. In dem zweiten Kinde kann anstatt $v x$ auch $y z$ sich rorfinden, in dem ersten Kinde auch $y z$ und in dem zweiten $v x$ usw. Die Anzahl der Kombinationen, in welchen die in der Mutter enthaltenen Ahnenplasmen, von denen jedes Kind zwei erlıält, in dem überlebenden Kinderpaar fortbestehen können, ist allgemein ausgedrückt $\iota^{2}$, demn es handelt sich hierbei um "Variationen mit Wiederholung", wobei $a$ die Anzahl der möglichen „Elemente", hier der Keimplasmahälften, und 2 die „Klasse", zu welcher die Elemente kombiniert sind, bedeutet. Die Anzahl der möglichen Keimplasmahälften beträgt aber, allgemein ausgedrückt, $\frac{n(n-1)(n-2) \ldots(n-m+1)}{1.2 .3 \ldots m}$, denn es handelt sich hierbei um „Kombinationen olne Wiederholung". Für $n$ Elemente, die zur $\frac{n}{2}$ ten Klasse kombiniert werden, gilt also die formel

$$
\frac{n(n-1)(n-2) \ldots\left(n-\frac{n}{2}+1\right)}{1.2 .3 \ldots \frac{n}{2}},
$$

woraus sich in unserem Falle die Formel $\frac{4.3}{1.2}$ ergiebt, und diese Anzahl wollen wir $a$ nemnen. $a$ bedeutet also die Anzahl der möglichen Ahnenplasmenhälften der Mutter und $a^{2}$ die ihrer möglichen Kombinationen in beiden Kindern zusammengenommen.

Da nun jede Keimplasmahälfte nur durch eine bestimmte andere Keimplasmahälfte, in unserem Falle beispielsweise $v x$ nur durch $y z$ er- 
gänzt wird, da also die Anzahl der möglichen Fälle, in welchen in dem Kinderpaar der Mutter wieder sämtliche Almenplasmen der letzteren enthalten sind, nur eine beschränkte ist, so lässt sich die Walırscheinlichkeit berechnen, mit welcher alle Almenplasmen der Mutter in dem Kinderpaar erhalten bleiben.

Es sind in unseren obigen Falle 6 in der Möglichkeit liegende mütterliche Keimplasmahälften vorhanden, und unter den obigen $36 \mathrm{Kom}-$ binationen dieser Keimplasmahälften finden wir wieder 6 , in welchen sämtliche mütterliche Ahnenplasmen enthalten sind. Bei 8 Keimplasmahälften würden wir 8 finden, und bei $a$ wieder $a$, denn jede Hälfte wird eben nur durch eine bestimmte andere zum mütterlichen Ahnenbestand ergänzt, $v x$ in unserem obigen Falle nur durch $y z$, vy nur durch $x z, v z$ nur durch $x y$. Da aber' $v x, v y, v z$ sowohl im ersten als auch im zweiten Kinde enthalten sein können, so ist eben die Anzahl der alle mütterlichen Abnenplasmen enthaltenden Kombinationen von Keimplasmahälften ebenso gross wie die Anzahl der möglichen Keimplasmahälften selbst, in unserem Falle also $=6$ oder, allgemein ausgedrückt, $=a$, während $a^{2}$, wie wir gesehen haben, die Anzahl der Kombinationen von mütterlichen Keimplasmahälften bedeutet, welche überhaupt möglich sind. Die Wahrscheinlichkeit, dass sämtliche mütterliche Ahnenplasmen in dem überlebenden Kinderpaar enthalten sind, ist also $\frac{a}{a^{2}}=\frac{1}{a}=\frac{1}{6}$.

Wenn in unserem Beispiele die Wahrscheinlichkeit, dass sämtliche Ahnenplasmen eines Individuums erhalten werden, auch noch $1 / 6$ beträgt, so ist dieselbe Wahrscheinlichkeit für 2 Individuen schon auf $1 / 36$ gesunken, denn nach den Regeln der Wahrscheinlichkeitsrechnung müssen wir die beiden Wahrscheinlichkeiten miteinander multiplizieren. Für 3 Individuen beträgt die Wahrscheinlichkeit nur noch 1/216, für 1000 endlich $\frac{1}{6^{1000}}$ oder, allgemein ausgedrückt, $\frac{1}{a^{1000}}$. Die meisten Organismenarten bestehen aber aus vielen Millionen von Individuen, unter denen jedes einzelne nach Weisman n zahlreiche Ahnenplasmen enthalten kann, durch welch letzteren Umstand natürlich We ismann's Sache noch unhaltbarer wird. Noch geringer aber erscheint die Möglichkeit der Erhaltung sämtlicher Ahnenplasmen, wenn wir uns erinnern, dass die natürliche Zuchtwahl eifrig an der Vernichtung ungünstiger Ahnenplasmen-Kombinationen und somit, da die gleichzeitig lebenden Individuen einer Art sich durchweg gleich bleiben, der Ahnenplasmen selbst mitarbeiten würde. Ja, es würde wahrscheinlich sein, dass die natürliche Zuchtwahl dafür sorgt, 
dass jedes der beiden überlebenden Kinder eines Elternpaares eine gleiche oder nahezu grleiche Kombination von Ahnenplasmen erhielte, dass also, falls wir annehmen, dass die Anzahl der Ahnenplasmen in einer Generation einer Organismenart $n$ beträgt, und dass diese Ahnenplasmen und somit ihre 'Träger sämtlich untereinander verschieden sind, in der nächsten Generation wahrscheinlich nur noch $\begin{gathered}n \\ 2\end{gathered}$ Ahnenplasmen wären, während ihre Träger, die Individuen dieser Generation, sich teilweise gleichen würden. Wenn aber die Verhältnisse auch nicht so einfach lägen, wie wir es hier angenommen haben, wenn immer auch einige ungünstige Ahnenplasmen in jedem Keimplasma erhalten blieben, so müsste deren Anzahl doch von Generation zu Generation abnehmen, denn ron allen erzeugten Organismen gehen die allermeisten ohne Nachkommen zu Grunde.

Aus diesen Betrachtungen ergiebt sich die unabweisbare Folgerung, dass, falls die oben citierte Weismann'sche Ansicht richtig ist, die heutige Nachkommenschaft der ältesten sich ungeschlechtlich fortpflanzenden Organismenarten viel weniger Ahnenplasmen enthalten müssen, als die ersten Organismen mit geschlechtlicher Fortpflanzung, bei denen sich die in einer Keimzelle mögliche Anzahl von Ahnenplasmen ja sehr bald erreichen liess. Wenn aber die verschiedenen Ahnenplasmen einer Organismenart im Laufe der Stammesgeschichte bedeutend an Anzahl abgenommen haben, so müssten die höheren Tiere weniger variieren als die niederen. Das stimmt aber nicht zu den Thatsachen, denn wir sehen, dass gerade die höchststehenden Tiere und Pflanzen am ausgiebigsten variieren. Man denke nur an den Menschen, an den Hund und alle hoch organisierten Geschöpfe.

Die konsequente Durchführung der alten Weismann'schen Ahnenplasmentheorie stösst also auf Widerspruch mit den Thatsachen und zeigt deshalb, dass die Theorie in dieser ursprünglichen Form falsch ist.

Indessen hat Weismann sie im weiteren Verlaufe des Keimplasmabuches nicht in dieser Form beibehalten. Liest man Seite 85, welcher wir den oben citierten Satz entnommen haben, so muss man allerdings meinen, dass er die alte Ahnenplasmentheorie trotz meines ibr verhïngnisvoll werdenden Einwandes noch unverändert beibehält; aber in der zweiten Hälfte seines Buches, und zwar in dem Abschnitte, welcher über das Abändern der Arten handelt, nimmt er, wie er es ja auch konsequenterweise thum muss, an, dass die Ide für sich varieren, dass also 
auch diejenigen Ide voneinander verschieden werden können, welche von einen einzigen Urid abstammen. Das ist mit Sicherheit aus Weismann's Ausführungen zu entnehmen.

Es steht also dieser Teil des Buches in vollkommenem Widerspruch mit dem citierten Satze auf Seite 85. Wir wollen aber auf diese Nebensache kein Gewicht legen, sondern annehmen, dass Weismann der Satz auf Seite 85 aus Versehen aus der Feder geflossen ist, und dass seine inzwischen gewonnene bessere Einsicht, wonach jedes Id für sich variieren kann, eine Berücksichtigung meines Linwandes von Jahre 1888 unnötig nachte. Aber dann muss ich leider den Einwand in einer anderen Form wiederholen, und es wird sich zeigen, dass dadurch die aus der alten Ahnenplasmentheorie hervorgegangene Theorie der Amphimixis als durchaus unhaltbar nachgewiesen wird.

Um darzuthun, dass Weismann's Theorie der Amphimixis auch danı unhaltbar ist, wenn die Manuigfaltigkeit der von den Urwesen herstammenden Ide nicht durch natürliche Zuchtwahl vermindert wird, wollen wir annehmen, dass das Plasma einer befruchtungsbedürftigen Zelle, also eines Eies oder Samenfadens, in welchem durch die Reduktionsteilung die Anzahl der Kernstäbchen auf die Hälfte herabgesetzt ist, $\iota$ Ide enthält, dass demnach jede Körperzelle der betreffenden Organismenart aus $2 a$ verschiedenen Biophorenstämmen zusammengesetzt, bezw. durch $2 a$ verschiedene Determinanten bestimmt wird. Wir wollen ferner annehmen, dass die von dem Erzeuger unserer befruchtungsbedürftigen Keimzelle herstammenden Ide alle aus gleich guten Determinanten zusammengesetzt waren, dass aber in den in diesem Elter erzeugten Keimzellen jede Determinante in jedem Id anfängt, in irgend einer der überhaupt möglichen Richtungen zu variieren, dass die zu befruchtende Keimzelle demgemäss schon mehr oder minder abgeänderte Ide enthält.

Jede Determinante soll nach $b$ verschiedenen Richtungen variieren können. Dass die Anzahl dieser Richtungen sehr gross ist, darf als sicher angenommen werden, denn wenn man bedenkt, wie gross etwa die Anzahl der Säugetierarten ist, und in Betracht zieht, dass beispielsweise die Haare jeder Säugetierart von denen jeder anderen Art verschieden sind, ja dass sie an einem und demselben Säugetierkörper in hohem Grade voneinander abweichen können, sowolıl was ihre Grösse und Form, als auch was ihre Färbung und Zeichnung anbelangt, so muss man, wenn man einmal auf dem Boden der Präformationstheorie steht, 
zu der Einsicht gelangen, dass die Anzahl der Richtungen, in welcher die Determinanten der einzelnen Zellen variieren können, eine a usserordentlich grosse ist. Da wir aber ferner sehen, dass bei wildlebenden Tieren die Beschaffenheit der Haare äusserst konstant bleibt, so müssen wir zu der weiteren Folgerung gelangen, dass unter allen möglichen Richtungen, in welchen die Determinanten der einzelnen Zellen variieren können, nur einige wenige gute sind, ja dass eigentlich nur eine einzige den jeweiligen Bedürfnissen der betreffenden Art am besten entspricht.

Wir wollen, wie Weismann es thut, des weiteren annehmen, dass jede Zelle, die aus unserer Keimzelle hervorgeht, nur durch eine einzige Determinante aus jedem Id und ferner, dass sie nur durch eine Art von Biophoren bestimmt wird. Wenn also 2a Ide die Organismenart charakterisieren und jede der $2 a$ Determinanten für jede einzelne Zelle in $b$ verschiedenen Richtungen variieren kann, so ist die Anzahl der Variationsmöglichkeiten für die Hälfte der Determinantengruppe jeder Körperzelle, die aus unserer noch zu befruchtenden Keimzelle entsteht, gleich $b^{a}$. Das ergiebt sich, wenn wir folgende Betrachtung anstellen.

Würden etwa in der betreffenden Keimzelle nur 2 Ide vorhanden sein, würde also jede Zelle des Körpers, der sich aus dieser Keimzelle entwickelt, nur durch 4 homologe Determinanten bestimmt werden, und könnte jede der beiden aus den in der reduzierten Keimzelle noch vorhandenen Iden des Elters stammenden Determinanten einer Körperzelle nur nach zwei Richtungen hin variieren, so könnte, wenn wir die eine elterliche Determinante mit $x$ und die andere mit $y$, und wenn wir die beiden Variationsmöglichkeiten mit $p$ bezw. mit $q$ bezeichnen, $x$ sowohl in der Richtung nach $p$, als auch in der nach $q$ variieren, und dasselbe würde für $y$ gelten. Wir könnten also eine Zelle erhalten, in der sowohl $x$ als auch $y$ in der Richtung nach $p$ abgeändert sind; wir könnten aber auch eine Zelle erhalten, in welcher $x$ nach $p, y$ nach $q$ hin verändert ist, oder auch eine solche, in welcher $x$ nach $q$ und $y$ nach $p$ hin variiert hat, endlich eine, in welcher sowohl $x$ als auch $y$ nach der Richtung $q$ abgeändert worden sind. Es giebt also im ganzen bei 2 Iden in der reduzierten Keimzelle und bei 2 Variationsmöglichkeiten für jedes Stück eines Paares homologer Determinanten der beiden Ide 4 Fälle, und wer mit den Anfangsgründen der Kombinationslehre vertraut ist, wird ohne weiteres sehen, dass es sich in unserem Falle um diejenige Art von Kombinationen handelt, die man „Variationen 
mit Wiederholung" nennt. Für diese gilt aber die Formel $n^{\text {min }}$, wobei $n$ die Anzahl der „Elemente" angiebt und $m$ die „Klasse" bezeichnet, also angiebt, wie viele von den $n$ Elementen eine Kombination zusammensetzen sollen. Bei $a$ Iden in unserer unbefruchteten Keimzelle und bei b Variationsmöglichkeiten lautet also die Formel der möglichen Fälle, welche die Abänderungen für die Hälfte der Determinanten einer Körperzelle bezeichnet, wie oben angegeben, $b^{a}$, denn $b$ ist die Anzahl der Elemente, der Variationsmöglichkeiten, zwischen denen gewählt werden kann, und $a$ bezeichnet die Klasse und giebt an, wieviel der Elemente, zwischen denen eine Wahl möglich ist, in die Kombination eintreten. Die Klasse hängt ja von der Anzahl der Ide in der zu befruchtenden Keimzelle ab, und die Anzahl der verschiedenen Elemente, zwischen denen gewählt werden kann, wird durch die Zahl der Variationsmöglichkeiten der Determinanten einer Zelle im Keiniplasnia bestimmt.

Wir können nun ferner annehmen, dass, wie es ja der Wirklichkeit in den meisten Fällen entsprechen wird, die Anzahl der Richtungen, welche zu einer günstigen Umbildung der Determinanten führt, nur gleich 1 ist. Han könnte allerdings auch wohl annehmen, dass unter $x b$ Variationsmöglichkeiten vielleicht $b$ günstige wären. Es ist aber für die Rechnung einfacher und ändert am Resultate nichts, wenn wir nur $b$ Variationsmöglichkeiten, unter denen nur eine günstige ist, annehmen. Wenn also eine durch $2 a$ homologe Determinanten bestimmte Körperzelle in günstiger Weise abändern soll, so muss mindestens die Anzahl der in vorteilhafter Richtung abgeänderten Determinanten 1 mehr als die Hälfte der Gesamtzahl, also in unserem Falle $a+1$ betragen. Wir wollen nunmehr die Wahrscheinlichkeit berechnen, mit der dieser Fall eintritt.

Wir können zunächst annehmen, dass sich alle $a$ homologen mütterlichen oder väterlichen Determinanten der betreffenden Zelle günstig verhalten, sei es, dass sie in günstiger Richtung abändern, oder dass sie ebenso gut bleiben, wie sie waren, was ja dasselbe sein wïrde. Wenn unter den $b$ verschiedenen Variationsmöglichkeiten nur eine günstig ist, so ist die Anzahl der Fälle, in welcher sich alle a Determinanten des einen Eiters günstig verhalten, nur gleich 1, wie ja leicht einzusehen.

Wenn sich nur 1 der $a$ Determinanten ungünstig verhält, so erhalten wir a Gruppen von Fällen, da jede der a Determinanten eine ungünstige Richtung einschlagen, oder, wie wir uns ausdrücken wollen, 
ein Nichttreffer sein kann. Der Nichttreffer kann aber, da er ja, wie sein Name sagt, nicht in der einen vorteilhaften Richtung abgeändert ist, nur nocl in $b-1$ beliebigen Richtungen variieren. Die Gesantzahl der Fälle, in welchen nur je 1 der aus einem Elter stammenden Determinanten einer bestimmten Körperzelle in ungünstiger Richtung abgeänder't ist, beträgt also $a(b-1)$. Diese Fälle sind dem Falle, in welchem sich 0 Determinanten ungünstig verhalten, zu addieren.

Die Anzahl der Fälle, in welchen sich 2 Determinanten ungünstig rerhalten, ergiebt, da diese beispielsweise die erste und zweite, oder die zweite und dritte, oder aucl die erste und vierte, die füntte und siebente, die sechste und achte usw. sein können, $\frac{a(a-1)}{1.2}$ Gruppen von Kombinationen, da es sich hierbei, wie leicht einzusehen, um „Kombinationen im engeren Sinne ohne Wiederholung" handelt, für welche die Formel $\frac{n(n-1)(n-2) \ldots(n-m+1)}{1.2 .3 \ldots . m}$ gilt, wobei $n$ die Anzahl der Elemente und $m$ die Klasse bedeutet. In unserem Falle, wo sich 2 Determinanten ungünstig verhalten, haudelt es sich also um a Elemente zur 2 ten Klasse, und daraus ergiebt sich die obige Fornel. Da nun jeder der 2 Nichttreffer wieder in $b-1$ Richtungen abweichen kann, ergeben sich folgende Möglichkeiten: Der erste der beiden Nichttreffer kann, wenn die erste der $b$ Richtungen eine günstige $A$ bänderung bedeutet, also für Nichttreffer nicht in Betracht kommt, etwa nach der Richtung 2 , der zweite etwa ebenfalls nach der Richtung 2 oder auch nach der Richtung 3, der erste aber auch nach der Richtung 4 und der zweite nach der Richtung 5, oder auch der erste nach der Richtung 7 und der zweite nach der Richtung 4 abgeändert sein usw. Es ergeben sich mit anderen Worten so viele Möglichkeiten, wie durch diese Verhältnisse bedingt werden, also $(b-1)^{2}$, weil es sich hier wiederum um "Variationen mit Wiederholung" handelt, wobei die Anzahl der Elemente gleich $b-1$ und die Klasse gleich 2 ist. $b-1$ Variationsmöglichkeiten sind für jeden der beiden Nichttreffer gegeben, und da es sich nur un 2 Nichttreffer handelt, so ist $(b-1)^{2}$ die Anzahl der Variationsmöglichkeiten, die für unsere beiden nicht günstig abändernden homologen Determinanten einer Zelle gegeben ist. Wir haben also die Zahl ${ }_{1.2}^{a(a-1)}$ nit $(b-1)^{2}$ zu multiplizieren, um die Anzahl der Fälle zu erhalten, welche bei zwei ungünstig abäudernden unter $a$ homologen Determinanten möglich sind. 
Bei 3 Nichttreffern würde diese Anzahl, wie nummehr leicht einzusehen, $\frac{a(a-1)(a-2)}{1.2 .3} \cdot(b-1)^{3}$ sein, und bei $a$ Nichttreffern würden wir $\frac{a(a-1(a-2)(a-3) \ldots \ldots 1}{1.2 .3 \ldots a} \cdot(b-1)^{a}$ Fälle erhalten.

Aus diesen Erwägungen geht hervor, dass die Gesamtheit aller möglichen ron einem Elter stanmenden Determinanten-Kombinationen in einer Zelle auszudrücken ist durch die aus $a+1$ Gliedern bestehende Formel:

$$
\begin{aligned}
1+a(b-1) & +\frac{a(a-1)}{1.2}(b-1)^{2}+\frac{a(a-1)(a-2)}{1.2 .3}(b-1)^{3} \ldots \\
& +\frac{a(a-1)(a-2) \ldots 2}{1.2 .3 \ldots(a-1)}(b-1)^{a-1}+\frac{a(a-1)(a-2) \ldots 1}{1.2 .3 \ldots a}(b-1)^{a} .
\end{aligned}
$$

Ebenso gross würde die Anzahl der von dem zweiten Elter stammenden Kombinationen sein, und diese würden genau dieselben Einzelfälle aufweisen.

Uns wird dadurch ermöglicht, die Wahrscheinlichkeit zu berechnen, mit welcher eine Körperzelle in günstiger Richtung abändern wird. Es können beispielsweise sämtliche Determinanten väterlicher und sämtliche $a$ Determinanten mütterlicher Seite in günstiger Richtung variieren, was 1 Fall giebt. Es können sich aber auch zwar sämtliche väterliche Determinanten günstig, sämtliche mütterliche aber ungünstig verhalten, was $1 . \frac{a(a-1)(a-2) \ldots 1}{1.2 .3 \ldots a}(b-1)^{a}$ Fälle geben würde. Auch das Umgekehrte könnte stattfinden, wodurch man dieselbe Anzahl von Fällen erhalten würde. Aus dieșen Beispielen ersehen wir, dass die Gesamtzahl der möglichen Fälle auszudrücken ist durch die Formel:

$$
\begin{gathered}
1 \cdot\left[1+a(b-1) \ldots \frac{a(a-1)(a-2) \ldots 1}{1.2 .3 \ldots a}(b-1)^{a}\right] \\
+a(b-1) \cdot\left[1+a(b-1) \ldots \frac{a(a-1)(a-2) \ldots 1}{1.2 .3 \ldots a}(b-1)^{a}\right] \ldots \\
+\frac{a(a-1)(a-2) \ldots 1}{1.2 .3 \ldots a}(b-1)^{a} \cdot\left[1+a(b-1) \ldots \frac{a(a-1)(a-2) \ldots 1}{1.2 .3 \ldots a}(b-1)^{a}\right] .
\end{gathered}
$$

Diese lange Formel, von der wir hier nur drei Glieder niedergeschrieben haben, wird uns gleich weitere Dienste thun; sie lässt sich aber viel kïrzer ausdrücken durch die Formel $\left(b^{a}\right)^{2}=b^{2 a}$, denn für die aus einem Elter stammenden Determinanten einer Zelle ist die Anzahl verschiedener Variationsmöglichkeiten $=b^{a}$, weil wir $b$ Variationsrichtungen haben, die zur aten Klasse kombiniert sind. Da aber jede Variationenkombination der die Zelle bestimmenden homologen Determinanten des einen Elters mit jeder Variationenkombination der homologen Zelldeterminanten des zweiten 
Elters zusammentreffen kann, so nüssen wir $b^{a}$ mit $b^{a}$ multiplizieren, wodurch wir die obige Anzahl aller möglichen Fälle, nämlich $b^{2 a}$ erhalten.

Unter allen möglichen Fällen sind aber nur diejenigen günstig, in welchen mindestens $a+1$ Determinanten in der erforderlichen Richtung abgeändert sind, denn sonst würde die Zelle nicht in dieser Richtung variieren können, und die natürliche Zuchtwahl müsste sie beseitigen. Zu der Anzahl der günstigen Fälle gelangen wir aber durch die Aufstellung derjenigen Kombinationen, welche $a+1$ in günstiger Richtung abgeänderte Determinanten enthalten, und zwar in folgender Weise: Der eine Fall, in welchem alle a Zelldeterminanten des einen Elters in günstiger Weise abgeändert sind, darf sich mit den $1+a(b-1)+\frac{a(a-1)}{1.2}(b-1)^{2}$ $\ldots+\frac{a(a-1)(a-2) \ldots 2}{1.2 .3 \ldots(a-1)}(b-1)^{a-1}$ Fällen, in welchen sich $a$, beziehungsweise $a-1, a-2 \ldots 3,2,1$ Determinanten vom anderen Elter günstig verhalten, verbinden, ebenso dürfen sich die $a(b-1)$ Fälle, in welchen siclı nur 1 Determinante des einen Elters ungünstig verhält, mit den

$$
1+a(b-1)+\frac{a(a-1)}{1.2}(b-1)^{2} \ldots+\frac{a(a-1)(a-2) \ldots 3}{1.2 .3 \ldots(a-2)}(b-1)^{a-2}
$$

Fällen, in welchen $a$, beziehungsweise $a-1, a-2, a-3 \ldots 4,3,2$ Determinanten des anderen Elters in der erforderlichen Weise abgeändert sind, kombinieren. Setzen wir unsere Ueberlegungen in dieser Weise fort, so erhalten wir für die Anzahl der Fälle, in welchen mehr als die Hälfte der $2 a$ Determinanten einer Zelle abgeändert sind, die Formel:

$$
\begin{gathered}
\text { 1. }\left[1+a(b-1)+\frac{a(a-1)}{1.2}(b-1)^{2} \ldots+\frac{a(a-1)(a-2) \ldots 2}{1.2 .3 \ldots(a-1)}(b-1)^{a-1}\right] \\
+a(b-1)\left[1+a(b-1)+\frac{a(a-1)}{1.2}(b-1)^{2} \ldots\right. \\
\left.+\frac{a(a-1)(a-21 \ldots 3}{1.2 .3 \ldots(a-2)}(b-1)^{a-2}\right]+\ldots+\left[\begin{array}{c}
a(a-1)(a-2) \ldots 2 \\
\frac{1.2 .3 \ldots(a-1)}{2}(b-1)^{a-1}
\end{array}\right] .1 .
\end{gathered}
$$

Diese Anzahl der günstigen Fälle durch die Anzahl aller möglichen, welche $b^{* a}$ betrug, dividiert, giebt die Wahrscheinlichkeit, mit welcher eine Körperzelle, die durch $2 a$ Determinanten, von denen jede in $b$ Richtungen, und zwar in $b-1$ ungünstigen und 1 günstigen abändern kann, in günstiger Weise variiert.

Einige Beispiele werden schnell darthun, was unsere Formel zu lehren im stande ist.

Gesetzt, es handelte sich für eine Körperzelle nur um eine Variationsmöglichkeit, d. h. sie würde seitens jedes Elters nur durch 1 Determinante bestimmt, und diese könnte sich nur in einer sich stets gleich- 
bleibenden Weise verhalten, so würde die Wahrscheinlichkeit, dass dieses Verhalten eintritt, gleich 1 sein, also Gewissheit bedeuten. Wenn die Anzahl der Determinanten eines Elters, also $a$ in unserer Formel, gleich 2 ist, und wenn jede sich nur in einer Weise verhalten könnte, wenn also die Anzahl der Variationsmöglichkeiten $b$ unserer Formel gleich 1 ist, so ist die Wahrscheinlichkeit, dass sich alle Determinanten auch so rerhalten, wieder gleich 1 , oder wieder Gewissheit. Wenn aber $a=1$ und $b=2$ ist, so ist die Wahrscheinlichkeit $W$ nur gleich ${ }_{4^{*}}^{1}$. Ist $a=2$ und $b=2$, so ist $W=\frac{5}{16}=\frac{1}{3,2} ; a=3$ und $b=2$ giebt, wie man leicht mit unserer Formel ausrechnen kann, $W=\frac{1}{2,9}$.. und bei $a=2$ und $b=3$ ist $W=\frac{1}{9} . \quad a=3$ und $b=3$ giebt $W=\frac{1}{9,9 \ldots} ;$ ist aber $a=4$ und $b=3$, so ist $W$ nur $=\frac{\mathbf{5 7 7}}{\mathbf{6 5 6 1}}=\frac{1}{\mathbf{1 1 , 3}}$. Das gilt schon für eine einzige Zelle des Körpers. Besteht dieser aber aus vielen Zellen, die alle durch vier nach drei Richtungen variierende Determinanten seitens jeden Elters bestimmt werden, so müssen wir diesen Wahrscheinlichkeitsbruch so oft miteinander muliplizieren, wie die Anzahl der Zellen angiebt.

Wir wollen einmal annelimen, dass unser Wahrscheinlichkeitsbruch nur $\frac{1}{10}$ betrüge, dann wäre die Wahrscheinlichkeit, dass bei einem aus zwei Zellen zusanımengesetzten Körper beide in gleicher Richtung variieren, gleich $\frac{1}{10} \cdot \frac{1}{10}=\frac{1}{100}$; bei drei Zellen wäre sie $\frac{1}{1000}$. Bestände aber der Körper aus 1000 Zellen, was ja immer noch eine sehr geringe Anzahl sein würde, so wäre die Wahrscheinlichkeit, dass alle 1000 Zellen sich günstig verhalten, gleich einem Bruche, dessen Zähler gleich 1 ist und dessen Nenner durch eine Zahl ausgedrückt wird, die vorn mit einer 1 und darauf mit 1000 Nullen geschrieben wird, d. h. jedes Individuum einer Tierart, deren Vertreter aus je 1000 Zellen bestehen, müsste in unserem Falle so viele Nachkommen haben, wie durch jene gewaltige Zahl angegeben wird, falls die Möglichkeit gegeben sein soll, dass ein einziger von diesen nur aus guten Zellen besteht.

Ich überlasse es Weismann und seinen Anhängern, sich die mit 1000 Nullen zu schreibende Zahl vorzustelleu und sie in Worten auszusprechen. Um ihnen dabei zu Hülfe zu kommen, will ich nur die bekannte Anekdote vom Schachbrett anführen: „Ein König in Indien, namens Sheran, verlangte nach dem Berichte des arabischen Schrift- 
stellers Asephat, dass Sessa, der Erfinder des Schachspiels, sich selbst eine Belohnung wählen sollte. Dieser erbat sich hierauf die Summe der Weizenkörner, die herauskommt, wenn 1 fürs erste Feld des Schachbrettes, 2 fürs zweite, 4 fürs dritte und so immer für jedes der 64 Felder doppelt so viele Körner als für das vorhergehende gerechnet werden." Durch die Rechnung fand man zum Erstaunen des Königs die ungeheure Summe von 18446744073709551615 Weizenkörnern, eine Summe, die, verglichen mit derjenigen, welche der Nenner unseres Wahrscheinlichkeitsbruches angiebt, verschwindend klein ist, da sie nur 20 Stellen zählt. Die Menge Weizen aber, welche dieser winzigen Summe entspricht, kann nach mässiger Berechnung erst in melır als 70 Jahren gewonnen werden, auch wenn man alles feste Land auf der ganzen Erde zum Anbau von Weizen benutzte.

Ist die Natur wirklich so produktiv, wie sie es sein müsste, wenn Weismann's Theorie der Amphimixis richtig wäre? Ich glaube kaum!

Weismann dürfte diesen Auseinandersetzungen allerdings entgegenhalten, dass es nicht nötig ist, dass sich $a+1$ Ide günstig verhalten; auch a oder noch weniger würden, so könnte Weismann sagen, genügen, ja schon 2 günstig variierende Ide würden der Zelle den Charakter aufdrücken können, falls diese sich nur lauter in Bezug auf die betreffende Determinante untereinander verschiedenen ungünstigen Iden gegenüber befänden.

Dieser Einwand würde aber unstatthaft sein. Zwei identische Kwillingsbrüder richten nicht mehr gegen ein Dutzend gleichstarker Knnaben aus, als zwei ebenso starke, aber ungleiche Knaben. Handelt es sich aber nicht um sich balgende Knaben, sondern um Determinanten aus rerschiedenen Iden, die gleichzeitig in einer Zelle in ihre Biophoren zerfallen, so ist das Verluältnis nicht anders. Gesetzt, wir luätten 2 gleiche Biophoren, die zusammen mit 12 ungleichen eine Zelle zu bestimmen haben, und alle Biophoren verdoppelten sich durch Teilung, so stünden 4 gleiche Biophoren 24 ungleichen, aber ebenso starken gegenüber, und das Verhältnis ron 1:6 bliebe auch bei ferneren Verdoppelungen dasselbe.

Die Annahme, dass die zwei gleichen Biophoren schneller assimilieren, sich schneller vermehren und dadurch die Überhand gewinnen würden, wïrde eine völlig willkürliche und durchans unzulässige sein. Wollte man sie machen, so könnte man ebenso gut annehmen, dass 2 gleiche Hunde 12 gleichstarken Hunden anderer und unter sich verschiedener 
Rassen das Futter wegfressen würden, weil sie beide derselben Rasse angehörten, die übrigen aber alle unter sich verschieden wären.

Soll Weismann's Amphimixis ïberhaupt einen Sinn haben, so muss er allen Biophoren, die sich in einer Zelle treffen können, gleiche Assimilationskraft zuschreiben. Will man, wozu Weismann allerdings sehr geneigt zu sein scheint, ungleiche Assimilationskraft für Biophoren aus verschiedenen Iden annehmen, so kann ja leicht der Fall eintreten, dass eine einzige Biophorenart alle anderen an Assimilationskraft übertrifft. Diese Biophorenart kann aber im übrigen recht ungünstig sein, beispielsweise eine rote Zelle anstatt einer grünen erzeugen. Was wäre also dann mit Amphimixis gewonnen? Bei Amphimixis kommen nur diejenigen Biophoren in Betracht, die gleiche Assimilationskraft haben. Sind sie darin ungleich, so ist Amphimixis ebenso schädlich wie nützlich, denn dann bestimmt entweder nur ein Id durch die betreffende Determinante die Zelle, oder höchstens deren wenige, nämlich die, deren Biophoren am schnellsten assimilieren. Da diese Biophoren aber sonst recht ungünstige sein können, so kann dadurch leicht eine schädliche Variation bedingt werden. Man muss also entweder gleiche Assimilationskraft für alle in einer Zelle zusammentreffenden Biophoren annehmen, und dann bestimmen die „homodynamen“, die gleichwertigen, nach Massgabe ihrer Anzahl die Zelle, und unsere Formel besteht zu Recht, oder man lässt die Assimilationskraft ungleich sein; und dann wird durch Amphimixis die Wahrscheinlichkeit, dass die betreffende Zelle in günstiger Richtung abändert, nicht erhöht.

Wir haben also recht daran gethan, zu verlangen, dass sich mindestens $a+1$ Ide in Bezug auf die Bestimmung einer Zelle günstig verhalten, ja wir hätten sogar annehmen dürfen, dass alle $a$ Ide jedes Elters die in der erforderlichen Richtung abgeänderten Biophoren in die Zelle entsenden, denn nur diejenigen Zellen sind die besten, die ausschliesslich von der einzigen brauchbaren Art von Biophoren aufgebaut werden; nur sie haben die grösste Aussicht im Kampfe ums Dasein.

Unsere Berechnung der Wahrscheinlichkeit günstigen Variierens eines aus 1000 Zellen bestehenden Individuums, dessen einzelne Zellen nur durch 2 mal 4 Determinanten mit je 3 Variationsmöglichkeiten, ron denen eine günstig ist, bestimmt werden, ist richtig. Dasselbe gilt aber auch von ihren Prämissen, weil die Anzahl der günstigen Variationsrichtungen immer viel geringer sein wird, als die der ungünstigen. Um aber keinen Zweifel darüber aufkommen zu lassen, dass, abgesehen 
von der unerlässlichen Forderung, dass sich mindestens $\imath+1$ Ide günstig verhalten müssen, unsere Prämissen in der That die Weismann'schen sind, lassen wir hier folgenden Passus aus Weismann's „Keimplasma" abdrucken, wobei wir uns diejenigen Stellen, auf welche wir die Leser aufmerksam machen möchten, durch gesperrten Druck herrorzuheben erlauben. Weismann sagt in einer Zusammenfassung auf Seite 566 ff. seines Werkes:

„Fassen wir das bisher Gesagte kurz zusammen, so ist der Beginn einer Variation unabhängig ron Selektion wie von Amphimixis: er beruht auf den unaufhörlich wiederkehrenden kleinen Unregelmässigkeiten der Eruährung des Keimplasma's, von welchen je de Det e rminante getroffen wird, bald in dieser, bald in jener Weise, verschieden nicht nur bei verschiedenen Individuen, sondern auch in den verschiedenen Regionen des einzelnen KeimplasmaBaues. Diese Abweichungen sind zuerst minimal, können sich aber summieren und müssen dies thun, sobald die Ernährungs-Modifikationen, welche sie hervorriefen, durch mehrere Generationen hindurch fortdauern. Auf diese Weise können Abweichungen im Bau einzelner Determinanten und Determinantengruppen entstehen, vielleicht zwar nie in allen Iden, aber doch in mehreren oder vielen zugleich. Auf dieselbe Weise kann Verdoppelung gewisser Determinanten des Keimplasma's entstehen. Amphimixis wird bei der Summierung solcher abgeänderter Determinanten eine bedeutsame Rolle spielen, indem sie die bisherige Minorität derselben in den beiden Eltern durch Kombination ihrer Keimplasma-Hälften zur Majorität erheben kann. Dann erst beginnt Selektion einzugreifen.

„Die ausserordentliche Bedeutung der geschlechtlichen Fortpflanzung für die Unwandlungsprozesse wird aber erst in ihrem vollen Umfange ersichtlich, wenn man sich klar macht, dass es sich in der Natur selten oder nie nur um eine einzelne Abänderung handelt, vielmehr meist um viele zugleich. Nur durch Amphimixis war es möglich, den Selektionsprozessen stets so mannigfaltige Kombinationen aller Charaktere darzubieten, dass die richtige Auswahl getroffen werden konnte. Wenn meine seit lange schon festgehaltene Ansicht richtig ist, so kommt es überhaupt nie vor, dass nur ein Charakter gezüchtet wird, sondern der gesamte Komplex sämtlicher Charaktere einer Art unterliegt unausgresetzt der Kontrolle der Naturzüchtung, und sowobl die Konstanz der augenblicklichen Artcharaktere, als die Beseitigung überflüssig 
gewordener, als schliesslich die Umwandlung vorhandener und Hervorrufung neuer Charaktere beruht auf der nie rastenden od er a ussetzenden Kontrolle der Auslese. Dies ist nur denkbar bei fortwährender Vernu ischung allervorkommenden Modalitäten dieser Charaktere und diese kann nur durch Amphimixis bewirkt werden. Wenn deshalb Amphimixis auch nicht die tiefste Wurzel der individuellen Variation sein kann, so ist sie doch für die Selektion eine un erlässliche Voraussetzung, denn sie allein kombiniert erst das Material an Variationen derart, dass Selektion damit operieren kann.

„Die hier vorgetragene Theorie der Variation giebt noch nach einer anderen Seite hin befriedigendere Auskunft, als sie von anderer Basis aus möglich ist. Wer die unbegrenzte Menge der Anpassungen der Organismen an ihre Lebensbedingungen überblickt, der ist immer wieder von neuem überrascht von der w underbaren Plastizität der Arten. Man hat den Eindruck, als könne jede, auch noch so unerwartete Abänderung von einer Art hervorgebracht werden, sobald sie nur der Art von Nutzen sein kann. Denkt man allein an die Nachahmungen von Pflanzen und Pflanzenteilen durch Tiere in Farbe, Gestalt und Zeichnung, oder an die anderer Tiere, so möchte man glauben, dass jeder Teil eines Tieres je nach Bedürfnis in diese oder jene Form gebracht, in beliebiger Weise gefärbt und gezeichnet werden könnte.

"Gewiss ist dies nicht wörtlich zu nehmen; nicht alles ist möglich, aber doch so vieles, dass man diese unzähligen Anpassungen unmöglich auf seltene, zufällig einmal vorkommende Variationen beziehen kann. Die nötigen Variationen, aus denen Selektion ihre Umwandlungen zusammensetzt, müssen immer und an vielen Individuen wieder und wieder sich darbieten.

„Ein solches immer fluktuierendes Material primärer Variationen geht aber aus der hier vorgetragenen Theorie von selbst hervor. Es muss darnach ein jeder Teil einer Art, jede ,Determinante', im Laufe der Generationen jede überhaupt mögliche Variante darbieten, immer wieder in anderen Individuen, und bald durch eine grössere, bald durch eine kleinere Majorität von abgeänderten Iden gestützt. Da absolut gleiche Ernährung der homologen Determinanten werler in den verschiedenen Individuen, noch in den verschiedenen Iden desselben Keimplasma's überhaupt denkbar ist, und da jede noch so kleine Variation einer Determinante nicht von selbst und auch nicht mit ihrem Träger, dem Individuum, wieder verschwindet, sondern direkt 
in das Keimplasna der nächsten Generation übergeht, so kann es nie an Variationen jeder Determinante fehlen, und das geforderte Jaterial an allen möglichen Variationen aller Teile erscheint theoretisch begründet.

"Ehe ich auf die Veränderungen eingehe, welche das Keimplasma als Ganzes bei der Artumwandlung erleiden muss, möchte ich einem Einwurf begegnen, der gemacht werden könnte. Wenn alle Determinanten unausgesetzt kleinen Ernährungsdifferenzen und damit kleinen Variationen unterworfen sind, woher kommt dann die so überaus grosse Hartnäckigkeit, mit welcher die Species sich erhält, ohne ihren Typus zu verändern? woher die Konstanz der Species? Man sollte denken, dass dann alle organischen Formen sich in einem fortwährenden Flusse befinden müssten, dass keine Form und kein Organ lange Bestand haben könnte.

„Ich glaube, man vergisst dabei mehrerlei. Einmal steht jede Art unter unausgesetzter Kontrolle der Naturzüchtung, wie man am besten aus dem Verkümmern bedeutungslos gewordener Teile sicht. Nachdem, wie mir scheint, die alte Annahme von der Vererbung somatogener Abänderungen endgültig aufgegeben werden muss, bleibt zur Erklärung dieser Rückbildung nichts übrig, als Panmixie, d. h. Aufhören der Kontrolle der Naturzüchtung bei dem nicht mehr nützlichen Teil. Daraus aber, dass diese Rückbildung immer eintritt, dürfen wir schliessen, dass Schwankungen in den Determinanten immer und überall vorkommen; daraus aber, dass die Rückbildung immer sehr langsam vor sich geht, schliesse ich weiter, dass trotz ihrer Häufigkeit diese Schwankungen nur sehr allmählich zu sichtbaren Variationen sich häufen.

"Wie gleich anfangs gesagt wurde, müssen wir uns die einzelnen Schwankungen der Determinanten ungemein klein vorstellen. Direkt könnte Naturzüchtung nichts mit der einzelnen Variation anfangen; sie könnte sie nicht summieren; die Summierung kann lediglich durch Amphimixis bewirkt werden, und ich möchte annehmen, dass darin die eine Hälfte ihrer Bedeutung liegt. Sie kann Minoritäten abgeänderter Determinanten zu Majoritäten summieren, indem sie die Keimplasma-Hälften zweier Individuen mischt. Sie kann aber auch nivellieren und ausgleichen, indem sie je nach Zufall die gleichsinnig abgeänderten Determinanten eines Individuums wieder zerstreut mittelst der Reduktionsteilung. 
„Man darf auch niclit vergessen, dass die kleinen primären $\mathrm{Ab}$ änderungen einer Determinante durchaus nicht immer in derselben Richtung weiter gehen müssen; entgegengesetzte Ernährungseinflüsse werden sie häufig wieder zurückbilden. Erst wenn sie durch längere Zeit anhaltende gleiche Einflüsse ${ }^{1}$ ) einen stärkeren Betrag von Abänderung erreicht und wenn zugleich die homologen Determinanten mehrerer Ide gleichsinnig abgeändert ${ }^{1}$ ) haben, wird die Variation durch Amphimixis summiert sichtbar werden können. Und auch damn bildet sie noch keineswegs einen dauernden Besitz der Art, sondern darüber, ob sie dies werden soll, entscheidet nun Naturzüchtung."

Im Anschluss an diese Ausführungen Weismann's weise ich noch einmal darauf hin, dass die Vererbung in Weismann's Theorie schliesslich auf den krassesten Zufall hinauskommt und thatsächlich überhaupt nicht existiert. Weismann ist sich überhaupt nicht klar darüber, was Vererbung eigentlich ist. Das geht aus dem wunderbaren Passus hervor, durch den er seine Ahnenplasmentheorie gegenüber etlichen gegen sie vorgebrachten Einwänden zu schützen vermeint:

„Wir finden nirgends," sagt W e isman n, „einen Zustand, in welchem noch sämtliche Ide gleich angenommen werden könnten, es verhält sich vielmelır so, wie ich schon früher einmal darlegte, die Ungleichheit der Individuen datiert von den Urwesen her, von der Zeit, in welcher noclı keine Amphimixis und noch kein Idioplasma bestand, in welcher aber der individuelle Stempel jedem Einzel-Bion direkt durch die ungleichen äusseren Einflüsse aufgeprägt werden musste. Von diesen übertrug er sich auf die Einzelligen, da diese doch nicht aus einem einzigen Einzel-Bion von Urwesen entstanden sein können, sondern polyphyletisch, jede Art aus einer grossen Menge gleichsinnig ${ }^{2}$ ) ab-

1) „Längere Zeit anhaltende gleiche Einflüsse“" und ,gleichsinnig abgeänderte homologe Determinanten mehrerer Ide" sind Annahmen, die sich der Amphimixistheorie nur bei Anwendung von Gewalt fügen.

$\mathrm{H}$.

2) Wenn die eine Protozoenart bildenden Ur'wesen ,gleichsinnig" abänderten, woher kommt dann die „Ungleichheit der Individuen"? Oder liegt hier ein Druckfehler vor? Soll es heissen „ungleichsinnig"? Aber die natürliche Zuchtwahl wählte doch wohl immer die zweckentsprechendsten Urwesen, also, da jede Art aufs genaueste den Lebensbedingungen angepasst ist, gleichsinnig abändernde aus? Die Einzelligen entstanden also doch wohl durch Zusanmenfügung gleicher Plasmen? Wer errettet uns aus diesem Labyrinth von Widersprüchen?

H. 
ändernder Bionten. Man hat dies oft falsch rerstanden ${ }^{1}$ ) und unter anderem gefragt, wie ich denn Anpassungen ron Blumen, Früchten oder Samen, wie sie bei Phanerogamen vorkommen, von der Kombination ron Charakteren ableiten wolle, die bei ihren formlosen Urvorfahren erworben wurden. Aber nicht die Charatere erbten sich ron den

1) Weismann irrt sich! Nieht diejenigen, welche rom Weismann'schen Standpunkte aus die Notwendigkeit der Ableitung ron Blumen, Früehten und anderen Charakteren der höheren Organismen vou der Kombination der von formlosen Urvorfahren erworbenen Charaktere erkannten, haben Weismann's Ahnenplasmentheorio falsch verstanden, sondern er selbst rersteht seine eigene Theorie uicht! In seiner Schrift über "Die Bedeutung der sexuellen Fortpflanzung für die Selektions-Theorie" (Jena 1886), in welcher Weismann seine Ahnenplasmentheorie aufgestellt hat. sagt Weismann: „Ohne das Vorkommen solcher direkt die Keime verändernder Einflüsse ganz in Abrede zu stellen, muss ich doch glauben, dass sie am Zustandehommen erblicher individueller Charaktere keinen Anteil haben." Weismann führte also die Versehiedenheit der Indiriduen auf die Urwesen zurüek. Wenn es ihm trotzdem beliebte, eine Veränderung der von den $\mathrm{Ur}$ wesen herstammenden Ahnenplasmen durch äussere Einflüsse zu stande kommen zu lassen, so standen ihm nur z woi Wego offen. Entweder musste er annelmen, dass die Nachkommen eines individuellen Ahnenplasma's, die natürlieh auf sehr viele 01 ganismen verteilt sein konnten, trotz aller durch äussere Einflüsse an ihnen herrorgebrachten Veränderungen einander völlig gleich blieben, oder er musste sie infolge verschiedener äusserer Einflüsse ungleieh werden lassen. That er das letztere, so wurde er sich selbst untreu, wie ein Blick auf den in dieser Anmerkung citierten Satz lehrt; Weismann's Gegner honnten aber moht amehmen, dass Weismann die Absicht hatte, diesen Satz sofort wieder zu negieren. Wollte Weismann aber das erstere thun, so wurde er wiederum sieh selbst untreu, denn die Annahme einer erblichen Abänderung der von den Urwesen herstammenden Ahnenplasmen hätte das Zugeständnis enthalten, dass auch die Nachkommen eines und desselben Ahnenplasma's infolge äusserer Einflüsse ungleich worden mussten; oder will Weismann allen Ernstes behaupten, dass sie sich zwar verändern, aber nicht ungleich werden kounten?! Will Woismann uns glauben maehen, dass aus dem Plasma eines Urwesens das komplizierte Id eines Mensehen werden kann infolge von äusseren Einflüssen, dass die gleichen Biophoren eines Urwesens infolge der letzteren ungleieh werden könneu, dass sich aber alle von diesem Urwesen herstammenden Ide, die auf die rerschiedensten Individuen verteilt sein konnten, trotz der Notwendigkeit, die Biophoren eines Urids infolge verschiedenartiger iusserer Einflüsse ungleich werden zu lassen, vollständig

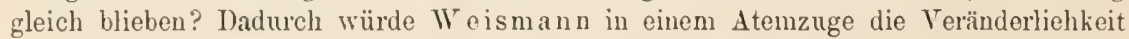
und dio Unveränderlichkeit der Biophoren behaupten! Wer logisch denkt, konnte zu gar keiner anderen Schlussfolgerung gelangen, als der, dass die Veränderlichkeit der IV eismann'sehen Ahnenplasmen bei den mehrzelligen Naehtommen der einzelligen L'wesen nach Weismann's Ansicht aufgehört hätte, dass also Blumen, Früehte usw. ron der Kombination der von formlosen Urvorfahren erworbenen Charaktere herzuleiten seien. Wenn Weismann sich also daüuber beklagen will, dass man seine alte Ahnentheorie missverstanden habe, so richte er seine Beschwerdo dorthin, wohin sie gehört, an den Lrheber dieser Theorie, an Herrn August Weismann in Freiburg i. Br.! - In 
Urwesen her fort, sondern die Variabilität, die Ungleichheit der Individuen!" 1)

Es war bisher in der Entwickelungslehre üblich, V'ererbung und Variabilität als zwei Dinge zu betrachten, die sich in jedem Einzelfalle wechselweise ausschliessen. Eine Eigenschaft, die von dem Elter auf das Kind vererbt wird, hat in diesem Falle nicht variiert, ein Organ, das beim Kinde andere Eigenschaften zeigt als beim Elter, hat seine Eigenschaften nicht vom Elter auf das Kind vererbt, es hat variiert, es hat sich verändert. Vererbung einer Eigenschaft ist Niclitveränderung dieser Eigenschaft, Nichtvererbung einer Eigenschaft ist Veränderung dieser Eigenschaft. Vererbung und Nichtvererbung, Veränderung und Nichtveränderung, Vererbung und Veränderung, Nichtvererbung und Nichtveränderung sind kontradiktorische Gegensätze. Weismann aber ist es vorbehalten geblieben, eine Vererbung der Nichtrererbung festzustellen! Dass er dabei auch noch "Variabilität" und "Ungleichheit der Individuen" miteinander verwechselt, ist nicht weiter zu verwundern!

Offenbar ist nur zweierlei möglich: Entweder lässt man die Un-

eincr Anmerkung zu dem oben citierten Aufsatz, die Wcismann im Jahre 1892 gelegentlich desscn Wiederabdruckes hinzufügte, sagt cr, man braucht nicht, wie er es in diesem Aufsatze gethan bätte, ,die Wurzcl der individuellen Verschicdenheit in den niedersten Organismen zu suchen, sondern wird sie in don wechselnden Einflüssen erkennen, welche die Elemente des Keimplasma's unausgesetzt treffen müssen." Damit giebt Weismann seine Ahnenplasmentheorie preis! Aber in seinem Werke: „Das Kieimplasma", das ganz kurze Zeit nach den gesammclten „Aufsätzen über Vererbung und verwandte biologische Fragen", denen wir den eben citierten Satz cntnommen haben, erschien, steht der im Textc citierte Satz: "Dic Ungleichheit der Individucn daticrt von den Urwesen her!" - Ich beneide Weismann! Es muss ein tröstliches Gefühl sein, sich bald auf diese, bald auf jene von zwei gleichzcitig geäusscrtcn, aber sich gegenseitig absolut widersprechenden Ansichten berufen zu können! Aber WV eismann möge bedenken, dass er es seinen Gegnern, die nicht wisscn, an welche der gleichzeitig geäusserten sich gegenseitig ausschliessenden Weismannn'schen Ansichten sie sich zu halten haben, schwcr macht, mit ihm zu kïmpfen. Meine Leser mögen es mir deshalb verzeihen, dass ich sie durch diese nachträgliche Anmerkung aufhaltc. Ich habe das Gefühl, dass es mir nur schlecht gelungen ist, sie in dem Labyrinthe des Weismannismus herumzuführen. Sollte der letztere neue Freunde gewinnen, so werden uns hoffentlich unter dicsen auch einige Weismannforscher erstehen. Haben wir doch auch Goetheforscher! Dic Aufgabe dieser Weismannforscher würde es dann sein, in jedem Einzclfalle zu untersuchen, was Weismann gesagt hat und gemeint haben könnte, und nicht geäussert hat und nicht gedacht haben kann! Ich selbst bin wcit davon entfernt, auch nur eine halbwegs vollständige Blumenlese Wcismann'scher Widersprïche gegeben zu haben.

1) Siche Anmerkung 2 auf Seite 99. 
gleichheit der Individuen von den sich ungeschlechtlich fortpflanzenden Urwesen herstammen. Wenn man das thun will, dann darf man die Veränderungen der Individuen bei Organismen mit geschlechtlicher Fortptlanzung nur kurch „Amphimixis" zu stande kommen lassen; denn wenn man eine Veränderlichkeit der ron den Urwesen herstammenden "Ide" oder "Ahnenplasmen" auch noch bei den geschlechtlich sich fortpflanzenden Organismen annimmt, dann braucht man die „Ungleichheit der Individuen" nicht auf die „Urwesen" zurückzuführen. Thut man aber das letztere, dann muss man auch "Anpassungen von Blumen, Früchten oder Samen, wie sie bei Phanerogamen vorkommen, von der Kombination ron Charakteren ableiten", „die bei ihren formlosen LrVorfahren erworben wurden". Entweder führt man also die ,Ungleichheit der Individuen" auf die variabehn Urwesen zurück und zieht die sich daraus ergebenden wunderbaren Konsequenzen, wonach beispielsweise der Mensch ein Konglomerat ron "Urwesen" ist, oder man lässt „Urwesen" Urwesen sein, gesteht auch den sich geschlechtlich fort. pflanzenden Organismen "Variabilität", d. h. nichtererbte Veränderlichkeit (man gestatte uns angesichts der Begriffsverwirrung bei We is mann diese Tautologie!) zu und giebt damit den "Ahnenplasmen", den "Iden", der "Amphimixis" und, da ohne diese der Präformismus nicht bestehen kann, auch dem letzteren den Abschied. Ein Drittes giebt es nicht! Der Präformist und Amphimixistheoretiker hat zwischen zwei Dingen, deren jedes für ihn ein Übel bedeutet, zu wählen! Weismann möge mit gutem Beispiele rorangehen!

Weismann's Theorie der Amphimixis muss unter allen Umständen fallen. Indessen giebt es wirklich Organismen, die aus polyplasmatischen Zellen aufgebaut sind; das sind die Bastarde zwischen rerschiedenen diten und die Blendlinge zwischen rerschiedenen Rassen einer Art. Es fragt sich aber, ob die Keimzellen, die von Bastarden und Blendlingen erzeugt werden, auch ihre Zusammensetzung aus zwei Plasmaarten bewahren. Die Züchtungsversuche, die ich zur Entscheidung dieser Frage angestellt habe, lehren, dass sie es nicht thun. Dio Züchtungsergebnisse früherer Forscher sind, wo sie meinen Resultaten zu widersprechen scheinen, mit Zweifel aufzunehmen, denn die früheren Experimentatoren, die ja durchweg Züchtungsversuche mit PHanzen anstellten, haben keine geniigend laugen Stammbäume über die von ihnen gezüchteten Individuen gefïhrt und ihre Versuche nicht auf Grund einer leitenden Idee angestellt. Mir dagegen stehen lange Stammbäume von 
über 3000 Mäusen in vielen verschiedenen Rassen zur Verfügung, und aus diesen geht hervor, dass polyplasmatische Individuen wieder monoplasmatische Keimzellen erzeugen, und zwar, wie ich glaube, auf dem Wege der Reduktionsteilung.

Ich habe japanische T'anzmäuse, scharf charakterisierte Tiere, die sich dadurch auszeichnen, dass sie unsicheren Schrittes hin- und herlaufen und oft auf einem Flecke im Kreise herumwirbeln, mit anderen Mäusen gepaart, die ich, da sie besser klettern können als jene, Klettermäuse nennen will, und Kreuzungsmäuse erhalten, die nicht tanzten. Meine Versuche ergeben nun, dass in den von diesen Tieren erzeugten befruchtungsfähigen Keimzellen nur eine Art von Keimplasma enthalten ist, entweder Tanzmausplasma, das wir mit T' bezeichnen wollen, oder Klettermausplasma, das wir $\mathrm{K}$ nennen wollen. Wenn man zwei solcher Kreuzungsmäuse miteinander paart, so sind demnach folgende Fälle möglich: 1) Ein Spermatozoon, das nur I' enthält, kann sich mit einer Eizelle verbinden, die auch nur ' $\mathrm{T}$ enthält; wir erhalten dadurch wieder eine reine Tanzmaus. 2) Ein Spermatozoon aus 'T verbindet sich mit einer Eizelle aus K, wodurch wieder eine Kreuzungsmaus entsteht. 3) Wenn sich ein Spermatozoon aus $\mathrm{K}$ mit einer Eizelle aus $\mathrm{T}$ verbindet, entsteht ebenfalls wieder eine Kreuzungsmaus. 4) Dagegen entsteht wieder eine reine Klettermaus, wenn ein Spermatozoon aus $\mathrm{K}$ in eine Eizelle aus $\mathrm{K}$ eindringt. Nun gleichen zwar die Kreuzungsmäuse in Bezug auf ihr Verhalten den Klettermäusen; allein fortgesetzte Züchtungsversuche zeigen, dass aus Kreuzungsmäusen wieder reine Tanz- und reine Klettermäuse gezüchtet werden können, während das bei anderen, ihnen äusserlich gleichenden, die nur Klettermausplasma enthalten, nicht möglich ist. Hat man auf dem Wege des Rückschlags wieder reine Tanzmäuse erhalten, so kann man die Züichtung so lange fortsetzen, wie man Lust hat, ohne jemals wieder Klettermäuse zu erhalten, obwohl diese Tanzmäuse unter ihren Vorfahren Klettermäuse haben. Das Gleiche gilt mutatis mutandis von Klettermäusen. Die Reduktionsteilung bewirkt also keineswegs Amphimixis, Mischung verschiedener Plasmen, sondern vielmehr Apomixis, Entmischung zweier nicht zusammengehöriger Keimplasmen, wobei freilich nicht ausgreschlossen zu sein braucht, dass kleine Mengen fremden Plasma's dem Plasma einer im übrigen monoplasmatischen Keinzelle beigemischt sind.

Meine Versuche zeigen ausserdem, dass jedesmal, weun zwei ungleiche Plasmen aufeinander einwirken, jedes der beiden etwas verändert 
wird, und zwar besteht die Teränderung in einer Ausgleichung von Ungleichheiten. So haben gescheckte Tanzmäuse oft Enkel, die zwar reine Tanzmäuse, im übrigen aber einfarbig sind. Da nun, wie sich später zeigen wird, die Scheckung eine Störung des plasmatischen Gleichgewichts bedeutet, so ist bei diesen Tanzmäusen eine Wiederherstellung des Gleichgewichts eingetreten. Geschlechthiche Fortpflanzung bewirkt also auch in dieser Beziehung die Ausgleichung ungleich abgeänderter Plasmen; sio arbeitet also auf Apomixis, nicht auf Anıphimixis hin.

Es bleibt gewiss ein grosses Verdienst Weismann's, auf die Reduktionsteilung der Keimzellen als einen bedeutungsvollen Vorgang hingewiesen zu lıaben, aber die Bedeutung der Reduktionsteilung ist Entmischung, Apomixis, und nicht Vermischung zahtreicher Individuen oder Amphimixis. Letztere wird durch die Reduktionsteilung verhindert. Die Präformationstheorie kann aber, wie Weismann so schön ausgeführt hat, ohne die Annahme einer Amphimixis nicht bestehen, denn nach ilı ist jede Determinante jedes Ides für sich variabel, und da sie viel leichter in ungünstiger Weise als in günstiger Richtung abändern kaun, so kann günstige Variation einer Zelle nur durch Zusammenhäufung einer Majoritït günstig veränderter, aus verschiedenen We ism a n n'schen Iden stammender Biophoren zu stande kommen. Ohne Amphimixis kein Präformismus. Dementsprechend ist mit dem von uns in strengster Form geführten Nachweise, dass Amphimixis zum Untergange der Organismenarten führen müsste, wenn sie plötzlich eingeführt würde, dass es also keine Amphimixis geben kanu, auch der Präformismus beseitigt.

So ergiebt sich denn aus der Gesamtheit unserer bisherigen Ausführungen, dass der Präformisuns auf der ganzen Linie geschlagen ist. Un uns diese Thatsache noch eimmal in eindringlicher Weise vor Augen zu fülıren, wollen wir die Lrgebnisse, zu denen wir gelangt sind, kurz zusanmenfassen.

\section{h. Zusammenfassung - Beweise für die Vererbung erworbener Eig'enschaften.}

Ein Rückblick auf unsere bisherigen Betrachtungen, durch welche wir ethiche Konsequenzen des Prüformismus gezogen haben, was von seinem Hauptvertreter Weismann unterlassen worden ist, zeigt, dass 
der Präformismus nicht bestehen kann, ohne einen Dualismus zwischen Schöpfer und Geschaffenem und gleichzeitig die Endlichkeit des Geschaffenen anzunehmen. Er gerät dadurch in Widerspruch mit den Gesetzen wissenschaftlicher Forschung, der es verboten ist, die Grenzen des Naturerkennens zu überschreiten. Die Epigenesislehre hingegen bleibt den Prinzipien der Naturforschung treu.

Aber gesetzt auch, die Präformationslehre wäre wissenschaftlich zulässig, so würde ihre Durchführung doch fortwährend mit den Thatsachen in Widerspruch geraten. Der Präformismus kann olıne die Annahme eines Paramorphismus, d. h. einer Gleichwertigkeit aller Formen, nicht auskommen, weil diese nach Ansicht des Präformismus nur durch den Kampf uns Dasein gezüchtet worden sind, während die Epigenesislehre nicht alles durch die gefärbte Brille des Nützlichkeitsprinzips anzusehen brauclit, sondern einen Epimorphismus, wie er thatsächlich in der Natur besteht, anerkennt. Dieser Epimorphismus bezieht sich sowohl auf die ungleiche Höhe der Entwickelungsstufe, gänzlich abgeselren von der Bedeutung der Einrichtungen für die Organismen, als auch auf die ungleich gute Anpassung einzelner Organe und ganzer Organismen. Nur dieser doppelte Epimorphismus lässt sich mit den Thatsachen vereinigen.

Damit in Zusammenhange steht, dass die Epigenesislehre die Entwickelung nach bestimmten Richtungen li in feststellt, wonach die variierenden Organismen und Organe sich nicht durch ungewisses Hin- und Herschwanken umbilden, sondern den einmal eingeschlagenen Weg fortsetzen, sei es durch Erklimmen einer höheren Formenstufe, sei es durch Vollendung ilurer Anpassung oder durch von Generation zu Generation zunehmende Entartung. Die Präformationstheorie kommt dagegen nur mit der Annahme einer Entwickelung nach zahllosen Seiten hin aus, da sie sonst nicht genügende Auswahl für die Selektion zu schaffen weiss. Eine Variabilität nach allen Seiten hin stelt aber in Widerspruch mit den Thatsachen, weil die einzelnen Teile eines Organismus nicht unabhängig voneinander variieren, sondern weil jeder 'Teil mit allen anderen in Korrelation steht. Diese Korrelation, die notwendigerweise zur Epigenesistheorie führen muss, wird von den Präformisten rundweg geleugnet. Nach dem Präformismus variiert jeder kleine Teil des Keimplasma's unabhängig von allen übrigen, und diese Annalme ist notwendig, weil die natürliche Zuchtwahl, die nach Ansicht der Präformisten allein die Einrichtungen vervollkommnet, mit den einzelnen Teilen des Plasma's zu rechnen hat. Soll jedes Organ immer vollkommen an 
die Aussenwelt angepasst sein, solange es noch erforderlich ist, so muss es auch für sich variieren können, denn olıne diese Annalıme hätte die Vollkommenheit der einzelnen Organe nie erreicht werden können, falls, wie der Präformismus behauptet, keine Vererbung erworbener Eigenschaften stattfindet.

Prüft man aber die Eigenschaften der Organismen im einzelnen, so findet man, dass neben bedeutungsvollen Eigenschaften aucl eine grosse Anzahl von indifferenten bestelen, und dass es unter den bedeutungsvollen auch eine grosse Anzahl von solchen giebt, die mit zunelımender Vervollkommnung im einzelnen immer unzwecknässiger für den Gesantorganismus geworden sind. Dass Organismen mit solchen Organen aussterben mussten, spricht gegen die Präformationstheorie, denn wenn ihre Prämissen richtig sind, so hätte natürliche Zuchtwahl leicht ein Zuviel der Anpassung in bestimmter Richtung verhindern können. Da das aber nicht geschehen ist, da einseitig angepasste Tiere thatsächlich in grosser Anzahl ausgestorben sind, so sind eben andere Faktoren als die natürliche Zuclitwahl thätig, um die Anpassung der Organe zu bewirken. Der Präformismus muss aber mit der Annalıme einer alles beherrschenden Auslese allein auskommen und bei dieser der dotationellen Individualselektion die erste Rolle zuschreiben. Diese Art der Auslese hat wiederum zur Voraussetzung, dass das Keimplasma aus „Iden" gebildet wird, wie Weismann konsequenterweise annimmt, dass jedes Id aus rielen die einzelnen Zellen bestimmenden „Determinanten“ aufgebaut ist, und dass sich jede Determinante aus „Biophoren" zusammensetzt, die den Charakter der einzelnen Zellen bestimmen. Diese Biophoren können nach allen möglichen Richtungen lim unabhängig voneinander variieren, und demnaclı wird es nötig, dass viele Ide im Keimplasma sind, weil die Determinanten immer nur bei einem Bruchteil in günstiger Richtuvg abändern, weil also durch Amphimixis eine möglichst grosse Anzalıl von in günstiger Weise abgeänderten Biophoren in einer Zelle zusammentreffen muss. ' $/ u$ welch ungeheuerlichen Konsequenzen diese Anmahme führt, haben wir in unwiderleglicher Weise dargethan.

Wir haben weiterhin durch Anfülrrung unserer Züchtungsergebnisse gezeigt, dass die Theorie der Amphimixis mit den Thatsachen in direktem Widerspruche steht, dass gemischtes Keimplasma durch Ampomixis, durch Entmischung wieder einheitlich wird.

Aus alledem ergiebt sich, dass die Prïformationslehre nicht nur an und für sich unwissenschaftlich ist, sondern dass sie überall mit den 
Thatsachen in Kontlikt gerät und nur dann ein eingebildetes Scheinleben führen kann, wenn sie widerstrebende Thatsachen rücksichtslos beiseite schiebt. Wir haben also in bündiger Weise nachgewiesen, dass allein die Theorie der Epigenesis eine wissenschaftliche Erklärung der Gestaltung und Vererbung zulässt. Sie hat aber die Vererbung erworbener Eigenschaften zur notwendigen Voraussetzung; die unerlässliche Vorbedingung ihrer Herrschaft besteht in der Anerkennung der Thatsachen, welche die Wissenschaft in Bezug auf die Vererbung erworbener Eigenschaften beigebracht hat.

Diese Thatsachen sind so zahlreich, wie der Sand am Meer. Wo wir irgend ein kleines selbstthätiges Organ, ein Organ, das durch seine aktiven Leistungen Bedeutung für den Organismus hat, antreffen, haben wir es mit einer Erwerbung zu thun, die durch Vererbung im Laufe der Generationen befestigt und durch fortgesetzten Gebrauch erhalten und verrollkommnet worden ist. Die Eigenschaften, die wir, wenn wir die Weismann'sche Begriffsbestimmung annehmen, nicht als erworbene betrachten dürfen, sind, verghichen mit den erworbenen, ausserordentlich gering an Anzahl, und die allergrösste Mehrzahl von ihnen bezieht sich nur auf Eigenschaften wie die Färbung und andere nicht direkt bedeutungsvolle Einrichtungen, die es ja überall auch in der anorganischen Natur giebt. Was den Organismus zum Organismus macht, ist der Besitz erworbener Eigenschaften.

Derjenige ist also sicher im Iritum, der da glaubt, dass man nach Beweisen für die Vererbung erworbener Eigenschaften suchen müsste. Wer nicht durch unzulängliche Vererbungstheorien an dem freien Gebrauch seiner gesunden Sinnesorgane und seines korrekt arbeitenden Gehirns gehindert ist, der braucht nur irgend ein Tier oder eine Pflanze zu betrachten, um sich davon zu überzeugen, dass die $\mathrm{Org}_{\mathrm{r}} \mathrm{n}$ ismen der Hauptsache nach Eigenschaften besitzen, die ihre Torfahren durch die Thätigkeit ihrer Organe erworben haben. Ich weiss aber wohl, dass manche Naturforscher fragen werden, wo der "experimentelle" Beweis für diese, ,Behauptung" sei. Meine Antwort ist die, dass die gesamte Organismenwelt das Ergebnis eines grossartigen Vererbungsexperimentes ist, das die Natur angestellt hat. Von der Natur zu verlangen, dass sie ihre Züchtungsexperimente so einrichte, dass sie ohne weiteres von grübelnden Laboratoriumsgelehrten nachgemacht werden können, scheint mir über die Grenzen berechtigter Forderungen hinauszugehen. In der That steht die Forderung, man solle die 
Vererbung erworbener Eigenschaften experimentell beweisen, auf gleicher Stufe mit der, ich weiss nicht mehr von welchem Laien in der Descendentheorie aufgestellten, man solle doch erst einmal einen Hund aus einer Katze züchten.

Welch ein ungeheuerliches Ansinnen an die Natur gestellt wird, wenn man etwa verlangt, dass Nachkommen ron weissen Mäusen, denen man die Schwänze abschneidet, mit verkürzten Schwänzen geboren werden sollen, geht am besten aus einem Beispiel herror. Ich habe oben von dem verkümmerten Zeigefinger an der Hand des Plumplori gesprochen und den Nachweis geführt, dass er durch Nichtgebrauch zurückgebildet worden ist. Dieser Finger ist einige Millimeter lang, und er mag nach Maassgabe des besonders stark ausgebildeten Mittelfingers früher etwa $1-1 \frac{1}{2} \mathrm{~cm}$ lang gewesen sein. Heute ist seine länge auf etwas mehr als $1 / 2 \mathrm{~cm}$ reduziert. Wenn man nun etwa annimmt, dass der Plumplori 10 Jahre alt werden muss, um sich fortzupflanzen, und die Rückbildung seines 'Zeigefingers im Laufe ron 10000 Jahren erfolgt sein lässt, so dass die Vorfahren des heutigen Plumplori noch in jüngstvergangener geologischer Zeit rollkommene Zeigefinger gehabt hätten, Annahmen, die doch wohl nicht günstiger gemacht werden können, so würden wir zu dem Ergebnis gelangen, dass mindestens 1000 Generationen dazu nötig gewesen wären, den Zeigefinger durch die vererbten Folgen des Nichtgebrauches auf seine heutige Länge zu reduzieren. Wir wollen nun ferner annehmen, dass er um einen vollen Centimeter zurückgebildet sei; dann wäre er also in jeder Generation um 1/100 $\mathrm{mm}$ kürzer geworden, und angesichts dieses Ergebnisses verlangt man, dass weisse Mäuse, die man in jeder Generation durch Abschneiden des Schwanzes an dessen Gebrauch verhindert, schon nach 20 oder 30 Generationen merklich kürzere Schwänze haben müssten, falls erworbene Eigenschaften vererbt werden?

Wozu die Natur wahrscheinlich Jahrmillionen gebraucht hat, das glaubt man im zoologischen Institut zu Freiburg i. Br. während des Direktorates eines einzigen präformistischen Professors fertig bringen zu können, und da das nicht wohl angeht, so leugnet man einfach die Vererbung erworbener Eigenschaften! Ich würde behaupten, dass die Nachkommen der entschwänzten Freiburger Jäusealbinos thatsächlich schon kürzere Schwänze bekommen haben, dass deren Schwänze vielleicht schon durchschnittlich 1/1000 mm kürzer sind, als die ihrer beschwänzten Vorfahren es waren, wenn ich es nicht für ebenso wahrscheinlich hielte, dass 
die Schwänze infolge fortgesetzten, durch die Abschneidung bewirkten Reizes durchschnittlich $1 / 1000 \mathrm{~mm}$ länger geworden sind! Wie dem aber auch sei, das Beispiel vom Zeigefinger des Plumplori hat uns gelehrt, dass derjenige Betrag, um welchen ein Organ durchschnittlich im Laufe einer Generation infolge ron Nichtgebrauch verkleinert wird, weit innerhalb der normalen Variationsamplitude liegen muss und deshalb nicht festgestellt werden kann. Der etwa durch Nichtgebrauch im Laufe von 100 Generationen hervorgebrachte Betrag von Reduktion der Schwanzlänge bei Mäusen, die man durch Abschneiden des Schwanzes an dessen normalen Gebrauch verhindert hat, müsste weit innerhalb der Beobachtungsfehlergrenzen liegen.

Mir ist der Gedanke, meine Züchtungsversuche mit Mäusen auch auf die Vererbung der Folgen von Verstümmelungen auszudehnen, gar nicht in den Sinn gekommen, obwohl solches leicht hätte geschehen können, da ich ohnehin die Mäuse halten musste. Meine Mäuse behielten ihre Schwänze, und trotzdem wurden merkwürdig viele geboren, die nur $2 / 3$ oder $1 / 2$ der normalen Schwanzlänge ihrer Eltern besassen. Das zeigt, wie unsicher Züchtungsexperimente über die Vererbung erworbener Eigenschaften sein müssen, wenn man sie nicht von der Natur selbst anstellen lässt, und wenn man der Natur nicht erlaubt, ibren eigenen Gesetzen zu folgen, sondern wenn man sie zwingen will, sich Vorschriften ron den Präformisten machen zu lassen. Diejenigen, welche die Vererbung erworbener Eigenschaften leugnen, begehen, indem sie die Natur den einseitigen Anschauungen, zu welchen sie gelangt sind, entsprechend umwandeln, einen zwar verzeihlichen Denkfehler, der aber dennoch nicht unenthüllt bleiben darf. Wenn man verlangt, dass die Wirkungen des Gebrauchs und Nichtgebrauchs der Organe schon nach ein paar Generationen sichtbar werden sollen, so vergisst man, dass die Natur viele Jahrmillionen dazu gebraucht hat, um Unterschiede hervorzubringen, die unserm blöden Auge sichtbar sind.

Übrigens wird der gerügte logische Fehler, den die Leugner der Vererbung erworbener Eigenschaften machen, nicht immer deshalb begangen, weil die Wissenschaft, die ohne die Anerkennung der Vererbung erworbener Eigenschaften nicht auskommt, nicht die unbillige Forderung erfüllen kann, das, wozu die Natur Jahrmillionen gebraucht hat, in ein paar Jahren im Laboratorium nachzuexperimentieren, sondern auch deshalb, weil einige zunächst den Fehler gemacht haben, die Iöglichkeit einer Vererbung erworbener Eigenschaften zu bestreiten, 
weil sie selbst diese Vererbung nicht erklären können. Wenn Weismann nicht den rechten Weg gefunden hat, um die Vererbung erworbener Eigenschaften auf Grund einer epigenetischen Theorie zu erklären, so beweist das doch nicht, dass der Weg, den er nach langem Hin- und Herschwanken, wie es scheint, endlich eingeschlagen hat, und der ihn bei konsequenter Fortsetzung in das Lager der alten Einschachtelungstheoretiker führt, der richtige ist, und dass es ausser diesem und den übrigen von Weismann eingeschlagenen Irrwegen keinen von Weismann unentdeckten Weg giebt, um die Vererbung erworbener Eigenschaften auf dem Boden einer epigenetischen Theorie zu erklären. Weismann verlangt von anderen Naturforschern, sie sollen zu keinen besseren Theorien gelangen, als es sein Präformismus ist; denn dass eine epigenetische Theorie von vornherein besser ist als eine präformistische, wird Weismann um so weniger leugnen wollen, als er ja zugesteht, dass er lange Zeit hindurch nach einer epigenetischen Theorie gesucht hat, und dass die zweckmässige Einrichtung der Organismen sich viel einfacher durch die Annahme einer Vererbung erworbener Eigenschaften erklärt.

Wenn also der Nachweis geführt werden kann, dass erworbene Eigenschaften sich nicht nur vererben $k$ önnen, sondern vererben $m$ üssen, wenn gezeigt werden kann, dass die durch den Gebrauch oder äussere Einflüsse bewirkte Veränderung eines Organes sich notwendigerweise auf die Nachkommen übertragen muss, und zwar auf dasselbe Organ, in entsprechender Beschaffenheit, wenn ferner die komplizierten Einrichtungen eines hochentwickelten Organismus auf ein monotones Keimplasma zurückgeführt werden können, so wird auch Weismann zugeben, dass eine solche Vererbungstheorie in der That besser ist als die Aufführung eines noch so grossartigen und sorgfältig einstudierten Zaubermärchens, in welchem die Rollen an ein Corps ungleicher Ide und Idanten, Biophoren und Determinanten verteilt sind.

Ich werde den Nachweis, dass Epigenesis die Entwickelung der Organismen beherrscht und dass erworbene Eigenschaften sich mit Naturnotwendigkeit vererben müssen, im nächsten Hauptabschnitt dieses Buches führen. Dass ich dies kann, habe ich der Berücksichtigung des gesamten Thatsachengebietes der organischen Natur zu verdanken. Dass ich aber im gegenwärtigen Hauptabschnitt in der Lage gewesen bin, die völlige Haltlosigkeit des Präformismus blosszustellen, verdanke ich der Lektüre des im vorigen Jahre erschienenen Werkes von A ugust Weismann: „Das 
Keimplasma. Eine Theorie der Vererbung". Weismann hat endlich seinen vielen „Aufsätzen über Vererbung und verwandte biologische Fragen", deren Anzahl und stets wechselnder Standpunkt das Studium des Weismannismus zu einem so mühsamen machte, dass sich nur selten jemand an dessen Bekämpfung heranwagte, ein umfangreiches Werk über die notwendigen Konsequenzen der „Kontinuität des Keimplasma's“ folgen lassen, ohne freilich die letzten, aber ebenso unvermeidlichen Konsequenzen zu ziehen. Durch deu minutiösen, überaus eingehenden, greif- und angreifbaren Ausbau seiner Präformationstheorie hat Weismann es mir leicht gemacht, die Unmöglichkeit des Präformismus nachzuweisen, und dafür, dass er die allerletzten Konsequenzen dieser Irrlehre nicht gezogen hat, bin ich ihm zu aufrichtigem Danke verpflichtet. Die Wissenschaft aber wird es Weismann danken, dass er den Präformismus so eingehend geschildert hat, dass das von W e ismann aufgeführte Phantasiegebäude unter der kleinsten von anderen hinzugefügten Belastung zusammenbrechen musste. Mit Recht glaubt Weisman n nicht, "vergeblich gearbeitet zu haben; denn auch der Irrtum, wofern er nur auf richtigen Schlüssen beruht, muss zur Wahrheit führen". Wie wir gesehen haben, wird Weismann früher, als er es vielleicht zu hoffen gewagt hat, die Genugthuung zu teil, dass er nicht umsonst gearbeitet und dass sein Irrtum zur Wahrheit geführt hat, obwohl dieser Irrtum wenigstens nicht ausnahmslos auf richtigen Schlüssen beruhte! 


\section{Gestaltung und Vererbung.}

\section{a. Die Aufgaben der Theorie.}

Das Problem der Vererbung ist im Grunde genommen ein höchst einfaches, da die Erblichkeit einen Teil der aller Materie zukommenden Eigenschaften bildet. Sie ist nichts weiter als eine Form der Trägheit, des Beharrungsvermögens. Das Träigheitsgesetz, das als eines der physikalischen Grundgesetze keiner Erklärung bedarf, besagt, dass ein Körper so lange in clem einmal eingenommenen Zustande verhart, als er nicht darin gestört wird. Dieses Gesetz gilt selbstverstïndlich für die Elemente des Plasma's sowohl wie für jeden anderen Körper. Die Plasmaelemente sind aber die letzten Träger der Vererbung. Sie werden ron dem Zeugenden auf das Gezeugte übertragen und behalten ihre Eigenschaften so lange bei, als diese nicht durch äussere Einflüsse verändert werden. Freilich ist eine solche Veränderung unausbleiblich, sobald die Aussenwelt ü ber'h a upt einen Einfluss auf das Plasma hat. Wer diesen nicht leugnen will, der gelangt zu der Schlussfolgerung, dass sich das Plasma in langsamer, aber stetiger Umbildung befindet. Schon das älteste Plasma, das auf der Erde entstand, wurde von äusseren Einflüssen getroffen. Diese bildeten es etwas um und sahen sich dann einem etwas anders gearteten Plasma gegenüber, auf welches sie wieder einwirken kounten. Auch wenn die äusseren Bedingungen sich gleich blieben, musste dennoch eine stetige Umbildung stattfinden, weil sie sich fortwährend neuen Plasmanodifikationen gegenüber befanden. Eine Vererbung im strengsten Sinne des Wortes giebt es also überhaupt nicht; es giebt nur fortwährende Gestaltung. Wir dürfen von dieser immer und überall stattfindenden langsamen Umbildung des Plasma's aber absehen, weil, wie die Tiere, die sich seit den ältesten Zeiten der Erd- 
geschichte fast unverändert bis auf unsere Tage erhalten haben, z. B. Lingula, zeigen, diese stetige Umbildung nicht messbar ist. Das V ererbungsproblem kommt also auf die Frage hinaus, auf welche Weise aus den rom Erzeugenden auf das Erzeugte ïbertragenen Plasmaelementen wieder die Körperform des Erzeugers zu stande konme. Das Vererbungsproblem füllt demnach mit dem Problem der keimesgeschichtlichen Gestaltung zusammen. Aus der Form der Plasmaelemente in der befruchteten Keimzelle mus die Form des Organismus zu erklären sein.

Die Form dieser Plasmaelemente muss aber veränderlich sein, denn sonst wäre eine U mbildung der Organismen nicht möglich. Die Fragen, welche Eigenschaften dieser Form ihre Veränderung ermöglichen und welche Einflüsse die Veränderung bewirken, bilden das stammesgeschichtliche Gestaltungsproblem, das zwar nicht mit dem Vererbungsproblem zusammenfällt, aber zugleich mit ihm gelöst werden muss. Wir können es das Gestaltungsproblem schlechthin nennen.

Ehe wir an den Versuch einer epigenetischen Lösung unserer beiden Probleme herantreten, haben wir die Bedingungen dieser Lösung zu prüfen und die berechtigten Anforderungen an eine Theorie der Vererbung und Gestaltung festzustellen.

Eine rein physikalische Lehre hat beispielsweise $\mathrm{Haeckel}$ aufgestellt, der sich die Vererbung als eine Wellenbewegung denkt; die Moleküle des Plasma's, die Plastidule, sollen sich nach $\mathrm{Haeckel}$ in einer schwingenden Bewegung befinden, und diese Bewegung soll von einer Generation auf die folgende übertragen werden. Wird diese Wellenbewegung durch äussere Einflüsse gestört, so wird sie abgeändert und überträgt sich nun in der abgeänderten Form auf die Nachkommen.

In letzter Linie muss sich ja auch die Vererbung, wie alles andere, rein physikalisch erklären lassen; allein vorderhand sind wir noch nicht so weit, und vor allem lässt sich die Mathematik noch nicht für die Zwecke der Biologie dienstbar machen. Eine kurze Betrachtung lehrt, dass wir mit einer rein physikalischen Vererbungstheorie noch nicht auskommen. Wenn wir uns den Lebensprozess mit Haeckel als eine Wellenbewegung vorstellen, so müssen wir amehmen, dass in den Keimdrüsen, in den Eierstöcken und in den Hoden die Übertragung. der Wellenbewegung der Plastidule des elterlichen Individuums auf die der Keimzellen erfolgt und dass die Plastidule der Keimzellen diese Bewegung fortsetzen. Eine solche Vorstellung wäre immerhin möglich, 
wenn die Körperhälften zweiseitiger Tiere inmer symmetrisch oder die Teilstücke aller strahligen Tiere absolut kongruent wären. Dann würde ron jedem einem Eierstocke oder einem Hoden entsprechenden Körpersegmente die gleiche Bewegungsform auf die Elemente der Keimzellen übertragen werden. Allein viele Tiere sind unsymmetrisch; die linke Körperhälfte des Menschen ist anders beschaffen als die rechte; das Gleiche gilt von vielen anderen Tieren, und es würde auch von den Staubgefässen bei Pflanzen mit sogenannten unregelmässigen Blüten gelten. Ton den zwei unteren Staubgefässen eines Lippenblüters würden andere Bewegungsformen ausgehen müssen, als von den zwei oberen, und von dem rechten Eierstock und Hoden des Menschen müssten andere ausgehen, als von den Keimdrüsen der linken Seite. Trotzdem finden wir, dass das Herz beim Menschen, von einzelnen Ausnahmefällen abgesehen, immer auf der linken Seite liegt, dass die Schnecken, soweit wenigstens die meisten Arten in Betracht kommen, immer dieselbe Abweichung von der Symmetrie zeigen. Es giebt zwar Ausnahmen; aber diese treten weit zurück gegenüber der Regel, dass die Abweichungen ron der Symmetrie erblich sind.

Man könnte sich nun etwa vorstellen, dass beispielsweise beim Menschen nur dann eine Befruchtung erfolge, wenn ein Ei aus dem rechten Eierstock von einem Spermatozoon ans dem linken Hoden befruchtet wird, oder wenn umgekehrt ein Spermatozoon der rechten Seite in ein $\mathrm{Ei}$ aus dem linken Eierstock eindringt. Wenn dem so wäre, ‘lann müssten die Eier der Vögel, welch letztere nur einen linken Eierstock haben, nur von Spermatozoen der rechten Seite befruchtet werden können, eine Vorstellung, die wohl niemand adoptieren möchte. Wir halten durch diese Betrachtungen die Unmöglichkeit einer rein physikalischen Vererbungstheoric dargethan, weil es ja klar ist, dass, falls der ganze Lebensprozess eine verzweigte Wellenbewegung darstellt, diese Bewegung auf der rechten Seite unsymmetrischer Tiere eine andere sein müsste, als auf der linken, und weil die Übertragung der Bewegung nicht von der Mittelebene des Körpers aus erfolgt, sondern von den beiden Seiten aus. Die Wellenbewegung müsste von jeder Seite aus in verschiedener Weise übertragen werden, und dann sähe man nicht ein, weshalb die Abweichung von der Symmetrie eine erbliche ist.

Durch dieselben Betrachtungen scheint mir der Nachweis geführt zu sein, dass auch eine rein chemische Vererbungstheorie nicht möglich ist. Plasmamolekülen, in welchen die Atome unsymmetrisch ge- 
lagert sind, kömnten bei zweiseitig-symmetrischen Tieren zwar andere entsprechen, in welchen die Atomlagerung der in den ersteren spiegelbildlich gleich ist. Dergleichen Moleküle giebt es allerdings; aber eine rein chemische Theorie erklärt nicht, weshalb die Abweichungen von der Symmetrie erblich sind. Was wir gegen eine rein physikalische Theorie angeführt haben, gilt auch hier.

Da die Abweichungen von der Symmetrie sich mit grosser Zähigkeit vererben, so kommen wir nur mit einem Keimplasma aus, dessen Elemente schon einen bestimmten morphologischen Bau haben. Dieser muss notwendigerweise eine Vererbung der Symmetrieverhältnisse bewirken, und iclı darf hier wohl anführen, dass es Betrachtungen wie die obigen gewesen sind, welche mich auf meine Vererbungstheorie gebracht haben. Keine der verschiedenen rein physikalischen und rein chemischen Vererbungstheorien, die ich aufzustellen suchte, erklärten die Symmetrieverhältnisse. Ein glücklicher Gedanke führte mich endlich auf die morphologische Vererbungstheorie, die ich in diesem Buche vortragen werde.

Wer diese Theorie beurteilen will, muss sich zunächst klar darüber sein, was überhaupt von einer Vererbungstheorie verlangt werden kann. Nägeli sagt, dass die Lösung des grössten Rätsels der Abstammungslehre gewonnen wäre, wenn wir die Konfiguration der Plasmaelemente zu erkennen vermöchten. Er bestreitet aber, dass dies möglich sei, und meint auch merkwürdigerweise, dass es unnütz und unfruchtbar wäre, eine Gesamtanordnung der Plasmaelemente auszudenken, die den wichtigsten Anforderungen Genüge leistet. Er setzt hinzu, dass die Erforschung der Konfiguration des Plasma's keine geometrische, sondern eine stammesgeschichtliche Aufgabe wäre, dass die richtige Anordnung der Plasmaelemente nur auf dem Wege erkannt und konstruiert werden könnte, auf dem der Organismus dazu gelangt sei.

Diese Anschauung muss ich bekämpfen. Die Feststellung der Konfiguration des Plasma's ist ganz sicher eine geometrische Aufgabe; eine mechanische Aufgabe aber ist es, den Weg zu erkennen, auf welchem der Organismus diese Konfiguration gewonnen hat. Um das letztere zu thun, müssten wir, wie Nägeli sagt, die ganze Ahmenreihe einer Sippe von dem primordialen Plasmatropfen an, mit welchem die organische Entwickelung begonnen hat, kennen; davon sind wir, meint $\mathrm{N}$ ägeli, noch weit entfernt. Das gilt gewiss für irgend eine bestimmte Pflanze oder irgend ein bestimmtes Tier; allein es ist sehr wohl möglich, 
sich eine allen allgemeinen Verhältnissen entspre chende Vorstellung ron der Art und Weise zu machen, wie die Konfiguration des Flasma's der lieute lebenden Organismen zu stande gekommen ist, und auch ron der Art und Weise, auf welche durch die Form der Plasmaelemente die Gesamtform des rollendeten Organismus bedingt wird. Wer ïberhaupt eine Vererbungstheorie aufstellen will, muss der Forderung Genüge leisten, die Form des entwickelten Körpers aus der Form seiner Plasmaelemente zu erklären. Das hat auch Weismann gefühlt, als er ein Keimplasma annahm, das nach ihm zwar nicht so kompliziert ist, wie der fertige Organismus, sicherlich aber einen noch riel verwickelteren Bau haben müsste, weil es allen Keimesstufen gerecht werden muss. Weismann übersieht, dass damit überhaupt nichts erklärt ist; denn wenn er das zu Erklärende einfach auf den Keim überträgt, so ist das keine Erklärung. Man muss vielmehr verlangen, dass sich die Form des fertigen Körpers aus einer für alle Elemente des Keimplasma gleich angenommenen einfachen Form ergiebt. Das ist die erste Leistung, die unumgänglich von einer Tererbungstheorie gefordert werden muss. Eine brauchbare Theorie muss ferner die Übertragung erworbener Eigenschaften erklären, muss darthun können, warum ein bestimmter Körperteil, der infolge veränderten Gebrauches oder durch Nichtgebrauch umgebildet ist, seine veränderte Form auf die Nachkommen vererbt.

Die Vererbung muss also durch die Annahme bestimmt geformter Plasmaelemente erklärt werden, wenn anders die Theorie das leisten soll, was ron ihr berechtigter Weise verlangt werden darf. Eine diesen Anforderungen entsprechende Erlibirung wird unsere Theorie geben: aber man darf nicht von ihr verlangen, dass sie auch zeigen soll, warum die einzelnen Bausteine des Plasma's diejenige bestimmte Gestalt haben, die wir ihr zuschreiben werden. Weshalb das Gold im regulären und der kohlensaure Kalk bald im hexagonalen und bald im rhombischen System kristallisiert, wissen wir ebensowenig, als wir nachweisen können, weshalb die Plasmaelemente eine bestimmte Form laben, durch deren verschiedenartige Aneinanderlagerung der Formenaufbau des fertigen Organismus zu erklären ist. Abgesehen aber von dieser unerfüllbaren Forderung wird, wie ich glaube, unsere Vererbungstheorie jene ebenso berechtigten wie unerlässlichen Forderungen im Prinzip erfüllen. 


\section{b. Die Gemmarienlehre.}

Das Problem der Gestaltung und Vererbung bei den Organismen ist ein morphologisches. Es betrifft die Formenverhältnisse des Körpers. Wollen wir diese verstehen, so müssen wir verschiedene Stufen der Individualität unterscheiden und die Grundformen der einzelnen Individuen bestimmen. Es ist eines der grössten Terdienste Haeckel's, dass er in seiner "Generellen Morphologie" die Individualitäts- und Grundformenlehre eingehend begründet hat, und die meisten seiner darauf bezüglichen Auseinandersetzungen haben noch heute volle Gültigkeit.

Beschränken wir uns auf die Betrachtung der Tiere, so überzeugen wir uns bald, dass sich mit Sicherheit drei Individualitätsstufen unterscheiden lassen, die des Stockes, 'der Person und der Zelle, und diesen Stufen der tierischen Individualität entsprechen ähnliche Stufen im Pflanzenreiche. Wir sehen nun, dass allen drei Kategorien von tierischen Individuen bestimmte Grundformen zukommen können. So finden wir unter den Korallen bei den Pennatuliden Stöcke von streng bilateral-symmetrischem Bau. Dass die Personen der Tiere, also diejenigen Individualitätsstufen, welche etwa dem Individuum beim Menschen entsprechen, einen festen geometrischen Bau haben, brauche ich nicht weiter hervorzuheben, aber es ist nötig, zu betonen, dass ein solcher Bau auch sehr vielen Zellen zukommt. Wir finden ihn bei einzelligen Tieren, wo beispielweise unter den Radiolarien alle im Tierreich nur möglichen Grundformen von einer Zelle dargestellt werden, und neuerdings hat man sich auch überzeugt, dass den Eiern der Tiere schon in vielen Fällen dieselben Grundformen zukommen, wie den erwachsenen Personen, die sich aus ihnen entwickeln. Das Ei der Insekten beispielsweise ist streng bilateral-symmetrisch gebaut, und diese Symmetrie tritt nicht etwa am Kern, sondern am Plasma des Zellleibes in die Erscheinung.

Ich glaube, man würde in der Vererbungslehre weiter gekommen sein, wenn man $\mathrm{Haeckel's} \mathrm{Individualitäts-} \mathrm{und} \mathrm{Grundformenlehre} \mathrm{zum}$ Ausgangspunkte der Betrachtungen gemacht hätte, und ich werde zeigen, dass sich auf dem Boden der Individualitäts- und Grundformenverhältnisse eine befriedigende Vererbungslehre errichten lässt.

Die Eizellen mit bestimmten Grundformen müssen, da diese Grundformen an das Plasma und nicht an den Kern gebunden sind, ihre Erklärung in der Annalıme finden, dass das Plasma der Zelle aus untergeordneten 
Individualitäten zusammengesetzt wird, und dass diese Individuen eine bestimmte Form haben, die ihren Lagerungsbeziehungen eine bestimmte Richtung giebt und dadurch die Grundform der Zelle bedingt. Es ist ohne weiteres klar, dass kleine aneinander gefügte Kugeh ein anderes Bild geben müssen, als lang gezogene Ellipsoide oder als Eielemente mit einem sehr stumpfen und einem rerhältnismässig spitzen Pole. Es werden sich also die Formenverhältnisse der Eizellen aus der Annahme erklären lassen, dass ilır Plasma aus Individuen mit bestimmter Form zusammengesetzt ist. Wir wollen diese Individuen Ge mmarien nennen, um gleich dadurch unsere Vererbungslchre von anderen, die gleichfalls mit Plasmaelementen operieren, zu unterscheiden. Wir hätten also, um die erblich geregelten Grundformenverhältnisse der Eizelle zu crklären, diesen Gemmarien eine bestimmte Form zuzuschreiben. In einer streng kugeligen Eizelle müssten Gemmarien von anderer Form sein, als in einer bilateral-symmetrischen. Wir würchen also zu dem Schluss gelangen, dass die verschiedenen Formen der Tiere und Pflanzen sich unterscheiden durch die Form ihrer Gemmarien.

Dass mit dieser Erklärung zunächst noch nichts gewonnen ist, leuchtet ohne weiteres cin; denn wenn wir bei den Gemmarien stehen bleiben wollten, so würde unsere Vererbungstheorie nicht viel besser sein, als diejenige Weismann's, der ja seinen Iden auch einen festen architektonischen Bau zuschreibt, ohne den letzteren irgendwie zu erklären. Wir müssen ausserdem auch zeigen, dass sich zweiseitig-symmetrische Tiere aus strahlenförmigen entwickeln konnten, und eine Theorie der Formbildung und Vererbung muss auch nachweisen können, auf welchen Wegen das geschehen ist. Wir dürfen also nicht bei den Gemmarien stehen bleiben und wähnen, dass wir dadurch, dass wir ihnen eine bestimmte Gestalt geben, die Gestaltung und Vererbung erklärt hätten, sondern wir müssen die verschiedenen Formen der Gemmarien auf eine einzige Urform zurückführen und zeigen, dass sich alle Formentverhältnisse der Tiere und Pflanzen auf Grund der Annahme, dass die letzten Elemente des Plasma's überall im wesentlichen dieselbe Form laben, im Prinzip rorstehen lassen. Da aber die Gemmarien eine den Arten nach verschiedene Form laaben unüssen, so können sie nicht die letzten morphologischen Elemente des Plasma's sein, und wir nehmen deshalb an, dass sie zusammengesetzt sind aus untergeordneten Individualitäten, die wir Gemmen nennen wollen, die aber nicht mit den "Gemmulae" Darwin's zu verwechseln sind. 
Wir haben den Namen Genmen gewählt, weil wir durch diesen Namen ausdrücken wollen, dass diese Gemmen eine regelmässige Form haben, und es hat sich gezeigt, dass eine gerade rhombische Sïule, als Form aller Gemmen angenommen, all e Grundformverhältnisse des Tierkörpers erklärt. Ein Botaniker wird sie auch leicht als geeignet zur Erklärung der Formverhältnisse der Pflanzen nachweisen können. Wodurch aber die Form der Gemmen selbst bedingt wird, wissen wir nicht, so wenig wie wir erklären können, weshalb das Wasser im hexagonalen System kristallisiert. Die Form der Gemmen muss bedingt werden durch die chemische Zusammensetzung ihrer Moleküle, aus denen wir uns die Gemmen in ähnlicher Weise zusammengesetzt denken, wie wir uns einen Kalkspatkristall. aus Molekülen des kohlensauren Kalks, an welche Kristallwasser gebunden ist, aufgebaut denken. Es ist damit noch nicht gesagt, dass die Gemmen olme weiteres als Kristalle bezeichnet werden können; indessen werden sie ihrer Natur nach wenig ron diesen abweichen und vielleicht nur dadurch von ihnen unterschieden sein, dass sie eine wechselnde Menge von Kristallwasser aufnehmen können.

Aus solchen Gemmen denken wir uns die Gemmarien zusammengesetzt. Die Gemmen können sich auf zweierlei Weise aneinander lagern, nämlich erstens mit ihren rhombischen Grundfächen aneinander treten und dadurch gerade rhombische Gemmensäulen bilden, und sich zweitens mit einer ihrer Seitentlächen aneinander lagern, wodurch schiefe Säulen mit rechteckigen Grundflächen zu stande kommen. Säulen der ersten Art denken wir uns nun ferner der Länge nach aneinander gelagert, wodurch es möglich wird, eine grosse Anzahl verschiedener Gemmarienformen zu konstruieren. Die Grösse der Ciemmen darf ja als ausserordentlich gering angenommen werden, ihre Anzahl in einem Gemmarium überaus gross sein, so dass eine unübersehbare Mannigfaltigkeit von Geunmarienformen möglich ist. Denken wir uns nun, das diese Gemmarien sich gegenseitig anziehen, so müssen sie sich nach Massgabe ihrer Form in bestimmter Weise in der Zelle anordnen, und die Beobachtung lehrt, dass es das Centrosoma der Zelle ist, das hierbei den organischen Mittelpunkt der letzteren bildet. Vom Centrosoma gehen Plasmastrahlungen aus, die entweder, wie es bei manchen Pigmentzellen der Fall zu sein scheint, von Beständigkeit sind, oder wenigstens dann gebildet werden, wenn die Zelle in Teilung begriffen ist. Auch in den Eizellen der Tiere werden die Plasmaelemente in bestimmter Weise um das Centrosoma herum angeordnet sein, sonst könnte es beispiels- 
weise keine bilateral-symmetrischen Eizellen geben. Wir werden demnächst nachzuweisen haben, dass sich in der That die Grundformenverhältnisse der Tiere leicht und bequem auf die Form ihrer Gemmarien zurückführen lassen, falls wir diesen eine bestimmte Zusammensetzung aus kleinen rhombischen Säulen geben. Diese rhombischen Säulen der Keimzelle können wir als morphologisch und chemisch identisch betrachten und ebenso die Gemmarien, welche sie zusammsetzen.

Wir werden zu zeigen haben, dass die Assimilation in der Weise erfolgen muss, dass die Anzahl der gleichen Gemmen und Gemmarien in Organismus stetig vermehrt wird, und nehmen zunächst an, dass dieser Nachweis, der, wie sich ergeben wird, unschwer zu führen ist, sehon erbracht wäre, und ebenso der nicht weniger schwer zu führende, dass die Grundform des Tierkörpers durch die Form der Gemmarien und diese durch ihre Zusammensetzung aus Gemmen zu erklären ist. Wir werden dadurch zu der Anschaumg gelangen, dass das Keimplasma eines Organismus ein monotones ist, dass die Plasmaelemente der Keimzelle einander völlig gleich sind. Es wäre also dadurch gezeigt, dass eine Theorie der Epigenesis im stande ist, die Gestaltungs - und Vererbungserscheinungen zu erklären, denn die Gestaltung müsste ja durch die Form der Gemmarien, die Vererbung durch die Ubertragung der Gemmarien ron einer Generation auf die nächstfolgende bedingt werden. Dass eine solche Theorie alles im Prinzip erklärt, werden wir im ferneren Verlaufe dieses Buches zeigen. Hier können wir zunächst davon absehen, um die Skizze der Gemmarienlehre und der auf ihr begründeten Theorie zu vollenden.

Aus der Form der Gemmarien muss also der Aufbau des Organismus erklärt werden, und damit. wäre eine Erklärung der Vererbung überkommener Eigenschaften gegeben.

Der Nachweis ferner, dass sich auch erworbene Eigenschaften mit Notwendigkeit vererben müssen, ist leicht zu führen. Wenn die Gemmarien eine bestimmte Gestalt haben, die durch die Form der Aneina nderlagerung ihrer Gemmen bedingt wird, wenn aber, wie wir ja annehmen müssen, die letztere eine wechselnde ist, weil sonst die Möglichkeit einer Entwickelung ausgreschlossen wäre, wenn sich demnach die Gemmen und Gemmenreihen innerhalb der Gemmarien gegeneinander verschieben können, so muss durch äussere Einwirkungen auf den Organismus die Form der Gemmarien eine andere werden. In den Gemmarien bilden die Gemmen ein Gleichgewichtssystem, 
und da sich die Gemmarien gegenseitig anziehen, so bilden auch die Genmarien der Eizelle ein solches, und dasselbe gilt für alle Zellen, welche den Organismus zusammensetzen. Dieses Gleichgewichtssystem wird bedingt durch die Form der Gemmarien, die von einer Generation auf die andere übertragen werden. Ändert sich in den äusseren Verlültnissen der betreffenden Abstammungsreibe nichts, so bleibt dieses Gleichgewichtssystem dasselbe, wird dagegen aus irgend welchen Ursachen der Organismus in einer ihm bis dahin fremden Weise beeinflusst, so muss sich die Form seiner Gemmarien ändern, und das gilt nicht nur von Einwirkungen der Wärme, der Nahrung und anderer den gesam ten Körper treffender physikalischer und chemischer Umbildungsursachen, sondern insbesondere auch von den Wirkungen des Gebrauchs und Nichtgebrauchs der Organe. Die äusseren Einflüsse wirken aber den inneren Gestaltungskräften entgegen.

Wir wollen annehmen, dass die Tiere einer bestimmten Art durch irgend welche Lebensbedingungen gezwungen werden, eines ihrer Organe in neuer Weise zu gebrauchen. Es könnte beispielsweise eine südamerikanische Affenart sich veranlasst sehen, mit der Schwanzspitze Gréifbéwegungen auszuführen. Dadurch, dass des Schwanz mit seiner unteren Fläche mit Baumästen und dergleichen in häufige Berührung konmmt, würden hier die Haare abgenutzt werden und die Epidermis würde sich etwas anders ausbilden. Im Inneren des Schwanzes würde die Form der Gelenke anders werden und die Muskeln sich der neuen Aufgabe anpassen. Da aber alle ursprüngliche Formenverhältnisse des Schwanzes erblich waren, d. h. bedingt durch die überkommene Form der Gemmarien, da die letzteren mit Notwendigkeit die Gestaltung des Schwanzes, ehe dieser sich der neuen Aufgabe anpasste, bedingen mussten und solches fort und fort $z u$ thun bestrebt sind, so wirken sie der Ungestaltung durch den veränderten Gebrauch, die also lediglich auf äussere Einflüsse, auf die veränderte Art und Weise, mit welcher nunmehr der Schwanz in Berührung mit Baumästen und dergleichen kommt, zurückzuführen ist, bis zu einem gewissen Grade entgegen. Es arbeitet also der äussere Bildungstrieb, wie wir mit Goethe die Gesamtheit der Einflüsse, welche auf den Organismus einwirken, nennen können, dem inneren Bildungstrieb entgegen.

Der innere Bildungstrieb ist durch die Form der Gemmarien und durch die Anziehung, welche sie aufeinander ausüben, gegeben. Er muss eine bestinmte Gestaltung der Zellen des Körpers und die Form 
ihrer gegenseitigen Anordnung bedingen. Beides wird aber gestört durch den äusseren Bildungstrieb, durch die neue Anwendung, welche in unserem Falle die Individuen der betreffenden Affenart von ihrem Schwanze machen.

Um uns die Art und Weise vorzustellen, wie äusserer und innerer Bildungstrieb gegeneinander wirken, können wir etwa die Form ron seifenblasen, die wir in ruhiger Luft herrorbringen können, und die eine kugelige sein wird, vergleichen, mit ihrer Form, wenn ein Windhauch sie nach der Seite hin verzerrt, oder wenn ein schwerer Flüssigkeitstropfen sie in die Länge zieht. Stellen wir uns vor, dass ihre urspritingliche Form durch Gebilde ähnlich unseren Gemmarien bedingt werden könnte, und lassen wir die Form, welche die letzteren hervorbringen, rurch äussere Einflüsse gestört werden, so müssen die Gemmarien in einer ihrer Gestaltung und den Richtungen ihrer Anziehungspole widrigen Weise gegeneinander verschoben werden, und es könnte dabei nicht fehlen, dass sich auch die Gemmen innerhalb der Gemmarien gegeneinander verschieben müssten, dass die Form der Gemmarien eine andere w ürde.

Nehmen wir nun ferner an, dass es sich nicht um eine einzelne Blase handelte, sondern um ein System von Blasen, wie es etwa bei der Entleerung einer Bierflasche in letzterer zurückzubleiben pflegt, und lassen wir dieses System bedingt sein durch die Gestalt von gemmarienähnlichen Gebilden, so haben wir einen Vergleich mit dem aus Zellen aufgebauten Körper gewonnen. Wir könnten ja etwa noch voraussetzen, dass es sich dabei nicht um hohle Blasen, sonderm um solide kugelige Gebilde handelte, die im Inneren einen strahligen Bau besitzen, wie man es bei einer sich teilenden Zelle beobachtet; wir wollen aber zunächst einmal den Vergleich mit den Blasen in einer Bierflasche weiter verfolgen. Denken wir uns zunäclıst einmal die Flasche fort, so wird dieses Blasensystem, falls es durch seine inneren Gleichgewichtsverhältnisse bedingt wird, die Entfernung der Flasche äusserlich zum Ausdruck bringen. Wir stellen uns nun ror, dass sich ein solches ungestörtes Blasenwerk in einer Flasche allnählich heranbildet, und sehen dann sofort, dass seine Form durch die Form der Flasche beeinflusst werden muss, sobald die Blasen die Flasche berühren, dass also wechselnde Flaschenform das Blasenwerk in wechselnder Weise beeinflussen muss.

Die Anordnung der Blasen in einer Bierflasche wird freilich lediglich durch die Gesetze der Flüssigkeitsmechanik geregelt, würde sie aber, 
wie wir annehmen, durch die Form der die Blasen zusammensetzenden elementaren Gebilde bedingt, so hätten wir einen Vergleich mit den Verhältnissen im Organismus. Die Anordnung der Zellen in einem Organismus folgt dem inneren Bildungstriebe, $d$. h. wird ursächlich hervorgebracht durch die Form der Elemente des betreffenden Stoffes, durch die Gestalt der Gemmarien des Plasma's. Wird diese Anordnung aber gleich der Anordnung der Blasen in der Bierflasche durch äussere Einflüsse gestört, so muss sie eine andere werden, ob nun äussere Umbildungsursachen von allen Seiten auf sie einwirken oder nur von einer einzigen. Wenn in einer Bierflasche eine Blase infolge störender Einflüsse platzt, so ordnet sich, wie man leicht beobachten kann, das Blasenwerk neu an, und entsprechendes nuss im Organismus geschehen, wenn eine Zelle oder ein Zellkomplex in der Entwickelung gestört wird.

Dass eine solche Neuanordnung thatsächlich erfolgt, ist ja leicht durch die Beobachtung festzustellen; Verwundungen bedingen eine andere Anordnung der Zellen als die, welche zuvor bestand, und Umstimmungen von Zellen finden statt, wenn Stücke eines Tieres sich zu einem vollständigen Tiere regenerieren. Eine Neuanordnung der Zellen muss aber, da die ursprüngliche durch die Gemmarien bedingt wurde, einen störenden Einfluss auf die Form der letzteren haben, denn diese können die Zelle nicht mehr in der Weise ausgestalten, wie es ohne die störenden Einflüsse möglich gewesen wäre. Ihre Anziehungspole werden gegeneinander verlagert; in der gestörten Zelle entsteht ein neues Gleichgewichtssystem, und da das ursprüngliche durch die Form der Gemmarien bedingt wurde, so muss sich die Form der Gemmarien infolge der Einwirkungen von aussen ändern. Die Gemmen verschieben sich innerhalb der Gemmarien gegeneinander; an dieser Stelle eines Gemmariums bröckeln Gemmen ab, an jener setzen sich andere an, und es bilden sich auf diese Weise neue Anziehungspole, die der neuen Form der Zelle entsprechen. Da aber der Gesamtorganismus durch ein monotones Keimplasma bedingt wurde, da er nur der Ausdruck des Gleicligewichtsverhältnisses seines Plasma's ist, so entsteht nicht nur in den ron äusseren Einflüssen umgestalteten Zellen ein neues Gleichgewichtsverhältnis, sondern es muss sich im ganzen Organismus ein solches bilden. Gleich allen anderen Zellen werden auch die Keimzellen von diesem Gleichgewichtssystem betroffen werden, denn sie hängen ja mit den übrigen Zellen des Körpers zusammen. Sie werden von diesen ernährt; zwischen ihnen und den anderen Zellen, ebenso zwischen allen 
aneinanderstossenden Zellen bestehen plasmatische Verbindungen, was heute wohl kein Zoologe oder Botaniker mehr zu bezweifeln wagt, da in vielen Fällen diese Verbindungen bereits durch die Beobachtung nachgewiesen sind. Wenn aber jede Zelle des Organismus direkt oder indirekt mit allen übrigen durch Plasmabrücken verbunden ist, und wenn auch die Keimzellen hiervon nicht ausgeschlossen sind, so muss eine Veränderung des Gleichgewichts in einer einzigen Körperzelle das Gleichgewicht in allen anderen Zellen gleichfalls verändern. Durch äussere Beeinflussung irgend einer Zelle wird also auch die Keimzelle verändert.

Bezeichnen wir das Gleichgewichtssystem in einer somatischen oder Körperzelle mit $\mathrm{S}$ und das ihm entsprechende in einer Keimzelle mit $K$. so stehen diese beiden Gleichgewichtsverhältnisse der einzelnen Zellen ihrerseits miteinander im Gleichgewicht, d. h. eine Keimzelle mit dem Gleichgewichte $\mathrm{K}$ bedingt eine Körperzelle mit dem Gleichgewichte $\mathrm{S}$. Bleibt das Gleichgewicht $K$ ungestört, so ist dasselbe bei dem Gleichgewichte $S$ der Fall. Wird aber eine befruchtete Keimzelle in ihrem Gleichgewichtsverhältnisse gestört, nimmt sie also etwa das Gleichgewichtsverluältnis $\mathrm{K}^{1}$ an, so muss auch in der Körperzelle ein neuer Gleichgewichtszustand $\mathrm{S}^{1}$ eintreten. Wenn die Zelle $\mathrm{K}$ die Körperzelle $\mathrm{S}$ hervorgebracht hat, so bringt die in ihren Gleichgewichte veränderte Keimzelle $\mathrm{K}^{1}$ die Körperzelle $\mathrm{S}^{1}$ hervor.

Es muss sich aber auch umgekehrt das Gleichgewicht der Keimzelle ändern, wenn nicht sie, sondern eine Körperzelle in ihrem Gleichgewichtsverhältnisse gestört wird. Wird durch irgend welche äussere Einflüsse, etwa durch den Gebrauch der Organe, aus dem Gleichgewichte S einer somatischen Zelle das Gleichgewicht $\mathrm{S}^{1}$, so wird aus dem Gleichgewichtsverhältnis $\mathrm{K}$ der in diesem Körper befindlichen oder von ihm noch zu erzeugenden Keimzelle das Gleichgewichtsverhältnis $K^{1}$. Diese heimzelle trennt sich später von dem Kiörper und behält dabei ihr verändertes Gleichgewicht bei, denn dass die Keimzelle das Gleichgewicht, das sie im liürper hatte, bewahren muss, wenigstens in der Weise, dass durch ihre Isolierung bei einem vorherigen Gleichgewichte $K$ ein der isolierten Keimzelle entsprechendes Gleichgewicht Ki eintreten muss, ist ohne weiteres klar. Hat num das Gleichgewichtsverhältnis der somatischen Zelle S dem der in Verbindung mit dem Körper befindlichen Keimzelle entsprechenden Gleichgewichte $\mathrm{K}$ die Wage gehalten, und hat das Gleichgewichtsverhältnis $\mathrm{Ki}$ der isolierten Keimzelle wieder das Gleichgewichtsverhältnis $\mathrm{S}$ der somatischen Zelle in der folgenden Generation 
hervorgebracht, so muss das durch äussere Einflüsse veränderte Gleichgerwichtsverhältnis $S^{1}$ der somatischen Zelle das Gleichgewicht der in Verbindung mit den übrigen Zellen des Körpers befindlichen Keimzelle rerändern; aus $K$ wird $K^{1}$, und aus dem Gleichgewichtsverhältnis $K i$ der isolierten Keimzelle wird das Gleichgewichtsverhältnis Ki ${ }^{1}$. Wenn nun $\mathrm{S}$ und $\mathrm{K}$ sich das Gleichgewicht gehalten haben, und wenn Ki wieder $\mathrm{S}$ hervorbrachte, wenn sich $\mathrm{S}^{1}$ und $\mathrm{K}^{1}$ gegenseitig balanzieren, so muss $\mathrm{Ki}^{1}$ auch wieder $\mathrm{S}^{1}$ hervorbringen.

Damit ist die Vererbung erworbener Eigenschaften als ein Vorgang nachgewiesen, der mit absoluter Notwendigkeit stattfinden muss. Die Vererbung erworbener Eigenschaften leugnen, heisst das Gesetz von der Erhaltung der Kraft negieren. Wenn sich, um wieder auf unsern Affen zurückzukommen, durch fortgesetzten Gebrauch eine Greiffläche an der Unterseite seiner Schwanzspitze gebildet hat, so muss diese mit Notwendigkeit wieder bei seinen Nachkommen auftreten, vorausgesetzt, dass auch das Individuum, mit welchem es sich parte, in derselben Weise abgeändert war.

Aus dem ron uns geschilderten Bau der Gemmarien geht herror, dass diese ron sehr rerschiedener Festigkeit sein müssen. Je nachdem die Gemmen lockerer oder fester aneinandergefügt sind und der gesante Verband mehr oder weniger leicht durch äussere Einflüsse rerändert werden kann, werden die Gemmarien und die Organismen, deren Plasma sie aufbauen, leichter oder schwieriger durch schädigende Einflüsse rerändert werden können. Bei manchen Organismen wird der Bau der Gemmarien ein derartiger sein, dass sie nur schwer schädigenden äusseren Einflüssen zu widerstehen vermögen, und sie werden infolgedessen zu Grunde gehen. Dieses gilt natürlich nicht für Rassen oder Arten, solange diese nicht von erheblichen Veränderungen betroffen werden, sondern es gilt zunächst für die Individuen einer Art oder Rasse.

Wir wissen, dass von den Individuen, welche erzeugt werden, eine grosse Anzahl zu Grunde geht, dass im grossen und ganzen nur so viele übrig bleiben, dass die Anzahl der Individuen in jeder Generation ungefähr dieselbe ist, solange wenigstens, als die Art kein grösseres Terbreitungsgebiet erobert. Es findet demnach fortwährend eine Indiridualselektion statt. Die Indiriduen, deren Genmariengefiige ein lockeres ist, gehen zu Grunde, während die mit festerem Gefüge überleben. Auf diese Weise muss almählich das Gefüge immer mehr befestigt werden, und dadurch müssen die Organismenarten sich rerändern. 
Da eine Tier- oder Pflanzenart ihr Plasmagefüge inmer ins Gleichgewicht mit den Bedingungen, unter welchen sie lebt, setzen muss, so ist schon hierdurch eine grosse Übereinstimmung der Individuen gegeben. Sie werden sich auf einem Gebiete, wo Kreuzung nach allen Seiten mögliclı ist, nur wenig voneinander unterscheiden, denn wenu auch sehr viele verschiedene Gemmarien in Bezug auf ihre Festigkeit gegenüber äusseren Einflüssen gleich gut beschaffen sind, so wird doch durch die Mischung der Individuen das Gefüge in seinem wesentlichen Bau ausgeglichen werden. Da das Gefüge aber fortwährend an Festigkeit zunehmen muss, so ist dadurch eine Entwickelung nach einer Richtung hin gegeben. Diese Entwickelung muss auch dann ihren Fortgang nebmen, wenn sich die Lebensbedingungen der Art nicht ändern, also bis zu einem gewissen Grade unabhängig vom Wechsel derjenigen äusseren Einflüsse sein, welche alle Individuen der Art in gleicher Weise treffen, weil, auch wenn diese sich durch viele Generationen hindurch vollständig gleich bleiben, dennoch eine stets zunehmende Festigung des Gefüges von Vorteil für die Erhaltung der Art sein wird.

Die Gefügefestigung durch Individualselektion ist aber deshalb möglich, weil die Individuen der betreffenden Art durch die geringen Unterschiede in der Art und Weise, wie sie mit der Aussenwelt in Berührung kommen, auch in ihrem Gefüge voneinander verschieden werden müssen. Bei etlichen wird das Gefüge lockerer werden, bei anderen fester, und da der Kampf ums Dasein fortgesetzt die allermeisten Individuen, welche geboren werden, wieder vernichtet, da die grosse Mehrzahl der Vertreter einer Art direkt vertilgt werden, da also eine konstitutionelle Individualselektion stattfindet, so muss das Gemmariengefüge in der betreffenden Art fortgesetzt an Festigkeit zunelmmen. Die Gefügefestigung ist also keineswegs von äusseren Einflüssen unabhängig und darf nicht verwechselt werden mit einer Entwickelung aus inneren Ursachen, wie sie Nägeli angenommen hat, denn sie beruht auf Veränderung der Gemmarien, und die Ursachen, durch welche diese in ihrem Aufbau aus Gemmen veründert werden, sind für sie rein äussere, auch wenn sie, wie es ja selbstverständlich ist, durch den Körper des Organismus hierdurch verïndert werden.

Dadurch, dass jede Organismenart gezwungen ist, sich in einer bestimmten Riclitung weiter zu entwickeln, weil die nie aussetzende konstitutionelle Individualselektion immer die Individuen mit dem festesten 
Gemmariengefüge ausliest, werden diese in ihrer Körperform und ihren chemischen Eigenschaften verändert werden. Es ist z. B. möglich, dass die Vorderbeine bei einer Tierart infolge von Gefügefestigung durch Individualselektion fort und fort verlängert, dass die Hinterbeine in jeder Generation etwas verkürzt werden. Dadurch werden die Tiere gezwungen werden, sich diesen neuen Verhältnissen in der relativen Grösse ihrer Gliedmaassen anzupassen, d. h. die Art und Weise, mit welcher die Gliedmaassen mit ihrer Ungebung in Berührung kommen, muss eine andere werden. Notwendigerweise wird dadurch eine neue Anpassung bewirkt. Aus einer Tierart, für welche lange, zum Springen eingerichtete Hinterbeine charakteristisch sind, kamn eine solche werden, bei welcher die Hinterbeine erheblich verkürzt, die Vorderbeine dagegen verlängert sind. Geschieht das, so müssen die Individuen dieser Art sich daran gewöhnen, mehr zu laufen als zu springen. Selbstverständlich erfolgt dies ganz unmerklich, so dass unmittelbar in jeder Generation eine Anpassung an die geringen Veränderungen, welche die Art durch Gefügefestigung erlitten hat, erfolgt.

Aus diesen Betrachtungen geht hervor, dass es nicht bloss Anpassungen an äussere Verhältnisse giebt, sondern auch an solche, die durch die Veränderungen, welche die Gefügefestigung im Bau der Tiere herrorbringt, bedingt werden. Es können sich die Organismen also auch weiter entwickeln, ohne dass die äusseren Lebensverhältnisse sich ändern. Der Gang dieser Entwickelung ist der, dass die überall wechselnden äusseren Einflüsse kleineren Betrages zunächst die einzelnen Individuen in verschiedener Weise treffen und dadurch ihren Gemmarienbau abändern, dass dann diejenigen ausgewählt werden, die den festesten Gemmarienbau haben, wodurch eine Veränderung des Gesamtbaues im Körper gezüchtet wird, und dass sich endlich die Organe der Tiere diesen Veränderungen anpassen.

Da aber die Verbreitungsgebiete der einzelnen Tierarten sehr verschieden gross sind, so muss die Umbildung einer Tierart, die ein weites Verbreitungsgebiet einnimmt, schneller sein, als die einer Tierart, welche ein enges Verbreitungsgebiet bewohnt; denn auf einem weiten Gebiete können mehr Individuen leben als auf einem engen, und die Individualselektion findet deshalb auf dem ersteren ein reichlicheres Material zur Auswahl vor. Allein es ist fraglich, ob unmittelbar hierdurch eine schnellere Umbildung der Arten in einem weiten Gebiete bewirkt wird. Die meisten Organismenarten sind mehr oder weniger sesshaft; ihre In- 
diviluen schweifen nicht weit umher, und es findet Kreuzung deshalh immer nur unter den Individuen eines verhältnismässig kleinen Gebietes statt. Immerhin wird der Grössenunterschied solcher Gebiete, in welchen freie Kreuzung nach allen Seiten hin stattfinden kann, zur Folge baben, dass in den grösseren die Individuen einer Art etwas fester gefügt sind als in ten kleineren; sie werden deshalb im Kampfe ums Dasein auch grössere Aussichten haben und sich somit leichter über benachbarte frebiete verbreiten können. Dadurch wird eine Rassenselektion ermöglicht; die Rassen mit festerem Gefüge verbreiten sich schneller und kommen dadurch in Wettbewerb mit den Rassen mit weniger festem Gefüige, wobei die letzteren unterliegen müssen.

Hat sich nun eine Rasse mit festgefügtem Plasma über das ganze ron der Stammart eingenommene Areal verbreitet und sind die übrigen Rassen im Wettbewerb mit dieser unterlegen, so kann in jedem Teilgebiete des ron ihr bewohnten Areals die Individualselektion von neuem einsetzen und wieder zur Bildung einer grossen Anzahl ron einzelnen Rassen führen, wodurch dann abermals die Verbreitung der Rasse mit bestgefügtem Plasma über das ganze Gebiet herbeigeführt wird, so dass auch wiederum eine Rassenselektion stattfinden kann. . Dadurch muss eine Art, die ein grosses Gebiet, etwa ein Land ron der Grösse Sibiriens bewobnt, viel schneller umgebildet werden, als eine, die auf eine kleine Insel beschränkt ist.

Wülnend sich aber die Individualselektion bloss auf die Gefügefestigkeit (les Körpers erstreckt, wird die Rassenselektion nicht unter allen Umständen das Gefüge begünstigen, sondern es kann auch die Ausr üstung, die Dotation, für das Überleben einer Rasse ausschlaggebend sein. Wenn cine Tierart ein Wüstengebiet bewohnt, so werden immer dicjenigen Rassen die grösste Aussicht laben, sich über das ganze Gebiet rerbreiten zu können, die in ihrer Farbe an besten der Wüste angepasst sind. Freilich wird unter Rassen, welche sich in Bezug auf lie Farbe gleichen, immer noch eine Auslese stattinden können, die zum Überleben derjenigen Rasse führt, welche das festeste Gefüge besitzt. Ls kann also zwar die dotationelle Rassenauslese der konstitutionellen entgegenwirken, insofern als Rassen mit gnter Ausrüstung unter I'mstïnden überleben können, auch wenn ihr Gefüge nicht ganz so fest ist als dasjenige, bei welchem die Ausrïstung nicht so gut ist; allein die konstitutionelle Rassenselektion wird immer das ihrige thun, Arten zu ziichten, die in Bezug auf ihr Gefüge den Lebensbedingungen einiger- 
massen entsprechen, und nur in Ausnahmefällen wird die rotationelle Rassenauslese die C̈berhand über die konstitutionelle gewinnen, namentlich in allen den Fällen, wo eine besonders rorteilhafte Ausrïstung von einer Rasse erworben worden ist.

Auch die Ausrüstung ist selbstrerständlich ein Werk der konstitutionellen Individualselektion, sofern sie nicht auf direkte äussere Einwilkungen zurückzuführen ist. Die Indiridualselektion kauu bei einer weit verbreiteten Tierart in diesem Gebiete schwarze, in jenem grane, in einem dritten gelbe Tiere heranzüchten, ohne dass dotationelle Individualselektion etwas zur Auswahl dieser Farben beiträgt. Es kaun auf diese Weise der Fall eintreten, dass in einem Wüstengebiete eine schwarze Tierrasse entsteht, und diese wird keine grosse Aussicht auf Fortbestand haben. Entsteht in einem anderen Teile desselben Gebietes eine gelbe Rasse, und kommen beide Rassen später dadurch, dass sie sich über ihr engeres Verbreitungsgebiet ausbreiten, in Wettbewerb, treten nummehr viele Feinde auf, die den Tieren beider Rassen nachstellen, so wird die mit gelbeu Kleide grössere Aussicht haben, zu überleben und dadurch ihre Rasseneigentïmlichkeiten zu erhalteu. Es kann so weit kommen, dass die Iudividuen der schwarzen Rasse alle vertilgt werden, so dass nuumehr die gelbe das ganze Gebiet beherrscht. Bei ihr kann der Selektionsprozess abermals beginuen, so dass die Art immer mehr durch ilıre Farbe dem Wohnorte augepasst ist. Wir müssen dabei anuehmeu, dass die Rassen, die in einem Teilgebiete eines grossen Verbreitungsgebietes entstandeu sind, sich schon so weit voneinander unterscheiden, dass sie sich erstens nicht mehr miteinander mischen, und dass zweiteus ihre Ausrüstung schon so sehr voneinander abweicht, dass die dotationelle Auslese die Möglichkeit einer Auswahl vorfiudet.

Durch diese Ausführungen werdeu die Schwierigkeiten beseitigt, mit welchen die Selektionstheorie Darwin's zu kämpfen hatte. Wenn wir in jedem kleinen Verbreitungsgebiete nur die konstitutionelle Individualselektion als ausschlaggebend erkannt habeu, so gelangen wir zu der Eiusicht, dass in der That eine dotationelle Auslese zwischen deu in deu eimzelnen Gebieten durch konstitutionelle Individualselektion erzeugten ueuen Rassen, die später miteinander iu Berührung kommen, möglich ist. Wir wissen aber, dass sich eine Tier- oder eine Pflanzenart unter Umstïndeu leicht ein ausserordentlich grosses Gebiet erobern kann, und sind deshalb nie in Verlegenheit, wenn wir das nötige Material für die Entfaltung einer wirksamen Rassenzuchtwahl nachweisen sollen. Eine Tier- 
art, die sich weit über die Erde verbreitet und in ihren einzelnen Wohngebieten zu neuen Rassen umgebildet hat, ist beispielsweise die Schleiereule. Man hat die Schleiereulen der Erde zwar in verschiedene Arten trennen wollen, indessen unterscheiden sich diese nur durch untergeordnete Jerkmale voneinander, so dass wir sie als Rassen einer Art betrachten liönnen. Da sich die Vorfahren clieser Rassen leicht über die ganze Erde verbreiten lionnten, so wird es auch eine der neu entstandenen Rassen unschwer thun können, und dadurch müssen die Indi. viduen dieser Rasse mit denen der übrigen Rassen in Wettbewerb) gebracht werden. Die Rassenauslese wird dann darüber zu entscheiden haben, welche der miteinander in Berührung kommenden Rassen überleben soll.

Durch die vorhergehenden Betrachtungen ist eine vollständige Skizze der Gemmarientheorie gegeben. Diese Lehre erklärt nicht nur die V'ererbung der überkommenen, sondern auch die der erworbenen Eigenschaften. Sie zeigt, warum eine konstitutionelle Zuchtwahl die Fortbildung der Art bewirken muss und wie durch diese Fortbildung die Organismen gezwungen werden, sich fortwährend ilnrer Umgebung neu anzupassen. Die Gemmarienlehre erklärt aber nicht allein die Entstehung zweckmässiger Eimrichtungen durch direkte Anpassung, sondern sie zeigt. dass auch Erwerbungen, welche mit dem direkten Gebrauch oder Nichtgebrauch der Organe nichts zu thun haben, wie beispielsweise die Färbung eine ist, gezüchtet werden können, weil unsere Lelne einen Unterschied zwischen konstitutioneller und dotationeller Zuchtwahl, zwischen Individual- und Rassenselektion macht. In den folgenden liapiteln dieses Hauptabschnittes werden wir des näheren darlegen, dass die Gemmarienlehre in der That die Erscheinungen der organischen Entwickelung zu erklïren berufen ist.

\section{c. Das Wesen der Assimilation.}

Eine Gestaltungs- und Tererbungslehre der Organismen würde unrollständig sein, wem sie das Wesen der Assimilation unberührt lassen wollte. In der That ist eine Einsicht in das Wesen der chemischen Vorgänge, welche die Assimilation, d, h. die Verarbeitung der Nahrung zu Plasma und anderen in der Zelle enthaltenen Stoffen, bedingen, eine notwendige Voraussetzung der morphologischen Erforschung der 
Organismen. Es genügt aber, wenn wir eimen allgemeinen Einblick in das Wesen der Assimilation thun können, da von einer eingehenden chemischen Erklärung der Verarbeitung der Nalıung zu den Bestandteilen des lebenden Körpers wohl noch lange nicht die Rede sein kann.

Wenn ich es unternelme, hier eine Art provisorischer Theorie der Assimilation zu entwickeln, so habe ich die Jöglichkeit dazu nicht eigenem Nachdenken, sondern der Benutzung der Ideen zweier anderer Forscher zu verdanken. Hatschek hat in geistreicher Weise eine $\mathrm{H}_{\mathrm{y}}$ pothese über das Wesen der Assimilation aufgestellt, und diese ist es, die ich meinen Betrachtungen zu Grunde lege. Terworn aber hat mit grossem Glück, wie ich glaube, versucht, die Bewegungen der lebenden Materie auf die Assimilation, auf den Stoffwechsel zurückzuführen, und seinen Anregungen verdanke ich es ebenfalls, dass ich die hier vorzutragenden Anschanumgen gewinnen konnte. Ehe ich diese darlege, muss ich aber einige Worte über die Bedentung des Zellkernes und anderer Zelleinschlüsse vorausschicken.

Ich habe auf den bisherigen Seiten dieses Buches immer nur von Plasma schlechtweg gesprochen. Es ist aber jetzt an der Zeit, dass ich den Begriff des Plasma's, wie ich ihn verstehe, näher definiere. Ich verstehe darunter diejenige Substanz, aus welcher die Gemmarien des Zellleibes zusammengesetzt sind, und glaube, dass das Plasma in den Gemmen der Keinzellen einer Organisntenart überall mehr oder weniger dieselbe chemische Beschaffenheit hat. Es ist dieser. Stoff, den die Moleküle, aus welchen sicl die Gemmen aufbauen, darstellen; er ist der Träger der morphologischen Eigenschaften der Organismen, aller jener Eigenschaften, welche die Form des Tierkörpers bedingen. Diese Form kann insofern durch die chemischen Eigenschaften des Plasma's beinflusst werden, als diese sich ändern können und als dadurch die Form der Plasmamoleküle und damit auch die Form der Gemmen, welche die Genmarien zusammensetzen, eine andere werden muss. Allein auf die Anordnung der Gemmen innerhalb der Gemmarien hat, wie ich glaube, die chemische Beschaffenheit des Plasma's nur insofern Einfluss, als diese Anordnung etwas anders werden muss, wenn die Winkel der rhombischen Prismen, aus welchen sich die Gemmarien aufbauen, etwas andere werden. Die Verschiebung der Gemmen innerhalb der Gemmarien ist dagegen unabhängig von der chemischen Beschaffenheit der Plasmamoleküle; sie ist keine chemische, sondern eine rein morphologische Eigentïmlichkeit der Organismen. Den 
Stoff aber, aus welchem sich die einzelnen Gemmen der Gemmarien zusammensetzen, wollen wir kurzweg Plasma nemnen, und was ich ron dem monotonen Plasma, das nach der Theorie der Epigenesis den Bildungsstoff der Organismen darstellt. gesagt habe. bezicht sich lediglich anf das Plasma der Gemmen.

Es wird übrigens auch wohl keiner meiner Leser angenommen haben, dass ich neben diesem Plasma nicht noch andere Bestandteile in den Zellen anerkenne; aber allen diesen kann ich für den Formena ufbau des Organismus nur insofern eine Rolle zuschreiben, als durch den Stoffwechsel, welchen sie beeinflussen, die Form der Gemmen, d. h. die chemische Beschaffenheit der Molekïle, aus welchen die Gemmen zusammenkristallisieren, bedingt wird. Ich will mich nicht damit aufhalten, die Zelleinschlüsse, die namentlich bei Pflanzen in grösserer Anzahl vorhanden sein können, aufzuzählen, sondern will mich darauf beschränken, die Bedeutung des Zellkernes für den Mechanismus der Assimilation darzulegen.

Ich spreche dem Stoffe des Zellkernes keineswegs das Gestaltungsvermögen ab, aber ich glaube, dass er auf die Form des Organismus so wenig Einfluss hat, wie die einzelligen Algen, welche in der Hỵdra leben, auf die Form der letzteren. Dagegen werden die Kernstoffe, von denen wir ausschliesslich diejenigen ins Auge fassen wollen, welche die Chromosomen zusammensetzen, die Form des Kernes bedingen, oder wenigstens die seiner Chromosomen, die ja in hohem Grade charakteristisch ist.

Diese Chromosomen sind, wie es scheint, in allen Fällen zusammengesetzt aus den Nikrosomen, den ,Iden“ Weismann's, und in den Mikrosomen haben wir vielleicht Wesen gleich den Zellen oder möglicherweise gleich den Bakterien zu erblicken. In der That ist nach meiner Anschauung die \%elle als ein gleich dem der Flechten zusammengesetzter Organismus zu betrachten, als eine Lebensgenossenschaft oder Symbiose zwischen dem Kern, insbesondere seinen Mikrosomen, und dem Plasma der Zelle, dessen wesentlichster Bestandteil und organischer Mittelpunkt der Polkörper oder das Centrosoma ist. Ich bin überzeugt, dass diejenigen, welche sich mit diesem Gedanken befreunden, dadurch in überraschender Weise cin Verständnis für manche Vorgänge im Zellleben gewinnen werden, das uns bis dahin verschlossen war. Ich muss mich aber dagegen verwahren, dass die ältesten Zellen etwa dadurch entstanden seien, dass bakterienartige Wesen in kernlose Moneren 
einwanderten, sondern habe vielmehr die Ansicht, dass Kern und Plasma der Zelle sich gleichzeitig in steter Wechselbeziehung bildeten und sich, um mit Verworn zu sprechen, in lückenloser Deszendenz ron Stoffen herleiten, die in lebhafter chemischer Umbildung begriffen waren. Allerdings wäre es auch wohl möglich, dass bakterienartige Wesen eine Hülle ron Plasma erzeugt hätten, und dass diese endlich die Hauptbedeutung gewonnen hätte. Indessen ist es müssig, auf derartige Spekulationen näher einzugehen, da wir noch zu wenig über die Umstände unterrichtet sind, die ein Hervorgehen des Organischen aus dem Unorganischen und von Zellen aus Wesen, die in der Hauptsache nur aus Kernstoff bestanden, veranlasst haben. Genug, dass wir es zur Zeit, ron einigen zweifelhaften Fällen abgesehen, durchweg nur mit Symbiosen zwischen Zellkernen und Plasma zu thun haben.

Wir wissen namentlich durch die schönen Untersuchungen Verworn's, dass weder der Kern ohne das Plasma, noch das letztere ohne den ersteren leben kann, dass es sich in der That um eine erbliche Symbiose zwischen beiden handelt, und über die Eigenart dieser Symbiose wollen wir im nachfolgenden eine Torstellung zu gewimnen suchen.

Um einen Einblick in das Wesen der Assimilation zu thun, wollen wir das Plasma einer in lebhaftem Stoffwechsel befindlichen Zelle $\mathrm{P}$ und ihre Kernstoffe $\mathrm{K}$ nennen; die Nahrung, welche von aussen in die Zelle aufgenommen wird, wollen wir mit $\mathrm{N}$ bezeichnen und den zum Leben der Zelle nötigen Sauerstoff mit O. Ausser dem Plasma unterscheiden wir im Zellleibe aber noch die Sarkode S, die wir als einen ungeformten Stoff betrachten wollen. Wir nehmen an, dass mit dieser Sarkode auch Plasmamoleküle oder Molekülgruppen von Plasma gemischt sind, und dass diese es sind, die sich vor allem am Stoffwechsel der Zelle beteiligen; dass dagegen das Plasma, welches die Gemmen und Gemmarien zusammensetzt, mehr oder weniger lange in Ruhe befindlich ist, aber durch den Assimilationsprozess im Körper fortwährend rermehrt wird. Diese Vermehrung stellen wir uns nun folgendermassen ror: Dadurch, dass Nahrungsstoff $\mathrm{Y}$ in die Sarkode $\mathrm{S}$ gelangt, wird diese chemisch verändert. Es wird daraus die labile Sarkode S'. Wir düıfen uns in Anlehnung an Hatschek's geistreiche Hypothese rorstellen, dass die Moleküle von $\mathbf{S}^{\prime}$ bedeutend grösser sind als die von $\mathrm{S}$, so dass sie, wenn sie auf einen Reiz hin zerfallen, zwei Moleküle S liefern und ausserdem noch andere Produkte, die mit $N^{\prime}$ bezeichnet werden mögen 
und eine Modifikation der Nahrung vorstellen. Die aus S durch Nahrungsaufnahme herrorgegangenen Moleküle $S^{\prime}$ müssen wir als im hohen Grarle labil oder explosir betrachten. so dass sie auf die geringsten Reize hin in zwei oder mehrere Moleküle ron $S$ und in die mit $N^{\prime \prime}$ bezeiclneten Produkte zerfallen. Wir wollen num ferner annehmen, die letzteren beständen aus Nährstoffen, wie sie der Kern gebrauchen kann, dass also durch den Zerfall der Moleküle S' nicht bloss neue Sarkode gebildet wird, sondern dass dadurch auch Nührstoffe für das Kernplasma $K$ gebildet werden. Für den Kern müssen wir Ähnliches annehmen, wie für die Sarkode. In ihn hinein gelangt durch die Kernmembran der durch den geschilderten Assimilationsvorgang im Zellleibe gebildete Nährstoff $\mathrm{N}^{\prime}$, und ebenso wie wir uns die Sarkodemoleküle s durch die chemischen Umsetzungen, welche sie in Verbindung mit den Nahrungsstoffen N eingegangen sind, in grosse, im hohen Grarle explosive Moleküle umgebildet denken, können wir auch annehmen, dass die Moleküle der Kernstoffe, die wir $K$ genannt haben, durch eine chemische Verbindung mit den Xährstoffen $N^{\prime}$ zu sehr labilen Iolekülen $K^{\prime}$ ungebildet werden. Wir dürfen auch in analoger Weise wie beim Plasma annehnen, dass durch den Zerfall der Moleküle $\mathrm{K}^{\prime}$ zwei oder mehrere Moleküle $\mathrm{K}$ nebst einer ahermaligen Modifikation ron Nährstoffen, die wir $\mathrm{N}^{\prime \prime}$ nennen wollen. gebildet werden. Diese durch den Zerfall der gesättigten Kermmoleküle $\mathrm{K}^{\prime \prime}$ gebildeten Nährstoffe $\mathrm{N}^{\prime \prime}$ dienen nun dazu, die Noleküle des Plasma's P zu ernähren, d. h. sie umzuwandeln in die neuen Moleküle $\mathrm{P}^{\prime}$. Die veränderten Plasmamoleküle $\mathrm{P}^{\prime}$ denken wir uns als wahlverwandt, als chemotropisch zum Sauerstoff der Umgebung, und sie mögen es sein, die bei den Wurzelfüssern die Bewegung des Plasma's rerursachen, indem sie, wie Verworn so schön auseinandergesetzt hat, durch den Sauerstoff gewissermassen aus dem Körper herausgezogen werden. Diese Moleküle nehmen Sauerstoff auf, werden dadurch zu übersättigten Molekïlen $\mathrm{P}^{\prime \prime}$, die auf geringe Reize explodieren, wobei sie in zwei Molekïle des Plasma's $\mathrm{P}$ zerfallen und ausserdem noch Exkrete E, die nach aussen geschaffit werden, liefern.

Durch den geschilderten Stoffwechselprozess, der in Wirklichkeit riel komplizierter sein mag, als wir ihn rler Anschaulichkeit wegen annehmen. wird also die Menge des Plasma's, die der Kernstoffe und die der Sarkode vermehrt, solange nur Nahrung und Sauerstoff in genïgender Menge rorhanden sind. Um diesen Stoffwechselvorgang uns noch eimmal vor Augen zu führen, wollen wir ihu in folgende Formeln bringen: 


$$
\begin{aligned}
& \mathrm{N}+\mathrm{S}=\mathrm{S}^{\prime}=2 \mathrm{~S}+\mathrm{N}^{\prime} \\
& \mathrm{N}^{\prime}+\mathrm{K}=\mathrm{K}^{\prime}=2 \mathrm{~K}+\mathrm{N}^{\prime \prime} \\
& \mathrm{N}^{\prime \prime}+\mathrm{P}=\mathrm{P}^{\prime} \\
& \mathrm{P}^{\prime}+\mathrm{O}=\mathrm{P}^{\prime \prime}=2 \mathrm{P}+\mathrm{E}
\end{aligned}
$$

Durch die geschilderten Vorgänge wird die Anzahl der zum Aufbau der Gemmen und Mikrosomen nötigen Moleküle rermehrt, ebenso die Masse der zum Stoffwechsel nötigen Sarkode. Wir könmen uns nun rorstellen, dass infolge des in der Zelle bestehenden Chemismus und ihrer physikalischen Verhältnisse die Plasmamoleküle durch Aneinandexlagerung stets Gemmen ron gleicher Gestalt bilden, und für diese Anschauung laben wir in der anorganischen Natur Analoga.

Wenn an einem windstillen Wintertage einzelne Schneesteme langsam aus der Luft auf die Erde herabfallen und ron uns auf einer dunkeln Unterlage aufgefangen werden, so gewahren wir, dass sie alle gleiche Form haben. Das zeigt, dass es die an dem betreffenden Tage herrschenden physikalischen und chemischen Bedingungen in der Atmosphäre sind, welche die Form der Schmeesterne bedingen. Schon der nächste Wintertag kann Schneesterne von anderer Form bringen; aber auch diese sind alle wieder untereinander gleich. Die Vorstellung, dass die physikalischen und chemischen Verhältnisse in den Zellen die Gestalt der Gemmen bedingen, stösst also keineswegs auf Schwierigkeiten, denu sie ist ebenso leicht odel ebenso schwer zu gewinnen, wie eine Vorstellung von der Entstehung der Schneesterne in ruhiger Luft; diese zeigen zu einer und derselben Zeit alle die gleiche Form, die lediglich durch die gerade in der Atmosphäre herrschenden chemischen und physikalischen Zustände bedingt sein kann.

Auch das Wachstum und die Vermehrung der Gemmarien lässt sich unschwer rorstellen. Die Gemmarien sind ja ron Gemmen aufgebaut, die sich zunächst mit ihren Grundflächen aneinanderlagern und dadurch längere Säulen, als sie selbst sind, bilden. Diese Säulen legen sich wieder aneinander und bilden dadurch die Gemmarien. Da nun die Gemmen in den die Gemmarien bildenden Gemmenreihen durch kleine Zwischenräume, die wir uns mit Wasser angefüllt denken können, getreunt sind, so können wir uns auch rorstellen, dass in die die Gemmen umgebende Flüssigkeit neugebildete Plasmamoleküle hineingelangen und hier zu Gemmen zusammenkristallisieren. Dafür, dass die Gemmen die richtige Lage erhalten, sorgen die sie umgebenden fertigen Gemmen, von denen wir annehmen dürfen, dass sie die neu sich bildenden Gemmen 
schon, solange diese noch klein sind, in die richtige Lage lineindrängen. Durch diesen Wachstumsprozess müssen die Gemmarien verlängert werden; sie werden aber auch rerdickt, indem sich zwischen den Gemmensäulen neue Gemmen bilden, welche die Gemmensäulen auseinanderdrängen und den Platz, den die letzteren einnehnen, erobern. Sowohl beim Längen-

Fig. 1.
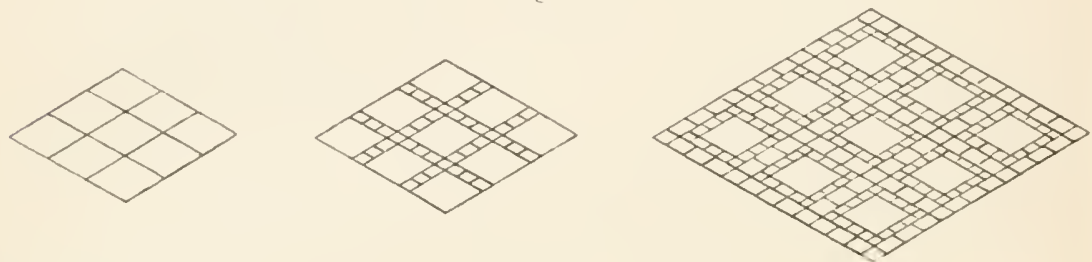

a
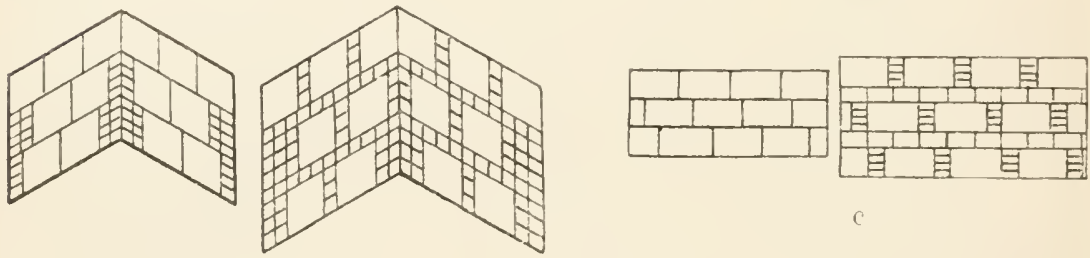

b

Schemata zur Erliuterung des Gemmarienwaehstums.

a) Wachstum inuerhalb eines regehmässigen Gemmarienquerschnittes.

b) Wachstum innerhalb eines unregelmässigen Gemmarienquerschnittes.

c) Wachstum imerhalb eines Gemmarieulängsschuittes.

als auch beim IDickenwachstum bilden sich fortgesetzt neue Gemmen in den durch die Vergrösserung der vorhergebildeten Gemmen entstehenden Zwischenräumen. Notwendigerweise werden durch das Wachstum der Gemmarien die alten Gemmen teilweise, sowohl in der Längs-, als auch in den beiden Querrichtungen des Femmariums, nach aussen gedrängt, wobei, wie ein Blick auf obige Figuren zeigt, die Kionfiguration des Querschnittes seinen äusseren Umrissen nach dieselbe bleiben muss und auch die Anordnung der Gemmen in Längsreihen nicht gestört wird. An der Oberfläche angelangt, werden die Gemmen, falls die Grösse, welche den Gemmarien zukommt, durch Lebenseigentümlichkeit der betreffenden Zelle bedingt ist, ganz oder stückweise abbröckeln und sich mit der Sarkode der \%elle mischen. Hier können sie, aus dem Verbande des Gemmariums befreit und in den Stoffwechsel der Zelle hineingerissen, in ihre Moleküle zerfallen. Nahrung assimilieren und auf diese Weise wieder nenes Plasma bilden, das, aufgelöst in der Zellenflüssigkeit, wieder in die Zwischen- 
räume der die Gemmarien bildenden Gemmen hineingelangt und hier aufs neue einen Wachstumsprozess einleitet. Diesen Wachstumsprozess müssen wir uns, solange die Zelle lebt, als einen ununterbrochenen vorstellen.

Zur Erklärung der Gemmarienvermehrung dürfen wir annehmen, dass die Gemmarien durch das Längenwachstum so lang werden, dass sie endlich in der Mitte auseinanderbrechen. Aus einem Gemmalium entstehen auf diese Weise zwei, die sich an den Bruchenden zu ganzen Gemmarien vervollständigen. Es werden also auch neue Gemmarien gebildet, welche die Gestalt der alten, aus deren Teilung sie hervorgegangen sind, haben müssen. Dadurch wird die Anzahl der Gemmarien in der Zelle beträchtlich vermehrt, so dass diese sich teilen kann.

Ähnliche Prozesse wie im Leibe der Zelle werden im Kern vor sich gehen. Die Anzahl seiner geformten und nicht geformten Elemente wird vergrössert und auch er wird dadurch zur Teilung genötigt; dass diese, d. h. der Zerfall seiner Mikrosomen und Chromosomen in doppelt so viel Stïcke in mehr oder minder grosser Unabhängigkeit von der Teilung des Zellkörpers vor sich geht, wissen wir durclı die Beobachtung. Die sich auseinanderschiebenden Polkörper einer sich teilenden Zelle können zwar die durch die Teilungsrorgänge im Kern gebildeten Teilstïcke der Mikrosomen und Chromosomen auseinanderziehen, nicht aber leiten sie deren Teilung ein.

Durch die geschilderten Vorgänge wird, wie ich glaube, in anschaulicher Weise die Assimilation, die in letzter Linie zur Bildung neuer Zellen führt, erläutert. Diese Prozesse gewähren uns aber auclı noch einen Einblick in die Bedeutung des Zellkernes als Träger etlicher erblicher Eigenschaften.

Die Anschauung, dass im Zellkern, d. h. in seinen Chromosomen, bezw. in deren Mikrosomen, die Träger der Gestaltungsrorgänge im Organismus zu suchen sind, muss ich verwerfen. Dagegen ist es sicher, dass dem Kern eine grosse Bedeutung als Organ des St offwechsels zukommt. Das ist durch viele Untersuchungen, in letzter Zeit namentlich durch die bedeutenden Arbeiten Terworn's, unzweifelhaft dargethan. Dass der Kern indirekt durch seine chemischen Eigenschaften, mittelst deren er in den Stoffwechsel der Zelle eingreift, die Form der Gemmen und dadurch die der Gemmarien der Zelle und des Gesamtorganismus beeinflusst, bezweifle auch ich nicht; allein dass er, wie Weismann 
und andere wollen, geformte Bausteine in die Zelle hineinsendet, ist eine Anschauung, der ich nach allem bisher Gesagten nicht zustimmen kann. Diese Anschauung gründet sich auch auf keinerlei Beobachtungen, während wir unter den Mikroskop olne weiteres erkennen, dass das Centrosoma die gestaltenden Torgänge im Zellleben beherrscht.

A ber ebenso wichtig, wie das Centrosoma für den morphologischen Aufbau des Körpers, ist der Kern für den chemischen. Er giebt Stoffe an die Sarkorle ab, die, wie wir geselıen haben, auch im Stoffwechsel des Gemmenplasma's eine Rolle spielen. Ausser diesen Stoffen wird er aber, worauf wir oben keine Rücksicht genommen haben, auch Exkrete erzeugen, die wir uns als Lösungen oder auch als kleine feste IIassen rorstellen können. Zu diesen Exkreten mögen alle die vielen Stoffwechselprodukte, die wir bei Tieren und Pflanzen kennen, gehören. Bei den Pflanzen gehören dahin der Honig, die ätherischen Öle, die Farbstoffe und viele andere; bei den Tieren der Speichel, die Milch, der Schweiss und die unzähligen anderen Ausscheidungsprodulte. Diesen möchte ich vor allem auch die Farbstoffe der Togelfeder, des Süugetierhaares, der Pignentzellen und viele andere beigezählt wissen, sei es, dass diese Farbstoffe und die übrigen Exkrete direlit durch den Kern, oder erst durch die Wirkung ron dessen Stoffwechselprodukten in der sarkode des Zellleibes gebildet werden. Der Kern ist mithin allerdings der Träger sehr wichtiger erblicher Eigenschaften; aber mit den Gestaltungsrorgängen im Organismus hat er direkt gar nichts und indirelit nicht eben viel zu thun.

Ich latte deshalb wohl recht, wenn ich in meiner "Schöpfung der Tierwelt" den Satz niederschrieb, dass im Plasma selbst der hauptsächlichste Träger der Vererbung gesucht werden miisse, denn unter dem Problem der Vererbung versteht man ror allem die Lösung der Frage, durch welche Bestandteile der Zelle die erbliche Übertragung der Körperform bewirkt wird, und ich glaube die Leser dieses Werkes daron zu überzeugen, dass diese nur durch die Gemmarien des Plasma's bewirkt werden kann. Wenn man aber, wie es ja eigentlich geschehen muss, den Chemismus des Organismus als ebenso wichtig betrachtet, wie seine Gestaltungsvorgïnge, obwohl diese allein bis jetzt Gegenstand der Tererbungstheorie gewesen sind, so gelangt man zu dem von Verworn aufgestellten Satz, dass dasjenige, was vererbt wird, der Stoffwechsel zwischen Kern und Plasma sei. 
Wir können diesem Satze nur beistimmen. müssen aber doch betonen, dass das Problem der Vererbung vorderhand ein morphologisches, kein phrisiologisches ist, und dass zwei Organismen, in welchen der Chemismus fast identisch ist, sich ihrer Form nach sehr wesentlich voneinander unterscheiden können. Dadurch wird die Bedeutung des Zellkernes für die Tererbung auf ihr richtiges Mass zurückgeführt. Er ist ein Organ des Stoffwechsels und dieses Stoffwechselorgan wird direkt auf die Nachkommen übertragen.

\section{d. Die Entstehung der Grundformen.}

Eine Gestaltungs- und Tererbungslehre hat in erster Linie die G r undformen der Organismen zu erklären. Diese Erkenntnis würde eine allgemeinere sein, wenn die Grundformenlehre oder Promorphologie nicht in auffälliger Weise vernachlässigt würde. Jan kennt nicht einmal den Begriff des Wortes "Grundform": in sehr vielen Fällen wird er mit dem des Wortes Urform oder Stammform rerwechselt und anstatt dieses gebraucht. Man spricht von den "Grundformen" der Wirbeltiere, der Hydrozoen usw. und meint damit deren Stanm- oder Urformen, die gemeinsamen Vorfahren, von denen man die betreffenden Tiere ableitet. Unter der Bezeichnung Grundform sind aber nicht diese, sondern die stereometrischen Formen der Organismen zu verstehen, die durch die S y mmetriererhältnisse des Körpers bedingt werden.

Wenn ich, wie ich glaube, ein Verständnis für diese gewonnen habe, so habe ich das in erster Linie dem eingehenden Studium der Promorphologie in Haeckel's "Genereller Morphologie" zu rerdanken. Schon in meiner Erstlingsarbeit habe ich auf die hohe Bedeutung der Grundformenlehre hingewiesen, und ich bin auch heute noch von ihr durchdrungen. Unter dem vielen, was ich meinem Lehrer Ernst $\mathrm{H}$ a e ckel zu verdanken habe, halte ich seine Grundformenlehre für das Beste. Ich rermag es deshalb nicht zu verstehen, dass Driesch die Haeckel'sche Promorphologie, die er selbst zu den wenigen positiven Leistungen zählt, welche die Biologie zu Tage gefördert haben soll, als unfruchtbar erklärt. Das thut er, indem er sagt, dass sie nicht die Vorläuferin ursächlichen mechanischen Erkennens der Organismenformen geworden wäre.

Ich glaube, auch Driesch hätte sich von ihrer grossen Leistungsfähigkeit überzeugen können, wenn er versucht hätte, die äusseren For- 
men der Organismen auf die Formen ihrer Plasmaelemente zuriickzufüluen, denn es kann keinem \% weifel unterliegen, dass der stereometrische Aufbau des Körpers nur zu begreifen ist, wenn seine Bausteine, also die Elemente des Plasma's, eine feste Fol:m haben. Aus unbehauenen Bausteinen, die regellos durcheinander geworfen werden, kann kein Gebäude mit wohlgeordneten Symmetriererhältnissen entstehen. Auch Dreyer wïrde bei seiner Erklärung der Radiolarienskelette weiter gekommen sein, wenn er von der Notwendigkeit durchdrungen gewesen wäre, den Elementen des Plasma's cine bestimmte Form zuzuschreiben. Was Dreyer geliefert hat, ist der Nachweis, dass die Form der Skelette lediglich eine Art V'ersteinerung des Blasengeriustes, das rom Plasma gebildet wird, bedeutet. Wie aber dieses Blasengerïst selbst zu stande kommt. das hat D reyer nicht gezeigt und nicht zeigen können, weil er annimmt, dass es ein mehr oder minder zufälliges sei und lediglich ron den Gesetzen der Flüssigkeitsmechanik beherrscht werde. Wie die Flüssigkeitsmechanik so regelrechte Formen hervorbringen kann, wie es die Radiolarien sind, ist mir unbegreiflich. Es ist wohl mit grosser Torsicht möglich, Seifenblasen regelmässig anzuordnen; bläst man aber durch ein Glasrolı in eine Schüssel mit Seifenwasser hinein, so wird man niemals eine regelmässige Anordnung der Blasen erhalten. Das Plasma ist eben kein Seifenschaum, und in den Wänden des rom Plasma der Radiolarien gebildeten Wabenwerkes haben die Plasmaelemente oder Gemmarien, wie ich sie nenne, eine feste Anordnung, und zwar die, welche ihnen rernöge ihrer stereometrischen Form zukommt. Die Gemmarien aber werden ron Generation auf Generation vererbt; sie erzeugen ihresgleichen durch Assimilation und bewirken dadurch, dass die Nachliommen wieder dieselbe Form haben wie ihre Eltern.

Es ist nun möglich, aus der sichtbaren Form des Organismus Schlüsse auf die Form der Gemmarien, welche sein Plasma zusammensetzen, zu zichen, und es ist weiterhin möglich, sich die Gemmarien aufgebaut zu denken aus Elementen, welche eine bestimmte und im undifferenzierten Plasma gleiche Gestalt haben. Diese Elemente hatten wir Gemmen genannt und als eine Art kleiner organischer Kristalle betrachtet, deren Form selbstrerständlich auf die der sie zusammensetzenden Moleküle, die uns freilich unbekannt ist, zurückgeführt werden muss. Über die Form, welche wir diesen Gemmen zuschreiben, müssen wir uns etwas näher aussprechen. 
Ich bin darauf rerfallen, den Gemmen die Form einer geraden rhombischen Säule zu geben, weil diese mir an besten geeignet erscheint, die Grundformenverhältnisse der Organisnıen zu erklären. Gründe dafür, dass dies die wirkliche Form ist, habe ich mich sonst nicht aufzufinden bemüht, weil ich nicht hoffen konnte, dass sich aus mikroskopischen Befunden die Gestalt der Gemmen ableiten liesse. Ich liess mich also von Zweckmässigkeitsrïcksichten leiten, als ich den Gemmen die Form einer geraden rhombischen Säule zuschrieb. Wenn sich der Nachweis führen liesse, dass nur diese Form die Grundformenverhältnisse der Organismen zu erklären im stande ist, so würde die Wahrscheinlichkeit, dass diese Form eine reale ist, bedeutend zunehmen. Noch mehr müsste sie das thun, wenn wir unter dem Mikroskop Gestaltungsverhältnisse beobachten könnten, die sich am einfaclısten durch die Annahme, dass die Form der Gemmen ein gerades rhombisches Prisma ist, erklären lassen, und ich glaube, dafür lassen sich Beobachtungen ins Feld führen. Solche Beobachtungen gewinnen eine um so grössere Bedeutung; wenn sie unabhängig von jegticher Theorie über die Formenverhältnisse der Tiere angestellt worden sind und dennoch mit einer Theorie übereinstimmen, die unabhängig von dergleichen Beobachtungen aufgestellt wurde. In diesem gegenseitigen Verhältnisse steht zu meiner Gemmarientheorie das berühmte Bild, das Max Schultze ron den Psendopodien der Gromia oviformis gegeben lıat. Dieses Bild habe ich auf S. 142 reproduzieren lassen, wobei ich einzelne Stetlen der Pseudopodien mit Buchstaben bezeichnet habe, um auf solche Stellen besonders aufmerksam zu machen.

Wenn wir das Bild ansehen, so fällt uns sofort auf, dass die Pseudopodien sich unter Winkeln verzweigen, die im hohen Grade konstant sind; sie mögen etwa $20^{\circ}$ betragen. Wie ist dieses konstante Verhalten der Pseudopodien von Gromia zu erklären? In den Scheinfüsschen schieben sich Plasmaelemente in der Richtung, welche durch die Psendopodien angegeben werden, entlang, und zwar bewegen sich die einen vom Körper weg, die anderen auf den Körper zu; es werden also die Elemente des Plasmaleibes fortwährend gegeneinander verschoben, sie werden durch die Aussenwelt stark beeinflusst, wie es beispielsweise bei a durch eine Diatomee, die mit den Pseudopodien in Berührung gekonmen war, geschehen ist. Trotz alledem bewahren sie ihre Verzweigungsverhältnisse, wie am besten aus den Stellen $b, c$ und $d$, wo verschiedene Pseudopodien durch Terschmelzung zu einer grösseren 
Ansammlung ron Plasma geführt haben, hervorgeht. Besonders lehrreich ist die Plasmaansammlung bei $c$, weil sie annähernd die Gestalt Fig. 2.

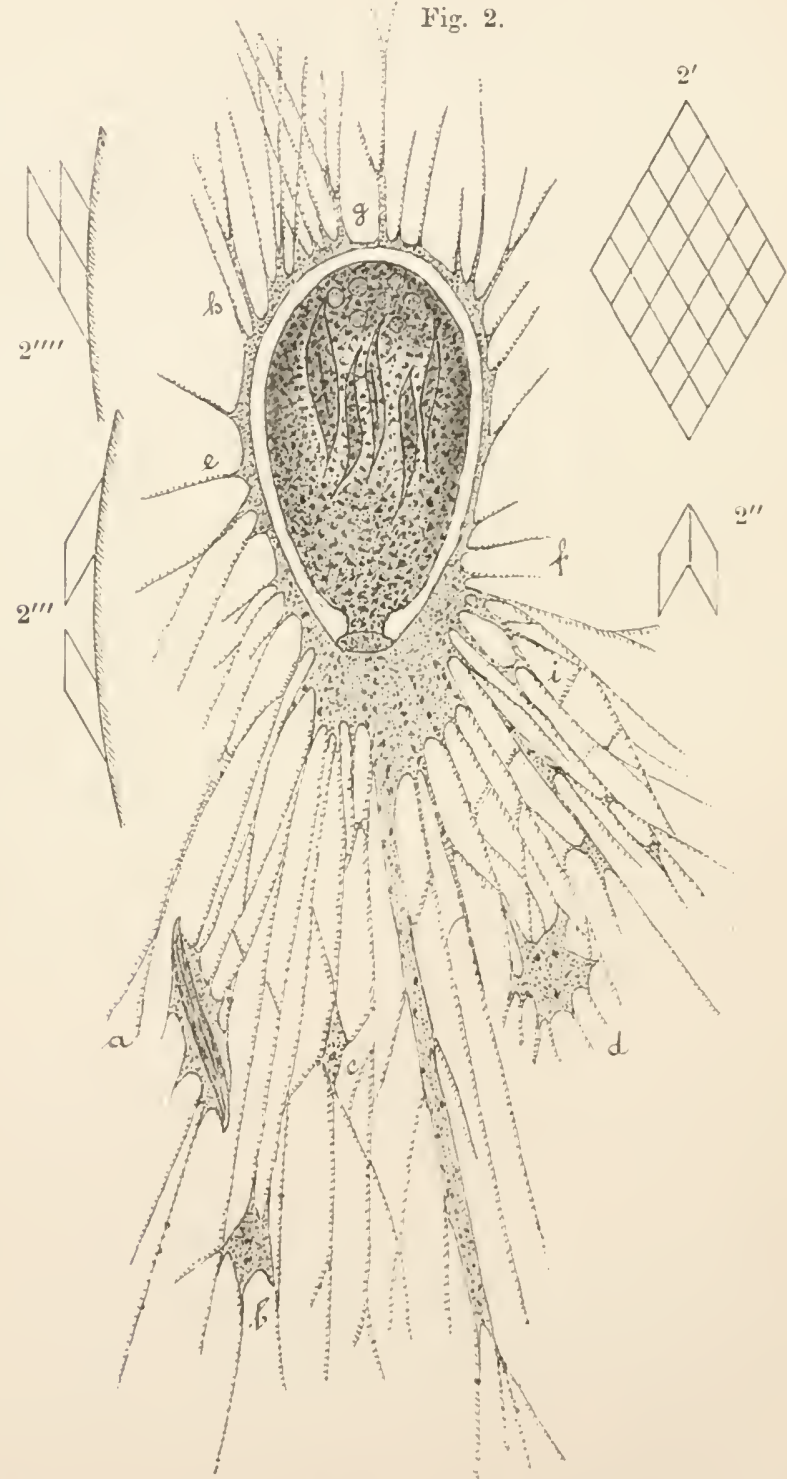

Gromia oviformis (aus O. II ertwig, nach M. Schultzo) nebst Scbematen zur Erläuterung der Pseudopodienverzweigung bei Gromia.

eines Rhombus besitzt. Aber auch die unregelmässigen Plasmaklumpen bei $b$ und $d$ und ebenso die Plasmaansammlung, welche die Diatomee 
bei a umgiebt, sind an ilnen Ecken durch Winkel begrenzt, die im hohen Grade mit den Trerzweigungswinkeln der Pseudopodien, deren Öffnungsweite für Gromia typisch ist, übereinstimmen.

Diese äusserst konstanten Verzweigungsverhältnisse lassen sich anı einfachsten durch die Annahme erklären, dass die Elemente des Plasma's der Gromien zusammengesetzt sind aus Elementen, welche die Form kleiner rhombischer Säulen lıben, mit einer Grundfläche, deren spitze Winkel ungefähr $10^{0}$ betragen. Solche kleine rhombische Säulen könnten sich zu grösseren zusammenlagern, wie Fig. 2' zeigt, die eine von der Grundfläche gesehene grössere Säule darstellt. Auch diese grösseren rhombischen Säulen, die wir als die Gemmarien des Plasma's ron Gromia betrachten können, müssen spitze Winkel von $10^{\circ}$ Teite haben. Legen sich nun zwei solcher Gemmarien in der in Fig. '2" dargestellten Weise aneinander, so entstehen dadurch Winkel ron $20^{\circ}$ Weite, wie sie den Verzweigungen der Pseudopodien bei Gromia entsprechen. Es lassen sich also diese Verzweigungen zurückführen auf die Form, die wir aus ihnen für die Elemente des Plasma's erschlossen haben.

Dass diese Form die reale Form der Gemmarien des Gromienplasma's ist, wird uns noch wahrscheinlicher, wenn wir die Terzweigungsverhältnisse der Pseudopodien an verschiedenen Stellen des Körpers etwas näher ins Auge fassen, und insbesondere die Winkel betrachten, welche die Pseudopodien mit der Gromienschale bilden. Bei $e$ betragen diese Winkel bedeutend mehr als $20^{\circ}$; dasselbe gilt von den Winkeln bei $f$ und $\%$. An diesen drei Stellen nähern sich die Winkel, unter denen sich die Pseudopodien von der Gromienschale erheben, einem rechten Winkel, und das wird uns begreiflich, wenn wir bedenken, dass sich ein Gemmarium des Plasma's nach zwei verschiedenen Richtungen hin an die Schale anlegen kann, wie es Fig. $2^{\prime \prime \prime}$ zeigt. Wo solches eintritt, müssen notwendigerweise die Winkel, unter denen sich die Pseudopodien von der Schale abzweigen, andere werden, als an Stellen, wo, wie bei $h$, die Gemmarien in gleicher Richtung der Schale anliegen, wie es durch Fig. 2'"' veranschaulicht wird.

Wo aber die Anordnung der Gemmarien nicht gestört ist, namentlich also bei den freien Velzweigungen der Pseudopodien, im umgebenden Wasser, müssen die Verzweigungsverhältnisse allein durch die Form der Gemmarien bedingt werden. Deshalb nähern sich auch die Terzweigungswinkel desto mehr einer Kionstanten, je entfernter sie von der Schale sind. Wo allerdings Plasmabrücken, wie bei $i$, entstanden sind, kann 
die regelmässige Anordnung der Psendopodien gestört werden, aber auch in solchen Fällen deutet sie auf eine bestimmte Form der Plasmaelemente hin, wie es z. B. die Stelle $c$ und andere thun.

In den Verzweigungsverhältnissen der Pseudopodien von Gromia darf ich also wohl eine ziemlich direkte Bestätigung für die Richtigkeit meiner Ansicht erblicken, dass die Form der Gemmarien bei den Organismen die eines geraden rhombischen Prisma's ist, und wir werden nunmehr sehen, dass sich aus dieser Form die gesamten Grundformenverlaältnisse der Tiere erklären lassen.

Die Grundformen der Tiere, auf welch letztere wir uns beschränken müssen, lassen sich nach ihren Sy m m etriev er hält n iss en unterscheiden. Demmach wird eine $K u g e l$ durch einen Mittelpunkt gekennzeichnet, durch welchen unendlich viele Srmmetricebenen gelegt werden können. Terlängern wir einen Durchmesser der Kugel über deren Oberfläche hinaus, oler rerkürzen wir ihn an beiden Enden gleichmässig, so gelıt die Kugel iiber in das Ellipsoid, das nicht mehr durch einen Mittelpunkt, sondern durch eine Nittel achse gekennzeichnet wird. Eine Ebene, welche durch den Mittelpunkt dieser Achse geht und senkrecht zu ihr steht, teilt das Ellipsoid in zwei Hälften, die sowohl kongruent, als auch șrmmetrisch gleich sind. In der Richtung dieser Achse und senkrecht zu der eben genaunten Symmetrieebene lassen sich unendlich viele Ebenen legen, von denen gleichfalls jede das Ellipsoid in kongruente und symmetrische Hälften teilt. Lassen wir nun den einen Pol des Ellipsoids rerschieden von dem anderen werden, so geht das Ellipsoid über in das Oroid, das ebenfalls durch eine Mittel achse und unendlich viele Halbierungsebenen, welche so durch die Achse gelegt werden können, dass diese in die Ebenen hineinfällt, gekennzeichnet wird. Aber das Oroid unterscheidet sich dadurch rom Ellipsoid, dass sich in seiner Achse kein Punkt mehr befindet, durch welchen senkrecht zur Achse eine Ebene gelegt werden könnte, die das Ovoid in liongruente und sỵmmetrische Hälften teilte. Das Charaliteristische des Oroids ist also eine ungleich polige Hauptachse, während das Ellipsoid durch eine gleichpolige Hauptachse gekennzeichnet wird. Beide besitzen unendlich viele Nebenachsen. Lassen wir eine dieser Tebenachsen sich an beiden Enden gleichmässig verlängern oder verkürzen, so geht das Oroid über in ein flachgedrücktes Ovoid, das durch eine ungleichpolige Hauptachse und zwei zu einander und zu der Hauptachse senkrecht stehende Nebenachsen charakterisiert wird. Wir können cin solches flachgedrücktes Oroid auch cin zwei- 
schneidiges Ovoid nennen. Wird in diesem zweischneidigen Oroid auch noch eine der Nebenachsen ungleichpolig, so erhalten wir die zweiseitig-symmetrische Grundform, wie sie den meisten Tieren eigen ist. Die zweiseitig-symmetrische Grundform ist demnach charakterisiert durch eine ungleichpolige Hauptachse, eine gleichpolige und eine ungleichpolige Nebenachse. Ihr Zentrum ist nicht mehr eine Achse, sondern eine Ebene, die Symmetrieebene, und diese teilt die zweiseitigsymmetrische Grundform nicht mehr in kongruente, sondern nur noch in spiegelbildlich-gleiche Hälften. Wird endlich auch noch die gleichpolige Nebenachse der zweiseitig-symmetrischen Grundform ungleichpolig, so geht die letztere über in die unsymmetrische Grundform, die durch drei ungleiche Achsen gekennzeichnet ist.

Wir sind bei diesen Betrachtungen von der Kugel ausgegangen, hätten aber auch ebenso gut vom regulären Polyeder ausgehen können, um aus dieser Grundform die regelmässige Doppelpyramide und daraus nacheinander die regelmässige einfache Pyramide, die zweischneidige, die bilateral-symmetrische und die unsymmetrische Pyramide zu erlıalten. Ausser diesen von der Kugel oder von dem regelmässigen Vielflächner ausgehenden Formen giebt es aber bei den Tieren noch andere, die wir als Schiefstrahler bezeichnen können. Ein aus zwei Strahlen bestehender Schiefstrahler würde etwa die Form eines lateinischen $\mathrm{S}$ haben. Die Anzahl der Strahlen ist aber mehr oder minder unbeschränkt.

Das wären die einfachen Grundformen, die wir bei den Tieren antreffen können. Wir finden aber auch häufig gemischte Grundformen. Sehr oft ist die zweiseitig-symmetrische mit der unsymmetrischen Grundform verbunden, wie es beispielsweise beim Menschen der Fall ist, dessen Herz auf der linken Seite liegt. Bei den Kammquallen ist der schiefe ' Zweistrahler kombiniert mit der zweischneidigen Pyramide, und bei einer von mir an der südaustralischen Küste entdecliten Qualle ist die Quadratpyramide mit der unsymmetrischen Grundform verbunden.

Nach diesem für unsere Zwecke genügenden Ueberblick über die Grundformen, welche wir bei den Tieren antreffen, wollen wir unsere Aufgabe etwas schärfer ins Auge fassen.

Wir haben von einer Gestaltungs- und Vererbungslehre verlangt, dass sie die Grundformenverhältnisse der Organismen erklärt. Die bisherigen Lehren sind dieser unerlässlichen Forderung geflissentlich aus dem Wege gegangen, falls man nicht etwa Weismann's Erklärung I a acke, Gestaltung und Vererbung. 
adoptieren, die Grundformen als nützliche Einrichtungen bezeichnen und sie in den Iden rorgebildet sein lassen will. Allein mit solchen Erklärungen ist nichts gewonnen, und wir haben nummehr die Aufgabe, die Grundformen mit Hilfe der Gemmarienlehre zu erklären. Unsere nächste Obliegenheit ist die, zu versuchen, die keimesgeschichtliche Entwickelung der Grundform aus den Formenverhältnissen des befruchteten Eies abzuleiten, ebenso wie wir diese aus der Gestalt der das Keimplasma zusammensetzenden Gemmarien erklären müssen. Dabei kommen uns die schönen Entdeckungen zu Hilfe, die neuerdings über die Bedeutung der ersten Furchungsebene des tierischen Eies gemacht worden sind.

Wir haben diese Entdeckungen den ausgezeichneten Untersuchungen und Anregungen ron Roux zu rerdanken. Roux weist in, wie ich glaube, mwiderleglicher Weise nach, dass die erste Furchungsebene des Froscheies mit der späteren Symmetricebene des Froschkörpers zusammenfüllt. Höchstens kann die erste Furchungsebene Torn und Hinten roneinander trennen, wie es bei vielen Tieren normalerweise der Fall ist, und erst die zweite Rechts und Links roneinander scheiden. Viele andere Autoren haben die Untersuchungen Roux's an anderen Tieren bestätigt. "So haben," sagt Roux, ,ausser mir selbständig Newport und Pflüger für den Frosch erwiesen, dass die erste Furche normalerweise schon die Medianebene des Embryo darstellt; ebenso konnten Seeliger, sowie ran Beneden und Julin bestimmen, dass auch bei Ascidien die erste Furche der Medianebene des Embryo entspricht und dass die dritte Furche das Ekto- und Entodermmaterial voneinander scheidet, welch letzteres von M. v. Davidoff für das von ihm untersuchte Objekt, Distaplia, bestätigt wird. Für die Achordaten liegt gleichfalls eine grosse Anzahl entsprechender Beobachtungen vor, welche die festen Beziehungen zwischen den Hauptrichtungen des Embryo und den ersten Furchungsebenen darthun: Bei den Coelenteraten stellt die Durchschnittslinie der beiden ersten Furchungsebenen des Eies zugleich die Hauptachse des Tieres, die Verbindung des oralen und aboralen Poles dar; und die dritte dazu rechtwinkelig stehende Furche scheidet Ektodermmaterial von Entodermmaterial. Bei den Ḱtenophoren entsprechen ausserdem die beiden crsten Furchungsebenen den beiden gekreuzten Srmmetrieebenen des Embryo. Bei den Polykladen entstehen durch die beiden ersten Furchen zwei kleine dem aboralen und zwei grosse dem oralen Pole entsprechende Zellen; und von den beiden letzteren entspricht die grössere dem Hinterende, die kileinere dem Vorderende des Tieres. Bei den Orthonectiden 
und Dycyemiden ist gleichfalls Vorn und Hinten gleich anfangs zu unterscheiden. Bei den Nematoden scheidet die erste Furche den Ektodermteil des Eies rom Meso- und Entodernteile, und bei Rhabditis nigrorenosa ist nach $G \ddot{b t t e} z u$ dieser Zeit auch schon die rentrale und dorsale Seite, sowie das Torder- und Hinterende des Embryo charakterisiert. Bei den Rotatorien sind nach der zweiten Furchung schon alle drei Richtungen des Embryo als bestimmt erkennbar; und die grösste der vier Zellen liefert das Ento- und Mesoderm. Bei den Polycchäten liefern die nach der dritten Furchung rorhandenen oberen kleineren Zellen das Ektoderm, die unteren, grösseren das Entoderm. Bei den Oligochäten sind nach der dritten Furchung schon alle Hauptrichtungen des Embryo kenntlich. Die Eier der Hirudineen haben eine Aclise mit kenntlichem animalen Pol, und schon nach der ersten Furchung sind alle Hauptrichtungen normiert. Bei Balanus (Krustaceen) entsteht an dem länglichen $\mathrm{Ei}$ zuerst eine Furche, welche eine vordere protoplasmatische, den Ektoblast liefernde Zelle, von der lintern, dotterkörnerhaltigen, dem Entoblast entsprechenden Zelle scheidet. Bei Cirrhipeden (Policipes) entspricht nach Nussbaum das Kopfende des Nauplius dem stumpfen Eipole, das Schwanzende dem spitzen oder Befruchtungspole. Das Insektenei lässt schon vor der Befruchtung an seiner Gestalt drei Hauptrichtungen erkennen, welche der dorsalen und ventralen Seite, sowie dem Kopfende und Hinterende und den lateralen Seiten entsprechen, so dass alle Hauptebenen des Embryo schon vor der Befruchtung bestimmt sind."

Durch diese Ergebnisse embryologischer Untersuchungen ist unzweifelhaft dargetban, dass entweder schon das Ei, oder doch wenigstens der sehr junge Embryo dieselben Symmetrieverhältnisse zeigt, wie das erwachsene Tier. Man hat nun diese Ergebnisse für die Präformationstheorie auszubeuten gesucht, und es lässt sich auch nicht leugnen, dass die Präformationstheorie, wenn sie überhaupt möglich wäre, in ihnen eine grosse Stütze finden würde; indessen ebenso sehr und vielleicht in noch höherem Grade wird die Epigenesislehre durch jene Ergebnisse gestützt. Sie ermöglichen es uns geradezu, uns eine konkrete Vorstellung über die Form der Plasmaelemente, welche die befruchteten und auch schon die unbefruchteten Eier der Tiere zusammensetzen, zu bilden. Wir wollen dabei ausgehen von der zweiseitig-symmetrischen Grundform.

Der organische Mittelpunkt der Zelle ist das Polkörperchen oder Centrosoma. Un dieses herum gruppiert sich das Plasma der Zelle in 
Strahlen, wie wir es an so vielen Zellen beobachten können. Die Anordnung dieser Strahlen muss notwendigerweise vonder Art abhängen, wie die Plasmaelemente aus Gemmarien aufgebaut sind. Die Form der Gemmarien kommit dadurch zu stande, dass sich die Gemmen mit ihren Grundflächen aneinauderlegen und lïngere oder kürzere rhombische Säulen bilden, die sich wiederum mit den Längsseiten aneinanderlagern. Der Querschnitt dieser Säulen wird demnach gebildet durch eine Figur, dic sich aus Rhomben zusammensetzt. Da die Gemmen ausserordentlich klein gedacht werden müssen, so ist eine grosse Mannigfaltigkeit ron Gemmarien-Querschnitten (s. Fig. 3) möglich, und von der Form dieser Querschnitte hängt die Form der Zelle ab, denn wir müssen uns rorstellen, dass schon die

Fig. 3.

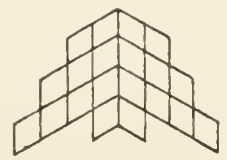

Gemmarienquersehnitt
Fig. 4.
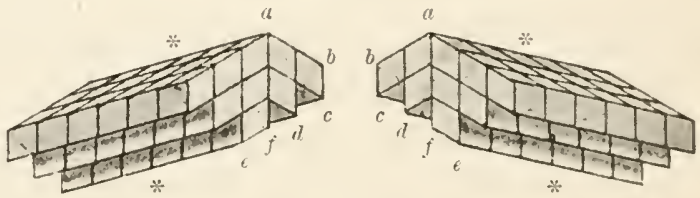

Zwei zweiseitig-symmetrische Gemmarien.

Die Lage der Symmetrieebenen der Gemmarien ist dureh * angegeben.

Form des Centrosoma, das aus Gemmarien zusammengesetzt ist, durch die Form seiner Gemmarien bedingt wird. Die Form der letzteren kann etwa eine solche sein, wie sie Fig. 4 zeigt, die zwei zweiseitig-symmetrische Gemmarien, zwei Gemmarien, daron jedes nur durch eine einzige Mittelebene in zwei symmetrische Hälften zerlegt werden kann, darstellt. Diese zweiseitig-symmetrischen Gemmarien können sich in verschiedener Weise aneinanderlegen, je nachdem ihre Hauptanziehungsrichtung in die eine oder in die andere ihrer drei Achsen fällt. Die Anziehungsrichtung wird aber wahrscheinlich durch die Form der Gemmarien selbst bedingt. Füllt sie etwa bei den beiden in Fig. $t$ abgebildeten Gemmarien mit der Längsachse der letzteren zusammen, so werden sich zwei derartige (iemmarien mit je einem Ende aneinander fügen, und zwar müssen sie dabei wieder symmetrisch zu liegen kommen, weil sie sonst kinen (Hleichgewichtszustand darstellen. Ausser den Endpunkten der Hauptachse der Gemmarien müssen sich beispielsweise auch die Punkte $\iota$ und $a$, $b$ und $b, c$ und $c$ usw. anziehen, und dadurch werden eben die Gemmarien in eine symmetrische Lage zu einander gebracht. 
Nachdem aber zwei derartige Gemmarien den organischen Mittelpunkt der Zelle, den Kern ihres Centrosoma's, gebildet lıben, müssen sich die anderen Gemmarien in entsprechender Weise anfügen, so dass durch ihre Orientierung ein bilateral-symmetrisches Strahlensystem zu stande kommt, wie es Fig. 5 im Grundriss, im Aufriss und in der Seitenansicht zeigt. Etwa so, wie in dieser Figur, werden die Plasmaelemente in dem Froschei orientiert sein. Teilt sich ein solches Ei, so zerfällt dabei das Centrosoma in zwei Polkörper; wodurch zwei Anzie-
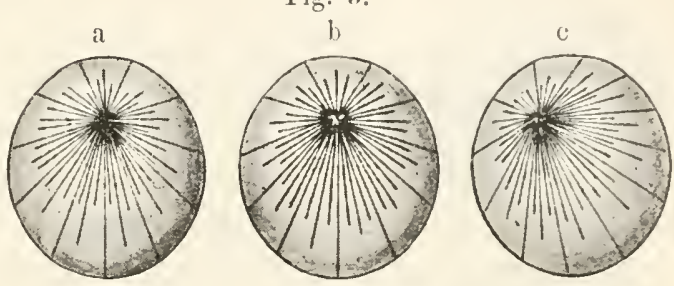

Schema einer zweiseitig-symmetrischen Zelle. a Aufriss. b Grundriss. e Seitenansicht. ziehungsmittelpunkte gebildet werden und zwei Strahlensysteme entstelıeı, die sich durch Verlängerung der Strahlen roneinander entfernen. Würde die Trennung eine vollkommene sein, so würden wir anstatt einer $z$ wei bilateral-symmetrische Zellen erhalten. Die Furchungskugeln der Eier mehrzelliger Ticre bleiben aber miteinander in Verbindung, und zwar, wie wir uns vorstellen können, infolge starker gegenseitiger Anziehung. Es bleiben Plasmabrücken zwischen den Zellen bestehen, und letztere halten einander das Gleichgewicht

Es ist nun unschwer zu verstehen, dass das durch die erste Furchung entstandene Gebilde seinerseits bilateral-sỹmmetrisch sein muss. etwa so, wie es Fig. 6 darstellt. Da die beiden ersten Furchungszellen sich genau das Gleichgewicht halten müssen, so ist es selbstverständlich, dass die weiteren Furchungen nach einem bestimmten Plane erfolgen. Die Zellen können

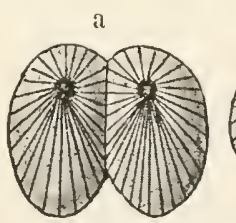
Fig. 6.

Schema eines zweiseitig-symmetrischen Zweizellenstadiuns.

a Aufriss. b Grundriss. e Seitenansicht. sich nur in ganz bestimmten Richtungen teilen, je nachdem ibre Gemmarienstrahlen so oder anders angeordnet sind. Solches sehen wir denn auch in der That eintreten, wie es beispielsweise die schematische Darstellung eines nach Oscar Hertwig kopierten Froscheies (Fig. 7) zeigt und ja übrigens genügend bekannt ist. Sind die Gemmarien der Eizelle vollkommen bilateral-symmetrisch, so muss 
endlich bei dem erwachsenen Tier jede Zelle auf der rechten Körperseite einer ganz bestinmten Zelle auf der linken Körperseite entsprechen, und zwar mit absoluter Notwendigkeit. Zu dieser vollkommenen Symmetrie führt die Gestalt der Gemmarien unfehl-

Fig. 7 .
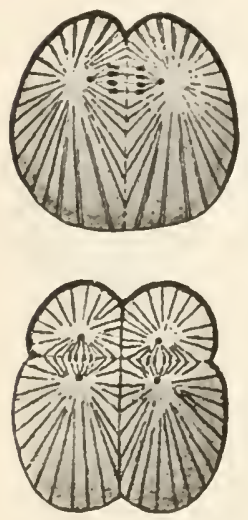

Sihema der 'Teilung des Froscheies (nach u. Hertwig). bar hin, und dass es so ist, ist nicht schwer zu verstehen. Es ist in der That nicht leicht zu begreifen, weshalb man nicht schon früher darauf gekommen ist, die Formenverhältnisse des Körpers aus der Gestalt seiner Plasmaelemente zu erklären.

Ebenso leicht, wie sich die zweiseitig-symmetrische Grundform eines erwachsenen Tieres aus derjenigen seiner Eizelle und zuletzt aus der Form der Gemmarien herleiten lässt, lassen sich die übrigen Grundformen erklären. Es ist nicht nötig, dass wir eine nach der anderen der Reihe nach rornehmen, denn einige wenige Beispiele werden genügen, um zu zeigen, dass unsere Gemmarienlehre in der That geeignet ist, dasjenige allgemeine Verständnis des Formenaufbaues der Organismen zu geben, das bei dem gegenwärtigen Zustande der Biologie, der Chemie, Physik und Mathematik überhaupt möglich ist. In der That werden wir, wie ein mathematischer Freund mich belehrt hat, ein tieferes Verständnis für die Formenverhältnisse der Organismen erst von einem noch zu schaffenden neuen System der Mathenatik erwarten dürfen.

Die unsymetrische Grundform eines Tieres ist aus unsymmetrischen Gemmarien herzuleiten. Ich habe mir diese in meiner "Schöpfung der 'Tierwelt" so rorgestellt, dass in ihre Zusammensetzung Ciemmensäulen eingetreten sind, deren einzelne Genmen sich mit einer ihrer Seitenflächen aneinander gelagert hatten. Es ist zwar nicht unwahrscheinlich, dass solches geschieht, es lässt sich aber auch leicht zeigen, dass es genügt, wenn wir nur eine Art und Weise der Aneinanderlagerung von Gemmen bei der Säulenbildung annehmen. Wir brauchen uns nur rolzustellen, dass in einem bilateral-symmetrischen Gemmarium eine oder mehrere Gemmensäulen nach der einen oder andern Seite hin rerschoben sind, so dass sie über das Ende des Gemmariums herausragen, wie es in Fig. $\checkmark$ dargestellt ist. Diese Figur zeigt uns nun, dass zwei Gemmarien, die der Hauptsache nach bilateral-symmetrisch sind, aber durch eine oder wenige Gemmenreihen ron der bilateralen 
Symmetrie abweichen, sich so anordnen müssen, dass daraus ein unsymmetrisches Strahlensystem entsteht, wie es in Fig. 9 in drei Ansichten dargestellt ist. Die Teilung einer solchen Zelle giebt notwendigerweise zwei Furchungszellen, die in ihrer Grösse und in ihren Formenverhältnissen roneinander abweichen müssen. Blieben diese beiden Furchungszellen nicht miteinander in Verbindung, so würden wir allerdings zwei Zellen erhalten, die dieselbe Form haben würden wie die ursprüngliche Fig. 8.

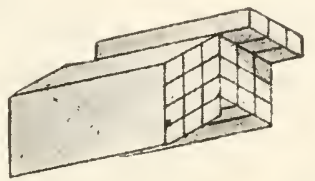

Zwei im wesentlichen zweiseitig-symmetrische Gemmarien mit unsymmetrischer Verschiebung etlicher Gemmenreihen.

Eizelle. Dergleichen Zellen werden beispielsweise gebildet durch ein sich teilendes, unsymmetrisch gebautes Infusorium, etwa einen Stentor, aber bei den Eiern vielzelliger Tiere bleiben die beiden Zellen in Zusammenhang, wodurch notwendigerweise ein unsymmetrischer Körper entstehen muss. Fig. 10 zeigt uns die ersten beiden Furchungszellen einer Fig. 9.

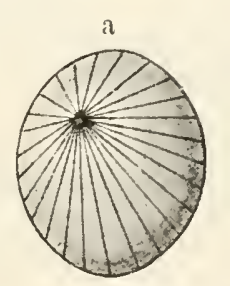

Schema einer unsymmetrischen Eizelle. a Aufriss. b Grundriss. c Seitenansicht. unsymmetrischen Eizelle in drei Ansichten. Es ist nicht schwer zu begreifen, dass aus diesen beiden Furchungszellen, die zwar im grossen und ganzen symmetrisch sind, aber etwas von der Symmetrie abreichen, ein Organismus entstehen muss, der gleichfalls der Hauptsache nach durch eine Medianebene gekennzeichnet ist, aber eine ungleiche Ausbildung

Fig. 10.

a

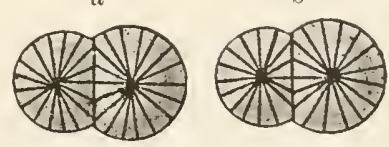

Schema eines unsymmetrischen Zweizellenstadiums. a Aufriss, b Grundriss, c Seitenansicht. seiner beiden Körperhälften zeigt. Die Notwendigkeit, dass sich ein solcher Organismus aus einer unsymmetrischen Eizelle entwickeln muss, leuchtet sofort ein, wenn wir bedenken, dass die beiden Seiten unserer unsymmetrischen Eizelle etwas roneinander abweichen und dass sich die beiden Furchungszellen ebenso verhalten müssen. Die rechte Seite 
der linken Furchungszelle ist mit der ihr unșmmetrischen linken Seite der rechten Furchungszelle rerwachsen, und die dadurch bedingte Asymmetrie des Ganzen muss sich durch den gesamten Körper hindurch fortsetzen.

Nicht schwieriger als die \%urückfühnung einer unșrmmetrischen Grundform auf die Gestalt der ihr I'lasma zusammensetzenden Gemmarien ist die Erklïrung eines Schiefstrahlers, wie er sich beispielsweise bei den Segelquallen (Velella usw.) findet. Die Form dieser Tiere lässt sich einigermassen vergleichen mit einem lateinischen $S$. Die beiden Enden der Hauptperson von Velella sind einander kongruent, aber nicht symmetrisch gleich, gerade so, wie es beim $\mathrm{S}$ der Fall ist. Denken wir uns Gemmarien mit bilateral-symmetrischem Querschnitt, in welchen Gemmensäulen auf der einen Seite dieses Querschnittes über das eine Ende des Gemmariums hinausgeschoben sind, mit ihren geraden

a

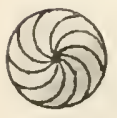
Fig. 11

$$
\text { b }
$$
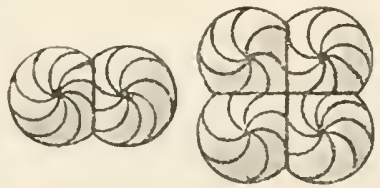

Entstehung eines Sehiefstrahlers. a Linzellenstadium. b /weizellenstadium. c Vierzellenstadium.

Abschnittsenden aneinandergelegt, so resultiert darans durch Anfiigung neuer Gemmarien und Strahlenbildung eine Zelle, wie sie Fig. 11a im Durchschnitt zeigt. Wemn sich diese Zelle teilt, so erhalten wir Fig. $11 \mathrm{~b}$ und weiterhin Fig. $11 \mathrm{c}$, und es ist num nicht mehr schwer einzusehen, dass durch fortgesetzte Zellteilung ein schiefstrahliger Körper entstehen muss. Es lässt sich somit auch die Form des Schiefstrahlers auf die seiner Gemmarien zurủckführen.

Dagegen scheint eine Grundform, wie sie die in Fig. $12 \mathrm{a}$ und $\mathrm{b} a \mathrm{~b}-$ gebildete Qualle zeigt, zunächst jedes Erklärungsversuches spotten zu wollen. Wir haben es hier mit einem 'Tiere zu thun, dessen Grundform die einer regulären Quadratprramide ist. In jedem Quadranten der Pyramide liegen zwei Mundarme, die zu einem Paare vereingt sind, und nur in einen Quadranten trägt dieses Mundarmpaar ein langes Anliängsel, den sogenaunten 'Terminalknopf, aber auch nur an einem, und zwar an dem linken seiner beiden Arme. Daron, dass es immer der linke ist, habe ich miclı an vielen Exemplaren der Monorhiza überzeugt. Diese Qualle lässt sich weder in kongruente, noch in symmetrische Hälften zerlegen. Indessen lässt auch ihre Grundform sich durch Annahme einer bestimmten Form ron Gemmarien erklären. 
Im wesentlichen hat die Qualle die Form einer Quadratpyramide, und hieraus ergiebt sich eine Gemmarienform, wie sie der symmetrische Teil des Querschnittes ron Fig. 13 zeigt. Legen sich vier Gemmarien mit einem

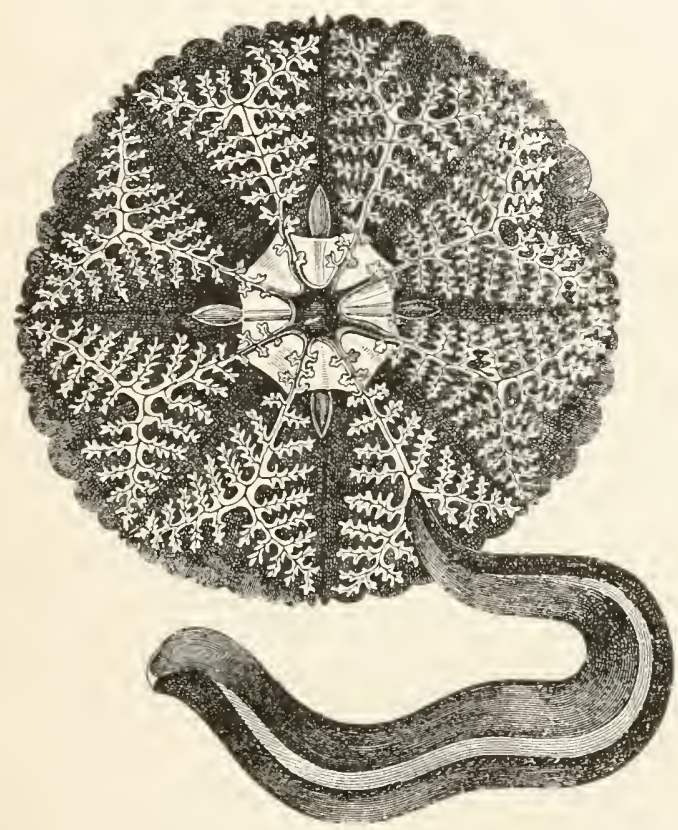

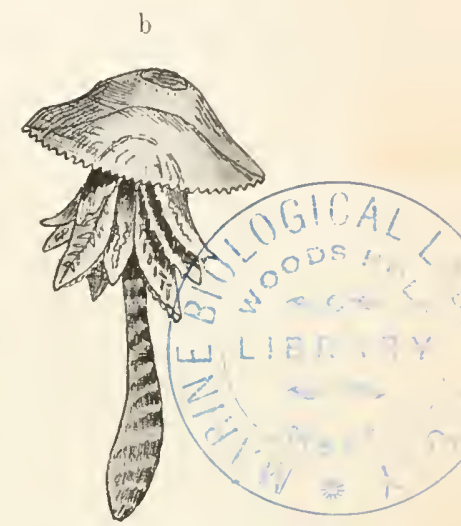

Monorhiza haeckeli.

a Von unten.

b Yon der Seite.

(Nach Haacke. Der

Terminalknopf in

Fig. $12 \mathrm{a}$ ist irltüm-

licherweise dem

rechten Mundarm des

betreffenden Quadran-

ten angefügt worden.)

derartigen Querschnitt mit den Enden aneinander, wobei sie infolge gegenseitiger Anziehung gleiche Abstände bewahren müssen, so resultiert daraus eine Zelle, die durch die beiden ersten Furchungsebenen in vier kongruente Zellen zerfallen würde. Allein unsere Qualle ist nur der Hauptsache nach quadratpyramidal. In der Stellung, wie Fig. 12a uns die Meduse zeigt, haben wir ein oberes und ein unteres Quadrantenpaar. Das obere unterscheidet sich etwas ron dem unteren, und zwar durch den Besitz des dreikantigen

Fig. 13.

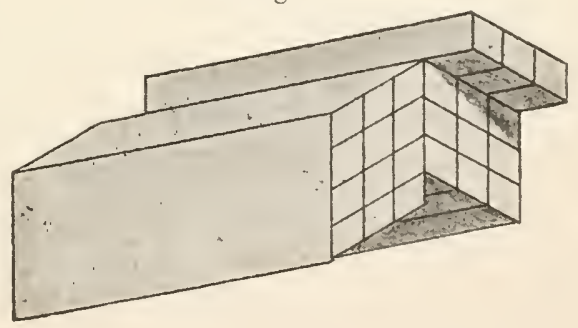

Hypothetische Gemmarienform von Monorhiza. Terminalknopfes. In dieser Stellung ergiebt sich also für die Meduse, wenn wir zunächst absehen von der Asymmetrie der Anhef- 
tungsstelle des Terminalknopfes, eine zweiseitig-symmetrische Grundform, denn wir künnen ein Oben und Unten, ein Vorn und Hinten und ein Rechts und Links an der Qualle unterscheiden. Ihre Grundform muss also nicht durch nur quadratbestimmende, sondern durch gleichzeitig bilateralitätbestimmende Gemmarien bedingt werden. Wir hätten also an den Gemmarienquerschnitt noch einige Gemmarienreihen anzufügen, die zweiseitige Symmetrie bedingen würden. Sie würden es erklären, warmm das Ei der Meduse sich in zwei symmetrisch zu einander gelegene Zellen teilt. Aber die beiden oberen Quadranten der Meduse weichen dadurch roneinander $a b$, dass nur dem einen ron ihnen der Terminalknopf zukommt. Es müssen also in den Gemmarien der Meduse anch einige (iemmenreihen liegen, welche Asymmetrie bedingen, und diese können zugleich die, welche wir uns vorher als die symmetriebestimmenden dachten, unterstützen. Beide werden, da die Abweichung der Meduse von der regulären Quadratpyramidenform ja nur eine sehr geringe ist, an Anzalıl sehr hinter den Gemmenreihen zurückstehen, welche die Quadratpyramide bedingen, so dass ein Gemmarium der Meduse etwa aussehen würde, wie es die Fig. 13, ron der wir vorher nur den einen Teil ins Auge gefasst haben, zeigt. Das Ei der Meduse würde ein System ron Plasmastrahlungen erhalten, wie es Fig. 14 a reranschaulichen soll. Symmetrisch zu der punktierten Linie in dieser Figur stehen Strahlen, die Plasmastrahlen darstellen sollen. Sie sind aus Gemmarien zusammengesetzt, die neben der regulären Pyramidenform gleichzeitig Symmetrie und Asymmetrie bedingen, Gemmarien, wie eines in Fig. 13 abgebildet ist. Der zweiseitig-symmetrische Teil des Querschnittes dieser Gemmarien bedingt die reguläre Pyramidenform; die unteren vorderen und die rerschobenen Gemmenreihen aber bedingen die symmetrische Anordnung der un symmetris chen Plasmastrahlen aus diesen Gemmarien. Unsymmetrisch müssen diese Plasmastrahlen deshalb sein, weil die Gemmarien zwei ungleiche Enden haben. Dagegen unterstïtzt eben derselbe Teil der Gemmarien, der diese Ungleichlheit der Enden bedingt, die symmetrische Anordnung der Gemmarienstrahlen. Die verschobenen Gemmenreihen nehmen infolge gegenseitiger Anziehung eine symmetrische Lage zu der durch die punktirte Linie dargestellten Mittelebene der Zelle ein, aber in den rechts ron dieser Mittelebene gelegenen strahlen muss der überstehende Teil der Gemmarien nach aussen, nach der Peripherie, gerichtet sein, wenn er in den Strahlen auf der linken Seite nach innen gerichtet ist, oder ungekehrt. Durch ein 
Modell würde dieses ohne weiteres klar werden. In Fig. 14 habe ich die symmetrische Anordnung der Gemmarienstrahlen durch die senkrecht zu den Strahlen stehenden Strichelchen, die Asymmetrie der Strahlen selbst durch die schrägen Strichelchen auf der andern Seite jeden Strahles anzudeuten gesucht. Einfacher wäre es gewesen, die senkrechten Strichelchen fortzulassen. Die Figur soll zeigen, dass die Gemmarien, aus welchen wir uns die Strahlen zusammengesetzt

Fig. 14.
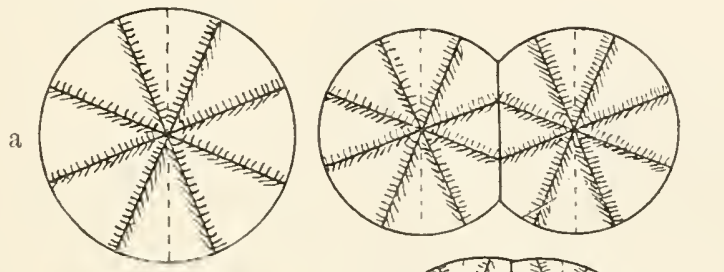

b
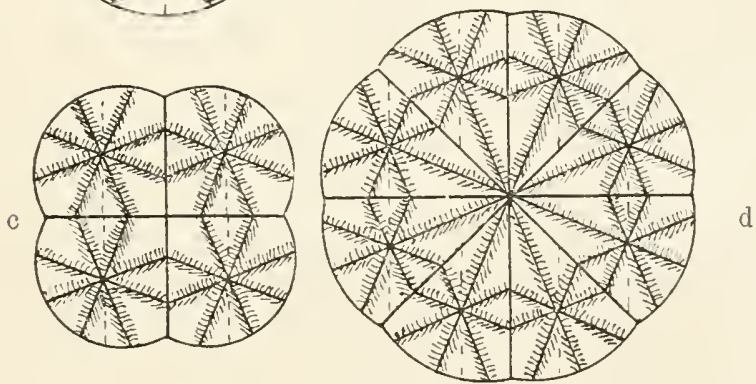

Hypothetisches Schema der Eifurchung ron Monorhiza.

a Einzellenstadium. b Zweizellenstadium. c Vierzellenstadium. d Achtzellenstadium.

denken, kongruent sind und durch ihre Form die beschriebene Anordnung bedingen müssen.

Wer sich in diese schwierigen Formenverhältnisse hineindenkt und sich dessen erinnert, was wir oben über die Furchung symmetrischer und unsymmetrischer Eier gesagt haben, wird verstehen, dass aus dem durch Fig. 14a symbolisch dargestellten Medusenei zwei Furchungszellen, wie wir sie in Fig. $14 \mathrm{~b}$ sehen, und dass aus diesen weiterhin vier und acht mit der durch Fig. 14c und d ausgedrückten Anordnung der Plasmastrahlen entstehen müssen. Die Notwendigkeit der ungleichen Form dieser Zellen geht aus einem genauen Studium der Figuren hervor.

Es ist zwar nicht wahrscheinlich, dass das gefurchte Ei der Monorhiza in Wirklichkeit beträchtliche Unterschiede zwischen den einzelnen Furchungszellen erkennen lässt, und die Furchung mag in ganz anderer 
Weise verlaufen, als wir es hier hypothetisch amnehmen. Auf alle Fälle muss aber die Anordnung der Zellen sich nach der Form der Gemmarien richten, und unsere hypothetischen Figuren lehren deutlich, dass die Zellen ungleich werden müssen. Diese Ungleichheit muss im ferneren Verlauf der Entwickelungsgeschichte von Monorhiza beibehalten werden. Da die Gemmarienform eine bestimmte ist, so muss die Aufeinanderfolge der ungleichen Zellen bei jeder Keimesentwickelung eines Indiriduums ron Monorhiza dieselbe sein, und wir begreifen deshalb, warum der Terminalknopf immer nur in einem Quadranten und immer nur an dem linken Stücke des in diesem Quadranten liegenden Jundarmpaares entsteht.

Die Abweichung der Monorhizagemmarien von der Symmetrie braucht durchaus lieine bedeutende zu sein, denn es ist nichts weiter nötig, als dass die Anfänge des Terminalknopfes gebildet werden. Dieser bildet sich dann durch den Gebrauch ron selbst weiter aus, denn junge, durch die Teilung des Scyphostoma entstandene Quallen sind ja ausserordentlich klein, und man kann sich recht gut rorstellen, dass ihre Weiterentwickelung zum grossen Teile daron abhängt, dass sie sich schwimmend im Meere umherbewegen und auf Nahrung ausgehen.

Die Monorhiza ist nicht nur deshalb von grosser Wichtigkeit für nns, weil sie die allseitige Anwendung unserer Gemmarienlehre auf die Grundformenverhältnisse der Tiere in schönster Weise darthut, sondern auch deshalb, weil sie uns verstehen lehrt, warum an einer kleinen Stelle des Körpers eine unbedeutende Abweichung von der Umgebung und von der Symmetrie entstehen und vererbt werden kann. Weismann kann sich nicht vorstellen, wie auf Grund einer epigenetischen Vererbungstheorie die Übertragung eines kleinen Jittermales verständlich werden kann; aber unsere Monorhiza lehrt uns, dass solches nicht nur möglich, sondern auch vorstellbar ist. Ein unsymmetrisch gelegener Leberfleck rerdankt seine Entstehung einer minimalen Vergrösserung der Abweichung von der Symmetrie, welche die Gemmarien des Menschen ohnehin haben müssen, weil ja etliche Organe des Menschen, wie das Herz, eine unsymmetrische Lagerung haben. Werden ausser den wahrscheinlich ziemlich zahhreichen Gemmenreihen, welche diese normale Abweichung von der Symmetrie bedingen, noch eine oder einige wenige unsymmetrisch gelegene Gemmenreihen dem Genmarium angefügt, so müssen diese die Asymmetrie des menschlichen Körpers allerdings rergrössern, aber sie sind nicht im 
stande, es in so hochgradiger Weise zu thun, dass es äusserlich sichtbar würde. Nur an der einen oder der anderen Seite des Körpers, nur an einer besonders geeigneten Stelle, wird endliclı diese verstärkte Abweichung von der Symmetrie zum Ausdruck kommen, wie sie es durch Bildung eines Muttermales oder eines Leberfleckes thut. Eine derartige minimale Abweichung von der Synmetrie kann nur an den Zweigspitzen des Zellenstammbaumes sichtbar werden, der durch den menschlichen Körper dargestellt wird. Das können wir uns an der Hand der beifolgenden Abbildung klar machen.

Fig. $15 \mathrm{~b}$ veranschaulicht einen Zellenstammbaum, der aus einer in geringem Grade von der Symmetrie abweichenden, im übrigen aber zweiseitig-symmetrischen Zelle lierrorgeht. Wäre die Zelle rollkommen symmetrisch, so würrle sie sich in der Weise verzweigen, wie es Fig. 15a zeigt. Durch die punktierte Linie, welche den Winkel, den die beiden ersten Äste des Stammbaumes a bilden, lialbiert, soll ausgedrückt sein, dass diese Äste einander vollkommen symmetrisch gleich sind. Dagegen ist der Winkel, den in Figur b der rechts gelegene erste Ast des Zellenstammbaumes eines aus einer etwas unsymmetrischen Zelle herrorgegangenen Körpers mit der punktierten Linie bildet, ein wenig grösser als der neben ihm liegende. Aber diese Abweichung von der Symmetrie ist so gering, dass sie unserem Auge kaum wahrnehmbar ist. Die weiteren Zweige des Zellenstammbaumes sind in Figur a immer symmetrisch zueinander gelegen, so dass sie mit dem rorhergehenden Zweige immer gleiche Winkel bilden, während diese Winkel in Figur b immer um ein weniges voneinander verschieden sein sollen. Aus unserer mit grosser Sorgfalt angefertigten Zeichnung ist nun leicht zu ersehen, dass die Asymmetrie des Zellenstammbaumes b mit jeder neu linzukommenden Zweigbildung deutliclıer wird, und ganz ähnlich muss es sich im Tierkörper verhalten, falls eine Eizelle durch Gemmarien auf-

Fig. 15.

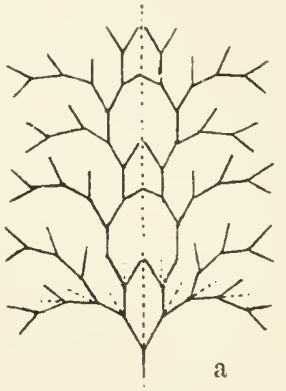

a

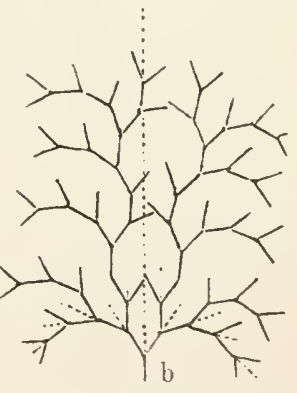

Symbole für Zellenstammbäume

a) eines rein zweiseitigsymmetrischen Körpers,

b) eines zweiseitig-symmetrischen Körpers mit geringer Abweichung ron der Symmetrie. gebaut wird, die eine mininale Abweichung von der die bilaterale Sym- 
metrie des Körpers bedingenden Grundform haben. Solche Abweichungen werden gelegentlich zu Tage treten, sei es durch Ablagerung von Pigment an besonders dazu geeigneten Stellen, sei es in etwas gröberer Weise, und es ist klar, dass sie sich vererben müssen, falls sie einer Abweichung der Gemmarien ron der Symmetrie ihre Entstehung verdanken. Es ist also die Tererbung von Mluttermalen u. dgl. auf Grund unserer epigenetischen Vererbungstheorie sehr wohl verständlich.

Die von uns gegebenen Figuren sind gewiss im hohen Grade schematisch und reranschaulichen nur in höchst roher Weise die Notwendigkeit, mit welcher eine bestimmte Grundform des Körpers aus einer bestimmten Gemmarienform resultiert. Allein, dass sie es thun muss, geht, glaube ich, mit volliommener Sicherheit aus unseren Auseinandersetzungen hervor. Wenn die Gemmarien eine bestimmte Form haben, wenn sie sich, wie wir früher gezeigt haben, durch Assimilation vermehren können, und wenn sie sich gegenseitig anziehen, so müssen sie sich in jeder Zelle in ganz bestimmter Weise zusammenlagern, und zwar geschieht dieses um einen gemeinsamen Mittelpunkt, das Centrosoma, herum. Ist die Zelle isoliert, so erhält sie dadurch diejenige Grundform, die ihr vermöge der Form ihrer Gemmarien mit Notwendigkeit zukommt. Steht sie aber mit anderen Zellen in körperlichem Verbande, so wird ihre Form selbstverstïndlich durch die Form der benachbarten Zellen beeinflusst, und der ganze Körper erhält dann die Grundform, die seiner Eizelle durch die Gestalt ihrer Gemmarien zukam.

Diese Gestalt bedingt es auch, dass die Plasmastrahlungen sich nicht ganz gleichmässsig um das Centrosoma herum verteilen, sondern dass sie je nach dem Orte, welchen sie einnehmen, dichter oder weniger nahe bei einander stehen. Wo sie weniger dicht stehen, wird sich ungeformte Substanz, Nahrungsdotter, ansammeln können, und dieser macht es begreiflich, dass eine Sonderung ron verschieden grossen Zellen eintreten muss. Aus der Teilung einer nahrungsdotterhaltigen Zelle muss ein Keim hervorgehen, dessen eine Hälfte kleinere und plasmareichere Zellen enthält als die andere, in welcher grössere Zellen, die reicher an Nahrungsdotter sind, liegen, und dadurch wird, wie wir später sehen werden, die Entstelung eines zweischichtigen lieimes, einer Gastrula, begreiflich, und weiterhin die fortgesetzte Faltenbildung im Körper, wie sie besonders schün in der Keimesgeschichte und in dem Körperbau des Amphioxus zum Ausdruck gelangt. Die Gemmarienlehre erklärt also nicht allein die Vererbung der Grundform, sondern auch die der Organe, und ge- 
nügt deshalb allen Ansprüchen, die an eine Theorie der Formbildung zu stellen sind.

Dass sie auch auf die Entstehung der Formen bei den Pflanzen anwendbar ist, wird nach allem Vorhergehenden nur der bezweifeln, der sich noch nicht völlig in die allerdings äusserst schwierigen stereometrischen Vorstellungen hineingefunden hat, die zum Verständnis unserer Gemmarienlehre unerlässlich sind. Nur wer ein genügend ausgebildetes stereometrisches Vorstellungsvermögen, wie es leider nicht allzu häufig ist, besitzt und die Mühe intensiven Nachdenkens nicht scheut, wird in das Verständnis der Gemmarienlehre eindringen und sich auch mit Hilfe von Zeichnungen und Modellen in der Ableitung der Grundformen der Organismen ron den Formen ihrer Gemmarien zurechtfinden. Er wird auch einsehen, dass der Kern in den verschiedenen Zellen des Körpers immer eine bestimmte Lage einnehmen muss, dass er sich wahrscheinlich dort finden wird, wo er den geringsten Widerstand findet.

Die Anordnung der Gemmarien in bestimmter architektonischer Weise ist natürlich dort nicht möglich, wo eine lebhafte Plasmaströmung stattfindet, wie wir sie bei den Pflanzen sehen. Aber in dem Urmeristem der Pflanzen lässt sich eine solche Plasmaströmung nicht nachweisen, denn was man als solche gedentet hat, lässt sich sehr wohl durch die Annahme erklären, dass diese Zellen wachsen und dabei ja natürlich ilrre Plasmaelemente etwas gegeneinander verschieben müssen. Im grossen und ganzen bleibt die Anordnung der letzteren in den Meristemzellen dieselbe, und diese müssen sich deshalb in bestimmter Weise gruppieren und dadurch zu dem architektonischen Aufbau führen, der uns an den Pflanzen in so greifbarer Weise entgegentritt.

Was wir vom Kern gesagt haben, gilt auch für die anderen Zelleinschlüsse, so auch für die Takuolen. Dass diese beispielsweise bei den Infusorien einen festen Platz haben, wissen wir bestimmt; aber auch bei den Radiolarien müssen sie in einer regelmässigen, durch die Form der Gemmarien bedingten Weise angeordnet sein. Sie bilden sich da, wo sie den geringsten Widerstand finden, und dasselbe muss ron den viel kleineren Vakuolen, die nach $B$ ütschli eine wabenförmige Anordnung des Plasma's bedingen, gleichfalls gelten. Eine solche schaumförmige Terteilung der kleinen Vakuolen mag immerhin in den meisten Zellen bestehen; allein es ist nicht richtig, in diesem Wabenwerk die Struktur des Plasma's zu erblicken, denn aus Plasma bestehen nur die Wände der Vakuolen und nicht der Inhalt der einzelnen Hohlräume. 
In den Wänden der Takuolen kann sich aber das Plasma der Form seiner Gemmarien entsprechend anordnen, und diese Anordnung braucht nicht durch die Takuolen gestört zu werden, solange keine Plasmaströmung, wie in den Pflanzenzellen, eintritt. Ich habe also keine Veranlassung, Bütschli zu widersprechen, wenn er für das Plasma einen wabenförmigen Bau annimmt, aber die Struktur der plasmatischen Wände dieses Wabenwerkes hängtlediglich vouder Gestalt der Gemmarien ab.

Wir haben in einer, wie ich hoffe, rerständlichen Weise nunmehr die Ontogonie der Grundformen erklärt, sie auf die Gestalt der Gemmarien der befruchteten Eizelle zurïckgeführt. Die Gemmarienform ist aber eine erworbene, eine Gestalt, welche sich im Laufe der stammesgeschichtlichen Entwickelung rerändert hat; und wir haben nummehr zu zeigen, wie wir uns diese Veränderung zu denken haben.

Die Stammesgeschichte der tierischen Grundformen bewegt sich, wie wir gesehen haben, in einer ganz bestimmten Richtung. Bei den niedersten Urtieren, z. B. bei den Amöben, ist die Grundform durchaus unregelmässig, dass aber die Gemmarien des Plasma's bei ihnen schon eine bestimmte Gestalt haben, lässt sich folgern aus der charakteristischen Form der Scheinfüsschen bei diesen und anderen Urtieren. Bei den Sonnentieren hat das Plasma schon eine bestimmtere Form angenommen, insofern als hier die Kugel die herrschende Grundform ist, und die Sonnentiere leiten hinüber zu den Radiolarien, bei welchen wir alle Grundformen, die überhaupt im Tierreich vorkommen, rertreten finden; hier muss die erbliche Form der Gemmarien in jeder einzelnen Art eine sehr bestimmte sein. Die Kammertiore weisen gleichfalls Reihen auf, in welchen die Grundform mit dem Fortschreiten ron unten nach oben an Bestimmtheit gewinnt, und dasselbe ist bei den Flagellaten und Infusorien der Fall; unter diesen beiden Gruppen haben wir schon unsymmetrische Tiere. Wir haben also schon bei den Urtieren sämtliche Hauptformen, die wir bei den Darmtieren wiederfinden, durch einzelne Zellen verwirklicht, und daraus geht herror, dass auch die Eizelle der Darmtiere dieselben Crundformverhältnisse zeigen kann, wie der einzellige Leib der Urtiere.

Unter den Darmtieren finden wir älnliche Stufenfolgen wie bei den Urtieren. Von den Schwämmen angefangen nimmt die Grundform an Bestimmtheit zu, je weiter wir uns ron diesem Ausgangspunkt entfernen. Unter den Schwänmen sind noch viele mehr oder minder formlos, inso- 
fern wenigstens, als die erwachsenen Stücke in Betracht kommen, während allerdings die Eizelle der meisten Schwämme eine eiförmige sein mag, was auch ron der Gastrula der Schwämme gilt. Das heranwachsende Schwanmindividuum büsst dagegen mehr und mehr seine ursprüngliche Grundform ein, d. h. es wird durch die Aussenwelt so beeinflusst, dass es bald in dieser, bald in jener Richtung wächst. Nur verhältnismässig wenige Schwämme haben eine feste erbliche Grundform auch für die erwachsenen Individuen gewonnen; zu ihnen gehört beispielsweise der bekannte Venusblumenkorb.

Bei den Nesseltieren ist die Grundform viel bestimmter als bei den Schwämmen, selbst schon bei den tiefststehenden unter ihnen, beispielsweise bei der Hydra unserer süssen Gewässer. Allerdings ist bei ihr die Anzahl der Tentakel noch nicht erblich fixiert, und dasselbe gilt von vielen anderen Hydroidpolypen; aber bei manchen der letzteren ist die Anzahl der Tentakel schon mehr oder minder konstant geworden, so dass wir auch hier eine zunehmende Bestimmtheit der Grundformen konstatieren können.

Bei den Hydromedusen finden wir ähnliches. Sie nehmen ihren Ausgang von regulär-quadratpyramidalen Formen, die in die Grundform einer zweischneidigen und einer zweiseitig-symmetrischen Pyramide übergehen. Bei den Ktenophoren und Siphonophoren finden wir dann auch Formen, bei welchen die Ausbildung eines Schiefstrahlers angebahnt ist. Die Scyphomedusen haben zwar fast alle die reguläre Quadratpyramidenform, indessen haben wir in der Monorhiza, die jedenfalls auf einer sehr hohen Entwickelungsstufe steht und zu der höchststehenden Abteilung der Scheibenquallen gehört, eine auffällige Abweichung von der strahligen Symmetrie, und ähnliches finden wir bei Aurelia, die einen Übergang von der Quadratpyramide zu einem vierzähligen Schiefstrahler darstellt.

Bei sämtlichen übrigen Tierstämmen ist die Grundform ursprünglich die bilateral-symmetrische. Diese geht bei den Echinodermen wieder in die fünfstrahlige über, aus Ursachen, auf welche wir hier nicht näher eingehen wollen. Allein diese fünfstrahlige Grundform nähert sich mehr und mehr der zweiseitig-symmetrischen, je weiter wir die Reihen der Echinodermen nach oben hin verfolgen. Wir sind bei diesen Tieren in der glücklichen Lage, die Entwickelung der Grundform paläontologisch begründen zu können, was wenigstens bei den Seeigeln möglich ist. Diese nehmen ihren Ausgangspunkt von einer beinahe völlig regulären fünfstrahligen Form und langen bei einer nahezu röllig zweiseitig-sym- 
metrischen Grundform an. Die erstere wïrden wir beispielsweise bei den Palechiniden, die letztere bei der Gattung Pourtalesia finden. Eine ähnnliche Formenreihe wie die Seeigel weisen die Seegurken auf, wenn sich die Stammesgeschichte ihner Grundformen auch nicht paläontologisch begründen lässt.

Wenden wir uns ron den Echinodermen zu den Weichtieren, so haben wir hier viele Beispiele dafür, dass die zweiseitige Grundform in die unsynmetrische überzugehen bestrebt ist. Mit alleiniger Ausnahme der Käferschmecken bekunden sämtliche Gruppen der Weichtiere das Bestreben, unșmmetrisch zu werden. und ähnliches ist bei den meisten Wirbeltieren der Fall. Dic Lage der Baucheingeweide ist bei fast allen Wirbeltieren eine unșmmetrische, aber keine beliebige, sondern sie bekundet, dass die Grundform in ganz bestimmter Richtung ron der șmmetrischen abweicht. Ausserlich freilich scheinen die meisten Wirbeltiere noch zweiseitig gebaut zu sein; aber es giebt doch Gruppen, wie die Plattfische, die auch äusserlich völlig unsymmetrisch geworden sind. Am wenigsten wird man bei den Säugetieren und Vögeln von rornherein unsymmetrische Grundformen zu erwarten geneigt sein, und doch ist nicht nur der innere Leibesbau dieser Tiere ein melr oder minder unsymmetrischer, sondern es zeigen sich in vielen Fällen auch äusserlich starke Abweichungen von der Symmetrie. Ich will nur daran erinnern, dass beim Haushund der Schwanz in den allermeisten Fällen nach der linken Seite hin ron der Mittelebene abweicht; beim Menschen ist die rechte Hand erblich stärker als die linke; der Schädel vieler Wale ist unsymmetrisch, und beim Narwal ist nur an einer Seite ein Stosszahn ausgebildet; ebenso pflegt beim Renntier der Augenspross an der einen Geweihstange stärker zu sein, als an der anderen.

Man sollte meinen, dass es äusserlich unsymmetrische Tögel überhaupt nicht geben könnte, und doch fand man auf Neuseeland einen Togel, dessen Schnabel nach einer Seite hin umgeknickt war. Man lielt dies anfünglich für eine Missbildung, bis man fand, dass diese Abweichung von der Symmetrie eine für die betreffende Art charakteristische ist.

Auch unter den Gliederfüssern kommen unsymmetrische Formen vor, namentlich bei den höheren Krebsen. Manche Krabben haben auf der einen Seite eine grössere Scheere als auf der anderen, und die Einsiedlerkrebse haben einen stark unsymmetrischen Bau; indessen ist es mögliclı, dass dieser auf Ampassung an die Lebensweise zurückzuführen 
ist, während sonst die Entstehung unsymmetrischer Formen aus symmetrischen, die Entwickelung dieser aus strahligen und das Hervorgehen der letzteren aus unbestimmten weder durch direkte Anpassung an eigenartige Existenzbedingungen, noch durch das Zweckmässigkeitsprinzip zu erklären ist; durch das letztere wenigstens nicht, soweit dabei die dotationelle Auslese in Betracht kommt.

Die Umwandlung der Grundformen, die überall, wo direkte Anpassung an die Umgebung nicht störend eingegriffen hat, einen fest vorgezeichneten Gang innehält, ist vielmehr durch Gefügefestigung zu erklären.

Durch äussere Einflüsse kann das Gemmariengefüge eines Organismus gefestigt und gelockert werden. Die Individuen mit gelockertem Plasmagefüge können äusseren Einflüssen nicht so leicht widerstehen wie die mit festerem. Diese werden durch konstitutionelle Zuchtwahl ausgelesen und können ihre durch äussere Einwirkungen erworbene Gefügefestigkeit auf ihre Nachkommen vererben, wodurch das Gefüge innerhalb der Stammesreihe mehr und mehr an Festigkeit gewinnt, während selbstverständlich die Formen der Gemmarien fort und fort an Bestimmtheit zunehmen müssen. Den unbestimmten Formen einer Amöbe oder eines Süsswasserschwammes müssen auch Gemmarien mit leicht wechselnder Form entsprechen. Bei diesen Gemmarien sind die einzelnen Gemmen noch leicht gegeneinander verschiebbar; deshalb wird die Körperform dieser Tiere, wie es ja namentlich die Schwänmme in ausgezeichneter Weise zeigen, durch äussere Einflüsse leicht verändert. Bei den Hydroidpolypen ist das schon weniger leicht möglich, weil hier die Gestalt der Gemmarien an Bestimmtheit gewonnen hat. Sie wird Hand in Hand mit der zumehmenden Gefügefestigung eine immer charakteristischere.

Es lässt sich nun, wie ich glaube, unschwer zeigen, dass wechselförmige Gemmarien, wie sie bei den Amöben und Schleimpilzen volkommen mögen, zunächst übergehen mussten in solche, die eine etwas bestimmtere Grundform als die der genannten bedingten, etwa eine solche, wie wir sie bei manchen Flagellaten und Hydroidpolypen finden. Die Genmarien, welche die Grundform dieser Tiere bedingen, dürften etwa die Form eines Stabes haben, an welchem die beiden Enden und ebenso die rechte und linke Seite einander gleich sind, während die obere von der unteren abweicht. Ein solcher Stab bietet an seinen Enden einer-, seinen beiden gleichen Seiten anderseits gleich günstige Angriffs- 
punkte für schädigende äussere Einflüsse. Wird dagegen die rechte ron der linken Seite verschieden, so geht die Form des Stabes dadurch in die eines zweiseitig-symmetrischen Gebildes über. Die beiden Enden dieser Gemmarienform bieten noch gleich günstige Angriffspunkte für Störungen von aussen, dagegen werden sich die obere von der unteren Seite und die rordere von der hinteren durch den Grad ihrer Widerstandsfähigkeit gegen schädigende äussere Einflüsse unterscheiden. Ein solcher Gemmarienstab bietet also nur noch vier günstigste Angriffspunkte, nämlich an jedem der beiden Enden einen, an den beiden Längsseiten, die sich ja in Bezug auf die Widerstandskraft gegen äussere Einflüsse unterscheiden müssen, zusammen einen und ebenso an der Ober- und Unterseite zusammen einen, während der vorher betrachtete Stab noch fünf günstigste Angriffspunkte bot, nämlich an den beiden Enden und an den beiden Längsseiten je zwei und an der oberen und unteren Seite zusammen einen. Bei einem runden Stabe, oder einem Stabe, dessen Querschnitt ein regelmässig vielseitiger ist, ist die Zahl der Angriffspunkte natürlich bedeutend grösser. Noch zahlreicher müssen die Angriffspunkte sein bei locker gefügten Gebilden, wie es die Gemmarien der Amöben sein mögen. Dagegen bietet ein Gemmarienstab, der eine ron der zweiseitigen Symmetrie abweichende Grundform bedingen würde, nur noch drei günstigste Angriffspunkte für schädigende äussere Einflüsse, nämlich an den beiden Längsseiten zusammen einen, an Ober- und Unterseite zusammen einen und an den beiden Enden zusammen einen.

Aus alleden geht hervor, dass nach und nach aus lockeren Gemmarien solche gezüichtet werden mïssen, die der Reihe nach einen runden oder polygonalen, einen zweischneidigen, einen zweiseitig-symmetrischen und einen unsymmetrischen Querschnitt haben. Die Gemmarien mit unregelmässigem Querschnitt unterscheiden sich dann weiterhin dadurch, dass ihre Enden einander symmetrisch gleich oder unsymmetrisch sein köunen. Solchen Genmmarienstäben entspricht aber notwendigerweise die Grundform des entwickelten Tieres, denn die genannten Gemmarienformen bedingen der Reihe nach wechselförmige Tiere, wie die Amöben, eiförmige, wie manche Radiolarien, Flagellaten und Hýdroidpolypen, zweischneidige, wie manche Medusen, zweiseitig-symmetrische, wie eine grosse Anzahl von Darmtieren, und unsymmetrische, wie es die Schnecken und Plattfische sind. Diese Grundformen sind also durch die konstitutionelle Individualselektion herangezüchtet worden, und daraus erklärt 
sich, weshalb der Schein einer nach einer bestimmten Richtung zielenden Entwickelungsbewegung zu stande kommen muss.

Von einer "Zielstrebigkeit", einer Vervollkommnung aus ,inneren" Ursachen kann für den Naturforscher selbstrerständlich nicht die Rede sein; dagegen verstehen wir ohne weiteres, dass festes Gefüge Bestand hat, während lockeres dem Untergange geweiht ist, sei es, dass es sich dabei um Tiere, um Pflanzen, un Kristalle oder um irgend welche andere unorganische Gebilde handle, sei es, dass wir es mit Naturobjekten oder mit Erzeugnissen der menschlichen Kunstfertigkeit zu thun haben, sei es, dass es sich um Gleichgewichtszustände auf der Erde oder am Sternenhimmel handelt. Je stabiler ein Gleichgewichtssystem ist, desto längeren Bestand hat es.

Da nun, wie wir gezeigt haben, der Festigkeit der Gemmarien bestimmte Formenverhältnisse zu Grunde liegen, da sich diese nach der Seite der abnehmenden Symmetrie hinbewegen, so muste die Entwickelung der Grundformen im Tierreich so ror sich gehen, wie sie es thatsächlich gethan hat. Wo allerdings störende Einflüsse der Gefügefestigung durch konstitutionelle Zuchtwahl entgegenarbeiteten, wo die Grundformen vorwiegend durch äussere Einflüsse bedingt waren, wie bei den Schwämmen, wurde der konstitutionelle Selektionsprozess rerlangsamt. Er konnte gelegentlich auch wohl aufgehoben werden. Beides konnte namentlich bei festsitzenden Tieren geschehen, wie es die Korallen und viele Echinodermen sind. Gleichwohl finden wir auch bei den Korallen Formen, die wenigstens in Bezug auf ihre inneren Organe nur zwei, häufig auch nur eine Symmetrieebene haben. Dagegen geht aus der vergleichenden Ontogenie und der Paläontologie der Echinodermen hervor, dass bei ihnen die ursprüngliche zweiseitige Symmetrie nach und nach einer fünfstrahligen Grundform gewichen ist, weil diese Tiere ein festsitzendes Leben führten und deshalb von allen Seiten mit der Aussenwelt in gleiche Berührung kamen. Es hat also hier die direkte Anpassung an die Aussenwelt die Wirkung der Gefügezuchtwahl aufgehoben, und wemn auch beispielsweise die Seesterne wieder zur kriechenden Lebensweise übergegangen sind, so war die Ausbildung der Arme ihrer festsitzenden Vorfahren doch schon so weit gediehen, und die Arme waren sich schon so gleich geworden, dass die Seesterne in der Richtung jedes beliebigen Armes weiterkriechen konnten, wodurch bald dieser, bald jener Arm in Anspruch genommen wurde, was eine gleichmässige Einwirkung der Aussenwelt auf alle Arme bedingte. Deshalb sind die Seesterne nicht 
wieder zur zweiseitigen Grundform zurïckgekehrt. Dagegen ist das der Fall gewesen bei den Seeigeln und bei den Seegurken; bei beiden ist der Körper nicht wie bei den Seesternen in Arme aufgelöst, und sobald die Vorfahren dieser Tiere ihre festsitzende Lebensweise wieder aufgegeben hatten, konnte die Gefügezuchtwahl wieder zur Geltung kommen, die den Körper wieder etwas zweiseitig-symmetrisch machte. Nachdem das geschehen war, konnten sich die betreffenden Tiere nur noch nach einer Richtung hin leicht bewegen, und dadurch musste die Anpassung an die Umgebung, die nunmehr nicht mehr nach allen Seiten hin die gleiche war, mit der Gefügefestigung durch konstitutionelle Zuchtwahl Hand in Hand arbeiten, so dass dadurch eine stets zumehmende bilaterale Symmetrie gewährleistet war.

Ich glaube, dass durch die obigen Auseinandersetzungen die Leistungsfähigkeit der Gemmarienlehre als erklärendes Prinzip in ein helles Licht gesetzt worden ist, und dass sie unsere Berechtigung darthun, unsere Theorie wenigstens als den Versuch einer allgemeinen Entwickelungsmechanik der Organismen zu bezeichnen.

\section{e. Die Entstehung der Organe.}

Wir haben im rorigen Abschnitte das Problem der Formentstehung ohne Rücksicht auf die rerschiedenen Qualitäten der einzelnen Zellen, die sowohl bei der Keimes - wie bei der Stammesgeschichte der Organismen entstehen, behandelt. Eine epigenetische Vererbungstheorie muss aber notwendigerweise auch diese erklären, wenn sie nicht den Vorwurf auf sich laden will, dass sie gerade das unerklärt lässt, was in erster Linie ron ihr gefordert werden müsse. Wir glauben aber zeigen zu können, dass auch die Entstehung qualitativ verschiedener Zellen durch eine epigenetische Theorie erklärt werden kann, dass also eine Präformationstheorie von vornherein überlaupt keine Berechtigung hat.

Es empfiehlt sich, die Entstehung der Organe zunächst an der Hand ihrer mutmasslichen Stammesgeschichte zu betrachten, um darauf die Vererbung durch den Gebrauch veründerter Organe zu veranschaulichen und die keimesgeschichtliche Sonderung der Organe ins Auge zu fassen. Wir müssen uns bei alledem auf die Tiere beschränken, zumal diese ja eine riel weitergehende Sonderung der Organe besitzen, als die Pflanzen. 
Es kann keinem Zweifel unterliegen, dass sich die vielzelligen Tiere nicht aus solchen Urtieren entwickelt haben, die gleich den Radiolarien and Infusorien aus einer hochentwickelten Zelle bestehen, sondern aus Urtieren, die gleich den Amöben noch auf einer sehr tiefen Entwickelungsstufe stehen. Die Amöben haben einen formenwechselnden Körper, und der erste Schritt zur Entstehung vielzelliger Tiere war vielleicht der, dass dieser Körper eine mehr oder minder beständige kugelförmige Grundform annahm, wie sie den Sonnentieren bereits zukommt. Aus einem derartigen, ans einer einzigen kugelförmigen Zelle bestehenden Tiere konnten sich dann mehrzellige dadurch entwickeln, dass die durch die Teilung des einzelligen Urtieres entstehenden Zelłen im Zusammenhang miteinander blieben. Das letztere wird begreiflich durch die Überlegung, dass die Gefügezuchtwahł Tiere schaffen musste, deren plasmatischer Bau schon dermassen gefestigt war, dass die einzelnen Zellen, die aus der Teilung der Zelle hervorgingen und im Zusammenhang miteinander blieben, sich so stark anzogen, dass sie sich nicht mehr roneinander trennen konnten. Aus einzelligen Tieren werden zunächst zweizellige und aus diesen solche vierzellige entstanden sein, bei welchen die vier Zellen in einer Ebene nebeneinander lagen. Dadurch, dass sich auch diese vier Zellen teilten, entstanden achtzellige Tiere, deren acht Zellen den Ecken eines Würfels entsprachen. Gingen nun aus solchen achtzelligen Tieren 16-, 32-, 64zellige herror, so konnten die einzelnen Zellen dieser mehrzellig gewordenen Tiere nicht mehr einen soliden Haufen bilden, sondern mussten, da jede von ihnen nur mit den benachbarten in Verbindung bleiben konnte, eine einschichtige Zellenblase formen.

Die einzelnen Zellen dieser Hohlkugel werden so lange im Zusammenhange geblieben sein, wie es die konstitutionelle Gefïgefestigkeit dieses auf der Grenze zwischen $\mathrm{Lr}$ - und Darmtieren stehenden Tieres zuliess, d. h. so lange die schädigenden äusseren Einflüsse, welche das Tier während seines Lebens erlitt, noch nicht lockernd auf den Zellenverband dieser Hohlkugel eingewirkt hatte. War aber der Punkt erreicht, wo die Gefügefestigkeit des Tieres den äusseren Einflüssen nicht mehr widerstand, so konnte es in die einzelnen Zellen zerfallen. Diese konnten sich durch die Verbindung mit den Zellen eines anderen Tieres wieder auf eine Weise, die wir später kennen lemen werden, festigen, und aus zwei kopulierten und zu einer einzigen verschmolzenen Zelle konnte sich das Tier wieder entwickeln.

Wir wollen uns nun rorstellen, dass die kugelförmige Eizelle eines 
solelıen Hohlkugeltieres allmählich infolge ron konstitutioneller Zuchtwahl überging in eine ovale, dass also die Gemmarien eine derartige Gestalt annahmen, dass die Plasmastrahlen nicht mehr gleichmässig um den Mittelpunkt der Zelle verteilt waren, sondern dass sie an einem nunmeln hervortretenden Pole dichter standen, als an dem gegenüberliegenden. An dem letzteren sammelte sich infolgedessen Nahrungsdotter an, d. h. hier ging die Assimilation der Nahrung zu Plasma nicht so schnell von statten wie an dem gegenüberliegenden Pole, wo die Gemmarienstrahlen dichter standen und das Plasma in innigere Berührung mit den Nährsubstanzen kam. Teilte sich eine solche Zelle in zwei miteinander in Zusammenhang bleibende Zellen, so konnte die Teilungsebene entweder durch die Hauptachse der eiförmigen Zelle gehen, oder sie konnte quer zu dieser Hauptachse erfolgen. Im ersteren Falle entstanden zwei gleiche und mit ihren Polen gleich orientierte Zellen, im letzteren eine kleinere Zelle mit mehr Plasma und eine grössere mit mehr Nahrungsdotter.

Wir wollen den ersten Fall, wo zwei gleiche Furchungszellen entstanden, weiter verfolgen. Hier lionnten durch die zweite Zellteilung ein Paar kleinerer Zellen mit viel Plasma und ein Paar grösserer mit viel Nahrungsdotter roneinander getrennt werden. Wir nehmen aber an, dass die zweite Zellteilung derartig erfolgte, dass aus ihr vier gleiche und gleich orientierte Zellen hervorgingen, vier Zellen mit je einem plasmareichen und je einem nahrungsdotterreichen Pole. Die dritte Zellteilung lonnte damn diese vier Zellen sondern in vier kleinere plasmareiche und vier grössere nahrungsdotterreiche. Durch fortgesetzte Zellteilungen musste aus diesen acht Zellen eine Hohlkugel entstehen mit einer Sonderung der sie zusammensetzenden Zellen in zwei Gruppen, nämlich in eine, die aus kleinen plasmareichen, und eine andere, die aus grossen nahrungsdotterreichen Zellen bestand.

Eine ähnliche Hohlkugel musste entstehen, wenn die erste Zellteilung schon eine kleine plasmareiche von einer grossen nahrungsdotterreichen Zelle geschieden hatte, denn auch in diesem Falle musste das Endergebnis dasselbe sein.

Etwas ähnliches musste auch herauskommen, wenn die Sonderung des dotterreichen 'Teiles der Zelle ron dem plasmareichen erst sehr spät erfolgte, wenn zunächst eine grosse Anzahl ron Zellteilungen stattfand, aus welchen immer gleiche Zellen herrorgingen. Man hätte sich freilich vorstellen kömmen, dass die Zellen sich, solange die dotterreichen 
Zellen nicht von den plasmareichen geschieden wurden, in einer Ebene ausbreiten mussten. Allein die vier ersten Furchungszellen der Eizelle blieben in körperlichem Zusammenhange miteinander. Die folgenden Zellteilungen konnten aus diesem Grunde nicht mehr parallel zu einer der beiden ersten erfolgen, sondern mussten die beiden ersten Teilungsebenen unter einem Winkel schneiden, wie unsere Fig. $16 \mathrm{c}$ es reranschaulicht. Es ist leicht zu begreifen, dass durch fortgesetzte Zellteilungen, die immer gleiche Teilungsprodukte lieferten, eine Kugel ent-

Fig. 16 .
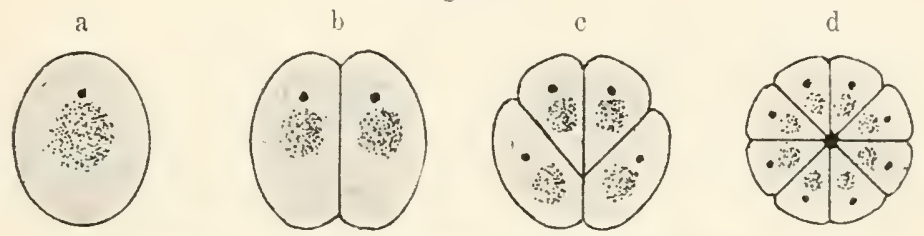

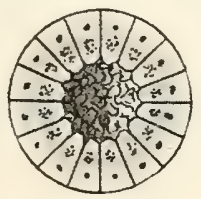

e

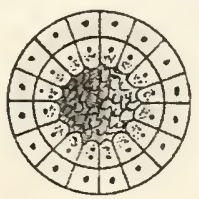

$\mathrm{f}$

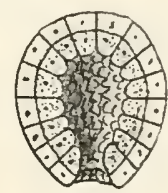

g

Schematische Darstellung der Entstehung einer Gastrula delaminata.

a Eizelle. b Zweizellenstadium. c Achtzellenstadium (nur vier Zellen sind sichtbar),

d Vielzellenstadium. e Einschichtiges Hohlkugelstadium. f Zweischichtiges Hohlkugelstadium. g Fertige Gastrula. Die punktierten Stellen bezeichnen den Nahrungsdotter.

stehen musste, wie sie in unserer Fig. $16 \mathrm{~d}$ im Durchschnitt dargestellt ist. In dem Innern dieser Kugel konnte sich Flüssigkeit ansammeln, wodurch eine Hohlkugel entstand. Erfolgte endlich gleichzeitig eine Teilung sämtlicher Zellen dieser Hohlkugel, welche den plasmareichen von dem dotterreichen Teile der Zelle trennte, so entstand eine zweischichtige Hohlkugel, die sich an dem einen Pole, wo, wie Fig. 16c zeigt, die Zellen ursprünglich auseinanderklafften, wieder öffnete. Auf diese Weise können wir uns die Entstehung eines Urdarmtieres, einer „Gasträa“, anschaulich vor Augen führen.

Dem geschilderten Vorgange entsprechen noch heute die Kieimesgeschichten mancher Tiere, die durch eine sogenannte Gastrula delaminata, durch eine durch $\mathrm{Abblätterung} \mathrm{entstandene} \mathrm{Darmlarve} \mathrm{charakterisiert}$ sind. Eine Gastrula entsteht aber nicht bloss durch Abblätterung, sondern auch durch Einstülpung, und zwar rollzieht sich diese an einer Hohlkugel, wie wir sie vorhin beschrieben haben. 
Bei dieser bildeten sich zwei verschiedene Gruppen ron Zellen aus, aber die Scheidung der kleinen plasmareichen und der grossen dotterreichen Zellen konnte nicht zur Entstelıung ron Zellen führen, die entweder ausschliesslich aus Plasma oder a usschliesslich aus Nallrungsdotter bestanden. Vielmehr mussten auch die plasmareichen Zellen noch etwas Nahrungsdotter und die dotterreichen noch etwas Plasma erhalten. Dieses Plasma musste aber nach einer und derselben Richtung hin orientiert sein, wie es aus unseren schematischen Bildern in Fig. 17

Fig. 17.

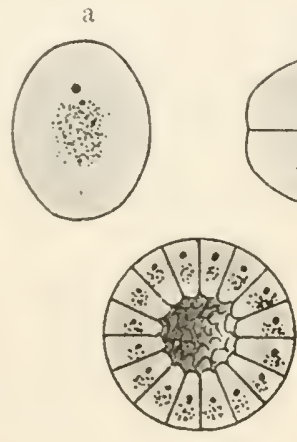

e b

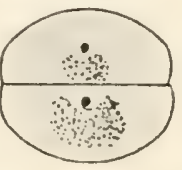

c

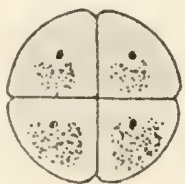

a

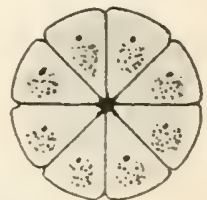

Entstehung der Gastrula durch Einstiilpung.

a Eizelle. b Zweizellenstadium. c Acbtzellenstadium (nur vier Zellen sind sichtbar). d Vielzellenstadium. e Hohlkugelstadium. f Einstülpungsstadium. g Fertige Gastrula.

hervorgeht. Wo der (punktierte) Dotter angelı̈̈uft war, war die Zelle nachgiebiger, wähırend sie an dem plasmareichen Pole widerstandsfähiger war. Da nun, wie unsere Abbildung zeigt, das Plasma an dem einen Pole der aus der Einfurchung hervorgegangenen Hohlkugel nalıe an der Peripherie liegt, während es am anderen Pole dem inneren Hohlraum zugewendet ist, so müssen sich diese beiden Pole auch rerschieden verhalten. Der Pol der plasmareichen Zellen, den man gewöhnlich den animalen nennt, muss an der Peripherie der Hohlkugel stärker waclısen, während der Pol der dotterreichen Zellen sich an der inneren Begrenzungsfläche des Binnenraumes stärker ansdelinen muss, als an der entgegengesetzten Seite der betreffenden Zellschicht; denn sowohl in den dotterreichen, wie in den dotterarmen Zellen wird der Dotter allmählich assimiliert, zu Plasma verarbeitet. Da nun die Assimilation so erfolgen muss, dass der um den organischen Mittelpunkt jeder Zelle gelegene plasmareiche Teil am stärksten wäclıst, denn un das Centrosoma herum ist ja das 
Plasma am dichtesten angehäuft, so muss sich der Pol der dotterreichen Zellen mit dem Verschwinden des Dotters durch Assimilation allmählich abflachen, weil die einzelnen Zellen hier die Unterschiede ihrer äusseren und ihrer inneren Pole mehr und mehr ausgleichen.

Ähnliche Vorgänge müssen auch bei den Zellen des plasmareichen Poles stattfinden; aber hier ist die Veränderung der beiden Pole der einzelnen Zellen von einem entgegengesetzten Effekt begleitet, weil diese Zellen an der Peripherie sehr viel Plasma haben. Eine Abflachung kann also nur an Pole der ursprünglich dotterreichen Zellen stattfinden und muss endlich, da die einzelnen Zellen in ihrem plasmareichen Teile durch Assimilation des Nahrungsdotters wachsen, während sie im ursprünglich dotterreichen an Masse abnehmen, in eine Einstülpung übergehen. Wir hätten somit die Entstehung des Urdarmtieres und der Gastrula auch in diesem Falle mechanisch aus unserer Gemmarienlehre erklärt.

Diese Erklärung habe ich ohne Rücksichtnahme auf irgend welche speziellen Fälle versucht, weil erst ein Fundament zu gewinnen war für die phylogenetische Entstehung der Gasträa und die ontogenetische Ausbildung der Gastrula. Die letztere kann ja auf anscheinend sehr verschiedene Weise gebildet werden. Ich glaube aber, dass ihre Entstehung sich in allen Fällen aus ähnlichen mechanischen Gesichtspunkten heraus begreifen lässt, wie wir sie bei der vorhergehenden Schilderung angenommen haben, und ich hoffe demnächst an einem anderen Orte darthun zu können, dass sich in der That alle Formen der Gastrula auf eine der beiden ursprünglich möglichen Entstehungsarten zurückführen und dadurch mechanisch erklären lassen. Hier möchte ich noch darauf hinweisen, dass die durch Einstiilpung entstandene Darmlarve, die „Gastrula invaginata", nicht von der durch Abblätterung entstandenen, der "Gastrula delaminata", verschieden ist, denn es geht aus unserer Schilderung klar hervor, dass der Urdarm der Gastrula, sei es, dass sie durch Einstülpung, sei es, dass sie durch Abblätterung entsteht, in beiden Fällen derselbe ist.

Man darf den Hohlraum, der bei der durch Einstülpung entstehenden Gastrula durch Auseinanderweichen der Zellen und durch Bildung einer dadurch hervorgebrachten Hohlkugel entstanden ist, nicht vergleichen mit dem Hohlraum, der bei einer durch Abblätterung entstehenden Gastrula schon vor der Teilung der aus der Eifurchung hervorgegangenen Zellen in eine plasmareiche und eine dotterreiche Zelle besteht. Die Urdarmhöhle der einen Gastrula so gut wie die der anderen liegt von 
vornherein an der Aussenseite der dotterreichen Zellen und behält ihre Lage in beiden Larvenformen bei, nur dass sie bei der durch $A b$ blätterung entstehenden Gastrula ron romherein konkar, bei der durch Einstülpung entstehenden aber zunächst kon rex war. Es ist also falsch, wenn man, wie es noch jüngst Ken nel in seinem "Lehrbuch der Zoologie* gethan hat, sagt, dass man den Urdarm der durch Einstülpung entstandenen Gastrula nicht mit dem ron einer durch Abblätterung entstandenen Gastrula umschlossenen Hohlraum vergleichen könne, dass der Hohlraum im letzteren Falle eine Furchungshöhle sei, während diese bei der durch Einstülpung entstandenen Gastrula rerschwunden wäre. Die Sache liegt vielmehr so, dass bei der durch Einstïlpung entstandenen Gastrula zunächst eine Furchungshöhle gebildet wird, während dieses bei der durch Abblätterung entstandenen erst sehr spät geschieht. Eine Furchungshöhle kommt dadurch zu stande, dass Zellen, die an einem Pole plasma - und am anderen dotterreich sind, sich früher oder später in plasmareiche und dotterreiche Zellen teilen. Bei der durch Einstïlpung entstehenden Gastrula kann sich die Trennungsebene sehr bald zu einer Furchungshöhle umbilden, während das bei der durch Abblätterung entstehenden Gastrula zunächst nicht möglich ist. Später freilich trennen sich auch bei dieser die Zellen, welche den Körper nach aussen, und die, welche den Urdarm begrenzen. Es entsteht also bei der Gastrula delaminata die „Furchungshöhle“, die hier nur eine trennende Grenze benachbarter Zellen darstellt, erst nachdem die Gastrula schon fertig ist, während sie bei der durch Einstülpung entstandenen schon lange ror der Einstülpung da war. In beiden Fällen ist diese „Furchungshöhle“ aber homolog.

Es besteht also kein wesentlicher Unterschied zwischen einer Gastrula invaginata und einer Gastrula delaminata. Der einzige Unterschied ist der, dass bei der letzteren die Bildung der nur durch eine Zellgrenze angedeuteten Furchungshöhle auf ein spätes Stadium verschoben worden ist. Die Trennung der Zellen des äusseren und des imneren "Kieimblattes" erfolgt bei der durch Abblätterung entstandenen Gastrula sehr spät, während sie bei der durch Einstülpung entstandenen sehr früh stattfindet.

Wir sind auf diese Verhältnisse etwas näher eingegangen, weil sie uns lehren, dass wir uns die Entstehung des Urdarmtieres auf beide Arten gleich gut erklären können; dass in der That beide Wege nicht nur zu demselben Ziele führen, sonderu auch ron demselben Punkte 
ansgehen, und dass die mechanischen Ursachen in dem einen wie in dem anderen Falle dieselben sind. Diese mechanischen Ursachen sind zu suchen in dem Übergange der kugelförmigen Eizelle eines aus lauter gleichen Zellen zusammengesetzten hohlkugelförmigen Tieres in eine eiförmige, deren Entstehungsursache die Gefügefestigung durch konstitutionelle Zuchtwahl ist. Aus den dargelegten mechanischen Entwickelungsvorgängen, welche die Entstehung der Gasträa beziehungsweise der Gastrula bewirkt haben, geht aber ausserdem hervor, dass sich auch andere Einfaltungsvorgänge aus der Form der Eizelle und ihrer Gemmarien mechanisch begreifen lassen werden. Wir werden sie wenigstens im Prinzip verstehen können und haben damit eine Direktive für den weiteren Ausbau der Entwickelungsmechanik gewonnen.

Bekanntlich ist es His gewesen, der mit Erfolg die Keimesgeschichte der Tiere auf Einfaltungs - und Verwachsungsprozesse zurückgeführt hat, und wenn auch manches von ihm Geäusserte keinen Bestand gehabt hat, so haben doch die neueren Untersuchungen über die Entwickelungsgeschichte der Tiere gezeigt, dass Einfaltungsvorgänge und Verwachsungsprozesse die Hauptrolle bei der Entwickelung der Tiere gespielt haben. Nur muss man sie, wie wir es gethan haben, auf die Form der Eizelle oder vielmehr auf die der die letztere zusammensetzenden Gemmarien, von deren Form ja die der Eizelle abhängt, zurückführen. Wer unbefangen die Thatsachen, die durch die ontogenetischen Untersuchungen zu Tage gefördert worden sind, überblickt, wird sich der Überzeugung nicht verschliessen können, dass die Erklärung dieser Vorgänge mechanisch zu begründen sein muss und vielleicht über kurz oder-lang mechanisch begründet werden wird.

Die Entwickelungsgeschichte des Lanzettfischchens, das eigentlich nichts weiter ist, als eine zusammenhängende, vielfach eingefaltete Zellschicht, berechtigt zu der Anschauung, dass alle Tiere hervorgegangen sind aus Hohlkugeln, deren Zellwände sich eingefaltet haben. Daneben kommen allerdings eine Reihe anderer Entwickelungsprozesse, wie die, welche durch die Auswanderung von Zellen dargestellt werden, in Betracht. Allein auch alle diese sind im Prinzip nicht schwer zu begreifen. Vorderhand freilich ist es unmöglich, im einzelnen den weiteren Entwickelungsvorgängen nachzugehen, welche jene Hohlkugel und die aus ihr entstandene Gasträa in der Umbildung zu den verschiedenen Stämmen der Darmtiere durchlaufen hat. Es wird aber wahrscheinlich in nicht allzu ferner Zukunft möglich sein, auch über diese Vorgänge Licht zu 
rerbreiten durch das Studium der Keimesgeschichte, das auf die uns hier beschäftigende Frage ein besonderes Augenmerk zu richten haben wirl. Dass erneute Bestrebungen ron Erfolg gekrönt sein müissen, mag noch an dem Beispiel der Entstehung einer zweiseitig-șrmmetrischen Tierform aus einer eiförmigen dargethan werden.

Wir haben die Entstehung der Gastrula inraginata dadurch zu erkiären rersucht, dass wir annahmen, die Eizelle eines einer vollkommenen Hollkugel gleichenden Tieres wäre infolge von Gefügefestigung durch konstitutionelle Indiridualselektion in eine eiförmige übergefülnrt worden, und zwar dadurch, dass sich an den Gemmarien dieser Eizelle Teränderungen vollzogen, die notwendigerweise ihre kugelförmige Form in eine eiförnige ïberführen mussten. Nehmen wir nun an, dass weitere Gemmenreilıen den Gemmarien einer eiförmigen Eizelle angefügt werden. wodurch die Grundform der Fizelle in eine zweiseitig-symmetrische übergeführt wird, so kann die Einstülpung der Gastrula nicht melı in der Richtung der Hauptachse erfolgen, d. ls. die Einstülpungsachse kann nicht mehr zusammenfallen mit der Hauptachse der ehemaligen Eizelle, sondern die Einstïlpungsachse wird zwar noch in dieselbe Ebene fallen, wie die Hauptaclsse der bilateral-symmetrisch gewordenen Eizelle, aber einen Winkel mit ihr bilden, so dass dadurch die Gastrula eine zweiseitigsymmetrische wird. Unsere Fig. 1S-23 zeigen bei genauem Studium, dass dieses niclıt anders sein kann. Sie thun dar, dass die Lage des Nahrungsdotters, der in keiner bilateral-symmetrischen Eizelle fehlt, wenn er auch oft nicht nachgewiesen werden kann, die Modifikation der Einstiilpung bedingt. Wir haben geselen, dass bei der Bildung der Gastrula durch Einstülpung die letztere dort erfolgt, wo der Nahrungsdotter, der in unseren Figuren punktiert ist, zunächst der Peripherie des Keimes liegt. Aus einer zweiseitig-symmetrischen Eizelle, wie sie in Fig. 18 im Aufriss (a), im Grundriss (b) und in der Seitenansicht (c) dargestellt ist, muss auf den Wege, wie ihn die Fig. 19-21 zeigen, durch fortgesetzte Zellteilungen ein blasenförmiger Keim hervorgehen, wie er in Fig. 22 in einem den Keim in zwei symmetrische Hälften teilenden Durchschnitt dargestellt ist. 1)ie Lage des Nahrungsdotters in den Zellen dieses Keimes bewirkt die zu einer bilateral-symmetrischen Gastrula führende Einstülpung (Fig. 23). Zweiseitig-symmetrische Darmlarven finden wir bei vielen Tieren, beispielsweise beim Frosclı; aber die Verfolgung der weiteren Entwickelungsrorgänge an solchen zweiseitig-symmetrischen Keinformen und ihre mechanische Begriundung stösst 
auf Schwierigkeiten, deren Beseitigung eingehenden Untersuchungen überlassen werden muss. Indessen glauben wir zur Gen̈̈ge dargethan zu haben, dass es die Form der Gemmarien ist, von welcher alle morphologischen Veränderungen im Tierkörper bedingt werden.

Fig. 18 .
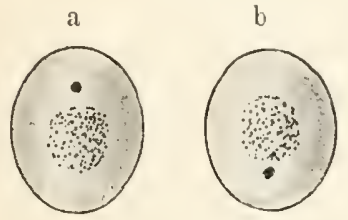

Fig. 19
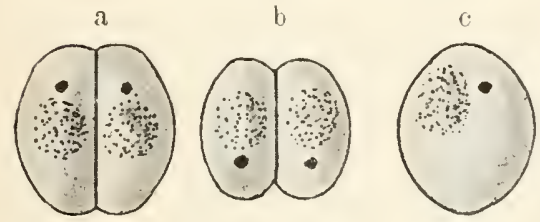

Fig. 20 .

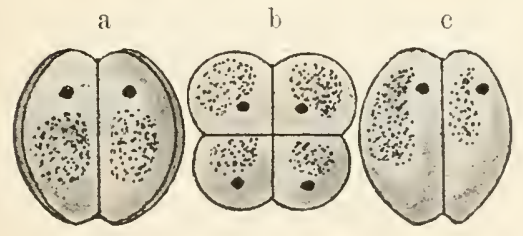

Fig. 21.

a
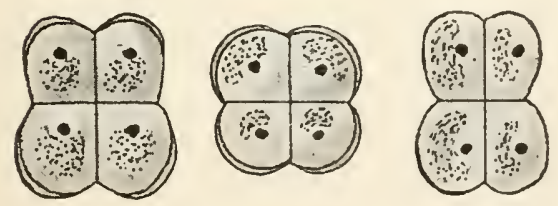

Fig. 22.

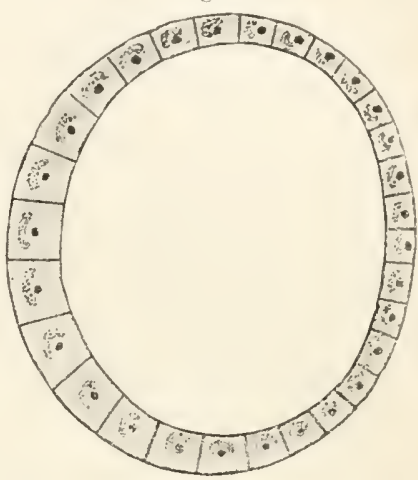

Fig. 23,

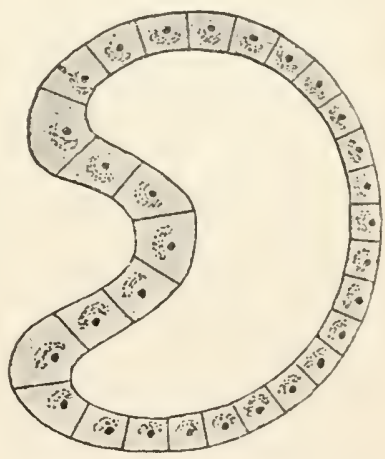

Schematische Darstellung der Entstehung einer zweiseitig-symmetrischen Gastrula.

Durch diese morphologischen Veränderungen sind Gebilde entstanden, die sich infolge eigener Thätigkeit und direkter Anpassung zu den Organen des Körpers umbilden konnten, und die stammesgeschichtliche Entstehung der Organe ist keineswegs schwierig zu begreifen, wenn wir bedenken, dass durch die infolge von Gefügefestigung eingetretenen und von Verwachsungsvorgängen begleiteten Einfaltungsprozesse die Lage der einzelnen Zellen des Körpers gegenüber den anderen und in Beziehung zur Aussenwelt eine sehr verschiedene wurde. Bei der aus einer Zellen- 
schicht bestelıenden blasenförmigen Urform, aus welcher die Darmtiere wahrscheinlich hervorgegangen sind und welcher eine regelmässige kugelförmige Grundform zukam, verhielt sich jede Zelle sowohl der Aussenwelt als auch den übrigen Zellen gegenüber in derselben Weise. Deshalb war es unmöglich, dass sich bei einem derartigen Tiere aus verschiedenartigen Zellen bestehende Organe herausbilden konnten, denn die Zellen eines solchen Hohlkugeltieres kamen fortwährend mit der Umgebung in gleiche Berührung und konnten sich deshalb gar nicht rerschiedenartig ausbilden; wenn auch jede einzelne sich verändert haben mag, so waren liese Veränderungen doch nur solche, wie sie auch in allen ïbrigen Zellen der einschichtigen Blase rorkamen. Aber schon durch die Einstïlpung dieser Blase zu einem zweischichtigen eiförmigen Tiere wurden lie beiden Zellenschichten, die dadurch entstanden, in sehr verschiedenartige Berührung mit der Umgebung gebracht. Die Zellen des äusseren Kieimblattes, wie wir die nach aussen liegende Zellenschicht jetzt nennen können, kamen mit der Aussenwelt in völlig anderer Weise in Berïhrung, als die des inneren Keimblattes. Während bei dem rollkommen kugelförmigen Blasentiere alle Zellen sowohl an der Nahrungsaufnahme wie an dem Scluutze des Tieres beteiligt waren, konnte sich bei der Gastrïa eine Arbeitsteilung vollziehen; die Zellen des äusseren Keimblattes kamen häufig mit der Umgebung in unsanfte Berührung, und sie allein konnten Organe bilden, die zur Fortbewegung des ganzen Körpers und zu seinem Schutze gegen iussere Unbilden dienen konnten. Die Zellen des inneren Keimblattes dagegen, die mit der Aussenwelt weniger häufig in Berïhrung kamen, kounten weicher bleiben und wurden infolgedessen geeigneter, Nahrung aufzunehmen und zu rerarbeiten. Sie passten sich dabei direkt der Nahrungsaufnahme an, während die Zellen des äusseren Keimblattes sich der Fortbewegung und dem Schutze des Körpers anpassten.

Die Vorgänge, die hierbei im Innern der Zellen stattfanden, sind noch in völliges Dunkel gehüllt; es wird sich aber vielleicht Licht darüber verbreiten lassen, wenn man die während des Lebens stattfindenden Anpassungen mikroskopisch auf die Umänderungen, welche die einzelnen Zellen dabei erleiden, untersucht. Genug, dass wir erkannt haben, dass die verschiedene Lage der Zellen in Körper zu verschiedener Ausbildung der letzteren führen musste.

Nachdem die Gasträa zweiseitig geworden war, bewegte sie sich vorwiegend nur noch nach einer Richtung hin, und dadurch waren 
weitere Anlässe zur Bildung von Organen gegeben. Dasjenige Körperende, welches sich nach rom bewegte, kam in anderer Weise mit der Umgebung in Berührung als das hintere. Die Oberseite erlitt andere Einflüsse als die Unterseite. Nerröse Organe werden sich infolgedessen an solchen Stellen ausgebildet haben, die mit der Aussenwelt in besonders häufige Berührung gekommen sind, und deshalb finden wir das Gehirn oder den oberen Schlundknoten der Darmtiere in der Nähe seines rorderen Körperendes. Dadurch, dass vorwiegend gewisse Zellen von äusseren Reizen, die Empfindung erzeugten, getroffen wurden, dadurch, dass sich diese Reize wiederum ungleichmässig durch den Körper verteilten, nämlich vor allem auf diejenigen Zellen fortpflanzten, welche vermöge ihrer Lagerung im Körper besonders leicht zu reizleitenden Organen werden konnten, entstanden Sinnesorgane und die zu ihnen gehörigen Nerven aus besonderen Zellen und Zellenreihen der Oberfläche, beziehungsweise der inneren Teile des Körpers. Ähnlich musste es sich mit den Muskeln verhalten. Nicht alle Zellen in dem durch Einfaltung verwickelt gewordenen Bau des Körpers konnten sich in gleich guter Weise bewegen, sondern nur die, die vermöge ihrer Lage besonders dazu geeignet waren. Aus diesen haben sich Muskelzellen gebildet. Schutz- und Stützorgane entstanden dagegen an solchen Orten, wo die Zellen weder zur Ernährung des Körpers, noch zur Aufnahme und zur Leitung von Reizen, noch auch zur Ausführung von Bewegungen veranlasst wurden. In derartigen Zellen konnte sich feste organische oder anorganische Substanz ablagern und dadurch zur Bildung von inneren und äusseren Skeletten führen. Der Zusammenhang der einzelnen Zellen im Körper musste an verschiedenen Stellen ein sehr ungleich fester werden, so dass Körperstellen entstehen konnten, bei welchen leicht einzelne Zellen aus dem Verband der übrigen austreten konnten, und solche konnten dann zu Fortpflanzungszellen werden. Derartige Zellen werden sich ror allem an Körperstellen gebildet haben, die den Einflüssen der Aussenwelt mehr oder weniger entzogen waren und sich deshalb nicht zu Organen der Empfindung, der Bewegung oder des Schutzes umbilden konnten. Die Lage der Fortpflanzungsorgane, die so oft eine versteckte ist und nicht selten dazu dienen musste, ein Argument gegen die Vererbung erworbener Eigenschaften zu bilden, ist also nicht darauf zurückzuführen, dass natïrliche Zuchtwahl die Lage der Eierstöcke und Hoden den Unbilden der Aussenwelt, durch welche Vererbung erworbener Eigenschaften bewirkt worden sein könnte, entzogen hätte, sondern sie erklärt sich einfach da- 
durch, dass sich am ehesten an versteckten Kürperstellen, wo die Zellen nicht anderweitig in Anspruch genommen waren. Zellen aus dem gemeinsamen Terband loslösen und dadurch zu Keimzellen werden konnten.

Aus den obigen Betrachtungen geht hervor, dass die Zellen sich in sehr verschiedener Weise an die Aussenwelt und an ihre Nachbarn anpassen mussten, je nachdem sie diese oder jene Lage haiten; dadurch wurden sie sowohl morphologisch als auch chemisch verändert. Die morphologischen Teränderungen betreffen die Anordnung der Gemmarien, welche auf die Anordnung der cinzelnen Gemmen innerhalb der Gemmarien zurückwirken musste; die chemischen Teränderungen aber sind zu verstehen als solche, welche den chemischen Aufbau der Organe, die sich aus der Zelle entwickelten, betreffen. Wo Zellen ron Sinnesreizen getroffen wurden, sei es, dass diese in Druck, in akustischen, optischen, thermischen oder endlich auch in chemischen Einflüssen der Aussenwelt ihre Ursache hatten, musste der Chemismus ein anderer werden; dadurch wurden die Stoffwechselvorgänge in den betreffenden Zellen verändert, es bildeten sich hier solche Verbindungen, welche den betreffenden Sinnesreizen widerstanden. Wir haben ja den Stoffwechsel zurückgeführt auf den Zerfall von gesättigten Molekülen, d. h. von solchen, deren atomistische Zusammensetzung eine derartige geworden ist, dass sie leicht auf irgend welche äusseren Reize zerfallen müssen und dadurch zu weniger gesättigten, aber stabileren Molekülen werden. Es ist nun nicht schwer, sich vorzustellen, dass, um ein Beispiel zu nennen, intensive Lichteinwirkung einen andersartigen Zerfall der Moleküle bewirken musste, als etwa schwache Wärmereize. In dem einen Falle entstanden also andere chemische Terbindungen, andere Moleküle als in dem anderen. Auch diese Moleküle konnten sich zu Gebilden höherer Einheit, zu Gemmen der Nerven, der Muskeln usw. anordnen, und auch diese Gemmen konnten in ihrer Weise spezifische Gewebegemmarien bilden. Freilich sind dabei wohl niemals alle Gemmen des ursprünglichen Keimplasma's zu spezifischen Gemmen umgeändert worden, denn wir finden ja in fast allen 'Zellen Reste des ursprünglichen Plasma's, und es scheint, dass diese Reste es sind, die nicht nur manchen Zellen niederer Tiere die Entwickelung zu einem vollkommenen Tiere gestatten, sondern dass sie auch die Anordnung der Zellen in Körper regeln und erbliche Übertragung erworbener Eigenschaften bewirken.

Die stammesgeschichtliche Entstehung der Organe ist nach allem Vorhergehenden also keineswergs schwierig zu begreifen. Wir haben aber 
hier unter stammesgeschichtlicher Organbildung diejenige verstanden, welche durch äussere Einflüsse hervorgebracht, durch diese im einzelnen Tierkörper und seinen Zellen bewirkt wird, und haben uns nummehr mit der Frage zu beschäftigen, wie die vou den Individuen erworbenen Anpassungen auf die Keimzellen übertragen werden konnten. Ich glaube nicht, dass diese Übertragung schwer zu begreifen ist, wenn man bedenkt, dass alle Zellen des Körpers in direktem oder indirektem Verbande miteinander stehen. Abgesehen ron Wanderzellen giebt es wohl keine, die nicht in irgend einer plasmatischen Verbindung mit einer oder mehreren benachbarten Zellen ständen, und auch die Wanderzellen werden zeitweilig in eine solche Verbindung mit dem Körper treten, und dasselbe gilt von den Eizellen und den Samenmutterzellen. Haben doch viele Keimzellen geradezu Vorrichtungen, durch welche sie in Verbindung mit den Zellen des benachbarten Gerrebes gesetzt werden, wie wir es beispielsweise bei manchen Korallen finden, bei denen ein Zapfen ron Zellen in das Plasma der Eizelle eingreift. Bei anderen Eizellen, z. B. bei denen der Säugetiere, ist die Zellhaut von feinen Kanälen durchsetzt, und es ist wohl nicht zu bezweifeln, dass durch diese Kanäle hindurch plasmatische Terbindungen den Leib der Eizelle mit dem Plasma der umgebenden Zellen des Eierstocks in Verbindung setzen. Auf welche Weise es also verhindert werden soll, dass keine Beeinflussung der Keimzellen seitens der Körperzellen stattfindet, ist angesichts solcher Einrichtungen schlechterdings nicht zu begreifen. Die Zellen müssen ja doch ernährt werden und können ihre Nahrung doch nicht wohl anderswoher beziehen, als aus den sie umgebenden Zellen. Es ist also für jeden, der keine unzulänglichen Vererbungstheorien zu vertreten hat, von roruherein wahrscheinlich, dass sich erworbene Eigenschaften übertragen müssen. Dass dies nit Notwendigkeit geschehen muss, werden wir aber sofort einsehen, wenn wir uns auf den Boden unserer Gemmarienlehre stellen.

Wir haben gesehen, dass aus einer bestimmten Form der Gemmarien eine bestimmte Anordnung der Zellen im Körper resultieren muss. Sämtliche Zellen des Körpers stehen fortwährend miteinander im Gleichgewicht; wo das Gleichgewicht in einer einzigen Zelle gestört wird, muss auch eine Gleichgewichtsveränderung in sämtlichen übrigen Zellen eintreten. Das Gleichgewicht kann aber dauernd nur dadurch gestört werden, dass die Form der Genmarien sich ändert, d. h. dass ihre Gemmen sich gegeneinander verschieben, dass sich neue Gemmenreihen bilden und andere verschwinden, dass die einen Gemmenreihen kürzer, 
die anderen länger werden, dass also die Anordnung der Gemmen innerhalb der Gemmarien anders wird; denn wenn sie so bleibt, wie sie vordem war, so muss notwendigerweise das ursprüngliche Gleichgewicht und damit die ererbte Körperfor'm wieder hergestellt werden. Wird aber eine Zelle dauernd etwa durch äusseren Druck oder durch beständigen Lichtreiz beeinflusst, so muss sie sich in ihrem plasmatischen Gleichgewicht mit diesen äusseren Einflüssen abfinden; das kann sie aber nicht anders als dadurch, dass sie die Form ihrer Gemmarien ändert, denn es sind ja diese, in welchen die Anordnung der Gemmen durch die äusseren Einflüsse verändert wird. Diese Anordnung kann unmöglich dieselbe bleiben, wenn die Anordnung der Gemmarien, welche durch die gegenseitige Anziehung der letzteren und durch ihre Form bedingt wird, gewaltsam geändert wird. Dann kommen die Anziehungspole der Gemmarien in andere gegenseitige Berührung als rordem; die Kräfteverteilungen innerhalb der Gemmarien werden andere, und die Folge daron ist, dass alte Gemmarienreihen verschwinden und neue sich an anderen Stellen ansetzen.

Dass solches eintreten muss, kann man sich leicht an einigen schematischen Abbildungen klar machen. Gesetzt, die beiden Rhomben in Figur 24a seien zwei sich anziehende Gremmarien, deren Lage durch

Fig. 24 .

a
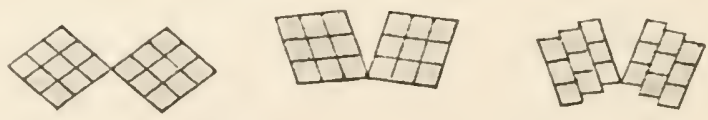

Schemata zur Erläuterung der Gemmarienumformung.

die ihnen vermöge der Anordnung ihrer Gemmen zukommenden Anziehungspole bestimmt wird; es soll dadurch die in unserer Figur angegebene gegenseitige Lagerung bewirkt werden. Diese Gemmarien sollen nun infolge äusseren Drucks gegeneinander dauernd verschoben werden, so dass ihre Anziehungspunkte zum Teil ausser Thätigkeit gesetzt, zum Teil in anderer Weise in Anspruch genommen werden, wie es in Figur 24b dargestellt ist. Dadurch werden die einzelnen Teile der Gemmarien in anderer Weise mit dem sie umgebenden und das ganze Plasma durchsetzenden ungeformten Nährstoff, den wir als Sarkode bezeichnet haben, in Berührung gebracht. Ihr Stoffwechsel wird ein anderer, manche ilnrer Gemmen, die frïher dem Stoffwechsel mehr ent- 
zogen waren, werden in diesen hineingebracht, sie zerfallen, und an anderer Stelle der Gemmarien können neue Gemmen ankristallisiren, so dass die Form der Gemmarien vielleicht die wird, die wir in Figur $24 \mathrm{c}$ sehen. Diese Veränderungen müssen sich natürlich durch den ganzen Körper hindurch fortsetzen und auch die Gemmarienform der Keimzellen beeinflussen, und schwer zu verstehen ist diese Beeinflussung nicht.

Stellen wir uns vor, dass durch $K z$ in Figur 25 a zwei symmetrische Keimzellen im Inneren eines vielzelligen Tieres bezeichnet würden, durch $O z$ dagegen zwei Organzellen, die durch äussere Einflüsse, etwa durcl fortwährenden Reiz oder durch reränderten Gebrauch in ihrem Gefüge verändert werden. Nehmen wir ferner an, dass durch die Strahlenfiguren, die wir den Symbolen unserer Keim- und Organzellen gegeben haben, die Anordnung der GemmaFig. 25.

rien in ilmen und die der Gemmen in den einzelnen Gemmarien ausgedrückt werde, so werden die beiden Keimzellen $K_{z}$ nach ihrer Ablösung wieder einen Tierkörper hervorbringen, wie er durch unsere symbolische Fig. 25 a dargestellt ist und sowohl mit den Keimzellen $K z$ als auch mit den Organzellen $O z$ im Gleichgewichte steht. Dieser Tierkörper soll nun durch äussere Einflüsse, die seine beiden Organzellen $O z$ treffen, umgeändert werden. Dadurch wird das Gefüge in diesen Zellen ein anderes, und diese Veränderung setzt sich durch den ganzen Körper fort und überträgt sich auch auf die Keimzellen $K z$. Die Veränderung, die der Körper und die Keimzellen erleiden, soll durch die Konfiguration der Zellen in Figur $25 \mathrm{~b}$ angegeben werden. Es stelıen also in dem durch die symbolische Figur 25 a dargestellten Körper die Keimzellen $K z$ mit den Körperzellen $O z$ im Gleichgericht und in dem durch die srmbolische Figur 25 b wiedergegebenen, durch äussere Einflüsse reränderten Körper die Keimzellen $K z^{\prime}$ mit den Organzellen $O z^{\prime}$. Hat nun $K z$ wieder den Körper $a$ und also auch die Organzellen $O z$ erzeugen können, so muss $K z^{\prime}$ auch wieder den Körper $b$ und die Organzellen $O z^{\prime}$ hervorbringen 
können. Wenn $K z$ mit $O z$ im Gleichgewichte steht und $K z^{\prime}$ mit $O z^{\prime}$, so heisst es das Gesetz von der Erhaltung der Kraft leugnen, wenn man zugiebt, dass $K z$ zwar $O z$ erzeugt, aber bestreitet, dass die Keimzelle $K z^{\prime}$ die Organzelle $O z^{\prime}$ hervorhringen kann. Diejenigen Naturforscher, welche die Tererbung erworbener Eigenschaften bezweifeln, bezweifeln damit die allgemeine Gültigkeit des obersten Naturgesetzes.

Fast ebenso leicht, wie sich die Vererbung einer durch äussere Einflïsse hervorgebrachten morplologischen Umwandlung der Zellen dadurch erklärt, dass sich Terschiebungen innerhalb der Gemmarien einer Zelle durch den ganzen Körper bis zu den Keimzellen hindurch fortsetzen müssen, ist es zu begreifen, warum auch die durch äussere Einflüsse hervorgebrachten chemischen Umwandlungen der Zellen vererbt merden. Zum Verständnis dieser Art der Tererbung führen dieselben Überlegungen, die die Übertragung der Gemmenanordnung erklären, denn der Körper bildet nicht nur in Bezug auf die Lage seiner einzelnen Zellen ein Gleichgewichtssystem, sondern auch in Bezug auf deren chemische Zusammensetzung. Durch äussere Einflüsse wird nicht nur der morphologische Aufbau des Körpers erblich verändert, sondern auch dessen Chemismus, und in Bezug auf diesen bestelıt gleichfalls ein Gleichgewichtsverhältnis zwischen den einzelnen Zellen des Körpers. Wenn der Stoffwechsel in einer Körperzelle durch Einflüsse von aussen verändert wird, so muss auch der Stoffaustausch zwischen dieser Zelle und den benachbarten ein anderer werden, und mit derselben Notwendigkeit, mit der sich morphologische Veränderungen durch den Körper hindurch bis zu den Keimzellen fortpflanzen, müssen es auch chemische thun. Wenn demnach eine Körperzelle im chemischen Gleichgewichte mit dem gesamten Körper und folglich auch mit seinen Keimzellen steht, und der Stoffwechsel der betreffenden Körperzelle ändert sich, so muss es auch der des Gesamtkörpers thun und damit auch der der Keimzelle. Wenn also die Keimzelle $K z$ nicht nur in morphologischer, sondern auch in chemischer Beziehung die Organzelle $O z$ herrorgebracht hat, so muss durch Unwandlung der Organzelle $O z$ in $O z^{\prime}$ auch die lieimzelle $K z^{\prime}$ in $K z^{\prime}$ übergehen, und $K z^{\prime}$ muss wieder $O z^{\prime}$ reproduzieren, denn der Ort, welchen die durch fortgesetzte Teilung der befruchteten Eizelle entstehenden Organzellen im Körper erhalten, muss auf den Chemismus der Kürperzellen einen grossen Einfluss ausüben und ihr Plasma chemisch unändern, und ebenso wie sich bei der durch äussere Einflüsse bewirkten stammesgeschichtlichen Umbildung der Zellen ein grosser Teil 
des ursprünglichen Plasma's in andere Plasmaarten, wie es beispielsweise Nerven- Ind Huskelmasse sind, umsetzte, muss dieselbe Umsetzung auch bei der Ontogenie der Organe wiederholt werden.

Ein noch besseres Verständnis der Vererbung clemischer Umänderungen im Körper werden wir gewinnen, wenn wir später die periodischen Schöpfungsmittel näher ins Auge fassen. Hier haben wir zunächst noch das Verlältnis zu besprechen, in welchem der Gang der Keimesgeschichte zu dem der Stammesgeschichte steht, und ror allem den Parallelismus zwischen Ontogenie und Phylogenie zu erklären.

Bekanntlich hat $\mathrm{Haeckel}$ ein „Grundgesetz der organischen Entwickelung" aufgestellt, sein ,biogenetisches Grundgesetz", wonach die Keimesgeschichte eine kurze und gedrängte Wiederholung der Stammesgeschichte ist, und wir müssen zugeben, dass, obwohl die Keimesgeschichte manche Züge aufweist, die der Stammesgeschichte fremd waren, doch im grossen und ganzen ein auffälliger Parallelismus zwischen Ontogenie und Phylogenie besteht. Es ist die Aufgabe einer Vererbungs- und Formbildungslehre, diesen Parallelismus ursächlich zu erklären. Der Präformationslehre in ihrem neuesten, durch We ismann herbeigeführten Stadium ist das nicht möglich. Nach ihr besteht die Ontogenie darin, dass die Ide der befruchteten Keimzellen in ihre Determinanten zerlegt werden, und dass, sobald eine Determinante isoliert ist, die sie zusammensetzenden Biophoren aus dem Kern der betreffenden Zelle in das umgebende Plasma eintreten, sich hier vermehren und so den Charakter der Zelle bestimmen. Wie die natürliche Zuchtwahl dazu gekommen sein sollte, bei dieser Zerlegnng eine so grosse Umständlichkeit, wie sie wegen der bedeutenden Komplikation der keimesgeschichtlichen Vorgänge doch thatsächlich angenommen werden müsste, bestehen zu lassen, ist schlechterdings nicht einzusehen, um so weniger, als We ismann und seine Anhänger das krasseste Selektionsprinzip rertreten.

Die Zerlegung eines aus ungleichen Teilen bestehenden Körpers, wie es ein Id ist, in seine einzelnen Qualitäten, ist auf ausserordentlich verschiedene Weise möglich. Trotzdem finden wir, dass die Keimesgeschichte im grossen und ganzen eine Wiederholung der Stammesgeschichte ist, und dieser Umstand ist es, der die Präformationstheorie Weismann's unfähig macht, Licht über die Keimesgeschichte zu rerbreiten. Wenn es bei der Keimesgeschichte lediglich darauf ankommt, die Determinanten des Ids auf die Zellen des sich entwickelnden Körpers zu verteilen, so müsste die Keimesgeschichte einen viel schnelleren Gang 
nehmen, als sie es thatsüchlich thut, um so mehr, als ein Tier, das schnell zur Ausbildung gelangt, grosse Torteile im Kampf ums Dasein haben müsste, und wenn man die Berechtigung dieser Schlussfolgerung anerkennen will, so wird man des weiteren nicht begreifen, warum bei allen Tieren ein meln oder minder ausgesprochener Parallelismus zwischen Ontogenie und Phylogenie besteht, denn die natürliche Zuchtwahl müsste darauf hinarbeiten, in jeder Tiergruppe denjenigen Gang der Keimesgeschichte, d. h. diejenige Zerlegung der Ide in Determinanten herbeizuführen, die für die betreffende Tiergruppe am schnellsten zum Ziele führt. Es müsste also, wie gesagt, eine grosse Verschiedenheit in Bezug auf den Gang der Keimesgeschichte in rerschiedenen Tiergruppen eingeführt worden sein, was bekanntlich nicht der Fall ist; demn darüber sind sich nachgerade alle Zoologen einig, dass Haeckel mit seinem biogenetischen Grundgesetze im grossen und ganzen das Richtige getroffen hat. Da also ein Verständnis für die Ontogenie nicht auf dem Wege einer präformistischen Vererbungstheorie zu gewinnen ist, müssen wir uns zu unserer epigenetischen Anschauung wenden, um ron ihr eine Erklärung der Keimesgeschichte zu fordern, und diese Erklärung ergiebt sich aus unserer Lehre in einfachster Weise.

Die Veränderungen, die durch äussere Einflüsse, sei es, dass diese in den allgemeinen phỵsikalischen und chemischen Verhältnissen der Ungebung oder in dem veränderten Gebrauche der Organe bestehen, zu stande kommen, vollziehen sich an einem Körper, dessen Zellenzahl nicht in allen Generationen dieselbe ist, sondern ron Generation zu Generation zunimmt, solange die Gefügezuchtwahl ihre Wirksamkeit entfalten kann. Das Körpergefüge wird immer mehr befestigt, so dass immer mehr Zellen gebildet werden und in Zusammenhang mit den schon vorhandenen bleiben können. Der Zellenstammbaum, welchen der Körper darstellt, erhält also immer neue Äste und Zweige, und die rorlıandenen Zweige werden immer stärker und dadurch zu Hauptzellenbahnen, während sich an sie fortwährend nevere kleinere Zweige ansetzen. Die während der Ontogenie zuerst gebildeten Zweige müssen also notwendigerweise auch den stammesgeschichtlich zuerst entstandenen Verzweigungen des Zellenstammbaumes entsprechen, denn die Tererbung bewirkt, dass sich zunächst in jeder Ontogenie diejenigen Zellenreihen wieder bilden, die schon bei den Eltern des betreffenden Organismus bestanden. Wenn sich aber an den Spitzen dieser Zellenreihen neue Zellen entwickeln und dadurch die Lünge der einzelnen Zweige 
des Zellenstammbaumes rergrössern, so muss neben der keimesgeschichtlichen Reproduktion des ererbten Zellenstammbaumes der Eltern ein Wachstum über das ererbte Mass hinaus stattfinden, und Eimer hat das Richtige getroffen, wenn er die stammesgeschichtliche Entwickelung mit einem Wachstumsprozesse vergleicht. Dieser Prozess wird zwar in jeder neuen Ontogenese durchbrochen, aber wenn eine Organismenart sich in Umbildung befindet, so wird auch bei jeder Keimesentwickelung die Zweiglänge des Zellenbaumes etwas vergrössert, die Äste und Zweige dieses Baumes laufen deshalb nur bis zu dem Punkte, ron welchem an diese Verlängerung erfolgt, mit den Zellenbäumen der Eltern des betreffenden Organismus parallel; hier werden die während der Ontogenese dieser Tiere neu hinzugefügten Zellen angesetz.t.

Es ist klar, dass dieser Parallelismus ein immer geringerer wird, je weiter wir ron einer heute lebenden Generation auf ihre Vorfahren zurückgehen. Während die heute lebenden Organismen sich vielleicht nur in Bezug auf die Länge einzelner äusserster Zweigspitzen des Zellenbaumes von ihren nächsten Vorfahren unterscheiden, fehlen bei weiter zurückliegenden Vorfahren die kleinsten Verzweigungen im Zellenstammbaume der heutigen Organismen schon gänzlich. Gehen wir noch weiter zurück, so sehen wir auch Äste ron beträchtlicher Grösse schwinden, und auch diese nehmen an Anzahl und Länge ab, wenn wir uns abermals weiter in der Stammesgeschichte zurückrersetzen. Zuletzt besteht der ontogenetische Zellenstammbaum nur noch aus einigen wenigen Ästen, und endlich schwinden auch diese. Unsere Epigenesislehre, welche die stammesgeschichtliche Fortbildung der Hauptsache nach durch die Annahme einer konstitutionellen Zuchtwahl erklärt, begründet also in einer Weise, wie es bisher nicht möglich war, den ursächlichen Zusammenhang zwischen Keimes- und Stammesgeschichte, den Parallelismus der ontogenetischen und phylogenetischen Entwickelung, und sie erklärt auch, warum, wie es ron Eimer mit solchen Nachdrucke betont worden ist, das organische Wachsen ein gesetzmässiges sein muss.

Dieses organische Wachsen kann nämlich im Laufe der Stammesgeschichte dadurch abgeändert werden, dass sich einzelne Äste des ontogenetischen Zellenstammbaumes verkürzen, und dass sich andere verlängern und stärker werden, dass sich endlich hier und da neue Terzweigungen bilden. Die letzteren müssen an ganz bestimmten Stellen entstehen, nämlich dort, wo die Lage der betreffenden Zellen eine neue Verzweigung zulässt. Bei verwandten Tieren wird das an korrespondierenden Körper- 
stellen der Fall sein und deshalb werden solche Tiere unabhängig roneinander dieselben neuen Entwickelungsbahnen einschlagen. Daraus erklärt sich aber die gesetzmässige Cmbildung beispielsweise der Zeichnung, wie sie durch Eimer's schöne Untersuchungen bekannt geworden ist. Während aber Eimer diese gesetzmässige Umbildung zunächst nur empirisch feststellen konnte, ist es nunmehr möglich geworden, die Ursachen des sich nach einer Richtung hin bewegenden phylogenetischen Entwickehungsganges zu verstehen. Diese Ursache ist durch die Gefügefestigung gegeben. Durch äussere Einflüsse wird das plasmatische Gefïge eines Körpers verändert, entweder gestärkt oder geschwächt, und die konstitutionelle Zuchtwah! bewirkt, dass immer nur die Individuen mit dem festesten Gefüge überleben. Dadurch kommt die in so hohem Grade gesetzmässige und nach bestimmten Richtungen hin erfolgende Entwickelung der Organismen zu stande, die Karl Ernst von Baer und andere Naturforscher nur durch die Annahme einer Zielstrebigkeit erklären zı können glaubten, während Xägeli dafür einen Mechanismus der Entwickelung seines Idioplasma's ersann, wie er thatsächlich nicht bestehen kann, denn die Anstösse zur Fortentwickelung einer Organismenart kommen in allen Fällen ron aussen und nicht ron innen heraus. Bleiben die äusseren Lebensbedingungen dieselben, so setzt sich das Plasma mit ihnen ins Gleichgewicht, und die betreffende Organismenart bildet sich desto langsamer um, je mehr dieser Gleichgewichtszustand erreicht ist. Thatsächlich aber sind die Einflüsse, ron denen die rerschiedenen Individuen einer Art betroffen werden, verschieden, so dass immer eine Auswahl unter Individuen mit verschieden festem Gefüge möglich ist. Freilich wird sich zu einer solchen Auswahl in grossen Umbildungsgebieten viel ausgiebigere Gelegenheit bieten, als in kleinen, wodurch es dem zu erklären ist, dass in den letzteren eine verhältnismässig langsame Umbildung stattfindet.

Die hier vorgetragene Lehre bahnt also ein wirkliches mechanisehes Verständnis für die Entstehung der Körperformen bei phylogenetischer und ontogenetischer Entwickelung, für die Vererbung erworbener Eigenschaften und den Parallelismus von Keimes- und Stammesgeschichte an, während frühere Vererbungs- und Formbihlungslehren nur empirische Gesetzmässigkeit feststellen konnten, ohne dafür die wahren Ursachen beibringen zu können, und der Präformismus sich überhaupt unfähig erweist, irgend etwas wirklich zu erklären. Wir dürfen deshalb für unsere Lehre prinzipiell die Bezeichnung einer Entwickelungsmechanik in An- 
spruch nehmen; sie macht uns die Gleichgewichtsverhältnisse der organischen Körper mechanisch begreiflich.

Aus der Gemmarienlehre geht auch ohne weiteres herror. warum die Ontogenie auch bei solchen Tieren keine rollkommene Wiederholung der Phylogenie sein kann, welche nicht durch embryonale Anpassungen in ihrer keimesgeschichtlichen Entwickelung beeinflusst worden sind. Wo das letztere der Fall ist, wo das sich entwickelnde Tier sich an eigenartige Lebensverhältnisse, beispielsweise an den Aufenthalt in dem Fruchtbehälter seiner Mutter, angepasst hat, ist es von vornherein verständlich, dass diese Anpassung eine Einwirkung auf den Gang der keimesgeschichtlichen Entwickelung haben musste. Allein viele Tiere sind nicht an solche Verhältnisse angepasst; beispielsweise kann man bei den Scheibenquallen, die sich aus einem Becherpolypen durch Teilıng des letzteren entwickeln, nicht ron weitgehender Anpassung an das Kieimlingsleben sprechen. Gleichwohl ist auch bei diesen Tieren der ontogenetische Entwickelungsgang abgeändert. Die einzelnen aufeinanderfolgenden Entwickelungsstufen der Scheibenquallen gleichen zwar noch annälıernd, aber 'doch nicht mehr vollkommen ihren phylogenetischen Vorfahrenstufen, und sie können es deshalb nicht, weil das Plasma, aus welchem sie sich entwickeln, eben dasjenige ihrer eignen Art und kein anderes ist. Deshalb müssen sie auch schon auf der Stufe der befruchteten Eizelle verschieden sein, auch wenn ihre Verschiedenheiten für uns nicht wahrnehmbar sind. Die Verschiedenheiten treten aber bald genug herror, so dass es für den Geübten nicht schwer sein wird, auf tiefer ontogenetischer Entwickelungsstufe stehende Scheibenquallen voneinander artlich zu unterscheiden, und dasselbe gilt von allen übrigen Tieren und auch von den Pflanzen. Die Unterschiede des Plasma's sind in den Keimzellen der Organismen ebenso gross wie die der erwachsenen Tiere und Pflanzen, und deshalb kann die keimesgeschichtliche Entwickelung sich nicht mehr volkommen mit der stammesgeschichtlichen decken. Wenn demnach das Haeckel'sche biogenetische Grundgesetz, wie wir oben gezeigt haben, eine Stütze in unserer Gemmarienlehre findet, so findet es anderseits auch eine notwendige Einschränkung durch eben diese Lehre, und dadurch, wie mir scheint, eine nur um so festere Begründung. Unsere Lehre erklärt, warum beispielsweise die Keimesgeschichte des Säugetieres in viel hölıerem Grade von der des Amphioxus abweichen muss, als die der Amphibien, warum sich der Polyp der Becherquallen viel weiter von der Hydra entfernt hat, als der Polyp 
der Schleierquallen. Diese Unterschiede liessen sich früher keineswegs ohne weiteres verstehen. Die Gemmarienlehre, welche ein monotones Keimplasma annimmt, begründet zu gleicher Zeit die notwendigen Übereinstimmungen und Verschiedenheiten der Keimesgeschichte rerschiedener Organismenarten und erweist sich dadurch als ein mechanisches Erklärungsprinzip. Dass sie auch die Erklärung für die Aupassung des sich entwickelnden Organismus an seine besonderen Lebenshedingungen giebt, werden wir in dem Abschnitte über die Entstehung der periodischen Entwickelungsvorgänge sehen.

\section{f. Die Entstehung der Ausrüstung.}

Wir haben in dem rorhergehenden Abschnitt dargethan, dass reränderte Lebensbedingungen notwendigerweise auf den Organismus einwirken und neue Anpassungen herbeiführen, und dass diese vererbt werden müssen. Durch direkte äussere Einflüsse kann erstens die Form der Gemmarien eine andere werden, und zwar dadurch, dass sie entweder fester oder lockerer wird. Die Individuen mit dem festesten Gemmariengefüge überleben, während die übrigen zu Grunde gehen. Es wird also dadurch eine stammesgeschichtliche Umgestaltung bewirkt, die unablängig ist ron Anpassungen der einzelnen Organe an neue Lebensbedingungen.

Wir müssen aber auch zweitens solche Anpassungen unterscheiden, welche direkt durch den reränderten Gebrauch der Organe infolge von auf Gefügefestigung beruhenden Formveränderungen des Körpers herbeigeführt und vererbt werden. Ob diese Veränderungen zweckmässig sind, d. h. ob sie geeignet sind, der betreffenden Organismenart eine lange Existenz zu sichern, hängt von den sonstigen Lebensbedingungen der Art und ron dem in Zukunft eintretenden Wechsel der letzteren ab. Denn die Anpassungen, welche durch den Gebrauch oder Nichtgebrauch der Organe entstehen, brauchen keineswegs immer erhaltungsmässige zu sein, und dasselbe gilt ron der Grundform, die, wie wir gesehen haben, durch Gefügefestigung im Laufe der Stammesgeschichte der Tiere abgeändert wird. Die Gefügefestigung kann aber drittens noch weitere Veränderungen mit sich bringen, sie kann beispielsweise die Färbung beeinflussen, und das Gleiche gilt ron den Abänderungen der einzehnen Organe, denn wenn eine einzige Zelle sich ändert, so müssen alle 
anderen Zellen sich gleichfalls verändern und dadurch den gesamten Organismus in allen seinen Teilen umbilden. Aut diese Weise entstehen neue Eigenschaften, die erhaltungsmässig oder nichterhaltungsmässig oder endlich auch indifferent sein können, und die Lebensbedingungen einer abgeänderten Organismenart haben darüber zu entscheiden, ob die Nebenerzeugnisse, wie wir die durch Gefügefestigung und Organumbildung auf korrelativem Wege hervorgebrachten Abänderungen nennen körinen, zum Besten oder zum Nachteil der betreffenden Art ausfallen oder endlich für das Fortbestehen der Art gleichgültig sind. Es wird also leicht eine Auslese $z w i s c h e n$ verschiedenen uächstverwandten Arten oder Rassen, deren Verbreitungsgebiete sich so verschieben, dass sie teilweise zur Deckung gelangen, eine Rassenzuchtwahl zu stande kommen können, welche die Ausrüstung, die Dotation der Organismen betrifft.

Wir nehmen also mit $\mathrm{D}$ arwin eine Zuchtwahl an, aber, sofern die A usrüistung' und nicht das Gefüge betroffen wird, u ur zwischen verwandten Rassen einer Art oder verwandten Arten einer Gattung. Durch solche dotationelle Rassenselektion kann man sich beispielsweise die Entstehung der Schutzfärbung erklären, und dass unsere Lehre auch geeignet ist, die Entstehung hochgradiger Mimikry zu erklären, will ich an dem folgenden von Seitz mitgeteilten Beispiel darzuthun versuchen.

„Weit rerbreitet über Indien und die angrenzenden Länder," sagt Seitz, ,findet sich eine nachweisbar geschützte Danaide; nachweisbar geschützt, denn ihre Raupe lebt an Giftpflanzen (Asclepiadeen). Auf Ceylon fliegt sie in einer sehr lebhaft gelbroten (plexippus) Form, auf Java ist sie düsterer (melanippus) u. s. f. Mit ihr zusammen fliegt eine nicht geschützte Satyride (Elymnias undularis, Raupe an Palmen), die im weiblicheu Geschlechte jene Danaide aufs genaueste rachahmt und auf Java düsterer, auf Ceylon heller ist (= var. fraterna). Das Männchen dieser Elymnias ist vorwiegend schwarz und blau und hat weder mit seinem Weibchen, noch mit der Danaide die geringste Ähnlichkeit. Es gelang mir nun, auf der Insel Singapur einen Ort aufzufinden, wo die braune Danaide fehlt, oder richtiger gesagt, wo sie infolge eines Albinisnus einen vollständig anderen Habitus angenommen hat (= var. hegesippus); auch auf dieser Insel kommt die Elymnias undularis vor, hier aber - und damit ist die Probe auf die Mimikry - Theorie gemacht ist das Weibchen genau wie das Männchen gefärbt (= var. nigrescens Btlr.). Wir sehen also, dass nicht etwa eine, zufällige Gleichheit der 
klimatischen oder phỵsikalischen Verhältnisse den Grund zur mimetischen Färbung liefert, sondern dass es sich in der That bei der Mimikry um eine ,Nachahmung' handelt."

Während ich Seitz in Bezug auf diesen letzten Satz beistimme, rermag ich es nicht anzuerkennen, dass dadurch, dass auf Singapur im Bezirke der durch Albinismus abgeänderten braunen Danaide das Weibchen der Elymnias dem Männchen gleicht, die Probe auf die MimikryTheorie gemacht sein soll; ich glaube vielmehr, dass dadurch die Mimikry -Theorie in ihrer jetzigen Form widerlegt wird. Um aber meine Anschauung darïber zu entwickeln, muss ich etwas weiter ausholen.

Schmetterlinge giebt es schon seit alten Zeiten, und sehr viele Arten, beispielsweise der Distelfalter, haben Gelegenheit gehabt, sich über einen grossen Teil der Erde zu verbreiten. In früheren Zeiten, als auch bei uns im Norden noch ein wärmeres Klima herrschte, muss solches noch viel eher möglich gewesen sein, und es wird oft rorgekommen sein, dass eine durch schlechten Geschmack oder Geruch geschützte Art über ein weites Gebiet zusammen mit anderen rerbreitet war, welche nicht geschützt waren. Es ist nun möglich, dass in irgend einem engeren Bezirke dieses weiten Gebietes zufällig eine Rasse einer nicht geschützten Art entstand, die der geschützten Art melı oder weniger ähnelte. Die Individuen dieser Rasse werden grössere Aussichten im Kampf ums Dasein gehabt lıaben, als die Individuen der anderen Rassen derselben Art, die der geschützten Art unähnlich blieben. Die nachahmende Rasse konnte sich deshalb über das ganze grosse Gebiet rerbreiten, während die übrigen Rassen zum 'Teil wenigstens im Kampf ums Dasein unterliegen mussten, und nachdem die durch Nachahmung begünstigte Rasse sich so weit wie möglich ausgebreitet hatte, konnte sie selbst innerhalb der kleineren Bezirke ihres gesamten V'erbreitungsgebietes wiederum irgendwo eine Rasse bilden, die noch mehr als sie der durch schlechten Geschmack geschützten fremden Art ähnelte. Dieser Prozess konnte sich öfters wiederholen, so dass endlich eine hochgradige Ähnlichkeit zwischen der geschützten und nachahmenden Art entstand. Es ist aber wohl möglich, dass bei diesen Prozesse der Rassenzuchtwahl Rassen unterlagen, welche an und für sich besser zum Leben befähigt waren, als die nachahmende Rasse, dass die letztere ihre weite Verbreitung und ihr Fortbestehen auf Kosten ihrer líonstitution eingetauscht hatte. Solches ist, wie es scheint, oft der Fall gewesen, und deshalb sind nachahmende Tiere, Tiere, die in hohem Grade durch Mimikry ausgezeichnet sind, oft 
recht individuenarm, während man nach dem Darwinismus das Gegenteil erwarten sollte.

Der ron Seitz mitgeteilte Fall scheint gegen unsere Theorie der Rassenzuchtwahl, welche weite Gebiete gebraucht, zu sprechen; es scheint, dass auf Ceylon, Jara usw. ein indiridueller. Zuchtwahlprozess stattgefunden hat, welcher die A usrïstung einer Schmetterlingsart betraf, während er auf Singapur nicht stattfand. Der Fall ist aber anders zu erklären. Wir dürfen annehmen, dass sowohl die geschützte als auch die nachahmende Art ursprünglich sehr weit verbreitet war, dass sich aber in rerschiedenen Gebieten besondere Rassen der geschützten Art heranbildeten. Zunächst mag die Danaide die auf Java lıerrschende Färbung angenommen haben. Diese wurde in irgend einem Bezirke ron der Satyride nachgeahmt; die betreffende Rasse der letzteren wurde die herrschende, rerbreitete sich über das Gesamtgebiet der Danaide und gelangte auch nach Jara. Aber die Danaide veränderte sich im grössten Teile des ron ihm bewohnten Gebietes; sie nahm rielleicht die jetzt auf Ceylon gefundene Färbung an, und auch diese wurde ron irgend einer Rasse der sich gleichfalls verändernden Satyride nachgeahmt. Nunmehr wurde diese die herrschende Rasse der geschützten Art und gelangte unter anderm auch nach Ceylon. Beide Arten konnten sich noch weiter verändern, aber auf Jara und Ceylon behielten sie ihre Eigentümlichkeiten bei, weil sich auf diesen kleinen Gebieten die Veränderungen äusserst langsam vollziehen, eine Eigentümlichkeit der Inselfaunen, die wir im nächsten Abschnitte verstehen lernen werden. Die jetzt auf Singapur rorkommende Rasse der Danaide erlitt aber infolge äusserer Einflüsse Abänderungen, die Seitz als Albinismus deutet. Sicher sind doch nun auch die auf Singapur lebenden Individuen dieser Danaide geschützt; auch ihre Raupen werden sich ron Giftpflanzen nähren, und es ist nach der üblichen Theorie der Mimikry nicht einzusehen, weshalb nicht auch auf Singapur die Satyride schützende Ähnlichkeit beim Weibchen aufweisen sollte. Wenn sich nach der herrschenden Ansicht auf Java und Ceylon ein Prozess dotationeller Individualselektion an der Satyride rollziehen komnte, so konnte er es doch auch wohl auf Singapur. Warum also giebt es hier keine Mimikry bei der Satyride? Die Probe auf die Richtigkeit der herrschenden Mimikry-Theorie wäre zwar auch noch nicht gemacht, wenn auch auf Singapur das Weibchen der Satyride ebenfalls der Danaide gliche, aber die Theorie erlitte dann wenigstens keinen Stoss. Dieser Fall zeigt eben, dass Mimikiky 
nicht durch dotationelle Individualselektion entstanden sein kann, dass es sich dabei viehmehr um Rassenzuclitwahl handelt. Ich weiss nicht, wie weit die Unterart der Satyride, in welcher das Weibchen dem Männchen gleicht (var. nigrescens), verbreitet ist, möchte aber annehmen, dass sie kein grosses Gebiet bewohnt und dass in diesem, vielleicht in einzelne Bezirke zerrissenen Gebiete die Danaide entweder fehlt oder, wie auf Singapur, einen völlig veräıderten Habitus zeigt. In solchen Bezirken hätte sich dann eine Rasse der Satyride, die ihre Färbung in beiden Geschlechtern lediglich der konstitutionellen Individualselektion verdankt, halten können.

Unsere Ausführungen zeigen, dass hochgradige Mimikry nur dadurch zu stande kommen konnte, dass von vornherein mindestens in einem Gebiete sämtliche Individuen der dort lebenden Rasse einer ungeschützten Art Ähnlichkeiten mit einer geschützten Art hatten, denn wie durch Indiridualselektion hochgradige Ähnlichkeit zweier ursprünglich völlig verschiedener Rassen zu Wege gebracht werden kann, ist nicht einzusehen, weil die konstitutionelle Zuchtwahl unter In dividuen einer Rasse jedenfalls über dotationelle Individualselektion, die ja nur geringe individuelle Unterschiede betreffen könnte, die Oberliand behalten muss. Dagegen kann eine Rasse, die durch konstitutionelle Individualselektion zufällig einer geschützten fremden Art ähnlich geworden ist, möglicherweise im Wettbewerb mit anderen Rassen überleben, auch wenn die letzteren besser konstituiert sind. Wir ersehen daraus, dass die verschiedenen Arten der Zuchtwahl nicht immer Hand in Hand zu arbeiten braucheı, sondern auch gegeneinander wirken können, und dass es nicht immer das Überleben des Bestausgestatteten, des Bestgeriisteten ist, das die Fortentwickelung der Arten bedingt hat. Die Ausstattung wird zunächst ohne Rücksicht auf Zweckmässigkeit durch die Individualselektion herangezüchtet oder direkt durch äussere Einflüsse oder durch den Gebrauch und Nichtgebrauch der Organe hervorgebracht, aber darüber, ob sie bestehen bleibeu soll, entscheidet nicht die Individualselektion, sondern die Rassenauslese. Auf Grund der Unterscheidung dieser beiden Arten der Auslese wird auch, wie wir bereits gesehen haben und im nächsten Abschnitt noch des näheren sehen werden, die Entstehung der Faunen verständlich. 


\section{g. Die Entstehung der Faunen.}

In meiner ...Schöpfung der Tierwelt" labe ich den Nachweis geführt, dass die Landfaunengebiete, die wir auf der Erde unterscheiden können, eine auffällige Stufenfolge darstellen. Auf der tiefsten Stufe steht Neuseeland, auf einer etwas höheren Australien; es folgen Madagaskar und die grossen Antillen, Südamerika,.,Afrika und Indien, dann Nordamerika, bis wir endlich in Europa und Nordasien die höchstentwickelte Landfauna antreffen. Solches gilt für die Süugetiere, und ähnliches lässt sich für die Vögel und für manche andere Tiere feststellen. Australien steht noch heute in Bezug auf seine Säugetierfauna auf einer Entwickelungsstufe, die der Norden der Erde während der Sekundärzeit durchlaufen hat, und die Fauna Madagaskars mag einer alttertiären Säugetierfauna unserer Gegenden entsprechen. Wo wir altertümliche Tiere oder Tiergruppen antreffen, finden wir sie meistens im Süden der Erde. Ein Blick auf eine Erdkarte zeigt uns, dass die Entwickelungshöhe der Faunen Hand in Hand geht mit der Isolierung und der melır oder minder grossen Ausdelnung der Faunengebiete, und wenn wir bedenken, dass aller Wahrscheinlichkeit nach die Konfiguration der grossen Kontinentalmassen der Erde im grossen und ganzen vor alter geologischer Zeit dieselbe war wie heute, so gelangen wir zur Aufstellung des Satzes, dass die Entwickelungshöhe der Tiere eines Faunengebietes ceteris paribus proportional ist der Ausdehnung des letzteren, vorausgesetzt, dass das betreffende Gebiet nicht leicht einer Einwanderung von aussen zugänglich, also wirklich ein für sich bestehendes Gebiet ist.

Schon im Jahre 1886 habe ich den Satz aufgestellt, dass sich alle grösseren Gruppen der Landtiere, etwa schon alle Gruppen von der Bedeutung einer Ordnung, von dem in der nördlichen Erdhalbkugel gelegenen Kontinentalkomplex aus, dessen Mittelpunkt der Nordpol ist, über die Erde verbreitet haben, und ich labe diesen Satz folgendermassen zu begründen gesucht: „Solche Erdregionen, welche neben ausgedehnten Landmassen eine in Laufe der Zeiten wechselnde Verteilung von Land und Wasser und damit eine ausgedelınte Verschiebung der klimatischen und faunistischen Verhältnisse aufweisen, würden meiner Ansicht nach in ganz hervorragender Weise befähigt gewesen sein, neue Tiergruppen ins Dasein zu rufen." Ich gelangte dam zu dem Ergebnis, "dass etwa die nördlichen zwei Dritteile der Nordhemisphäre das einzige grössere Kon- 
tinentalgebiet der Erde bilden, in welchem während früherer Erdperioden grössere Landmassen bald miteinander verbunden, bald voneinander getrennt waren, dass also nur dieses Gebiet, dessen Mittelpunkt der Nordpol ist, den Schauplatz für die Entstehung grösserer Systemgruppen des Tierreiches abgeben konnte. Ist dieses aber der Fall gewesen," fuhr ich fort, „dann müssen die neu entstandenen Tiergruppen die älteren mehr und mehr nach Süden bis in die entferntesten Erdenwinkel gedrängt haben. Ist unsere Schlussfolgerung richtig, dann müssen wir in südlichen entfernten Erdenwinkeln heute die letzten überlebenden Vertreter alter und grösstenteils ausgestorbener Tiorgruppen finden, während die Reste ihrer früher lebenden Vorfalren und Anverwandten auch in den Erdschichten der nördlichen Hemisphäre abgelagert sein müssen." Ich konnte behaupten, dass beides der Fall sei, und habe seitdem in meiner "Schöpfung der Tierwelt" gezeigt, dass sich nicht bloss die früher von mir namhaft gemachten Tiere, nämlichı die straussartigen Vögel, die Ursïuger, Beuteltiere, Halbaffen, Zahnarmen und Insektenfresser, den Forderungen meiner Verbreitungstheorie fügen, sondern dass der Satz, dass dort, wo seit langer Zeit die grössten Landmassen angehäuft sind, auch die lebhafteste Fortentwickelung der Landtiere stattfindet, allgemeine Gültigkeit hat und mutatis mutandis auch für die Bewohner des lleeres und des süssen Wassers gilt. Ich habe aber auch gelernt, diesen Satz durch meine Gemmarienlehre mechanisch zu begründen.

Gewiss sind die Einwirkungen, dic in cinem grossen Lündergebicte durch wechselnde klimatische Verhältnisse, durch Bildung von Meeresarmen, von Inscln und dergleichen mchr auf die 'lierwelt ausgeübt werden, von grosser Bedeutung; allein auch wo sie fehlen, muss sich die Ticrwelt eines grossen Gebietes schneller umbilden, als die eines kleinen, das im übrigen dieselben Existenzbedingungen gewährt, denn auf einem grossen Gebiete kann die Gefügezuchtwahl viel ausgiebiger eingreifen, als in einem kleinen, weil sie melır Material hat, um ihre Auswahl zu treffen. Je grösser das Gebiet ist, desto mehr wird es auch in seinen einzelnen T'eilen geringe Verschiedenheiten zeigen und desto mehr Faunengrenzen von untergeordneter Beckeutung werden sich in ilım finden. Es kann sich also in jedem einzelnen Teilgebiete des grossen Gesamtgebietes aus einer ursprünglich über das ganze (iebiet rerbreiteten Tierart eine neue Rasse entwickeln, und mnter den neuen Rassen, in welche die früher über das ganze Gebiet verbreitete 'lierart zerfallen ist, wird diejenige, welche in Bezug auf Gefügefestigkeit und Ausstattung am vorteilhaftesten um- 
gebildet worden ist, sich über das Gesamtgebiet verbreiten und die anderen Rassen verdrängen können, und dieser Prozess kann sich, wie schon im vorigen Abschnitt ausgeführt, oft wiederholen, was in einem kleinen Gebiete nicht möglich ist. Es ist deshalb kein Wunder, dass die Fortbildung der Tierwelt in grossen Gebieten unter übrigens gleichen Umständen viel schneller stattfindet, als in kleinen; dagegen kann direkte Anpassung an die äusseren Lebensverhältnisse viel eher in kleinen Gebieten zu stande kommen, weil hier die Gefügefestigung der Anpassung nicht entgegenarbeitet, weil in kleineren Gebieten deshalb eher eine Verschiebung der Zellen des Körpers und der Gemmen innerhalb der Gemmarien möglich ist, weil hier das Gefüge der Tiere weniger fest ist, als in grossen Gebieten. Und in der That finden wir in manchen südlichen Gebieten weitgehende Anpassungen an einseitige Lebensweise, und dasselbe gilt von isolierten Inseln. Ich erinnere an die flügellosen Vögel Neuseelands, an die einseitige Ausbildung des Känguruhfusses, an die eigentümliche Umbildung der Kiefer bei den Ursäugern, an die Greifschwänze vieler Säugetiere Südamerikas und Australiens, an die flugunfähigen Käfer von Madeira und an die schwerfälligen ausgestorbenen Taubenvögel ron den Maskarenen. Beispiele für einseitige Anpassung liessen sich noch in grosser Menge aufführen, und man würde finden, dass sie hauptsächlich in südlichen Gebieten angetroffen werden. Das findet seine Erklärung in unserer Gemmarienlehre, während mir keine andere Lehre bekannt ist, die zur Begründung dieser auffälligen tiergeographischen Befunde dienen könnte.

Allerdings ist die Anschauung, dass die hauptsächlichste Umbildung der Landtiere in Europa und im Norden von Asien stattgefunden hat, nicht neu. Ich habe schon in meinem oben citierten Aufsatze darauf hingewiesen, dass sie im wesentlichen diejenige des bedeutendsten Tiergeographen der Gegenwart, Wallace's, ist. Seit der Veröffentlichung meines Aufsatzes hat dann der englische Geistliche und Ornithologe Tristram gleichfalis den Satz aufgesteltt, dass die Tiere sich rom Norden aus über die Erde verbreitet laben; aber er begründet diesen Satz anders, als ich es gethan habe. Tristram knüpft an die Vügel an und sagt, dass dort die Heimat eines Trogels zu suchen sei, wo er brüte, dass beispielsweise unsere Zugrögel früher jahraus, jahrein bei uns im Norden lebten. Er meint num, dass sich von hier aus die Erde berölkert habe, und dass die abweichenden Formen der südlichen Vertreter nordischer Tiere darauf zurückzuführen seien, dass sie sich mehr von denı 
gemeinsamen Ursprung entfernt hätten, als diejenigen, die im Norden geblicben sind.

Diesem Satze kann ich nicht zustimmen, da ich im Gegenteil der Ansicht bin, dass die Umbildung der 'liere im Norden viel rascher erfolgt ist, als im Süden. Allerdings weichen sïdliche 'liere oft in hochgradiger Weise ron ihren nordischen Verwandten ab; allein nicht diese sind es, die auf der ursprünglichen Entwickelungsstufe stehen geblieben sind, sondern die des Südens. Die letzteren sind zwar oft in einseitiger Weise den Lebensverhältnissen der südlichen Länder angepasst und weichen dadurch von den typischen, im Norden wohnenden Vertretern ihrer Gruppe ab, aber trotz alledem sind letztere weiter entwickelt, wie sie es ja nach unserer Gemmarienlehre sein müssen, falls die grossen Landmassen, welche wir heute im Norden finden, schon seit langer Zeit bestanden haben, falls die grossen Kontinentalsockel seit uralten geologischen Zeiten dieselben geblieben sind. Und gerade diejenige Tiergruppe, welche 'Tristram in erster Linie zur Begründung seiner Ansichten heranzieht, nämlich die der spechte, stimmt viel besser zu meiner Theorie, obwohl sie dieser auf den ersten Blick teilweise zu widersprechen scheint.

Im Norden der Erde finden wir typische Spechte, beispielsweise unseren Schwarzspecht und den Herrenspecht Nordamerikas. Je weiter wir uns rom Norden alus nach dem Süden zu entfernen, desto mehr Vögel treffen wir an, die noch nicht zu so vollkommenen Spechten geworden sind, wie die hochentwiekelten nordischen Vertreter der Gruppe. Tun sind diese allerdings einseitiger angepasst als beispielsweise die kleinen Weichschwanzspechte des Südens, aber bei unserer Vogelgruppe kommen besondere Verhältnisse in Betracht. Die einseitigen Anpassungen der Spechte beruhen auf der eigentümlichen meisselartigen Umbildung des Sihnabels, auf dem Kletterfuss, den starren Sclwwanzfedern und der langen hervorstreckbaren \%unge. Da aber die grosse Mehrzahl der Spechte Waldrögel sind, und da wir uns den Specht nur in Waldgebieten entstanden denken können, so leben sie sowohl in Norden als auch im Süden der Erde unter denselben Lebensbedingungen. Im Norden konnte nun eine intensive Gefügezuchtwahl stattfinden, und dadurch wurde die Körpergrösse der nordischen Spechte allmählich viel beträichtlicher, als sie es ursprünglich gewesen ist und als wir sie bei vielen südlichen Spechten hente noch finden. Die fortgesetyte Anpassung an das Baumleben musste aber sowohl im Norden als auch im süden in derselben Richtung 
wirken, und deshalb konnte auch die Gefügezuchtwahl im Norden nicht viel gegen die direkte Anpassung ausrichten.

Da die nordischen Spechte mit der Zeit durch Gefügezuchtwahl viel grösser geworden waren, als die südlichen, so konnten die einseitigen Umbildungen, die der Specht infolge von Anpassung an seine eigenartige Lebensweise erlitten hat, im Norden viel a uffülliger werden. Die mächtigen Hammerschläge, die der Schwarzspecht mit seinem Schnabel ausführen kaun, müssen stärker umbildend auf den letzteren einwirken, als es bei den winzigen Zwergspechten des Südens möglich ist. der Druck, den die grossen nordischen Spechte auf ihre Schwanzfedern dadurch, dass sie sich auf diese stützen, ausüben, ist gleichfalls ein viel stärkerer als bei den kleinen Spechten des Südens. Aus diesen Gründen mussten die nordischen Spechte viel typischere Tertreter ihrer Gruppe werden, als die südlichen, sofern diese nicht erst neuerdings ans dem Norden gekommen sind. Und wenn die nordischen Spechte auch einseitiger angepasst sind, als viele südliche, so sind sie doch immerhin vermöge ilırer Körpergrösse und sonstiger Eigentümlichkeiten, die nicht auf direkter Anpassung beruhen, beispielsweise in Bezug auf Färbung und Zeichnung die höchstentwickelten Vertreter ihrer Familie.

Ähnliches finden wir auch bei anderen Tieren, die nicht so einseitig' angepasst sind wie die Spechte. Typische Raben, Hirsche, Marder, um nur einige Beispiele zu neunen, finden wir ror allem im Norden, und dasselbe gilt ron allen anderen Landtieren, sofern deren Verbreitungsgebiet nicht allzusehr ron klimatischen Verhältnissen abhängig ist. Wo, wie es etwa bei den Schmetterlingen, ferner bei den Kriechtieren und Lurchen geschehen ist, eine Verschiebung des Hauptverbreitungsgebietes vom Norden nach den Tropen zu stattfand, weil im Norden ein unwirtliches Klima eintrat, da ist allerdings der Norden neuerdings in der Entwickelung zurückgeblieben. Aber zu einer 'Zeit, in welcher noch überall auf der Erde warmes Klima herrschte, muss der Norden auch die höchststehenden Vertreter dieser Tiergruppen beherbergt haben, wenn thatsächlich im Norden immer die meisten Landmassen angesammelt gewesen sind. Es haben sich also niclıt die Tiere des Südens, wie Tristram meint, von den nordischen entfernt, sondern das Umgekehrte hat stattgefunden: die nordischen Tiere liaben sich infolge der grossen Ausdehnung ilıres Heimatsgebietes ron ihren ursprünglichen Torfahren entfernt, wälrend Verwandte der letzteren, die nach dem Süden der Frde hingelangt waren. im grossen und gauzen auf derselben Stufe stehen geblieben 
sind, die ihre Vorfahren einnahmen, als sie in ihr heutiges südliches Terbreitungsgebiet einwanderten.

lch habe in meiner früheren kleinen Ablandlung allerdings nicht genug betont, dass die Umbildung der Landtiere in Norden der Erde eine viel schnellere sein musste, als im süden, was ich aber bereits in meiner "Schöpfung der Tierwelt" gethan habe. Aber schon im Jahre 1886 habe ich die höhere Entwickelung der nordischen Tiere mit ihrem grossen Verbreitungsgebiete in Zusammenhang gebracht, und jetzt bin ich in der Lage, die Abhängigkeit der Entwickelungshöhe der Tiere eines Faunengebietes von dessen Ausdehnung mechanisch durch die Gemmarienlehre zu begründen, wie ich es auf den vorhergehenden Seiten gethan habe. Meine Ansicht ist deshalb eine wesentlich andere als die des englischen Ornithologen.

Übrigens hat schon lange vor uns beiden Gustav Jäger in einer kleinen, ziemlich unbeachtet gebliebenen Abhandlung gleichfalls den Satz vertreten, dass sich die Tiere des Landes von Norden aus über die Erde verbreitet haben; aher er hat diesen Satz weder empirisch, noch auch theoretisch in genügender Weise begriindet. Jäger's Begründung seiner Anschauungen war die folgende: Er dachte sich, dass sich früher um den Tordpol der Erde herum ein im grossen und ganzen kreisförniges offenes Meer befand, und dass sich an den Ufern dieses Meeres eine circumpolare Tierwelt entwickelt hatte, die sich nach und nach ron hier aus über die Erde verbreitete. Nachden dann die im Norden zurückgebliebenen Tiere weiter umgebildet waren, konnten sich neue Tierringe von den Gestaden des kreisförmigen Polarmeeres aus ïber die Erde ausdehmen, und auf diese Weise, meint Jäger, seien die Übereinstimmungen zu stande gekommen, die wir in denselben Zonen verschiedener Kontinente finden. Beispiele dafür würden die Verbreitung der Beuteltiere in Australien und Südamerika, die der straussartigen Vögel in Neuseeland, Australien, Madagaskar, Afrika und Südamerika, und die Terbreitung der Papageien, deren Hauptmasse südlich vom Ïquator gefunden wird, bilden. Jäger hat dagegen nicht dargethan, dass die Tiere des Nordens sich schneller umbilden mussten, als die des Sürlens, und er hat auch nicht betont, dass die grossen Landmassen hauptsächlich im Norden der Erde angehäuft sind. Was er zu zeigen versuchte, war die annähernd sternförmige Anordnung der Kontinente, wie sie uns auf der äusserst brauchbaren, ron Jäger erfundenen und seiner Abhandlung beigegebenen Karte in Steruprojektion entgegentritt. Der flichtigste 
Blick auf eine solche Karte zeigt ja, dass allerdings die Übereinstimmungen in den faunistischen Verhältnissen südlicher Ländler am besten dadurch erklärt werden, dass man zurückgeht auf eine nordische Fauna, weil diese sich am ehesten über die Erde verbreiten konnte. Allein die Annahme, dass ein kreisförmiges Nordpolarmeer dazu gehörte, um die heutige Verteilung der Tierwelt herbeizuführen, scheint mir im hohen Grade gesucht.

Auch ich habe in meiner Ablandlung über den "Nordpol als Schöpfungszentrum der Landfauna" den Pol zu sehr in den Vordergrund gestellt, wenn ich auch hervorgehoben habe, dass das Gebiet, welches ich ais einen Hauptumbildungsherd der Landfauna betrachte, etwa bis zum 40. Grade nördlicher Breite hinunterreicht. Andere Naturforscher haben anf das Wort "Nordpol" in dem Titel meiner Abhandlung ein grösseres Gewicht gelegt, als ich selbst ihm beigemessen habe. Wenn auch die Wirkungen der klimatischen Verhältnisse der Erde eine grosse Rolle in der Verbreitung der Tiere spielen, so sind diese doch wohl zn unterscheiden von dem Einflusse, den grosse Landmassen auf die Umbildung der Tierwelt gehabt haben. Ich glaube deshalb auch, dass man die Erde nicht in eine nördliche und südliche Halbkugel teilen muss, wenn man die faunistischen Verhältnisse rerstehen will, sondern in eine Land- und in eine Wasserhalbkugel. Nicht der Nordpol ist demnach das Schöpfungszentrum der Landfauna, sondern der Mittelpunkt der Landmassen. Man darf aber nicht annehmen, wie es von etlichen Seiten nach Lektüre meines Aufsatzes in Bezug auf den Nordpol geschehen ist, dass die Umbildung der Tierwelt gerade in unmittelbarster Nähe des Mittelpunktes der Landhemisphäre stattgefunden hätte, sondern man muss als das Hauptumbildungsgebiet der Landtiere den grossen Kontinentalkomplex betrachten, der diesem Mittelpunkte benachbart ist. In der That habe ich auch nichts anderes gewollt, und ich habe auch gesagt, dass sich alle grösseren Gruppen der Landtiere von dem in der nördlichen Erdhalbkugel gelegenen Kiontinentalkomplex aus, dessen Mittelpunkt der Nordpol ist, über die Eirde verbreitet haben. Heute würde ich anstatt Nordpol Mittelpunkt von Centralasien sagen. Mittelasien scheint wirklich seit alten Zeiten der Hauptumbildungsherd der Tierwelt des Landes gewesen zu sein. Von hier aus haben Europa und, so oft es anging, auch Nordamerika, Einwandererschübe erhalten. Dass die Umbildung der Tierwelt im Osten von Europa schneller ror sich gehen muss als im Westen, lehren beispielsweise schon manche unserer deutschen 
Vögel. Der Dompfaff", der Raubwürger, die Nachtigall, der Uhu und manche andere laben im Osten grössere und höherstehende Vertreter, und hier haben ja auch noch in jüngstrergangener geologischer Zeit Riesentiere wie das Mammut gelebt.

Wer unbefangen die Verbreitungsserhältnisse der Tiere überblickt, der wird zu dem Satze gelangen, dass die Entwickelungshöhe eines Tieres unter übrigens gleichen Umständen beleutender ist, je mehr sich dessen Terbreitungsgebiet dem Mittelpunkte von Centralasien nähert, und ich kann auch mit Genugthuung konstatieren, dass die von mir entwickelten Anschaungen, meines Wissens wenigstens, mehr Zustimmung als Widerspruch gefunden haben. Ich hoffe, dass meine Ausführungen noch mehr Beachtung finden werden, nachdem ich im vorliegenden Werke die Faunistik mechanisch durch meine Gemmarienlehre begründet habe, und nachdem ich in der "Schöpfung der 'Tierwelt" viele Beweise für die Richtigkeit meiner Verbreitungslehre beigebracht habe. Ich glaube auch, dass die Fortbildung, welche ich mit den Ideen von Moritz Wragner vorgenommen habe, der Beachtung wert ist.

In der Form, in wolcher dieser ausgezeichnete Tiergeograph seine Anschauungen vorbrachte, mussten sie viel Widerspruch erfahren. Ich glaube aber den Nachweis führen zu können, und werde es in einem voraussichtlich im nächsten Frühjahı erscheinenden Werke thun, dass Wagner mit dem Satze recht hatte, dass nächstverwandte Tierarten netz- oder kettenförmig ïber die Erde rerbreitet sind. In ther Begründung dieses Satzes, wie ron Wragner schon viel besser rorgenommen ist, als ich es jemals zu thun im stande sein werde, liegt das grosse Verdienst des leider viel zu wenig beachteten und ohne grosse Ancrkennung verstorbenen Begründers cines der wichtigsten Sätze nicht nur der Ticrgeographie, sonden der Entwickelungslehre äberhaupt. Ich kimn nicht mmhin, meiner Genugthuung darïber Anstruck zu geben, dass ich die Thatsachen, auf welchen Wagner fusst, kausal durch dic fiemmarienlehre begründen konnte.

Dass in manchen faunengebieten die Tiere in der Entwickelung zurückgeblicben sind, hat auch, frilich erst im Jahre 1858, Eimer hervorgehoben, wobei or insbesondere darauf hinwies, dass che Säugeticre Australiens auf einer tiefen stufe der Entwickelung stehen geblichen sind. Allerdings vermag ich ihm nicht beizustimmen, wenn er meint, dass die Gleichförmiglieit des australischen Gehietes für die Einförmigkeit der dortigen 'lier- und l'flanzenwelt mit rerantwortlich gemacht 
werden muss. Allerdings lat sic eine untergeordnete Rolle gespielt; allein die Hauptursache des /urïckbleibens der australischen Säugetiere liegt in der Kleinheit des australischen Kontinents. Aber Eimer hat recht, wenn er die einseitigen Anpassungen mancher australischer Beuteltiere, die gewissermassen die Nagetiere, Wierlerkäuer und andere Säugergruppen der ausseraustralischen Gebiete rertreten, auf ummittelbare Anpassungen zurüickfülırt.

Eimer hat ein Gesetz der Genepistase oder des Entwickelungsstillstandes aufgestellt, und ich glaube, dass anch dieses Gesetz in der Gemmarienlehre seine Begründung findet, namentlich in dem Satze. dass die 'Tielarten auf kleinen Gebieten hinter denen der grösseren Gebiete in der Umbildung zurückbleiben müssen; denn der Entwickelungsstillstand muss notwendigerweise seine Ursache in äusseren Terhältnissen haben.

Wenn ich demnach in Bezug auf die Erklärung der Faunenentwickelung vielfache Berührungspunkte mit früheren Forschern und mit solchen, die sich erst nach dem Eischeinen meines oben citierten Aufsatzes über die Faunenverhältnisse in ähnlicher Weise wie ich ausgesplochen haben, feststellen kann, und gerne anerkenne, dass ich namentlich Wrallace und Moritz Wagner zu grossem Danke rerpflichtet bin, so muss ich doch auch andererseits betonen, dass die kausale Begründung der bisherigen Tiergeographie eine ungenügende war, und dass erst die Gemmarienlehre ein Verständnis der Ursachen anbahnt, welche die Tiere des einen Gebietes unaufhaltsam weiter fortschreiten, die des anderen auf tiefer Entwickehungsstufe stehen bleiben liess. Aus der Gemmarienlehre ergiebt sich der Hauptsatz für die Tiergeographie der Zukunft, und dieser Satz lautet: Wenn alles andere sich gleich bleibt, sei es, dass es sich um Landtiere, un Meeresbewohner oder um Tiere des Süswassers handelt, so findet dort die schnellste Umbildung der Tiere statt, wo sich das ausgedehnteste Wohngebiet erstreckt. Ich glaube, dass auch die Botaniker diescm Satze ihre Zustimmung in Bezug auf die Pflanzenwelt nicht versagen werden.

Mit der hier entwickelten Ansicht ron der Entstehung der Faunen scheint sich auf den ersten Blick eine andere, die neuerdings ron Pfeffer dargelegt worden ist, nicht zu vertragen. Pfeffer sucht sich die Entstelung der Faunen, und zwar in erster Linie der Meeresfaunen, auf Grund der Anmalme zu erklären, dass das Meer urspriunglich ron 
einer einheitlichen Tierbevölkerung bewohnt wurde. Nach dem Eintreten von klimatischen Unterschieden hätten sich dann aus den Eismeeren und den gemässigten Meeren diejenigen Tiere äquatorwärts zurüickgezogen, die der Kälte nicht zu widerstehen vermochten, und nur solche Tiere seien in den gemässigten und kalten Meeren geblieben, die von vornherein der Kälte Trotz zu bieten vermochten. Diese Tiere hätten freilich auch in den Meeren der heissen Zonen gelebt, wären aber hier von den Tieren, die nur in warmen Meeren fortkommen konnten, gewissermassen überwuchert worden und zu Grunde gegangen. Daraus erkläre sich die grosse Übereinstimmung der Tierwelt der nördlichen und südlichen Meere, die durch lleere mit einer sehr versehiedenen Fauna roneinander getrennt sind. Auf ähnliche Weise sucht Pfeffer die Entstehung der Tiefsee- und Süsswasserfauna zu erklären. Solche Tiere hätten sich zu Tiefsee- und Süsswassertieren umgebildet, die von vornherein dazu befähigt waren, und da sie früher gleichmïssig über alle Meere der Erde verteilt waren, so musste die Tiefseefauna einerseits, die des Süsswassers andererseits eine so grosse Einförmigkeit erlangen, wie wir sie in Bezug auf diese Faunen feststellen können. Auf die Tierwelt des Landes ist Pfeffer nicht näher eingegangen, aber er scheint geneigt zu sein, auch für sie eine ursprünglich viel gleichmässigere Verteilung anzunehmen.

Ich bin den lichtrollen Ausfïhrungen Pfeffer's mit grossem Interesse gefolgt und glaube nicht, dass sie meinen tiergeographischen Anschauungen widersprechen, denn unsere Ansichten lassen sich sehr wohl vereinigen. Pfeffer wird gewiss nicht annehmen, dass es in Australien neben Beuteltieren früher Löwen und 'Tiger, Hirsche und Faultiere, Bisons und Dachse, Antilopen und Guanakos, Pferte und Gürteltiere gegeben habe, denn die Sonderung der Fauna Australiens von der der übrigen Erde hat sich schon zu einer Zeit vollzogen, als es solche Tiere überhaupt noch nicht gab. Sie konnten nicht nach Australien gelangen, und es kamn daher von einer Australien umfassenden Einheitlichkeit der Landfauna unserer Erde nur insofern die Rede sein, als frühere Erdperioden in Betracht kommen. Gewiss ist es möghich, und das nimmt anch Pfeffer, wie es scheint, an, dass die Sängetierbevölkerung Australiens, um bei dieser zu bleiben, zur Sekundärzeit ungefähır dieselbe war, wie etwa bei uns in Deutschland, aber seitlem haben nur diejenigen Erdteile an der Fortentwickehung der Tierwelt der grossen nordischen Gebiete teilnehmen können, die mit ilmen im Zusammenhang blieben orler, auch wenn das nicht der Fall war, der Einwanderung der nordischen 
Tiere keine unübersteiglichen Grenzen entgegensetzten. Wenn keine Faunengrenzen auf der Erde vorhanden wären, wenn Neuseeland, Australien und Madagaskar noch heute mit dem Norden verbunden wären, wenn Südamerika, Australien und Indien leichter vom Norden aus zugänglich wären, als sie es sind, und wenn eine bequeme Landverbindung zwischen Nordamerika und dem Norden der alten Welt existierte, so würde wahrscheinlich die Landfauna der Erde überall dieselbe sein, vorausgesetzt, dass auch die Lebensbedingungen an allen Orten die nämlichen wären. Die meisten Tierarten würden dann genügende Zeit gehabt haben, sich über die ganze Erde zu verbreiten, wie es trotz aller möglichen Hindernisse etliche Arten auch thatsächlich gethan haben. Allein es haben seit jeher auf dem Lande mehr oder minder scharfe Faunengrenzen bestanden, und da diese in völlig regelloser Weise die Oberfläche des Landes in verschieden grosse und verschieden beschaffene Gebiete teilten, so musste sich in allen diesen Gebieten eine besondere Tierwelt entwickeln, und eine Verbreitung auf die iibrigen Gebiete war vor allem den Tieren desjenigen Gebietes möglich, das vermöge seiner weiten Ausdehnung eine lebhafte Gefüge- und Rassenzucitwahl zuliess. Die Anschauung Pfeffer's, wonach sämtliche Tiere ursprünglich gleichmässig verteilt waren, muss demnach bis zu einem grewissen Grade modifiziert werden. Ist das aber geschehen, so lässt sie sich sehr wohl mit dem oben formulierten Grundgesetz der Tierverbreitung vereinigen.

Ich kann diesen Abschnitt nicht schliessen, ohne auf die Bedeutung hinzuweisen, welche die Tiergeographie für die allgemeine Entwickelungslehre besitzt, und dieser Wert ist auch in anderen Ländern, namentlich in England und Nordamerika, schon erkannt. Bei uns in Deutschland hingegen, wo den Tierkundigen mehr und mehr die Kunde von unzerstückelten Tieren, namentlich von Säugetieren und Vögeln, insbesondere auch von denjenigen unseres eigenen Vaterlaudes, abhanden gekommen ist, bleiben tiergeographische Bestrebungen seitens der Mehrzahl der Zoologen völlig unbeachtet. Ich wollte schon hier auf diesen Zustand hinweisen, werde aber Gelegenheit haben, in einem späteren Abschnitte darauf zurückzukommen. Hier möge es genügen zu betonen, dass derjenige, dem es um das Verständnis der allgemeinen Entwickelungslehre zu thun ist, einer eingehenden Kenntnis der Tiergeographie nicht zu entraten vermag. 


\section{h. Die Erklärung des Epimorphismus.}

Eine Erklärung der stufenfulge der organischen Entwickelung. die wir als Epimorphismus bezeichnet hahen, ist schon durch die rorherigen Abschnitte gugreben. Wir haben unter Epimorphismus die \%unelumende Höhe der Entwickelungsvollkommenheit rerstanden, die im Laufe der stammesgeschichtlichen Entwickehng zu Tage tritt, und rlie wir auch noch an den heute lebenten Organismen beobachten können. Wir können diese letzteren in Reihen ordnen, die ron Anfang bis zu Ende eine stetig zunchmende Vollkommenheit der Formbildung zeigen. Diese Entwickelungsvollisommenheit darf nicht verwechselt werden mit Anpassungsrollkommenheit, wie es seitens der othodoxen Darwinisten geschicht: sie ist nicht durch die ,uatiirliche Zuchtwahl. Darwin's und seiner Anhänger zn stande gekommen. Freilich müssen wir diese letztere Behauptung etwas einengen, nachdem wir gezeigt haben, rlass eine Individual- und (ine Riksenselelition, eine konstitutionelle und eine dotationclle Auslese zu unterscheiden sind. Die Anpassungsrolliommenheit ist zu stande gekommen teils durch direkte äussere Einflüsse und den Gebranch und Niehtgebrauch der Organe, teils durch dotationelle Rassenselektion: dagegen ist die Entwiekehmgsvollkommenheit lediglich durch die anf ras Plasna festigend einwirkenden änsseren Einflüsse und durch eine konstitntionelle Indixidualselektion, welche die Individuen mit gefestigtem Plasma zur Fortsetzung des Stammes bestimmte und die mit gelockertem Gefü̈ge zn Grunde gehen liess, erzielt worden.

Organismen. deren Plasma cin festeres ist als das der nächsten Verwandten, konnten schäıligenden ̈̈usseren Linflüssen, wie sie in grosser Anzahl auf den Ther- und P'tlanzenkïrper einwioken, leichter widerstehen, als solche mit gelorkertem Plasmagefüge. Sie hatten deshalb auch (ielegenheit, ans der Nahrung neues Plasma zn assimilieren, dadurch ihr Wachstum zn berhleungen und rino beträchtlichere Körpergrösse zu erlangen. Da ihr l'lasma ein immer festeres wurde, so lionnten immer mehr \%ellen im Zusimmenhang mit den schon bestehenden Zellenverbande des Körjurs bleiben. so dass die Körpergrösse immer boträchtlicher werden musstr. I)ic nel hinzukommenden Zellen entstanden aber nicht an allen hörperstellen, sondern namentlich an den Spitzen des ontogenetischen \%ellenbal.mes, als welchen wir den 'T'ier- und Pflanzenkörper auffassen können. Die Fortentwiclichung der Organismen musste dadurch eine ganz bestimmte Richtung changen. Ls kam thin aber noch ein Zureites, 
nämlich die im Laufe der Phylogenese stetig abnehmende Selbstbestimmung der einzelnen Zellen. Der Zellenverband des Körpers wurde infolge der Gefügefestigung durch konstitutionelle Zuchtwahl ein immer innigerer, und dadurch mussten die einzelnen Teile des Organismus immer ungleicher werden, denn der Organismus wurde mit der abnehmenden Autonomie der ihn zusammensetzenden 'Zellen ein immer einheitlicheres Gebilde. Notwendigerweise musste dadurch die Anzahl der homologen Teile herabgesetzt oder, sofern dies nur in beschränkter Weise stattfand, die ungleichmässige Ausbildung homologer Teile eine immer stärker herrortretende werden. Da, wie wir gesehen haben, das Plasma der Keimzelle schon dasjenige sein muss, das die Art überhaupt charakterisiert, so hat es auch schon alle Eigenschaften, welche den Plasma der betreffenden Art zukommen. Es müssen demnach schon die ersten Generationen des Zellenstammbaumes des Körpers einen viel festeren Zellenverband darstellen, als bei auf tiefer Entwickelungsstufe stehenden Organismen, und dadurch wurde es verhindert, dass sich an manchen Stellen Zellen bildeten, an welchen früher noch welche entstanden waren, um zur Entwickelung zahlreicher homologer Teile zu dienen. Je einheitlicher der Zellenverband des Körpers wurde, desto mehr mussten bestimmte Richtungen der Zellteilungen begünstigt werden. Der Körper konnte sich nicht mehr so gleichmässig nach allen Seiten hin entwickeln wie früher, und die Wirkung davon war, dass homologe Teile ungleich wurden und an Zahl nach und nach abnahmen.

Aus diesem Epimorphismus der Entwickelungshöhe erklärt sich dann auch der Epimorphismus der Anpassungsrollkommenheit, der auf Grund des reinen Darwinismus überhaupt nicht zu verstehen ist. Durch die Erhöhung der Entwickelungsvollkommenheit oder, was dasselbe ist, der Gefügefestigkeit, d. h. der Stabilität des plasmatischen Gleichgewichts, wurden, wie wir eben geseheu haben, homologe Teile mit Notwendigkeit ungleich, dadurch konnten sie nicht mehr alle auf dieselbe Weise mit der Aussenwelt in Berührung kommen, und die einen mussten sich deshalb in anderer Weise der Úmgebung anpassen, als die anderen. Wir wollen dies an einem Beispiel, etwa an dem fünfzehigen Fusse eines Tieres, dessen Zehen alle gleich lang waren und alle in gleicher Weise mit der Aussenwelt in Berührung kamen, erläutern.

Gefügefestigung soll die Zehen ungleich g'emacht haben. Lief das Tier etwa auf den Zehenspitzen, so mussten diejenigen Zehen, welche die längsten waren, am ausgiebigsten mit dem Boden in Berührung 
kommen; sie wurden deshalb durch den Gebrauch gestärkt, während die anderen infolge von vermindertem Gebrauch geschwächt wurden. Die Ungleichheit in der Länge der Zehen musste also eine immer stärkere werden, je nachdem die einzelnen Zehen in mehr oder minder ausgedehnte häufige Berührung mit dem Boden kamen. Dazu kam, dass auch die Gefügefestigung weiter arbeitete und die Zehen mehr und mehr ungleich machte. Es arbeiteten sich also Gefügefestigung und direkte Anpassung Hand in Hand, und auf diese Weise konnten Tiere entstehen, die, wie die Pferde, an allen vier Füssen nur noch eine einzige entwickelte Zehe und ausserdem nur noch sehr schwache Rudimente von zwei anderen haben. Gewiss ist der Pferdefuss eine höchst zweckmässige Einrichtung, und wemn wir auch den Neudarwinisten zugestehen wollten, dass er unter Unständen durch die natürliche Zuchtwahl im Sinne Darw in's erklärt werden könnte, so würde es doch unmöglich sein, auf Grund des Darwinismuss eine Erklärung für die allgemeine und ausnahmslose Regel zu finden, wonach die Anpassung eines Organes stets in einer Richtung weiter geht, wenigstens die solcher Organe, wo direkter Gebrauch und nicht indirekter Nutzen, wie etwa bei der Färbung, in Betracht kommt.

Die Entwickelungsreihen, die wir auf Grund der Organvergleichung aufstellen können, zeigen nie und nirgends einen Rückschritt in der einmal eingeschlagenen Anpassungsrichtung, wenn die Anpassung aber allein bedingt wäre durch Auslese zwischen Organen, die jederzeit nach allen möglichen Richtungen hin variieren, wie es der Darwinismus annimmt, so müssten wir Formenreihen aufstellen können, in denen, um auf unser vorheriges Beispiel zurückzuliommen, etwa ein fünfzehiger Fuss mit lauter gleichen Zehen überging in einen solchen, bei dem die Zehen sehr ungleich geworden waren, während dieser sich etwa wieder in einen gleichzehigen Fuss verwandelte und der letztere wieder ungleichzehig wurde, aber in völlig anderer Weise als vorher. Entwickelungsreihen, in welchen solches oder ähuliches stattgefunden haben könnte, kennen wir uicht, und doch müssten sie zahlreich sein, wenn dotationelle Individualselektion die Formenbildung beherrschte. Indessen haben wir diesen Gegenstand schon früher erörtert und branchen deshalb nur nochmals hervorzuheben, dass der Epimorphismus der Entwickelungsvollkommenheit sowohl wie der der Anpassungsvollkommenheit allein durch die Theorie der Epigenesis in befriedigender Weise zu erklären ist. 


\section{i. Geschlechtliche Fortpflanzung.}

Das Wesen der geschlechtlichen Fortpflanzung ist durch keine der bisherigen Theorien in befriedigender Weise aufgeklärt worden. Die allermeisten Forscher, die darüber nachgedacht haben, betrachten die geschlechtliche Fortpflanzung als eine Art Verjüngung; aber Weismann hat recht, wenn er diese Erklärung als ungenügend bezeichnet, denn es müsste doch gezeigt werden, wie durch Verbindung zweier verschiedener Plasmen eine Verjüngung zu stande kommen kann. Das ist bis jetzt nicht geschelıen. Wir werden zwar sehen, dass man die Wirkung der geschlechtlichen Fortpflanzung in der That als ein Ergebnis betrachten kann, den man, wenn man will, den Namen Verjüngung beilegen darf, allein es wird sich zeigen, dass erst unsere Theorie Anspruch darauf erheben darf, das, was durch die geschlechtliche Fortpflanzung erreicht wird, als eine Art Verjüngung zu bezeichnen. Ehe wir aber dazu übergehen, das Wesen der geschlechtlichen Fortpflanzung aus der Gemmarienlehre zu erklären, müssen wir auf W eismann's Theorie über die Bedeutung der geschlechtlichen Fortpflanzung etwas näher eingehen.

Weismann betrachtet die geschlechtliche Fortpflanzung als eine Einrichtung, dazu bestimmt, immer neue Kombinationen von Ahnenplasmen, von Iden, zu schaffen, um dadurch der natürlichen Zuchtwahl Gelegenheit zu geben, die günstigsten Kombinationen auszuwählen. Wie diese Einrichtung zu stande gekommen ist, hat Weisman n nicht gezeigt. Man könnte annehmen, dass die natürliche Zuchtwahl Organismen mit geschlechtlicher Fortpflanzung allmählich herangezüchtet hätte; aber durch diese Annahme wird weder üher den Ursprung der geschlechtlichen Fortpflanzung, noch über die Entstehung der Bedeutung, die sie nach Weismann besitzt, Licht verbreitet. Wenn sie allmählich herangezüchtet worden ist, so müsste sie doch erst eimmal dagewesen sein, d. h. es müsste Organismen gegeben haben, die sich gelegentlich vereinigten, um fortan einen einzigen Organismus zu bilden. Was die Organismen zur Vereinigung trieb, darüber hat uns Weismann rollständig in Dunkel gelassen, und es dürfte auch unmöglich sein, die erste Lintstehung der geschlechtlichen Fortptlanzung auf Grund der Weismann'schen Lelıre zu erklären. Wir wollen aber einmal annehmen, dass bei einer Organismenart, wo bis dahin noch keine geschlechtliche Fortpflanzung bestand, etliche Individuen anfingen, mit anderen zu verschmelzen. Durch die Verschmelzung zweier Individuen zu einem 
einzigen wnrde ein grösseres Indivirluum geschatfen, als es sonst bei der betreffenden Organismenart üblich war, und man kïnnte nun annehmen, chass gerade solche Individuen einen Vorteil im Kampfe ums Dasein vermöge ibrer Körpergrösse gुclabt häitten. Wenn wir aber bedenken, dass nach Weismann's Annalume alles geziichtet ist, so ist es auch die Körpergrösse, und wenll diese bei der betreffenden Organismenart eine bestinnte war, was wir doch annehmen minssen, da eben alles, was existiert, nach Weismann nuitzlich ist und deshalb nicht innerhalb weiter Grenzen valieren kann, so kaun furch Verschmelzung zweier Individuen zu einem einzigen kein Vorteil erreicht worden sein. Man kann nun allorlings sagen, dass nicht \%wei ausgewachsene Individuen, sondern zитеi Individuen, die durch T'uilung ihrer Eltern entstanden waren. rerschmelzen, und dass deshalb der durch die Verschmelzung grebildete nene Organismus nicht grösser war, als die Filtern der beiden rereinigten Individuen. Allein bei dieser Annahme sieht man nicht ein, weshalb die Eltern sich zu teilen brauchten, denn wenn sie es thaten, so kamn es doch nur deshalb geschehen sein, weil sie die Grenze des individuellen Maasses erreicht oder bereits überschritten hatten. Dadurch, dass sich zwei aus der Zweiteilung hervorgegangene Individuen wieder zu einem einzigen rereinigten, wurde also ein Organismus grzengt, der wiederum die Grenze der individuellen Grösse bereits erreicht oder auch schon wieder überschritten hatte. Es wäre also durch die Vereinigung auf keinen Fall etwas gewonnen gewesen.

Ich glanbe auch nicht, dass We ismann Annahmen, wie wir sie eben gemacht haben, gelten lassen würde, sondern dass er die Bedeutung rer geschlechtlichen Fortpflanzung auch fïr solche Organismen, bei denen sie bis dahin noch nicht hestand, in anderen Umständen suchen wïrde. Wil wollen also eimmal die Ammalme machen, dass ein aus der Kopulation zweier bis dahin getrenuter ludividuen erzengtes neues Individum deshalb einen Vorteil iiber nicht durch Kopulation entstandene Individuen hatte, weil in seinem Körper \%wei verschierlene Plasmenarten vereinight waren. Diese Annahme ist aber zu allgemeiner Natur, und wir müssen deshalb versuchen, uns darüber eine Vorstellumg zu maclien, weslaalb die Vereinigung zweier verschiedoner Plasmen von Vorteil für das durch Tíopulation entstandene Individnmm war. Da es siclı dabei nur um allereinfachste Organismen laandeln kann, weil ja die geschlechtliche Fortpflanzung eine malte und bei den heute lebenden Organismenarten eine fast allgencine ist, so nüissen wir annehmen, flass die hetreffende Organismen- 
art nur eine einzige Art ron Plasma in jedem Individuum barg, d. $\mathrm{h}$. dass sie nur durch eine "Determinante" in jedem Individuum bestimmt war. Diese Determinante wird freilich, wie wir nach Weismann annehmen müssen, etwas verschieden gewesen sein von allen oder wenigstens von den meisten anderen Determinanten der übrigen Individuen unserer Organismenart, und daraus würde sich der Schluss ergeben, dass die Vereinigung zweier verschiedener Determinanten, oder zweier verschiedener Ide, deren jedes aus einer Determinante bestand, vielleicht von Vorteil für das durch diese Kopulation erzeugte Individuum war und deshalb als nützliche Einrichtung weiter gezüchtet wurde. Es ist aber nicht einzusehen, auf welche Weise das hätte geschehen können, denn es sind doch nur drei Fälle denkbar. Wir können erstens annehmen, dass die beiden sich vereinigenden Ide gleich gut für den Kampf ums Dasein ausgerüstet gewesen sind, dass sie alle beide im höchsten Grade den Anforderungen entsprachen, welche die Lebensverhältnisse der Art erhoben. Dann würde der Vorteil der Vereinigung doch nur in einer Zunahme der Masse bestehen, und dass dies ron keinem Vorteil sein konnte, haben wir soeben gezeigt. Wir können aber auch zweitens eine Verschiedenheit in der Anpassungsvollkommenheit der beiden sich vereinigenden Plasmen annehmen, so dass das eine besser den Anforderungen, welche die Aussenwelt stellte, entsprach, als das andere. Das erstere würde dann von der Vereinigung nur einen $\mathrm{N}$ achteil gehabt haben, und es wäre nicht einzusehen, weshalb natürliche Zuchtwahl die Vereinigung zweier Plasmen, von denen das eine nicht gut angepasst war, begünstigt haben sollte, denn es wäre doch viel einfacher gewesen, das gut angepasste nicht durch Vereinigung mit einem schlecht angepassten zu verschlechtern, sondern das schlecht Angepasste zu Grunde gehen und das gut Angepasste fortbestehen und sich fortpflanzen zı lassen. Es bleibt also auch bei dieser zweiten Annahme unverständlich, wie die Einrichtung der geschlechtlichen Fortpflanzung durch Naturziichtung zu stande gekommen sein soll. Nehmen wir aber gar drittens an, dass beide sich vereinigende Plasmenarten nicht besonders gut angepasst waren, so konnte auch durch ihre Vereinigung nichts entstehen, was natürliche Zuchtwahl begïnstigt haben könnte.

Wir haben durch diese Betrachtungen gezeigt, dass eine Lehre, wie sie Weismann vorgetragen hat, der Erklärung der ersten Entstehung geschlechtlicher Fortpflanzung völlig ratlos gegenübersteht, und es ist überhaupt nicht einzusehen, wie durch Hischung ron Plasmen verschie- 
dener Güte etwas Besseres zu stande kommen soll, als wenn die gut angepassten Plasmen für sich bleiben. Es ist doch wahrlich viel einfacher, anzunehmen, dass natiirliche Zuchtwahl eben nur die gut angepassten Plasmen bestehen lässt; thut sie aber das, so bleibt die geschlechtliche Fortpflanzung unerklärt.

Wir wollen aber einmal annelımen, dass in der That durch Mischung verschiedener Plasmen ein Vorteil zu erzielen wäre, dass also die durch Kopulation gebildeten Individuen einer Organismenart, bei welcher geschlechtliche Fortpflanzung bis dahin nicht eingeführt war, im Kampfe ums Dasein überlebten, während die anderen Individuen zu Grunde gingen. Aber auch, wenn wir diese Annahme machen, so verstehen wir nicht, wie die aus der Teilung solcher Individuen hervorgehenden Nachkommen dazu gekommen sein sollten, sich ihrerseits wieder mit anderen Individuen zu verbinden. Man wird einwenden, dass sie die Fähigkeit dazu von ihren Eltern, die ja auch durch Kopulation entstanden wären, ererbt hätten. Allein es muss doch erklärt werden, wie eine solche Tererbung zu stande kommen konnte, und das vermag die Weismann'sche Lehre nicht darzuthun. Wir haben ja schon vorhin gezeigt, dass Weismann nicht zu sagen rermag, warum plötzlich einmal zwei Individuen dazu kommen sollten, sich zu vereinigen, wie ja überhaupt die Weismann'sche Lehre uns bezüghich der wirklichen Ursachen der Umbildung der Organismen vollständig im Dunkel lässt. Wir wollen aber annehmen, dass bei zwei sich vereinigenden Individuen irgend eine Ursache vorhanden war, welche diese Individuen zur Vereinigung trieb. Aber auch dann bleibt es unverständlich, weshalb die aus Teilung solcher Individuen hervorgehenden Tochterindividuen wiederum diesen 'Trieb haben sollten, denn durch Vereinigung zweier rerschiedener Plasmen wird ja etwas Neues erzeugt, das andere Eigenschaften hat, als jedes der beiden Plasmen vor der Vereinigung, und es ist nicht einzuschen, weshalb sich der Trieb, der die beiden ursprïnglichen Plasmen zur Vereinigung bestimmte, vererbt haben sollte. Man könnte nun zwar sagen, die beiden Plasmen hätten sich bei der Fortpflanzung des durch liopulation entstandenen Individuums wieder getrennt, hätten dadurch ihre ursprünglichen Eigenschaften zurückerhalten, und zu diesen gehörte der Trieb, sich mit anderen Plasmen zu verbinden. Durch eine solche Annahme würden wir aber in Widerspruch geraten mit der Annahme einer Amphimixis, denn wenn cine solche besteht, so musste es verhindert werden, dass sich beide Plasmen wieder voneinander tremnten. 
Wir müssten also wohl die Annahme machen, dass aus der Fortpflanzung eines durch Kopulation entstandenen Indiriduums wieder Tochterindividuen mit zwei Plasmen herrorgingen und dass diese den Tereinigungstrieb ihrer Grosseltern geerbt hätten. Wie das aber möglich war, ist nicht zu begreifen, denn der Vereinigungstrieb mïsste doch durch die erfolgte Vereinigung befriedigt worden sein, und er konnte niclit wieder aufleben, wenn die vereinigten Plasmen sich nicht wieder voneinander trennten. Die Vererbung des Vereinigungstriebes bleibt also unerklärt, und damit ist ein Verständnis der Entstehung der geschlechtlichen Fortpflanzung durch natürliche Zuchtwahl unmöglich gemacht. Es bleibt eben dann keine andere Annalıme, als dass die Plasmen, welche sich ursprünglich vereinigten, von einem so unersättlichen Kopulationstriebe beseelt gewesen wären, dass fortgesetzte Vereinigung nötig war. Dass eine solche Anuahme nichts erklärt, liegt auf der Hand.

Die Weismann'sche Lehre erweist sich also, wie man die Annahmen auch drehen und wenden mag, als absolut unzureichend zur Erklärung einer so allgemeinen Ein richtung, wie es die geschlechtliche Fortpflanzung ist. Wir haben ja überdies gezeigt, dass das, was Weismann Amphimixis nennt, konsequenterweise zu Folgerungen führt, denen die Natur unmöglich entsprechen kann. Je mehr verschiedenartige Plasmen sich vereinigen, desto mehr Individuen müssen erzeugt werden, damit überhaupt ein den Anforderungen der Aussenwelt entsprechendes Individum zu stande kommt. Es lässt sich leicht zeigen, dass die Fortpflanzung eine über alle Begriffe grosse Menge von Individuen in jeder Generation erzengen muss, so gross, dass die Oberfläche der Erde sich zu der eines Weltkörpers, auf welchem die notwendige Anzahl ron Individuen Platz finden könnte, verhalten müsste wie die einer Erbse zu der der Sonne. Es wäre also eigentlich überflüssig gewesen, hier den hoffnungslosen Tersuch zu unternehmen, die Entstehung der geschlechtlichen Fortpflanzung auf Grund der Weismann'schen Amphimixislehre zu erklären. Allein, bei der Zähigkeit, mit welcher We ismann an unhaltbaren Annahmen festhält, haben wir es für gut gehalten, auch in diesem Abschnitte zu zeigen, dass We ismann's Lehre völlig unfähig ist, die Thatsachen der Biologie zu erklären, dass sie ihre Existenz nur fristen kann, wenn sie sich einfach über diese Thatsachen hinwegsetzt. Wir wenden uns deshalb wieder jenen älteren Anschauungen zu, die in der geschlechtlichen Vererbung eine Art Verjüngung des Individuums erblicken, und wollen nunmehr zeigen, dass es sich dabei in der That um etwas handelt, was, wie schon 
oben gesagt, allenfalls als Verjüngung bezeichnet werden könnte. Wir werden aber darzuthum haben, dass sich für den unbestimmten und im Grunde genommen nichtssagenden Begriff der Verjüngung ein Begriff bestimmten Inhalts substituieren lässt.

Nach unserer Lehre ist das Plasma aus Gemmarien ron bestimmtem Bau zusammengesetzt, und diese selbst sind aus Gemmen aufgebaut, die sich in einer bestimmten Art und Weise aneinander gelagert haben. Diese Aneinanderlagerung ist lediglich bedingt durch die allgemeinen phrsikalischen und chemischen Zustände der Aussenwelt und durch besondere Verhältnisse im Aufbau der verschiedenen Organismenarten, sie verändert sich also, wenn sich die äusseren Einflüsse verändern, und wenn die Organe der Organismen in anderer Weise gebraucht werden als bisher. Dadurch kann, wie wir genugsam betont haben, und wie ja aus unserer Annahme olne weiteres herrorgeht. sowohl eine Lockerung, als auch eine Festigung des Gemmariengefüges, d. h. des Aufbaues der Gemmarien aus Gemmen, herrorgebraclit werden. Es entstehen also durch äussere Einflüsse Individuen mit festerem und mit gelockertem Gefüge, voll welchen die ersteren in Kampfe ums Dasein bestehen, während die letzteren zu Grunde gehen. Dass die letzteren sterben, könnte aber dadurch verhindert werden, dass ihr Gefüge wieder so gefestigt wird, dass sie ebensoviel Aussicht im Kampfe ums Dasein, wie diejenigen Individuen, bei welchen keine Lockerung des Gefüges eingetreten ist, haben. Eine solche Wiederbefestigung kann aber stattfinden, wenn sich zwei Individuen mit etwas rerschiedenem Plasma zu einem einzigen rereinigen. Durch die Vereinigung müssen die Gemmarien der beiden Plasmaarten miteinander vermischt werden, so dass sich in vielen Fällen Gemmarien der einen Art an Gemmarien der anderen anfügen können. Es wird den Gemmarien dadurch Gelegenheit gegeben, sich miteinander ins Gleichgewicht zu setzen, d. h. ihre Ungleichheiten a uszugleichen. Wie das geschehen kamn, sehen wir, wemn wir bedenken, dass sich die Gemmen innerhalb der Gemmarien notwendigerweise gegeneinander rerschieben müssen, wie es etwa geschehen würde, wenn zwei mit anziehenden Kräften und verschiebbaren Winkeln begabte Parallelogramme sich mit einer ihrer als gleichlang angenommenen Seiten aneinanderlegen. Die ungleichen Winkel der beiden Parallelogramme würden sich durch gregenseitige Einwirkung ausgleichen, d. l. es würden dadurch zwei gleiche Parallelogramme entstehen, und zwar zwei Parallelogramme, deren Seiten sich nicht so leicht verschieben, wie es bei den 
beiden aufeinander einwirkenden Parallelogrammen möglich war. Denn der Winkel, der bei dem einen der letzteren zu gross war, war bei dem anderen zu klejn, und umgekehrt. Ähnliches müsste auch bei der Vereinigung zweier Gemmarien stattfinden. Es müssten dadurch nene Gemmarien entstehen, deren Gefüge weder nach der einen, noch nach der anderen Seite hin zu sehr ron derjenigen Gleichgewichtslage abweicht, welche die am wenigsten labile ist.

Aus diesen Betrachtungen geht also hervor, dass die geschlechtliche Vereinigung von grossem Vorteile für die Organismen sein muss, denn durch sie wird das gelockerte Gefüge der Gemmarien ein festeres und weniger leicht hinfälliges. Es handelt sich also bei der geschlechtlichen Fortpflanzung nicht darum, dass eine Mischung verschiedener Plasmen zu stande kommt, sondern dass diese eine annähernde Ausgleichung zur Folge liat, dass auch das geschlechtlich gezengte Individuum aus festerem Plasma besteht. Die Bedeutung der geschlechtlichen Fortpflanzung wäre also nicht die Erzielung eines aus vielen verschiedenen Plasmen gemischten Bildungsstoffes, sondern die fortgesetzte Wiederherstellung des plasmatischen Gleichgewichts durch Vereinigung zweier Gemmarienformen, ron denen jede etwas, aber jede in anderer Weise von der erforderlichen Stabilität ihres Gemmenaufbaues abweicht.

Wir haben hierdurch aber nur gezeigt, dass die geschlechtliche Fortpflanzung von grossem Torteil für die Organismen sein muss, nicht aber, wie sie ursprünglich entstanden ist: denn sie konnte nicht elıer von Vorteil sein, ehe sie rorhanden war, und eine vollständige Lösung des Problems ron der Bedeutung der geschlechtlichen Fortpflanzung hat naclizuweisen, durch welche Ursache die Tereinigung zweier Plasmen bedingt wird.

Wie mir scheint, ist diese Ursache nicht schwer aufzufinden, denn es ist eine allgemeine Eigenschaft getrennter Portionen gleichen Stoffes, sich zu vereinigen. $\mathrm{Zu}$ einem Kristall, der sich in einer gemischten Mutterlauge bildet, fügen sich nur solche Moleküle zusammen, die in dem betreffenden Kristallsystem kristallisieren. Stoffe, ron denen der eine im hexagonalen, der andere im triklinen System kristallisiert, treten nicht in die Zusammensetzung eines und desselben Kristalles ein, und was von Kristallen gilt, gilt ron allen anderen Substanzen, welche gleiche chemische Zusammensetzung oder wenigstens dieselbe Molekülform haben. Öltropfen, welche auf dem Wasser schwimmen, fliessen 
leicht zusammen, weil zwischen ihren Teilen eine starke Kohäsion besteht. In der That ist es das, was die Phrsiker Oberflächenspan nung nennen, was bei Vereinigung ron getrennten Stoffportionen in Betracht kommt, und wir dürfen annehmen, dass die Ursache der Vereinigung ron Portionen eines und desselben Stoffes in der gleichen Form ihrer Moleküle zu suchen ist. Moleküle gleicher Art haben alle dieselben Anziehungsrichtungen, sie können deshalb aufeinander einwirken und leieht einen zusammenhängenden Körper bilden, was bei Molekülen verschiedener Art mit verschiedenen Anziehungsrichtungen nicht möglich ist. Auf diese Weise haben wir uns die Vereinigung zweier einzelliger Urtiere oder zweier Keimzellen vorzustellen. Sie bestehen aus Plasmamolekülen von annähernd gleicher Form und fliessen deshalb zusammen; sie ziehen sich gegenseitig an.

Die Ursache der geschlechtlichen Fortpflanzung ist also nicht in irgend welchen besonderen Eigensehaften der Organismen begrïndet, sondern sie ist dieselbe, die auch die Tereinigung zweier getrennter Portionen gleicher unorganischer Substanz bewirkt. Zwischen den Molekülen einer und derselben Substanz besteht keine Oberflächenspannung, weil ihre Anziehungsrichtungen dieselben sind, während Oberflächenspannung da vorhanden ist, wo Moleküle ungleiehen Baues zusammenkommen. Zwisehen den Molekülen eines Öles besteht keine Oberflächenspannung, ebensowenig zwischen den Molekülen des Wassers. Dagegen besteht eine starke Oberflächenspannung zwisehen Ölmolekülen und Wassermolekülen, und deshalb misehen sich Öl und Wasser nicht miteinander. Die geschleehtliche Fortpflanzung ist also ein Vorgang, dessen Entstehung überhaupt nicht erklärt zu werden braucht, weil er eine allgemeine Eigenschaft der IIaterie bedeutet. Wo sich zwei gleiche Plasmen treffen, vereinigen sie sich miteinander, und deshabb ist die geschlechtliche Fortpflanzung auch nur zwischen Individuen möglich, die zu einer Art oder zu einander sehr nahestehenden Arten gehören. Sehr ungleiche Plasmen rereinigen sieh nicht miteinander. Die weite Verbreitung der geschlechtlichen Fortpflanzung erklärt sich also einfach aus denselben Gründen, aus denen sich die Vereinigung gleicher Moleküle überhaupt erklärt.

Allerdings sind die Plasmen zweier versehiedener Individuen auch bei einer und derselben Art nie völlig einander gleich, aber sie sind auch nicht so ungleich, dass sie sich nicht rereinigen könnten. Es treten ja auch Moleküle verschiedener chemischer Substanzen zur Bildung eines 
einzigen Kristalles zusammen, solange sie nur in demselben System kristallisieren, und deshalb ist es auch den Plasmen zweier verschiedener Individuen einer Art möglich, sich miteinander zu vereinigen.

Es ist aber nicht in allen Fällen nötig, dass diese Vereinigung eintritt, deun riele Organismen pflanzen sich durch Jungfernzeugung oder Parthenogenesis fort, und bei manchen Urtieren und vielen Pflanzen werden viele Generationen auf ungeschlechtlichem Wege erzeugt, ehe wieder eine geschlechtliche Vermischung stattfindet. Ob aber, abgesehen von Bakterien und anderen niedersten Urwesen, Orgauismen leben, bei welchen überhaupt keine geschlechtliche Fortpflanzung nötig ist, müssen wir bezweifeln, und dass Organisnien vorkommen, bei denen geschlechtliche Fortpflanzung nicht gelegentlich eintritt, sobald die Möglichkeit dazu gegeben ist, darf bestritten werden, denn dadurch würden wir ja Stoffe kennen lernen, die sich dem allgemeinen Naturgesetze, dass sich Moleküle eines gleichartigen Stoffes miteinander vereinigen, nicht fügen.

Aus der Gemmarienlehre ergiebt sich eigentlich ganz von selbst, weshalb viele oder die meisten Organismenarten nicht ohne geschlechtliche Fortpflanzung bestehen können; denn das Plasma wird durch die sclı̈digenden Einflüsse der Aussenwelt gelockert, und es wird vielleicht überhaupt nur dadurch wieder befestigt, dass es sich mit einer anderen Plasmenmodifikation vereinigt und dadurch seine ehemalige Festigkeit wieder gewinnt.

Viele einzellige Organismen scheinen sich $z$ war lange Zeit hindurch ohne geschlechtliche Fortpflanzung erhalten zu können; dagegen wissen wir, dass die meisten mehrzelligen Tiere und Pflanzen nicht ohne geschlechtliche Fortplanzung bestehen kömmen, sofern sie sich nicht auch zu gleicher Zeit durch Knospung oder Teilung fortpflanzen. Wo diese besteht, kann allerdings geschlechtliche Fortpflanzung durch viele Generationen hindurch entbehrt werden. Vielzellige Organismen dagegen, die sich nur durch Bildung von Keimzellen fortpflanzen können, bedürfen durchweg der geschlechtlichen Fortpflanzung, der Befruchtung ihrer Keimzellen, und diese Nötigung scheint durch den Umstand verursacht zu sein, dass die betreffenden Organismen mehrzellig sind. Von dem befruchteten $\mathrm{Ei}$ bis zur Bildung neuer Keimzellen ist meistens ein weiter Weg, und wenn sich auch die Keimzellen sehr bald während der Ontogenese bilden, wenn sie auch gelegentlich, wie es bei den Fliegen der Fall ist, schon durch die erste Zellteilung des befruchteten Eies ron den ïbrigen Zellen gesondert werden, so rergeht doch noch lange Zeit, 
ehe sich aus ihnen wieder ein Organismus entwickeln kann. Dadurch ist aber ausgiebige Gelegenheit gegeben, das Plasma zu schädigen, zu lockern. Infolge dieser Lockerung, welche die Kieimzellen während der Zeit, in welcher das Individuum noch nicht geschlechtsreif ist, erleiden, scheint bei den allermeisten Tieren und Pflanzen die Fähigkeit zur Fortpflanzung erloschen zu sein, sofern sich die Keimzellen nicht mit anderen Keimzellen verbinden und dadurch wieder die erforderliche Beschaffenheit ihres Gemmariengefüges erlangen. Dass dieses allerdings nicht absolut notwendig ist, dass geschlechtliche Fortpflanzung zur Entwickelung der Keimzellen nicht unerlässlich ist, geht aus dem Bestehen von Tierarten herror, die sich lediglich auf dem Wege der Parthenogenese fortpflanzen.

Wir glauben durch die rorhergehenden Betrachtungen gezeigt zu haben, weshalb geschlechtliche Fortpflanzung, d. h. die Verbindung zweier getrennter Plasmen, urspringlich eintrat: wir fühnten sie auf die allgemeinen Eigenschaften der Materie zurück, und wir glauben auch ferner dargethan zu haben, dass sie bei den meisten Organismen nnerlässlich ist, sobald es sich um die Fortpflanzung des Individuums durch eine einzige Zelle handelt, die sich aus dem Terbande der übrigen Zellen des Körpers gelöst hat. Dadurch dürfte die geschlechtliche Fortpflanzung so weit mechanisch erklärt sein, wie es ïberhaupt möglich ist, denn dass sie nicht unerlässlich ist, haben wir ja gesehen. Wir brauchen deshalb auch nicht den Nachweis zu führen, dass geschlechtliche Fortpflanzung eine Eigenschaft ist, die sich nicht ron dem Begriff des Organismus trennen lässt. Jedenfalls sind wir nunmehr in die Lage rersetzt, deu Begriff der geschlechtlichen Fortpflanzung schärfer zu fassen.

Die Bedeutung der geschlechtlichen Fortpflanzung ist allerdings die einer Art Verjüngung, d. l. durch die geschlechtliche Fortpflanzung wird wieder dasjenige Gleichgewichtsşrstem des plasmatischen Gefüges hergestellt, bei welchem sich die Lebenserscheinungen der betreffenden Organismenart am besten abspielen. Es entwickeln sich nur diejenigen befruchteten Eier, in welchen zwei genügend fest gefügte Plasmen rereinigt sind. Plasmen, die so beschaffen waren, dass das, was dem einen fehlte, bei dem anderen zu viel rorhanden war, so dass eine Ausgleichung stattfinden konnte.

Durch diese neu gewonnene Anschaung über die Bedeutung der geschlechtlichen Fortpflanzung wird auf eimmal ein helles Licht über die Vorteile der Kreuzung und die Nachteile der Inzucht rerbreitet, wozu 
der Weismannismus durchaus unfähig ist. Weismann rermag nicht zu zeigen, weshalb, wie die Thatsachen der Tier- und Pflanzenzucht zur Genüge darthun, bei Inzucht so leicht eine Degeneration eintritt, während diese durch Kreuzung verhindert wird, denn nach W eismann bestelit ja das Keimplasma aus sehr vielen verschiedenen Iden, und warum diese bei der Inzucht so schnell zu einer Degeneration führen sollen, ist, wie wir noch im Speziellen in dem Abschnitt über Mischung und Rückschlag darthun werden, nicht einzusehen. Denn wenn die Anzahl der Ide so gross ist, wie sie Weismann annimmt und annehmen muss, so ist immer eine genügende T'erschiedenheit der homologen Determinanten der einzelnen Zellen vorhanden, wenigstens ist diese auf lange Zeit hin gewährleistet. Ganz anders ist es dagegen, wenn das Plasma eines Individuums ein monotones ist. Ist es das, dann kann es in einseitiger schädlicher Weise durch äussere Einflïsse umgebildet werden. und wenn es dadurch eine zu grosse Hinfälligkeit bekommen hat, so wird an dieser dadurch nichts geändert, dass es sich, wie es bei der Inzucht geschieht, gewissermassen wieder mit sich selbst vereinigt.

Es geht also aus dem ron uns angenommenen Bau der Gemmarien unmittelbar hervor, dass Inzucht schädlich sein muss. Indessen können wir erst näher auf die Bedeutung ron Inzucht und Kreuzung in dem Kapitel über Mischung und Rückschlag eingelıen. Das gegenwärtige Kapitel hat uns darüber belehrt, dass die Bedeutung der geschlechtlichen Fortpflanzung sich unmittelbar aus unserer Gemmarienlehre ergiebt, und das ist, wie ich glaube, ein Umstand, der geeignet ist, diese Lehre del' Würdigung aller derjenigen zu empfehlen, die sich bestreben, die Ursachen der biogenetischen Vorgänge zu ergrïnden.

\section{k. Ungeschlechtliche Fortpflanzung und Regeneration.}

Die Thatsachen der Parthenogenesis oder Jungfernzeugung lehren, dass Eizellen sich auch ohne Befruchtung entwickeln können, und die sogenannte Pädogenesis, die Jugendzeugung mancher Tiere, zeigt, dass auch schon unerwachsene Tiere Eizellen erzeugen können, die sich obne Befruchtung entwickeln. In solchen Fällen müssen wir annehmen, dass es sich um Tiere liandelt, deren Gefügefestigkeit eine beträchtliche ist, so dass die Konstitution der Keimzellen nicht leicht geschädigt werden kann. Besonders leicht ist aus diesem Gesichtspunkte 
heraus die Pädogenesis zu verstehen, weil die Eizellen von Tieren, die noch nicht rollständig entwickelt sind, noch viel weniger schädigende Einflüsse erfahren haben können, als Eizellen von Tieren, die zu ihrer Entwickelung eine sehr lange Zeit gebrauchen. Im übrigen brauchen wir uns nicht weiter bei den Thatsachen der Jungfern- und Jugendzeugung aufzuhalten, demn sie erheischen keine besondere Erklärung, sondern lehren nur, dass Eizellen auch ohne Befruchtung im stande sind, sich wieder $z u$ einem vollständigen Tiere zu entwickeln. Dass solches nur bei Tieren stattfinden kann, die ein rerhältnismässig stabiles Gefüge haben, deren Eizellen also nicht leicht geschädigt werden können, liegt auf der Hand.

Von der Parthenogenesis unterscheiden sich nur wenig die Thatsachen der Knospung. Nenere Untersuchungen haben gezeigt, dass man unter dem Begriffe der Knospung am besten nur diejenigen Fälle zusammenfasst, in welchen es sich um die Entwickelung einer tierischen Person aus einer einzigen Zelle handelt. Solche Zellen besitzen eine genügende Menge unveränderten Keimplasma's und können sich ohne Befruchtung zu einer vollständigen Person entwickeln. Sie bleiben aber dabei, und dadurch unterscheidet sich die Knospung von der Entwickelung durch Keimzellenbildung, wenigstens eine Zeit lang, in vielen Fällen immer, in Zusammenhang mit dem elterlichen Individuum. Dass bei Zellen, die noch eine genügende Menge ron unverändertem Keimplasma haben, leicht eine Entwickelung zu einer vollständigen Person eintritt, ist deshalb leicht zu verstehen, weil diese Zellen reichlich durch ihre Ungebung ermährt werden, und weil sie an solchen Körperstellen liegen, die ihrer Entwickelung nicht hindernd im Wege stehen.

Soll aber Knospung, d. h. Entwickelung einer im Zusammenhang mit dem elterlichen Individuum bleibenden Zelle erfolgen, so darf dieser Zusammenhang ein nicht allzu fester sein, und die betreffende Zelle darf nicht allzuseln von anderen Aufgaben in Ansprucl genommen werden, d. h. sie darf sich noch nicht zu einer Muskel- oder Nervenzelle oder zu ciner Zelle irgend eines anderen Gewebes von ausgeprägtem Charakter umgebildet haben.

Solche Zellen treffen wir, wie ron vornherein ersichtlich, vorzugsweise bei niederen Tieren an. Wir finden deshalb die Knospung weit rerbreitet im Stamme der Pflanzentiere, und zwar sind es rorzugsweise die nicht zu loch entwickelten Arten, die sich noch heute durch Knospung fortpflanzen, oder wenigstens die Jugendzustände, also etwa die 
Polypenformen, von Arten, die im übrigen auf höherer Entwickelungsstufe stehen. Inwieweit bei anderen Tieren noch Knospung in der schärferen Fassung, die wir hier dem Begriffe gegeben haben, vorkommt, müssen spätere Untersuchungen lehren. Auf jeden Fall wird sich zeigen lassen, dass sie sich bei Tieren findet, die gleich den Pflanzentieren auf tiefer Entwickelungsstufe stehen, weil bei derartigen Tieren die Körperzellen noch weniger scharf differenziert sind, als bei höheren Tieren, und weil die Anpassung der Zellen an bestimmte Aufgaben bei niederen Tieren noch nicht so weit gediehen ist, wie bei jenen. Es giebt bei diesen noch eine grosse Anzahl von Arten, bei denen ein grosser Teil der Zellen befähigt ist, das ganze Tier wieder zu reproduzieren. Bei den höheren Tieren ist dagegen Knospung nicht mehr möglich, weil ausser den Keimzellen sämtliche andere Zellen des Körpers zu sehr von besonderen Aufgaben in Anspruch genommen sind, weil sie ihr Plasma in einseitiger Richtung in Anpassung an diese Aufgaben umgebildet haben.

Für die andere Art der ungeschlechtlichen Fortpflanzung, welche man als Teilung bezeichnet, gilt in grossen und ganzen dasselbe wie für die Knospung. Die Teilung unterscheidet sich dadurch von der letzteren, dass bei ihr nicht bloss eine einzige Zelle zum neuen Tiere wird, sondern deren mehrere, sie ist aber durch Übergänge mit der Knospung verbunden. Fälle, in denen sich ein Tier etwa derartig teilt, dass jedes Teilstïck die Hälfte des elterlichen Tieres erhält, leiten hinüber zu solchen, bei welchen nur wenige Zellen die Grundlage für das neue Tier abgeben. Es ist deshalb in manchen Fällen schwierig zu entscheiden, ob es sich um Teilung oder um Knospung handelt. Wollen wir die Begriffe scharf voneinander trennen, so müssen wir den Begriff der Knospung auf diejenigen Fälle beschränken, wo das neue Individuum aus einer einzigen Zelle entsteht, die nicht zu den eigentlichen Keimzellen gehört.

Auch die Teilung findet sich nur bei Tieren, die auf verhältnismässig tiefer Entwickelungsstufe stehen; so bei Pflanzentieren, bei Würmern und etlichen anderen niederen Tieren, dagegen nicht mehr bei Insekten und anderen Gliederfüssern und bei Wirbeltieren. Dass die Teilung hier fehlt, ist auf die zu grosse Gefügefestigkeit dieser Tiere zurückzuführen.

Wenn sich bei niederen Tieren ein Zellenkomplex mehr oder weniger von der Umgebung unabhängig gemacht hat, wie es ja nur bei Tieren mit geringer Gefügefestigkeit und bei solchen, deren einzelne Zellen noch nicht in zu weitgehender Weise besonderen Aufgaben angepasst sind, vor- 
kommen kann, können sich die Gemmarien der Zellen dieses Komplexes wieder neu ordnen und gemäiss ihrer Gestalt wieder dasjenige gegenseitige Lagerungsverhältnis eingehen, das für die Art charaliteristisch ist. Es ist weder schwer einzusehen, wie dadurch eine Umstimmung der Zellen zu stande kommen kann, noch auch zu begreifen, weshalb das nur bei 'Tieren möglich ist, bei welchen der Zellenverband des Körpers noch nicht in so hohem Grade ein einheitlicher geworden ist, wie etwa bei den Insekten oder lıöheren Wirbeltieren.

Sobald eine Gewebspartie durch irgend einen normalen oder abnormen Entwickelungsvorgang gelockert ist, hören die Verbindungen der diese Partie zusammensetzenden Zellen mit den umgebenden Zellen des in Zusammenhang mit dem elterlichen Individuum bleibenden Gewebes auf, und dadurch müssen die gegenseitigen Beziehungen des sich loslösenden 'Teiles der Zellen zu einander geändert werden. Sie nehmen dasjenige Gleichgewicht an, das ihnen vermöge der Gestalt ihrer Gemmarien zukommt, und es muss deshalb notwendigerweise ein Tier derselben Art aus ihnen entstehen, solange die sonstigen Bedingungen günstige sind. Oft braucht sich nur ein Teil der Zellen eines durch Teilung entstandenen Tieres umzustimmen.

Die Regeneration erliärt sich nach dem Torhergehenden ganz ron selbst. Wenn ein Salamander ein verloren gegangenes Bein oder eine Eidechse den abgebrochenen Schwanz regeneriert, so müssen sich die neu entstehenden Zellen notwendigerweise so anordnen, wie es ihnen durch die Konfiguration der nicht verloren gegangenen und die Gestalt ihrer Gemmarien rorgeschrieben wird.

Die Thatsachen, welche uns zeigen, dass Teilung, Knospmng und Regeneration nur bei verhältnismässig niederen Tieren vorkommen, stehen im schönsten Einklange mit der Gemmarienlehre, während We ismann einen grossen Aufwand an Hypothesenbildung machen muss, um die betreffenden Thatsachen ron dem Standpunlite seiner Theorie aus zu erklären.

Weismann glaubt, dass Teilung, Jinospung und Regeneration allmählich herangezüchtet worden seien, dass diese wie jene beiden für die betreffenden Arten nützliche Einrichtungen bedenten. Ohne Zweifel ist das letztere der Fall, indessen giebt es riele Fïlle, wo wir absolut nicht zu verstehen vermögen, wie Naturzüchtung die Fähigkeit zu ungeschlechtlicher Fortpflanzung und zur Regeneration hervorgebracht haben könnte. Icl erinnere namentlich an Thatsachen, wie sie 
neuerdings durch Driesch bekannt geworden sind. Driesch hat die beiden ersten Furchungszellen von in Entwickelung begriffenen Seeigeleiern durch Schütteln getrennt, und er hat gesehen, dass solche Zellen in manchen Fällen zur Bildung eines neuen Individuums führen, und zwar eines solchen Individuums, das sich nur durch seine Grösse ron normalen Individuen unterscheidet. Wie will Weismann diese Thatsache, die trotz seiner daran geäusserten Zweifel unumstösslich feststeht, erklären? Wenn das Vermögen einer isolierten Furchungszelle des zweizelligen Stadiums eines in Entwickelung begriffenen Seeigels, sich zu einem vollständigen Individuum zu entwickeln, durch Naturzüchtung hervorgebracht sein sollte, so müsste es doch häufig rorkommen, dass die Furchungszellen ron Seeigeleiern roneinander getrennt werden. Dafür ist aber weder ein Beweis beigebracht, noch ist es überhaupt wahrscheinlich, dass eine solche Trennung oft eintritt. Natürliche Zuchtwahl kann also hier nicht in Spiele sein, und wenn sie dennoch Angriffspunkte fände, wenn Seeigeleier häufig in ihre Furchungszellen zerfielen, so bleibt noch zu erklären, woher diese letzteren das Vermögen erhalten haben, das vollständige T'ier zu bilden? Man müsste doch annelımen, dass die einen isolierten Furchungszellen sich wieder zum vollständigen Tiere entwickelt hätten, die anderen aber nicht, und dass die ersteren im Kampf ums Dasein den Sieg davongetragen hätten. Allein woher sie ihr Vermögen zur Neubildung des vollständigen Tieres erhalten haben soll, bleibt durchaus unverständlich. Es müssten sich doch schon bei der ersten Teilung etliche "Ide" unverändert erhalten, um das vollständige Tier reproduzieren zu können, wie diese Ide aber dazu kommen sollten, ist nicht zu begreifen.

Weismann verzichtet übrigens auf eine Erklärung wie die von mir in seinem Sinne rersuchte, um die von Driesch an Seeigeln und von Chabry bei Seescheiden beobachteten Thatsachen zu begreifen. Was bleibt ihm aber dann übrig? Nun, er weiss es:

„Dann bleibt zunächst die folgende Auffassung übrig. Die erste Teilung bewirkt die Trennung der Determinanten-Gruppe für die linke und die rechte Körperhälfte; jede von diesen ist zwar kein volles Keimplasma, insofern sie nicht jede Determinante doppelt enthält, aber es ist sehr wahrscheinlich, dass diese Ide das Vermögen besitzen, sich unter Umständen in der Weise zu teilen, dass sie sich dabei rerdoppeln. Ein solches Keimplasma würde dann zwar ein Muttermal oder irgend eine 
Asymmetrie der andern Körperhälfte nicht enthalten können, würde aber ein rollständiges Tier liefern."

"Ein rollständiges Tier" zu liefern, dazu würde es absolut nicht im stande sein, muss ich mir einzuwenden erlauben; denn wenn ich nicht sehr irre, sind Seeigellarren und Seescheiden bilateral-symmetrische Tiere, deren Körperlälften nicht kongruent sind. Hatten die ron Driesch und Chabry gezüchteten Larren nur zwei linke oder nur zwei rechte Körperhälften? Oder giebt es etwas, was uns "sicherer leiten" kann, als solche ,nie ganz reine und unzweifelhafte Versuche", wie die genannten Forscher sie anstellten? "Torsichtige Schlüisse", die Weismann jenen Versuchen rorzieht, sind es aber nicht, die Weismann zu dem Ergebnis geführt haben, dass eine der beiden ersten den beiden symmetrischen Körperhälften entsprechenden Furchungszellen eines bilateral-s ymmetrischen Tieres durch Verdoppelung „ein vollständiges Tier liefern“ würde. Wenn Weismann seine Determinantenlehre aufrecht erhalten will, dann wird or wohl zugeben müssen, dass vorsichtigere Schlïsse, als er sie gezogen hat, uns daron ïberzeugen, dass die Determinanten der rechten Körperhälfte eines bilateralsymmetrischen Tieres, dessen Körperhälften nicht kongruent sind, nur die rechte, die der linken nur die linke Körperhälfte, aber kein „vollständiges Tier" liefern können.

Mit der citierten Weismann'schen "Auffassung“" ist es also nichts.

"Aber die Regeneration der ersten Blastomeren zum ganzen Embryo," sagt Weismann, ,ist noch einer andern Auslegung fähig. Ascidien rermehren sich nicht bloss auf geschlechtlichem Wege, sondern auch intensir durch Knospung; Seeigel thun dies zwar nicht, aber sie besitzen cin ungemein hohes Regenerationsrermögen. In diesem Kapitel wurde das letztere durch die Annahme erklärt, dass bestimmten Idstufen der Ontogenese ein ,Neben-Idioplasma' beigegeben sci, zusammengesetzt aus den für die Regeneration nötigen Determinanten. In einem folgenden Kapitel werde ich zu zeigen haben, dass wir für die Knospung dieselbe Annahme machen müssen. Diese Annahmen sind unerlässlich, sobald man auf der Kemplasma- und Determinantenlehre fusst. Das zur Knospung erforderliche Neben-Idioplasma bringt das ganze Tier wieder hervor, muss also alle Determinanten des Keimplasma's enthalten und muss schon ror der ersten Furchung im Ei enthalten sein, um dann in latentem Zustande durch alle Entwickelungsstadien hindurch gewissen Zellfolgen beigegeben zu bleiben. Wemn nun dieses Neben-Idioplasma durch irgend 
welche abnormale Einflüsse, z. B. die Tötung der andern Blastomere, aktiv werden könnte, so würde auch auf diesem Tege eine Regeneration des ganzen Embrỵo zu stande kommen können."

Schade nur, dass das „ungemein hohe Regenerationsvermögen" der Seeigel eine Weismann'sche Vision gewesen ist! Für die Seeigel muss deshalb eine andere Erklärung gesucht werden, als für die Ascidien, und die wird dann wohl auch auf die letzteren passen. Weismann aber hat sie nicht gefunden, und er kann sie auch nicht finden.

Überaus charakteristisch ist für das Wesen seiner Präformationstheorie, was er im Anschluss an die oben citierten Sätze sagt. Ich lasse es hier olne weiteren Kommentar folgen:

„Alles dies sind zwar nur Möglichkeiten, deren Aufzählung ich mir gern erspart hätte, da ich ihre Unrollkommenheit und Unsicherheit sehr wohl erkenne, ich wollte aber doch zeigen, dass die erwähnten Beobachtungen nicht jeder Erklärungs-Möglichkeit spotten, wenn wir auch zur Zeit eine irgend sichere Deutung noch nicht geben kömnen, vor allem schon deshalb nicht, weil die betreffenden Beobachtungen selbst noch viel zu unvollkommen und lückenhaft sind. Ich gehe aus diesem Grunde auch nicht auf eine $n$ ähere Erklärung der Embryologie dieser Fälle ein. „Auf eines aber möchte ich doch noch hinweisen, nämlich auf das entgegengesetzte Terhalten des Froscheies und der Eier der Ascidie und des Seeigels. Aus einer Blastomere des Froscheies entsteht nur ein halber Embryo, wenn wir von der besonders zu betrachtenden ,Postgeneration' absehen, aus einer Blastomere der beiden anderen Eiarten entsteht dagegen das ganze Tier. Mögen meine Erklärungs-Andeutungen noch so unvollkommen sein, die ihnen zu Grunde liegende Annahme muss im allgemeinen richtig sein, d. h. es muss das Ei des Frosches in seiner ersten Blastomere ein Vermögen nicht enthalten, welches bei den anderen Eiern in ihr enthalten ist. Da aber Kräfte an Substanzen gebunden sind, so wird es wahrscheinlich, dass die Blastomere der Ascidie und des Seeigels ein Plus ron Substanz enthalten, welches sie zur Regeneration befähigt und welches der FroschBlastomere abgeht - Neben-Idioplasma. Driesch äussert zwar, wie oben angeführt wurde, den Zweifel, ob nicht etwa die Blastomere des Frosches sich ebenso verhalten würde, wie die des Seeigels, wenn man sie wie diese von der operierten Blastomere wirklich trennen und isolieren könnte; allein dieser Zweifel ist wohl kaum berechtigt, da auch bei den Ascidienei eine solche Isolierung der normalen Blastomere durch 
Chabry's Versuch nicht bewirkt wurde, und dennoch die Entwickelung zum ganzen Tier ebenso eintrat, wie beim Seeigelei.

..Wenn nun auch das halbe Froschei sich zunächst nur zu einem halben Embryo entwickelt, so kann sich doch ein solcher Halb-Embryo verrollständigen durch einen sehr eigentïmlichen Regenerations-Torgang, welchen Wilhelm Roux an seinen Halb - und Dreiviertels-Embryonen beobachtet und ,Postgeneration' genannt hat.

„Roux beobachtete, dass die ihrer Entwickelungsfühigkeit beraubte Furchungszelle des Froscheies wieder , belebt werden kann. Aus der normal entwickelten Eihälfte tritt eine grössere Zahl von Zellkernen in die Dottermasse des rerletzten Teiles, die sich rermehren und zu Zellen gestalten. Die postgenerative Bildung der Keimblätter geht in dem durch die nachträgliche Cellulation gebildeten Zellmaterial ror sich, indem der Prozess der Differenzierung in dem ruhenden Zellmaterial fortschreitet.' Es kann auf diese Weise, wie Roux gesehen zu haben glaubt, zu einer vollständigen Ergänzung des Embryos kommen, der lebensfähig ist und auch wirklich längere Zeit am Leben erhalten wurde.

,Gewiss mit Recht haben diese Beobachtungen grosses Aufsehen erregt; sie sind in jedem Falle im höchsten Grade interessant. Ob sie aber so, wie sie uns bis jetzt rorliegen, schon rollständig genug sind, um fundamentale theoretische Schlüsse darauf zu bauen, das muss ich doch bezweifeln. Bei aller Hochachtung vor der Beobachtungs-Sicherheit und Experimentierkunst von Roux kann ich doch nicht umhin, mir zu sagen, dass diejenigen Habembryonen, welche sich später zu ganzen Tieren ,postgenerierten', möglicherweise solche waren, bei denen der Stich mit der heissen Nadel den Kern der Furchungszelle nicht getrofien hatte. Jedenfalls konnte der Thatbestand darüber und ïber die ganze spätere liette von Torgängeu, welche zur Ergänzung führten, immer nur an anderen Individuen beobachtet werden, als an den sich schliesslich ergänzenden. Es ist doch immerhin ein relativ roher Eingriff, wemn man mit der heissen Nadel in eine Furchungszelle stösst, und das, was dabei zerstört wird, kann in jeden Falle wieder etwas anderes sein. Nicht nur könnte die Kernsubstanz als Ganzes unter Umständen unversehrt bleiben, sondern möglicherweise auch bloss einzelne Idanten derselben. Diese könnten sich später durch Terdoppelung zur Normalzahl derselben ergänzen und dann die Entwickelung der Eihälfte einleiten. Allerdings sagt Roux, dass die Postgeneration nicht auf demselben Wege erfolge, wie die normale Entwickelung der primär gebildeten Hälfte, also nicht 
durch selbständige Anlage der Keimblätter, allein die Vorgänge im Innern des Eies lassen sich nur anf Schnitten verfolgen, und die Anfertigung dieser gebietet die Tötung des Embryos. Bei solchen Experimenten ist aber kein Fall dem andern gleich, und man wird über ein sehr grosses Material gebieten müssen, um mit einiger Sicherheit sagen zu können, dass das in Schnitte zerlegte $\mathrm{Ei}$ in seiner innerlichen Beschaffenleit einem andern gleich gewesen sei, dessen Entwickelung und Postgeneration man verfolgt hat.

„Roux hat drei Arten von, Tiederbelebung" der operierten Eihälfte beobachtet, unter ąderem auch eine, Umwachsung der getöteten Hälfte von der äusseren Zellenschicht der lebenden Hälfte aus; diese fülırte aber nicht zur Postgeneration, vielmehr nur die oben erwähnte Art durch Eindringen einiger ,Kerne ron der lebenden Hälfte in die operierte, welches aber nu r bei schwacher pathologischer Veränderung des Dotters erfolgte, und auch dann nicht immer. Der Gedanke liegt nahe, es möchte die Postgeneration nur da erfolgt sein, wo die Zerstörung eine geringe war und Kernmaterial übrig gelassen hatte, von dem nachträglich eine Zellbildung ausgehen konnte. - Damit soll nicht bezweifelt werden, dass auch lebende ,Kerne von der anderen Seite her in die operierte Hälfte des Eies eingedrungen seien; die Furchungszellen haben ja auch im normalen Entwickelungsgang noch eine ungeheuere Vermehrung zu leisten, und es kann somit nicht Wunder nehmen, dass sie - nach Aufhebung des Wachstumswiderstandes durch Operation der andern Eihälfte - sich auch auf Kosten dieser vermehren, aber dass in jenen Fällen, in welchen die andere Hälfte des Embryos sich nachträglich ergänzte, diese Ergänzung auf dem Wege einer Art von Zellen-Infection stattgefunden labe, derart, dass das blosse Anstossen z. B. an Ektodermzellen die noch undifferenzierten Zellen der operierten Eihälfte bestimmte, sich ebenfalls zu Ektodermzellen auszugestalten, das Anstossen an Mesoblastzellen aber sie zu Mesoblastzellen bestimmte, einer solchen, alle unsere bisherigen Anschauungen über den Haufen werfenden Annahme könnte ich nur zustimmen, wenn unwiderlegliche Thatsachen sie bewiesen.

"Roux selbst aber hat seine Arbeit nur als, eine erste Abschlagszahlung an das grosse Thema' betrachtet und eine Fortsetzung seiner Versuche in Aussicht gestellt. Solange aber hier nicht ganz unzweideutige Thatsachen vorliegen, werden wir die in so zahlleichen Thatsachen wurzelnde, gerade auch durch den ersten Teil der Roux'schen Haacke, Gestaltung und Vererbung. 
Versuche mächtig gestiitzte Vorstellung von der Prädestinierung der Zellen durch Zuerteilung bestimmter Determinanten und Determinantengruppen nicht aufgeben dürfen. Ein Aufgeben aber dieser Vorstellung würde unvermeidlich sein, wenn es Thatsache wäre, dass die Zellen der Keimblätter wirklich die Fähigkeit hätten, etwa durch den Ort, an den sie zufällig gelangen, oder durch ihre zufällige Nachbarschaft in ihrem Wesen bestimmt zu werden."

Driesch hat nachgewiesen, dass dieses Thatsache ist; Weismann wird es also nicht remeiden können, seine Präformationstheorie aufzugeben. Iclı aber unterschreibe gern den folgenden Satz Weismann's: "Ich bin überzengt, dass eine noch mehr ins Einzelne gehende erneute Durchforschung des von Roux eröffineten Untersuchungsfeldes uns che Thatsachen in noch anderem Licht zeigen und eine Tersöhnung mit unseren übrigen Vorstellungen über die Ursachen der Ontogenese ermöglichen wird"; denn ich bin nicht der Ansicht, dass ,alle unserige bisherigen Anschauungen über den Haufen" geworfen werden durch die Annahme, dass der Charakter einer Zelle Funktion ihrer Lage im Organismus ist. Diese "Annahme" ist seit Caspar Friedrich W olff's Zeiten das Fundament der Entwickelungslehre, ein Fundament, das $W$ e ism an n sich rergebens, über den Haufen zu werfen" bemüht hat.

Weismann irrt sich, wenn er meint: „Für den Augenblick aber halte ich es noch nicht für erspriesslich, allen den Möglichkeiten nachzugehen, welche bei einem Erklärungsrersuch der ,Postgeneration' in Betracht kommen müssten." Diese wie alle anderen Arten der Regeneration lassen sich gleich den Thatsachen der Knospung und Teilung nur verstehen auf Grund der Annahme eines mo notonen Plasma's, das desto regenerationsfähiger ist, je weniger das betreffende Tier, sei es in stammesgeschichtlicher, sei es in keimesgeschichtlicher Entwickelung vorgeschritten ist. Bei auf tiefer stammesgeschichtlicher Entwickelungsstufe stehenden erwachsenen Tieren ist oft Knospung oder Teilung und neben beiden Regeneration verloren gegangener Körperteile möglich; und wo die Tiere, beispielsweise Frösche, schon zu weit in ihrer stammesgeschichtlichen Entwickelung und damit in der Gefügefestigung vorgeschritten sind, besitzen sie häufig noch Furchungszellen, Jugend- oder Embryonalformen, die entweder in hohen Grade der Regeneration fähig sind, oder sich auf ungeschlechtlichem Wege durch hinospung oder Teilung vermehren können. 
Dass Gefügefestigung nach und nach die Fähigkeit zur Knospung und Teilung und zur Wiederersetzung verloren gegangener hörperteile verringert und endlich völlig verschwinden lässt, ist nicht nur a priori wahrscheinlich und eine Annahme, die mit unserer Theorie in völligem Einklange steht, die eine Konsequenz dieser Theorie bildet, ohne dass wir nötig hätten, irgend welche Hilfshypothesen zu ersimnen, sondern auch sämtliche Thatsachen, die wir über Knospung, Teilung und Regeneration kennen, lehren uns, dass es eben immer nur verhältnismässig niedere Tiere sind, bei welchen das eine oder andere stattfindet. Höhere Tiere besitzen zwar noch oft ein mehr oder weniger ausgeprägtes Regenerationsvermögen, aber auch dieses ist bei den höchsten Tieren häufig ein sehr beschränktes. Bei vielen Tieren kann es höchstens noch zu einer Heilung voll Wunden kommen.

Dass die Fähigkeit zur Regeneration und zur Knospung und Teilung für höhere Tiere nicht nützlich sein sollte, wäre eine Annahme, die in keiner Weise begründet werden kann. Höhere Tiere pflanzen sich viel langsamer fort als niedere, und deshalb wäre es gerade für sie wichtig, dass natürliche Zuchtwahl auch bei ihnen hohe Regenerationsfähigkeit und Knospung und Teilung eingeführt hätte, wie sie es nach W e ismann bei den niederen Tieren gethan hat. Aber der orthodoxe Darwinismus, welchen W e ism an n vertritt, krankt ja schon lange.an unzulänglichen Annahmen, durch welche nichts gewonnen ist, welche die Biologie nur auf Abwege führen und sie verhindern, den wahren Ursachen nachzuspïren. Was sollen wir dazu sagen, wenn Weismann die Flosse eines Fisches als ziemlich wertlos hinstellt? Ist es We ismann gleichgültig, wenn einem Dampfer, auf welchem er sich auf hoher See befindet, die Schraube oder, falls es ein Raddampfer ist, eines der Räder bricht? Hat W eis mann noch nie ein Aquarium besucht?

Die wahre Ursache, warum hochstehende Organismen weder ein gutes Regenerationsvermögen haben, noch auch sich durch Knospung und Teilung fortpflanzen können, liegt eben in ihrer zu weit gegangenen Gefügefestigung. Diese ist aber nicht mit Komplikation des Baues zu verwechseln, die nach Weismann ein Hindernis der Regeneration bei höheren Tieren ist. Dass das Ange eines Molches wieder erzeugt wird, vermag We ismann sich vorzustellen. Giebt es Organe, die viel komplizierter sind, als das Wirbeltierauge?

Völlig unhaltbar erscheinen uns aber die Weismann'schen Annahmen über Reservedeterminanten. Er lässt sowohl die Fähigkeit zur 
Knospung und Teilung wie zur Regeneration durch Ide oder Determinanten zu stande kommen, die in den Organen der Tiere herumliegen und erst in Tirksamkeit treten, wenn es nötig ist. Wir wollen ganz daron absehen, dass die Annahme ron schlummernden Iden und Determinanten an und für sich schon ein Unding ist, denn wenn ein Teil der Ide und Determinanten einer sich entwickelnden Keimzelle sich in seine Determinanten und Biophoren auflöst, so ist durchaus nicht einzusehen, weshalb die übrigen es nicht auch thun sollen, da sie doch unter den gleichen Lebensbedingungen stchen. Die Annahme, dass sie es nicht thun, ist eine röllig willkürliche, die wieder zu Gunsten der Weismann'schen Theorie ersonnen worden ist. Prüfen wir aber, abgesehen ron diesen Schwierigkeiten, die Weismann'sche Lehre im einzelnen, so stossen wir auf andere Schwierigkeiten. über welche wir ebensowenig hinwegkommen. Es giebt Seesterne. bei welchen sich einzelne Arme abschnüren, oder wo einzelne Arme leicht durch äussere Gewalt abgebrochen werden können. Es ist nun nicht nur der an dem Seestern zurückgebliebene Stumpf fähig', sich zu einem rollständigen Arme zu regenerieren, sondern der abgebrochene Arm rermag auch die ganze Iittelscheibe des Seesternes nebst den übrigen Armen wieder zu erzeugen. Iran müisste also rom Standpunlte des Darwinismus aus annehmen, dass sowolll an der Bruchfläche des im Zusammenhang mit dem Tiere bleibenden Armstumpfes, wie an derjenigen des abgebrochenen Armes Regenerationsdeterminanten liegen. Nun ist es klar, dass die Determinanten am Armstumpf ganz anders beschaffen sein müssen, als diejenigen am abgebrochenen Arme, denn die ersteren haben nur einen einzigen Arm zu erzeugen, während die anderen die Mittelscheibe und die übrigen Arme wieder herrorzubringen haben. Wemn das Seesternid einen derartigen architektonischen Bau hat, dass es sich leicht in zwei Stïcke zerlegt, Ton denen das eine dem abgetrennten Arme, das andere dem rerstümmelten Seesterne entspricht, so müssten in dem letzteren die ersteren Teilstiicke des Ides und in dem abgebrochenen Arme die dem verstümmelten Tiere entsprechenden zur Entwickelung gelangen, oder, kürzer ausgedrückt, wenn ein regenerationsfähiges Tier in die beiden ungleichen 'Teilstücke a und b zerfällt, und wenn seine Ide sich dementsprechend leicht in die Teilstücke « und $\beta$ zerlegen können, so müssen die an der Bruchfläche ron a zufällig liegrenden Reserveide, zur Zeit, als die Regenerationsfähigkeit durch natürliche Auslese herangezüchtet wurde, zufällig in die Teilstïcke a und $\beta$ zerfallen sein, und zwar so, 
dass die Teilstücke $\beta$ zufällig an der Bruchfläche von a, die Teilstücke « zufällig an der Bruchfläche von b zu liegen kamen, und dass die einen wie die anderen sich zufällig zur Entwickelung reranlasst sahen. Wie sie aber zu allen diesen Dingen zufällig kommen sollten, das rermag Weismann uns nicht zu zeigen; er müsste schon die Annahme machen, dass Polarität den Aufbau des Tierkörpers beherrscht. Wenn er aber diese Annahme, die ohne allen Zweifel richtig ist, macht, so hat er keine Reservedeterminanten mehr nötig; dann rermag sich das Plasma wieder so zu ordnen, wie es durch die Polarität seiner Gemmarien bedingt ist. Will We is mann sich aber nicht zu einer epigenetischen Theorie rerstehen, dann ist es das einfachste, dass er seine eigene Tererbungstheorie preisgiebt und zu derjenigen des, grossen britischen Forschers" zurückkehrt. Will er auch das nicht, so würde er in der de Tries'schen Theorie eine Lehre finden, die, wenn man nur die "Pangene" oder „Biophoren" mit dem erforderlichen Ordnungssinn ausstattet, vollständig genügen würde, um die Reproduktion zusammengesetzter Organe zu erklären. Allein gegen diese Lehre hat Weismann mit grossem Scharfsinn und, wie ich glaube, mit grossem Glück angekämpft. Die Zumutung, die durch die Ausstattung der Pangene oder Biophoren mit einem solchen Ordnungssinn an den Naturforscher gestellt würde, wäre auch zu stark. Ich habe Weismann's bezügliche Auslassungen oben citiert und kann sie, soweit sie nicht der von mir vorgetragenen Vererbungslehre widersprechen, nur gutheissen. Die Präformationstheorie W eismann's kommt aber trotz alledem ohne ordnungsliebende Biophoren nicht aus.

Sobald eine „mehr oder minder komplizierte Zusammensetzung des Körpers aus bestimmt angeordneten, verschiedenartigen Biophoren besteht", sagt Weismann, ,genügt die einfache Zweiteilung des Bion nicht mehr, um die Eigenschaften des Muttertieres auf die Nachkommen zu übertragen. Wenn Vorn und Hinten, Rechts und Links, Oben und Unten an dem Tiere verschieden ist, so ist keine Art ron Halbierung mehr im stande, den beiden Teilsprösslingen alle Elemente, d. h. alle BiophorenArten und Biophoren-Gruppierungen derart zu übermitteln, dass sie durch blosses Wachstum sich wieder zu einem dem Mutter-Bion ähnlichen Wesen ergänzen müssten. Hier werden also besondere Mittel angewandt sein, um diese Ergänzung und damit die volle Tererbung zu ermöglichen, und diese Mittel haben wir" nach Weismann, sofern es sich nicht um die Ergänzung der Ide selbst handelt, ,in der Scliaffung eines Zellkernes zu sehen". 
Wie aber kommen die Ide, die sich doch auch teilen, dazu, sich zu ergänzen? Hier müssen auch ,besondere Mittel angewandt sein, um die Ergänzung und damit die volle Vererbung zu ermöglichen", denn an den Iden zweiseitig-symmetrischer Tiere muss ,Vorn und Hinten, Rechts und Links, Oben und Unten" verschieden sein, auch bei ihnen „, ist keine Art der Halbierung mehr im stande, den beiden Teilsprösslingen alle Elemente, d. h. alle Biophoren-Arten und Biophoren-Gruppierungen derart zu übermitteln, dass sie durch blosses Wachstum sich wieder zu einem dem MIutter-Bion ähnlichen Wesen ergänzen müssten“. Da Weismann aber nicht konseruent genug sein wird, um auch für die Ide ,besondere Mittel angewandt sein" zu lassen, um ilıre „Ergänzung und damit die volle Vererbung zu ermöglichen“, da er die Aufforderung, zur alten Einschachtelungstheorie zurückzukehren, als eine unerhörte Zumutung ron der Hand weisen wird, so bleibt ihm nichts übrig, als seine Ide mit einem Vervollständigungstrieb auszustatten.

„Ich will nicht besonders betonen, dass dieser Vervollständigungstrieb gar keine allgemeine Erscheinung ist, dass es Pflanzenteile giebt, die sich nicht als Stecklinge fortpflanzen lassen usw.; ich beschränke mich einfach darauf, daran zu erinnern, dass die Annahme einer allgemeinen Reproduktionskraft des Protoplasma's, selbst wenn sie eine Thatsache wäre, doch sicherlich keine Erklärung ist. Sie wäre eben das, was erklärt werden soll!"

Warum steht dieser Passus zwischen Anführungszeichen? - Weil er ron Weismann stammt und nicht ron mir!

Weismann's Determinantenlehre ist also unfähig, die Thatsachen der ungeschlechtlichen Fortpflanzung und der Regeneration irgendwie verständlich zu machen. Um das zu thum, oder um den Schein zu erwecken, dass sie es liönnte, muss sie die abenteuerlichsten Annahmen machen und giebt dadurch jede wissenschaftliche Berechtigung preis.

Eine Vererbungs- und Formbildungslehre, die nicht ohne Hilfshypothesen auskommen kann, die, wie die Weismann'sche, gezwungen ist, eine ganze Legion ron solchen aufzustellen, und dabei starke Zumutungen an unser Gehirn macht, die genötigt ist, die einfachsten Thatsachen der Biologie in erzwungene Erklärungen hineinzupressen, die hat ïberhaupt auf den Namen einer wissenschaftlichen Theorie keinen Anspruch.

Unsere epigenetische Vererbungstheorie hat keinerlei Hilfshypothesen nötig, sie erklärt die in diesem Abschnitte behandelten Erscheinungen 
auf die ungezwungenste Weise, ohne dass wir überhaupt genötigt wären, über die Erklärung der betreffenden Erscheinungen nachzudenken. Diese Erklärung ergiebt sich aus der Gemmarienlehre ganz von selbst. Sie ist übrigens nicht neu. Herbert Spencer hat schon mit seiner Regenerationstheorie im wesentlichen das Richtige getroffen. Freilich, Weismann - wir glauben es gern! - weiss nichts mit ihr anzufangen. "Wer zeigt den ,Einheiten ${ }^{6}$ an, was fehlt und wie sie sich diesmal anzuordnen haben?" ruft er aus. Wir aber sekundieren ihm: Wer zeigt den Biophoren de $r$ sich teilenden Ide an, was fehlt und wie sie sich diesmal anzuordnen haben?

\section{Mischung und Rückschlag.}

Nach Weismann ist die geschlechtliche Fortpflanzung eine „Einrichtung“, die dazu dienen soll, eine immer wechselnde Kombination verschiedenartiger Vererbungstendenzen in einem Keimplasma zusammenzubringen. Weismann's Ide stammen nach einer seiner Ansichten von Urwesen her, die nur ein Id in ihrem Körper hatten und dadurch mehrere erhielten, dass sie sich miteinander rerbanden. Nachdem bei diesen Urwesen die geschlechtliche Fortpflanzung eingeführt ॠar, kounte sich in ihrem Keimplasma eine grosse Ansammlung von rerschiedenen Iden sammeln. Allmählich aber wurde der Zellkern, in welchem nach Weismann's Ansicht die einzelnen Ide aufgestapelt sind, zu klein, um die gesamte Menge der Ide fassen zu können, und es musste eine Einrichtung getroffen werden, um die Hälfte der Ide aus dem Kerne zu entfernen. Das geschah dadurch, dass die halbe Anzahl der Idanten bei der Keimzellenreifung ausgestossen wurde, so dass auf diesem Wege der "Reduktionsteilung" zwei befruchtungsfähige Keimzellen entstanden, aus deren Vereinigung mit anderen wieder eine Zelle hervorging mit der für die Art charakteristischen Anzahl von Idanten und Iden.

In der That haben neue Untersuchungen festgestellt, dass die Keimzellen einem Reduktionsprozess unterworfen sind. So teilt sich die Samenmutterzelle des Pferdespulwurmes zunächst auf dem Wege der gewöhnlichen Zellteilung in zwei Zellen, und jede dieser beiden Zellen wird darauf dem Reduktionsprozess unterworfen, der die Zellen befruchtungsfähig macht. Es wird die Hälfte der Chromosomen, die in jeder dieser beiden Zellen sind, in je eine der beiden aus jeder sich bildenden Samen- 
zellen übergefühır. Ganz ähnlich verläuft die Reifung der Eizellen. Die Mutterzelle des Eies teilt sich zunächst auf dem Wege der gewöhnlichen Zellteilung in eine grosse und eine kleine Zelle. Jede dieser beiden Zellen teilt sich wieder, und zwar ertält jede der daraus herrorgehenden vier Zellen die Hälfte der bei dieser Art wechselnden Anzahl von zwei oder vier Chromosomen. Die grosse Zelle teilt sich wiederum in eine grössere, aus der die Eizelle wird, und in eine kleinere, die zu Grunde geht. Zu Grunde gehen ausserdem die beiden aus der Teilung der zuerst genamnten kleineu Zelle herrorgehenden Zellen, und erhalten bleibt nur die grosse Eizelle. Die drei kleinen zu Grunde gehenden Zellen hat man Richtungskörper genamnt. Sie haben weiter keine Bedeutung, sind aber theoretisch ron grosser Wichtigkeit. Weil sie zeigen, dass der Prozess der Keimzellenreifung bei den männlichen und bei den weiblichen Zellen der gleiche ist, soweit wenigstens der Pferdespulwurm in Betracht kommt. Die Samenmutterzelle zerfällt in zweimal zwei Zellen und ebenso die Eimutterzelle; in jedem Falle erhalten wir 4 Zellen. Die 4 mämnlichen Zellen, deren jede die halbe Anzall der Chromosomen der Mutterzelle erhält, werden zu Samenzellen; von den drei weiblichen Zellen gehen aber drei, weil sie zu klein sind, zu Grunde, und nur die vierte wird zur Eizelle. Indessen ist, abgesehen von der beträchtlichen Crösse dieser vierten Zelle, der Keimzellenreifungsprozess im männlichen wie im weiblichen Geschlechte derselbe, und offenbar ist dieser Prozess zuerst rom Mämnchen erworben und später aufs Weibchen übertragen worden. Das Männchen schreitet ja bei vielen Tieren in der Entwickelung voran, und nach und nach nimmt auch das Weibchen männliche Eigenschaften an, die es frülıer nicht hatte. Als eine solche dürfen wir die Anzahl der bei der Kieimreifung gebildeten Zellen betrachten, denn was lıätte es für einen Zweck, dass auch der zuerst gebildete Richtungskörper noch durch Redultionsteilung in zwei Zellen zerfällt, da die beiden ja zu Grunde gehen. In anderem Lichte erscheint der Torgang dagegen, wenn er aus nicht auf einen Zweck gerichteten Ursachen, denselben, die bei der Reifung der Samenzellen wirlisam sind, erfolgt. Es fragt sich nun, welches diese Ursachen sind.

Tre ism an n, der in seinem ganzen dicken Buche über „Das Keimplasma“ ron wirklichen Ursachen kaum redet, sondern immer und immer wieder alles durch die natürliche \%uchtwahl entstanden sein lässt, die doch nur unter dem, was durch wirkende Ursachen herrorgebracht worden ist, eine Auswahl treffen kamn, geht nicht weiter darauf ein, zu 
zeigen, wie die Zellen, aus denen die definitiven Keimzellen herrorgehen, dazu gekommen sind, sich der Hälfte ihrer Chromosomen zu entledigen. Weismann erblickt darin eben eine nützliche Einrichtung, die aus irgend welchen Ursachen, denen er nicht weiter nachzuspüren für nötig hält, entstand und durch Zuchtwahl zu einem Torgange ron allgemeiner Bedeutung geworden ist. Wenn, wie er annimmt, bald diese bald jene Kombination ron Chromosomen und damit ron den nach seiner Meinung in den Kernstäben steckenden Iden ausgestossen wird, wenn also das befruchtete Ei dadurch eine Anzahl anderer Ide als die, welche im mütterlichen Organismus steckten, bekommen hat, wenn alle seine Ide rerschiedene Vererbungstendenzen haben, die ron den sich noch ungeschlechtlich rermehrenden Urwesen, welche die Torfahren der geschlechtlich differenzierten Organismen waren, herstammen, wenn alle diese abenteuerlichen Annahmen wahr sind, dann allerdings ist eine grosse Variabilität der einzelnen Individuen der Organismenarten gesichert.

Dass aber mit dieser Tariabilität im We ism a n n'schen Sinne nichts anzufangen ist, haben wir schon gezeigt. Die Indiriduenrermehrung der Organismenarten müsste eine über alle Begriffe ungeheuere sein, weın ïberhaupt eine Anzahl zum Überleben tauglicher Individuen entstehen soll. Die Wahrscheinlichkeit, dass letzteres geschähe, erweist sich als verzweifelt gering, wenn wir konsequent, wie wir es gethan haben, auf den We ismann'schen Prämissen weiterbauen. Thatsächlich bewirkt aber auch das, was Weismann Amphimixis nennt, nämlich die Termischung ron Individuen, deren Keimzellen einer Reduktionsteilung unterworfen sind, nicht Variabilität, sondern Einförmigkeit unter den Individuen einer Art in einem Verbreitungsgebiete, wo nach allen Richtungen hin freie Kreuzung möglich ist. Freie Kreuzung arbeitet der Variabilität entgegen, sie macht die Individuen einander gleich, und dass sie das kanı, rerdankt sie der Reduktionsteilung der Keimzellen. Nicht eine Amphimixis, eine bunte Jischung verschiedener Tererbungstendenzen wird dadurch ermöglicht, sondern der Keimzellenreifungsprozess bedeutet eine Entmischung, für die ich den Namen A pomixis vorschlage.

So wenig, wie ich Weismann's Determinantenlehre anerkenne, vernag ich seine Anschauungen zu teilen, dass in den Chromosomen eine Anzahl ron Iden enthalten sind, deren jedes für sich allein im stande wäre, ein Indiriduum der betreffenden Art zu erzeugen. Wir wissen nichts ron Iden und Idanten, Biophoren und Determinanten, 
sondern kennen an der Zelle nur das Plasma mit seinem organischen Mittelpunkte, dem Centrosoma, und den Kern, der bei der Zellteilung in Chromosomen zerfällt, die, wie es scheint, aus kleineren Körpern, den Mikrosomen, zusammengesetzt sind. Ich möchte diese Körper vergleichen mit Bakterien; ein Kernstab, in welchem die Mikrosomen hintereinander liegen, würde also eine Kette bakterienartiger Wesen vorstellen, falls es sich nämlich herausstellen sollte, dass sich die von mir mit Bakterien verglichenen Mikrosomen erhalten, auch nachdem sich die Kernstäbe zurückgebildet haben. Wie dem aber auch sei, jedenfalls ist der Organismus der Zelle aufzufassen als eine Symbiose zwischen Plasma und Kernsubstanz. Dass auch die letztere aus einer Art Plasma besteht, ist nicht zu bezweifeln, aber dieses Plasma hat nichts mit dem formengebenden Plasma des ausserhalb des Kernes gelegenen Zellleibes, insbesondere des Centrosoma's, zu thun, abgesehen daron, dass ein Stoffwechsel zwischen Zellkeib und Kern der Zelle besteht und dass durch die chemischen Eigenschaften des Kernes vielleicht die Form der Gemmarien des Plasma's beeinflusst wird.

Es ist aber zweckmässig, den Stoff des Kernes nicht mit dem Tamen Plasma zu bezeichnen, sondern unter dem Namen Plasma den Baustoff des Zéllleibes zu verstehen; in diesem Sinne habe ich das Wort bisher in diesem Buche sowohl, als auch in meiner "Schöpfung der Tierwelt" gebraucht. Dieses Wort macht alle anderen Bezeichnungen, ron denen es ja eine erkleckliche Anzahl giebt, übertlüssig. Das Wort Plasma- oder Bildungsstoff sagt deutlich genug, dass dieser Stoff es ist, der den Körper plastisch bildet.

Sowohl die Kernstoffe als auch das Plasma werden bei der Zeugung von dem elterlichen Individuum auf das kindliche übertragen, und wo geschlechtliche Fortpflanzung stattfindet, mischen sich dabei sowohl die beiden von Vater und Mutter stammenden Plasmen, als auch die beiden Kernstoffe in melır oder minder inniger Weise. Jede Zelle des Körpers, die aus einer befruchteten Eizelle herrorgeht, erhält in der Regel sowohl väterliches und muitterliches Plasma, als auch die Kernstoffe beider Eltern gemischt, es sei denı, dass besondere Verhältnisse, auf die wir später zu sprechen kommen, ein Überwiegen einer Plasma- oder einer Kernstoffart bedingen.

Dass die Vererbungsstoffe der Eltern, und zwar sowohl die formengebenden, also die Plasmen, als auch die chemischen, nämlich die Kernstoffe, in allen Zellen, die aus einer befruchteten Eizelle herrorgehen, gemischt 
sind, zeigen die Thatsachen der Vererbung. Ich habe darüber ausgedehnte Untersuchungen angestellt, und zwar an Ziegen und Schafen, Hunden und Katzen, an Ratten und namentlich an Yäusen, und glaube, dass ich mir ein Urteil über das erlauben darf, was bei der geschlechtlichen Vermischung zweier Individuen stattfindet. Meine Züchtungsversuche mit Mäusen habe ich in einem so grossen Massstabe betrieben, wie dergleichen Versuche meines Wissens bisher noch nicht ausgeführt worden sind. Die Ergebnisse dieser Versuche, für deren Mitteilung ich mir die Abfassung eines besonderen grösseren Werkes rorbehalten muss, kann ich hier nur im Auszuge mitteilen, aber das, was ich darüber zu sagen habe, genügt, um den Beweis zu führen, dass die Weismann'schen Anschauungen völlig irrtümliche, willkürliche und phantastische sind, dass sie den Thatsachen widersprechen, dass sie mit ihnen völlig unvereinbar sind. Wer in einer so bestimmten Weise, wie Weismann es thut, über Vererbung mitsprechen will, der widme ror allen Dingen einige Jahre seines Lebens und einen grossen Teil seiner Zeit und Arbeitskraft, nicht minder aber auch einen zweckmässig eingerichteten Raum und das zur Besoldung eines Wärters und zur Bestreitung der Einrichtungs-, Fütterungs- und Pflegekosten nötige Geld daran, um auf Grund eigener Untersuchungen den Thatsachen der Vererbung näher zu treten. Ich verdanke es der "Neuen Zoologischen Gesellschaft" in Frankfurt am Main, dass mir die Anstellung eines Züichtungsversuches im grössten Massstabe möglich wurde, habe aber jahrelang einen grossen Teil meiner Freizeit auf die Überwachung meiner Mäusezucht verwenden müssen. Ich hebe alle diese Dinge nur deshalb hervor, weil Weismann denjenigen das Recht abspricht, in Vererbungssachen mitzureden, die der Ansicht sind, dass es mehr als einen Träger der Vererbung in den Keimzellen giebt, nämlich ausser der Kernsubstanz auch noch das Zellplasma. Weismann meint, dass der, welcher solchen Ansichten huldigt, den Thatsachen der Vererbung und ihrer Erklärung noch recht fern stehe. Ich muss nun gestehen, dass ich, ehe ich ausgedehnte Untersuchungen über diese Thatsachen anstellte, ihnen allerdings noch recht fern stand; denn was man auch darüber bei Darwin und anderen Schriftstellern nachlesen mag, erweist sich als völlig ungenügend, sobald es gilt, die Vererbungslehre durch eigenes Nachdenken zu fördern. Gerade die Vererbungslehre ist ein Gebiet, dem man erst näher treten kann, wenn man sehr ausgedehnte eigene Züchtungsergebnisse zur Verfügung hat. Mehr als in irgend einem anderen Gebiete der Biologie sind eigene Unter- 
suchungen hier unerlässlich, weil die Thatsachen der Tererbung in der That äusserst verwickelt erscheinen, wenn man ihnen. wic Weismann es gethan hat, fern bleibt, indem man sich auf die Lektüre dessen, was ältere Schriftsteller dariiber gesagt haben, beschränkt. Ich kann also nicht umhin, ausdrücklich zu betonen, dass Weismann den Thatsacheu der Vererbung sehr fern steht, und dass er ihnen erst durch eigene Untersuchungen näher treten muss, ehe er daran denken darf, seine im Jahre 1892 veröffentlichte, röllig phantastische, überaus widerspruchsrolle und gänzlich haltlose Trererbungstheorie durch eine bessere zu ersetzen.

Das Endergebnis meiner Untersuchungen ist in der That ein ausserordentlich einfaches: Die beiden rerschiedenen Plasmen $P$ und $P$, die sich bei der Befruchtung rereinigt haben, trennen sich wieder bei der Reduktionsteilung der Kieimzelle, und dasselbe gilt von den beiden Kiernstoffen $K$ und $K^{\prime}$. Diese Tremnung ist in manchen Fällen, wie es scheint, eine völlige, so dass die Plasmen und die liernstoffe, abgesehen ron den mehr oder minder weitgehenden, aber niemals vollkommenen Ausgleichungen ihrer Eigenschaften, die durch gegenseitige Beeinflussung stattfinden müssen, ebenso rein aus der Tereinigung hervorgehen, als sie in diese hineingetreten sind. Die Ursachen dieser Trennung lassen sich aber begreiflich machen.

Wir haben gesehen, dass diejenigen Zellen, aus welchen die Keimzellen entstehen, im Laufe des Lebens der elterlichen Tiere so vicle schädigende Einflüsse erfahren, dass sie in ihren Gefüge verändert, und zwar gelockert werden. Sie lösen sich aus dem Terbande der übrigen Zellen der Eltern und leben auf eigene Hand weiter. Die erste Lebensäusserung ist die, dass sie ihre Gefiigelockerung dazu benutzen, um dasjenige wieder rückgängig zu machen, was bei der Befruchtung eingetreten ist, nümlich die Mischung verschiedener Plasmen und Kernstoffe. Sowohl die formgebenden, als auch die chemischen Tererbungsstoffe der Zellen entmischen sich wieder; die beiden individuellen Plasmen- und Kernstoffarten trennen sich roneinander. Dass dies möglich ist, ist bedingt durch die Gefügelockerumg, welche die betreffende Zelle im Laute des Lebens ihres Elters erlitten hat. Diese ermöglicht es, dass die Gemmarien und die Kiernstoffelemente gleicher Art sich wieder zusammenfinden. Die Gemmarien $G$ des l'lama's $P$ fügen sich wieder aneinander und nicht minder auch die Gemmarien $G^{\prime}$ des Plasma's $P^{\prime}$. Ein ebensolcher Prozess findet bei den Elementen des Fernstoffes $K$ und den Elementen des Kernstoffes $K^{\prime}$ statt. Es herrscht also zwischen den Elementen ver- 
schiedener Tererbungsstoffe eine Art Oberflächenspannung, vermöge deren sich diejenigen Elemente sondern, welche nicht dieselbe Form und nicht dieselbe chemische Beschaffenheit haben.

Nun aber ist der Kernstoff $K$ nicht so innig an das Plasma $P$ gebunden, dass er notwendigerweise diesem folgen müsste, und ebensowenig gilt ein solches Gebundensein ron dem Plasma $P^{\prime}$ und dem Kernstoff $K^{\prime}$; denn der Organismus der Zelle stellt ja eine Symbiose dar, und die Symbiose zwischen dem Plasma $P$ and dem Kernstoff $K$ kann einer Symbiose zwischen dem Plasma $P$ und dem Kernstoff $K^{\prime}$ oder zwischen dem Plasma $P^{\prime}$ und dem Kernstoff $K$ Platz machen. Haben sich also bei der Befruchtung die Kernstoffe $K$ und $K^{\prime}$ und die Plasmen $P$ und $P^{\prime}$ miteinander verbunden, so können bei der Reduktionsteilung der Keimzellen, die ron einem aus dieser Verbindung hervorgegangenen Tiere erzeugt werden, Befruchtungszellen entstehen, in welchen 1) das Plasma $P$ wieder mit dem Kernstoff $K, 2$ ) das Plasma $P$ mit dem Kernstoff $\left.K^{\prime}, 3\right)$ das Plasma $P^{\prime}$ mit dem Kernstoff $K$ und 4) das Plasma $P^{\prime}$ mit dem Kernstoff $K^{\prime}$ verbunden sind. Haben wir etwa durch Kreuzung der beiden Individuen $P K$ und $P^{\prime} K^{\prime}$ ein Männchen und ein Weibchen erhalten, von denen jedes aus den Plasmen $P$ und $P^{\prime}$ und den Kernstoffen $K$ und $K^{\prime}$ zusammengesetzt sein muss, so kann jedes dieser beiden Tiere die eben genannten vier Arten von Befruchtungszellen bilden. Pflanzen sich nun diese Tiere miteinander fort, so können wir folgende 9 Arten ron befruchteten Eizellen erhalten, nämlich:
1) $P P, K K$
4) $P P^{\prime}, K K$
7) $P^{\prime} P^{\prime}, K K$
2) $P P, K K^{\prime}$
5) $P P^{\prime}, K K^{\prime}$
8) $P^{\prime} P^{\prime}, K K^{\prime}$
3) $P P, K^{\prime} K^{\prime}$
6) $P P^{\prime}, K^{\prime} K^{\prime}$
9) $P^{\prime} P^{\prime}, K^{\prime} K^{\prime}$

Wir erhalten also 1) Individuen, die dem einen der Grosseltern völlig gleichen $(P P, K K=P, K), 2)$ Individuen, die dem anderen der beiden Grosseltern völlig gleich sind $\left(P^{\prime} P^{\prime}, K^{\prime} K^{\prime}=P^{\prime} K^{\prime}\right)$, 3) Individuen, die aus dem Plasma des einen Grosselters und aus den Kernstoffen des zweiten Grosselters bestehen $\left(P P, K^{\prime} K^{\prime}\right.$ und $\left.\left.P^{\prime} P^{\prime}, K K\right), 4\right)$ Individuen, die aus dem Plasma eines Grosselters und aus den gemischten Kernstoffen beider Grosseltern bestehen $\left(P P, K K^{\prime}\right.$ und $\left.P^{\prime} P^{\prime}, K K^{\prime}\right)$, 5) Individuen, die aus den gemischten Plasmen beider Grosseltern und aus dem Kernstoff eines Grosselters bestehen $\left(P P^{\prime}, K K\right.$ und $P P^{\prime}$, $K^{\prime} K^{\prime}$ ), und 6) Individuen, die aus den gemischten Plasmen und aus den gemischten Kernstoffen beider Grosseltern bestehen $\left(P P^{\prime}, K K^{\prime \prime}\right)$. 
Was, wenn man von derartigen Tieren weiter züchtet, entsteht, kann man sich aus obigem leicht zusammenstellen, und ich darf versichern, dass meine Untersuchungen an Mäusen rollständig den theoretischen Konstruktionen entsprechen, die sich auf Grund der hier rorgetragenen Theorie ron vornherein machen lassen. Ich gehe dabei ron der Toraussetzung aus, dass die Farben der Mäuse an die Kernstoffe, die sonstigen Eigenschaften, das Tanzen der Tanzmäuse z. B., an die Plasmen gebunden sind.

Wenn wir etwa farbige japanische Tanzmäuse und weisse gewöhnliche Mäuse miteinander paaren, so erhalten wir von der dritten Generation an Mäuse, die, wie die mit diesen erzielten Züchtungsergebnisse zeigen, jenen neun Kombinationen entsprechen. Sind wir etwa bei weissen Tanzmäusen angelangt und züchten wir diese unter sich weiter, so tritt nie wieder ein Rückschlag auf farbige oder auf gewöhnliche Mäuse ein. Sind die Farben bei Tanzmäusen, die wir als durch die Kernstoffe bedingt betrachten, gemischt, so können sich diese wieder trennen, aber die Plasmen bleiben dieselben; es entstehen aus Tanzmäusen immer nur wieder Tanzmäuse. Man kann leicht berechnen, was in jedem Falle entstehen muss, wenn wir Tiere der neun Kombinationen miteinander paaren. Ich kann auf diese höchst interessanten Verhältnisse an dieser Stelle nicht viel Raum verwenden, sondern muss auf mein späteres Werk, das sämtliche von mir erzielten Zuchtergebnisse an der Hand ron genauen Stammbäumen geben wird, verweisen, will aber hier diejenigen Resultate herrorheben, die der Weismann'schen Lehre rollständig widersprechen.

Wenn wir von schwarz und weiss geschechten japanischen Tanzmäusen, die aus Japan importiert worden sind, weiter züchten, so erhalten wir immer wieder schwarz und weiss gescheckte oder höchstens blau und weiss gescheckte, aber immer gescheckte Mäuse und immer T'anzmäuse. Setzen wir die Reinzucht der schwarz und weiss und der blau und weiss gescheckten Tanzmäuse eine Zeit lang fort, so erhalten wir reinrassige Tiere, einerseits schwarz und weiss gescheckte, andererseits blau und weiss gescheckte, die wir zu weiteren Tersuchen verwenden können. Wir paaren die ersteren mit gewöhnlichen weissen Mäusen, wie sie bei uns in Deutschland schon seit langem gehalten werden. Es ist aber bei dieser Paarung Bedacht darauf zu nehmen, dass diese Mäuse auch wirklich nie mit gescheckten Yäusen gekreuzt worden sind, weil dadurch das Plasmagefüge verändert wird, auch wenn sich solches, weil die Mäuse 
weiss sind, nicht äusserlich kundgeben kann. Zu unserer Kreuzung benutzen wir also Tiere, die erstens die an das Plasma gebundenen Eigenschaften des Tanzens und zweitens die ebenfalls an das Plasma gebundene der Scheckung haben, während die schwarze Färbung der auf weissem Grunde befindlichen Flecken durch die Kernstoffe bedingt wird, und andererseits weisse Mäuse, deren Plasma nicht die Eigenschaften des Tanzens und auch nicht die der Scheckung besitzt. Durch diese Krenzung erhalten wir ungescheckte Mäuse, entweder schwarze oder dunkelgraue, welche nicht tanzen. Durch die Verbindung des gescheckten Tanzmausplasma's, wie wir uns kurz ausdrücken wollen, mit ungeschecktem gewöhnlichen Plasma entsteht ein Kreuzungsprodukt, das nicht tanzt und ungescheckt ist.

Weshalb es diese beiden Eigenschaften nicht zeigt, ist nicht schwer zu begreifen, denn dergleichen Eigenschaften, wie es Tanzen und Scheckung sind, können leicht verändert werden, weil sie in einer sehr labilen Form des plasmatischen Gefüges ihre Ursache haben. Paaren wir nun derartige ungescheckte Mäuse untereinander, so erhalten wir 1) gescheckte Tanzmäuse, 2) weisse Tanzmäuse, die aber, ohne dass man es sieht, gescheckt sein können, 3) ungescheckte schwarze oder graue nicht tanzende Mäuse, die aber geschecktes Tanzmausplasma und weisses gewöhnliches Plasma enthalten können, und 4) weisse nicht tanzende Mäuse, die aber geschecktes Tanzmausplasma enthalten können, aber keine farbigen Kernstoffe bergen. Ausserdem aber enthalten wir auch schwarze oder graue ungescheckte Tanzmäuse, die besondere Beachtung verdienen. Es zeigt sich nämlich, dass zwar in vielen Fällen ein vollständiger Rückschlag eintritt, wie er unseren theoretischen Voraussetzungen entspricht, dass aber durch die Vereinigung der beiden Plasmen insofern eine Ausgleichung ihrer Eigenschaften stattfindet, als dadurch ein festeres Gefüge bewirkt wird. Scheckung ist sicher auf Lockerung des Plasmagefüges zurïckzuführen, und dadurch, dass das gescheckte Plasma der Tanzmaus mit ungeschecktem Plasma einer gewöhnlichen Maus in Berührung gebracht wird, gewinnt es einen Teil seiner Gefügefestigkeit zurück, und damit die Fähigkeit, Farbstoffe gleichmässig in den Haaren der Haut zur Ablagerung gelangen zu lassen. Aber auch aus solchen Tanzmäusen, die eine gewisse Gefügefestigkeit, welche ihnen abhanden gekommen war, wieder erlangt haben, gehen niemals andere Mäuse als Tanzmäuse hervor. Es ist also dadurch, dass geschecktes Tanzmausplasma mit ungeschecktem Plasma einer gewöhnlichen Maus in innige Berührung gekommen ist, 
lem Tanzmausplasma ein Teil seiner verloren gegangenen Gefügefestigkeit zurïckgegeben worden, wihhend es sich allerdings der Hauptsache nach gleich geblieben ist. Wir haben demnach die aus der Zusammenstellung der obigen möglichen Fälle gewommenen Ergebnisse, die allerdings im grossen und ganzen den Zuchtergebnissen entsprechen, dahin zu modifizieren, dass sich allerdings die beiden bei der Befruchtung mitcinander gemischten Plasmen und Kernstoffarten bei der Reduktionsteilung der Keimzellen wieder trennen, dass aber aus dieser Trennung Plasmen mit etwas reränderten Eigenschaften herrorgegangen sind, und zwar haben sie ihre Eigenschaften teilweise ausgeglichen durch Verschiebung der Gemmen innerhalb ilnrer Gemmarien. Sie haben sich dadureh wieder der mittleren Gefügefestigkeit der betreffenden Art genähert und dadurch an Erhaltungsfähigkeit gewomnen.

Setzen wir unsere Züchtungsversuche mit Jäusen der dritten Generation weiter fort, so verhalten sie sich genau dem entsprechend, was durch die obigen Kombinationen ausgedrückt wird, mit der Einschränkung, dass sie, wie eben dargethan, wo Gelegenlıeit dazu ist, ihr Plasmagefïge etwas ausgleichen. Wir erhalten beispiclsweise aus weissen Tanzmäusen nie etwas anderes wieder als weisse Tanzmäuse, und aus gescheckten, die wir in dritter oder in einer späteren Generation erhalten, niemals etwas anderes wieder als gescheckte Tanzmäuse.

Wie sind nun diese Züichtungsergebnisse mit der Weisman n 'schen Lehre in Einklang zu bringen? Wie kommt es beispielsweise, dass aus der Paarung ron gescheckten Tanzmäusen mit gewöhnlichen weissen Mäusen Junge hervorgehen, die einfarbig schwarz oder grau sind? Das Resultat eines solchen Züchtungsversuches ist röllig unvereinbar mit Weismann's Determinantenlehre und widerlegt diese direkt. Hätte Weismann ein einziges Mal eine rein durchgezüchtete gescheckte Maus mit einer rein durchgezüchteten weissen Maus gekreuzt, so hätte er einfarbige graue oder schwarze Mäuse erhalten, ein Resultat, das a u snahmslos eintritt, und der Versuch, dieses Resultat mit seiner Lehre in Einklang zu bringen, lätte ihm gezeigt, dass die Lehre unhaltbar ist, wie sich sofort aus folgendem ergeben wird.

Der Umstand, dass es gescheckte Mäuse giebt, muss, wenn wir uns auf den Boden der Weisman n'schen Determinantenlehre stellen, darin seinen Grund haben, dass die einzelnen Partien der Behaarung ron verschiedenen, gesonderten Determinanten im Keimplasma bestimmt werden. Hätten sämtliche Haare einer Haus eine gemeinsame 
Deterninante, so müssten sie entweder alle weiss oder alle farbig sein. Wenn es also gescheckte Mäuse gicbt, so müssen die verschiedenfarbigen Flecken aurch durch verschiedene Determinanten bestimmt werden. Da aber die Scheckung sehr veränderlich ist, da wir Ủbergänge ron fast einfarbigen gefärbten Mäusen mit nur einenı einzigen weissen Fleck zu solchen haben, die beinahe weiss sind und sehr wenig Farbe zeigen. da also die Flecke in ihrer Ausdehnung sehr wechseln können, so folgt daraus, dass die Anzahl der Determinanten der Haare oder derjenigen Zellen, welche die Ablagerung des Pigmentes in den Haaren bewirken, eine ausserordentlich grosse sein muss. Es kann jedes Haar weiss oder farbig sein, so dass mindestens jedes Haar eine Determinante in den Iden des Keimplasma's haben muss. Wir wollen einmal einen Blick auf andere Tiere werfen, auf solche, die eine regelmässige Zeichnung besitzen, wie es etwa die Katzen oder die Tigerpferde sind, die an ganz bestimmten Körperstellen dunklere Flecke oder Streifen haben. Weismann hat die Zebrastreifen angeführt, um daraus de V ries gegenüber den Beweis zu erbringen, dass die Vererbungsträger eine bestimmte architektonische Anordnung im Keimplasma haben müssen, und wir können diese Anschauung nur als eine Konsequenz der W eismann'schen Lehre betrachten, denn sonst könnten bei regelmässig gezeichneten Tieren, wie es Zebras und Katzen sind, nicht immer wieder dieselben Flecke und Streifen auftreten; es müssten sich sonst dunkler und heller gefärbte Hautpartien bei der Vermischung der Individuen decken, und das würde die Zeichnung im höchsten Grade variabel machen, wenn es überhaupt eine Zeichnung zum Ausdruck kommen liess. Es müssen also die Biophoren homologer Determinanten der verschiedenen Ide im Keimplasma einer Katze in dieselben Körperzellen gelangen, wenn sie eine bestimmte Färbung und Zeichnung hervorbringen sollen. Beispielsweise müssen diejenigen Determinanten, welche den weissen Fleck bestimmen, der sich auf dem schwarzen Ohre mancher Katzen befindet, ihre Biophoren immer denselben Körperzellen übergeben. Aus dieser Notwendigkeit geht aber hervor, dass bei den Mäusen ähnliches stattfinden muss, sind doch die japanischen Tanzmäuse gew öhnlich bis an die Schultern gefärbt und hinten weiss. Wenn wir nun Iäuse miteinander kreuzen, so kommen dabei die Determinanten, welche die Farbe des Schwanzes bestimmen, mit solchen zusammen, welche gleichfalls die Farbe des Schwanzes bestimmen, die Ohrendeterminanten im Keimplasma eines Individuums vereinigen sich mit den Ohrendeterminanten im Plasma des anderen; kurz, 
die Determinanten der einzelnen Hautstellen, die von dem einen elterlichen Tiere herstammen, vereinigen sich durch ihre Biophoren mit denen, die ron dem anderen elterlichen Tiere herstammen. Hat ctwa eine Maus einen schwarzen Kopf und schwarze sichultern, wie es bei den echten japanischen Tanzmäusen die Regel ist, während sie im übrigen weiss ist, und paren wir eine solche Maus mit einer weissen Maus, so kommen die Biophoren der Determinanten, welche die schwarze Fürbung des Kopfes und der Schultern bei der gescheckten Maus bestimmen mit den Biophoren derjenigen Determinanten, welche die weisse Farbe des Kopfes und der Schultern bei der gewölnnlichen Maus bestimmen, in dieselhen Zellen der aus der Kireuzung hervorgehenden Mäuse zu liegen. Es müssten daraus also Mäuse entstehen, dir eine Mischung von Schwarz und Weiss an Kopf und Schultern zeigen. Dass sie an diesen Teilen oft grau gefärbt sind, wïrde sich also gut mit der Weismann'schen Theorie vereinigen lassen. und es widerspricht dieser Theorie auch woh] nicht, wemn es, was noch läufiger der Fall ist, K reuzungsmäuse giebt, die an Kopf und Schultern schwarz sind. Soweit wären also die Ergebnisse der Züchtung im vollen Einklang mit We ism an n's Determinantenlehre. Leider aber verhalten sich diejenigen Hantpartien, die weder bei den gescheckten, noch bei den weissen Mäusen gefärbt sind, nicht so, wie sie es tlnun

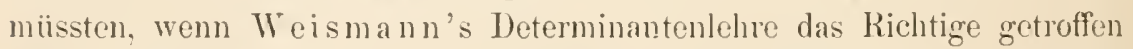
lätte. Obwolıl sich an den brtreffenden Hautstellen nur Biophoren weisser Determinanten mit Bioploren weisser Determinanten rerejnigen können, sind sie bei den Kleuzungsmäusen nicht woiss, wie sie es sein müssten, da Weiss und Weiss doch nichts anderes geben kann als wieder Weiss, sondern sie sind gleichfalls intensiv schwarz oder dunkelgrau.

Diese Thatsache ist so völlig unvercinbar mit der W eismann'schen Determinantenlehre, dass sie die letztere ohne weiteres umstösst. Es wird Weismann nichts helfen, zu sagen, dass diese Züchtungsergebnisse durch Rückschlag zu erklären seien, dass sich sowolıl unter den Färbungsdeterminanten der woissen Mäuse, als auch unter denjenigen der weissen Hautstellen der gescheckten Mäisse noch schwarze Determinanten befänden, die auf dem Wege der Amphimixis durch Rückschlag in der Melızahl in eine Zelle zu liegen liommen kïmnen, denn erstens diirften dann nicht alle Krenzungsmänse gleichmässig schwar\% oder grau gefürbt sein, und zweitens dürften nicht alle Hautstellen dieselbe Färbung zeigen, sondern es müsste eine ganz unregelmässige Scheckung \%u stande 
kommen, und auch an Kopf und Schultern solcher Kreuzungsmäuse müssten dann weisse Flecke auftreten. Denn wenn sich unter den weissen Determinanten der ungefärbten Hautstellen noch schwarze befinden, so ist es nicht mehr wie recht und billig, anzunehmen, dass zwischen den schwarzen Determinanten der schwarzen Hautstellen noch weisse liegen. We ismann hat also ron dem Versuche, unsere obigen Zuchtergebnisse als einen durch Amphimixis hervorgebrachten Rückschlag zu bezeichnen, nichts zu erhoffen. Wenn neben den weissen Determinanten der ungefärbten Hautstellen noch schwarze Determinanten vorkommen, wenn die weissen Determinanten der gewöhnlichen Mäuse noch schwarze unter sich haben, so müsste bei fortgesetzter Zucht weisser Mäuse auch einmal eime Maus geboren werden, die nicht weiss, sondern mehr oder minder gescheckt orler auch einfarbig schwarz oder grau ist. Das ist aber niemals der Fall. Durch Paarung weisser Mäuse untereinander hat noch kein Mensch irgend etwas anderes erhalten, als immer nur wieder weisse Iäuse, und wenn er die Mäusezucht auch im grössten Massstabe betrieben hat. Weismann hat ja über die Züchtung weisser Mäuse Erfallung; ist es ihm jemals vorgekommen, dass weisse Mauseltern schwarze oder graue Mausjunge hervorgebracht hätten? Ohne die bezüglichen Ergebnisse der We ismann'schen Züchtungsversuche zu kennen, darf ich mit absoluter Sicherheit behaupten, dass Weismann durch Paarung weisser Mäuse miteinander noch nie etwas anderes erhalten hat als weisse Mäuse. Wie aber will er dann die Thatsache erklären, dass weisse Mäuse mit gescheckten Mäusen gepaart einfarbige schwarze oder graue Iäuse geben? Ich habe mich bemüht, für dieses Zïchtungsergebnis irgend eine Erklärung auf Grund der Determinantenlehre zu finden; es ist mir aber nicht gelungen. Vielleicht hat ITeismann mehr Glück!

Diese Widerlegung der Weismann'schen Lehre durch das Züchtungsexperiment wäre zwar völlig genügend, indessen wollen wir noch ein anderes Züichtungsergebnis hier besprechen und den Tersuch machen, Weismann's Lehre damit in Einklang zu bringen.

Paaren wir schwarz und weiss gescheckte Tanzmäuse mit weissen gewölnnlichen Mäusen und lassen wir die Kreuzungsmäuse sich wieder untereinander fortpflanzen, so erhalten wir in der dritten oder in eine späteren Generation weisse Tanzmäuse. Nach der We isnann'schen Lehre müssen sich in dem Keimplasma solcher weisser Tanzmäuse eine. Anzahl ron unveränderten Iden gescheckter Tanzmäuse und ebenso eine 
Anzah! ron unveränderten Iden woisser gewöhnlicher Mäuse befinden. Es würden dann bei diesen weissen Tanzmäusen einerseits rlie Tanzdeterminanten der gescheckten Tanzmauside, andererseits die Färbungsdeterminanten der gewölmlichen Mauside zur Herrschaft in den \%ellen gelangt sein. Die letzteren hätten die rärbung der weissen Tanzmäuse bestimmt und die ersteren die Eigenschaft des Tanzens. Bei fortgesetzter Züchtung müssten also auch einmal wieder lläuse zum Torschein kommen, bei welchen die Fürbungsteterminanten der Tanzmäuse und die den Tanzdeterminanten der letzteren entsprechenden Determinanten der weissen Iäuse allein die betreffenden Zellen bestimmten. Es müiste also auch einmal wieder Mäuse geben, die nicht tanzen, aber gefärbt sind. Das ist aber niemals der Fall; weisse Tanzmäuse erzeugen immer wieder weisse Tanzmäuse, niemals Mäuse, welche nicht tanzen, und auch niemals Mäuse, die gefürbt sind. Es beweist also auch dieses Zuchtergebnis die völlige Haltlosigkeit der W $\mathrm{W}$ ismann'schen Determinantenlehre.

Trotzdem meine Züchtungsrersuche so kiare Ergebnisse liefern, so lassen sie doch nicht mit Sicherheit erkennen, ob die Torgänge, die dabei stattfinden, genau der oben ron mir aufgestellten Theorie entsprechen. Es wäre beispielsweise möglich, dass die Elemente des Plasmás einer auf dem Wege des Rückschlages entstandenen weissen Tanzmaus beispielsweise auch noch mit etlichen wenigen Gemmarien der gewöhnlichen weissen Maus gemischt wären. Ich hoffe auf die Besprechung dieser Frage näher in dem Werke über meine '/üchtungsergebnisse eingehen zu können und habe hier unı so weniger alle in Betracht kommenden Möglichkeiten zu erörtern, als so viel wenigstens mit Sicherheit aus meinen Versuchen herrorgeht, dass verschiedene durch Kreuzung zusammengebrachte Plasmen- und Kernstoffe sich wieder zil sondern bestreben nach dem auch für die Elemente des Zullleibes und des Kiernes geltenden Grundgesetz: Gleich und gleich gesellt sich ger'n.

Die hier vorgetragene Theorie wirt auch ein helles Licht auf die sich oft widersprechenden Züchtungsversuche über die Be de utung der Inzucht und der híreu\%ung. Ich muss aber zunïchst bemerken, dass lie Ziichtungsversuche, die man an Pflanzen darüber angestellt lat, nach meiner Ansicht irreführend sind. Denn wenn man eine Blïte mit ilurem eigenen Pollen befruchtet, so bringt man Zeugungsstoffe zusamnen, die nicht die gleiche Lebensenergie haben. Entweder eilt der Frachtknoten in seiner Entwickelung den Staubgefässen voraus, oder es findet 
das L'mgekehrte statt, und es ist deshalb nicht zu rerwundern, wenn die aus solcher Inzucht herrorgehenden Pflanzen schwächlich sind. Wenn man den Pollen einer Ptlanze dagegen auf die Narben einer anderen Ptlanze bringt, so ist viel eher die Wahrscheinlichkeit gegeben, dass Pollen ron Staubgefässen, die auf derselben Reifestufe wie die Narben stehen, zur Befruchtung verwendet wird. Ähnliche Verhältnisse kommen zwar, wie Düsing gezeigt hat, auch bei der Tierzucht in Betracht; aber es ist bei der letzteren viel eher Auskunft über die Bedeutung der Kreuzung und der Inzucht zu gewinnen, weil es sich dabei nicht um Experimente mit Zwittern handelt.

Die Experimente nit Tieren haben érgeben, dass Inzucht schädlich und Kreuzung rorteilhaft ist. Warum das aber der Fall ist, hat noch niemand völlig begreiflich zu machen gewusst. Aus unserer Gemmarienlehre geht ohne weiteres hervor, dass es so sein muss. Die individuellen Plasmen weichen immer etwas von der Norm ab. Bringt man also Nengen eines und desselben Plasma's bei der Befruchtung zusammen, so ist dadurch die Möglichkeit gegeben, dass diese Abweichung immer stärker wird, denn ein Plasma, das ein hinfälliges Gefüge hat, wird schädigende äussere Einflüsse viel weniger ertragen als ein fest gefügtes. Die Gefügefestigkeit wird aber, wie wir gesehen haben, durch die Kreuzung zurïckgewonnen, und zwar dadurch, dass sich die Gemmen zweier anfeinander wirkenden Gemmarien miteinander ins Gleichgewicht setzen, dass sie innerhalb der Gemmarien derartig rerschoben werden, dass ein weniger labiles Gleichgewicht zu stande kommt. Es geht aber aus dem, was wir über unsere Züchtungsergebnisse mit Jäusen nitgeteilt haben, des weiteren herror, dass nicht alle Individuen Inzuchtstiere sein können, sofern wir die Experimente mit zwei verschiedenen Tieren begonnen haben. Wir kömnen Geschwister, die aus einer Kíreuzung ron einer gescheckten Tanzniaus und einer gewölnnlichen Jaus herrorgegangen sind, paren, ohne dass wir zu befürchten brauchen, dass solches schädlich sein muss, denn die Mischungsverhältnisse der verschiedenen Plasmen- und Kernstoffe sind bei Mäusen der dritten Generation, wie wir gesehen haben, sehr verschiedene. Es ist also nicht die Inzucht an sich schädlich, sondern die Terbindung identischer Plasmen und Kernstoffe, weil jede individuelle Plasmenund Kernstoffart etwas von der die beste Konstitution bedingenden Norm abweicht, weil diese Norm erst wieder durch Verbindung mit einer andern Plasmenart hergestellt wird. Dadurch zeigt sich klar, weshalb 
nicht Inzucht an und für sich, sondern erst fortgesetzte Inzucht schädlich wird. Wenn wir Generationen hindurch inmer Geschwister miteinander paren, so wird dadurch die Walıscheinlichkeit, dass wir identische Plasmen und Kernstoffe zusammenbringen, eine immer grössere. Die Folgen der Inzuclit müssen deshalb ron lieneration zu Generation mehr hervortreten. Es zeigt sich also auch hier unsere (iemmarienlehre in Verbindung mit den ron uns gewonnenen Züchtungsresultaten in schönsten Einklange mit rlem, was die Tierzüchter schon längst festgestellt haben.

Dagegen ist es aus der Weismann'schen Lehre durchaus nicht ersichtlich, weshalb Inzucht so schnell zur Degeneration führen muss; denn soviel ist doch wohl klar, dass die ursprüngliche Terbindung ron zwei rerschiedenen Plasmen und ron zwei Kernstoffen bei fortgesetzter Inzucht viel leichter wieder dieselben individuellen Plasmen und Kernstoffe in eine befrnchtete Fizelle zusammenbringen muss, als es bei der Weismann'schen Annahme möglich sein kann. Wenn das Plasma aus vielen Iden zusammengesetzt ist, die alle individuelle Verschiedenheiten zeigen, so muss lange Zeit darüber rergehen, bis einmal in cinem Keimplasma lauter identisclue Idle zusammen zu liegen kummen, wie aus der Berechnung der Wahrscheinlichkeit, mit der dieser Fall eintreten wird, hervorgelien würde.

Ich brauche eine solche Berechnung hier nicht anzustellen, weil ron rornherein die geringe Grösse der Wahrscheinlichkeit evident ist, mit welcher identische Itle in demselben Keimplasma zu liegen liommen müssen, falls das Keimplasma ursprüngliclı aus sehr vielen individuell verschiedenen Iden zusammengesetzt war, zumal da in jedem Ide noch jede Determinante auf eigene Faust rariieren kann. Die Unwahrscheinlichkeit, dass wir bei Inzucht schon bald lauter gleiche Ide mit lanter gleichen Determinanten in einem Keimplasma erhalten, ist so ausscrordentlich gross, dass wir mit ihr die Thatsache, wonach Inzucht sehr schnell znr Degeneration führt, in keiner Weise rereinigen liönnen, wiihrend diese Thatsache auf Grund unserer Lehre sehr leicht verständlich ist. Wir können schon in dritter Generation Tiere erhalten, welche dieselben Kernstofle und dieselben Plasmen laben. Setzen wir nun die Inzucht mit solchen Tieren fort, so arbeiten wir immer mit denselben einseitig verschobenen Genmarien, und es ist deshalb kein Wnnder, wenn dadurch Tiere entstehen, die schädigenden Einflüssen leicht ertiegen, wie jeder weiss, der etwa weisse Mänse in 
grösserer Anzahl längere Zeit hindurch gezüehtet hat. Nach alledem können wir diese Betrachtungen mit dem Satze schliessen, dass es sich bei der geschlechtlichen Fortptlanzung nicht um Amphimixis, sonden un Apomixis lrandelt, dass diese dieselben Keimplasmen leicht in eine Zelle zusammenbringt, dass aber dort, wo verschiedene Plasmen miteinander in Berülırung kommen, ein teilweiser Ausgleich ihrer Eigenschaften stattfindet. Die gesehleelitliche Fortpflanzung hat also nicht die Bedeutung, ungleich e Individuen zu sehaffen, sondern sie bewirkt das ger ade Gegenteil, wie es übrigens jedem Unbefangenen schon lüngst bekannt ist.

Aus unseren obigen Auseinandersetzungen geht hervor, dass die Reduktionsteilung nicht gelegentlich einmal zufällig väterliche und mütterliche Plasmen und Kernstoffe voneinander scheidet, sondern dass dieser Vorgang ein regelmässiger und ursichlich begründeter, ein notwendiger ist, wenn auch die ścheidung in vielen oder vielleicht in den meisteu Fällen keine ganz reinliche ist, was bei der Mischung, welche die Plasmen bei der Befruchtung miteinander eingehen, auch nicht erwartet werden darf. Immerhin geht aber aus meinen Versuchen mit Mïusen und aus allen mir sonst bekannten Thatsachen der Vererbung hervor, dass bei der Reduktionsteilung eine melı oder minder ausgesprochene sonderung der bei der Befruchtung gemischten Plasmen und liernstoffe, also eine Apomixis, stattfindet, und dass von Zufälligkeit dabei absolut nieht die Rede sein kann. Was man sonst über V'ererbung weiss, zeigt gleichfalls, dass das Wesen der Reduktionsteilung in Apomixis besteht: und ich muss deshalb gestehen, dass ich nicht begreifen kann, dass Weismann bei Gelegenheit der Besprechung ron Rückschlägen, die bei Jungen von Kreuzungstieren auf eine der reinen Stammformen vorkommen, behaupten kann, dass solche Rückschlägre selten vorzukommen scheinen. Nach meinen Untersuchungen sind diese Ruickschläge allerdings nicht so häufig wie die Nachkommen mit gemischten Cliarakteren, aber sie sind auch keineswegs selten. Übrigens geht ja auch aus der hier vorgetragenen Theorie der Apomixis herror, dass reine Rückschläge auf eine der beiden Stammformen einer Kreuzung:srasse nicht so hüufig vorkommen können, als neue Mischungen. Man werfe einfach einen Blick auf die Tabelle S. 237. Aus dieser kann man die Wahrscheinlichkeit berechnen, mit welcher Rückschläge auf die reinen Stammformen vorkommen, und ich kann nur sagen, dass meine Züchtungsergebnisse dieser Wahrscheinlichkeit im grossen und ganzen ent- 
sprechen und dadurch den Beweis führen, dass meine Annahmen elurer das Richtige getroffen haben, als die We ismann'sehen.

Wenn nun Weismann sagt, lass da, wo Rückschlüge auf eine reine Stanmform rorkommen, irgend welelse uns noch unbekannten Umstände - die Halbierung des Keimplasma's der Mutterkeimzolde in einer bestimnten Teilungsebene bewirken, so darf ich hier wohl hervorheben, dass sich diese uns noch unbekannten Umstände ans dem, was ich oben auseinandergesetzt hahe, ohne weiteres ergeben. Diese Lmstände sind uns keineswegs unbekannt, sofern wir nicht zur. Weismann'schen Idantenlehre schwören, sondern sie betreffen eine allgemeine Eigenschaft der Ilaterie, nämlich die, dass die Elemente eines und desselben stuffes sich gegen die anderer Stoffe überall dort, wo sich Gelegenheit dazu bietet, abzusondern bestrebt sind. Die Behauptung Wrismann's aber, dass Rückschläge auf die reine Stammart selten sind, steht in Widerspruch mit den Thatsachen. Sie kommen sogar recht oft vor, und dass dem so ist, daron kann man sich überzeugen, wenn man selbst Züichtungsversuche mit Tieren anstellt. Dass Pflanzen viel weniger dazu geeignet sind, werden wir später sehen. Allerdings ist immer im Auge zu behalten, dass hreuzung das Gemmariengefüge etwas rerändert, und zwar festigt, so dass beispielsweise aus dem Plasma gescheckter Tanzmäuse cin Plasma entsteht, das einfarbige Tanzmäuse hervorbringt, aber das T'anzmausplasma sondert sich leicht wieder von dem Plasma der gewöhnlichen Maus, und ungekchrt.

Ebenso unhaltbar wie IV e ismann's Behauptung, dass Rürclischläge auf eine reine Stammform ron Krenzungstieren selten rorkommen, ist die, dass solche Rüekschlïge nicht möglich wären, went us lieine, Reduktionsteilung in seinem Sinne gäbe, oder wenn das Kímplasma eine homogene Iasse wïre, die sich hei der Bastardierung mit dem Keimplasma der anderen Alt völlig vermischte. Weismann meint, es würde dann auch mit der Reduktionsteilung niemals das heimplasma der eiren Art entfernt worren können, es wiirde diese Reduktion mur eine Massen-, aber keine Qualitätsedulition sein; dureh Befruchtung mit den eigenen Bastardzellen wïrden dann in keinem lalle Rückschlïge auf eine Stammform eintreten können. aber auch bei fortgesetzter Rücklireuzung mit der einen Stammart würde die liemplasmamischung der ersten Bastardgeneration nur mehr und mehr rerdünnt werden: röllig reines Keinplasma der einen Stammart könnte nie wieder entstehen. Subald wir aber Einheiten im Krimplasma annehmen, die wie die Idanten und Ide 
getrennt bleiben, meint $W^{-}$eismann weiter, wäre eine Entfernung sämtlicher Einheiten der einen Art aus dem Keimplasma der Bastardsprösslinge sowohl mit als ohne Riickkreuzung durchaus mögtich; ja scelbst im letzteren Falle müsste sie früher oder später bei einzelnen Nachkommen eintreten.

Es scheint, dass diese Ansichten Wreismann's loch wohl unter dem Banne seiner Determinantenlehre entstanden sind, dem dass die Elemente zweier verschiedenen Plasmen sieh nicht wieder entmischen könnten, ist eine Behauptung, die mit allem, was wir sonst wissen, völlig unvereinbar ist. Dieser Behauptung würde es gleichkommen, wenn man sagen wollte, dass es nicht möglich wäre, dass aus einer Ilutterlauge ein Körper rein herauskristallisieren könne. Aber bekanntlich ist Kristallisation das IIttel, reine Stoffe herzustellen.

lch darf daher wohl die oben citierten Anschaumgen W'eismann's auf sich selbst beruhen lassen; nicht aber darf ich eine andere seiner Schlussfolgerungen mit stillschweigen übergehen.

IV eismann sagt, die ,Reduktionsteilung muss irgendwann einmal in der Phylogenese der Amphimixis zuerst aufgetreten sein. Träre sie schon in den Keimzellen des ersten geschlechtlich erzengten Wesens aufgetreten, so würde sie - vorausgesetzt, jedes der elterlichen Keimplasmen habe vorher nur ans einem Id bestanden - immer das Id des einen Elters alls jeder Keimzolle des Kindes wieder entfernt haben, d. h. es würde ein Enkel niemals etwas von seinen beiden Grosseltern zugleich erben körmen."

Wer meine obigen Ausfürungen mit Aufmerksamkeit geleseu hat, wird sofort herausfinden, dass ich allerdings der Ansicht bin, dass Reduktionsteilung schon bei den Keimzellen des ersten geschlechtlich erzengten Wesens aufgetreten ist, dass jedes der elterlichen Keimplasmen

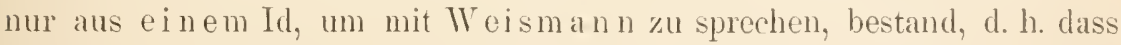
seine Gemmarien alle gleich waren, und dass bei jeder Reduktionsteilung immer das Id des einen Elters ans jeder Keimzelle des Kindes wieder entfernt wird. Ich habe nun oben weitläufig gezeigt, dass Enkel in den meisten Fällen etwas ron ihren beiden Grosseltern zugleich erben werden, vorausgesetzt, dass ihre Eltern Geschwister sind. Wr eismann hat sich also wohl nicht unzweideutig genug ausgedrückt; er meint sicher, dass ein Enkel in den Fïllen, wo keme Inzucht getrieben wird, niemals etwas ron den beiden Eltern des Vaters oder den beiden Eltern der Mutter zugleich erben kann, und ich muss zugestehen, dass das 
nicht angehen würde, falls in Körper der Eltern krine gregenseitige brrinflussungr ter Plasmen und Kémstoffe der Grosseltern möglich wäre. Dass diese aber stattfindet, zeigen meine einfarbigen schwarzen Tanzmäuse. Unsere Theorie wird atso anch der Thatsache srevecht, dass ein Kind etwas ron beiden Eltern seines Vaters oder von beiden Grosseltern mïtterlicherseits erhen kann. Un diese Thatsache zu erklären, haben wir keine ,'Theorie der zahtreichen Ide" nötig. Wir betrachten diese mit un so grösserem Misstrauen, als sie, wenigstens bei WeisIn a nn, wunderliche praktische Anwendungen zulässt.

Auf Seite 414 des Kémplasmabuches sagt Weismann: „Eines möchte ich hervorbeben, dass nämlich nach der (Weismann'schen) Theorje niemats ein Kind eine Mischung aus dem bilde \%weier Grosseltern sein kann." Ich muss nun freilich gestehen, dass ich den Unterschied, den We ismann zwischen ,etwas ron beiden Grosseltern erben“, was nach ihm ja möglich ist, und eine ., Mischung aus dem Bilde zweier Grosscltern sein" macht, nicht recht verstehe, und dass der Protest, den ich rom Borten ker Weismann'schen Thenrie aus gegen den zuletzt angeführten satz erheben muss, deshatb vielleicht nicht zutreffend ist. Indessen seheint es, hass Weismann zwar annimmt, ein Enkel könnte etwas ron zwei (irosseltern erben, indessen nur Eigrentümlichliciten der Art oder der Rasse, hingegen nicht individuelle Eigentümlichkeiten. Hören wir, was Weismann als Grund dafür angiebt, weshatb ein Kind niemals eine..Mischung aus dem Bilde zweier Grosselter"n" sein kann: "Einfach deshalb, weil mindestens die Hälfte der Idanten eines Keimplasma's das Bild des Kindes bestimme'n, weil aber immer nu ein Viertel der Idanten zweiel Grosseltern zugreich im Keimplasma des Kindes enthatten sein können."

Iir scheint, dass den Berechnungen Weismann's hier ein Irtum untergelaufen ist, wie sich aus folgendem Beispiel argeben wird. Die Individuen I und II mögen miteinander das Individuum III zeugen, und die Individuen IV und $Y$ das Individuum $V$ I, endlich mögen III und II das Individum VII zeugen. Es wären also I und II das eine (irosselternpatr und $I Y$ und $V$ das andere Grosselternpaar ron VII. Wir wollen nun annchmen, dass das Individuum I zusammengesetzt ist ans den Ldanten $a, b, c, d$, dass die Idanten in der Keimzelle des Individumms II e,f, l, h, die ron IV $i . l, l, m$ und die ron $Y n, o, l), l$ gewesen seien. Ehe sich die Keimzellen. welche das Individuum III bildeten, gegenseitig befruchteten, möge aus der Kémzche vom Individuum I die Idanten- 
gruppe $c d$ und aus der rom Individuum II die Idantengruppe $g h_{l}$ ausgestossen sein. Es würde also das Individuum III die Idantengruppe " $b$ e $f$ erhalten; ebenso soll ron den Idanten $i, k, l, m$ in der Keimzelle, die rom Individuum IV erzeugt wurde, die Gruppe $l m$, und in der Keimzelle, die vom Individum $V$ erzengt wurde, die Gruppe $p q$ durch die Reduktionsteilung beseitigt worden sein. Die befruchtete Eizelle des Individuums VI erhielt also die Idantengruppe $i k n o$. Es möge nun ferner aus der rom Individuum III erzengten Keimzelle, die mit einer Keimzelle rom Individuum VI das Individuum VII bildete, die Idantengruppe $c f$, und aus der Keinzelle rom Individum VI die Idantengruppe no ausgestossen sein, wodurch in den Enkel VII der Individuen I und II und IV und $V$ die Idanten $a, b, i, k$ zu liegen kommen. Nehmen wir num an, dass in dem Individum I die Idantengruppe $a b$ das Bild des Individuums bestimmte, was nach $W$ eismann ja angeht, da "mindestens die Hälfte der Idanten eines Keimplasma's das Bild des Kindes bestimmen", und dass in dem Individum IV das Bild durch die Idantengruppe $i i_{i}$ bestimmt wurde, nehmen wir ferner an, dass diese beiden im Indiriduum VII vereinigten Idantengruppen sich gegenseitig das Gleichgewicht halten, wogegen Weisman n nichts einzuwenden lraben dürfte, so dass sie beide ras Bild des Individuums VII bestimmen, so ist VII ein Enkel, der „eine Mischung aus dem Bilde zweier Grosseltern" darstellt. was nach Weismann nach seiner Theorie nnmöglich sein soll. Ich wüsste aber nicht, inwiefern die $\Lambda$ nnahmen, von welchen ich bei diesem Beispiel ausgegangen bin, irgendwie ron Weismann's Theorie abweichen, und in der That habe ich bei meinen Zuchtversuchen mit Mäusen oft genug Enkel erhalten, die „eine Mischung aus dem Bilde zweier Grosseltern" boten. Allein, es landelt sich augenblicklich nicht darum, ob die seiner eignen Theorie aufs grausamste widersprechende Behauptung Weisman n's mit den Thatsachen stimmt, sondern ob die Arithmetik der Idologie den Regeln der bei anderen Lehren ïblichen Arithmetik entspricht. Weismann sagt, dass im Keimplasma des Kindes immer nu* ein Viertel der Idanten zweier Grosseltern enthalten sein kann. In unserem Individuum VII sind aber 4 Idanten, wïhrend die Grosseltern je 4 Idanten haben. Die Anzahl der Idanten zweier (irosseltern beträgt also 8. Von diesen 8 Idanten sollen nie mehr als ein Viertel zugleich im Keimplasma des Enkels enthalten sein können. Wenn ich aber 4 Haufen Kirschen habe, von denen jeder aus $t$ Kirschen besteht, und ich esse von jedem Haufen 2 Kirschen, so bleiben $t$ Haufen, aus je 2 Kirschen 
bestehend. Jache ich aus diesen 4 Haufen 2 , inden ich je 2 und 2 zusammenthue, so chalte ich 2 Haufen mit je 4 Kirschen; verzehre ich ron diesen உ2 Haufen wieder je 2 Kirschen, so bleiben noch je ? hirschen in meinen beiden Haufen. Bilde ich aus diesen beirlen aus je 2- Kirschen bestehenden Haufen einen einzigen, so erhalte ich einen Haufen. Jer aus 4 Firschen besteht. Wir haben aber nach Treisman n bei der lieimzellenbildung und Befruchtung ganz rlasselbe. Es wird immer die Hälfte der Idanten aus jerler Keimzelle vor der Befruchtung entfernt, und wir erhalten deshalb obigem Beispiel entsprechend das lier folgende Bild,

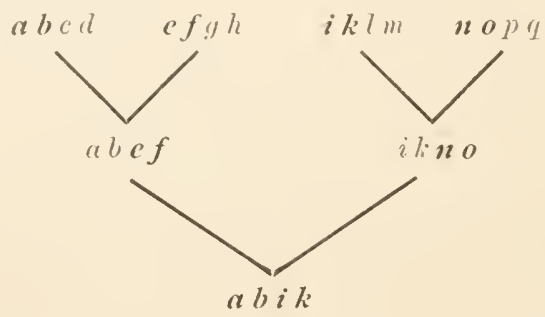

in welchem diejenigen Idantengruppen fett gedruckt sind, die das Bild des betreffenden Individuums bestimmen. Es geht darans herror. dass der Enkel, wie schon oben auseinandergesetzt ist, eine Jischung aus dem Bilde zweier Grosseltern sein kann, während er seinen Eltern nicht zu gleichen brancht, denn bei den Eltern hat die Idantengruppe of beziehungsweise $n o$ das Übergewicht über die Idantengruppe $a b$ beziehungsweise $i t_{k}$ darongetragen gehabt.

Ich habe mir grosse Nühe gegeben, einen Jrrtum in obigen Auseinandersutzungen zu entrlecken, weil es mir ferne liegt, We ismann unrechtmässigerweise cinen Torwurf zu machen, allein ich kann mit dem besten Willen nichts Unzulässiges in meinen Ausführungen auffinden, und glaube vielmehr, dass sie im strengen Einklang mit der II cismann'schen Theoric stehen. Teln will mich aber gerne belehren lassen, falls ich einem Irrtum zum Opfer gefallen bin.

Doch halt! Vielleicht wollte Weismann auf swiner Seite 414 sagen, dass ,niemals ein Kind eine Mischung aus dem Bilde" der Ejtern seines Vatersoder der Elternseiner II uttersein könne. Wenn Weismann dieses wirklich sagen wollte, so hätte er sich wolıl etwas deutlicher ausdrüeken dürfen, zumal er auf Seite 3!11 erklärt hat, dass ein Enlich zwalr sulten etwils ron ,.seinen beiten" (inosseltern erben wiirte. fas dieses ather nicht momoinglich erschiene. 
Wenn ich Weismann demnach hier auch keinen Widerspruch mit sich selbst nachweisen kann, so muss ich ihn doch einer höchst unklaren Behandlung eines einfachen arithmetischen Problems zeihen, denn angesichts der Thatsache, dass die Menschen - um diese handelt es sich - vier Grosseltern haben, musste Weismann sagen, welche zwei von den vieren er eigentlich meint. Ich mache ihm diesen Vorwurf deshalb, weil Weismann auf die arithmetische Behandlung seiner Theorie, zu welcher die letztere doch geradezu herausfordert, nicht die nötige Sorgfalt verwandt hat. Hätte er das gethan, so würde er auch die seiner Zeit ron mir vorgebrachten und auf Seite 83 ff. wiederholten streng arithmetischen Berechnungen, die eine verbesserte Auflage von Weismann's Ahnenplasmentheorie hätten verhindern müssen, nicht unbeachtet gelassen haben. Er hätte dann auch die von mir gebrachte Widerlegung seiner Determinantenlehre selbst besorgen und sein Keimplasmabuch unveröffentlicht lassen können. Das hätte freilich der Wissenschaft zum Nachteil gereicht, denn nichts wird so sehr den endgültigen Sieg der Epigenesislehre beschleunigen, als die im „Keimplasma" erfolgte Krönung des W eism an n'schen Lehrgebäudes.

Wir sind durch die Mitteilungen über die Ergebnisse meiner Zuchtversuche bei den Erscheinungen des $R$ ü ckschlages angelangt. müssen aber, ehe wir näher darauf eingrehen, zunächst die Eigenschaften von Kír eu zungsprodukten verschiedener Arten oder verschiedener Rassen einer Art besprechen. Wir wollen die ersteren Bastarde, die letzteren Blendlinge nennen. Wenn wir zwei verschiedene Arten miteinander kreuzen, so erhalten wir einen Bastard; kreuzen wir dagegen zwei Individuen zweier verschiedener Rassen, etwa eines Haustieres, miteinander, so erhalten wir Blendlinge. Die letzteren unterscheiden sich nun in auffälliger Weise von den ersteren, und zwar dadurch, dass Bastarde in den allermeisten Fällen eine Mischung der Charaktere der beiden Stammarten zeigen, während bei Blendlingen häufig die eine Rasse bei der Vererbung̣ überwiegt. Ich will dafür nur etliche von mir selbst beobachtete Beispiele anführen. Ich liess eine echte siamesische Hauskatze ron einem weissen Angorakater belegen und erhielt einen 6 oder 7 Köpfe starken Wurf von Kätzchen, die alle, abgesehen von einigen kaum sichtbaren schwarzen Tüpfeln auf dem Kopfe, in der Farbe und auch bis zu einem gewissen Grade in der Beschaffenheit des Haares den weissen Angorakater glichen. Ebenso liess ich weibliche Heidschnucken ron einem schwarzen Kameruner Schafbock belegen und erhielt dadurch Lämmer. 
die ron der Kamermmer Schafrasse nicht zu unterscheiden waren. Endlich kreuzte ich eine importicrte südamerikanische Nackthündin mit einem roin durchgezüchteten Dalmatiner. Sie warf vier Junge, von denen zwei der Nackthïndin grlichen, während die beiden übrigen weder mit dem Dalmatiner, noch mit der Hündin Älılichkeit hatten. Es geht also aus diesen und vielen anderen Beispielen hervor, dass bei der Blendling:zucht die Eigenschaften der einen Rasse selır häufig überwiegen, wälırend es allbekannt ist, dass Bastarde in den allermeisten Fällen eine innige Mischung der Charaktere der beiden Stammarten zeigen.

Auf Crund der Gemmarienlehre ist dieser Unterschied nicht schwer zu rerstehen. Bei der Blondlingszucht handelt es sich um Haustiere. bei der Bastardzucht entweder $u$ wilde Tiere oder doch wenigstens $11 \mathrm{~m}$ zwei röllig voneinander verschiedene Haustierarten. Haustiere sind aber in ihrem Gefïge geschwächt, weil bei ihnen infolge der fürsorgenden Teilnahme des Menschen die konstitutionelle /uchtwahl zum urrossen Teil in Fortfall gekommen ist. Aus diesem Grunde sind auch Haustiere so oft gescheckt, während unregelmaissige Scheckung bei wild lebenden Tieren iiberhaupt kaum als Artcharakter vorkommt. Bei der Bastardzucht kommen zwei Plasmen zusammen, die sich in Bezug auf Fefügefestigkeit die Wage halten. Es bringt deshalb jedes dieser beiden Plasmen seine Eigenschaften zum Ausdruck, während in einem Blendlinge oft ein Plasma überwiegt, weil es in seinem Gefüge weniger gelockert ist als das andere. D arwin hat schon auf diese Eigentiimlichkeit hingewiesen, olne sie aber in befriedigender Weise erklären zu können. Es findet also bei Mischung verschiedener Individuen eine Alt $\mathrm{K}$ ampf der Plasmen statt, wie ihn auch We ismann annimmt. Während aber bei der Bastardzucht meistens lieines der beirlen Plasmen als Sieger aus lem Kampfe hervorgeht, kommt bei der Blendlingszucht oft der Fall ror, llass ein Plasma das andere völlig besiegt.

Dieser Kampf der Plasmen ist von grosser Berleutung für die Mischung persönlicher Eigrenschaften bei den Produkten einer ersten Kreuzumg zweier rerschiedener Haustierrassen und nicht minder bei den Nachkommen von solchen Kreuzungstieren. Für die Pflanzen gilt dasselbe. Auch bei rer Vererbung individueller Figenschaften bei Menschen spielt der Kampf der Plasmen eine grosse Rolle. Dieser Kampf kann nun ein derartiger scin, dass schon in der befruchteten Eizelle das Plasma des Vaters oder ler Hutter zur Herschaft gelangt, und dass demnach das Kind der Hauptsache nach einem der Eltern gleicht, ein Fall, der beim Menschen 
oft senug vorliommt und sogar die Regel bildet. Es ist jedoch auch der andere Fall möglich, dass die beiden Plasmen sich das Gleichgewicht larlten und beide das Bild des Kindes bestimmen. Endlich ist es auch möglich, dass in dem einen Körperteil dieses, in dem anderen jenes Plasma das Übergewicht bekonmt, so dass einzelne Körperteile individuelle Eigenschaften des Vaters zeigen, während andere den betreffenden Körperteilen der Mutter gleichen. Allerdings ist es meistens recht schwierig zu sagen, in welchen \%ügen das Kind melır dem Vater und in welchen es mehr der Mutter gleicht, und namentlich ist der Mensch ein sehr ungeeignetes Objekt zur Prüfung von vererbungstheoretischen Fragen, weil es unmöglich ist, genaue Vergleiche zwischen dem Menschen und seinen Eltern anzustellen, da die Unterschiede, die durch das verschiedene Alter bedingt werden, beim Menschen beträchtlicher sind, als bei irgend einem anderen Tier, und deshalb leicht zu Irrtümern Anlass geben. Noch viel weniger ist man in der Lage, ein Kind mit einem seiner Grosseltern, geschweige denn mit allen seinen Grosseltern oder mit noch früheren Torfahren leicht vergleichen zu können. Allein es ist auf Grund der Ciemmarienlehre wohl zu verstehen, dass nicht immer alle Körperteile des Kindes entwerler denen eines der Eltern oder beider zugleich älnlich sind, sondern dass ein Teil sich nach dem einen Elter und ein anderer nach dem andern Elter richtet, und ebenso muss es auch möglich sein, dass ein Kind eine derartige Mischung ron den Eigenschaften zweier seiner Grosseltern zeigt.

Die Erscheinungen, um welche es sich hier handelt, sind namentlich an Pflanzen studiert worlen. Im landwirtschaftlichen botanischen Garten in Jena konnte ich infolge der Güte des Herrn Professor Liebscher Bastarde zweier Arten von Gerste sehen, und zwar solche der zweiten Generation. Die der ersten Generation hatten die Charaktere der beiden Stammrassen gemischt, und zwar so, dass man annehmen konnte, dass jede Zelle sowohl väterliche als auch mütterliche Eigenschaften hatte. Dagegen zeigten die Nachkommen dieser Bastarde Mischungsverhältnisse, die völlig verschieden ron denen der Eltern und auch unter sich waren. Die Ähren dieser Bastarde glichen in manchen Teilen völig der einen, in anderen genau der zweiten Stammart, während aber bei den einen dieses Mischungsverhältniss zmm Ausdruck kam, kam bei den anderen jenes zur Geltung, und es fragt sich, wie sich diese Erscheinungen mit unserer Gemmarienlehre vereinigen lassen. Ich glaube, dass ihre Erklärung auf Grund unserer 'Theorie nicht schwierig ist. 
Schom Liebscher hat gelegentlich der Beschreibung seiner Bastarde larauf hingewiesen, dass dabei eine Lockerung des Plasmagefüges stattgefunden habe. We ismann weiss zwar nicht, wie er sich eine sulche Lockerung rurzustellen hat, aber ich glaube, dass er aus vorliegendem Werli ersehen wird, dass man sich derglriehen recht greifbar vor Augen fïhren kann. Ans dieser Annalmme einer lockerung erlilärt es sich, warum die ursprïglichen Bastarle noch in allen ihren Teilen die Eirenschaften ihrer Stammarten gemiseht zeigten, während dies bei ihren Tachkommen nicht mehr der Fall war. Bei den ursprünglichen Bastarden waren eben zwei Plasmen miteinander in Berührung gekommen, die sich noch gegenseitig das Gleichgewicht hielten. Dadurch aber, dass diese beiden P'asmen aufeinander einwirken konnten, sind sie in ihrem Getügre gelockert worden, weil es sich dabei um Plasmen verschiedener Arten gehandelt hat. Ans diesem Grumble sind die Mischungsverhälnisse bei den Nachkommen der Gerstenbastarde so schwankende, ungleichmässige geworlen, weil bald das eine, balıl das andere Plasma das Übergewicht erhielt, je nach den Umständen, unter welchen die Gerstenptlanzen erzengt und aufgewachsen waren. Allerdings ist es möglich, dass die Erscheinungen bei Pflan\%en, weil es sich dabei meistens um Stöclie handelt, wïhrend wir es bei den Tieren mit Personen zu thun haben, andere sind als bei den letzteren, und ich werde noch später auf diese Iöglichkeit zurïckkommen. Soviel aber dürfte aus dem Gesag̨ten hervorgehen, dass der Ausgang des Kampfes zweier rerschiedener Plasmen sehr versehieden sein muss bei verschiedenen Individuen und in verschiedenen Teilen des Leibes eines Individuums, je nach den äusseren Umständen und den sonstigen Eigenschaften der betreffenden Individuen.

Fs bleibt mir noch ïbrig, auf einen merkwïrligen Unterschied zwischen Bastarden und Blendlingen aufmerlisam zu machen, nämlich anf die bekannte Thatsache, dass Bastarde meistens unfruchtbar sind, Blendlinge dagegen nicht, ja dass die letzteren oft fruchtbarer sind als ihre Stammlassen. Dieser Unterschied ist nicht schwer zu begreifen. bei der Bastardzïchtung liommen P'lasmen miteinander in Berührung, die in sich gefestigt sind mnd dadurch, dass sie in einer und derselben Zelle rereinigt werten, cine Lockerung ihres Gefiiges erleiden. Diese Lockerung geht so weit, dass Bastarde meistens nicht mehr im stande sind. entwickelnngstähige Keimzellen zu erzeugen. Dagegen werden bei der Blendlingszucht, weil es sich dabei um Ha ustiere handelt, die infolge der schüdligenden Einfliisse der Domestikation eine in einseitiger 
Weise erfolgte Gefügelockerung erlitten haben, zwei nach rerschiedenen Seiten hin abgeänderte Gemmarienformen mit lockerem Gefüge zusammengebracht. Sie haben Gelegenheit, durch gegenseitigen Einfluss aufeinander ihre Ungleichheiten auszugleichen und damit wierler ihre (iefügefestigkeit zum 'Teil oder völlig zurückzugewinnen, und es ist deshalb nicht zu verwundern, rlass Blendlinge sich oft dureh grosse Fruchtbarkeit und durch kräftige Konstitution auszeichnen.

Wir sind nummehr in der Lage, etwas genaner auf die Erscheinungen des $R$ ückschlages einzugehen.

Weismann erklärt alle Rückschlagserscheinungen durch seine Theorie der Amphinixis. Diese ist allerdings geeignet, gewisse Rückschläge zu erklären; allein sie lässt im Stich bei der Erklärung anderer Arten von Rückschlägen und muss deshalb in solchen Fällen durch nene Hilfshypothesen gestützt werden. Bei alledem ist sie nicht im stande, darzuthun, warum in manchen Fällen kein Rückschlag eintritt wo er, wie aus der Abstammung der Tiere herrorgeht, doch leicht eintreten müsste.

Weismann und alle seine Vorgänger machen keinen scharfen Unterschied zwischen den einzelnen Arten des Rückschlages, obgleich diese in völlig verschiedenen Ursachen ihren Grund haben. Deshalb ist W e ism an n, obwohl er beispielsweise Rückschlag auf individuelle Charaktere, auf Rassencharaktere und auf die Eigenschaften entfernter Vorfahren unterscheidet, gezwungen, alle diese Rückschlagserschein ungen aus seinem Prinzip der Amphimixis heraus zu erklären, bei welcher Gelegenheit dann eine Reihe von neuen Hilfshypothesen gemacht werden. Wir werden hingegen sehen, dass es vier Gruppen von Rückschlagserscheinungen giebt, deren jedle in einer anderen Ursache ihren Grund hat, dass sich aber sämtliche vier Gruppen aus unserer Gemmarienlelıre heraus erklären lassen.

Die erste Gruppe ron Rückschlägen umfasst jene Fälle, wo ein Enkel auf einen oder zwei seiner Grosseltern oder auch seiner Urgrosseltern oder etwas entferntere Vorfahren zurückschlägt. Solche Rückschlagserscheinungen habe ich im einzelnen bei meiner Mäusezucht studiert, und ich bin deshalb in der Lage, sie genau prüfen zu können. Alles, was ich dabei beobachtet habe, erklärt sich leicht aus unserer Annahme, wonach das Plasma eines Individuums bei geschlechtlich sich fortpflanzenden Tieren der Hauptsache nach aus zwei individuell verschiedenen Plasmen zusammengesetzt ist, während für den Kern dasselbe gilt. Ich 
miisste alles, was ich oben ïber die Zucht ron Ziermäusen augrefuhrt habe, wiederholen, wenn ich hier näher auf die bei ihnen beobachteten Rückschlagserscheinungen eingehen wollte. Ich darf mich daher damit begrnügen, meine leser einfach auf clas oben Gesagte zu verweisen, und will aus den dort aufgeführten möglichen Fällen des Rückschlages nur ein par herausgreifen, un daran zu zeigen, dass Weismann's Theorie der Amphimixis unfähig ist, die Erschciunngen des Rückschlages zu elklären, wie sie derjenige, der selbst Züchtungsversuche anstellt, beobachtet.

Paren wir eine schwarz und weiss geschechte japanische Tanzmaus mit einer weissen gewöhnlichen Maus, so erhalten wir schwarze oder dunkelgraue Mäuse, die in ihrem Benchmen unseren gewöhnlichen Hausmäusen gleichen. Wenn wir von solchen Jungen unter sich weiter züchten, so können wir unter anderm rein weisse Tanzmäuse erhalten. Wrie diese zu stande kommen, habe ich oben gezeigt. Da $W$ e is m a n n's Theorie von Iden ausgeht, ir welchen alle Eigenschaften der betreffenden Art oder Rasse, wenn auch in individueller Färbung, durch Determinanten und Biophoren vorgebildet sind, so müssen wir annehmen, dass in den Idanten einer solchen weissen Tanzmaus sowohl Ide der schwarz und weiss gescheckten Tanzmaus, als auch Ide der gewöhnlichen weissen Maus enthalten sind. Es würden diejenigen Zellen, auf welchen die Eigenschaft des Tanzens beruht, damn durch die Tanznauside, dagegen diejenigen, welche die Earbe der Haare bedingen, durch lde der gewölmlichen weissen Maus bestimmt werden. Da es nun leicht ist, aus grauen oder schwarzen Kreuzungsmäusen auf dem Wege des Rückschlages wieder geschechte Tanzmäuse zu erzielen, so sollte man annelmmen, dass die Weiterzucht der weissen Tanzmäuse gelegentlich auch einmal wieler gescheckte Tanzmäuse ergeben würde. Dieser Fall tritt aber niemals ein. Zwar habe ich die Zucht der weissen Mäuse nicht sehr lange fortsetzen können, indessen, was ich darïber beobachtet habe, lässt mich mit Bestimmtheit erkennen, dass weisse Tanzmäuse immer nur wieder weisse Tanzmäuse erzengen werden, dass sie nie gescheckte Tanzmäuse und anch nie Mäuse, welche nicht tanzen, hervorbringen werden, obwohl sie doch von gescheckten Tanzmäusen und ron nicht tanzenden weissen Mäusen abstammen. Ich kamn deshalb den Verehrern des Weismannismus nur raten, doch einmal selbst meine Behauptungen durch eigne /uchtversuche zu prüfen. Ich brauche die Ergebnisse einer solchen Prüfung nicht zu scheuen, da ich über 3000 Mäuse gezüchtet habe, ein Material, das ich demnächst unverkürzt den Vererbungstheoretikern rorlegen werde. 
Es sei mir gestattet, aus diesem Material noch ein anderes Beispiel herauszugreifen. Ausser schwarz und weissen Tanzmäusen erhalten wir aus Japan auch solche, die nicht schwarz und weiss, sondern blau und weiss gescheckt sind. Was ich hier "blau" nenne, ist ungefähr ein bläuliches Aschgrau, das gelegentlich einen Stich ins Fahle zeigt. Im grossen und ganzen bin ich aber berechtigt, die betreffende Farbe kurzweg als blau zu bezeichnen. Die Eigenschaften blau und weiss gescheckter Tanzmäuse sind streng erblich, falls man zu den betreffenden Zuchtversuchen echte, aus Japan stammende Tanzmäuse nimmt. Paart man Mäuse mit dieser individuellen Färbung immer miteinander, so erhält man nie etwas anderes, als blau und weiss gescheckte Tanzmäuse. Solche Mäuse habe ich mit gewöhnlichen weissen Mäusen gepaart und von ihnen Junge erhalten, die ron unserer gewöhnlichen wilden Hausmaus uur schwer oder überhaupt nicht zu unterscheiden waren. Diese grauen Mäuse kann man nun miteinander paaren, um dadurch einfarbige blaue gewöhnliche Mäuse zu erzielen. Man kann die Versuche aber auch komplizierter machen, und das habe ich durchweg gethan. Ich habe aber auch dann auf dem Wege des Rückschlages einfarbige blaue Mäuse, die nicht tanzten, erhalten. Wenn man nun diese untereinander weiter züchtet, so erhält man nichts weiter als einfarbige blaue Mäuse, welche nicht tanzen, obwohl sie von Tanzmäusen abstammen und vou diesen ihre Färbung ererbt haben. Nacb Weismann's Theorie der Amphimixis müssen aber in den Idanten solcher einfarbiger blauer Mäuse zahlreiche Ide von Tanzmäusen enthalten sein, da diese ja allein die Farbe der blauen Mäuse bestimmen. Ich habe die Zucht mit blauen Mäusen lange fortgesetzt, aber nie etwas anderes erhalten, als einfarbige blaue \äuse, die höchstens einmal einen kleinen weissen Fleck an dieser oder jener Körperstelle hatten. Wie kommt es nun, dass bei solchen Mäusen kein Rückschlag auf die eine oder die andere der beiden Vorfahrenformen mehr eintritt? Die Erklärung ist höchst einfach. Das Plasma solcher Mäuse ist das gewöhnlicher Mäuse, aber die Kernstoffe sind die der blau und weiss gescheckten Tanzmäuse. Die Scheckung und das Tanzen werden bei diesen durch das Plasma des Zellleibes bestimmt, während die Färbung der Haare durch ihre Kernstoffe bestimmt werden. Da nach unserer Theorie leicht gleiche Plasmen und gleiche Kernstoffe der Grosseltern in den Enkeln oder späteren Nachkommen vereinigt sein können, so kann selbstverständlich kein weiterer Rückschlag mehr eintreten. 
Wührend unsere Theorie also genau mit den Thatsachen, denen Weisna nn noch näher zu treten hat, übereinstimmt, ist die Amphimixislelne Weismann's mit diesen Thatsachen röllig nuvereinbar. Ich glaube. dass alle Vererbungserscheinungen, welche zur Kategorie der Rückschläge auf (irosseltern oder andere nicht weit entfernte Torfahren gehören, auf ähnliche Weise zn erklären sein werden, wie die, welche ich bei den Mänsen gefunden habe, nämlich durch die Annahme, dass die Reduktionsteilung der Keimzellen die beiden bei der Befruchtung zusammengekommenen individuell verschiedenen oder auch durch Rasseneigentümlichkeiten sich unterscheidenden Plasmen tind ebenso die beiden Kernstoffe wieder trennt, wobei die Plasmen ihre Kernstoffe gegenseitig austauschen können. Selbstrerständlich ist diese Trennung wohl nur in seltenen Fällen eine völlig reine, nnd es mögen beispielsweise zwischen den Gemmarien von Tanzmäusen, die zu ihren Vorfahren gewöhnliche Mäuse zählen, auch einige Cremmarien solcher Mäuse liegen, und ähnliches mag für die Kernstofye gelten. Im grossen und ganzen glaube ich aber das Richtige getroffen zu haben, und ich bin auch überzengt, dass meine Erklärung sich auf die bei P'lanzen beobachteten Vererbungserscheinungen, die allerdings einer erneuten Kontrolle durch das Züichtungsexperiment bedürfen, auwenden lässt.

Alle Pflanzen, welche zu Züchtungsexperimenten gedient haben. unterscheiden sich nämlich von Mäusen und anderen Tieren, mit welchen man Zuchtversuche angestellt lat, dadurch, dass sie stöeke bilden und nicht eine einzelne Person darstellen. IIt der L'erson beim Tiere, deren Charakteristikum der Besit\% eines Mageus ist, lüsst sich, wie es rou seiten Haeckel's gesehehen ist, der Sploss der Pflanze vergleichen. Insbesondere dürfen wir die Blüten direkt nit den Personen der Tiere in Parallele stellen. Es fragt sich nun, ob bei der Sprossenbildung der Pflanzen nicht Plasmensonderungen stattfinden, namentlich bei Bastarlen der zweiten orler dritten Generation, bei denen, wie wir oben gezeigt laben, und wie auch schon Liebscher angenommen lat, eine Luckerung des plasmatischen Gefüges, die eine leichte Trennung der verschiedenen Plasmen ermöglicht, stattgefunden hat. Fs liann deshalb bei rem einen spross diese, bei dem anderen jene Plasmenart allein die Eigenschaften bestimmen, so dass wir sehr verschiedene Bastarde erhalten, wie ich sie \% B. in Jena als Ergebnisse der Zuchtversuche Professor Liebscher's gesehen habe. Es rlarf also das, was man bei Pflanzen beobachtet hat, nicht ohne weiteres mit den Rüickschlagserscheinungen 
bei Tieren in Parallele gestellt werden. Es sind vielmehr neue Versuche nötig, und diese werden, wie ich überzeugt bin, ergeben, dass meine Erklärung der Rückschlagserscheinungen richtig ist. Ebendasselbe wird auch eine genaue und sorgfältige Untersuchung der Rückschlagserscheinungen beim Menschen, die allerdings nicht eben leicht ist, zeigen.

Von den bisher betrachteten Rückschlägen auf Grosseltern oder auf Torfahren, die nicht viel weiter zurückliegen als diese, unterscheiden sich die Rüickschlagserscheinungen der zweiten Kategorie dadurch, dass sie zwar nicht sehr weit entfernte Vorfahren betreffen, aber die Stammarten ron Haustierrassen oder Kulturpflanzen. Es ist bekannt, dass man durch Kreuzung verschiedener Taubenrassen wieder die Felstaube erhält, und ähnliches kann man bei Hühnern und anderen Tieren beobachten. Diese Art des Rückschlages hat ihre Ursache in Gefügefestigung. Das Gefüge bei Haustierrassen und Kulturpflanzen ist gelockert; es wird dadurch wieder gefestigt, dass Gemmarien zweier verschiedener Rassen miteinander gemischt werden und sich gegenseitig ins Gleichgewicht setzen, und zwar durch eine Verschiebung ihrer Gemmeu, oder durch Abwerfung von Gemmen, die bei der einen Rasse nicht vorkommen, oder endlich durch Anfügung von Gemmen, die der einen Rasse verloren gegangen sind, aber bei der wilden Stammart und bei den Gemmen der anderen Rasse vorkommen. Ein Blick auf unsere Fig. 26 wird

a

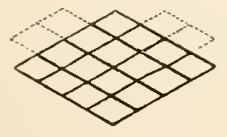

Fig. 26.

b

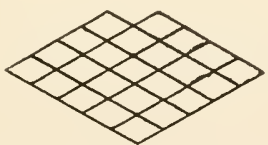

c

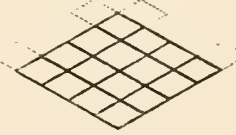

Schemata zur Erläuterung des Rückschlages.

die Art und Weise veranschaulichen, auf welche der Rückschlag auf eine Stammart durch Veränderung der Gemmarien der miteinander gekreuzten Kulturrassen zu stande kommen kann. a und c stellen Querschnitte durch Gemmarien zweier Kulturrassen dar, während b einen Querschnitt durch die Gemmarien der Stammart darstellt. In a und $c$ sind diejenigen Gemmen, welche Rasseneigentümlichkeiten der Kulturrassen bedingen, punktiert. Diese Gemmen sind in a andere als in c. Legen sich nun die den Querschnitten a und e entsprechenden Gemmarien mit eben diesen Querschnitten aufeinander, so finden etliche ihrer Gemmenreihen im anderen Gemmarium solche, mit welchen sie sich ins Gleich- 
gewicht setzen können, und da die betreffenden Genmenreihen, wie wir annehmen müssen, dem Gemmarium leicht angefügt werden können, so müssen sich die Gemmenreihen der Stammrasse, die in a und c zum Teil, aber in der Weise fehlen, dass sich a und c ergänzen, wiederherstellen. lis ist also wieder eine Gefügefestigung eingetreten, die zu einem Rüchschlag auf die wilde Stammart fülıt.

Eine dritte Art der Rückschlagserscheinungen betrifft Fälle ron Rückschlïgen, wie wir sie etwa an den Maultieren beobachten. Während das Hauspferd und der Hausesel an den Beinen nicht gestreift sind, treten lıäufig Tigerpferdstreifon bei Maultieren auf. Diese kommen dadurch zu stande, dass sich gewissermassen die ontogenetischen Zellenstammbäume ron l'ferd und Esel so weit aufeinanderlegen, als ihre Äste parallel laufen, und da die stammesgeschichtliche Entwickelung ein Wachsen der Äste des ontogenetischen Zellenstanmbaumes bedeutet, so werden die Strecken, welche beim Pferde und beim Esel noch einigermassen parallel sind, auch parallel denen der älteren gestreiften Pferde, ron welchen Pferd und Esel abstammen, sein, während die nicht parallelen \%weigspitzen beim Bastarde zum Teil in Fortfall kommen. Es crklärt sich also daraus der Rückschlag auf die Tigerpferde, den man bei Haultieren beobachten kann, auf sehr einfache Weise.

Derartige Bastarde thun auch, wie nebenbei bemerkt sein mag, die Unhaltbarkeit der Weismann'schen Determinantenlehre dar. Die Plasmen, die miteinander in einer Keimzelle rereinigt sind, bedingen die Entwickelung so weit, als ihre normale Entwickelung einander parallel laufen wïrde. Darïber hinans wird diese Entwickelung nicht fortgesetzt. Das letztere müsste aber möglich sein, wenn IV eismann 's Determinantenlelıe richtig ist. Sobald die homologen Determinanten, die in beiden Plasmen rorkommen, anfgebraucht sind, müsste die Bildung von Zellen aufhören, die Determinanten aus beiden Plasmen lıaben. Dagegen würden sich noch Zellen bilden müssen, die nur Determinanten der einen Stammart haben. An etlichen Körperstellen würden beispielsweise etwa bei der Kíreuzung ron Pferd und Esel die Determinanten des Pferdes, an anderen die des Esels zur Geltung kommen. Iclı lıabe aber nic von Bastarden gehört, die im grossen und ganzen die Mitte halten \%wischen den beiden Stammarten, ausserdem aber noch, auf verschiedene Körperstellen verteilt, die reinen Charalitere der cinen oder der anderen Stanmart zeigen. Bastarde erster Generation halten vielmelır, sofern sie nicht die Charaktere der einen Stammart allein besitzen, 
genau die Mitte zwischeu den beiden Stammarten, und das kann nach unserer Lehre nicht anders sein, während diese Thatsache der Weisman n'schen Determinantenlehre durchaus widerspricht. Es muss, falls das in einer Keimzelle nach erfolgter Reduktionsteilung befindliche Plasma ein monotones ist, bei der Bastardzüchtung eine Entwickel ungshemmung eintreten, weil sich die beiclen Plasmen nur so weit Hand in Hand entwickeln könmen, als die Äste und Zweige der Zellenstammbäume der betreftenden Arten parallel laufen. Sobald sie merklich auseinandergehen, ist keine Entwickelung mehr möglich. Der Rückschlag, den wir bei den Bastarden rou Pferd und Esel beobachten, ein Rückschlag auf die gemeinsame Vorfahrenform der Gattung, hat also in einer Entwickelungshemmung seine Ursache.

Ausser den drei genannten Cruppen von Rückschlägen kommt eine vierte vor, die Rückschläge auf einzelne verloren gegangene Charaktere betrifft, welche bei weit entfernten Vorfahren gut entwickelt waren. Solche Rückschläge finden wir beispielsweise bei den Pferden, die gelegentlich au zwei oder an vier Beinen eine überzählige Zehe besitzen und dadurch an ausgestorbene Vorfahren der Pferde erinnern. Auch bei den Hunden, die an den Hinterbeinen nur vier Zehen haben. tritt nicht selten ein Rückschlag dadurch ein, dass die verloren gegangene fünfte Zehe, die bei del Torfahren gut entwickelt war, wieder erscheint, und ähnliches habe ich an den Hinterfüssen von Meerschweinchen beobachtet, die normalerweise nur drei Hinterzehen haben, aber mitunter noch eine kleine vierte Afterzehe erhalten. Alle diese Fälle ron Rückschlag auf Charaktere, die bei weit entfernten Vorfahren vorhanden waren, aber längst verschwunden sind, wurden an $\mathrm{H}$ austieren beobachtet, und es ist mir nicht bekannt, dass solche Rückschläge auch bei wildlebenden Tieren vorkommen. Inmerhiu mögen sie sich auch bei diesen ab und zu finden, aber unter allen Umständen kommen Rückschläge dieser Gruppe bei weitem läufiger bei Haustieren vor, und zwar infolge des Ausfalles der Gefügezuchtwahl und als Wirkung der schädigenden Finflüsse der Domestikation.

Die Gefügelockerung ermöglicht es, dass ein ontogenetischer Zellenstammbaum wieder Zweige entwickelt, die zwar noch angedeutet sind, aber gewöhnlich nicht mehr äusserlich zum Ausdruck kommen. Die im Laufe der Stammesgeschichte erfolgte Gefügefestigung hat bestimmte Zweige des ontogenetischen Zellenstammbaumes begïnstigt. Die Anzahl dieser Zweige ist bei höheren Tieren geringer als bei niederen, aber dafür sind 
die einzehnen Äste und \%weige des \%ellenstammbanmes bei höheren Tieren mit festem Gefüge stïrlier entwickelt, als bei niederen Tieren mit lockerem Gefüge. Wird nun das Gefü̈re durch Domestiliation wieder gelockert, so hönnen sich auch '/weige, die zwar noch rorhanden, aber rudinentär geworden, und in den meisten Fällen nur in Spuren oder überhanpt nicht anatomisch nachweisbar sind, wieder stärker ausbilılen, wodurch verloren gegangene Charaktere, wie es die fünfte \%ehe an den Hinterfüssen der Hunde und die rierte an denen der Meerschweinchen. ebenso die überzähligen Zehen am Pferdefusse sind, wieder crscheinen. Gefügelockerung ist also die Ursache des Rückschlages auf verloren gegangene Charaktere, die bei selı weit entfernten Vorfihren vorhanden waren.

W e isman n erklärt die Rückschläge dieser Gruppe dadurch, dass er annimmt, in einzelnen Iden des Keimplasma's der betreffenden Tiere seien noch Determinanten der verloren gregangenen Charaktere vorhanden. Wenn eine genügende Anzahl solcher Ide zufällig in einem und demselben Keimplasma zusammen zu liegen kommt, soll ein Rückschlag auf jene alten Charaktere cintreten. Abgeselıen davon, dass diese Anschauung es nicht erklärt, warum derartige Rückschläge bei Haustieren viel häufiger sind, als bei wild lebenden, bein Haushunde beispielsweise viel öfter beobachtet werden, als beim Wolf; von welchem unzweifelhaft eine grosse Anzahl der Haushundrassen abstammen, muss die Weismann'sche Annahme wieder eine neue Hilfshypothese einführen, die Hypothese nämlich, dass es noch lde giebt, in welchen unveränderte oder wenig veränderte Determinanten von Vorfalıen liegen, die schon vor langer erdgeschichtlicher Zeit ausgestorben sind. Warum die natürliche Zuchtwahl, die doch nach $W$ eismann geradezu alles beherrscht, dergleichen Determinanten nicht beseitigt hat, ist nicht einzuselien. Freilich hilft sich Weismann durch die Annahme, dass die natiirliche \%uchtwahl inmer nur das besorgt, was absolut nötig ist, dagegen das Übrige gehen lässt, wie es will. Allein diese Amalme bringt We ismann mit sich selbst in Widerspruch, denn man sieht nicht ein, warum Rü̈chschläge auf überflüssig gewordene Charalitere so selten wieder eintreten, wenn es gleichgültig ist, ob in einer grüsseren Anzahl von Iden noch die Determinanten solcher Chariktere vorhanden sind oder nicht. Die Rückschläge müssten bei der W $\mathrm{W}$ ismann'schen Anuahme viel häufiger sein, konmen aber bei wild lebenden Tieren nur äusserst selten (oder gar nicht?) vor. Der Unterschied zwischen den letzteren und den Haustieren, bei welchen 
derartige Rückschläge nichts Seltenes sind, zeigt eben, dass diese Rückschläge ihre Ursache in der Gefügelockerung haben.

Bei den Hauskatzen, die von der in Nordustafrika lebenden Falbkatze abstanmen, sind Rückschläge auf eine altertümliche Zeichnungsform des Katzenfells nichts Ungewöhnliches. Es giebt viele Hauskatzen, bei wechen die Flecken in Längs- und Querreihen angeordnet sind, wie wir sie etwa beim Serval und anderen wild lebenden Katzen finden. Die Falbkatze ist dagegen im grossen und ganzen einfarbig und hat nur noch Andeutungen einer Querstreifung, die nach Eimer die höchststehende Zeichnung des Katzenfells darstellt. Ich habe mich vielfach mit der Frage nach der Zeichnung des Katzenfells beschäftigt und kann Eimer nur beistimmen. Warum giebt es nun bei der wild lebenden Falbkatze lieine Exemplare, die zu gleicher Zeit eine Anordnung von Flecken in Längs- und in Querreihen zeigen? Wenn in den Iden der Hauskatze noch wenig veränderte Zeichnungsdeterminanten sind, die den genannten Rückschlag bedingen, so müssen sie auch in den Iden der Falbkatze vorhanden sein, gleichwohl tritt bei dieser kein Rückschlag ein. Ein solcher Rückschlag brauchte ja nur die Andentungen von Flecken hervorzubringen; diese könnten den betreffenden Tiere nicht schädlich werden, und altertiumliche Fleckenzeichnung müsste deshalb bei der Falbkatze gelegentlich angetroffen werden. Das wird sie aber nicht.

Die bei Haustieren eingetretene Gefügelockerung, auf welche die Scheckung und alle anderen Unregelmässigkeiten in der Ausbildung der Charaktere zurückzuführen sind, erklärt es auch, warum bei ihnen Rückschlag auf Charaktere weit entfernter Vorfahren oft nur an ein er Körperseite auftritt, wie es zum Beispiel beim Meerschweinchen der Fall ist, wo mitunter nur an einem Hinterbein eine vierte Zehe erscheint. Gemmarien mit lockerem Gefüge sind grossen Schwankungen in ihrer Form unterworfen. Schwanliende Symmetrieverhältnisse bei Haustieren sind deshalb nichts Auffälliges. Dagegen vermag Weismann es nicht zu erklären, warum Rückschläge auf alte Charaktere nur selten auf eine Körperhälfte beschränkt bleiben. Nach ihm zeichnen sich gerade Haustiere deshalb durch unsymmetrische Ausbildung der Zeichnung aus, weil diese von keinem Nutzen mehr ist, weil die natürliche Zuchtwahl deshalb die Färbungsdeterminanten auf jeder Körperhälfte ihre eignen Wege ziehen lässt. Sind aber die rudimentären überzähligen Zehen, die sich nicht allzuselten bei Hunden finden, von grösserer Wichtigkeit für diese, als etwa der Haustaube, die doch oft genug vom Habicht rerfolgt wird, 
die Färbung: Überzïllige \%ehen treten aber meistens an beiden Körperseiten auf. Warum gehen hier die Determinanten nicht auf jeder hïrperhälfte ihre eignen Wege: Warum sind sie nicht bei den einen Irlen auf der linken, bei den anderen auf der rechten Scite geschwunden? Vormag W eisman n das irgendwie durch seine Determinantenlehre begreiflich zu machen:

Ian wird hier vielleicht einwenden wollen, dass rudimentiire überzühlige Brustwar\%en, die beim Menschen, uncl zwar auch bei Männem(!), recht häufig rorkommen, meistens nur an einer liörperseite liegen. Allein der Mensch ist ein in viel höherem Grade unsymmetrisches Tier als etwa der Huncl. Rechte und linke Körperhälfte sind bei ihm ungleich ausgebildet. Daraus erklïrt sich das häufige einseitige Auftreten überz:̈hliger Brustwarzen unrl ilıre grössere Häufigkeit auf der linken Körperseite. Dieses Uंberwiegen der linken Seite, wass sich auch durch die sehr hüufige stärkere Ausbildung der linken weiblichen Brust ausspricht, ist eine Korrelationserscheinung, die durch Weismann's l'rüiformismus unerklärt bleibt.

Den obigen Ausführungen entsprechend haben wir die Rückschläge in vier Gruppen zu sondern, von denen die der einen in der Reduktionstrilung, in der Apomixis der Keimzellen, die der zweiten in Gefügefestigung, die der dritten in einer Entwickelungshemnung und die der vierten in (iefügelockerung ihre Ursache haben. Aber diese vier rerschiedenen Ursachen haben alle ihren Grund in der Zusammensetzung des Plasma's aus Gemmarien, die sich ihrerseits aus gegenein ander rersehiebbaren Gemmen aufbauen. Die Rïckschlïge sind der Ausdruck des wechselnden Gleichgewichtszustandes der Gemmarien und ihrer Gemmen und sind aus der Gemmarienlehre mechaniseh zu erklären.

Wie weit Weismann daron entfernt ist, die Rückschläge wirklich zu erklären. zeigen etliche seiner Ausführungen, durch welche er uns soine Theorie der Amphimixis in einer becienklichen Beleuchtung rorführt. Auf Seite 412 seines Keimplasmabuches sagt er, es sei .,zu belenken, dass die völlig gleichmässige Mischung rler beiden Elternbilıler im Kinde viel seltener ist, als man gewöln lich glaubt, und dass es schwer, ja häufig ummöglich ist, zu sagen, ob der mütterliche Anteil an einem Charakter wirklich dem Bilde der Mutter und nicht dem des MutterVaters oder der Mutter-Mutter entnommen ist. Meist sind es nur allgemeine Charaktere der mütterlichen Familie," fähıt er fort, „die sich mit 
allgemeinen Charakteren der räterlichen Familie gemischt haben. Charaktere aber, die schon durch Generationen hindurch vielen Giliedern einer Familie eigen waren, sind eben solche, die in zahtreichen Iden und Idanten vorkommen und die deshatb bei rielen Modalitäten der Reduktionsteilung in grösserer Anzahl in die Keimzellen gelangen. Für diese Übertrag'ung allgemeiner Familienähnlichkeit würde theoretisch nicht die dominierende Idantengruppe des Elters, sondern nur überhaupt eine Mehrzahl der Idanten dieser Gruppe erforderlich sein."

We ismann spricht diese Sätze in Bezug auf die Tererbung beim Ienschen aus. Wie aber allgemeine Charaktere in einer Familie zu stande kommen, darüber hat er sich nicht ausgelassen. Ein Mensch hat 2 Eltern, 4 Grosseltern, \& Urgrosseltern, 16, 32, 64, 128, 256. 512 Vorfahren der 5. beziehungsweise der $6 ., 7 ., 8 ., 9$. und 10. Generation. Wie also soll es möglich sein, dass etwa ein Deutscher, der nach Austratien auswandert und dort eine Engländerin heiratet, seine individu ellen Charaktere, wie es oft vorkommt, auf seine Kinder vererbt? Wenn Weismann's Annahme allgemeiner Familiencharaktere beim Menschen richtig' wäre, so müsste doch eine hochgradige Inzucht getrieben werden. Es mag ja nun in Weismann's Vaterstadt Frankfurt a. M., die bekanntlich lange eine freie Reichsstadt war, und deren Einwohner weder mit den umwohnenden Hessen, noch mit "Hergeloffenen" etwas zu thun haben wollten, vielfach Inzucht getrieben worden sein, allein in anderen Gegenden ist das nicht der Fall gewesen, und in neu gegründeten Kolonien, wo sich Leute aus sehr verschiedenen Gegenden nicht nur eines Landes, sondern vieler Länder treffen, kann von einer derartigen Inzucht vorderhand noch lange keine Rede sein. Weshalb auch hier so oft wie bei uns zu Hause ,die dominierende Idantengruppe“, um mit W eismann zu reden, in die der Amphimixis unterworfenen Keimzellen gerät, ist nicht einzusehen. Man könnte zwar einwenden, dass es sich dabei um Nachkommen verschiedener Menschen rassen, wenn man etwa die Engländer und Deutschen als verschiedene Rassen betrachten will, handelt; aber in vielen Fällen, und wohl in den meisten, beiraten die eingewanderten Deutschen in Australien und anderswo wieder Deutsche und die Engländer wieder Engländerinnen. 'T'rotzdem gleichen die Kinder eines deutschen Vaters, der in Australien eine Deutsche, die aus einer von seiner Heimat weit entfernten Gegend stammt, geheiratet hat, häufig diesem Vater oder auch ihrer Mutter. Mir ist ein Fall bekannt, in welchem die Tochter der MIutter, der Sohn aber dem 
Vater in hohem Grade ähnlich ist, nicht nur was Gesichtsbildung und Körperform anlangt, sondern auch in Bezug auf den Charakter. Die Mutter der Mutter stammt aus Thüringen, während ihr V'ater aus Holstein liam, der V'ater des Vaters und seine Mutter stammen allerdings beide aus der Prorinz Hannover, allein aus Gegenden, die nicht in Heiratsverliehr stehen. Wie ist es nun möglich, dass sowohl bei der Zeugung der Tochter als auch bei der cles Sohnes die Idanten der Keimzellen sich so verhalten haben, dass die Tochter die herrschende Idantengruppe ihrer Mutter, der Sohn die seines V'aters erhielt?

Sehr einfach erklären sich solche überaus häufigen Fälle der Ähnlichkeit der Kinder mit nur einem ihrer Eltern ans der Annahme, dass Organismen, die sich geschlechtlich fortptianzen, der Hauptsache nach immer nur aus zwei Plasmenarten zusammengesetzt sind, von denen selbstrerständlich entweder die eine oder die andere dominieren kann, während sich in manchen Fällen auch beide das Gleichgewicht halten können. Bei der Reduktionsteilung tremnen sich diese Plasmen.

Mir scheint, dass $W$ eismann, als er von allgemeinen Charakteren der väterlichen und mütterlichen Familie sprach, die iiblichen Stammbäume der plyylogenetischen \%oologie im Geiste vor Augen gehabt hat, die ja mit einem unverzweigten und sich dann gabelig oder anderweitig teilenden Stamme beginnen und an der Spitze eine weit verzweigte Krone zeigen, Stammbäume, für welche Haeckel in seiner ,Natürlichen Schöpfungsgeschichte" und anderswo manche Beispiele gegeben hat. Für die phylogenetische Zoologie sind solche Stammbäume äusserst brauchbar; aher mit denjenigen Stammbäumen, welche menschliche Familienverhältnisse darstellen sollen, haben sie nichts zu thun. Der Stammbaum eines menschlichen Individumms beginnt mit sehr vielen \%weigen, die sich nach und nach rereinigen und schiesslich in einem einzigen /weig, eben demjenigen, den clas Individum darstellt, auslaufen. Von welchem der 512 Vorfahren zehnter Generation stammen denn nun eigentlich Weismann's ,allgemeine Familiencharaktere* eines Menschen her? Es giebt Familiencharaktere, aber von diesen kann nur bei den Descendenten, niclit bei den Ascendenten eines menschlichen Individumms die Rede sein. Dass die grosse Unterlippe der Habsburger und die gebogene Nase der Bourbonen, dass das musikalische Talent der Familie Bach Familiencharaktere sind, bezweifele auch ich nicht; aber die Entstehung solcher Familiencharaktere, die, weil sie auf ein einziges Individuum zuriekzuführen sind und nicht 
infolge von Inzucht bei vielen Mitgliedern der Familie vorkommen, nichts mit den We ismann' schen zu thun haben, lässt sich nur auf Frund rer Annahme erklären, dass das Ḱeimplasma der Individuen, welche diese Familiencharaktere zeigen, aus zwei individuell rerschiedenen Plasmen zusammengesetzt ist, von denen das eine das Übergewicht über das andere hat und möglicherweise die Gemmarienform der letzteren in die seiner eigenen Gemmarien hineinzwängt. „Familiencharaktere" müssen mit Notwendigkeit entstehen, sobald irgend ein Vortahr einer grossen Familie ein solch festgefügtes Plasma hat, dass es allen Einfliussen trotzt. Ein solcher muss seine Claraktere auf die grosse Mehrzaht seiner Nachkommen rererben. Wie das aber möglich ist, wenn Amphimixis stattfindet, welche die Ide und Idanten ja fortwährend dnrcheinanderwirft und mit anderen Iden und Idanten zusammenbringt, das ist auf Grund der W eismann'schen Theorie nur dann zu verstehen, wenn man entweder annimmt, dass immer die "herrschende Idantengruppe“ in die Keimzellen aller dem Stammvater ähnlichen Nachkommen zu liegen kommt, eine Annahme, die das Gegenteil von Amphimixis bedeutet, oder wenn in der betreffenden Familie in hochgradiger Weise Inzucht getrieben wird. Letzteres geschieht aber glücklicherweise in den meisten Familien nicht, trotzdem auch hier die Tererbung inchividueller Charaktere nicht minder häufig ist, als in Ortschaften, die sich nach aussen hin mehr oder minder streng abschliessen, und wo die Leute nur Ortsangehörige oder womöglich Verwandte heiraten.

Es zeigt sich somit, dass Weismann durch seine Amphimixislehre zu Annahmen verführt worden ist, die an den Thatsachen keinen Rückhalt haben und mit der Amphimixistheorie selbst in unlösbarem Widerspruche stehen.

In Widerspruch mit dieser Theorie steht auch der Erkï̈rungsversuch des Rückschlages bei ungeschlechtlicher Fortpflanzung, den wir bei W eismann finden. Weismann bespricht insbesondere den Rückschlag bei Knospung, und zwar den ,panaschierter", d. h. teilweise bleichsüchtiger, Blätter auf gewöhnliche grüne Blätter und ausserdem den Rückschlag, der beim Pfropfbastard zweier Goldregenarten, bei Cytisus arlami, beobachtet wird.

Was den leicht zu beobachtenden Rückschlag panaschierter Blätter auf gewöhnliche grüne Blätter betrifft, so handelt es sich dabei um einen Rückschlag ron Kulturvarietïten auf ursprüngliche Verhältnisse. Panaschierte Blätter kommen nach meiner Ansicht und im Einklang mit 
miner Gemmarienlehre dadurch zu stande, dass das Gefüge der betreffenden Pflanze gelockert wird, so das eine ungleiche Verteilung des Chlorophylls stattfindet. Bei der Knospen- und Blattbildung der Pflanzen ist es nun sehr wohl möglich, dass etliche Zweige infolge von äusseren Einflüssen günstiger gestellt sind als andere, insofern als ihr frefüge lurch diese äusseren Einflüsse wieder ein festeres wird und den Rüclischlag auf grüne Blätter, d. h. auf eine gleichmaissige Verteilung des Pigmentes bedingt. Dieser Rückschlag erkläıt sich also auf sehr einfache und natiurliche Weise. Weismann dagegen ist gewungen, ihn durch seine Amphinixis zu erklären und muss zu diesem Zwecke eine neue Hilfshypothese erfinden, nämlich die, dass die Idanten auf ungleiche Weise bei der Zellteilung verteilt werden, so dass in die cine Zelle Idanten mit Determinanten panasehierter Blätter, in die andere solche mit Determinanten grüner Blätter zu liegen kommen. Thatsache ist aber, dass bei der gewölnlichen Zellteilung die Idanten der Länge nach halbiert werden und damit, wenn wir uns auf den Boden der Determinantenlehre stellen, auch die der Lünge nach in den Idanten aufgereihten Ide. Wreismann aber ist gezwungen, in denjenigen Fällen, wo grüne Sprosse an einer Pflanze mit panaschierten Blättern entstehen, eine $\mathrm{A}$ b w ei chung von dem nach allen vorliegenden Beobachtungen ausserordentlich gesetzmässigen Teilungsmodus der Zelle auzunehmen. Ungleiche Verteilung der Ide auf die Tochterkerne einer sich teilenden Zelle ist, wemn Weismann's Theorie konsequent sein will, nicht möglich. Sie steht mit dem, was Weismann sonst annimmt, in Widerspruch und stört den regelrechten Gang der Mechanik der Idzerlegung auf bedenkliche Weise. Olme eine streng gesetzmässige Teilung der Idanten und ihrer Ide hat aber Weismann's Determinantenlehre keinen Simn. Weismann's Präformismus und seine Amphimixis sind zwar von vornherein unbrauchbar, aber die 'Thatsache, dass bei Knospung Rückschläge eintreten, zeigt, dass sie auch dann unbrauchbar sind, wenn man sich redlich bemüht, die Erscheinungen der Vererbung durch sie zu erkłären. W eismann sagt: „Irgend eine derartige Unregelmässigkeit in der Verteilung der Ide muss bei don Kernteilungen vorkommen können, andernfalls würde es unerklärlich bleiben, wieso eine andere Mischung der Anlage im Laufe des Wachstums eintreten kann, wie wir sie doch thatsächlich bei Knospungsrückschlïgen eintreten sehen." Allerdings! Eine falsche Grundhypothese bedingt inmer eine grosse Reihe von unbrauchbaren Nebenhypothesen, und dass solche Nebenhypothesen gelegentlich 
in vollkonmenem Widerspruch mit der Haupthypothese stehen müssen, zeigt uns Weismann durch diesen Ausspruch. Durch eine liederliclie Verteilung der „Ide“ kann niemals ein Organismus mit geordnetem Zellenaufbau zu stande kommen.

Der Rückschlag bei dem Pfropfbastard des Adam'schen Goldregens besteht darin, dass die einzelnen Teile der Blüte bald auf die eine, bald auf die andere Stammform zurückschlagen. Dieselbe Blütenähre trägt nach Darwin zuweilen zwei Sorten von Blüten, und Darwin hat eine Blüte gesehen, die genau in zwei Hälften geteilt war. Die eine war hellgelb, die andere purpurn, so dass die eine Hälfte des einen Blattes gelb und vor bedeutender Grösse, die andere purpurn und kleiner war. Bei einer anderen Blüte war die ganze Korolle lıellgelb, aber genau die Hälfte des Kelches war purpurn; bei einer weiteren latte eins der sclimutzigroten, also gemischten, Flügelkronenblätter einen schmalen hellgelben Streifen, und endlich war in einer Blüte ein Staubfaden halb gelb und halb purpurn.

Wir haben hier keineswegs einen anderen Fall, als bei den oben angeführten Rückschlägen bei Gerstenbastarden, und können die Rücksclıläge bei Cytisus adami auf dieselbe Weise wie dort erklären. Bei Cytisus adami sind durch die Pfropfung zwei verschiedene Plasmen und zwei rerschiedene Kernstoffe in eine und dieselbe Zelle zu liegen gekommen, und in deren Nachkommen kann sehr wohl bald die eine und bald die andere Art der Plasmen und Kernstoffe zur Geltung kommen, weil das Plasmagefüge von Cytisus adami wahrscheinlich ein lockeres ist. Dieser Bastard verdankt einer abnormen Befruchtung sein Dasein. Wahrscheinlich wurden beim Pfropfen zwei durch Messerschnitte einer kïnstlichen Reduktionsteilung unterworfen gewesene Zellen zu einer einzigen vereinigt, und aus dieser entstand der Bastard. Dass das Gefüge eines auf so gänzlich abnorme Weise gebildeten Bastardes kein besonders festes ist, ist begreiflich.

Es ist dem Obigen zufolge nicht nötig; mit W $\mathrm{T}$ ismann anzunehmen, dass die Auzahl der Chromosomen bei Cytisus adami so gross sein muss, wie die der beiden Stammarten zusammengenommen, denn wahrscheinlich konnte Cytisus adami nur dadurch entstehen, dass die sich bei seiner Bildung vereinigenden Zellen zuvor einer künstlichen Reduktiousteilung. unterworfen wurden.

Nach Adam's Beobachtung hat sich ja auch nicht die ,schlafende Knospe" zum Bastard entwickelt, sondern eine erst im zweiten Jahre 
gebildete Knospe. Es hat sich ferner nur eine Bastaldknospe entwirkelt, nicht alle nenen Knospen des Pfropfstiickes sind Bastardknospen geworden, und da, wie wir nach den rorliegenden Angaben annehmen müssen, ron rornherein die Charaktere der beilen Stanmarten fortwïhrend wechselten, so dürfte unsere brklärung der von vornherein cingetretenen Rückschlïge die richtige scin. Die Bastardzellen besassen ein lockeres Ciefüge, und je nach den Umstïnden kam bald die eine und bald die andere Plasmen- und Chromosomenart zur Geltung.

Der von Weismann angeführte Fall ron .Rückschlag“ hei einem sich parthenogenetisch fortptlanzenden Muschelkrebse ist gleichfalls nicht schwierig zu erklären.

.In der Gegend von Freiburg," sagt W eismann, ,kommen in gewissen Sümpfen zwei Varictïten eines kleinen Muschelkrebses ror, der eine sehr auffällige Zeichnung der Schale hat. Die eine Abart, A. erscheint hell ockergelb mit fünf grünen Flecken auf jeder Schale, die andere, B, sieht dunkelgrïn ans, weil bei ihr der ockergelbe Grund ron sechs grossen Flecken stark eingeengt wird. Die Flecken ter beitlen Abarten entsprechen einander der Lage nach genau und sind nur bei $A$ viel hleiner als bei B, Fleck 6 fehlt sogar bei A ganz. Beide Abarten ptlanzen sich bei Freiburg nur durch Parthenogenese fort; Männchen kommen niemals ror."

Weismann hat nun gesehen, dass sowohl bei der $A$ bart $A$, Rïckschlïire" auf $B$, als auch bei $\mathrm{B}$, Rü̈ckschläge" auf $A$ rorkommen können. Es handelt sich bei dieser parthenogenetischen Fortpflanzung aber um weiter nichts, als um das, was wir oben bei dem Rïckschlag panaschierter Blïtter aluf grüne kennen geelernt haben. Offenbar ist die Abart A ron Cypris reptans eine bleichsüchtige Form der Abart B. Dass aber hleichsüchtige Individuen eine bessere Konstitution erhalten können. wissen wir aus der krfahrung, und rlasselbe kann auch bei den Nachkommen hleichsüchtiger Individuen geschehen. Sic können infolge suinstiger oder nach unserel Ausdrucksweise festigender Einflüsse anf den körper wieder normal werlen, und ebenso können normale Individuen infolge den Keim treffender schädlicher Einflüsse bleichsüchtig werden. Es handelt sich hier also überhaupt nicht um einen Rückschlag.

Weismann aber, ter bis auf weiteres an seine Theorie der Amphimixis gebunden ist, muss versuchen, auch diesen sogenannten Rüclischlag bei Parthenngenese unter allen Umstïnden mit seiner Theorie in Einklang 
zu bringen, und macht wieder einnal Hilfsannahmen, die mit dieser Theorie unvereinbar sind. Er sagt: „Äussere Einwirkungen für diese plützlichen Umwandhungen verantwortlich zu machen, geht deshalb nicht an, weil stets beide Formen neboneinander iu demselben kleinen Aquarium, also genau unter denselben Bedingungen auftraten."

Durch diesen Satz lebt Weismann seine Determinantenlehre einfach auf, denn die Verschiedenheit der Determinanten ist nach Weisman u dadurch zu stande gekommen, dass die verschiedenen Teile eines und desselben Ides, lem gegenüber auch das kleinste Aquarium so gross ist, wie unser Planetensystem verglichen mit einem Kieselstein. lureh verschiedenartige Ernälıungseinflüsse hervorgebraclut wurden. Was aber in diesen winzigen Id möglich ist, das soll nach Weismann in einem Aquarium nicht möglich sein. Die Determinanten in einen Id sollen verschieden ernälıt werden können, aber Krebse, die in einem Aquarium leben, nicht! Offenbar ist aber das letztere sehr wohl möglich, denn für einen kleinen Muschelkrebs ist ein auch noch so kleines Aquarium doch immerhin eine Welt, und wie man das Aquarium auch stellen möge, aus der notwendigerweise verschiedenen Beleuclitung, aus der verschiedenen Verteilung der Pflanzen in diesem Aquarium, kurz aus allen möglichen Umständen, ergiebt sich mit. Notwendigkeit, dass die verschiedenen in einem Aquarium lebenden kleinen Tiere wechselnden Ernährungsbedingungen unterworfen sind. Dazu kommt aber, dass auch die Keimzellen, die in einem und demselben Tier gebildet werden, nicht alle gleich gut entwickelt sein können, dass manche zu einer Zeit gebildet werden, in welcher eine ungünstige Beeinflussung des betreffenden Tieres von aussen stattfindet, und dass andere eine um so günstigere 'Zeit treffen können. Ein Rückschlag gut konstituierter Individuen in solche mit schlechter Konstitution und umgekehrt ist deshalb leiclıt möglich.

Aber nicht genug damit, dass Weismann zur Erklärung dieses Rückschlages gezwungen ist, seine Determinantenlehre indirekt zu verneinen, hat er auch noch eine neue Art der Redultionsteilung ersonnen. Er sagt, dass bei Arten mit regelnäissiger Parthenogenese, obwohl hiel keine Befruchtung eiutritt, dennoch eine Reduktionsteilung stattfindet, allerdings nur eine. Bei parthenogenetisch sich entwickelnden Eiern wird nur eine sogenannte Richtungszelle abgelöst, nicht deren zwei, wie bei geschlechtlicher Fortpflanzung. "Ohne Zweifel," fährt We ismann fort, „muss dieser e in en Halbierung der Idantenzalıl des Eies eine VerII a a ke, Gestaltung und Vererbung. 
doppelung derselben rorausgehen, ganz wie bei der geschlechtlichen Fortptlanzung. weil andernfalls die Idanten ron (ieneration zu Generation um die Hälfte rermindert und schliesslich auf einen gebracht werden müssten. Sobald nun aber eine Reduktionsteilung mit vorgängiger Verdoppelung der Idantenzahl stattfindet, ist damit auch die Möglichkeit des Rückschlages gegeben."

Durch das Aussprechen dieses Satzes fügt $\mathrm{W}$ e isman $n$ dem Hanfen der schwankenden Stützen seiner Theorie eine neue Hilfshypothese hinzu. Bekanntlich haben die Untersuchungen der Teilungsvorgänge bei Zellen gezeigt, dass sich die Chromosomen einfach teilen. Wenn in einer Zelle vier Chromosomen sind und jedes Chromosoma teilt sich, und wenn sich die eine Teilungshälfte in die eine und die andere in die andere Tochterzelle begiebt, so erhält jede Tochterzelle wiederum vier Clromosomen. Wenn die Richtungszellenbildung bei echt parthenogenetischen Tieren eine Reduktionsteilung ist, damn ist es jede Zellteilung.

Allerdings muss die Anzahl der Chromosomen ror der definitiven Teilung der Zelle rerdoppelt werden, wenn jede Tochterzelle die gleiche Anzahl erhalten soll, wie die Mutterzelle, aber dabei handelt es sich doch nicht $\mathrm{um}$ eine Reduktionsteilung, sondern um eine gewöhnliche 'Zellteilung, und etwas anderes beobachten wir auch bei der Bildung der Richtungszellen parthenogenetischer Tiere nicht. Die Verdoppelung der Chromosomen fällt nicht immer zusammen mit den übrigen Zellteilungsrorgängen, weil eben die Zelle eine Symbiose darstellt und keinen einheitlichen Organismus. Es ist deshalb garz rerkehrt, wenn Weismann die Bildung des Richtungskörpers bei parthenogenetischen Tieren auf dem Wege einer Reduktionsteilung zu stande kommen lässt, und hier ist anch der Ort, darauf hinzuweisen, dass We is mann eine ganz willkürliche Annahme macht, wenn er beispielsweise die Keimzellenreifung beim Pferdespulwurm so darstellt, als ob dabei durch die erste Teilung der Eizellenmutterzelle eine Durcheinandermischung der Chromosomen zu stande käme. Es wäre ja denkbar, dass solches geschähe, aber darüber wissen wir rorlänfig noch nichts. Wir wissen noch nicht einmal, ob es geschehen kann. Der Vorgang ist einfach der, dass sich die Chromosomen teilen und dass in die eine Tochterzclle die eine Hälfte nnd in die andere die andere Hälfte der Chromosomen hineinwandert. Die bei dieser Zellteilung entstelıenden ungleich grossen Zellen teilen sich nun beide in der Weise, dass ihre Chromosomen nicht lablbiert werden, sondern dass jede ans den Teilungen dieser beiden Zellen lrer- 
vorgehenden Zellen nur die Hälfte der Chromosomen erhält. D as sind die Teilungsvorgänge bei der Eizellenreifung beim Pferdespulwurm. Durch die erste Teilung der Mutterzelle werden die Chromosomen halbiert, bei der zweiten wird ihre Anzahl halbiert. Die erste Teilung ist eine gewöhnliche Zellteilung, die zweite eine Reduktionsteilung, bei welcher sich rerschiedene Plasmen und Kernstoffe voneinander sondern, und genau ebenso verläuft die Samenzellenbildung beim Pferdespulwurm, wie wir schon früher gesehen haben.

Bei den Keimzellen geschlechtlich sich fortpflanzender Tiere findet also eine Reduktionsteilung statt, bei strenger Parthenogenese dagegen nicht, und es ist eine völlig willkürliche Annahme Weismann's, wenn er sie dennoch eintreten lässt. Der Unterschied der Parthenogenese und der geschlechtlichen Fortpflanzung beruht eben darauf, dass bei Parthenogenese keine Plasmensonderung eintritt, weil das Gefüge parthenogenetisch sich fortpflanzender Tiere ein derart widerstandsfähiges geworden ist, dass die zur Zeit der geschlechtlichen Vereinigung der Vorfahren dieser Tiere zusammengebrachten Plasmen sich nicht mehr voneinander trennen. Aus diesem Grunde findet zwar die der ersten Teilung der Mutterkeimzelle entsprechende Teilung auch bei parthenogenetischen Tieren statt, dagegen bleibt die Sonderung der Plasmen und folglich die einzige bei nicht parthenogenetischen Eiern stattfindende Reduktionsteilung bei ihnen aus.

Weismann's Erklärung des vermeintlichen Rückschlages bei seinen Muschelkrebsen hat ihn also gleich nach zwei accessorischen Stiitzen seiner Amphimixistheorie suchen lassen, und er ist dabei ebenso glïcklich gewesen, wie bei dem Erfinden anderer Hilfshypothesen.

\section{m. Generationswechsel und Polymorphismus.}

Aus dem von uns angenommenen Bau der Gemmarien geht herror, dass die letzteren durch äussere Einflüsse mehr oder minder leicht in ihrem Gefüge rerändert werden können. Ihre Gemmen werden gegeneinander verschoben; dadurch ändert sich die Form des Gemmariums und die Verteilung seiner Anziehungspole. Die Zellen, die sich aus veränderten Gemmarien auf bauen, müssen gleichfalls andere werden, und dasselbe gilt für den ganzen Körper.

Die äusseren Einflüsse wirken nicht nur wïhrend einer beschränkten Periode des Lebens eines Individuums, sondern solange dieses ïberhaupt 
existiert. Schon die Keinzellen, ans welchen sich die Individuen entwicheln. sind durch äussere Einflüsse reränderlich, und dasselbe gilt ron allen Stadien der individuellen Entwickelung und des Lebens bis ins Alter hinein. Der 'Tod ist eine Folge der sich allmählich häufenden schädigenden Eintlïsse, die das Gleichgewicht der Gemmarien stören und endlich derartig lochern, dass ein rascher Zerfall eintreten kann, womit das Leben des Individuums aufhört.

Es sind also während der ganzen Lebensdaner eines Indiridumms stetig äussere Finflüsse wirksam, um seine Formen umzubilden; diese aber hängen zu einem grossem Teile ron den periodischen Torgängen ab, die in der Natur stattfinden, und welche sich durch den Wechsel von Tag und Nacht, Ebbe und Flut, ron Sommer und Winter und anderen geographischen Vorgängen kundgeben. Der Körper der Organismen ist fortwährend gezwnngen, sich mit diesen wechselnden periodischen Veränderungen der Aussenwelt ins Gleichgewicht zu setzen, und da die regelmässige Wiederkehr solcher periodischer Einflüsse durch den Umlauf der Erde um die Somne und durch ihre Achsendrehung bedingt wird, so wird ein regelmässiger Wechsel der P'erioden eingeführt, so dass die Organismen zu bestimmten Tages- oder Jahreszeiten immer ron denselben oder wenigstens ron ähnlichen äusseren Einflüssen getroffen werden. Der Unterschicd zwischen diesen äusseren Einflüssen ist in manchen Fällen so gross geworden, dass er eine erhebliche Differenz der Jahreszeitenformen herbcigeführt hat, so dass die zn verschiedenen Jahreszeiten erzeugten Formen stark roneinander abweichen, wie wir es z. B. bei etlichen Schmetterlingen beobachten.

Dieser sogemannte Saison-Dimorphismus der Schmetterlinge lïsst sich ohne weiteres auf den periodisehen Wechsel der Jahreszeiten zurückfühnen, aber das Gleiche ist auch möglich bei dem eigentlichen fienerationswechscl, wie wir ihn beispielsweise bei den Scheibenquallen antreffen. Bei ihnen entsteht aus dem befruchteten ki der Qualle in den meisten Fällen nicht wiederum eine Qualle, sondern ein Becherpolyp, der sich an Pflanzen und dergleichen festheftet und durch eine Art ron Teilung, die quer zu seiner Längsachse verläuft, eine Reihe von kleinen Medusen ron sich absehnürt, also auf dem Wege ungeschlechtlicher Eortpflanzung erst wieder die Gesehlechtstiere der Art herrorbringt. Wer Gelegrenheit gehabt hat, sich $m$ den Generationswechsel der ()hrenqualle unserer Ostsee zu kümmern, wirl wissen, dass die rerschiedenen aufeinanderfolgenden Entwickelungsstadien dieser Qnalle im grossen 
und ganzen an bestimmte Jahreszeiten geknüpft sind. Die Quallen werden im Spätsommer oder Herbst geschlechtsreif; aus ihren befruchteten Eier entwickeln sich zu dieser Zeit Larven, die zunächst an den Mundarmen der mütterlichen Qualle hängen und sich später auf Gegenstände am Meeresboden, auf Seegras, Tang und dergleichen festsetzen. Hier wachsen sie zu dem Scyphostoma oder dem Becherpolypen aus, und dieser erzeugt erst wieder im Frühjahr durch Querteilung neue Medusen, die zunächst die Larvenform der Ephyrula haben und nach und nach zu den geschlechtsreifen Quallen auswachsen. Wenn man bei uns im Binnenlande wobnt, sich von Zeit zu Zeit eine Partie Quallen aus dem Kieler Hafen schicken lässt und diese in ein Aquarium setzt, in welchen sie nicht weiter wachsen, so kann man schön die aufeinanderfolgenden Entwickelungsstufen der jungen Quallen beobachten, denn man erhält jedesmal bei dem Eintreffen einer neuen Sendung Quallen, die sich namentlich durch ihre Grösse, aber auch durch ilıre Formenverhältnisse von den Quallen der vorhergehenden Sendung unterscheiden. Im grossen und ganzen sind die Quallen des Kieler Hafens zu gleicher Zeit mehr oder weniger gleich gross, wenn natürlich auch zahlreiche Ausnahmen rorkommen. Es kommt num aber in milden Wintern vor, dass die geschlechtsreifen Quallen nicht, wie üblich, sterben, sondern dass sich etliche von ihnen den Winter über erhalten und im Frühjahr ron neuem Geschlechtsprodukte bilden. Haeckel hat nun im Winter 1850-81 eine Anzahl von Larren der Ohrenqualle durch meine Termittelung erhalten und beobachtet, dass diese sich im Aquarium des zoologischen Instituts in Jena zum Teil nicht erst zu Polypen, sondern gleich wieder zu Medusen entwickelten. Schon ehe Haeckel diese Beobachtung machte, hatte ich selbst im Erühjahr 1880 an einer überwinterten Qualle zahlreiche Larren gefunden, die sich, wie ich sofort sah, erheblich von den üblichen Larvenformen unterschieden und mich damals auf die Vermutung brachten, dass auch hier eine direkte Entwickelung der Meduse aus dem Ei stattfände. Leider gelang es mir nicht, diese Larven sich weiter entwickeln zu sehen, ich bin aber heute überzeugt, dass das warme Frühlingswetter die direkte Entwickelung von Larven überwinterter Medusen bewirkt, ähnlich wie es in Jena in den erwärmten Räumen des zoologischen Instituts bei Larven der Fall war, die nach dort aus dem winterlich kalten Wasser des Kieler Hafens gebracht worden waren. Diese Thatsachen zeigen, dass der Generationswechsel vom Jahreszeitenwechsel abhängig ist, wenigstens bei unserer Ohrenqualle. Gewöhnlich werden erst im Herbste Larven 
erzeugt: aus diesen bilden sich nur Becherpolypen, die erst wieder im Frühjahr junge Medusen hervorbringen. Dagegen kann aus den Eiern der Ohrenqualle sofort wieder eine junge Meduse entstehen. wenn das betreffende Ei oder eine sehr junge Larve einer beträchtlich erlı̈hten Temperatur ausgesetzt wird. Der Generationswechsel der Ohrenqualle erklärt sich also ohne weiteres aus dem Jahreszeitenwechsel. Aus den Eiern rer Ohrenqualle kann gewöhnlich nicht sofort wieder eine Qualle werden, weil diese Eier erst im Spätsommer oder Herbst erzeugt werden, also zu einer ungünstigen Jahreszeit. und der Becherpolyp kann erst junge Mledusen erzeugen, wenn die winterliche Kälte der milden Frühlingstemperatur weicht. Wir haben also gewissermassen in der Meduse die Wärmeform, in dem Polypen die Kälteform der Ohrenqualle ror uns.

So ist es wenigstens heute bei unserer Ohrenqualle; aber es giebt auch in den warmen Meeren Quallen, die sich durch denselben Generationswechsel auszeichnen, wie die Ohrenqualle, und es fragt sich deshalb, ob der Generationswechsel ursprïnglich dem Wechsel von kalten und warmen Jahreszeiten seinen Ursprung rerdankt, oder ob die Einflüsse der periodischen Vorgïnge auf der Erde, welche den Generationswechsel der Quallen ursprünglich herbeiführten, nicht anderer Art gewesen sind. Um den Generationswechsel der Scheibenquallen zu verstehen, müssen wir etwas weiter ausholen.

Man kann sich ihn auf dreierlei Weise entstanden denken. Erstens können die Scheibenquallen hervorgegangen sein aus Becherpolypen, aus deren Eiern früher immer nur wieder Becherpolypen entstanden, bis ein Generationswechsel der letzteren mit schwimmenden Quallen eintrat. Wie dieser herbeigeführt sein soll, ist schwer einzusehen. In Übereinstimmung mit der herrschenden Ansicht, habe ich in meiner "Schöpfung der Tierwelt" noch angenommen, dass die Becherpolypen phylogenetisch älter sind, als die Quallen. Allein ich bezweifle ${ }_{i}$ jetzt, dass diese Ansicht das Richtige getroften hat.

Man kann sich zweitens vorstellen, dass zuerst die Qualle da war, und dass aus iln erst später der Polyp entstand, der auf ungeschlechtlichem Wege wieder Quallen hervorbrachte. Diese Vorstellung hat eine viel grössere Wahrscheinlichkeit für sich als die vorhergenannte, demn die Larven der stets nur wieder Quallen erzeugenden ältesten Scheibenquallen konnten dadurch, dass sie etwa auf den Meeresboden gerieten, in solch ungünstige Lage lommen, dass zunächst keine weitere kint- 
wickelung zur Meduse möglich war, sondern dass durch die hier stattfindenden Einwirkungen ein Polyp entstand, aus welchem sich erst, nachdem er erheblich herangewachsen war, wieder Quallen bilden konnten, und zwar derart, dass das Mundende des Polypen sich in eine Qualle unwandelte, und dass dieser Prozess oftmals wiederholt und endlich so gesteigert wurde, dass ziemlich gleichzeitig eine grosse Anzahl von Quallen durch Umwandlung des Polypen entstand.

An meisten für sich hat aber drittens die Annahme, wonach Polypen und Quallen ein gleiches Alter haben, so dass weder der Polyp noch die Qualle als die ursprüngliche Form betrachtet werden können. Demnach hätten wir uns die Vorfahren der Scheibenquallen zu denken als eine Art Mittelform zwischen Polyp und Meduse. Diese ist thatsächlich von Haeckel beobachtet worden. Ausserdem aber giebt es eine grosse Anzahl von Quallen, die noch heute die Mitte zwischen Polypen und Medusen halten; dahin gehören die Lucernarien und alle Stauromedusen überhaupt und, wie mir scheint, auch die Kubonedusen und Peromedusen. Alle diese Tiere halten mehr oder weniger in ihrer Körperform die Mitte ein zwischen einem Polypen und einer Scheibenqualle, und in der That kennen wir auch nur bei den letzteren einen Generationswechsel. Ich habe zwar selbst Beobachtungen genacht, aus denen ich den Schluss ziehen zu dürfen glaubte, dass auch bei den Kubomedusen Generationswechsel besteht, indessen waren die Thatsachen, auf welche ich diesen Schluss grüudete, zu vereinzelt, als dass ich ihre Beweisklaft heute noch verteidigen möchte. Immerhin ist es nicht ausgeschlossen, dass auch bei den genannten Abteilungen der Medusen, die ich in Gegensatz zu den Scheibenquallen oder Diskomedusen als niedere Medusen bezeichnen möchte, hier oder dort Generationswechsel besteht.

Ich denke mir also die Vorfahrenform sämtlicher Becherquallen als ein Tier, das sowohl einem Polypen, als auch einer primitiren Meduse ähnelte, ein 'Tier, wie es noch heute Haeckel's Tessera ist, und das zu Zeiten schwamm, zu Zeiten aber auch auf dem Meeresboden ruhte. IIöglich, dass es gleich der Hydra unserer süssen Gewässer nach Art der Spannerraupen kriechen konnte. Von der Hydra unterschied es sich ausser durch sonstige Eigentïmlichkeiten namentlich durch die Befähigung zum Schwimmen. Aus den Eiern eines solchen Tieres konnten sich Larren entwickeln, die sich zunächst auf dem Meeresboden festsetzten und dort eine Zeit lang blieben, sich hier auch auf ungeschlechtlichem Wege durch 
Teilung fortpflanzten, aber später vom Boden lösten und fiei im Veere umherschwammen. Ich remnte, dass die Kubomedusen sich noch heute ähnlich verhalten. Die junge von mir beobachtete Charybdea, die im Gegensatz zu den würfelförmigen Formen der ausgewachsenen Meduse einer Pyramide glich, welche am Scheitel in eine Art Stiel ausgezogen war und hier eine Art Haftnapf trug, scheint mir cin Individum gewesen $\mathrm{zu}$ sein, das eben erst seine jugendliche Lebensweise alufgegeben und zu schwimmen begonnen hatte.

Die Jledusen sind Küstentiere; sie halten sich greme in seichtem Wasser auf, und etliche unter ihnen steigen auch eine Strecke weit in die Flussmündungen hinein. In Gegenden mit Jahreszeitenwechsel, sei es, dass dadurch winterliche Kälte bedingt war, oder dass zu gewissen Jahreszeiten dem Jleere und natürlich ror allem dem Küstenwasser eine grosse Quantitüt Süsswasser durch die Flüsse zugeführt wurde, konnte die Zeit, während welcher die junge Qualle eine festsitzende Lebensweise führte, schärfer bestimmt werden, und das musste schliesslich überall geschehen, denn ein Jahreszeitenwechsel besteht überall, sei es, dass er ein Wechsel ron kalter und warmer Temperatur ist, sei es, dass er durch die regelmässige Wiederkehr von Regenzeiten und Zeiten der Dürre dargestellt wird. Es musste also für die ïltesten Vorfahren der Scheibenquallen eine günstige und eine ungünstige Jahreszeit geben, und dieser Wechsel bedingte es, dass die junge Qualle erst immer in der günstigen Jahreszeit herumzuschwimmen pflegte, während sie während der ungünstigen eine festsitzende lchensweise fülnte. Dieser letzteren, sowie der schwimmenden Lebensweise \%ur günstigen Jahreszeit passte sie sich dadurch an, dass sie in der Jugend lange Fangarme, wie sie der Becherpolyp besitzt, hervorsprossen liess, während sie später Anpassungen an die schwimmende Lebensweise dureh Bildung eines Schirmes erhielt. Diese Anpassungen wurden bedingt und erhalten durch den Wechsel der Jahreszeiten, und es wurde dadureh der Entwickelungsgang der Medusen erblich beeinflusst. Während nun die polypenförmige Jugendform nur befïhignt war, sich auf ungeschlechthichem Wege durch 'Teilung fortzufflanzen, erzeugte erst die schwimmende Altersform Eier, und zwar zu einer Zeit, als ilıre Körpergrösse beträchtlich genug war, also, da sie zur günstigen Jahreszeit fortwährend zugenommen liaben wird, im Herbste, so dass die erste Entwickehung der Eier wieder in den Beginn der unginstigen Jahreszeit fiel, weshalb zunäichst wieder die polypenförmige Jugendform entstand. 
Auf diese Weise ist die Erklärung des Cenerationswechsels leicht möglich, und ebenso können wir uns den Generationswechsel bei anderen Medusen und allen anderen Tieren überhaupt, namentlich auch den der Bandwürmer erklären. Die Blasenwürmer sind verschlagene, an ungünstige Orte gelangte Bandwürmer, die sich hier nicht zu Bandwürmern entwickeln können, sondern bessere Zeiten, d. h. die Tersetzung in den Darm eines anderen Wirtes abwarten. Die Bandwürmer, die Quallen, sowie alle anderen sich geschlechtlich fortpflanzenden Indiriduen bei Arten, die einen Generationswechsel haben, sind also nichts weiter als die Altersformen der betreffenden Arten. Werden Qualleneier gleich wieder so günstigen Lebensbedingungen ausgesetzt, dass sie sich schneller entwickeln können als gewöhnlich, so entsteht aus ihnen nicht erst wieder ein Polyp, sondern gleich wieder eine Qualle. Dass Qualle und Polyp dasselbe Tier sind, geht hervor aus der Thatsache, dass das Scyphostoma thatsächlich in eine Reihe von kleinen Quallen zerfällt. Ähnliches findet bei den Bandwürmern statt, denn der Kopf des Bandwurmes wird schon in dem Blasenwurm erzeugt, und er wächst später zur Strobila aus Die Medusen der Hydroidpolypen werden zwar aus einer einzigen Zelle erzengt, aber auch, wie man es wenigstens bei Sarsia im Kieler Hafen beobachtet, erst zu einer günstigen Jahreszeit, nämlich im Frühjahr, während die Polypen der Sarsia vorher nur Polypen durch Knospung erzeugen. Je nachdem die Zelle, aus welcher' sich eine neue Person zu entwickeln im Begriffe steht, günstige oder ungünstige Jahreszeiten antrifft, wird daraus ein Polyp oder eine Qualle. Ein Polyp ist also weiter nichts als eine in der Entwickelung stehen gebliebene Qualle.

Ein wirklicher Generationswechsel findet also eigentlich gar nicht statt. Die verschiedenen Individuen der Arten, bei welchen Generationswechsel besteht, sind nur Entwickelungsformen eines und desselben P'lasma's, je nachdem das letztere diese oder jene Entwickelungsbedingungen antrifft. Der Generationswechsel unterscheidet sich nur dadurch von der geschlechtlichen Furtpflanzung, dass die Jugendformen von Tieren, bei welchen sogenannter Generationswechsel herrscht, zur ungeschlechtlichen Fortpflanzung befähigt sind. Das ist beispielsweise auch bei unserer Hydra der Fall, die aber auch auf ungeschlechtlichem Wege immer nur wieder Polypen erzeugt, bei welcher man deshalb nicht ron Generationswechsel spricht, trotzden ein Wechsel geschlechtlich und ungeschlechtlich sich fortpflanzender Individuen auch bei ihr vorhanden ist. 
1)ie Hydra ist eben ein Ticr, das es nicht weit in seiner stammesgeschichtlichen Entwickelung gebracht hat und deshalb keine ausgeprägten Jugendund Altersformen und somit auch keinen Wechsel ron Jugendformen, die sich ungeschlechtlich fortptlanzen, und sehr abweichenden Altersformen, die sich geschlechtlich fortpflanzen, aufweisen kann.

Der Generationswechsel ist also nielıt schwerel \%u erklïren, als etwa die Metamorphose der Insekten. Könnten sich Schmetterlingsraupen durch Knospenbildung oder Teilung fortpflanzen, so wiirde man auch bei den Insekten von Generationswechsel sprechen können, und aus diesem Vergleiche geht hervor, dass der Generationswechsel überhaupt keine andere Erklärung erheischt, als sie die ontogenetische Entwickelung überhaupt beansprucht. Weismann freilich hat zu seiner Erliärung wiederum eine neue Hilfshypothese ersinnen müssen, nämlich die der Doppelrleterminanten.

Nach Weismann's Theorie würde der (ienerationswechsel bei den Scheibenquallen etwa folgendermassen verlaufen: Das befruchtete Ei der Meduse wird in seine Determinanten und Biophoren zerlegt, ron welchen zunächst die, welche den Becherjolypen bestimmen, ,alitiw" werden. Da aus diesem Becherpolypen aber nicht etwa seitlich, wie bei den Hỵdroidpolypen, die Medusen hervorknospen, sondern da er sich direkt an seinem Mundende in die Medusen umwandelt, so müssen auch gleichzeitig die Determinanten zahlreicher Medusen in gesetzmässiger Weise zerlegt werden. Sie schlummern bis die \%eit ilırer Entwickelung herannalıt: wie aber dieses Schlummern zu stande kommen soll, darïber hat W eismann uns keinen Aufschluss gegeben. Seine Annahme ron inaktiven Determinanten setzt sich ebensoselır in Widerspruch mit allen Gesetzen der Physiologie, wie Weismann's Keimplasmalehre äberlaupt. Irgendwo müssen aber in dem Polypen auch unveränderte Ide reserviert sein, aus denen später die Keimzellen der Medusen werden. In einem ScyphostomaPolypen liegen also: 1) die aktiven Biophoren der Polypendeterminanten, 2) die inaktiven Biophoren der Medusendeterminanten, 3) aus Doppeldeterminanten bestelıende Ide, die gleich den Determinanten der Medusen rulıen und später in die Keimzellen der letzteren zu liegen kommen. Nachdem die aktiven Biophoren der Polypendeterminanten lange genug ihr Wesen gretrieben haben, kommen die der Medusen an die Reihe und gestalten den Polypen zu Merlusen um, und endlich werden in den Eiem der Medusen wieder die im Polypen unverïndert mitgeführten unzerlegten Irle thätig. Sie zerlegen sich in ihre Biophoren, und es entsteht, 
weil die Determinanten der Medusen sich unthätig verhalten, zunächst wieder ein Polyp. Die komplizierten Vorgänge, die zur Heranzüchtung eines derartigen Generationswechsels geführt haben müssen, falls We is mann's Theorie der Amphimixis richtig ist, überlasse ich der Torstellung der Präformisten Weismann'scher Gefolgschaft. Ich brauche mich um so weniger damit abzugeben, Weismann'sche Probleme zu lösen, als Weismann noch nicht in einem einzigen Falle gezeigt hat, dass die Vorstellungen, die er von der natürlichen Zuchtwahl hat, irgendwie möglich sind, und als ich selbst nachgewiesen habe, dass sie in der That unmöglich sind, sobald man sich klar gemacht hat, zu welchen Konsequenzen die Weismann'sche Theorie der Amphimixis führt.

Eine Konsequenz seiner Lehre, das will ich nicht bestreiten, sind W eismann's Doppeldeterminanten, mit deren Hilfe er auch die Erscheinungen des Polymorphismus zu erklären sucht, und die diesbezügliche Anwendung der Weismann'schen Theorie ist sehr geeignet, diese Theorie in die für sie erforderliche helle Beleuchtung zu setzen.

Unter Polymorphismus versteht man die Erscheinung, dass die Individuen einer und derselben Organismenart in zwei oder mehreren verschiedenen Formen auftreten können. Sind es nur zwei Formen, so handelt es sich dabei um geschlechtlichen Dimorphismus; es kann aber sowoll das Weibchen als auch das Männchen in mehreren Formen auftreten, so dass wir eine beträchtliche Anzahl verschiedener Arten des Polymorphismus erhalten, in welcher auch die des gewöhnlichen geschlechtlichen Dimorphismus einbegriffen sind.

Wo Polymorphismus vorkommt, nimmt Weismann, je nach dem besonderen Falle, Doppel- oder mehrfache Determinanten in den Iden des Keimplasma's an. Bei männlichen Tieren bleiben die weiblichen Determinanten inaktiv, bei weiblichen die männlichen. Um diese Weis mann'sche Lehre etwas näher zu prüfen, brauchen wir nur eine Tierart ins Auge zu fassen, wo etwa, wie beim Haushuhn, die sekundären Sexualcharaktere des Männchens erheblich von denen des Weibchens abweichen. In den befruchteten Eizellen, die zur Bildung einer Henne bestimmt sind, gelangen ausser den Determinanten des Eierstocks und der übrigen weiblichen Geschlechtsorgane die Determinanten des weiblichen Gefieders und sonstiger weiblicher Sexualcharaktere zur Entwickelung, während in der Eizelle, aus welcher ein $\mathrm{H}$ ahn wird, die Hodendeterminanten, die Determinanten der Sporen, des grossen Ḱammes, der grossen Sichelfedern des Schwanzes und aller übrigen sekundären ge- 
schlechtlichen Eigentümlichkeiten des männlichen Huhnes zur Entwickelung kommen. Jerkwürdig ist nun, dass nicht auch einmal bei einem Vogel, in welchem die Determinanten des Hodens zur Entwickelung gelangen, gleichzeitig die Determinanten des weiblichen Gefieders sich in Biophoren auflösen und die Zellen bestimmen, und umgekehrt. Denn auch im weiblichen Geschlechte werden die Determinanten der männlichen Charaktere in gesetzmïssiger Weise in die Zellen verteilt, bereit, sich zu entwickeln, sobald die Gelegenheit dazu gegeben ist. Diese Gelegenheit kann dadurch herbeigeführt werden, dass der Eierstock einer Henne degeneriert. In solchen Fällen ist häufig beobachtet worden, dass die Henne hahnenferlrig wird, dass sie die Sexualcharaktere des Hahnes entwickelt, unter anderem auch cinen sporn bekommt und anfängt $\mathrm{zu}$ krähen. Es ist also dadurch mit Sicherheit nachgewiesen, dass in allen Zellen der Henue das Vermögren entlualten ist, diese Zellen in männliche Zellen umzuwandeln. und W e ism a n n kann dieses Vermögen selbstverständlich nicht anders erklären als dadurch, dass er den meisten oder allen Zellen der Henne männliche Determinanten beigiebt. Aus der Thatsache, dass kastrierte Hemen, oder solche, bei denen der Eierstock degeneriert ist, zu Hühnern mit männlichen Charakteren werden, geht lierror, dass die Entwickelung dieser Charaktere gehemm t wurde durch die Gegenwart eines zeugungstäligen Eierstocks. Es zeigt sich also hier aut's deutlichste eine Korrelation zwischen der Ausbildung des Eierstockes und der der weiblichen Sexualcharaktere. Dasselbe zeigt sich beim Männchen. Wenn nan junge Hähne kastriert, so nehmen sie nur in bescluränkter Weise die sekundären Sexualcharaktere des Hahnes an, sondern bleiben mehr hennenähnlich. Hier hängt die Entwickelung der übrigen Eigentümlichkeiten des männlichen Geschlechts ron der Ausbildung funktionierender Hoden ab: auch hier besteht eine Korrelation zwischen primären und sekundären Sexualcharakteren: Auf welche Art Weismann diese Korrelation trklären will, weiss ich nicht. $\mathrm{Er}$ hat sich nicht darüber ausgelassen, obwohl es sich wohl rerlohnt liaben wïrde, seine Theorie der Amphimixis und der Doppeldeterminanten an dieser Thatsache zu priffen, diese Thatsache durch die Theorie zu erklären.

Nach unserer Theorie ist die Erklärung einfach. Wir müssen aber zunäichst die Thatsachen etwas schärfer ins Auge fassen, als es mir bisher geschehen zu sein scheint, und die Frage stellen, ob kastrierte Hälne wirkliclı völlig den Hennen, und kastrierte Hennen rollständig dem 
mänulichen Huhn gleich werden. Das ist nicht der Fall, und ebensowenig beobachten wir dergleichen bei anderen Tieren. Der Ochse erhält zwar längere Hörner als der Sticr, sein Fleisch wird mehr dem der Kuh ähnlich, aber eine Kuh wird er deshalb doch noch nicht, ganz abgesehen daron, dass manche Organe, beispielsweise die Ausmündungsstelle der Harnröhre, sich nicht ändern können. Was viehmehr dureh Kastration oder durch Degeneration der Geschlechtsdrïsen bewirkt wird, ist nicht eine Ausbildung der Charaktere des entgegengesetzten Geschlechts, sondern die Entwickelung mittlerer Charaktere, solcher, welche die Mitte halten zwischen männlichen und weiblichen. Die Hühner sind also thatsächlich nicht dimorph, sondern trimorph. Zwischen der männlichen und der weiblichen steht eine geschlechtslose Mittelform. die freilich niemals rein zur Ausbildung gelangen wird, weil die Kastration nicht schon bei der ersten Anlage der Geschlechtsorgane im Keime rorgenonmen werden kamn. Ich stelle mir den geschlechtlichen Dimorphismus nach Art und Weise des Dimorphismus bei den anorganischen kristallisierenden Naturkörpern vor. Der kohlensaure Kalk kristallisiert nicht bloss im hexagonalen, sondern auch im rhombischen System, und einen ähnlichen Dimorphismus besitzt der Schwefel, während andere Stoffe sogar trimorph sind. Ähnlich verhält sich der Polymorphismus der Organismen. Je nachdem diese oder jene Einflüsse bei der Bildung der Keimzellen oder zur Zeit der Befruchtung und der allerersten Entwickelung zur Geltung gelangen, entsteht die eine oder andere Sexualform oder auch die eine oder andere Form desselben Geschlechts. Wir wissen, dass sich die männlichen Bienen aus unbefruchteten Eiern entwickeln, wir wissen, dass die Bienenkönigin aus einer Larve entsteht, die besser gepflegt wird als dic, aus welcher sich die Arbeiterimnen entwickeln, wir wissen also, dass es lediglich äussere Terhältnisse sind, die zur Ausbildung der einell oder anderen Form führen.

Wie aber Weismann mit diesen Thatsachen seine Hiltshpothese der Doppeldeterminanten in Verbindung bringen will, weiss ich nicht. Soll man etwa annehmen, dass im Kalkspat die Molekïle des Aragonits unthätig schlummern und umgekehrt? Im Aragonit sind die Moleküle anders angeordnet, als im Kalkspat, und in männlichen Geschlecht ist die Anordnung der Gemmen in den Gemmarien eine andere, als im weiblichen. Diese Anordnung aber hängt ab ron äusseren Umstänrlen, wie uns die Bienen und andere Tiere in unwiderleglicher Weise zeigen. 
Was freilich in dem einen oder anderen Falle die Ausbildung dieser uder jener Form bedingt, worauf es beruht, dass aus unbefruchteten Bieneneiern Drohnen werden, das können wir noch nicht sagen.

Düsing hat vor Jahren die Hypothese aufgestellt, dass aus der Verbindung einer jungen Eizelle mit einem alten spermatozoon ein Weibchen, aus der Verbindung einer alten Eizelle mit emem jungen Samenfaden ein Männchen wird, und diese Hypothese hat allerdings vieles für sich, insofern man annehmen kann, dass die jüngere, also kräftigere Zelle dem sich aus ihr entwickelnden Organismus ihr eigenes Geschlecht aufdrückt. Allein dem steht entgegen, dass beim Menschen die Töchter den Vätern und die Söhne den Müttern gleichen kömnen. Würde das Geschlecht durch die mehr oder weniger grosse Jugendkraft der Eizellen, beziehungsweise der Spermatozoen bedingt, so müssten sich auch die sonstigen Charaktere des Vaters oder der Mutter auf die Kinder übertragen. Das geschicht aber in sehr vielen Fällen nicht, sondern der Sohn gleicht sehr häufig der Mutter und die Tochter dem Vater. Die ron der Mutter stammende Eizelle hätte also, wenn sie die kräftigere war, wenn sie den Sohn der Mutter ähnlich machen konnte, ihn nicht zum Manne, sondern zu einer Frau werden lassen müssen. Es lässt sich also vorderhand nicht zeigen, weshalb aus der einen Eizelle cin Männchen, aus der anderen ein Weibchen wird, und wir müssen uns damit begnügen, wenigstens die Überzeugung gewonnen zu haben, dass die Ausbildung des Geschlechts durch äussere Einflüsse herbeirgeführt wird. Es muss äussere Umstände geben, welche die in den Gemmarien der unbefruchteten Keimzellen noch die indifferente Lage einnehmenden Gemmen so beeinflusst, dass sie entweder die männliche oder die weibliche Lagerung annehmen, und es ist wahrscheinlich, dass es chemische Momente sind, welehe die Ausbildung des männlichen und des weiblichen Geschlechts bedingen, ebenso wie die verschiedenen Formen eines und desselben Geschlechts.

Emery hat kürzlich darauf hingewiesen, dass chemische Einflüsse vom activen Hoden und dem zeugungsfähigen Eierstock ausgehen und die Entwickelung der männlichen, bezichungsweise der weiblichen sekundüren Sexualcharalktere bedingen könnten. Hört dieser Einfluss infolge von Kastration oder ron Degeneration der Keimdrüsen auf, so lagern sich die Gemmen innerhalb der Gemmarien und demgemäss die letzteren auch innerhalb der \%elle um, und chas Individuum nimmt den indifferenten Zustand an, wie wir ilm etwa beim Oehsen sehen. Es werden 
also ron den Keimdrüsen bestimmte Stoffe erzeugt, der'en Gegenwart im ganzen Körper erforderlich ist, falls die secundüren Geschlechtscharaktere zur Ausbildung kommen und sich erhalten sollen. Wenn diese Stoffe nicht mehr erzeugt werden, so bilden sich diese Geschlechtscharaktere zum indifferenten Zustande um, oder dieser kommt überhaupt gleich zur Entwickelung. Man könnte also vielleicht annehmen, dass etwa dann ein Männchen entsteht, wenn das Ei bei der Befruchtung von einer grossen Masse männlicher Samenflüssigkeit umgeben ist, denn so gut wie man annehmen kann, dass die sekundären Sexualcharaktere von der Ausbildung der primären abhängig sind, darf man auch voraussetzen, dass die von den Geschlechtsorganen gelieferten Stoffe von vornherein die Wirkung haben können, die befruchtete Eizelle, je nachdem die rom Männchen oder vom Weibchen stammenden Stoffe das Übergewicht haben, zum Männchen oder zum Weibchen zu bestimmen. Ein Weibchen würde nach dieser Anschauung dann entstehen, wenn das Ei zur Zeit seiner Befruchtung nur von wenig Samen umgeben ist.

Einer solchen Anschauung steht nun freilich sehr vieles im Wege; aber immerhin haben wir hier nur die Andeutung einer vielleicht sehr entfernten Möglichkeit geben wollen. Es muss weiteren experimentellen Forschungen vorbehalten bleiben, über die Momente, welche die Ausbildung des einen oder des anderen Geschlechts bedingen, Aufschluss zu geben. Soviel aber sehen wir klar, dass die Annahme von Doppeldeterminanten und überlaupt von Determinanten nicht nötig ist, sondern dass sich die Erscheinungen des geschlechtlichen Dimorphismus und ebenso des Polymorphismus im Prinzip ebenso leicht aus unserer Gemmarienlehre verstehen lassen, wie die Erscheinungen des sogenannten Generationswechsels, den wir als eine Metamorphose erkannt haben. Was uns der Generationswechsel in nacheinander auftretenden Stadien zeigt, sehen wir beim Polymorphismus nebeneinander, aber in dem einen, wie in dem anderen Falle hängt es von äusseren Ursachen $a b$, ob diese oder jene Form zur Entwickelung gelangen soll. Es giebt Medusen, welche heute nur noch Medusen erzeugen, und es giebt vielleicht Tiere, bei welchen nur noch Weibchen vorhanden sind. Äussere Umstände haben in dem einen Falle das Verschwinden der einen sogenannten Generation, in dem anderen das des männlichen Geschlechts herbeigeführt. Äussere Umstände bestimmen, ob aus einem Bienenei eine Kiönigin oder eine Arbeiterin werden soll; äussere Einflüsse verursachen den Saisondimorphismus der Schmetterlinge, und alle diese Erscheinnmgen sind deshalb 
möglich, weil der Aufbau der Gemmarien sich jns Glerichgewicht setzt mit den Einflüsen der Tungebung, ganz ebenso wie es von ïusseren Umständen ablängt, ob der Schwefel in diesen oder junem System kristallisieren soll. Die Gemmarienlehre erklät im Prinzip den Polymorphismus wie den Generationswechsel.

Weisman nat versucht, von seiner 'Thenrie aus den pathologischen Dimorphismus zu erklären, der sich in der liluterkrankheit kundgieht. Diese Krankheit tritt nur bei Mämern auf und besteht darin, dass bei den mit ihr behafteten Individuen anf kleine Verletzungen ausserordentlich starke Blutungen erfolgen. Sir ist leicht vererbbar und wird, obwohl sie bei den Töchtern eines Bluters nicht auftritt, demnoch durch diese auf die männlichen Enkel vererbt. Die Erklärung, die Weismann von diesem pathologischen Dimorphismus und ler merkwärdigen Art seiner Übertragung giebt, setzt alle Schwächen der W e isma n n'schen Lelne in das grellste Licht.

Ve isman n meint, dass der Beginn der Anomalie bei einem mämnlichen Individumn stattgefunden haben muss, und ferner, dass die Determinanten del Blutgefïsse, welch letztere bei Blutern ausserordentlich schlaffe Wandungen haben, Doppeldeterminanten seien, ja er glaubt, dass bein IIenschen alle oder doch nahezu alle Determinanten des Keimes Doppeldeterminanten sind, halb männlich, halb weiblich, so class eine Determinante derselben Provenienz sich zum mämnlichen oder zum weiblichen 'Typus des betreftenden Charakters entwickeln kamn. Das erste Auftreten der Bluterklanliheit sull also bei einem männlichen lndiridum stattgrefunden haben, d. h. es sollen nur die männlichen Hälften der Doppeldeterminanten im Keime les betroffenden Individnums so variert laben, dass sie zu ciner abnormen Ausbildung der Gefiisswandungen fülmren mussten. Abgesohen daron, dass es vom Standpunlit der Determinantenlehre aus nicht einzusehen ist, weshalb alle Gefïssleterminanten auf eimmal ihre mämnlichen Hälften in gleichem Simne abündern liessen, jst ss merkwürdig, dass die Bluterkrankheit immer gerade bei Männern auftritt und nicht auch bei Frauen. Weismann spricht allerdings von einem männlichen Individum, das zuerst zn einem Bluter wnrde: aber stammen denn die anderen Pluter von diesem einen Individumm ab: Das thun sie doch wohl nicht, sondern die Krankheit entstand un abhiingig in verschierlenen männlichen Individuen, mnd daraus ergiebt sich der Schluss, lass es eine Figentiumlichkeit männ licher I n dividuen ist, zu Blutern werten zu können. Weismann allerdings wendet diese Erklärung 
nicht an, und er kann sie nicht anwenden, weil seine Determinantenlehre ihm notwendigerweise eine andere Erklärung an die Hand giebt. Diese wollen wir etwas näher betrachten.

Dass die Krankheit unabhängig bei verschiedenen Männern, die nicht miteinander verwandt waren, aufgetreten ist, wollen wir weiter nicht ins Treffen führen, denn der Zufall mag hier sein wunderbares Spiel getrieben haben - Gott Zufall spielt ja ohnehin die Hauptrolle in Weismann's Theorien - , sondern wir wollen an dem, was Weismann über die Vererbung der Bluterkrankheit sagt, seine Hypothesen und Hilfshypothesen prüfen. In dem einen von Weismann angeführten Fall waren die Söhne der Bluter nie wieder Bluter, in einem andern dagegen vererbte sich die Krankheit vom Vater aus auf die männlichen Glieder durch drei Generationen. "Beides lässt sich" nach W eisman n von seinem, ,Standpunkt aus verstehen, da keine individuelle Variation auf einer Variation der betreffenden Determinanten sämtlicher Ide des Keimplasma's beruht, sondern immer nur auf einer Majorität der Ide mit abgeänderten Determinanten". "Diese aber kann" sagt Weismann weiter, ,durch jede Reduktionsteilung und durch jede neue Amphimixis in eine Minorität verwandelt werden, womit dann die Variation aufhört, manifest zu werden. Sobald also nur eine schwache Majorität der Ide Bluter-Determinanten enthält, würde schon eine mässige Zahl und Vererbungsstärke der gesunden mütterlichen Gefäss-Determinanten den Sieg über die kranken väterlichen davontragen, und folglich die männlichen Nachkommen frei ron der Krankheit bleiben."

Mit dieser Erklärung können wir uns, falls wir uns auf den Weismann'schen Standpunkt stellen wollen, wohl einverstanden erklären, nicht aber mit der Erklärung, die Weismann von den Fällen giebt, in welchen die weiblichen Glieder einer Bluterfamilie mit verschiedenen gesunden Vätern lauter bluterkranke Söhne hervorbrachten. „Denn,“ sagt We ismann, ,die männliche Hälfte der Doppeldeterminanten beinahe sämtlicher(!) Ide könnte im Keimplasma dieser Mütter krankhaft abgeändert sein, ohne dass dies am Körper der Mutter zur Erscheinung käme; bei den Söhnen aber muss es zur Ausbildung der Krankheit führen, falls nicht eine ungewöhnlich günstige Reduktionsteilung das starke Übergewicht der krankhaften Determinanten beseitigt."

Eine einfache Überlegung lehrt, dass die Anwendung, die Weis man $n$ hier von seiner Amphimixislehre macht, auf einem groben Rechenfehler beruht. Gesetzt, ein Bluter, dessen sämtliche männliche Gefäss- 
determinanten in allen seinen Iden Bluterdeterminanten sind, heiratet eine gesunde Frau und erzeugt mit ihr eine Tochter; dann kann diese nur in sämtlichen männlichen Gefässdeterminantenhälften der vom Vater stammenden Ide, also nur in der Hälfte ihrer Ide, Bluterdeterminanten enthalten. Wir haben aber diesen Fall so grünstig angenommen wie nur möglich. Wir können doch nicht von der Voraussetzung ausgehen, dass die Bluter starke Inzucht treiben, sondern müssen annehmen, dass männliche Bluter gesunde Frauen heiraten; unsere Voraussetzungen können also nicht günstiger getroffen werden. Wir erhalten aber in der Tochter unseres bluterkranken Vaters dennoch nur ein Individuum, das nur in der Hälfte seiner Ide Bluterdeterminanten besitzt. Diese Tochter soll, wie es meistens der Fall sein wird, und bei der Seltenheit der Bluterkrankheit wahrscheinlich immer der Fall gewesen ist, einen vollständig gesunden Mann heiraten; denn dass die Bluter Inzucht treiben, ist doch, wie gesagt, wohl nicht ohne weiteres anzunelımen. Dann müssen wir die in den Keimzellen der Tochter stattfindende Reduktionsteilung so günstig annehmen, wie es irgend mögliclı ist, also sümtliche Bluteride, die von ihrem Vater stammen, in das der Reduktionsteilung unterworfen gewesene Ei übergehen lassen, aus welchem sich ein Sohn dieser Tochter entwickelt, damit dieser Sohn in der Hälfte seiner Ide Bluterdeterminanten erhält. Dieser günstigste Fall kann aber nach der Amphimixislehre nur selten eintreten. Dennoch giebt es nach Weismann Fälle, dass Töchter ron Blutern, die sich mit verschiedenen gesunden Männern verheirateten, la uter bluterkranke Söhne erzeugten. Bei allen diesen Söhnen hat also günstigster Zufall sein wunderbares Spiel getrieben! Will man uns zumuten, dies wirklich zu glauben?

W eismann spricht aber grar davon, dass die mämnlichen Hälften der Doppeldeterminanten „beinalıe sämtlicher Ide“ im Keimplasma ron Frauen, die von bluterkranken Väteru abstammen, krankhaft abgeändert sein können, also nicht nur die männlichen Hälften der Doppeldeterminanten der von dem Tater dieser Franen stammenden Ide, sondern auch noch die grosse Mehrzahl der Gefässdoppeldeterminanten, die von ihrer Mutter lerstammen. Wie dies aber möglich sein soll, verstehe ich nicht. Wenn bluterkranke Männer nicht etwa erpicht darauf sind, Töchter von bluterkranken Vätern zu heiraten, sondern unbelastete Frauen nehmen, so können sie höchstens Töchter zeugen, die nur in der Hälfte ihrer Ide eine Abänderung der männlichen Gefüssdeterminanten zu Bluterdeterminanten 
aufweisen können. Wie also soll es dort, wo keine Inzucht stattfindet, möghich sein, dass die männlichen Hälften der Doppeldeterminanten in „beinahe sämtlichen Iden" in Keimplasma solcher Frauen krankhaft abgeändert sind? Um es dennuch zu erklären, dass die männlichen Enkel von bluterkranken Grossvätern die Bluterkrankheit so merkwïrdig oft erben, muss man annehmen, dass die Bluter Inzucht treiben, ganz ebenso, wie man dieses auf Grund der Weismann'schen Amphimixislehre annehmen muss, um die W eis m ann'schen „allgemeinen Familieneigentümlichkeiten" zu erklären. Dass nun ein reicher Vater seine Tochter gern an ihren wohlhabenden Vetter verheiratet, damit das schöne Geld in der Familie bleibt, vermag ich zu verstehen; dass sich aber ein Bluter auf die Wanderschaft begiebt, um das erblich belastete Töchterchen eines seiner seltenen Blutergenossen zu erspähen und zu minnen, damit die interessante Krankheit in der Familie bleibt, daron habe ich wenigstens noch nicht gehört.

Um die Vererbung der Bluterkrankheit vom Grossvater auf die Enkel zu erklären, nuss also Weismann erstens annehmen, dass ganz zufällig die Bluterkrankheit unabhängig voneinander bei verschiedenen nicht miteinander verwandten Männern aufgetreten sei, dass sie deshalb, da nur die männliche Hälfte der Gefässdeterminanten von der abnormen Veränderung betroffen war, bei den weiblichen Nachkommen dieser Individuen nicht auftreten konnte; $z$ weiten s, dass unter der Nachkommenschaft solcher Bluter Inzucht getrieben wurde, denn sonst ist es nicht zu erklären, weshalb die weiblichen Glieder einer Bluterfamilie mit verschiedenen gesumden Vätern lauter bluterkranke Söhne hervorbrachten, wenigstens nicht, wenn man nicht wiederum einen wunderbaren Zufall annehmen will. Man könnte allerdings annehmen, dass es genügt, wenn, wie in unserem obigen Beispiel, die Hälfte der Ide bei dem Enkel eines bluterkranken Grossvaters Bluterdeterminanten enthalten, allein wenn unter den Nachkommen eines bluterkranken Mannes, wie es doch thalsächlich beobachtet worden ist, mehrere Bluter vorkommen, so müssen die Reduktionsteilungen immer in der Weise erfolgen, dass bei der Tochter eines bluterkranken Vaters, dessen sämtliche Ide Bluterdeterminanten enthielten, die bluterkranken Ide in die befruchtungsfähigen Eizellen zu liegen kommen, aus welchen sich die Söhne dieser Tochter entwickeln. Im allerbesten Falle hat also, wenn man sich auf den Boden der Amphimixislehre stellen will, bei der Ent- 
stehung und Vererbung der Bluterkrankheit der Zufall in einer Weise gewaltet, wie es sonst selbst beim Zufall nicht üblich ist.

Dass die We ismann'sche Hilfshypothese der Doppeldeterminanten gänzlich haltlos ist, wollen wir in Anschluss an diese Auseinandersetzungen noch kurz zeigen. Auf Seite 483 seines Werkes sagt Weisman $n$, es sei bisher meistens die Übertragung des Geschlechts als ein Akt der Vererbung aufgefasst worden. „Dies ist," fährt er fort, ,insofern irrig, als in jedem Keimplasma die Anlagen zu beiden Geschlechtern enthalten sind, und der Vererbungsvorgang selbst offenbar nichts mit der Bestimmung des Geschlechtes zu thun hat. Wenn das Kind einer Mutter weiblichen Geschlechtes ist, so folgt daraus noch keineswegs, dass das Gepräge der sekundären oder primären Sexualcharaktere dieser Tochter dasjenige der Mutter ist, wie oben schon erwähnt wurde." „Es können ebensogut die männlichen als die weiblichen Hälften der sexuellen Doppeldeterminanten der Mutter zur Entwickelung gelangen, ebensogut die weiblichen als die männlichen Hälften der sexuellen Doppeldeterminanten des Vaters."

Sehr oft tritt nun aber bei der Vererbung der Fall ein, dass nicht nur sämtliche Söhne, sondern auch sämtliche Töchter ausschliesslich dem einen ihrer Eltern in hohem Grade ähnlich sind, woraus sich die nicht abzuweisende Folgerung ergiebt, dass sowohl die männlichen als auch die weiblichen Hälften der Doppeldeterminanten dieses Elters in derselben Weise abgeändert worden sind. Weismann wirl dies einfach dadurch erklären, dass die beiden Hälften dieser Doppeldeterminanten ja bei einander lägen und deshalb von gleichen äusseren Einflüssen in gleicher Weise umgebildet werden müssen, und diese Annahme ist allerdings auch unerlässlich. Wie kommt es aber dann, dass überhaupt Doppeldeterminanten mit einer männlichen und einer weiblichen Hälfte entstehen konnten? Das war doch nur damn möglich, wenn die Hälften der Doppeldeterminanten unabhängig voneinander variieren! We ismann gerät also hier wieder einmal mit seiner eigenen Theorie in Widerspruch.

Auf Grund der Gemmarienlehre ergiebt sich die Erklärung der Vererbungserscheinungen bei der Bluterkrankheit in höchst einfacher Weise. Es ist eine Krankheit, die an die Eigentïmlichkeiten des männlichen Plasma's gebunden ist und reshalb bei Frauen ïberhaupt nicht, oder nur höchst selten, nämlich dann, wenn ihr Plasma nach der männliclıen Seite hin umgeändert ist, auftritt. Bis jetzt sind aber, wie es scheint, 
noch keine Fälle von weiblichen Blutern beobachtet worden. Die Tochter eines bluterkranken Vaters, der eine gesunde Frau geheiratet hat, besteht gleich allen menschlichen Individuen aus z wei voneinander etwas abweicheuden Plasmen, nämlich aus dem kraukhafteu Bluterplasma ihres Vaters und dem gesunden ihrer Mutter. Bei der Reduktionsteilung der von dieser Tochter erzeugten Eizellen sondern sich diese beiden Plasmenarten roneinander, und das Bluterplasma kann in den Keimzellen bleiben, aus welchen sich Söhne dieser Tochter entwickeln. Wenn auch die Väter dieser Söhne gesund sind, so ist es doch möglich, dass die Söhne sich aus irgend welchen Ursachen krankhaft entwickeln und danı Bluter werden.

Wenn die krankhaften Veränderungen, die im Bluterplasma stattgefunden haben, nur wirklich im männlichen Geschlecht auf Grund von dessen histologischen Eigentümlichkeiten Bluterkrankheit bedingen können, so erklärt sich die Thatsache, dass die Töchter eines bluterkranken Vaters selbst nicht bluterkrank sind, aber bluterkranke Söhne erzeugen könneṇ, auf die allereinfachste Weise. Die Annahme aber, dass das männliche Plasma vom weiblichen verschieden ist, hat nicht die allergeringste Schwierigkeit, sondern ist einfach eine Konsequenz unserer Gemmarienlehre, nicht aber, wie die We ismann'sche Annahme der Doppeldeterminanten, eine Hilfshypothese.

Bei den weiteren Auslassungen Weismann's über Polymorphismus, die ihn beispielsweise dazu führen, bei den Termiten gar vier für einander vikariierende Determinanten, von denen immer nur eine aktiv ist, im Keimplasma anzunehmen, brauchen wir uns nach allem Obigen nicht weiter aufzuhalten, dagegen erfordert das, was Weismann über die Dichogenie bei Pflanzen sagt, noch einige Bemerkungen.

Unter Dichogeuie versteht man mit de Tries und Weismann eine Art des Dimorphismus, die sich darin äussert, dass sich ein und dasselbe jugendliche Pflanzengewebe in dieser oder in jener Richtung umbildeu kanı, je nachdem diese oder andere Einflüsse es treffen. Wenn man auf dem Boden der Epigenesislehre steht, so erklärt sich diese sogenannte Dichogenie ganz von selbst. In der That wird die Natur einer Zelle lediglich durch die äusseren Einflüsse, welche sie treffen, bestinmt, und diese hängen ab von dem Orte, an welchem die Zelle liegt. Wird die Zelle in anderer Weise als bisher nit der Umgebung in Berührung gebracht, so verändert sie ihren Charakter. „Epheuranken," sagt Weismann, „treiben Blätter nach der Lichtseite, Wurzeln nach 
der Schattenseite; dreht man die Ptlanze um. so treibt dieselbe Ranke Blätter an der Seite, an welcher sie vorher Wurzeln trieb, und umgekehrt." Dieses Verhalten sucht Weismann dadurch zu erklären, dass es nicht dieselben Zellen sind, die sowohl Wurzeln als auch Blïtter bilden können, weil die Blätter viel spärlicher an der Epheuranke stehen, als die dichten kurzen Wurzeln. "Es kann somit,“ sagt er, "wohl nicht dasselbe Idioplasma sein, welches bei Beschattung Wurzeln, bei Belichtung Blätter bildet, sondern Wurzel-Determinanten müssen in ganz anderer Verteilung in den Zellen rorhanden sein, als Blatt-Determinanten." Nun hat aber Detmer darauf aufmerksam gemacht, dass bei Thuja die Zellen junger Sprosse, wenn diese umgedreht werden, sich anders entwickeln, als wenn sie ihre natürliche Lage behalten. Im ersteren Falle nehmen die Zellen der Unterseite den Charakter ron Zellen der Oberseite an, und umgekehrt. Es sind also hier dieselben Zellen, die, je nachdem sie ron äusseren Einflüssen getroffen werden, sich so oder anders entwickeln. "Die Erklärung dafür scheint mir," sagt We ismann, "darin gesucht werden zu müssen, dass hier die Determinanten beider Zellenarten in jerler der Zellen zusammen rorkommen, dass aber immer nur eine davon aktiv wird, je nach der stärkeren oder schwächeren Belichtung. Weshalb freilich diese Einrichtung hier getroffen wurde," fügt Weismann unbedachter Weise hinzu, "weiss ich nicht zu sagen." Und wir wollen es ihm gern glauben!

Die Erklärung, welche Weismann hier ron der Bestimmung der Thujazellen durch ihre Lage giebt, steht in schroffem Gegensatze zu dem, was er auf Seite 192 seines Werkes über die Prädestinierung der Zelle durch Zuteilung bestimmter Determinanten und Determinantengruppen sagt. Er sagt, ehe unzweideutige Thatsachen vorlägen, dürften wir diese Torstellung nicht aufgeben, und führt fort: „Ein Aufgeben aber dieser Vorstellung wïrde unrermeidlich sein, wenn es Thatsache wäre, dass die Zellen der Keimblätter wirklich die Fähigkeit hä̈ten, etwa durch den Ort, an den sie zufällig gelangen, oder durch ihre zufällige Nachbarschaft in ihrem Wesen bestimmt zu werden." Da es, wie Driesch gezeigt hat, Thatsache ist, dass die Zellen der Keimblätter wirklich die Fähigkeit lıaben, durch den Ort, an den sie zufüllig gelangen, in ihrem Wesen bestimmt zu werden, so müsste Weismann seine Determinantenlehre aufgeben, wenn er sich an Seite 192 seines Werkes gebunden fühlte. Allein, er hat glücklicherweise auf Seite ว02 nachgewiesen, dass die Blattzellen von Thuja \% wei Determinantenarten haben, von denen immer 
nur eine aktiv wird, je nach den äusseren Einflüssen, und diese Erklärung kann er ja auch auf die Ergebnisse der Driesch'schen Versuche anwenden, wonach aus der einen Furchungszelle eines einmal gefurchten Seeigeleies eine regelrechte Seeigellarre werden kann. Wenn er annimmt, dass in jerler Furchungszelle des Seeigeleies und der iibrigen Tiere, an welchen solche Erscheinungen, wie sie Driesch und Chabry mitgeteilt haben, beobachtet worden sind oder noch beobachtet werden, Reserveide liegen, so ist die Erklärung, dass aus einzelnen Furchungszellen sich ganze Tiere entwickeln können, höchst einfach. Weismann thut also besser daran, die auf Seite 187 rorgebrachte Erklïrung der Versuche von Driesch und Chabry durch eine der von ihm bei den Blättern von Thuja angewandten ähnliche zu ersetzen. Das bedeutet aber eine Adoption der de Vries'schen Theorie der „Intracellularen Pangenesis", nur dass anstatt der Pangene unzerlegte Ide in jeder Zelle des Organismus zu liegen kommen. Die solchergestalt gewonnene neue Lehre empfehle ich der Beachtung der Präformisten und schlage für sie den Namell "Intracellulare Panidogenesis" vor.

\section{n. Die Vererbung von Verstümmelungen.}

Weismann hat sich grosse Mühe gegeben, den Nachweis zu führen, dass ein Fall von Vererbung einer Verstümmelung noch nicht mit Sicherheit bekannt ist. Er hat sich dabei an die Fälle gehalten, in welchen gelegentlich ein Schwanz oder ein anderes Glied verloren geht, oder auch an solche, die eigens angestellt wurden, um die Vererbbarkeit oder Nichtvererbbarkeit von Verstümmelungen darzuthun. Mit allen diesen Fällen hat er leichtes Spiel gehabt, denn wenn es überhaupt möglich ist, dass ein Tier seine erworbene Schwanzlosigkeit auf seine Nachkommen vererbt, so wird ein solcher Fall ein höchst seltener sein, weil die Regeneration der Vererbung ron Verstümmelungen entgegenarbeitet. Bei vielen Eidechsen, denen man die Schwänze abbricht, wachsen diese wieder, und nicht selten wachsen an Stelle des einen Schwanzes deren zwei oder mehrere hervor. Ich liabe in Australien Geckonen mit vier Schwänzen gefunden, und eben dort leben Geckonenarten, bei denen normalerweise ein breiter Schwanzanhang vorkommt, der leicht verloren geht, aber wieder wächst. An der Stelle, wo er dem dünnen Schwanzstiele aufsitzt, bricht er ausserordentlich leicht ron diesem ab, so dass die Ver- 
mutung nahe liegt, dass sich hier infolge andauernden und in jeder Generation vielleicht seit Jahrtausenden oder seit Jahrmillionen eintretenden Schwanzverlustes, wodurch ein starker Reiz auf die betreffenden Gewebe ausgeübt wurde, ein viel breiterer und stärkerer Schwanz gebildet hat, als er bei den Vorfahren dieser Geckonen bestand. Von rornherein werden die verschiedenen aufeinander folgenden Stellen des Schwanzes in Bezug auf ihre /erbrechlichkeit voneinander verschieden sein, und wenn irgendwo eine Stelle höchster Zerbrechlichkeit vorhanden war, so musste an dieser Stelle der Schwanz immer wieder abbrechen und neu erzeugt werden. Auf diese Weise ist es zu erklären, dass bei den betreffenden Geckonen die Schwanzanhänge immer breiter geworden sind und dass sie mit immer grösserer Leichtigkeit abbrechen. Wir hätten also auch hier einen Fall von Vererbung einer erworbenen Eigenschaft, und wemn man will, einer Verstünmelung, denn die leichte Zerbrechlichkeit des Schwanzes kamn durch fortgesetzte Verstiummelungen gesteigert worden sein, falls wir annehmen, dass erworbene Eigenschaften vererbt werden. Allein ich will mich hierbei nicht aufhalten, weil es möglich sein würde zu behaupten, der breite Schwanz und seine Zerbrechlichleit an bestimmter Stelle wären allmählich von der Natur herangezüchtet worden, weil die betreffenden Geckonen häufig am Schwanz ergriffen würden, und es deshalb rorteilhaft wäre, dass dieser durch seine Grösse in die Augen fällt und leicht abbricht, damit das Tier selbst enttlichen und wieder einen neuen Schwanz produzieren kann. Ich habe den Fall nur angeführt, um zu zeigen, dass die Regenerationskraft ausserordentlich stark ist bei manchen Tieren, und dass wir deshalb von vornherein nicht erwarten können, dass sich plötzliche Organverluste vererben. Demn es ist ganz sicher, dass die Regenerationskraft bei Embryonen stïrker ist, als bei erwachsenen Tieren, und deshalb dürfen wir auch annehmen, dass Mäuse, denen der Schwanz abgeschnitten wird, Junge erzeugen, bei denen infolge der Regenerationskraft der Embryonen die Schwänze nicht merklich kürzer sind, als bei ilıren Eltern.

Wir müssen zwar annehmen, dass auch Verstümmelungen Eindruck auf das Keimplasma machen, aber dieses sucht auf dem Wege der Regeneration das gestörte Gleichgewicht wieder herzustellen, und deshalb ist keine hochgradige Vererbung gewaltsan hervorgerufener Schwanzlosigkeit oder anderer Verstïmmelungen zu elwarten, ja es wäre sogar möglich, dass Eltern, deren Schwänze abgeschnitten worden sind, Junge mit etwas längeren Schwänzen erzeugen, weil durch die gewaltsame 
Entfernung des Schwanzes ein Reiz auf das Keimplasma ausgeübt wurde, das dieses zu starker Reaktion antreibt.

Wenn man die Frage nach der Vererbung von Verstümmelungen prüfen will, so darf man sich nicht an Laboratoriumsexperimente halten. Ich habe ja schon früher dargethan, was von diesen zu erwarten ist. Weismann, der seinen Mäusen seit vielen Generationen die Schwänze abschneidet, erhält immer wieder Mäuse mit langen Schwänzen: meine Mäuse, denen die Schwänze nicht abgeschnitten wurden, haben oft Junge erzeugt, bei denen der Schwanz oft nur die Hälfte oder drei Viertel der normalen Schwanzlänge aufwies. Weismann mag also seine Mäuseversuche ruhig cinstellen, wenn er es inzwischen noch nicht gethan haben sollte, denn es wird nichts dabei herauskommen. Was sollen uns überhaupt Laboratoriumsversuche, selbst wenn einer sein ganzes Leben daran setzen wollte, über die Vererbung von Verstümmelungen aussagen? Was will ein Menschenleben bedeuten gegenüber der Zeit, die von der Stammesgeschichte der Organismen für ihre Experimente verwendet worden ist? Und was sind ein paar Käfige mit weissen Mäusen in irgend einem 'Zimmer eines zoologischen Instituts gegenüber dem grossen Laboratorium der Natur? An die Experimentierkunst der Natur müssen wir uns wenden, wenn wir Aufschluss über die Frage erhalten wollen, ob sich Verstiimmelungen vererben oder nicht, und die Natur zeigt uns, dass in der That eine Tererbung von Verstümmelungen stattfindet, wenn das betreffende Experiment nur genügend lange Zeit hindurch und in jeder Generation gründlich ausgeführt wird.

Fälle von Vererbung von Verstümmelungen sind keineswegs selten, sondern sogar recht häıfig, wenn wir uns unter den wildlebenden Tieren darnach umsehen; wenn Weismann also meint, dass aus seinen Mäuseversuchen so viel hervorgehe, dass einmalige Verletzungen sich in keinem Grade vererben, so begeht er einen schweren logischen Fehler, denn die erblichen Folgen von einmaligen Verstümmelungen müssen weit innerhalb der Grenzen der normalen Variation liegen. Bis zu einem gewissen Grade müssen sich einmalige Verletzungen vererben, falls ihre erblichen Folgen durch Häufung schliesslich sichtbar werden sollen. Entweder muss Weismann die Vererbung von Verletznngen überhaupt bestreiten, oder er muss wenigstens zugeben, dass die Folgen von einmaligen Verletzungen vererbt werden und sich dermassen häufen können, dass sie endlich sichtbar werden. 
Was aber den Apparat anlangt, den eine solche Vererbung voraussetzt, so ist der keineswegs ein so unendlich verwickelter und unfassbarer, wie $W^{+}$eismann meint, sondern die Notwendigkeit der Vererbung erworbener Eigenschaften auf korrespondierende Körperstellen lässt sich in selır einfacher Treise darthun, wie ich oben gezeigt habe. We ismann hat also kein Recht, die Möglichkeit der Existenz eines solchen Vererbungsapparates zu bezweifeln, auch wenn keine Thatsachen rorlägen, die beweisen, dass el dennoch vorhanden sein muss. Weismann irrt auch, wenn er glaubt, der Blumenbach'schen Forderung genügen zu können, welche die Verwerfung der Annahme einer Vererbung von Verstümmelungeu von dem Beweise abhängig macht, dass eine solche Vererbung überhaupt nicht stattfinden könne. W e ismann lıat keineswegs den Beweis geführt, dass das nicht möglich ist: seine Annahme, dass dazu allermindestens ein unendlich verwickelter Apparat gehören müsste, ist eine irrtümliche, und nicht Weismann, sondern Brock war im Recht, als er sagte, dass der Blumenbach'schen Forderung heute ebensowenig genügt werden könnte, als zu Blumenbach's Zeiten. "Sollte nun aber dennoch," ruft Weismann aus, „eine solche geheime Sympathie-Maschinerie zwischen den Teilen des Körpers und den Keimzellen vorhanden sein, durch welche es bewirkt wïrde, dass jede Veränderung der ersten sich in den letzteren gewissemassen in ein er a nderen Sprache abphotographierten, dann wirde diese wunderbare Maschinerie sicherlich in ihren Wirkungen wahrnehmbar und dem Experiment zugänglich sein." Und ich behaupte, dass diese ,wunderbare Maschinerie" nicht nur in ihren Wirkungen bemerkbar und dem Experiment zugänglich, sondern dass auch ihr Getriebe, wie ich grezeigt habe, ein sehr einfaches ist.

Man hat allerdings kein Recht, aus dem Nichtrorhandensein solcher Wirkungeu auf das Torhandensein erworbener Eigenschaften zu schliessen, aber wenn man diese Wirkungen wahrnimmt, so muss man anch auf das Vorhandensein der Vererbungsmaschinerie schliessen, die keineswegs wunderbar ist. Die Wirkungen kann aber jeder leicht sehen, der die Experimente der $\mathrm{Natur}$ zu Rate zieht. Es ist durchaus verkehrt, von unseren Laboratoriumsexperimenten aus auf solche Experimente der Natur zu schliessen, die der Natur der Sache nach gewaltige Zeiträume beanspruchen. Abgesehen aber von den grossen Unterschiede in der Länge der \%eit, welche die Natur zu ihren Experimenten nötig 
hat, und der, die auf Laboratoriumsexperimente verwandt wird, besteht zwischen diesen und jenen kein wesentlicher Unterschied.

Ein besonders lübsches Zü̈chtungsexperiment über die Tererbung von Verstünmelungen hat die Natur mit unserer Sa tkrähe angestellt. We ismann und andere, denen die einschlägigen Thatsachen nicht bekannt sind, werden über diese Behauptung staunen, demn We ismann laat den Fall der Saatkrähe für seine Keimplasmatheorie, wolche notwendigerweise die Annahme der Vererbung erworbener Eigenschaften bestreiten muss, auszubeuten gesucht. „Einen recht hübschen Fall" fülı't er nach Settegast an. „Die Krähenarten," sagt der letztere, „haben alle um Nasenlöcher und Schnabelwurzel steife, borstenartige Federn, nur die Saatkrähe nicht. Diese besitzt sie zwar auch, solange sie im Nest sitzt; bald wach dem Ausfliegen aber verlieren sie sich und ,kommen niemals mehr zum Vorschein'. Die Saatkrähe bohrt nämlich, indem sie ihrer Nahrung nachgeht, mit dem Schnabel tief in den Boden. Dadurch werden die Federn am Schnabel vollständig abgerieben und können bei dem unablässigen Bohren auch nicht wieder nachwachsen. Dennoch hat diese Eigentiimlichkeit, seit ewigen (?) $\left.{ }^{1}\right)$ Zeiten fortdauernd erworben, noch nie dahin geführt, dass in einem Neste ein Individuum mit angeborenem nackten Gesicht vorgekommen wäre."

Allerdings ist die Schuabelwurzel der jungen Saatkrähe ebenso befiedert wie etwa die einer Raben- oder einer Nebelkrähe, und dennoclı ist das nackte Gesicht der Saatkrähe angeboren. Man muss sich nur nicht an Nestjunge wenden, sondern an ältere Vögel. Zieht man junge Saatkrähen im Käfige auf, ohne ihnen irgend welche Gelegenheit zum Bohren im Boden oder zum Verstossen der Federn an der Schnabelwurzel zu geben, so fallen diese trotzalledem in einem gewissen Alter ganz ron selbst aus, um nicht wieder zu erscheinen. Von irgend welchem Abstossen ist dabei nicht die allergeringste Rede, sondern der Ausfall der Federn erfolgt, wie man zu sagen pflegt, „spontan", ohne dass die Federn selbst vorher verletzt sind. Das ist bereits vor Jahren ron Oudemans festgestellt worden, und ich habe die betreffenden Versuche wiederholt und bin deshalb in der Lage zu behaupten, dass hier in der That die Vererbung einer fortgesetzten Verstümmelung vorliegt. Die eingefleischten Darwinisten könnten allerdings behaupten, dass es gut wäre, wenn die 
Saatkrähe nicht erst ihre Federn abzustossen brauchte, sondern dass es höchst notwendig für die Existenz dieser Tierart wäre, dass die Federn ron selbst ausfallen. Dem könnte man entgegenlalten, dass nach der Annahme derselben eingefleischten Darwinisten die Natur ïberaus sparsam wäre und es deshalb wohl vorgezogen haben dürfte, auch den jungen Saatkrühen keine Federn um die Schnabelwurzel herum wachsen zu lassen, da diese ja doch später ausfallen. Aber wahrscheinlich werden hierauf die Ultradarwinisten antworten, dass es gut wäre, wenn die Nasenlöcher dieser zärtlichen jungen Vögel mit Federn bedeckt wären, damit die Tierchen keinen Schnupfen bekommen!

Aber bleiben wir ernsthaft! Die Saatkrähe bietet uns wirklich einen Fall, und gewiss einen „recht hübschen“, von Vererbung einer fortgesetzten Verstümmelung, und zwar treten die Folgen der Verstümmelung in demselben Lebensalter auf, in welchem die Verstümmelung erworben wurde. Nestjunge der Saatkrähe bohren noch nicht in der Erde herum, und deshalb haben sie auch noch befiederte Schnabelwurzeh. Wir haben es hier mit den vererbten Folgen eines periodischen Schöpfungsmittels, und zwar einer periodischen Verstümmelung zu thun, und es gereicht uns zur Genugthuung, diesen „recht hübschen Fall" We ismann's in sein Gegenteil umgekehrt zu haben. Oder will uns Weismann, der das nackte Gesicht der Saatkrühe durch Terstümmelung hervorgebracht sein lässt, das Recht bestreiten, diesen Fall für unsere Zwecke auszunutzen, nachdem es ihm unmöglich geworden ist, ihn für die seinigen $z$ verwerten? Ist das nackte Gesicht der Saatkrähe nun auf einmal nicht durch Verstümmelung entstanden? Logisch wäre diese Annahme zwar nicht, aber die Determinantenlehre, die ja alles erklärt, wird sich auch roraussichtlich mit dem Falle der Saathrähe abzufinden wissen.

Dieser Fall stelıt übrigens keinesweg's vereinzelt da. Derartige Verstümmelungen sind oft vererbt worden, wie uns ror allem die Süugetiere zeigen. An den Fusssohlen dieser Tiere, an den Gesässschwielen der Affen und an manchen anderen Körperstellen bei anderen Säugern ist das Haarkleid infolge von fortgesetzten Verstümmelungen geschwunden, und noch heute lassen sich noch ganze Stufenreihen von Säugetieren aufstellen, die mit solchen Fällen beginnen, in welchen die erblichen Folgen der fortgesetzten Terstümmelung sich erst eben bemerkbar machen, und mit solchen enden, wo überhaupt keine Haare mehr entstehen. Ich gedenke auf diese Stufenreihen vererbter Wirkun- 
gen von Verstümmelungen in einer ron mir geplanten Monographie des Säugetierkleides zurïckzukommen. Genug, dass durch sie und den Fall der Nebelkrähe die Vererbung von Verstümmelungen unwiderleglich dargethan ist, und wenn $W$ eismann auf Seite 545 seiner „Aufsätze über Vererbung" meint, das "Märchen" der Vererbung von Verletzungen in die "wissenschaftliche Rumpelkammer" verweisen zu kömmen, "ohne befürchten zu müssen, dass es später wieder daraus hervorgeholt werden möchte", so braucht er wenigstens jetzt von der Zukunft nichts mehr zu befürchten. Die Vererbung von Verletzungen ist weder ein ,Märchen“, noch auch mehr ein ,wissenschaftliches Problem", sondern eine wissenschaftliche Thatsache, wie uns der, ,hübsche Fall“ der Saatkrähe gezeigt hat.

\section{Zweifelhafte Vererbungserscheinungen.}

Weismann bespricht eine Reihe von zweifelhaften Vererbungserscheinungen, die sich schwer mit seiner Theorie in Einklang bringen lassen, und deren Existenz er deshalb bezweifelt. Zu ihnen gehören in erster Linie die sogenannten Xenien, Fälle, in welchen der Blütenstaub nicht nur auf die Eizelle einwirkt, sondern auch auf die übrigen Gewebe der mütterlichen Frucht erbliche Eigenschaften überträgt. Wenn gelbkörniger Mais durch Pollen von blaukörnigem befruchtet wird, so sollen zuweilen die Maiskörner blau werden. W e ism an n glaubt dies dadurch erklären zu können, dass er eine frühere Kreuzung der beiden Arten annimmt, und in der That sind wohl neue Untersuchungen nötig, um das wirkliche Bestehen sogenannter Xenien nachzuweisen. Wenn dieser Nachweis gelingt, so werden die Weismann'schen Theorien in grosse Verlegenheit versetzt werden, nicht aber die Anschauungen, welche wir in diesem Buche vertreten. Wir nehmen die Vererbung erworbener Eigenschaften an und setzen demgemäss eine Beeinflussung der Keimzellen durch die des Körpers voraus, weil die Keimzellen mit diesen im Gleichgewicht stehen und weil sich verändertes Gleichgewicht auch auf die Keimzellen übertragen muss.

Bei den Tieren wird die Eizelle durchweg erst befruchtet, wenn sie sich aus dem Verbande der ïbrigen gelöst hat, bei den Ptlanzen dagegen ist es anders. Hier bleibt sie zunächst in Zusammenhang mit den Geweben des mütterlichen Fruchtknotens, und es ist deshalb nach unserer Theorie durchaus nicht schwierig, die Übertragung von Ver- 
änderungen der Keimzellen, die durch Befruchtung bewirkt werden, auf die umgebenden Gewebe zu erklären. Das durch die Befruchtung veränderte Gleichgewicht der Eizelle verändert seinerseits das Gleichgewicht der umgebenden Zellen, weil die Eizelle noch mit diesen in Gleichgewichte steht. Je mehr letzteres der Fall ist, desto eher werden die Zellen des Fruchtknotens durch Einwirkungen auf die Eizelle verändert werden können, und am leichtesten werden sich chemische Veränder'ungen, wie sie den Kärbungen zu Grunde liegen, auf jene übertragen.

Ob also "Xenien" rorkommen oder nicht, ron ihrer Existenz hängt der Bestand unserer Vererbungslehre nicht $a b$, und ebenso rerhält es sich mit der sogenannten "Infektion des Keimes", der zufolge die Nachkommen einer Mutter gelegentlich mehr einem früheren Gatten als ihrem eigenen Vater gleichen sollen. Solehes will man beim Menschen beobachtet haben, und bei Tieren soll es oft vorgekommen sein. Einigermassen sichergestellt ist unter anderem der berühmte Fall, in welchem eine Pferdestute des Lord Morton, die einmal von einem Quaggahengst gedeckt war, später von einem arabischen Rapphengst zwei Füllen warf, die zum Teil graubraun und an den Beinen quaggaartig gestreift und mit einer kurzen aufrechtstehenden Mähne, wie sie das Quagga, nicht aber das Pferd besitzt, versehen waren. Kommt eine solche Infektion des Keimes wirklich vor, so ist sie vielleicht daraus zu erklären, dass der mütterliche Körper sich mit den in seinem Uterus befindlichen Enıbryonen ins Gleichgewicht setzt und dadurch die chemische und morphologische Beschaffenheit seines Plasma's ändert; oder man müsste anuehmen, dass männliche Zeugungsstoffe auf noch unentwickelte Eier eingewirkt hätten in der Weise, dass die letzteren einen Teil ihres Plasma's aus diesen Zeugungsstoffen bildeten. Auf keinen Fall würden aus einem sicheren Nachweis der Infektion des Keimes unserer Vererbungslehre Schwierigkeiten erwachsen, während We ismann's Theorie sich nur schwer damit abzufinden wissen wird.

\section{p. Periodisch erworbene Eigenschaften.}

In den vorhergehenden Abschnitten dieses Buches haben wir eine grosse Anzahl von periodischen Schöpfungsmitteln kennen gelernt, die den Bau der Organismen erblich beeinflusst laben; und wir müssen 
ihnen noch eine nähere Betrachtung widmen, weil die Art und Weise, auf welche sie erbliche Umbildungen hervorbringen können, nicht eben leicht $\mathrm{zu}$ verstehen ist.

Nach unserer Annahme besteht die befruchtete Eizelle im wesentlichen nur aus zwei Vererbungsträgern, nämlich aus den Kernstoffen, welche chemische Eigentümlichkeiten übertragen, und aus dem Plasma des Zellleibes, das am festesten im Centrosoma gefügt ist, und welchem die Übertragung morphologischer Eigentümlichkeiten obliegt. Wir haben versucht, aus einem monotonen Plasma, das in Wechselwirkung mit den Kernstoffen und mit der Aussenwelt tritt, den ontogenetischen A ufbau des Organismus zu begreifen. Es ist nicht schwer zu verstehen, dass die Teilung einer Eizelle, wozu der Anstoss durch die Befruchtung gegeben wird, zu einer Zellenanordnung führt, die durch die Form der Gemmarien bedingt sein muss. Dagegen ist es weniger leicht zu verstehen, weshalb die Zellen sich in bestimmter Weise qualitativ differenzieren. Wir dürfen uns keineswegs verhehlen, dass Weismann's Präformationstheorie und die Ansichten derjenigen Forscher, die mehr oder minder mit Weismann übereinstimmen, hier leichteres Spiel haben. Wie können wir beispielsweise durch unsere Vererbungstheorie erklären, dass die Federn, die bei der Saatkrähe um die Schnabelwurzel der Nestjungen herumstehen, von selbst ausfallen, sobald sie ein gewisses Alter erreicht liaben? Wir haben im vorigen Abschnitt angenommen, dass der Ausfall um diejenige Jahreszeit geschieht, in welcher die Jungen anfangen, in der Erde zu bohren. Es ist ja leicht zu verstehen, weshalb beispielsweise die Pflanzen zu einer gewissen. Jahreszeit blühen, denn wir sehen noch heute, dass die Blütezeit in hohem Grade ron dem Eintreten gewisser Witterungsverhältnisse abhängt, wenn sie auch immerhin schon in hohem Grade erblich fixiert ist, und es giebt eine eigene Wissenschaft, die sogenannte Phänologie, die sich mit den einschlägigen Fragen bescläftigt. Bei den Pflanzen ist noch immer der Eintritt einer bestimmten Jahreszeit nötig, um sie auch wirklich zum Blühen zu bringen. Zieht sich im Frühjahr der Eintritt warmen Wetters lange hinaus, so blühen die Pflanzen später auf als sonst. In dem Falle der Saatkrähe und in vielen anderen Fällen ist es aber anders. Hier braucht die Ursache, welche periodisch auf das Tier eingewirkt hat, nicht wieder von neuem einzutreten, um ihre Folgen von neuem hervorzurufen, sondern die letzteren sind schon derartig erblich fixiert, dass sie von selbst eintreten, sobald das Tier ein bestimmtes Alter erreicht 
hat. Man sollte annehmen, dass die Verstïmmehng der Schnabelwurzelfedern bei der Saatkrähe I'ögel erzeugt hätte, lie auch als Nestjunge eino nackte Umgebung der Schnabelwurzel haben, da ja, falls man eine Vererbung erworbener Eigenschaften annimmt, das Plasma so umgeändert sein muss, tass es einen Vogel mit nackter Schmabelwurzel erzeugen muss. Um es trotzdem zu erklären, dass die Nestjungen iler Saatkrühe noch befiederte Schnabelwurzeln haben, müssen wir weiter ausholen.

Jeder Organismus wird, falls er einem regelmïssigen Wechsel der äusseren V'erhältnisse unterworfen ist, Zeit seines Lebens nicht nu' jeweilig von einer einzigen äusseren Einwirkung, sondern gleichzeitig von einer grossen $A$ nzahl der letzteren beeinflusst, und einzelne Beeinflussungen von aussen, welche die Entwickelung erblicher Figenschaften auslösen, die ohne sic nicht so leicht oder überhaupt nicht zum Vorschein kommen, sind ron vielen anderen begleitet, die gleichzeitig stattfinden. Wir wollen, un uns das hier Auszufülırende verständlicher zu machen, einen hypothetischen Fall annehmen.

Gesetzt, es handle sich um ein durch Kiemen atmendes lurchartiges Wassertier mit einem Flossensaum am Schwanz und einer unbedeutenden Ausstülpung im vorderen Abschnitte des Darmrolıres. Dieses Tier möge einen 'Teich bewohnen, der periodischen Anstrocknungen unterworfen ist. Die Austrocknung würde zur Folge haben, dass die Kiemen des Tieres eintrocknen, der Flossensaum des Schwanzes sich zurückbildet, dass dagegen las 'Tier anfängt, die Ausstülpung seines Darmes zu einer Lunge umzubilden. Wenn solche periodische Austrocknungen vicle Generationen hindurch andanerten, so konnte ein Lurch entstehen. der nur in der Jugend noch seinen Vorfahren glich, im Alter dagegen etwa unserem Lirdsalamander, und nach meiner Ansicht ist die Entstehung ron luftatmenden, das Wasser bewohnenden Wirbeltieren durch ähnliche Annahmen zu erklïren, wie wir sie hier gemacht haben. Es handelt sich nun beim Übergange rom Leben im Wasser zu dem auf dem Lande nicht nur um rine einzige Einwirkung äusserer Einflüsse auf den Körper des betreffenden Tieres, sondern um deren viele. Der Kreislanf wird dadurch veründert, dass die Kiemen eintrocknen und die Lungen gezwungen sind, stärker zu atmen als früher. Die Schwan zflosse verkümmert, die Nahrung wirl eine andere, kurz auf den Körper wirken alle diejenigen Eintlïsse ein, die das Leben auf dem Lande im Gegensatz zu dem im Wasser mit sich bringt. Mit diesen zu gleicher Zeit auf verschiedene Weise einwirkenden neuen Lebensberlingungen muss sich unserer Theorie zufolge 
das Plasma ins Gleichgewicht setzen. Die Verïnderungen, die an den Kiemen, in den Lungen, an Schwanze und an allen anderen Körperstellen, die meist nichts miteinander zu thum haben, ror sich gegangen sind, setzen sich miteinander ins Gleichgewicht und erzeugen eine Gemmarienform, die alle diese Veränderungen wieder mit Notwendigkeit hervorbringen muss und desto sicherer wieder hervorbringt, je regelmässiger las periodische Schöpfungsmittel, das sie verursacht hat, wiederkehrt unrl das Plasma von neuem in der früheren Richtung beeinflusst. Die grosse Mehrzahl der periodischen Schöpfungsmittel kehrt aber mit grosser Regelmässigkeit wieder, weshalb es auch nicht schwer zu verstehen ist, dass sich die Eizellen der vielzelligen Tiere und Pflanzen immer wieder in derselben Weise entwickehn, wie die ihrer Vorfahren.

Die Eizelle, aus welcher sich ein Tier entwickelt, trifft in den allermeisten Fällen nach ihrer Befruchtung dieselben äusseren Lebensbedingungen an, wie die Eizellen, aus welchen sich seine Eltern und Grosseltern entwickelt liaben. Es ist deshalb nicht zu verwundern, dass sie wieder denselben Entwickelungsgang durchläuft; sie teilt sich zunächst in zwei Zellen, wodurch die Art und Weise, auf welche nunmehr die Aussenwelt auf den sich entwickelnden Keim einwirkt, etwas verändert wird. Mit jeder nenen Zellteilung wird das Verhältnis der einzelnen Zellen zu der Aussenwelt und zu einander ein anderes, aber jedes Zellstarlium trifft immer wieder dieselben äusseren Verhältnisse an, wie das entsprechende Zellstadium bei den Vorfahren. Daraus erklärt sich, warum immer wieder derselbe Entwickelungsgang durchlaufen wird. Ändern sich die periodischen Beeinflussungen, die diesen Entwickelungsgang bedingen, almmählich, so wird auch der Gang der Kieimesgeschichte nach und nach abgeändert, und es entsteht aus der betreffenden Organismenart eine neue. Immer setzt sich das Plasma des Körpers mit allen äusseren Verhältnissen, die jeweilig auf diesen einwirken, ins Gleichgewicht.

Gesetzt, es handelte sich um eine Keimzelle $k$, auf welche neue periodische Einflüsse einwirken. Es sollen diese der Reilıe nach mit den Zahlen 1-10 belegt werden; es würde also der'sich entwickelnde Keim infolge der äusseren Einflüsse die Stadien $k_{\hat{v}_{1}}-k_{k_{10}}$ durchlaufen. Nun soll $k_{10}$ dasjenige Stadium sein, in welchen sich neue Keimzellen bilden, die wiederun dem durch rlie Zahlen ausgedrückten periodischen Wechsel der Lebensbedingungen ausgesetzt werden. Während die dem Stadium $l_{10}$ entsprechenden Vorfahren des betreffenden Individuums die Keimzelle $k$ erzeugt haben, geht am Schlusse der individuellen EntwickeHacke, Gestaltung und Vererbung. 
lung der durch neue periodische Schöpfungsmittel becinflussten heimzelle $k$ diese ïber in $K$, auf deren Entwickelung wieder die Lebensbedingrungen 1-10 cinwirken. Allmählich wird sich das Plasma mit diesen ins Gleichgewicht gesetzt hahen, so dass aus der Keimzelle $K$ immer wieder ein Individuum mit dem Entwickelungsgange seiner Eltern entsteht, solange sich in den Verhältnissen der Umgebıng nichts ändert. Es fragt sich aber, ob sich aus der Keimzelle $K$ wieder derselbe Organismus entwickeln würde, wenn man sie in jeder Beziehung völlig neuen Einflüssen aussetzt. Dies ist nun ein Experiment, das sich nicht machen lïsst, denn man kann die Lebensbedingungen eines sich entwickelnden Keimes nicht derartig verändern, dass sie alle in hochgradiger Weise von den früheren abweichen. Was über die Becinflussung der Ontogenie durch die Lebensbedingungen des Keimes bekannt ist, zeigt sowohl, dass es nötig ist, dass sich eine gewisse Anzahl der Einflüsse, die auf die Vorfahren cingewirkt haben, wiederholt, als auch, dass nicht alle Einflüsse wiederzukehreu brauchen, welche in den entsprechenden Lebensaltern auf die Torfalıren der betreffenden Art eingewirkt haben. Wenn nun anch die eine oder andere dieser periodischen Einwirkungen wegfällt, so muss dennoch das, was sie früher hervorgerufen hat, wieder erscheinen, falls die $\[\mathrm{eh} \mathrm{rzahl}$ der ïbrigen periodischen Einflüsse, die im gleichen Lebensalter rereint mit ihr wirkten, fortbestehen. Das ist aber beispielsweise bei der Saatkrähe der Fall.

Auf die jungen Saatkrähen wirken zur Zeit, wo die Federn an der Schnabelwurzel ausfallen, genau dieselben periodischen Einflüsse eiı, wie bei ihren Tolfahren, mit alleiniger Ausnahme derjenigen, die das Ausfallen der Federn bedingten. Die periodischen Einflüsse, die zugleich mit den in einem bestimmten Lebensalter begonnenen Bohren in der Erde einwirken, die zugleich mit diesem die Form der Saatkrähe in diesem Lebensalter bestimnt haben, wirken fort. Mit ihren erblichen Folgen stehen diejenigen Gleichgewichtsverhältnisse der Gemmarien, die den Ausfall der Federn bedingen, im Gleichgewicht, und deshalb müssen die Federn ausfallen, anch wemn das Tier nicht in der Eide bohrt. Es ist aber wohl anzunehmen, dass zu der Zeit, wo sich die Federn bei den jungen Saatkrähen lockern, auch schon das Bolnen in der Erde begonnen hat, wenn es auch zum Ansfallen der Federn nicht mehr notwendig ist. Es wirkt also dieses periodische Schöpfungsmittel noch fortgesetzt weiter, und die Nachkommen der Saatkrähen könnten nur dadurch die Federn ilnrer Schnabelwurzeln während des ganzen Lebens 
behalten, dass die Art sich alhmählich daran gewöhnte, das Bohren in der Erde aufzugeben.

Ähnliches wie in diesem Falle lässt sich nun von allen periodischen Schöpfungsmitteln überhaupt sagen, die früher das Gleichgewicht des Plasma's verändert haben, es aber heute nicht mehr beeinflussen. Ihre Wirkungen standen alle im Gleichgewicht mit zahlreichen anderen, deren Ursachen noch fortwirken, und deshalb werden auch noch solche Eigenschaften durch die Vererbung übertragen, die nicht immer wieder von neuem durch periodische Schöpfungsmittel gefestigt werden. Dazu kommt aber, dass sich die Wirkungen der periodischen Schöpfungsmittel notwendigerweise auf ein immer früheres ontogenetisches Entwickelungsstadium übertragen mussten, und diesem Umstande haben wir noch eine kurze Betrachtung zu widmen.

Wir haben gesehen, dass erworbene Eigenschaften mit Notwendigkeit die Gemmarien der Keimzellen verändern müssen. Diese Keimzellen gleichen also dann nicht mehr ihren unveränderten Vorläufern und können deshalb die von den letzteren produzierten ontogenetischen Stufen nicht genau rekapitulieren. Der aus der abgeänderten Keimzelle hervorgegangene Organismus wird also schon von vornherein mehr dem durch äussere Einflüsse abgeänderten gleichen, als einem noch unabgeänderten. Deshalb werden auch die neu erworbenen Eigentümlichkeiten schon zum Ausdruck gelangen, sobald er sich in seiner Entwickehung einigermassen dem betreffenden ontogenetischen Stadium ge1 ähert hat. Auf diese Weise wird die neu erworbene Eigenschaft, falls die Anpassung in derselben Richtung weiter geht, auf immer frühere Stufen der Keimesgeschichte übertragen, falls nur das ursprünglich durch Anpassung entstandene Organ durch fortgesetzten Gebrauch auf seiner Höhe erhalten wird. Im Falle der Saatkrähe wird das fortgesetzte Bohren in der Erde endlich dazu führen, dass auch die Nestjungen keine befiederten Schnabelwurzeln mehr haben, rorausgesetzt, dass die Alt das dazu nötige Alter erreicht

Somit ergiebt sich, dass die durch periodische Schöpfungsmittel hervorgebrachten direkten Anpassungen, falls die periodischen Schöpfungsmittel fortwirken, auf immer früheren Stufen der ontogenetischen Entwickelung erscheinen.

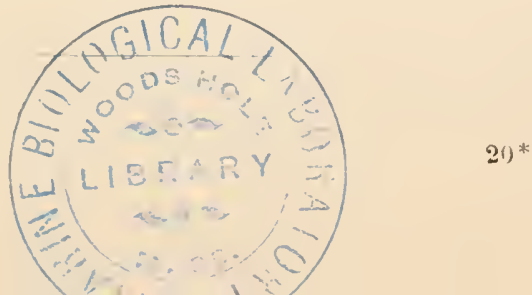




\section{Die Gemmarientheorie und ältere Ansichten.}

Die Darlegungen unseres Buches werden, obwohl nur skizzenhaft, doch genügen, um die Tragweite der ron uns entwickelten neuen Lehre darzulegen. Die Lehre ist aber nur als Ganzes genommen und in Bezug auf die einzelnen Teile nur in etlichen von diesen neu, und es ist deshalb nötig, ihr Verhältnis zu anderen Lehren zu besprechen, und zwar sowohl zu denen, welchen sie Anschauungen entlehnt hat, als auch zu ren mit ihr nicht $z u$ vereinigenden Theorien.

Die Theorie der Epigenesis ist ron Kaspar Friedrich Wolff aufgestellt, und unsere Darlegungen wollen einen Beitrag zur Verteidigung dieser Lehre gegen die Angriffe der Neupräformisten, deren Haupt We ismann ist, liefern. Ausserdem aber soll dieses Werk zu der Rehabilitierung des alten Lamarck beitragen. Wenn auch dessen Auschaumgen im einzelnen vielfach rerfe!lt sein mögen, so war doch seine Grundanschauung, wonach der Körper in Wechselwirkung mit der Aussenwelt sich selbst seine Organe bildet, richtig. Ebenso wie an Lamarck, schliesst sich unsere Lehre an die Anschaumgen Geoffroy st. Hilaires an, der physikalische und chemische Einflüsse der Aussenwelt die wesentlichste Rolle bei der Umbildung der Organismen spielen liess.

Die \%uchtwahlidee entnimmt unsere Lehre dem Darwinismus, aber sie unterscheidet schärfer, als es Darwin gethan hat, zwischen den verschiedenen Arten der Zuchtwahl, nämlich zwischen konstitutioneller und dotationeller Auslese und zwischen Individual- und Rassenselektion. Wir glauben den Nachweis geführt zu haben, dass es nur eine konstitutionelle, keine dotationelle Individualselektion giebt. Diese Auslese, welche die bestgefügten Individuen überleben lässt, findet auch in. 
der unorganischen Natur statt. Körper mit minder labilem Gleichgewicht lıaben eine grössere Aussicht zu überdauern, als solche mit sehr hinfälligen Gefïge.

Wir konnten des weiteren zeigen, dass die Annahme dotationeller Individualselektion mit Notwendigkeit zur Determinantenlehre und zur Theorie der Amphimixis führen muss, welch letztere ja allerdings schon in der Darwin'schen Keimchenlehre gewissermassen vorgebildet war. Dass aber das Gebäude der Determinantenlehre und der Amphimixistheorie auf Sand errichtet ist, glauben wir zur Genüge dargethan zu haben. Mit diesen unhaltbaren Lehren muss zugleich die I) arwin'sche Theorie der dotationellen Individualselektion - und das ist der Hauptteil des Darwinismus - fallen. Dotationelle Auslese können wir nur als Rassenselektion gelten lassen, und was diese Rassenselektion anbelangt, so erscheint es in höchstem Grade auffällig, dass auf dem Titel von Darwin's Hauptwerk von ihr und nicht von der Individualselektion die Rede ist. Es handelt sich dort um die Erhaltung der begünstigten Rassen, nicht um die der begünstigten Individuen, und in der That zeigt Darwin an vielen Stellen seines Werkes, dass er Augenblicke gehabt hat, wo er sich über den Unterschied zwischen Rassenauslese und Individualselektion nicht klar war. Ich habe übrigens mit der Hervorhebung dieses Unterschiedes nichts Neues gethan, denn es ist nacligerade oft genug betont worden, dass Ausstattungszuchtwahl erst anfangen kann zu wirken, wenn die Unterschiede der Individuen genügend gross sind. Solche Unterschiede zeigen aber nur die Indiriduen verschiedener $\mathrm{R}$ assen.

Wir haben zwar das Wesentliche des Darwinismus, denn das ist in der That Individual- und nicht Rassenselektion, sofern es sich auf die dotationelle Auslese bezieht, verwerfen müssen, haben dafür aber die natïrliche Zuchtwahl herangezogen zur Erklärung der Entstehung der Arten, die Darwin nicht erklärt hat. Die dotationelle Individualselektion erhält immer das festeste Gefüge, sie steigert deshalb die Gefügefestigkeit und führt dadurch zu immer höheren Formen, die sich nun unit der Aussenwelt abzufinden haben, d. h. sich an sie anpassen müssen. Dazu ist die Annahme einer Vererbung erworbener Eigenschaften nötig, und diese hat auch Darwin nicht verschmäht, wie er ja überhaupt viel weitsichtiger war, als seine Nachfolger. Viele daron haben, trotzdem sie den Namen Darwin's fortwährend auf den Lippen führen, eigentlich nichts gethan, um inı Sinne Darwin's weiter zu 
arbeiten. Darwin wollte die Entstchung der Arten erklären, aber um diese kümmern sich viele Biologen von heute, die sich fortwährend mit der Entwickelungshehre beschäftigen, überhaupt nicht.

Bei uns in Deutschland lat sich die Nachfolgeschaft Darwin's vorwiegend damit abgegeben, die grossen Tiergruppen miteinander genetisch zu verknüpfen, und daraus geht hervor, dass zwar die Abstammungslehre, welcher Darwin endgültig zum Siege rerholfen hat, bes uns ihre Anwendung findet, während der eigentliche Zweck des Darwinismus, die Erklärung der Artbildung und der Einrichtnngen des Organismus, nur in sehr ungenügender Weise verfolgt worden ist. Es zeigt sich also, dass Darwin seine grossen Erfolge bei uns in Deutschland nicht sowohl seiner eigensten Theorie, sondern der siegreichen Neubelebung der Abstammungslehre zu verdanken hat, und deshalb hat keiner der Herren, welche die Kenntnis der Tierarten verschmähen, Veranlassung, die ron uns und anderen begangenen Ketzereien zu tadeln.

Wer auf das Studium der einzelnen Tierarten, ihres Lebens und 'Treibens und ihrer geographischen und geologischen Verbreitung verzichtet, der hat kein Recht, in Sachen der Entstelungr der Arten mitzusprechen und sich über Anschauungen, die dem orthodoxen Darwinismus zuwiderlaufen, zu ereifern. Einen orthodoxen Glauben bewahrt sich immer derjenige am leichtesten, der sich nicht um Glaubensdinge kümmert, und deshałb verteidigen auch diejenigen den Darwinismus am meisten, die nicht auf dem Felde des Darwinismus arbeiten. Darwin's Wunsch ist es aber nicht gewesen, dass das von ihm eröffnete Forschungsgebiet unbeackert bleiben sollte, und deshalb arbeiten diejenigen, die die Haltbarkeit von Darwin's Ansichten prüfen, mehr in der Richtung des grossen britischen Naturforschers als Darwin's blinde Nachbeter, und zu den ersteren möchte auch ich mich gerechnet wissen. Ich stehe auf den Schultern Darwin's, wenn ich das Wirken der natiurlichen Zuchtwahl schärfer zu erfassen suchte, als es Darwin gethan hat.

Mein Widerspruch gegen Darwin begründet sich aber nicht allein darauf, dass er zu sehr die dotationelle Individualselektion in den Tordergrund geschoben hat, sondern auch auf den ablehnenden Standpunkt, den er Moritz Wagner gegenüber eingenommen hat. Ich bin mit Wagner der Ansicht, dass auf einem und demselben kleinen Gebiete, wo eine Kreuzmng der verschiedenen Individuen einer Tierart nach allen Richtungen hin möglich ist, aus dieser Art nicht zwei neue Arten entstehen können. Allerlings stimme ich darin nicht mit Wagner über- 
ein, dass er neue Arten nur durch Isolation entstehen lässt. Ich glaube, es genügt vollständig, wenn man die Verbreitung einer Art über ein weites Gebiet anuinmt, um in den einzelnen Gegenden dieses Gebietes neue Rassen entstehen zu lassen, denn die Individuen werden sich immer nur in einer bestimmten Gegend hin und her bewegen und nicht das Gesamtgebiet der Art fortwährend durchstreifen. Sie werden sich dabei an die Grenzen halten, die überall die freie Beweglichkeit nach allen Seiten hin etwas beeinträchtigen. Deshalb kann in jeder einigermassen in sich abgeschlossenen Gegend eine Umbildung der Art zu einer neuen Rasse stattfinden, ohne dass Isolation etlicher individuell abändernder Stïcke der Art nötig wäre. Auf diese Weise kann auch eine Rassenselektion, die etwa die Heranzüchtung eines Schutzkleides zur Folge hat, zu stande kommen, und wir brauchen nicht mit Wagner anzunehmen, dass die Tiere diejenigen Gegenden aufsuchen, wo sie am meisten Schutz durch ihre individuelle Färbung finden.

Aber trotz dieser Ausstellungen an der Lehre Moritz Wagner's muss ich wiederholt betonen, dass er es ist, der die Notwendigkeit einer gewissen Separation dargethan hat. Ich glaube, er hat unwiderleglich gezeigt, dass bei freier Kreuzung auf einen kleinen Gebiet aus einer Art nicht zwei oder mehrere neue Arten entstehen können, und selbst $N$ ägeli, der so heftig gegen Wagner polemisiert hat, macht an einer Stelle das Zugeständnis, dass die Verschiedenheiten der Rassen in letzter Linie durch die Verschiedenheit der Wohngebiete hervorgebracht würden. Auch er kommt also schliesslich auf die Separation zurück, und ich glaube nicht, dass irgend eine Artbildungslehre ohne diese auskommen wird, denn freie Kreuzung muss notwendigerweise die Eırtstehung von zwei oder mehr Rassen aus einer verhindern. Dieses gezeigt zu haben ist das Verdienst Moritz Waguer's, und andere Forscher, wie Romanes und Gulick, haben nicht mehr geleistet in Bezug auf das Hervorheben der Notwendigkeit der Sonderung für die Entstehung der Arten. Eimer meint zwar, dass die Sonderung einer Art in zwei auch auf dem Wege der Genepistase, d. h. des Stehenbleibens der Entwickelung erfolgen könne. Wenn etliche Individuen die Fortbildung einer Art nicht mehr mitmachen, sondern auf der einmal erreichten Stufe stehen bleiben, während andere sich weiter entwickeln, so soll dadurch eine Trennung in verschiedene Arten möglich sein. Ałlein stehenbleibende Individuen werden sich immer wieder auch mit rorwärtsschreitenden und nicht bloss mit ihresgleichen rermischen, und deshatb 
sehe ich nicht ein, wie durch Genepistase cine Tremmng einer Art in zwei oder mehrere hervorgebracht werden soll. Damit will ich aber nicht, wie sich später zeigren wird. das Prinzip der Genepistase überhaupt verwerfen. Ich glaube es im Gegenteil durch meine Anschaumngen fester begründen zu können, als es Eimer möglich war. Hier wollte ich nur hervorheben, dass Morit\% Wagner sich ein grosses Verdienst um die Lehre ron der Artbildung erworben hat, ein Verdienst, ebenso gross wie dasjenige (ler Selektionstheoric 1 ) ar win's. Es giebt nicht einen Beweis dafür, dass sich dort, wo Krenzung nach allen Seiten hin mögrlich ist, aus einer Organismenart zwei oler mehrere bilden kömnen, und wenn ich das auch in diesem Buche betont habe, so muss ich dabei II ritz W agner den 'Tribut der Dankbarkeit zollen.

Nicht minder stehe ich auf den Schultern meines Lehrers Ernst Haeckel, wenn ich die von ihm aufgestellte Grundformenlehre zu verwerten und mechanisch zu begrüuden versucht habe. Durch Haeckel's „Generelle Morphologie" bin ich auf die Bedeutung der Grundformen für das Verständnis der Organismen aufmerksam geworden, und ich muss mein Erstaunen darïber ausdrücken, dass diese Bedeutungr bisher so wenig gewïrdigt worden ist. Die Morphologie hat es mit der Erklärung der Formen zu thun; man sollte leshalb meinen, dass es in erster Linie darauf ankäme, die Sym metrieverhältnisse der Organismen aus den Formen der Plasmaclemente zu begreifen. Sovicl ich weiss, bin ich der Erste, der dies ïberlaupt zu thun rersucht hat.

Hacekel's Vererbungstheorie, die "Perigenesis der Plastidule", habe ich zwar aus den früher angegebenen Gründen nicht adoptieren liönnen; allein ich lehne mich doch insofern an sie an, als ich eine dy a mische Übertragung der erworbenen Eigensehaften auf das Plasma der Keimzelle annehme, und ich kanu deshalb nicht umhin, auch hicr die Vorläuferschaft $\mathrm{Hacckel's} \mathrm{zu} \mathrm{betonen.}$

Sehr viel verdanlie ich $\mathrm{N}$ ägeli, und es kömnte fast scheinen, dass die hier vorgetragene Lehre weiter nichts ist, als eine Ausführung der Nägeli'schen Ideen. Aber wer meine Lehre mit der Nägeli'schen vergleicht, wirl sehen, dass unsere Anschaumgen durchaus verschieden sind. Zwar nelme ich, gleieh Nägeli, als Bausteine des Organismus Plasmaelemente an, die aus mehreren oder vielen Molekiilen zusammengesetzt sind und eine bestimmte Form haben, aber während Xägeli's Micelle ungleich sind, sind meine Gemmen wenigstens in Bezug auf ilne Form cinander gleich, und ich lasse auch nicht die Verrollkommnung 
der Organismen vorwiegend von der Komplikation der Querschnitte der Gemmarien, die man etwa mit Nägeli’s Micellsträngen vergleichen könnte, abhängig sein. Von der geometrischen Form des Gemmarienquerschnittes, nicht nur von seiner Komplikation lıängt die Verrollkommung in der stammesgeschichtlichen Entwickelung ab, und die Aufgabe, die eine Formbildungslehre zu leisten hat, ist zunächst eine geometrische. Gerade dieses hat $\mathrm{N} \ddot{g} g \mathrm{eli}$ bestritten, und er hat damit meiner Ansiclit nach auf ein tieferes Verständnis der organischen Entwickelung verzichtet. Eine Vervollkommnung aus ,inneren" Ursachen, wie sie Nägeli annimmt, vermag ich nicht anzuerkennen. Nägeli lässt seine Hicelle sich fortwährend neu ordnen, während nach meiner Anschauung die Gemmarien nur durch Anstoss von aussen verändert werden können, sei es, dass die letzteren allgemeiner physikalischer oder chemischer Natur sind, sei es, dass der Gebrauch oder Nichtgebrauch der Organe dabei im Spiele ist. Ein Plasma, das fortwährend von denselben äusseren Einflüssen getroffen wird, muss sich mit diesen bald so ins Gleichgewicht setzen, dass eine weitere Veränderung nur äusserst langsam vor sich gehen kann. Wir selıen ja deshalb, dass Tiere isolierter Länder viel langsamer in der Entwickelung vorwärtsschreiten, als die, welche weit ausgedehnte Gebiete bewohnen. Die Thatsachen der Tiergeographie bilden eine direkte Widerlegung der Anschauungen Nägeli's, denen zufolge sich das Plasma aus inneren Ursachen vervollkommmet. Ich stimme aber mit Xägeli vielfach in dem, was er gegen den orthodoxen Darwinismus vorbringt, überein, und ebenso darin, dass unabhängig von irgend welchen Nützlichkeitsprinzipien eine Entwickelung nach einer Richtung hin, die zugleich eine Vervollkommnungsentwickelung ist, stattfindet. Aber die Vervollkommnung lasse ich doch wieder durch ein darwinistisches Prinzip, nämlich durch das der konstitutionellen Individualselektion zu stande kommen, während Nägeli es auf innere Umbildungsursachen zurückführt. Ich glaube also nicht, dass meine Theorie mit derjenigen Nägeli's irgendwie zu verwechseln ist.

Dagegen glaube ich eine grosse Strecke weit mit Eimer zusammengehen zu können. Eimer lat sich dadurch ein grosses Verdienst erworben, dass er die Entwickelung der Arten nach einer Richtung hin aus konstitutionellen Ursachen, d. h. aus Ursachen, die den Bau des Plasma's, abgesehen von äusseren nützlichen Einrichtungen, betreffen, vor sich gehen lässt. Auch er führt gleich mir diese Fortentwickelung 
nach einer Richtung hin auf ïussere Ursachen und nicht auf das Yägeli sche Verrollkommnungsprinzip zurïck. Er sieht gleich mir in der Formbildung der Organismen eine Art $\mathrm{Kristallisation.} \mathrm{und} \mathrm{er}$ bekämpft gleich mir den orthodoxen Darwinismus. Sein vorhin erwähntes Prinzip der Genepistase oder des Entwickelungsstillstandes glaube ich aus der mehr oder minder schnellen Umbildung, welche die Organismen infolge ihrer Verteilung auf verschieden grosse Gebiete crleiden müssen, erklären zu können. Dass auf einem und demselben Gebiete etliche Individucn zurïckbleiben und dadurch zur Trennung von einer Art in zwei führen, ist eine Auschaumng, die meiner Ansicht nach nicht haltbar ist, und nur in diesem einen Punkte habe ich die Anschauungen Eimer's zu bekämpfen. Im übrigen ist es mir ein Bedürfnis, hervorzubeben, dass ich in allen wesentlichen Punkten auf den von Eimer entwickelten Anschauungen weiterbaue. Was ich für mich beanspruche, ist ein tieferes Eindringen in den Bau des Plasma's und die Erklärung der nach einer Richtung hin erfolgenden Entwickelung aus der konstitutionellen Individualselektion. Auch hat Eimer es nicht versucht, die Grundformen der Tiere aus dem Bau des Plasma's zu erklären. Das grösste Terdienst hat sich aber Eimer dadurch erworben, dass er nachdrücklichst die Kenntnis der Arten betont hat, und dass er durch seine schönen Arbeiten über die /eichnung der Tiere geradezu eine Reform der Systematik angebahnt hat, wodurch diese erst eine wissenschaftliche Begründung erhält. Aus vollem Herzen stimme ich Eimer auch bei, wenn er die Einseitigkeit der heutigen akademischen Zoologie Deutschlands, die keine ganzen Tiere mehr kennt, gebührend šreisselt.

Mit Goette verbindet mich vor allem die Anschauung, clie übrigens auch von Eimer geteilt wird, dass die Entwickelung auf Korrelation beruht, dass jeder Teil eines Organismus sich in Abhängigkeit von allen anderen Teilen entwickelt, und ich glaube meinen Lesern durch das Hervorheben dieser universellen Korrelation keineswegs etwas Neucs gesagt zu haben.

Es ist das Verdienst von $\mathrm{H}$ is gewesen, auf die bei der Ontogenese vor sich gehenden Faltenbildungen und andere Vorgiinge neucrdings wicder hingewiesen zu haben, nachdem solches schon frïher durch Pander und Lotze geschehen war. His hat aber wohl nicht genug betont, dass das eigentliche Gescliehen bei der Ontogenese in die einzelnen \%ellen rerlegt werden muss, und ich glaube, dass in diesem Werke der erste 
Versuch vorliegt, die Einstülpungen und Faltenbildungen, die bei der Ontogenese stattfinden, wirklich u rsächlich zu erklären.

Wir sind damit bei der Besprechung derjenigen neueren Bestrebungen angelangt, welche die Begründung einer Entwickelungsmechanik zum Zwecke haben. Am konsequentesten scheint mir unter allen neueren Forschern Drever das mechanische Moment hervorgehoben zu haben. Es ist ihm in der That, wie ich glaube, gelungen, die Entstehung des Radiolarienskeletts und anderer Skelettformen mechanisch zu erklären. Aber er hat, wie ich schon früher hervorgehoben habe, die Erklärung: der Vererbung nicht in Angriff genommen und lässt diese überhaupt keine bedeutende Rolle spielen. Vollständig wird das Radiolarienskelett erst erklärt sein, nachdem auch gezeigt worden ist, weshalb sich die Plasmablasen, in deren Wänden es sich anlegt, so und nicht anders anordnen müssen, und ich glaube, dass diese Anordnung nur auf die Form der Elemente des Plasma's zurückgeführt werden kann.

Neben Dreyer hat sich vor allem Driesch Verdienste um die mechanische Betrachtung der Entwickelungsgeschichte erworben, nur scheint er mir in seinem Kampfe gegen den Darwinismus und die Abstammungslehre zu weit zu gehen. Ohne das Zuchtwahlprinzip können wir nicht auskommen; es herischt ja auch in der unorganischen Natur; und die Abstammungslehre müssen wir als unveräusserliche Errungenschaft der Wissenschaft betrachten. Würden wir die gesamte Vorfahrenreihe einer Tier- oder Pflanzenart kennen, so hätten wir keineswegs, wie Driesch mit dem Philosophen Liebmann meint, eine "Ahnengallerie", sondern wir hätten eine Formenreihe, die gesetzmässige Umbildungen zeigen würde, aus der wir Entwickelungsgesetze ablesen könnten. Die Vergleichung solcher Formenreihen mit der Ahnengallerie eines adeligen oder fürstlichen Schlosses ist durchaus unzutreffend, denn die letztere lässt sich nur vergleichen mit dem Stammbaum eines Pferdes oder eines Rassehundes, in welchem die verschiedensten Individuen zur Bildung eines Tieres zusammengewirkt haben.

Ich vermag auch mit Driesch in Bezug auf seine geringe Wertschätzung der Haeckel'schen Promorphologie nicht ïbereinzustimmen, sondern glaube in der That, in diesem Werk gezeigt zu haben, dass die Grundformenlehre mit Notwendigkeit zu einer mechanischen Begründung der Formenverhältnisse der Organismen führen muss, und dass die Symmetrieverhältnisse der Organismen die wirklichen Typen sind, nicht aber die sogenannten Typen der modernen Zoologie. Es giebt 
so riel Typen im Organismenreicl, als es tierische und p flanzliche frumblformen giebt: dagegen scheinen mir die sogrenannten Typen oder Stämme des Tierreichs sehr an Bedeutung zurïckzutreten. Ich glaube num, dass es sich mit Hilfe der von mil ursächlich begründeten Grundformenlehre zeigen lässt, dass im Tierreich anch alle diejenigen Grundformen wirklich existieren, die möglich sind, und dass keine anderen möglich sind als die, welche existielen. Es lässt sich also in Bezug auf die 'Tiere ein ähnlicher Nachweis führen als der, den Solnncke in Bezug auf die Kristallformen unternommen hat, der Sachweis, dass der Querschnitt eines Genmariums fünf rerschiedene Hauptformen hat und nur diese haben kann, während die beiden Enden des Gemmariums einander ș̌nımetrisch oder unsymmetrisch sein können.

Der Querschnitt kann e rstens noch nicht gefestigt sein, und daraus wïrde ein Tier mit noch nicht feststehender Grundform resultieren. Er kann zweitens rund oder regelmässig strahlenförmig sein, was ein kugelförmiges 'Tier ergeben würde. Aus einem mehr oder weniger rhombischen oder elliptischen Gemmariumsquerschnitt würde drittens ein 'Tier mit elliptischer', doppelkegel- oder doppelprramidenförmiger Grundform resultieren, dagegen viertens aus einem Gemmarium mit zweiseitig-symmetrischem Querschnitt ein eiförmiges. Wird fünftens der Querschnitt des Gemmariums unsymmetrisch, dadurch aber das Gemmarium selbst zweiseitig-symmetrisch, so erhalten wir ein zweiseitig-symmetrisches Tier, und werden endlich an einem Gemmarium die beiden Enden ungleich, so wird das letztere unsymmetriscli und führt zur Bildung unsymmetrischer 'iere. A usser diesen Gemmarienformen sind keine anderen möglich, und ebensowenig ausser den ihnen entsprechenden Grundformen, sofern es sich labei un das Wesentliche der Symmetriererhältnisse handelt.

Es lässt sich also selı wohl der Nachweis führen, dass die Crundformenlehre Haeckel's mit Notwendigkeit zu einem ursächlichen Verständnis der Grundformen der Organismen führen muss.

Driesch hat sich neuerdings für die ron de Vries entwickelten Anschaumgen ausgesprochen, denen ich nicht beistimmen kann. Ich glaube viehmehr, dass durch die schönen Untersuchungen ron Driesch selbst der Nachweis gefülurt ist, lass es lediglich der Ort ist, den eine Zelle im Körper einnimmt, der darüber bestimmt, was aus dieser Zelle werden soll. Es scheint mil nun wenig danit gewonnen zu sein, wenn 
man an einer Zelle alle möglichen Qualitäten annimnt; demn so gut, wie der Ort darüber bestimmen kann, welche von diesen Qualitäten, die an die Elentente des Plasma's gebunden sein müssen, welche Plasmaelemente also zur Weiterentwickelung kommen sollen, kann er auch rarüber entscheiden, welche Umänderungen ein monotones Plasma an einem bestimmten Ort zu erleiden hat. Die Anschauungen ron de Vries. die sich lediglich auf Befunde an Pflanzen stuitzen und in der tierischen Histologie keine Begründung finden, scheinen mir völlig überflüssig zu sein. Ich glaube, dass ,spezifische Formbildung b6 bestimmt wird durch die Form der Gemmarien, die jeder /elle ihren bestimmten Platz im Organismus anweisen, und dass es von diesem Platz abhängt, was aus der betreffenden Zelle wird. Mit Driesch stimme ich aber darin überein, dass spezifische Formbildung in letzter Linie transcendental ist; allein diesseits der allerletzten Elemente der Materie rermag ieh das Transcendentale der Formbildung nicht anzuerkennen.

Wenn ich nun auch dem Vorhergehenden zufolge manches an den Ansichten von Driesch auszusetzen habe, so verschliesse ich mich doch nicht der Bedeutung, welche die von ihm gefundenen Thatsachen und viele seiner allgemeinen Anschauungen beanspruchen, und ich glaube, dass die Entwickelungsmechanik der Organismen ihm schon viel zu verdanken hat und noch manches $\mathrm{zu}$ verdanken haben wird.

Vielleicht in noch höherem Grade dürfte das von Roux gelten, dessen geradezu epochemachende Untersuchungen auch ich bewundere. Diese Untersuchungen haben Roux aber leider in das Lager des Präformismus hineingetrieben, wohin ich ihm nicht folgen kann. Wesentlich auf $\mathrm{R}$ oux's Forschungsresultate, die von vielen anderen eine Bestätigung gefunden haben, begründet sich die von mir vorgetragene Lehre. Nach dieser muss mit Notwendigkeit die Sonderung der beiden Hälften eines bilateral-symmetrischen Tieres schon sehr frühzeitig während der Keimesgeschichte erfolgen, entweder schon durch die erste Furchungsebene des Eies oder durch eine bald darauf folgende, und dasselbe gilt ron den Symmetrieverhältnissen anderer Tiere. Roux und seine Nachfolger haben nun gezeigt, dass das in der 'That geschieht und haben sich dadurch ausserordentlich grosse Terdienste erworben, denn diese Untersuchungen beweisen, dass es die Form der Plasmaelemente ist, die ron vornherein auf die Grundform des späteren Tieres himarbeitet. Nun hat zwar Dries ch gezeigt, dass sich auch aus einem zweizelligen Seeigelkeim, dessen eine Furchungszelle abgetrennt worlen ist, noch eine nor- 
male, wenn auch kleinere Larre entwickeln kann, und ähnliches ist von Chabry bei Ascidien festgestellt worden, aber diese Forschungsresultate lassen sich sehr wohl mit denjenigen Roux's und seiner Nachfolger vereinigen. Wo das Gemmariengefüge noch ein derartiges ist. dass leicht eine Umordnung imnerhalb der schon in ihren Grundformenrerhältnissen bestimmten Zellen stattfinden kann, ordnen sich die Gemmarien wieder so, dass sie die Bildung eines normalen Tieres bewirken, wo aber das Gefüge der Zellen schon so fest ist, dass keine Umordnung mehr stattfinden kann, müssen Halb- und Viertelbildungen, wie sie von Roux beschrieben worden sind, entstehen. Auf diese Weise lassen sich die scheinbar widersprechenden Ergebnisse der Untersuchungen Roux's und seiner Nachfolger auf der einen, und derjenigen Driesch's und Chabry's auf der anderen Seite vereinigen. Die Gemmarienlehre weiss sich mit beiden abzufinden. Auch wenn wir die Untersuchungen Driesch's und Chabry's nicht kennten, so würden wir dennoch der Terwertung der Forschungsergebnisse Roux's zu gunsten des Präformismus nicht zustimmen können. Ich wenigstens wüsste nicht, wieso durch die gewöhnliche Art der Zellteilung eine Sonderung der Tererbungssubstanz in ihre rerschiedenen Qualitäten zu stande konmen soll.

Nach Roux's Anschaung wird eine solche sonderung durch die Teilung der Chromosomen bewirkt; aber dagegen, dass die Zellteilung immer verschiedene Qualitäten sondert, sprechen vor allem die Bastarde, die in den allermeisten Fällen aus Bastardzellen bestehen, sprechen auch solche einzelligen Tiere, bei denen es keine Qualitäten zu sondern giebt, sprechen endlich diejenigen Gewebezellen, aus deren Teilung gleiche Zellen hervorgehen. Ich kann also Oscar Hertwig nur beistimmen, wenn er den Präformismus Roux's bekämpft. Aber ich bin nicht sicher, ob die Anschauungen Hertwig's selbst nicht präformistische sind.

Auf Seite 275 seines Werkes über „Die Zelle und die Gewebe“ sagt Hertwig von den "Idioblasten", die nach seiner Ansicht die Kerne der Zellen, welche Hertwig als die Träger der Vererbung ansieht, zusammensetzen, selbständig wachsen und sich durch Teilung verrielfültigen können, dass sie in der Gesamtanlage des Organismus in einer gesetzmässigen Anordnung enthalteu seien. Hertwig fügt mit Recht hinzu: „Hier liegt der für unsere Vorstellung mit den grössten Schwierigkeiten verbundene Teil der Theorie." Ich glaube, dass dieser Teil der Hertwig'schen Theorie, der sich doch zum unverhüllten Präformismus bekennt, über- 
haupt unhaltbar ist. Fùr den Begriff des Präformismus kommt es nicht darauf an, dass man im Keim ein mikroskopisches Abbild des fertigen Organismus erblickt, sondern man braucht nur, wie Hertwig es thut, eine rorgebildete Anordnung qualitativ ungleicher Idioblasten in der Gesamtanlage anzunehmen, um mit rollen Segeln in den Hafen des Präiormismus hineinzusteuern. Ich glaube deshalb auch, dass Roux's Kritik der Hertwig'schen Anschauungen berechtigt ist, und dass Weismann's Ansicht vor derjenigen Her'twig's den Vorzug grösserer Konsequenz hat. Roux sagt, dass Hertwig sich nicht denken kann, „dass bei der indirekten Kernteilung die richtige qualitative Sonderung des Materials sich vollzöge. Kann er es sich deutlicher vorstellen, dass sie bei der Einwanderung des richtigen Kernmaterials in den Zellleib vor sich geht? Oder ist dabei keine typische qualitative Materialscheidung nötig?" "Entschliesst sich O. Hertwig," sagt Roux weiterhin, „um den Hauptteil seiner Vererbungstheorie aufrecht zu erhalten, zu der Annahme, dass die typischen Verschiedenheiten in der Auswanderung von Idioblasten in letzter Instanz doch von besonderen Beschaffenheiten der Zellkerne der verschiedenen Zellen abhängen, so muss er sciner Behauptung der vollkommenen Gleichheit aller Zellkerne widersprechen: bleibt er bei der Gleichheit aller Zellkerne, muss er das Wesentlichste seiner Vererbungstheorie, die Übertragung der Gestaltung durch das Kernmaterial fallen lassen."

Diesen Satz kann ich nur unterschreiben; dagegen bin ich anderer Ansicht als Roux, wenn er meint, das ganze Dilemma löse sich, sobald Hertwig mit ihm von Anfang der individuellen Entwickelung an aktive und inaktive Idioblasten unterscheide. Ich glaube, dass die Vorstellung von aktiven und inaktiven Idioblasten durchaus unphysiologisch ist, und dass sich das Dilemma, in welchem Hertwig sich befindet, löst, sobald Hertwig die homogenen Chromosomen des Kernes als Träger der chemischen, das Centrosoma und das den Elementen des letzteren gleiche monotone Plasma des Zellleibes aber als Träger der morphologischen Eigenschaften der Organismen auffasst, wic ich es thue. Dann wird die Qualität der einzelnen Zellen des Körpers lediglich durch ihre Lage im Organismus bestimmt, d. h. die verschiedenen Einflüsse, welche die Zellen ihrer verschiedenen Lage gemäss treffen, ändern das Plasma in einer dieser Lage entsprechenden Weise spezifisch um.

Diese Anschauung ist es, die schon von Herbert Spencer begründet wurde als dem ersten unter uns, der überhaupt eine Ver- 
erbungstheorie aufstellte. Ich glaube, dass seine Vererbungstheorie im wesentlichen die ist, die in dem rorliegenden Werke eine weitere Ausführungr gefunden hat. Um die Anschauungen Spencer's nicht im Lichte der meinigen wiederzugeben, führe ich das an, was Wr eismann darïber sagt :

„Den ersten Versuch unserer Zeit, die Vererbung theoretisch zu erlilären, hat wohl Herbert Spencer gemacht, indem er seine physiologischen Einheiten' aufstellte. Die Regeneration verloren gegangener Teile, z. B. eines Beines oder Schwanzes des Salamanders, führt ihn zu der Torstellung dieser Einheiten, in welchen allen das Termögen schlummert, sich in die Form dieser Art umzugestalten, gerade wie in den Iolekülen eines Salzes dic innere Fähigkeit schlummert, nach einem bestimmten System zu kristallisieren. Er bezeichnet dieses Vermögen als ,Polaritiit der organischen Einheiten' und bestimmt diese selbst als die Mitte haltend zwischen den chemischen Einheiten, den Moleküilen und len ,morphologischen' Einheiten, den Zellen; es müssen ,Einheiten unendlich viel komplizierterer Art sein, als die clemischen Einheiten', also Molekülgruppen. Es ist sehr interessant, sich heute, wo wir in der Theorie der Tererbung doch sehon etwas weiter vorgedrungen sind (? H.), sich darüber Rechensehaft zu geben, welche lähigkeiten und Kräfte Herbert Spencer seinen ,physiologischen Einheiten' zuschreiben zu müssen glaubte, um die Erscheinungen erklären zu künnen. Obgleich der Abschnitt über Tererbung und Regeneration ja nur ein kleiner T'eil seines grossen Werkes über die ,Prinzipien der Biologie ${ }^{6}$ ist und deshalb eine ins Einzelne goehende Durcharbeitung der Tererbungserscheinungen nicht enthalten kann, so lïsst sich doch seine Meinung darüber klar erkennen.

„Eimmal setzt sich der ganze Organismus aus diesen Einheiten zusammen, die alle untereinander gleich sind, dann aber enthalten auch die Keimzellen ,kleine Gruppen derselben. Das erstere befähigt jeden himreichend grossen Teil des Kürpers zur Regeneration, das letztere giebt der Keimzelle die Kraft, das Ganze aus sich hervorzubringen, beides dadurch, dass die ,Einheiten' mittels ilner ,Polaritït bestrebt sind, sich so anzuordnen, dass dadurch der ganze Kristall - der Organismus entweder bloss wieder hergestellt oder neu gebildet wird. Die blosse verschichene $\Lambda$ nordnung der in ihrem Wesen gleichen Ëinheiten also bedingt die Verschiedenheit der Körperteile, die Verschiedenheit der Arten aber und auch die der Individuen wird auf eine Verschiedenheit in der Zusammensetzung der ,Einheiten' bezogen. 
„Die Finheiten des Individums sind also gewissermassen in physiologischem Sinne proteusartig: sie können sich in unendlich vielfältiger Weise zusammenordnen und bilden so die rerschiedenartigsten Zellen, Ciewebe, Organe und Körperteile; sie thun dies aber immer nur unter lem dirigierenden Einfluss des Ganzen, so zwar, dass das Ganze den Finheiten eines Teiles die Notwendigkeit aufzwingt, sich gerade so anznordnen, wie es zum Zustandekommen des für die Harmonie des Ganzen noch erforderlichen Teiles nötig ist. Spencer sagt dariber: ,es scheint zunächst schwierig, sich rorzustellen, dass sich dies so verhalten könne; allein wir sehen, dass es so ist. Gruppen von Einheiten, die wir aus einem Organismus herausnehmen, besitzen in der That dieses Termögen, das Ganze von neuem aufzubauen, und wir sind somit genötigt, anzuerkennen, dass allen Teilen des Organismus das Streben imnewohne, die spezifische Form anzunehmen.' Die ,Einheiten' sind also physiologisch veränderliche Grössen, welche immer so thätig sind, wie es das cianze vorschreibt."

Aus diesem Citat geht hervor, dass die Theorie, die ich zu begründen versucht habe, nur eine weitere Ausführung der Spencer'schen Lehre ist. Diese älteste der nach Darwin's Auftreten aufgestellten Vererbungstheorien scheint mir ror allen ihren Nachfolgern den Torzug zu verdienen, und die irrtümlichste scheint mir diejenige W eisman n's zu sein, auf lie ich im nächsten Abschnitte noch einmal kurz zurückkommen muss. 


\section{Die Konsequenzen von Irrlehren.}

Weismann's Tererbungslehre setzt sich zunächst mit den Thatsachen in Widerspruch: sie ist vor allem gegründet auf die Annahme einer unabhängigen Variation der einzelnen Teile des Organismus, eine Annahme, die durchaus rerkehrt und nichts weiter ist, als eine leere Behauptung. Weismann's Lehre setzt sich aber auch vielfach mit sich selbst in Widerspruch, wie ich zur Genüge dargethan habe und noch an vielen Beispielen zeigen könnte. Durch die Theorie der Amphimixis hat Weismann seine Determinantenlehre selbst widerlegt; wir brauchen nur konsequent die Weismann schen Anschaumgen weiter zu verfolgen, um uns hierron fest zu überzeugen. Dass Weismann die seinen Anschauungen verderbenbringenden Einwände gern unberücksichtigt lässt, wie er es z. B. mit dem, was gegen seine Panmixietheorie vorgebracht worden ist, gethan hat, will ich ihm nicht weiter verdenken, denn ein jeder Vater hat seine Kinder lieb; ja ich glaube sogar, dass Weismann sich ein grusses Verdienst erworben lat, indem er die Theorie des Präformismus so weit ausgebaut hat, wie es überhaupt möglich war. Uns anderen bleibt nichts weiter übrig, als dem von Weismann aufgeführten Gebäude einen leichten Stoss zu versetzen, un es, und damit den Präformismus überhaupt, in Trümmer fallen zu sehen. Dadurch, dass er die endgültige Beseitigung des Präformismus in so sorgfältiger Weise rorbereitet hat, hat sich Weismann in der That das grösste Verdienst um die Fortentwickelung unserer Wissenschaft erworben, denn man bedenke doch nur, welche Richtung die Biologie nehmen müsste, wenn Lehren, wie sie Weismann rorgebracht hat, zur Herrschaft gelangen sollten.

Wer die Vererbung erworbener Eigenschaften - und mit deren Anerkennung oder Nichtanerkennung steht und fällt die wissenschaftliche Biologie - leugnet, der braucht nicht mehr nach der Ursache der Veränderungen der Organismen zu forschen, denn die Veränderungen der Weismann 'schen Biophoren sind ursächlich nicht zu begründen. Wenn alles nützlich, wenn allos demnach herangezüchtet worden ist, 
damn können wir das Suchen nach bewirkenden Ursachen getrost aufgeben. In der That begüigt man sich gewöhnlich mit dem Nachweis einer wirklichen oder erträumten Nützlichkeit irgend einer Einrichtung, unı auf weitere Forschungen in Bezug auf das betreffende Organ Terzicht zu leisten. „Das Organ ist nützlich; es ist also gezüchtet worden. Wir können zu einem anderen Organ übergeben," das ist die durchweg befolgte Forschungsmaxime der orthodoxen Darwinisten. Der orthodoxe Darwinismus erweist sich dadurch keineswegs als irgendwie besser als der alte Schöpfungsglaube. Im Gegenteil! Der letztere rerdient den Vorzug vor den ultradarwinistischen Ansichten Weismann's und Wallace's, weil diese Theoretiker der Herrschaft des Zufalls Thür und Thor öffnen. Nach der Anschauung des orthodoxen Darwinismus sind die heute lebenden und sich fortpflanzenden Vertreter der Tier- und Pflanzenarten die letzten Glieder von Abstammungsreihen, deren einzelne Glieder niemals vom richtigen Wege abgewichen sind, denn wären sie es, so hätte natürliche Zuchtwahl sie beseitigt, und sie hätten nicht zu Vorfahren langer Entwickelungsreihen werden können. Wir Menschen und ebenso alle heute lebenden Individien sämtlicher Tier- und Pflanzenarten sind ein Produkt des Zufalls; unsere hohe Organisation, unsere komplizierten körperlichen Einrichtungen, unser Gehirn sind durch den $\mathrm{Z}$ ufall entstanden. Wenn wir auch lange Zeit gebraucht haben, um zu dem zu werden, was wir sind, so wird dadurch nichts an der Anschauung geändert, dass etwa ein Walfisch, der nach Weismann's Ansicht in aller und jeder Beziehung dem Leben im Meere angepasst ist, ein reines Produkt des $/ \mathrm{ufalls}$ ist, dass dieser hochentwickelte Organismus zufällig alle diejenigen Bedingungen erfüllt, die von dem Körper eines Säugetieres gefordert werden müssen, falls es in der Weise eines Walfisches im Meere leben will. Denn was ist das Alter unserer Erde, die doch sicher nur ein losgelöster Teil der Sonne ist, gegenüber der Ewigkeit? Ich gestehe, dass ich mich lieber geradeswegs wieder der alten Schöpfungslehre in die Arme werfe, als dass ich dem Darwinismus mehr zugestehe, als unbedingt erforderlich ist.

Ton der Annahme oder Verwerfung der Vererbung erworbener Eigenschaften wird die Richtung der Biologie der Zukunft abhängen, und auf die Aufgaben, die unsere Wissenschaft in Zukunft zu lösen hat, möchte ich noch einen kurzen Blick werfen. 


\section{Die Aufgaben der Biologie.}

Lh fürchte fast. dass Weismann's Lehre bei solchen jüngeren Forschern an Boden gewinnen wird, die keine Gelegenheit gehabt haben, sich zu rielseitigen Biologen heranzubilden. Dreyer und Driesch würden in ihrer Geringschätzung der Abstammungslelıre sicherlich nicht so weit gegangen sein, wemn sie Gelegenheit gehabt bätten, srstematische, ökologische und tiergeographische Studien an höheren Organismen zu treiben. Wir müssen zur alten Zoologie und Botanik zurü ckkehren, denen es vor allen Dingen auf eine Kenntnis von T'ieren und Pflanzen und nicht bloss ron deren Teilen ankam; daneben allerdings, und darin stimme ich Driesch, Dreyer und anderen vollkommen bei, wird als neuer Zweig der Biologie ror allen die Entwickelungsmechanik zu kultivieren sein. Un meine Anschauung über das gegenseitige Verhältnis der Zweige unserer Wissenschaft darzulegen, möchte ich diese einteilen in drei Hauptzweige, die ich als Bionomie, Biosraphie und Biogenie bezeichnen möchte, wie ich es schon bei früheren Gelegenheiten gethan habe.

Unter Biononic verstehe ich die Lehre ron dem ursäehlichen Geschehen im 'Tier- und Ptlanzenleben. Sie wird die Gesetze zı ergründen lıaben, nach welchen die organischen Formen sich umbilden. Wir werden dabei überall auf dieselben Entwickelungsgesetze stossen. Die Bionomie wird \%oologie und Botanik zu einer Physik und Chemie der Urganismen machen.

Allein wir wollen keine Physiker und Chemiker werden; die Aufgabe der Zoologic und Botanik ist ror allen Dingen gleich der des reologen eine historisclıe, und deshalb nü̈ssen zur Bionomie die Biographie und Biogenie hinzulommen. Unter Biographie verstehe ich denjenigen Teil der Biologrie, der sich mit den im Tier- und 
Pflanzenleben stattfindenden period ischen Vorgänge n olme Rücksicht auf die geschichtliche Fortbildıng der Organismen befasst. Was im Laufe der Tages- und Jahreszeiten an den Organismen vorgeht, was sich an ihnen entweder gleich bleibt oder im regelmässigen Wechsel wiederholt, namentlich also auch die Keimesgeschichte und die spezielle Physiologie, ist Gegenstand der Biographie. Die Biogenie dagegen hat es mit der historischen Entwickelung des Tier- und Pflanzenreichs im Laufe der Erdgeschichte zn thun. Die Biogenie muss Hand in Hand mit der Geologie gehen, und auch diese lässt sich, gleich der Biogenie, in drei den Abteilungen der letzteren entsprechende Disziplinen, in Geonomie. Geographie und Geogenie, einteilen. Die erstere würde es mit den physikalischen und chemischen Gesetzen, die auf der Erde eine Rolle spielen, zu thun haben; die Geographie würde das, was sich auf der Erde gleich bleibt oder in regelmässiger Wiederkehr wiederholt, zu beschreiben und ursächlich zu erklären, die Geogenie endlich würde die geschichtliche Entwickelung der Erde zu erforschen haben. Die entsprechenden Teile der Biologie haben ihre Aufgabe in innigster Wechselwirkung mit der Geologie, der ich hier einen weiteren Umfang und Inhalt gegeben habe, als üblich, zu lösen. Unsere Einteilungen sollen nichts weiter bezwecken, als den Nachweis zu führen, dass die Biologie in der That eine vollständige Parallele zur Geologie bildet. Die verschiedenen Disziplinen unserer Wissenschaft, die sich allmählich praktisch herausgebildet haben, mögen immerhin weiter bestehen.

Unter ibuen hat, wemn wir hier von der Physiologie absehen, die Anatomie vor allen Dingen mehr als bisher in physiologischer Richtung zu arbeiten. Die vergleichende Anatomie der Tiere ist in mancher Beziehung zu weit gegangen, und viele Organe verschiedener Tiere, die sie aufeinander zurückzuführen gesucht hat, haben entweder ïberhaupt nichts miteinander zu thun, oder sind unabhängig voneinander entstanden. Die Anatomie hat die mechanische 7 weckmässigkeit im Bau der Organismen nachzuweisen und sie auf ihre Ursachen zurückzuführen.

Ebenso muss die $\mathrm{O}$ n togenie mehr in mechanischer Richung arbeiten, als es bisher geschehen ist. Vorgänge wie die Eifurchung, die Gastrulation, die Faltenbildung des Embryo sind auf ihre mechanischen Ursachen zurïckzuführen.

Dagegen haben die übrigen Disziplinen der Biologie die Umbildung der Organismenformen während ihrer Stammesgeschichte begreiflich zu 
machen. Die systematik hat vor allen Dingen die Verwandtschaftsverhältnisse der Arten einer Gattung und weiterhin der Gattungen einer Familie zu erforschen. Es kommt in der Zoologie weniger darauf au, die grossen Tierstämme miteinander zu verknüpfen, womit sich die bisherige Phylogenie meist abgegeben hat, ohne dabei irgend welche Erfolge erzielt zu haben. Dagegen hat die Plyylogenie kleinerer 'Tiergruppen schöne Resultate aufzuweisen. Ich erinnere nur an the Erforschung der Stammesgeschichte des Pferdes und an Eimer's schöne Arbeiten übel Schmetterlinge. Nach meiner Ansicht hat die Systematik der Tiere die stammesgeschichtliche Abstufung der einzelnen Merkmale des Tierkörpers festzustellen, einerlei, ob es ihr wirlilich gelingt, Blutsrerwandtschaft nachzuweiseu oder nicht. Die Biologie hat es mit der Ergrïudung von Entwickelungsgesetzen zu thun, und diese treten auch dort zu Tage, wo sich kein blutsverwandtschaftlicher Zusammenhang nachweisen lässt. Ich mache z. B. auf die Thatsache aufmerksam, dass sich in allen Gruppen der Süugetiere der Schwanz rückzubilden strebt, dass die Färbung und Zeichnung in vielen Tiergruppen unabhängig roneinander dieselbe Entwickelungsrichtung einschlägt. Solche Entwickelungsrichtungen festzustellen, nicht aber zweifelhafte Verwandtschaften zu begründen, ist vor allen Dingen die Aufgabe der Systematik.

Dabei wird sie der Ökologie oder der Lehre von der Lebensführung der Tiere nicht entbehren können. Auch hier lassen sich Abstufungen aufstellen; ich erinnere nur an die Stufenfolge der Instinkte. Die Ökologie lehrt uns die Abhängigkeit der Organismen ron der Aussenwelt keunen, und ich dächte doch, dass diese wohl einer Erforschung wert wïre. Diesen Umstand vergisst Driesch, wenn er die Biologie durchaus in Parallele zur Kristallographie zu bringen sucht. Allerdings hängt auch die Kristallisation ron den Einflüssen des umgebenden Jediums ab, aber in viel geringerem Grade ats der Organismus, und nur der letztere hat eine Stammesgeschichte, nicht aber auch der Kristall.

Teben der Ökologie wird sich die Tiergeographie eine viel grössere Beachtung erzwingen, als ihr heute zu teil wird. Ich glaube gezeigt zu haben, dass ihre Bedeutung keine geringere ist, als die irgend einer anteren Disziplin der Biologie, und wenn die jüngeren Forscher, die so sehr die mechanische Erklärung der Entwickelung betonen, tiergeogriaphische Kenntnisse hätten, so würden sie auch wohl der Tiergeographie ein Plätzchen in der Biologie gegönnt haben. 
Encllich hat die Vererbungslehre in ein neues Stadium einzutreten. Sie darf sich nicht damit begnügen, fort und fort die Werke D arw in's, des alten Kölreutter und anderer zu exzerpieren, sondern muss sich dazu verstehen, auf Grund eigener Untersuchungen weiter zu bauen. Wie dies zu geschehen hat, das hoffe ich an dem Beispiele der Ergebnisse meiner Untersuchungen über die Vererbung der Eigenschaften bei Mäısen zeigen zu können.

Ich betone deshalb die Notwondigkeit einer vielseitigen Entwickelung der Biologie und einer gleichmässigen Berücksichtigung aller ihrer Teile, weil doch schliesslich keiner unserer Biologen von Fach für sich arbeitet, wie es allerdings oft den Anschein hat. Ob wir persönliches Vermögen haben, oder ob wir vom Staatssückel und Kollegiengeldern zehren, wir haben für die Gesamtheit zu arbeiten. Wir haben zu forschen und zu lehren und, sofern wir Lehrer sind, vor allen Dingen dafür zu sorgen, dass der Staat brauchbare Beamte erhält. Diese können wir aber nur dann heranziehen, wenn wir uns nicht einseitig auf ein kleines Gebiet der Biologie verlegen. Wir müssen auch darin wieder mehr den alten Naturforschern nachzueifern streben, dass wir wieder vielseitiger werden; und wenn wir Botaniker und Zoologen sein wollen, so dürfen wir uns nicht schämen, auch Pflanzen und Tiere zu kennen, vor allem die unserer Heimat.

Es ist also ausser auf die bisher übliche Arbeit in den zoologischen Instituten und Seminarien vor allem auch auf Exkursionen, welche die Kenntnis der heimischen Tiere vermitteh sollen, auf den Besuch von Museen und zoologischen Gärten zu halten. Die II useen müssen sich bestreben, mehr als bisher den Bedürfnissen nach Belehrung gerecht zu werden, und ebenso müssen auch die zoologischen Gärten ihre Hauptaufgabe nicht in der Schaustellung von Löwen und Elefanten, sondern in der Belehrung des Volkes und auch der Fachleute suchen. Ich habe in meiner Praxis als Tiergärtner Erfahrungen gemacht, die nicht sehr zu gunsten der herrschenden Zoologie sprechen. Ich habe im Laufe von fünf Jahren vielfach Gelegenheit gehabt, Mänuer der verschiedensten Berufe in dem von mir geleiteten zoologischen Garten herumzuführen, von Königen und Herzögen herunter bis zum einfachen australischen Farmer, und ich muss leider gestehen, dass von allen diesen verschiedenen Leuten die Zoologen ron Fach sich am wenigsten aus den Tieren des zoologischen Gartens gemacht haben. Ich scheue mich trotz alledem nicht, meine Überzeugung dahin auszilsprechen, dass derjenige nicht zum Zoologen taugt, der keine genügende 
Kenntnisse hat, mm bei dem Besuche eines lluseums oder eines zoolugischen Gartens sich der Tiere zu freuen. Der Zoologe ron Fach hat nicht bloss die Aufgabe. Schüler seiner eigenen Richtung heranzuziehen. sondern in erster Linie hat er Lehrer der Jugend auszubilden, denen möglichst vielseitige Kenntnisse unerlïsslich sind. Dass es bei den Naturgeschichtslehrern unserer höheren Schulen oft sehr traurig mit den in der Schule brauchbaren zoologischen und botanischen Kenntnissen bestellt ist, davon habe ich genügende Gelegenheit gehabt, mich zu über\%eugen. Die Schuld liegt aber nicht an ihnen, sondern an dem einseitigen Cnterricht, den sie selbst erhalten haben.

Neben den genannten Anstulten haben atuch die zoologischen Stationen ihre eigenen Aufgaben, und ausser ihnen sind auch zahlreiche Anstalten für wissenschaftliche Tierzucht zu gründen, Institute gleich dem K̈̈ln n'schen in Halle, in denen es möglich ist, Züchtungsexperimente in grossen Massstabe an allen möglichen Tieren anzustellen und durch viele Jahrzehnte hindurch fortzusetzen.

Vor allem ist unserer Wissenschaft ein Eindringen in das Volk nötig, und nichts wird dazu melır geeignet sein, als der Nachweis, dass sich die wissenschaftlichen Ergebnisse der Zoolugie in der That in hohem Grade praktisch rerwerten lassen. Der 'l'echniker und der Lehrer der technischen Wissenschaften muss sich, falls er sich über Wasser halten will, unausgesetzt um alle neuen Fortschritte. die innerhalb seines Faches gemacht werden, kümmern. Leider hat dıs ein Biologe nicht nötig, und er darf deshalb auch ciner beschaulichen Einseitigkeit fröhnen, während der Techniker sich nach alken Seiten hin umsehen und seine Augen jederzeit offen halten muss.

Aber weit höher als die praktische Verwertbarkeit unserer Wissenschaft ist ihre ideale Bedentung zu stellen, denn ron der Biologie wird es wesentliclı mit abbängen, ob unsere ins Wanken geratene Weltanschaung wieder eine hamonische werden soll. Die Biologie wird aber nur dann dazu beitragen können, wenn sie selbst einsieht, dass allzu grosse Einseitigkeit ihr nicht frommt. Nur derjenige Forscher, der einen Überblick über das Gesamtgebiet seiner Wissenschaft hat, der jeden Augenblıck im stande ist, die Bearbeitung i r g e n d eines spezicllen Gebietes aufzunehmen, weil seine biologische Bildnug cine harmon iscle ist, wird auf die Entwickelung der Weltanschauung des zwanzigsten Jahrhunderts Einfluss gewinnen können. Daneben gilt es aber, wieder die naive 
Freude an der Natur im Cremüte des Tolkes zu wecken, und ich glaube nicht, dass dazu etwa Schnittserien durch Eingeweidewürmer geeignet sind. Die Biologie wird aber nur dann ihre hohen kulturellen Aufgaben erfüllen können, wenn sie sich von Irrlehren frei hält, namentlich von der sie gegenwärtig aufs neue bedrohenden Irrlehre des Präformismus, die in Weismann ihren Hauptvertreter gefunden hat. Eine vernünftige Weltanschauung ist nur auf Grund der Epigenesislehre möglich, welche die Qualität als Funktion der Nachbarschaft betrachtet. Wenn wir nun anch das Wesen der Qualität nicht begreifen können, so wird uns die auch auf die unorganische Natur auszudehnende Anschaung, dass spezifische Formbildung durch die Lage bedingt wird, die ewige Wahrheit jener Weltanschaumng beherzigen lassen, wonach der Geist Gottes in allen Dingen lebendig ist, der zufolge Schöpfer und Geschaffenes eins sind.

Auf solche Überzeugung war die Weltanschauung des grössten deutschen Dichters und Denkers begründet, und mit diesem Hinweis möchte auch ich das Thema der vorliegenden Blätter verlassen

„Im Namen Dessen, der Sich selbst erschuf.

Ton Ewigkeit in schaffendem Beruf;

In Seinem Namen, der den Glauben schafft,

Vertrauen, Liebe, Thätigkcit und Kraft;

In Jenes Namen, der', so oft genaunt,

Dem Tesen nach blieb immer unbekannt:

,So weit das Ohr, so wcit das Auge reicht.

Du findest nur Bekanntes, das Ihm gleicht,

Und Deines Geistes höclister Fcuerflug

Hat schon am Glcichnis, hat am Bild genug;

Es zieht Dich an, es reisst Dich weiter fort.

Und wo Du wandelst, schmücht sich Weg und Ort;

I) zählst nicht mehr, berechnest leine Zeit,

Und jeder Schritt ist Unermesslichkeit.

„Was wär' cin Gott, der nur ron aussen stiesse.

Im Kreis das $A l l$ am Finger laufen liesse!

Ihm ziemt's, die Welt im Innern zu bewegen,

Natur in Sich, Sich in Natur zu hegen,

So dass, was in Ilım lebt und webt und ist,

Nie Seine Kraft, nie Seinen Geist remisst."6 


\section{Litteraturverzeichnis.}

Bergh, Kritik einer modernen Hypothese ron der Übertragung erblicher Figenschaften. Zoologischer Anzeiger 1892.

Blumenbach, Über den Bildungstrieb und das Zeugungsgeschäft. 1781.

Boreri, Fin geschlechtlich erzeugter Organismus ohne mütterliche Figenschaften. Gesellschaft für Morphologie und Physiologie zu München. 1889.

Brock, Biologisches Centralblatt VIII.

Chabry, Contribution à l'embryologie normale et tératologique des Ascidies simples. Journ. de l'anat, et de la physiol. 1887.

Darwin, Gesammelte Werke.

Detmer, Biologisches Centralblatt. VII.

Dreyer, Ziele und Wege biologischer Forschung. Jena 1892.

D riesch, Die mathematisch-mechanische Betrachtung morphologischer Probleme der Biologie. Jena 1891.

- Zur Theorie der tierischen Formbildung. Biologisches Centralblatt XIII und die dortselbst citierten ïbrigen Abhandlungen rou Driesch.

D)̈ising, Die Kegulierung des Geschlechtsverhültnisses. Jena 188 t.

Eimer, Die Entstehung der Arten. Jena $18 \% 8$.

- Die Artbildung und Verwandtschaft bei den Schmetterlingen. Jena 1889.

- Bemerkungen zu dem Aufsatz von A. Spuler u. s. w. Zoologische Jahrbücher, Abteilung für Systematik u. s. w., Bd. VII.

Emery, Gedanken zur Descendenz- und Vererbungstheorie. Brologisches Centralblatt XIII.

Haacke, Die Schöpfung der Tierwelt. Leipzıg 1893.

- Der Nordjol als Schöpfungscentrum der Laudfauna. Biolorisches Centralblatt VI.

Haectel, Generelle Morphologie. Berlin 1866.

- Die Perigenesis der Plastidule. Berlin 187 (5.

Hatscheh, Hypothese über das Wesen der Assimilation. „Lotos". Neue Folge. XIV. Hertwig, O., Die Zelle und die Gewebe. Jena 1892.

Jäger, Gustar, Ergïnzungshefte zu Petermann's Mitteilungen. Gotla 1864.

Li ebseher, Vererbung u. s. w. Jenaische Zeitschrift für Naturwissenschaften 188.5.

Nïgeli, Mechanisch-physiologische Theorie der Abstammungslehre. Hünchen und Leipzig 1884.

Pfeffer, Versuch über die erdgeschichtliche Entwickelung der jetzigen Verbreitungsrerhältnisse unserer Tierwelt. Hamburg 1891.

Roux, Beiträge zur Entwickelungsmechanik des Embryo. Anatomische Hefte 1593, und die daselbst citierten Abhandlungen Roux's.

Seitz, Mitteilungen über eine lieise nach China und Japan. Verhandlungen der Deutschen Zoologischen Gesellschaft 189:.

Spencer, Die Principien der Biologie. Stuttgart 1876.

Tristram, The polar origin of life. Ibis 1887 .

Verworn, Die physiologisehe Bedeutung des Zellkernes. Pflüger's Archiv 1891.

- Die Bewegung der lebendigen Substanz. Jena 1892.

$\checkmark$ ries, de, Intracellulare Pangenesis. Jena 1889.

Wagner, Moritz, Die Entstohung der Arten durch räumliche Sonderung. Basel 1 S59. Wallace, Darwinism. Jondon 1889.

Wolff, Caspar Friedrich, Theorie ron der Generation. 1764.

IV eismann, Das Keimplasma. Jena 1892.

- Aufsitze über Vererbung. Jena 1892. 


\section{Lutorenregister.}

(Die Ziftern bedeuten die Seitenzahlen.)

Adam 271.

Baer, von 186.

Beneden, van 146 .

Bergh 51.

Blumenbach 298.

Boveri 51.

Brock 298.

Bütschli $159-160$.

Chabry 221. 222. 224. 295. 318.

Darwin 4-5. 14. 48. 59. 118. 129. 189. 204. 206. 235. 254. 271. 308-310. 312. 313. 321.327.

Davidoff, von 146 .

Detmer 294.

Dreyer 9-10. 140. 315. 324 .

Driesch 139. 221. 223. 225. 295. 315-318. 324. 326 .

Düsing 245. 286.

Eimer 25. 185-186. 200-201. 311. 313 bis 314.326 .

Emery 286.

Geoffroy St. Hilaire 308.

Goethe 121.

Goette 147. 314.

Gulick 311.

Haeckel 113. 117. 139. 183. 184. 187. 260. 268. 277. 279. 312315.316 .328$.

Hatscheck 131. 133.

Hertwig, 0. 10. 50. 149. 318. 319.

His 173.

Jäger, Gustav 198.

Jännicke 42 .

Julin 146.

Kennel 172.

Kölreutter 327.

Lamarck 48. 308 .

Liebmann 315.
Liebscher 255-25i, 260.

Lotze 314.

Möbius 63.

Morton, Lord 302.

Nägeli 28. 79-80.115. 126. 186. 311-314.

Newport 146.

Nussbaum 147.

Oudemans 299.

Pander 314.

Pfeffer 201-203.

Pflüger 146.

Plarre 5.

Romanes 70. 311.

Roux 9. 146. 224-225. 317-319.

Schultze, Max 141.

Seeliger 146 .

Seitz 189-191.

Settegast 299.

Sohncke 316 .

Spencer 70. 231. 319-321.

Tristram 195-197.

Verworn 51. 131. 133-134. 137-138.

Vries, de 9. 11-16. 35-39. 49. 229. 241. 293. 295. 316-317.

Wagner, Moritz 77. 79-80. 200. 201. 310 bis 312 .

Wallace 59. 195. 201. 323.

Wolff, Kaspar Friedrich 226. 308.

Weismann 5-6. 9-19. 22. 31 33. 35 . 39-41. 43-55. 59. 65-68. 70. 75. 77. 81-83. 85-88. 93-96. 99-102. 104. 110-111. 116. 118. 145. 156. 183. 207 bis 211 . 217. $220-2 \cdot 23$. 220-233. 235 . 236. 238 . $240-244.246 .248-254.256$ bis 260 . $262-275$. $282-285$. $288-295$. 297-303. 319-324. 329. 


\section{Sachregister.}

Achordaten 146.

Affen der alten Welt 34 .

Affen der neuen Welt 34 .

Afrika 193

Afterzehe, Meerschweinchen 40, 263, 265.

Afterzehen 55. 67. 69. 263.

Aktinien 23 .

Allinismus 45 .

Aneisenigel (Echidna) 39.

Ameisenpllanzen 36.

Ammoniten 63.

Amöben 160. 163. 164. 167.

Amphioxus 187.

Anatomie 325.

Angorakater, Kreuzung 253.

Anoa (Anoa depressicornis) 59.

Anoa, Hörnerform der 26.

Anoa. Haarbüschel 56 .

Anoa. Wangenflecken 58 .

Anstalten für Tierzucht 328.

Antillen, grosse 193.

Antilopen, Hörnerform der 26.

Antilopen, Wangenflecken 58.

Anzahl der Wirbel 24.

.. der Zehen $\mathbf{2 4}$.

Arara-Kakadu (Microglossus) 25.

Aras, Zeichnung der 25.

Artemia milhauseni 45 .

Artemia salina 45 .

Ascidien 146. 2:2.2.

Ascidieneier 223.

Asseln (Isopoden) 24.

Assehr, ron Fischreiher gefangen $\mathbf{7 5}$.

Asymmetrie 23.

Auge 32.

der Weichtiere 34.

Augenfleck auf Vogelfeder $\mathbf{1 5 .}$

Austratien 193.

Bakterien 22.
Balanus 147 .

Bandwürmer (Cestoden) 281.

Bastarde 102. 256.

Bastardzucht 254.

Becherpolypen (Seyphopolypen) 187.

Becherquallen (Seyphomedusen) 187. 279.

Beuteltiere (Marsupialien) 28. 29 194. 198.

Bienen 285. 287.

Biographie 324.

[201.

Biologie $3 \mathbf{2 4}$.

Bionomie 324.

Blätter, panaschierte 12 269-270.

Blasen in Bierflaschen 122.

Blasenwürmer (Cysticerken) 287.

Blattformen 36.

Blattrand 13. 36.

Blendlinge 102. 254. 256-57.

Blüten 24.

Blumenblätter 13. 38 .

Bluterkrankheit $288 \mathrm{fl}$.

Branchipus 45

Breituasen (Cebideu) 21.

Brombeerblätter (Rubus) 42. 59 .

lirustwarzen, überzählige 266 .

Büffel, Hörnerform der 26.

Büffelkälber, Höruerform der 26.

Cäcilien 32.

C'harybdea 280.

Cirrhipeden 147.

Coelenteraten $\mathbf{1 4 6}$.

Corviden 21

Corvus 21.

Cubomedusen 279.

Cyanea 41.

Cypris reptans 272.

Cytisus adami 269.

Dalmatinerhund 254.

Danaide 189.

1)armlarve (Gastrula) 169 . 
Datunen der Affen 34.

Dichogenie 293.

Dicyemiden 147.

Distaplia 146.

Dompfaffen (Pyrriula) 79.

Drohnen 286.

Echinodermen 71. 161. 165.

Edwardsien 23.

Eichhörnchen (Sciuriden) 34.

Eidechsensch wanz 295.

Eierform bei Vögeln 61 .

Einsiedlerkrebse (Paguren) 162.

Elbe als Verbreitungsgrenze $\mathbf{7 9 .}$

Elefant 22. 31.

Embryo, Hauptrichtungen $146-147$.

Emu (Dromaeus) 29.

Ephen (Hedera) 293.

Europa 193.

Europäer, rothaarige in Australien 46 .

Excursionen, zoologische 327.

Färbung, sympathisehe 76

Falbkatze (Felis maniculata) 265.

Faltenbildung der Haut 43 .

Faltenbildungen 314.

Faunengebiete 28-29.

Feder, mit Augenfleck 15.

Felstaube (Columba livia) 59.

Fische 24.

Fischflossen 227.

Fischrelher, Asseln erbeutend 75.

Fingertier (Chironys) 61.

Fingerverwachsung 40 .

Flachsarten (Linum), Blütenformen 37.

Flagellaten 160, 163. 164.

Fleckenzeichnung bei Säugetieren 25.

Fliegen (Dipteren), Keimzellen 215.

Flügel, Anzahl der, bei Insekten 24.

Flügellahme Vögel 71 .

Folgestücke (Metameren), Anzahl der bei Krebsen und Gliedertieren 24.

Forellenarten (Salmo) 76 .

Froschei 149-150. 223.

Froschei, Furchungsebene 146.

Furchungsebene, erste 146-147.

Gärten, zoologische 327.

Gastrula delaminata 169. 172.

,$\quad$ invaginata 170.172.

, zweiseitig-symmetrische 175 .
Geckonenschwanz 295.

Gegenstïcke (Antimereli) 40.

Geogenie 325.

Geographie 325.

Geonomie 325 .

Gerstenbastarde 255, 256.

Gesässschwielen 47 .

Gliederfüsser (Arthropoden) 162.

Gliedertiere (Artlıropoden) 24.

, Anzahl der Gliedmassen der 24.

" Folgestücke der 24.

$" \quad$ Metaineren der 24.

Gliedmassen, Anzahl der - bei Krebsen und Gliedertieren 24.

Gliedmassen, Gıössenverhältnisse der 25. ,$\quad$ relative Iänge der - bei

Säugetieren 25.

Gnu (Catoblepas), Hörnerform des 26.

Goldregen (Cytisus), Pfropfbastard 269.

Grösse, beträchtliche 63 .

Grössenverhältnisse der Gliedmassen 25.

Gromia oviformis 141-143.

Grossfusshühner (Megapodiiden) 29.

Grundformen 22. 23.

,$\quad$ der Korallen 26.

,$\quad$ der Stöcke 26.

" der Pennatuliden 26.

Grundformenverhältnisse 24 .

Haarbüschel am Unterkiefer ron Säugetieren 56.

Haare, rote, in Inneraustralien 46 .

Haare der Säugetiere 87. 88.

Haarstellung bei Säugetiereu 56-57.

Hähne, kastrierte 45 .

Halbaffen (Lemuroiden) 21.

Halbaffen, Verbreitung der 28.

Hausesel (Equus asinus) 262 .

Haushuhn (Gallus domesticus) 283.

Haushund (Canis familiaris) 67.

Haushund, Schwanzstellung 162.

Hauskatze (Felis domestica) 253. 265.

Hauspferd (Equus caballus) 262.

Hausratte (Mus rattus) 27, 74. 76.

Haustaube, Nackenfedern 59.

Haustiere 31. 264-265.

Heidschuucken 253.

Herrenspecht (Dryocopus principalis) 196.

Hirseh, Anzahl der Geweihsprossen 26. 
Hirsche. Haarbüschel 56.

Hirsche, typische 197.

Hirscheber (Babirussa) 64.

Hirschgereih 26. 39. 72.

Hirudineen 147.

Möhlentiere 68 .

Hörnerform der Anoa 26.

. $\quad$ der Antilopen 26.

.. der Büffel 26.

. der Büffelkälber 26.

,. des Ginu 26 .

,. des Kafferbüffel 26.

.. der Wiederkäuer 26.

Hühnerrögel, Verbreitung der 28.

Hund 56 .

.. Afterzehe 263.

"Schwanzflect 57.

Hundsaffen (Cercopitheciden) 21.

Hyacinth-Ara (Ara hyacinthina) 25.

IIydra 161. 187. 279. 281.

Hydroidpolypen 161. 163. 164. 281.

Hydromedusen 161.

Igel (Erinaceiden) 34.

Indien 193.

Infektion des Keimes 30:.

Infusorien 160. 167 .

Insehten, vierflügelige $\mathbf{2 4}$. zweiflügelige $\mathbf{2 4}$.

Inseltenei 117. 147 .

Insektenfresser (Insectivoren) 34. 194. ,$\quad$ von Madagaskar 28.

Insel rögel 74 .

Institute, zoologische 327 .

Interradiale Urgane 41 .

Inzucht 216. 244-246.

Jugendzeugung (Pädogenesis) 217.

Jungfernzeugung (Parthenogenesis) 217.

Käfer (Coleopteren), flugunfähige $\mathbf{1 9 5}$.

Läferschnecken (Chitoniden) 162.

Kälber, kastrierte $\mathbf{4 5}$.

Känguruh, Fuss 195.

liafferbüffel, Hörnerform des 26 .

Kakadus, Zeichnung der 25.

Kanerunschaf 253 . 254.

Kammertiere (Thalamophoren s. Foraminiferen) 160.

Kammịuallen (Ctenophoren) 24.

Kanarienvögel 45 .
Kasuare (Casuarius) 29.

Katzen, blauäugige 39.

. heller Fleck am Ohre 58.

. Querband am Vorderbein 57.

Katzenfell. Zeichnung 265.

Kirschen, Varietäten 37 .

Kiwi (Apteryx) 28-29.

Kilammeraffen (Ateles) 48 .

Klettermäuse 103.

Knospung 218.

Körpergrösse 21. 22.

Körperhälften 40.41 .

Kolibriarten (Trochiliden) $\mathbf{7 6}$.

Kolkrabe (Corvus corax) 21.

Korallen 23. 165.

,$\quad$ Eiel 179.

.. Grundform der 26 .

Krabben (Brachyuren) 24. 162.

Krallenaffen (Hajaliden) 21.

Krebse (Crustaceen) 24, 162.

"Anzahl der Gliedmassen der 24.

" Folgestücke der 24.

., Netameren der 24.

Kireuzung 244. 245.

., freie 233.

Kreuzungsmäuse 103.

Kriechtiere (Reptilien) 197.

Ktenophoren 24.146. 161.

Kulturvarietäten 269 .

Lüngsstreifen b. Säugetieren 25 .

Landfaunengebiete 193.

Lanzettfischchen (Branchiostoma s. Amphioxus) 173.

Lebertleck 156.

Linaria vulgaris $\mathbf{4 2 .}$

Lurche (Amphibien) 197.

Luzernarien 279 .

Madagaskar 193.

Mäuse 34 .

, entschwänzte 108. 296.

, Schwanzlänge 109.

Müusezüchtungsversuche 235 .

Marder (Musteliden), typische $\mathbf{1 9 7 .}$

Maultiere 262.

Heer, Tierwelt 202.

[263. 265.

Meerschweinchen (Cavia), Afterzehe 40.

Medusen 23. 24. 41. 164. 287.

Medusenlarven 41. 
Melanismus 45 .

Mensch, Anzahl der Zehen und Finger 24. Symmetric verhältnisse 162 .

Menschenaffen (Simiiden) 21.

Metameren, Anzahl der - bei Krebsen und Gliedertieren 24.

Milchdrüsen 39.

Mimikry 189.

Moa (Dinornis) 28.

Nolehe (Molge s. Triton), Augen 227.

Mollusken 23.

Monorhiza haeckcli 41, 42. 152-156. 161.

Mufflon (Ovis musimon) 64.

Muselielkrebse (Ustracoden) 272.

Museen, zoologische 327.

Muttermal 156.

Nachtigall (Erithacus luscinia) 79.

Nahrungsdotter 158, 168.

Nager (Rodentien) 34.

Narwal (Monodon monocerus) 162.

Nasenform 13.

Nauplius 147.

Nebclkrähe (Corvus cornix) 79.

Nebenstiiekc (Parameren) 40. 42.

Nematoden 147.

Nesseltiere (Cnidaricn) 161.

Neuseeland 193.

Nilgauantilope (Boselaphus tragocamelus

Nordamerika 193.

Nordasien 193.

Nordpol 193-194.

Nordpolarmeer, kreisförmiges 198.

Oberflächenspannung 214 .

Ochse 285.

Ökologie 326.

Öltropfen 213.

Ohrenquallen (Aurclia aurita) 277. 3-, 5- u. 6zählige 72 .

Ohtokorallen 23.

Oligochäten 147.

Ontogenie 325.

Orchideen 13.

Organe, tierische $\mathbf{2 0}$.

$" \quad$ rudimentäre 55. 66. 69. 70 .

" Verminderung homologer 24.

Orthonectiden 146.

Palechiniden 162.
Papagcien. Zeichnung der kleinen australischen $\mathbf{2 5}$.

Papaver 38.

Paradiesvögel, Zeichnung der 25.

Parameren 42.

Parasiten 19. 31. 33.

Parthenogenesis 217.

Pathologischer Dimorphismus 288.

Pennatuliden 26. 117.

Peromedusen 279.

Perradiale Organe 41.

Personen, tierische 20.

Pferd 263.

Pferd, Anzahl der Zehen 32.

" Vorfahren des 32.

Pferdespulwurm (Ascaris megalocephala), Keimzellenbildung 231. 274.

Phänologie 303 .

Pithecia 43.

Plattfisehe (Pleuronectiden) 162. 164.

Plumplori (Nyeticebus tardigradus) 56. 108

Pollen 245.

[bis 109 .

Policipes 147 .

Polychäten 147.

Polykladen 146.

Polyplasmatische Zellen 102.

Pourtalesia 162.

Primeln, Blütenformen 37.

Primula acaulis 13. 38.

Quallen (Medusen), Grundform 72

Querstreifen bei Säugetieren 25.

Raben (Corviden) 21.

" Zcichnung der 25.

Rabenkrähe (Corvus coronc) 79.

Radiolarien 10.117.140.159.160.164. 167.

Raubtiere von Madagaskar 28.

Raubvögel, Ange der 32.

Reduktion homologer Organe 25 .

Renutiel (Rangifer) 162.

Rhabditis 147.

Riesenhirsch (Cervus megacerus) 26. 64.

Riesensturmvogel (Ossifraga gigantea) 40 .

Riesentiere 21. 22. 64.

Rotatorien 147.

Saatkrähe (Corvus frugilegus) 299. 304.

Sackkrebse (Sacculinen) 33.

Säbeltiger (Machairodus) 64.

Säugetiere, Australiens 200. 202. 
Siiugetiere, relative Lainge der Gliedmassen (ler 25.

" Firundform 162.

"Auzalıl der Zehen bei 24.

"Schwanz 24. 25.

" Verbreitung der 28. 193.

. Zeichnung der 25.

Salbei (Salvia) 55.

Sarsia :st.

Satyrile 1s!).

Satansaffe (Pithecia satanas) 43.

Saurier 63

Schachbrett, Auekdote 93.

schafe, kastrierte 45.

subädelform 13.

Scheckung 104.

[25:2

Scheibenruallen (Discomedusen) 187. 27i

Schirrantilope (Antilope seripta 59.

schleiereule Strix thammea) 130.

Suchleimpilze (Mycetozoen s. Myxomy(eten) 1 ti.3.

Schmetterlinge 189. 197.

$\begin{array}{lll}" & \text { Kälteformen } 15 . & {[287 .} \\ " & \text { Saisondimorphismus } & 276 . \\ & \text { Zoichnung der } 25 . & \end{array}$

Schneclien 114. 16.t.

Schneetiere 74.

Schwïnme 160. 161. 163. 165.

Schwanz der Sïugetiere 24. 25.

Schwarzspecht (Dryocopus martius) 196.

Seegurken (Holothurien) 160.

reeigel (Echiniden) 23. 161. 166.

" Bastardierung 51.

, Furehungszelle 221. 223. 295.

. angebliches Regenerationsver'mögen 222-223.

, an den Strand geworfene 74 .

.4 u. 6zïhlige 72 .

buesterne (Asteroideen) 165.

" abgeschnürte Arme 2:8.

Seescheiden (dscidien), Chabry's Expelimente 221 .

segelqualle (Vulella) $15: 2$.

Seifenblasenformen 122.

Seminarien, zoologisehe 327 .

Sexualcharaktere 283

Siugrögelgruppen 21.

siphouphoren :26. 161 .

Somentiere (Heliozoen) 160. 167.
Sperhte (Pleiden) 62.

. Anpissung 196.

" nordische 197.

., Schnabel $61-62$

., Schnarren 61.

,$\quad$ Verbreltung der $\mathbf{2 9}$

Spitzhörnchen (Tupaiiden) 34 .

Spitzmäuse (soriciden) 34 .

Sprosser (Erithacus philomela) 79 .

Stachelbeeren, Varietäten 37.

Stachelschweine (Hystriciden) 34 .

Stationen, zoologische 325.

Stauromedusen 279.

Stentor 151.

Stichlıng (Gasterosteus) 45.

Stïcke, Cirundformen der 26 .

Stöcke der Siphonophoren 26.

Stöcke, tierische :20

Strauss (Struthio) 21.

Straussartige Vögel (Ratiten) 194. 198.

Südamerika, Tierwelt von 29. 193.

Süsswasserschwämme 163.

Sumpfueisen (Parus palustris ete.) 79.

Symmetrie 23.

Symmetrieverhiltnisse 312. 315.

Systematik $3: 6$.

Tanzmäuse 103.

Tanzmausfirbung 242.

Taubenrögrel, ausgestmrbene der Maskarenen 195.

Tansendfüsse (Myriopoden) 24.

Termiten 29:3.

Teilung 219.

Thuja $2 y 4$.

Tiere, strahleufömige $\mathbf{4 1}$.

Tiergeographie 32t.

Tierzucht, Anstalten für $32 \mathrm{~s}$.

'l'rgerpferde ss. 26:2.

'Trilobiten 63.

Unkenarten (Bombinator) iy.

Lrbüffol (Anoa), Wangenflecken is.

Ursïuger (Nonotremen) 194.

, Kiefer der 195.

. Verbreitung der 28. 29.

Urweichtiere 34.

Vakuolen 159.

Vakuolenflüssigkeit 10.

Velella $\mathbf{1 5 2 .}$ 
Verbreitung der lieuteltiere 28. 29.

$$
\begin{array}{ll}
. & \text { der Halbaffen } 28 . \\
" & \text { der Hühnervögel } 28 . \\
" & \text { der Spechte 29. } \\
" & \text { der Säugetiere } 28 . \\
" & \text { der Ursäuger 2s. } \\
\text { der Vögel 28. }
\end{array}
$$

Vererbungslehre 327 .

Vierhänder (Quadrumanen) 21.

Verminderung homologer Organe 24.

Verstümmelte Tiere 71, 72.

Vögel 24 .

., flügellose - Neu-Seelands 195.

. Grundform 162.

, unsymmetrische 162 .

, Verbreitung der 28.

. Zeichnung der $\mathbf{2 5}$.

W aldhühner (Tetraoniden) 29.

Walfisch 21. 22.

W'allnister (Megapodiiden) 29 .

Wanderratte (Mus decumanus) 27, 74, 76.

Wapiti (Cervus canadensis), Geweih des 26.

Weichschwanzspechte (Picumninen) 196.

Weichtiere (Jollusken) 34. 162.

Weichtiergruppen 34 .

Wiederbelebung $\mathbf{2 2 5}$.

Wiederkäuer (Ruminantien), Hörnerform der Wrirbel, Anzahl der 24.

Wirbeltiere (Vertebraten) 24.

[26.

Anzahl der Wirbel bei 24.
,$\quad$ Grundform 162.

Wolf (Canis lupus) 67. 263.

Wïstenpflanzen 36 .

WWüstentiere $\mathbf{7 4}$.

Xenien 301.

Zahnarme (Edentaten) 194.

Zahntaube (Didunculus) 5:\%.

Zebrastreifung 12-13.

Zehen, Anzahl der - beim Pferde 32.

.. Anzahl der - beim Menschen 24.

, der Säugetiere 24.

Zeichnung der Aras 25.

., der Kakadus $\mathbf{2 5}$.

" der kleinen australischen Papageien 25.

,$\quad$ der Paradiesvögel 25 .

" der Raben 25.

" der Säugetiere 25.

" der Schmetterlinge und Vögel

" symmetrische 43 . $\quad$ 25.

$" \quad$ der Tiere 57.

$" \quad$ unsymmetrische 265 .

Zeigefinger, abnorme 40.

Zelleinschlüsse 132. 159.

Ziege, Halstroddeln 59.

, Zitzenverdoppelung 41 .

Zitzenverdoppelung $\mathbf{4 1}$.

Zoologische Gärten, Kampf ums Dasein in

Zugvögel 195.

[71.

Zwergspechte (Picumninen) 197.

\section{E r r a t a.}

Auf Seite 25, Zeile 11 von oben lies: Länge anstatt Anzahl.

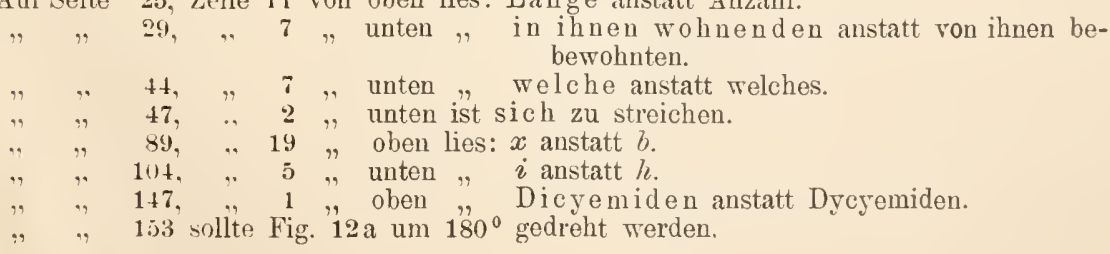




\section{Leipzig.}

Druck ron A. Th. Engelbardt. 
and

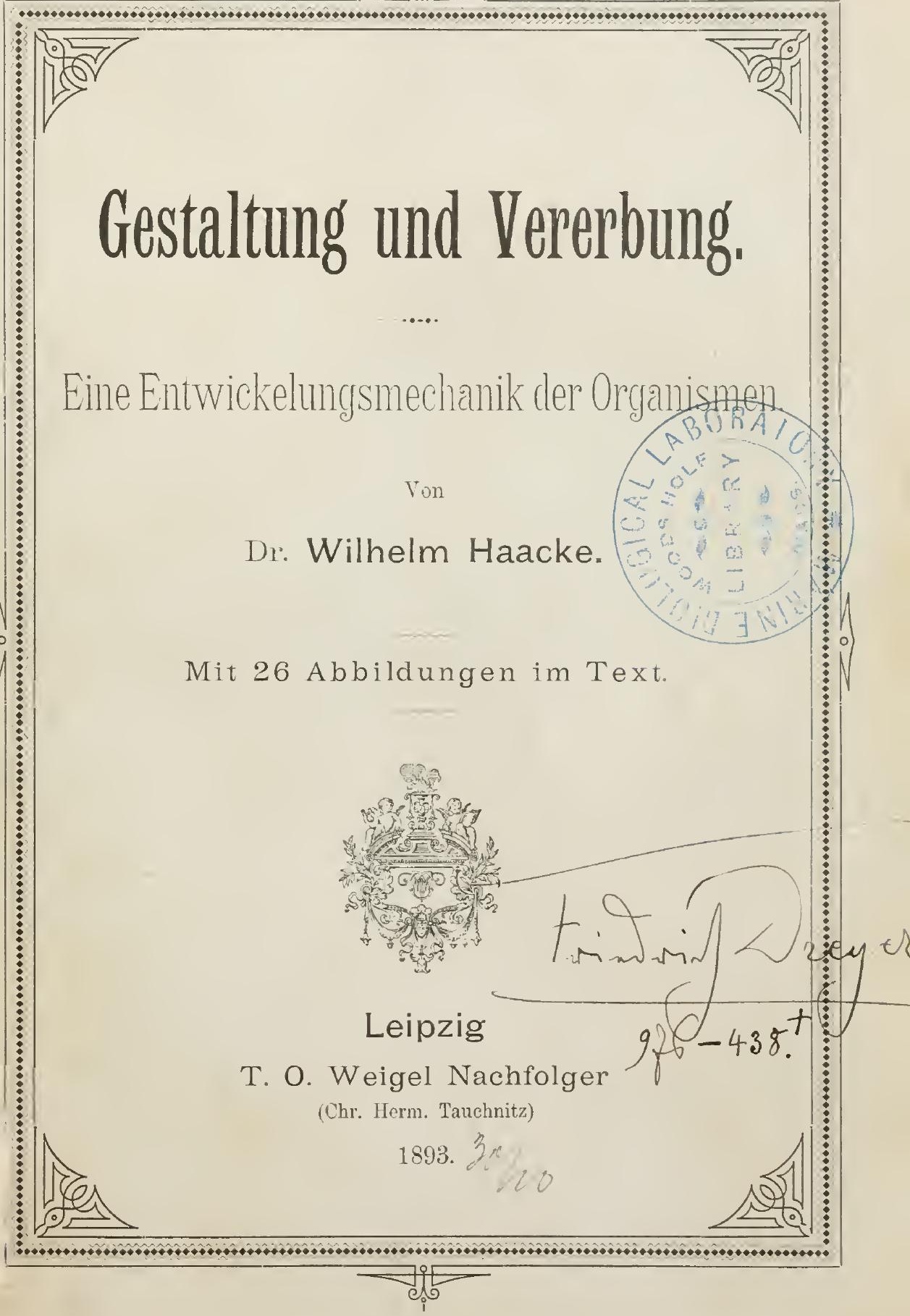










\section{Ilog}

妾,

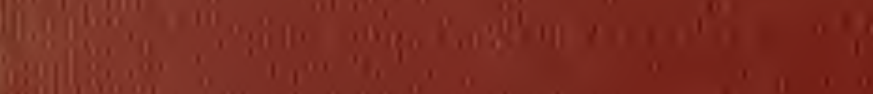
年,

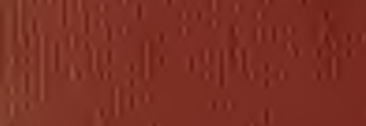

$\operatorname{lin}^{2}$, ing

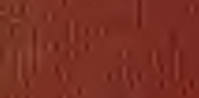

,

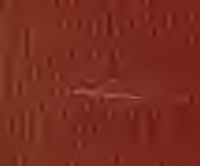

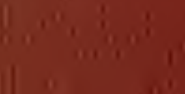

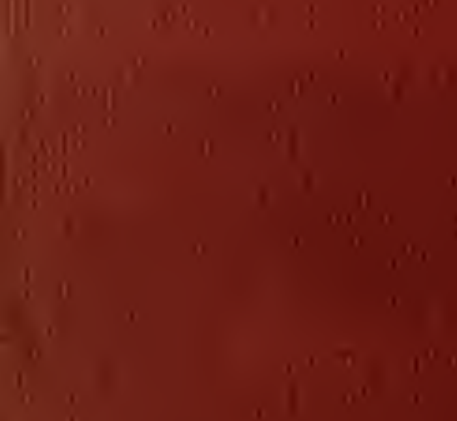

$x_{110}^{10}$

(i) 10

(if)

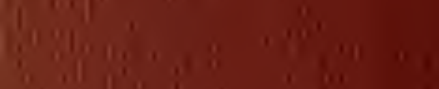

\section{3}

10

(1)

of

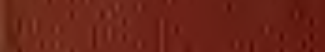

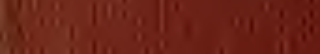
allonil

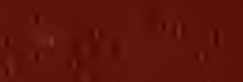
14

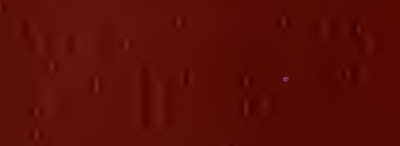

